Cochrane Database of Systematic Reviews

\title{
Non-invasive diagnostic tests for Helicobacter pylori infection
} (Review)

Best LMJ, Takwoingi Y, Siddique S, Selladurai A, Gandhi A, Low B, Yaghoobi M, Gurusamy KS

Best LMJ, Takwoingi Y, Siddique S, Selladurai A, Gandhi A, Low B, Yaghoobi M, Gurusamy KS.

Non-invasive diagnostic tests for Helicobacter pylori infection.

Cochrane Database of Systematic Reviews 2018, Issue 3. Art. No.: CD012080.

DOI: 10.1002/14651858.CD012080.pub2.

www.cochranelibrary.com 


\section{TABLE OF CONTENTS}

HEADER

ABSTRACT

PLAIN LANGUAGE SUMMARY .....

SUMMARY OF FINDINGS

BACKGROUND

Figure 1.

OBJECTIVES

METHODS

RESULTS

Figure 2.

Figure 3.

Figure 4.

Figure 5.

Figure 6.

Figure 7.

Figure 8.

Figure 9.

Figure 10.

Figure 11.

DISCUSSION

AUTHORS' CONCLUSIONS

ACKNOWLEDGEMENTS

REFERENCES

CHARACTERISTICS OF STUDIES

DATA

Test 1. Urea breath test-13C.

Test 2. Urea breath test-14C.

Test 3. Urea breath test - Unknown isotope.

Test 4. Serology.

Test 5. Stool antigen test.

Test 6. Urea breath test-13C (delta over baseline $>3 \%$ (20 minutes)).

Test 7. Urea breath test-13C (delta over baseline $>3 \%$ (30 minutes)).

Test 8 . Urea breath test- $13 \mathrm{C}$ (delta over baseline $>3.5 \%$ (30 minutes)).

Test 9. Urea breath test-13C (delta over baseline $>4 \%$ (10 minutes)).

Test 10. Urea breath test-13C (delta over baseline $>4 \%$ (20 minutes)).

Test 11. Urea breath test-13C (delta over baseline > 4\% (30 minutes)).

Test 12. Urea breath test-13C (delta over baseline $>4.5 \%$ (30 minutes)).

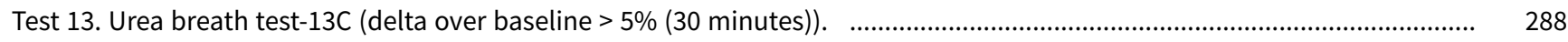

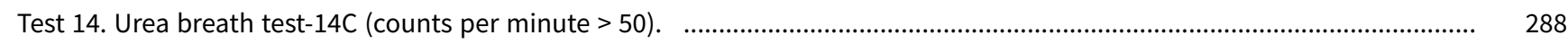

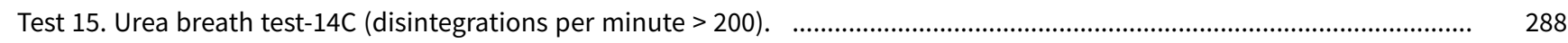

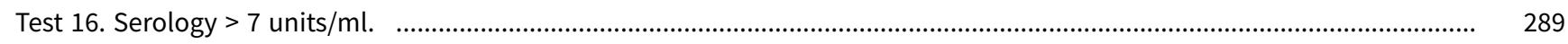

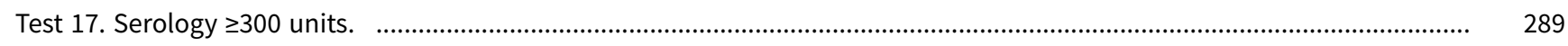

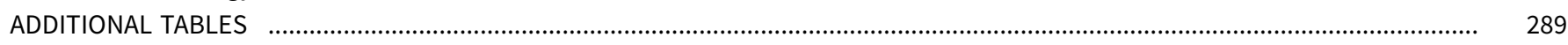

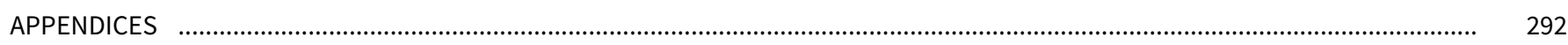

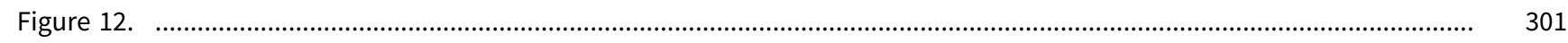

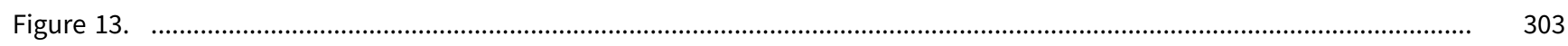

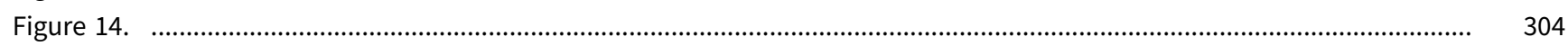

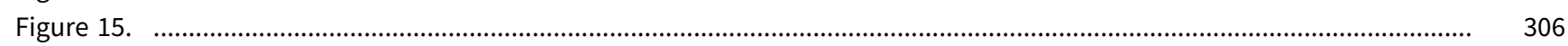

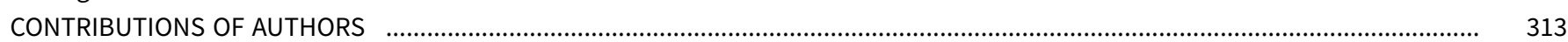

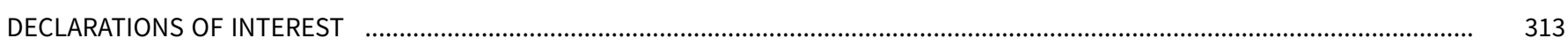

SOURCES OF SUPPORT 
[Diagnostic Test Accuracy Review]

\section{Non-invasive diagnostic tests for Helicobacter pylori infection}

Lawrence MJ Best ${ }^{1}$, Yemisi Takwoingi², Sulman Siddique ${ }^{3}$, Abiram Selladurai ${ }^{3}$, Akash Gandhi $^{3}$, Benjamin Low ${ }^{3}$, Mohammad Yaghoobi ${ }^{4}$, Kurinchi Selvan Gurusamy ${ }^{1}$

1Department of Surgery, Royal Free Campus, UCL Medical School, London, UK. 2Institute of Applied Health Research, University of Birmingham, Birmingham, UK. ${ }^{3}$ University College London, London, UK. ${ }^{4}$ Division of Gastroenterology, McMaster University and McMaster University Health Sciences Centre, Hamilton, Canada

Contact address: Kurinchi Selvan Gurusamy, Department of Surgery, Royal Free Campus, UCL Medical School, Rowland Hill Street, London, NW32PF, UK. k.gurusamy@ucl.ac.uk.

Editorial group: Cochrane Upper GI and Pancreatic Diseases Group.

Publication status and date: New, published in Issue 3, 2018.

Citation: Best LMJ, Takwoingi Y, Siddique S, Selladurai A, Gandhi A, Low B, Yaghoobi M, Gurusamy KS. Non-invasive diagnostic tests for Helicobacter pylori infection. Cochrane Database of Systematic Reviews 2018, Issue 3. Art. No.: CD012080. DOI: 10.1002/14651858.CD012080.pub2.

Copyright @ 2018 The Cochrane Collaboration. Published by John Wiley \& Sons, Ltd.

\section{A B S T R A C T}

\section{Background}

Helicobacter pylori (H pylori) infection has been implicated in a number of malignancies and non-malignant conditions including peptic ulcers, non-ulcer dyspepsia, recurrent peptic ulcer bleeding, unexplained iron deficiency anaemia, idiopathic thrombocytopaenia purpura, and colorectal adenomas. The confirmatory diagnosis of $H$ pylori is by endoscopic biopsy, followed by histopathological examination using haemotoxylin and eosin (H \& E) stain or special stains such as Giemsa stain and Warthin-Starry stain. Special stains are more accurate than $\mathrm{H} \& \mathrm{E}$ stain. There is significant uncertainty about the diagnostic accuracy of non-invasive tests for diagnosis of $H$ pylori.

\section{Objectives}

To compare the diagnostic accuracy of urea breath test, serology, and stool antigen test, used alone or in combination, for diagnosis of $H$ pylori infection in symptomatic and asymptomatic people, so that eradication therapy for $H$ pylori can be started.

\section{Search methods}

We searched MEDLINE, Embase, the Science Citation Index and the National Institute for Health Research Health Technology Assessment Database on 4 March 2016. We screened references in the included studies to identify additional studies. We also conducted citation searches of relevant studies, most recently on 4 December 2016. We did not restrict studies by language or publication status, or whether data were collected prospectively or retrospectively.

\section{Selection criteria}

We included diagnostic accuracy studies that evaluated at least one of the index tests (urea breath test using isotopes such as ${ }^{13} \mathrm{C}$ or ${ }^{14} \mathrm{C}$, serology and stool antigen test) against the reference standard (histopathological examination using $\mathrm{H} \& \mathrm{E}$ stain, special stains or immunohistochemical stain) in people suspected of having $H$ pylori infection.

\section{Data collection and analysis}

Two review authors independently screened the references to identify relevant studies and independently extracted data. We assessed the methodological quality of studies using the QUADAS-2 tool. We performed meta-analysis by using the hierarchical summary receiver operating characteristic (HSROC) model to estimate and compare SROC curves. Where appropriate, we used bivariate or univariate logistic regression models to estimate summary sensitivities and specificities. 


\section{Main results}

We included 101 studies involving 11,003 participants, of which 5839 participants (53.1\%) had $H$ pylori infection. The prevalence of $H$ pylori infection in the studies ranged from $15.2 \%$ to $94.7 \%$, with a median prevalence of $53.7 \%$ (interquartile range $42.0 \%$ to $66.5 \%$ ). Most of the studies (57\%) included participants with dyspepsia and 53 studies excluded participants who recently had proton pump inhibitors or antibiotics.There was at least an unclear risk of bias or unclear applicability concern for each study.

Of the 101 studies, 15 compared the accuracy of two index tests and two studies compared the accuracy of three index tests. Thirty-four studies (4242 participants) evaluated serology; 29 studies (2988 participants) evaluated stool antigen test; 34 studies (3139 participants) evaluated urea breath test-13C; 21 studies (1810 participants) evaluated urea breath test- ${ }^{14} \mathrm{C}$; and two studies (127 participants) evaluated urea breath test but did not report the isotope used. The thresholds used to define test positivity and the staining techniques used for histopathological examination (reference standard) varied between studies. Due to sparse data for each threshold reported, it was not possible to identify the best threshold for each test.

Using data from 99 studies in an indirect test comparison, there was statistical evidence of a difference in diagnostic accuracy between urea breath test- ${ }^{13} \mathrm{C}$, urea breath test- ${ }^{14} \mathrm{C}$, serology and stool antigen test $(\mathrm{P}=0.024)$. The diagnostic odds ratios for urea breath test- ${ }^{13} \mathrm{C}$, urea breath test-14C, serology, and stool antigen test were 153 (95\% confidence interval ( $\mathrm{Cl}) 73.7$ to 316$), 105$ (95\% Cl 74.0 to 150$), 47.4$ $(95 \% \mathrm{Cl} 25.5$ to 88.1$)$ and $45.1(95 \% \mathrm{Cl} 24.2$ to 84.1$)$. The sensitivity $(95 \% \mathrm{Cl})$ estimated at a fixed specificity of 0.90 (median from studies across the four tests), was $0.94(95 \% \mathrm{Cl} 0.89$ to 0.97$)$ for urea breath test- ${ }^{13} \mathrm{C}, 0.92(95 \% \mathrm{Cl} 0.89$ to 0.94$)$ for urea breath test-14C, $0.84(95 \%$ $\mathrm{Cl} 0.74$ to 0.91$)$ for serology, and $0.83(95 \% \mathrm{Cl} 0.73$ to 0.90$)$ for stool antigen test. This implies that on average, given a specificity of 0.90 and prevalence of $53.7 \%$ (median specificity and prevalence in the studies), out of 1000 people tested for $H$ pylori infection, there will be 46 false positives (people without $H$ pylori infection who will be diagnosed as having $H$ pylori infection). In this hypothetical cohort, urea breath test-13C, urea breath test- ${ }^{14} \mathrm{C}$, serology, and stool antigen test will give 30 (95\% Cl 15 to 58), 42 ( $95 \% \mathrm{Cl} 30$ to 58 ), 86 (95\% Cl 50 to 140 ), and 89 (95\% Cl 52 to 146) false negatives respectively (people with $H$ pylori infection for whom the diagnosis of $H$ pylori will be missed).

Direct comparisons were based on few head-to-head studies. The ratios of diagnostic odds ratios (DORs) were 0.68 ( $95 \% \mathrm{Cl} 0.12$ to $3.70 ; \mathrm{P}$ $=0.56$ ) for urea breath test- $13 \mathrm{C}$ versus serology (seven studies), and $0.88(95 \% \mathrm{Cl} 0.14$ to $5.56 ; \mathrm{P}=0.84)$ for urea breath test- $13 \mathrm{C}$ versus stool antigen test (seven studies). The $95 \% \mathrm{Cls}$ of these estimates overlap with those of the ratios of DORs from the indirect comparison. Data were limited or unavailable for meta-analysis of other direct comparisons.

\section{Authors' conclusions}

In people without a history of gastrectomy and those who have not recently had antibiotics or proton, pump inhibitors, urea breath tests had high diagnostic accuracy while serology and stool antigen tests were less accurate for diagnosis of Helicobacter pylori infection.This is based on an indirect test comparison (with potential for bias due to confounding), as evidence from direct comparisons was limited or unavailable. The thresholds used for these tests were highly variable and we were unable to identify specific thresholds that might be useful in clinical practice.

We need further comparative studies of high methodological quality to obtain more reliable evidence of relative accuracy between the tests. Such studies should be conducted prospectively in a representative spectrum of participants and clearly reported to ensure low risk of bias. Most importantly, studies should prespecify and clearly report thresholds used, and should avoid inappropriate exclusions.

\section{PLAIN LANGUAGE SUMMARY}

\section{Accuracy of different non-invasive methods for identifying Helicobacter pylori}

\section{Why is it important to know whether someone has Helicobacter pylori?}

Helicobacter pylori (H pylori) is a type of bacteria which may be present in the stomach of some people. $H$ pylori is believed to cause a number of cancers, including stomach cancer, pancreatic cancer, and throat cancer. $H$ pylori is also linked with other diseases including stomach ulcers, heart burn, and a bloated feeling. If $\mathrm{H}$ pylori is found in an individual, appropriate treatment can be started.

\section{What is the aim of this review?}

To compare the accuracy of three different types of test for $H$ pylori. These are: urea breath tests, blood tests (the specific blood test is called serology), and stool tests (in faeces).

\section{What was studied in this review?}

There are two types of urea breath test which use two different forms of carbon known as ${ }^{13} \mathrm{C}$ and ${ }^{14} \mathrm{C}$, as well as multiple versions of serology and stool tests.

\section{What are the main results of the review?}


We found 101 studies which included 11,003 people who were tested for $H$ pylori. Of these 11,003 participants, 5839 ( $53.1 \%$ ) had $H$ pylori infection. All the studies used one of the three tests listed above and compared these test results with the diagnosis given by endoscopic biopsy. Endoscopic biopsy involves obtaining tissue from the stomach using a thin flexible tube introduced through the mouth and testing for the presence of $\mathrm{H}$ pylori under the microscope. It is currently the most accurate available test, however it causes physical discomfort to the patient, with associated risks for harm. This is in contrast to the alternative non-invasive tests in this review which are significantly less uncomfortable and have minimal or no risk of harm, making them desirable alternatives if they can be shown to be as accurate at diagnosing $\mathrm{H}$ pylori as endoscopic biopsy. Most of the studies included participants with heart burn or similar problems in the stomach and excluded participants who had previously undergone partial removal of the stomach and those having treatment for $H$ pylori.

Thirty-four studies (4242 participants) used serology; 29 studies (2988 participants) used stool antigen test; 34 studies (3139 participants) used urea breath test-13C; 21 studies (1810 participants) used urea breath test-14C; and two studies (127 participants) used urea breath test but did not report the type of carbon used. Studies varied in the limit they used before saying a test was positive for $\mathrm{H}$ pylori infection and the type of stains used to examine the biopsy material. When we looked at all the data we found that urea breath tests were more accurate than blood and stool tests. The results mean that, on average, if 1000 people are tested, there will be 46 people without $H$ pylori who will be misdiagnosed as having $H$ pylori. Also, there will be $30,42,86$, and 89 people with $H$ pylori infection for whom the diagnosis of $H$ pylori infection will be missed by urea breath test- ${ }^{13} \mathrm{C}$, urea breath test- ${ }^{14} \mathrm{C}$, serology, and stool antigen test, respectively. When we looked at the seven studies which compared urea breath test- ${ }^{13} \mathrm{C}$ and serology, or urea breath test- ${ }^{13} \mathrm{C}$ and stool antigen tests in the same participants, the results were uncertain and we cannot tell which test is more accurate.

\section{How reliable are the results of the studies?}

Except for one study, all the studies were of poor methodological quality, which makes their results unreliable.

\section{Who do the results of this review apply to?}

These results apply to children and adults with suspected $H$ pylori infection, but only in those who have not previously undergone stomach operations and those who have not recently had antibiotics or treatment for $H$ pylori infection.

\section{What are the implications of this review?}

Urea breath tests, blood tests, and stool tests may be suitable for identifying whether someone has $H$ pylori infection. However, the level of the result of urea breath test, blood test, or stool test which should be used to make a diagnosis of $H$ pylori infection remains unclear.

\section{How up-to-date is the review?}

We performed a thorough literature search for studies reporting the accuracy of these different tests until 4 March 2016. 


\section{SUMMARY OF FINDINGS}

\section{Summary of findings 1 . Performance of non-invasive tests for diagnosis of $H$ pylori infection}

What is the best non-invasive test for diagnosis of $H$ pylori infection?

\begin{tabular}{|c|c|c|c|c|}
\hline Population & \multicolumn{4}{|c|}{ Children and adults with gastrointestinal symptoms } \\
\hline Setting & \multicolumn{4}{|l|}{ Primary care setting } \\
\hline Index tests & \multicolumn{4}{|c|}{ Urea breath test- ${ }^{13} \mathrm{C}$, Urea breath test- ${ }^{14} \mathrm{C}$, serology, and stool antigen test } \\
\hline Threshold & \multicolumn{4}{|c|}{ Various thresholds were used for each test } \\
\hline $\begin{array}{l}\text { Role and purpose } \\
\text { of test }\end{array}$ & \multicolumn{4}{|c|}{ Screening and diagnosis of $H$ pylori } \\
\hline $\begin{array}{l}\text { Reference stan- } \\
\text { dard }\end{array}$ & \multicolumn{4}{|c|}{$\begin{array}{l}\text { Endoscopic biopsy with Haemotoxylin \& Eosin stain, special stains, or combination of Haemotoxylin \& Eosin } \\
\text { and special stains }\end{array}$} \\
\hline $\begin{array}{l}\text { Quality of evi- } \\
\text { dence }\end{array}$ & \multicolumn{4}{|c|}{$\begin{array}{l}\text { Risk of bias was generally high or unclear with respect to the selection of participants, and the conduct and in- } \\
\text { terpretation of the index tests and reference standard. Applicability concerns were also generally high or un- } \\
\text { clear with respect to selection of participants }\end{array}$} \\
\hline Limitations & \multicolumn{4}{|c|}{$\begin{array}{l}\text { There was heterogeneity in thresholds and reference standards. Studies did not often prespecify or clearly re- } \\
\text { port thresholds used }\end{array}$} \\
\hline $\begin{array}{l}\text { Pre-test proba- } \\
\text { bility (prevalence } \\
\text { of Helicobacter } \\
\text { pylori) }\end{array}$ & \multicolumn{4}{|c|}{ Median (interquartile range) $=53.7 \%(42.0 \%$ to $66.5 \%)$} \\
\hline Index test & $\begin{array}{l}\text { Number of participants } \\
\text { (studies) }\end{array}$ & $\begin{array}{l}\text { Diagnostic odds ratio } \\
(95 \% \mathrm{CI})\end{array}$ & $\begin{array}{l}\text { Sensitivity }(95 \% \mathrm{CI}) \text { at } \\
\text { fixed specificity of } 0.90^{1}\end{array}$ & $\begin{array}{l}\text { Missed } H \text { pylori cases } \\
\text { per } 1000 \text { people tested } \\
(95 \% \mathrm{CI})^{2}\end{array}$ \\
\hline $\begin{array}{l}\text { Urea breath } \\
\text { test- } 13 \mathrm{C}\end{array}$ & $\begin{array}{l}3139 \text { participants } \\
\text { (34 studies) }\end{array}$ & $153(95 \% \mathrm{Cl} 73.7$ to 316$)$ & 0.94 (0.89 to 0.97$)$ & 30 (15 to 58$)$ \\
\hline $\begin{array}{l}\text { Urea breath } \\
\text { test-14C }\end{array}$ & $\begin{array}{l}1810 \text { participants } \\
\text { (21 studies) }\end{array}$ & $105(95 \% \mathrm{Cl} 74.0$ to 150$)$ & 0.92 (0.89 to 0.94$)$ & 42 (30 to 58$)$ \\
\hline Serology & $\begin{array}{l}4242 \text { participants } \\
\text { (34 studies) }\end{array}$ & $47.4(95 \% \mathrm{Cl} 25.5$ to 88.1$)$ & $0.84(0.74$ to 0.91$)$ & 86 (50 to 140$)$ \\
\hline Stool antigen test & $\begin{array}{l}2988 \text { participants } \\
\text { (29 studies) }\end{array}$ & $45.1(95 \% \mathrm{Cl} 24.2$ to 84.1$)$ & $0.83(0.73$ to 0.90$)$ & 89 (52 to 146$)$ \\
\hline
\end{tabular}

\section{Comparison of non-invasive tests for $\boldsymbol{H}$ pylori infection}

Based on an indirect comparison of the four tests using all the studies, there was statistical evidence of a difference in diagnostic accuracy $(\mathrm{P}=0.024)$. Direct comparisons were based on few head-to-head studies. The ratios of diagnostic odds ratios $(95 \% \mathrm{Cl} ; \mathrm{P}$ value) were $0.68(95 \% \mathrm{Cl} 0.12$ to $3.70 ; \mathrm{P}=0.56)$ for urea breath test- ${ }^{13} \mathrm{C}$ versus serology (seven studies), and $0.88(95 \% \mathrm{Cl} 0.14$ to $5.56 ; \mathrm{P}=$ 0.84 ) for urea breath test- ${ }^{13} \mathrm{C}$ versus stool antigen test (seven studies). The $95 \%$ confidence intervals of these estimates overlap with 
those of the ratios of diagnostic odds ratios from the indirect comparison. Data were limited or unavailable for meta-analysis of other direct comparisons.

\section{Conclusions}

In people with no history of gastrectomy and those who have not recently had antibiotics or proton pump inhibitors, urea breath tests had high diagnostic accuracy while serology and stool antigen tests had lower accuracy to detect $H$ pylori infection. Although susceptible to bias due to confounding, this conclusion is based on evidence from indirect test comparisons as evidence from direct comparisons was based on few studies or was unavailable. It should be noted that studies were generally of poor methodological quality. The thresholds used for the tests were highly variable and there is currently insufficient evidence to recommend specific thresholds for use in clinical practice.

${ }^{1}$ The sensitivities were estimated along the SROC curves at the median specificity across the studies included for the four tests.

2Based on the sensitivity estimated at the median specificity of 0.90 , and the median prevalence of $53.7 \%$ from the included studies, the numbers of missed $H$ pylori cases were calculated using a hypothetical cohort of 1000 people suspected of having $H$ pylori infection. The $95 \% \mathrm{Cl}$ for the number of missed cases is from the $95 \% \mathrm{Cl}$ for sensitivity. For a specificity of 0.90 and prevalence of $53.7 \%$, there will be 46 false positives. See Table 3 for results for other values of specificity and prevalence. 


\section{B A C K G R O U N D}

Helicobacter pylori (H pylori) is a gram negative spiral bacterium (NCBI 2014). Approximately $13 \%$ to $81 \%$ of people have $H$ pylori infection (Peleteiro 2014). Prevalence of the bacterium varies according to age (generally increasing with age, although infection rates tend to fall among older age groups in some Latin American and Northeast Asian countries); region (lower infection rates are seen in Australia and the UK, while higher rates are reported in Chile, China, Japan, Korea, and Latvia); race (more prevalent amongst Afrocarribeans compared to white people); and socioeconomic class (more common in poorer settings) (Graham 1991; Laszewicz 2014; Muhsen 2012; Peleteiro 2014).

Based on observational studies, $H$ pylori infection has been implicated in a number of malignancies, including gastric cancer, premalignant lesions of the stomach (atrophic gastritis and intestinal metaplasia), gastric lymphoma, pancreatic cancer, colorectal cancer, and laryngeal cancer (Huang 1998; Huang 2003; Wu 2013; Xiao 2013; Xue 2001; Zhuo 2008). However $H$ pylori is associated with a lower incidence of oesophageal adenocarcinomas (Islami 2008). H pylori is also associated with a number of non-malignant conditions, including peptic ulcers, nonulcer dyspepsia, recurrent peptic ulcer bleeding, unexplained iron deficiency anaemia, idiopathic thrombocytopaenia purpura, and colorectal adenomas (DuBois 2005; Franchini 2007; Gisbert 2004b; Huang 2002; Jaakkimainen 1999; Wu 2013).

Although a number of pathogenic factors such as cytotoxinassociated gene A (CagA), vacuolating cytotoxin A (VacA), and blood group antigen binding adhesin (BabA) are associated with increased virulence of $H$ pylori (Huang 2003; Malfertheiner 2012), detection of these pathogenic factors currently has no role in the management of $H$ pylori infection (Malfertheiner 2012). The recommended initial treatment for $H$ pylori infection is with a combination of a proton pump inhibitor, clarithromycin, and amoxicillin or metronidazole (triple therapy) in regions with low resistance to clarithromycin ( $<20 \%$ resistance rate in the area), and the triple therapy along with bismuth (quadruple therapy) in regions with high resistance to clarithromycin (> 20\% resistance rate in the area) (Malfertheiner 2012). If this results in failure of eradication, bismuth-quadruple therapy or levofloxacin-triple therapy (replacement of clarithromycin with levofloxacin in the classical triple therapy) when triple therapy was used as the initial treatment and levofloxacin-triple therapy when bismuth quadruple therapy was used as the initial treatment is recommended (Malfertheiner 2012). If even this treatment fails to eradicate $H$ pylori, then further treatment should be based on antibiotic susceptibility (Malfertheiner 2012). Eradication of $H$ pylori might lead to a decrease in malignant and non-malignant conditions associated with $\mathrm{H}$ pylori infection. Adverse events related to $\mathrm{H}$ pylori treatment include taste disturbance, diarrhoea, nausea, headache, skin rash, abdominal pain, dizziness, bloating, myalgias (muscle pain), and constipation (Ye 2014).

A glossary of terms is included in Appendix 1.

\section{Target condition being diagnosed}

Helicobacter pylori infection.

\section{Index test(s)}

\section{Urea breath test}

The urea breath test is based on the presence of urease enzyme in live $H$ pylori which breaks down urea into ammonia and carbon dioxide (McNulty 2005; Ricci 2007). After ingestion of urea labelled with either ${ }^{13} \mathrm{C}$ or ${ }^{14} \mathrm{C}$, breath samples are collected for up to 30 minutes by exhaling into a carbon dioxide-trapping agent (Ricci 2007). The urea breath test is performed by the clinician or the clinician's assistant. The thresholds used include the percentage of carbon recovered during the collection time or counts per minute (Ferwana 2015). Threshold levels above $4 \%$ or $5 \%$ are commonly used to diagnose $H$ pylori infection (Ferwana 2015). A wide range of threshold counts per minute, ranging from more than 25 counts per minute to 1000 counts per minute, have been used for diagnosis of $H$ pylori infection (Ferwana 2015).

\section{Serology}

These tests are based on circulating antibodies to $H$ pylori. There are three main methods for these tests: the enzyme-linked immunosorbent assay (ELISA) test, latex agglutination tests, and Western blotting (Ricci 2007). Of these, ELISA is the most commonly used method. Total immunoglobulin, immunoglobulin subtypes, and antibody response to specific antigens can all be tested. Since they do not require any special equipment, they can be easily performed (Ricci 2007). However, serology may be positive because of the presence of active infection at the time of the test, previous infection, or because of non-specific cross-reacting antibodies (McNulty 2005). Tests that use whole blood (rather than serum) and other bedside tests (using a bedside centrifuge) are also available, although these whole-blood tests and bedside serum tests are generally considered unreliable (Ricci 2007). Routine serum tests are performed by the laboratory technician and interpreted by the clinician. The bedside serum tests and whole-blood tests are performed by the clinician or the clinician's assistant. Different researchers evaluating the prevalence of $H$ pylori have used different thresholds to define the positivity of serology, for example Lindsetmo 2008 used a titre $\geq 300$ while Granberg 1993 used a titre $\geq 500$.

\section{Stool antigen tests}

These tests use monoclonal and polyclonal antibodies to detect the presence of $H$ pylori antigen in stools and active $H$ pylori infection can be diagnosed (McNulty 2005; Ricci 2007). Serum tests are performed by the laboratory technician and interpreted by the clinician. Several thresholds have been used for other tests, for example, an optical density of $\geq 0.15, \geq 0.16$, and $\geq 0.19$ have all been used as thresholds for diagnosis of $H$ pylori using monoclonal antibodies for stool antigen tests.

\section{Clinical pathway}

Evidence from randomised controlled trials (RCTs) showed that screening and eradication programmes for $\mathrm{H}$ pylori in populations at high risk of gastric cancer (e.g. East Asians) lowered the incidence of gastric cancer (Ford 2014). The Asia-Pacific Gastric Cancer Consensus conference recommended that screening and eradication of $H$ pylori was advisable in populations in countries at high risk of gastric cancer (i.e. Japan and Korea) (Talley 2008). The updated European Helicobacter Study Group (EHSG) Fourth Maastricht/Florence Consensus Conference guidelines suggest that 
people should be tested for $H$ pylori, and eradication of $H$ pylori (when present) has been recommended for the following conditions (Malfertheiner 2012):

1. People at high risk of gastric cancer.

2. Adults with dyspepsia with a locally-determined age cut-off point (depending on local incidence of gastric cancer in different age groups), and without 'alarm' symptoms or signs associated with an increased risk of gastric cancer such as weight loss, dysphagia, upper gastrointestinal bleeding, abdominal mass, or iron deficient anaemia.

3. Unexplained iron deficiency anaemia.

4. Idiopathic thrombocytopenic purpura.

5. Uninvestigated young patients with dyspepsia should also be considered for testing for $\mathrm{H}$ pylori when the prevalence of $\mathrm{H}$ pylori is high ( $\geq 20 \%)$.

The clinical pathway is shown in Figure 1.

\section{Figure 1. Clinical pathway}

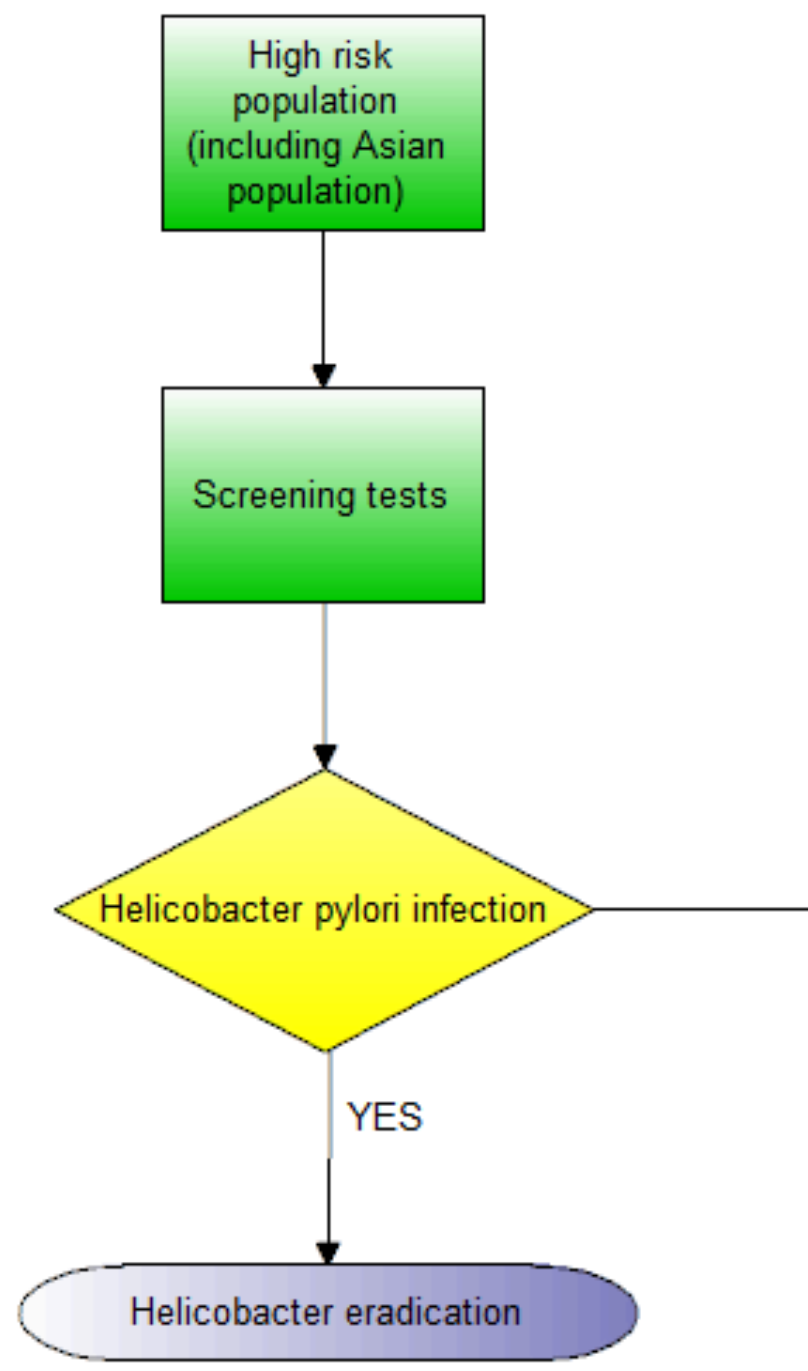

\section{Prior test(s)}

The index tests can be performed without any prior test.

\section{Role of index test(s)}

The index tests are used for screening and diagnosis of $H$ pylori.

\section{Alternative test(s)}

Other tests used in the screening and diagnosis of $H$ pylori infection include non-invasive saliva and urine antigen-based tests (Ricci 2007), and invasive gastric biopsy followed by Campylobacter- like organism (CLO) test, culture, histology, and polymerase chain reaction (PCR) (Van Doorn 2000). We do not include non-invasive saliva and urine antigen-based tests in this review because these tests are not commonly used (Ricci 2007).

\section{Rationale}

Testing for $H$ pylori and eradication of $H$ pylori have been recommended for a number of population groups (Clinical pathway). These tests have to be non-invasive so that a large number of people can be tested. People with undetected $H$ pylori continue to be at high risk of gastric cancer or continue to have 
dyspepsia, anaemia, or purpura. Overdiagnosis (false positive test results) of $H$ pylori means that patients are subject to unnecessary adverse events related to eradication therapy (approximately $27 \%$ of patients receiving eradication therapy develop mild adverse events such as bitter taste, nausea, diarrhoea, etc.). Comparing the diagnostic accuracy of different index tests will highlight the best test for the diagnosis of $H$ pylori infection.

\section{O B J E C T I VES}

To compare the diagnostic accuracy of urea breath test, serology, and stool antigen test, alone or in combination, for diagnosis of $H$ pylori infection in symptomatic and asymptomatic people, so that eradication therapy for $\mathrm{H}$ pylori can be started.

\section{Secondary objectives}

To investigate the following potential sources of heterogeneity: type of reference standard, risk of bias, publication status, prospective versus retrospective studies, symptomatic versus asymptomatic participants, recent or current use of proton pump inhibitors or antibiotics, different subtypes of tests, and the interval between the index test and reference standard.

\section{METHODS}

\section{Criteria for considering studies for this review}

\section{Types of studies}

We include studies that evaluate the accuracy of the index tests in the appropriate patient population (see Participants), regardless of language or publication status, or whether data were collected prospectively or retrospectively. However, we exclude reports that describe how the diagnosis of $H$ pylori was made in an individual patient or group of patients, and which do not provide sufficient diagnostic test accuracy data (i.e. the number of true positives, false positives, false negatives, and true negatives). We also exclude case-control studies because these are prone to bias (Whiting 2011).

\section{Participants}

Symptomatic and asymptomatic people in whom $\mathrm{H}$ pylori infection status is sought so that eradication therapy for $H$ pylori can be started. We exclude studies that included only people with acute upper gastrointestinal bleeding because such patients are likely to undergo endoscopy and invasive testing can be performed, if required.

\section{Index tests}

Urea breath test- ${ }^{14} \mathrm{C}$, urea breath test $-13 \mathrm{C}$, serology, and stool antigen test, alone or in combination. We included only initial testing and excluded repeat testing (monitoring success of treatment), since diagnostic accuracy may vary depending on the purpose of testing (Ricci 2007).

\section{Target conditions}

H pylori infection.

\section{Reference standards}

There is no gold standard for diagnosis of $H$ pylori infection and the diagnosis is made by a combination of tests following endoscopic biopsy; endoscopic biopsy followed by histology, endoscopic biopsy followed by polymerase chain reaction (PCR), and endoscopic biopsy followed by rapid urease testing all have excellent sensitivity and specificity (Chey 2007). However, PCR methodology is not standardised across laboratories (Chey 2007); it is an unreliable reference standard. Endoscopic biopsy followed by rapid urease testing has poor sensitivity following treatment with proton pump inhibitors (Chey 2007). Endoscopic biopsy with culture has high specificity but poor sensitivity (Chey 2007). We therefore considered only endoscopic biopsy followed by histology (using haemotoxylin and eosin ( $H$ \& E) stain, special histological stains such as Giemsa stain and Warthin-Starry stain, or immunohistochemical stain) as the reference standard in this review.

Immunohistochemical stains are more accurate than special stains, while special stains and immunohistochemical stains are thought to have better specificity than $\mathrm{H} \& \mathrm{E}$ stains for diagnosis of $H$ pylori infection (Laine 1997; Lee 2015b). For this reason,we considered endoscopic biopsy with histology using immunohistochemical stain as the best reference standard, and endoscopic biopsy with histology using $\mathrm{H} \& \mathrm{E}$ stain as the worst reference standard.

\section{Search methods for identification of studies}

We included all studies, irrespective of the language of publication and publication status. If we found articles in languages other than English, we obtained translations.

\section{Electronic searches}

We searched the following databases.

1. MEDLINE via OvidSP (January 1946 to 4 March 2016) (Appendix 2).

2. Embase via OvidSP (January 1947 to 4 March 2016) (Appendix 3).

3. Science Citation Index Expanded via Thomson Reuters Web of Science (January 1980 to 4 March 2016) (Appendix 4).

4. National Institute for Health Research (NIHR HTA) via Centre for Reviews and Dissemination, University of York. (www.crd.york.ac.uk/CRDWeb/) (4 March 2016) (Appendix 5).

\section{Searching other resources}

To identify additional studies, we examined references in the included studies to see if any might be relevant. We also searched for articles related to the included studies by using the 'related search' function in MEDLINE (OvidSP) and Embase (OvidSP). We conducted a 'citing reference' search (by searching articles which cited the included articles) (Sampson 2008) in MEDLINE (OvidSP) and Embase (OvidSP) on 4 December 2016.

\section{Data collection and analysis}

\section{Selection of studies}

Two review authors ( $K G$ and LB, SS, or AS) independently searched the references to identify relevant studies. We obtained the full text for references considered relevant by at least one of the two review authors. Two review authors independently screened the full-text papers against the inclusion criteria, resolving any differences in study selection by discussion. We attempted to contact study authors if there were doubts about the eligibility of a study. 


\section{Data extraction and management}

Two review authors (KG and LB, SS, or AS) independently extracted the following data from each included study, using a pre-piloted data extraction form, and resolving differences by discussion.

1. First author.

2. Year of publication.

3. Study design (prospective or retrospective cohort studies; crosssectional studies or randomised controlled trials).

4. Inclusion and exclusion criteria for individual studies.

5. Total number of participants.

6. Number of female participants.

7. Average age of the participants.

8. Initial testing versus testing after eradication.

9. Number of people with bleeding ulcers, gastric atrophy, lymphoma, and recent or current use of proton pump inhibitors or antibiotics.

10.Number of symptomatic participants.

11. Tests carried out prior to the index test.

12. Description of the index test.

13.Threshold used for the index test.

14. Reference standard.

15. Number of true positives, false positives, false negatives, and true negatives (i.e. $2 \times 2$ data) at each threshold reported.

If a study reported multiple index tests, we extracted the $2 \times 2$ data for each index test at each threshold. For studies that reported test accuracy for different reference standards, we extracted $2 \times 2$ data for only one of the reference standards. For this purpose, due to the accuracy of the stains, we preferred the immunohistochemical stain over special stains, which in turn we preferred over the $\mathrm{H} \& \mathrm{E}$ stain.

Although the number of uninterpretable index test results may provide information on the applicability of the tests in clinical practice and may affect the cost effectiveness of a test, we had planned to exclude patients with uninterpretable index test results from the meta-analyses. We made this decision because in clinical practice uninterpretable index test results would result in additional testing. Nevertheless, we would have extracted and reported such data if available from the studies.

If we suspected an overlap of participants between multiple reports due to common study authors and centres, we planned to contact the study authors for clarification; however, this was not required, since we could identify multiple reports of the same study using the information provided in the reports. We sought further information from study authors, if necessary.

\section{Assessment of methodological quality}

Two review authors independently assessed study quality using the QUADAS-2 tool (Whiting 2006; Whiting 2011), resolving differences by discussion. The criteria used for the assessment are shown in Appendix 6. We considered studies classified as 'low risk of bias' and 'low concern' in all the domains of the QUADAS-2 tool as studies with high methodological quality. It must be noted here that 'risk of bias' refers to internal validity (i.e. whether there were systematic errors in performing the study with respect to the particular domain), while 'applicability concern' refers to external validity (i.e. whether there were concerns that the population, index test or reference standard used in the studies matched the review question).

\section{Statistical analysis and data synthesis}

We plotted study estimates of sensitivity and specificity on forest plots and in receiver operating characteristic (ROC) space to explore between-study variation in the accuracy of each test. We examined the thresholds reported for each test and the reference standards used. Due to between-study variation in thresholds, we performed meta-analyses by using the hierarchical summary receiver operating characteristics (HSROC) model to estimate SROC curves (Rutter 2001). For these analyses, if a study reported test accuracy at multiple thresholds, we selected the threshold used by the study authors for their primary analysis.

Prior to comparative meta-analyses of the tests, we performed meta-analysis of each test separately for preliminary investigation of the shape of the SROC curve of each test and to assess heterogeneity in test performance. We used this approach to understand the data and to guide modelling assumptions we may need to make in the comparative meta-analysis. These preliminary analyses were done noting the availability of comparative studies. To compare the accuracy of the index tests, we added test type as a covariate to the HSROC model (Macaskill 2013). For the indirect comparison where we used all available data (i.e. not restricted to comparative studies), we assessed the effect of test type on the accuracy, threshold, and shape parameters of the HSROC model. We also explored the effect of test type on the variance of the random effects for accuracy and threshold. To determine the final meta-analytic model, we used likelihood ratio tests to assess model fit. Likelihood ratio tests were also used to determine the statistical significance of differences in test accuracy. When SROC curves are symmetric (i.e. HSROC model without the shape parameter), each curve can be described using the diagnostic odds ratio (DOR) to quantify the accuracy of the test. We used the ratio of DORs as a summary of the relative accuracy of two tests.

Summary sensitivities and specificities can be obtained from a HSROC model but they are not clinically interpretable here because we included studies with different thresholds. We therefore estimated sensitivities at points on the SROC curves that correspond to the lower quartile, median and upper quartile of the specificities from the studies included in the meta-analysis. When comparative studies that had evaluated two tests head-tohead were available, we performed direct comparisons of the tests (Takwoingi 2013). For these analyses, we fitted HSROC models with symmetric SROC curves, as the available data were insufficient for reliable estimation of the shape of the SROC curves (Takwoingi 2017).

If there were at least two studies that reported the accuracy of a test at the same threshold, we considered meta-analysis to obtain summary estimates of sensitivity and specificity. Due to the small number of studies in these analyses, we performed meta-analyses using univariate fixed-effect or random-effects logistic regression models, depending on the extent of heterogeneity observed in forest plots and in ROC space (Takwoingi 2017). When there were only two or three studies at the same threshold, and little or no heterogeneity observed in ROC space, we used univariate fixed-effect logistic regression models to pool sensitivities and specificities separately. When there were two or three studies and we observed heterogeneity, we did not perform meta-analysis, 
as random-effects models would be more appropriate in such situations. However, random effects cannot be reliably estimated with very few studies.

We performed meta-analyses using the NLMIXED procedure in SAS.

\section{Investigations of heterogeneity}

We used forest plots and scatter plots of sensitivity against specificity for preliminary investigation of potential sources of heterogeneity such as:

1. Type of reference standard (different histological stains).

2. Studies at low risk of bias in all the QUADAS-2 domains versus those at unclear or high risk of bias.

3. Full-text publications versus abstracts (may provide insight into publication bias if there is an association between the results of a study and full publication of the study) (Eloubeidi 2001).

4. Prospective versus retrospective studies.

5. Symptomatic versus asymptomatic participants.

6. Recent or current use of proton pump inhibitors or antibiotics, as these patients are at higher risk of false negative results for the urea breath test and stool antigen test, with serology being the only non-invasive test unaffected by the use of proton pump inhibitors or antibiotics (Malfertheiner 2012; Ricci 2007).

7. Different subtypes of tests (ELISA, latex agglutination test, and Western blot methods of serological tests; formal serological tests versus bedside serological tests; and monoclonal versus polyclonal antibodies for stool antigen tests).

8. Interval between index test and reference standard. Resolution of $H$ pylori infection in people with $\mathrm{H}$ pylori infection (usually with treatment) and infection in those without $H$ pylori infection may occur if there was a long interval between the index test and reference standard.

We formally investigated heterogeneity for each test by adding a covariate to a HSROC model (meta-regression). We used likelihood ratio tests to assess the statistical significance of differences in test accuracy by comparing models with and without the covariate.

\section{Sensitivity analyses}

We planned to examine the impact of data inconsistencies on the meta-analytic findings. For example, if test accuracy data reported in the text of a paper differed from those in the figures, we planned to assess the impact of using different data in sensitivity analyses; however, we did not find such inconsistencies.

\section{Assessment of reporting bias}

Due to limited data, we were unable to formally investigate whether test accuracy differed between studies that were published as full texts and those available only as abstracts.

\section{RE S U L T S}

\section{Results of the search}

We identified 23,896 references through electronic searches of MEDLINE, Embase, Science Citation Index, and NIHR HTA. We did not identify additional references through other searches. The flow of studies through the screening process is shown in Figure 2. After removing 10,313 duplicates, there were 13,583 references. Of these, we dropped 11,737 irrelevant references through reading the titles and abstracts. We could not obtain the full text of 11 references. The quality of copies of two references was too poor to allow translation and we were unable to obtain better copies. We assessed the full text of the remaining 1833 references. We excluded 1728 references (1727 studies) for reasons stated in Appendix 7 (also see Characteristics of excluded studies below). The remaining 107 references (101 studies) met our inclusion criteria. Two references reported diagnostic accuracy data separately for people who underwent gastrectomy and those who did not undergo gastrectomy, and so we considered these subgroups as separate studies (Adamopoulos 2009a; Adamopoulos 2009b; Sheu 1998a; Sheu 1998b). 
Figure 2. Study flow diagram.

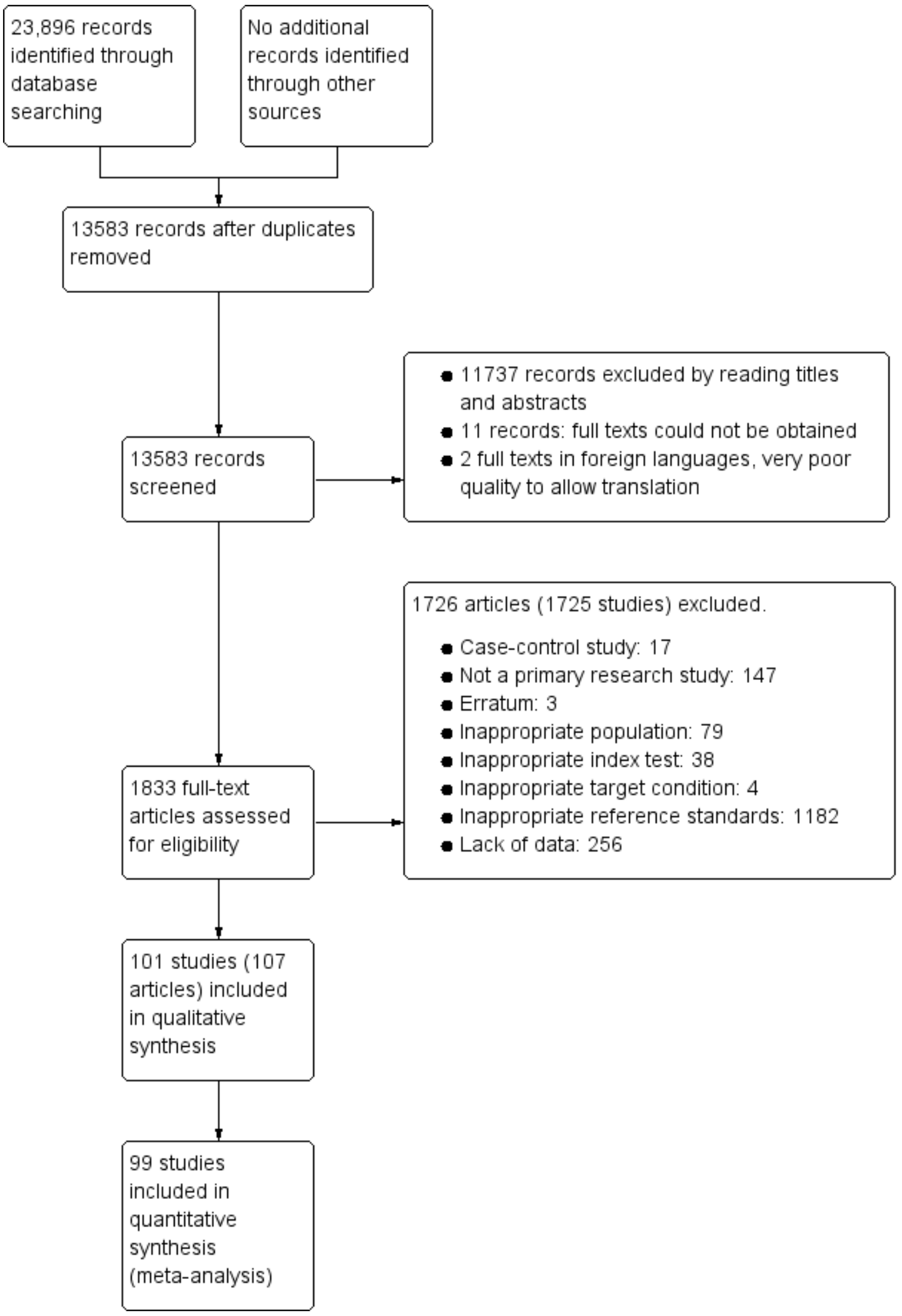




\section{Characteristics of included studies}

We summarise the characteristics of the 101 included studies in the Characteristics of included studies table. The studies included 11,003 participants, of which 5839 participants $(53.1 \%)$ had $H$ pylori infection. The prevalence of $\mathrm{H}$ pylori infection ranged from $15.2 \%$ to $94.7 \%$ with a median of $53.7 \%$ (interquartile range: $42.0 \%$ to $66.5 \%$ ).

Of the 101 studies, 34 evaluated urea breath test-13C; 21 evaluated urea breath test- ${ }^{14} \mathrm{C}$; two evaluated urea breath test but did not report the isotope used; 34 evaluated serology; and 29 evaluated stool antigen test. Seventeen studies evaluated more than one test. Of these, 15 evaluated two tests (Dede 2015; El-Din 2013; Eltumi 1999; Hafeez 2007; Inelmen 2004; Korstanje 2006; Kuloglu 2008; Lahner 2004; Lottspeich 2007; Mansour-Ghanaei 2011; Ogata 2001; Soomro 2012; Vandenplas 1992; Yoshimura 2001; Yu 2001), and two evaluated three tests (Monteiro 2001a; Salles-Montaudon 2002). Studies used different thresholds, with 15 studies reporting test accuracy at more than one threshold (Chey 1998; Dede 2015; Delvin 1999; Formichella 2013; Ladas 2002a; Mana 2001a; Misawa 1998; Monteiro 2001a; Morales 1995; Noguera 1998; Novis 1991; Ozturk 2003; Trevisani 2005; Weiss 1994; Yu 2001).

Eleven studies were prospective (Adamopoulos 2009a; Adamopoulos 2009b; Al-Fadda 2000; Arikan 2004; Dede 2015; Eltumi 1999; Fallone 1995; Kalach 1998a; Kuloglu 2008; Ogata 2001; Qadeer 2009); six studies were retrospective (Bosso 2000; Czerwionka-Szaflarska 2007; Graham 1996a; Iqbal 2013; Mion 1994; Wardi 2012), while the remaining 84 studies did not state whether they were prospective or retrospective studies. Six studies were published as abstracts only (Han 2012; Mohammadian 2007; Rathbone 1986; Sheu 1998a; Sheu 1998b; Thobani 1995), and the remaining 95 were full-text publications.

Fourteen studies included only children (Argentieri 2007; Behrens 1999; Czerwionka-Szaflarska 2007; Delvin 1999; Dinler 1999; Eltumi 1999; Hafeez 2007; Kalach 1998a; Kuloglu 2008; Lottspeich 2007; Ogata 2001; Rafeey 2007; Vandenplas 1992; Yoshimura 2001). Five studies clearly included only adults (Atli 2012; Chen 1991; Kamel 2011; Safe 1993; Salles-Montaudon 2002). Although not clearly specified in the remaining 82 studies, it appeared that most or all of the participants were adults. The mean or median age of the participants included in these studies ranged between 31 years and 85 years in the 45 studies that reported this information. One study included only participants without symptoms (Wang 2008). Fiftyeight studies included only participants with symptoms, usually abdominal pain or dyspepsia (Adamopoulos 2009a; Adamopoulos 2009b; Aguilar 2007; Al-Fadda 2000; Allardyce 1997; Behrens 1999; Bosso 2000; Ceken 2011; Chen 1991; Czerwionka-Szaflarska 2007; D'Elios 2000; Delvin 1999; Dinler 1999; Ekesbo 2006; El-Din 2013; El-Mekki 2011; El-Nasr 2003; Eltumi 1999; Fanti 1999; Faruqui 2007; Ferrara 1998; Germana 2001; Guo 2011; Gurbuz 2005; Hafeez 2007; Jordaan 2008; Kamel 2011; Kuloglu 2008; Ladas 2002a; Lahner 2004; Lee 1998; Lottspeich 2007; Mansour-Ghanaei 2011; Mion 1994; Misawa 1998; Mohammadian 2007; Morales 1995; Novis 1991; Ogata 2001; Ozturk 2003; Peitz 2001; Qadeer 2009; Rafeey 2007; Rasool 2007; Rathbone 1986; Safe 1993; Scuderi 2000; Segamwenge 2014; Selcukcan 2011; Sharbatdaran 2013; Sheu 1998a; Soomro 2012; Surveyor 1989; Thobani 1995; Vandenplas 1992; Villalobos 1992; Weiss 1994; Yoshimura 2001). The remaining 42 studies did not report the type of participants included. Five studies included only participants who had previously undergone gastrectomy (Adamopoulos 2009b; Lombardo 2003; Schilling 2001;
Sheu 1998b; Wardi 2012). Two studies included only participants with atrophic gastritis (Korstanje 2006; Ogata 2001). It was clear that participants who received recent proton pump inhibitors or antibiotics were excluded from 53 studies (Ceken 2011; Chey 1998; Debongnie 1991; D'Elios 2000; Delvin 1999; Duan 1999; El-Mekki 2011; El-Nasr 2003; Eltumi 1999; Fallone 1996; Fanti 1999; Ferrara 1998; Formichella 2013; Germana 2001; Guo 2011; Gurbuz 2005; Jekarl 2013; Jensen 1998; Jordaan 2008; Kalach 1998a; Kim 2016; Kuloglu 2008; Ladas 2002a; Lahner 2004; Lee 1998; Lombardo 2003; Lottspeich 2007; Mana 2001a; Mansour-Ghanaei 2011; Monteiro 2001a; Ogata 2001; Ozturk 2003; Peitz 2001; Peura 1996; Puspok 1999; Qadeer 2009; Rafeey 2007; Rasool 2007; Schilling 2001; Segamwenge 2014; Selcukcan 2011; Sharbatdaran 2013; Shin 2009; Tiwari 2014; Trevisani 2005; Vandenplas 1992; Villalobos 1992; Wang 2008; Weiss 1994; Yan 2003; Yoshimura 2001; Yu 1999; Yu 2001). It was not clear whether such participants were included or excluded in the remaining 48 studies.

Thirty-two studies used H \& E stain as a reference standard (Aguilar 2007; Al-Fadda 2000; Arikan 2004; Atli 2012; Behrens 1999; Ceken 2011; Chen 1991; Chey 1998; Czerwionka-Szaflarska 2007; D'Elios 2000; Dinler 1999; Eggers 1990; El-Nasr 2003; Fallone 1996; Faruqui 2007; Graham 1996a; Gramley 1999; Gurbuz 2005; Iqbal 2013; Jordaan 2008; Kalach 1998a; Kamel 2011; Lee 1998; Logan 1991a; Noguera 1998; Puspok 1999; Segamwenge 2014; Selcukcan 2011; Sheu 1998a; Sheu 1998b; Tiwari 2014; Yu 2001); 24 studies used special stains such as Warthin-Starry stain, Giemsa stain, or silver stain (Argentieri 2007; Bosso 2000; El-Din 2013; Fallone 1995; Guo 2011; Hafeez 2007; Han 2012; Ivanova 2010; Kim 2016; Ladas 2002a; Lahner 2004; Mion 1994; Mohammadian 2007; Morales 1995; Novis 1991; Ozturk 2003; Peura 1996; Qadeer 2009; Schilling 2001; Scuderi 2000; Shin 2009; Soomro 2012; Villalobos 1992; Yan 2003); two studies used immunohistochemical staining (Ekesbo 2006; Misawa 1998); and the remaining 43 studies used a combination of different stains.

The interval between the index test and reference standard was reported only in 21 studies. The interval was less than two weeks in 19 of the 21 studies (Adamopoulos 2009a; Adamopoulos 2009b; Bosso 2000; Debongnie 1991; Duan 1999; Fallone 1995; Fallone 1996; Formichella 2013; Gurbuz 2005; Hafeez 2007; Lahner 2004; Lee 1998; Logan 1991a; Lottspeich 2007; Mansour-Ghanaei 2011; Mion 1994; Ozturk 2003; Peura 1996; Safe 1993), and was between 15 days and 23 days in one study (Dede 2015); it was within 30 days in the remaining study (Lombardo 2003).

\section{Characteristics of excluded studies}

We excluded 1726 references (1725 studies). The reason for exclusion is stated for each study in Appendix 7 and summarised below.

- Case-control study: 17

- Not a primary research study: 147

- Erratum: 3 
- Inappropriate population: 79

* In monitoring: 33

* Not in humans: 1

* Only in $H$ pylori negative people: 2

* Only in H pylori positive people: 39

* Only in people with gastrointestinal bleeding: 2

* Selection of participants was based on the results of other $H$ pylori tests: 1

* Includes people who were being monitored for $\mathrm{H}$ pylori status: 1

- Inappropriate index test: 38

- Inappropriate target condition: 4

- Inappropriate reference standards: 1182
- Lack of data: 256

* Insufficient diagnostic test accuracy data: 25

* No diagnostic accuracy data: 42

* Not a diagnostic test accuracy study of non-invasive $H$ pylori diagnosis: 188

* Incorrect data (correct information could not be obtained): 1

\section{Methodological quality of included studies}

The methodological quality of the included studies is summarised across all studies in Figure 3. None of the included studies was of high methodological quality (i.e. low risk of bias in all the domains). Appendix 8 shows the results for individual studies for urea breath test- ${ }^{13} \mathrm{C}$, urea breath test- ${ }^{14} \mathrm{C}$, serology and the stool antigen test, respectively.

Figure 3. Risk of bias and applicability concerns graph: review authors' judgements about each domain presented as percentages across included studies. For each domain, the numbers shown on the bar represent the number of studies that were scored as high, unclear or low in terms of risk of bias or applicability concern.

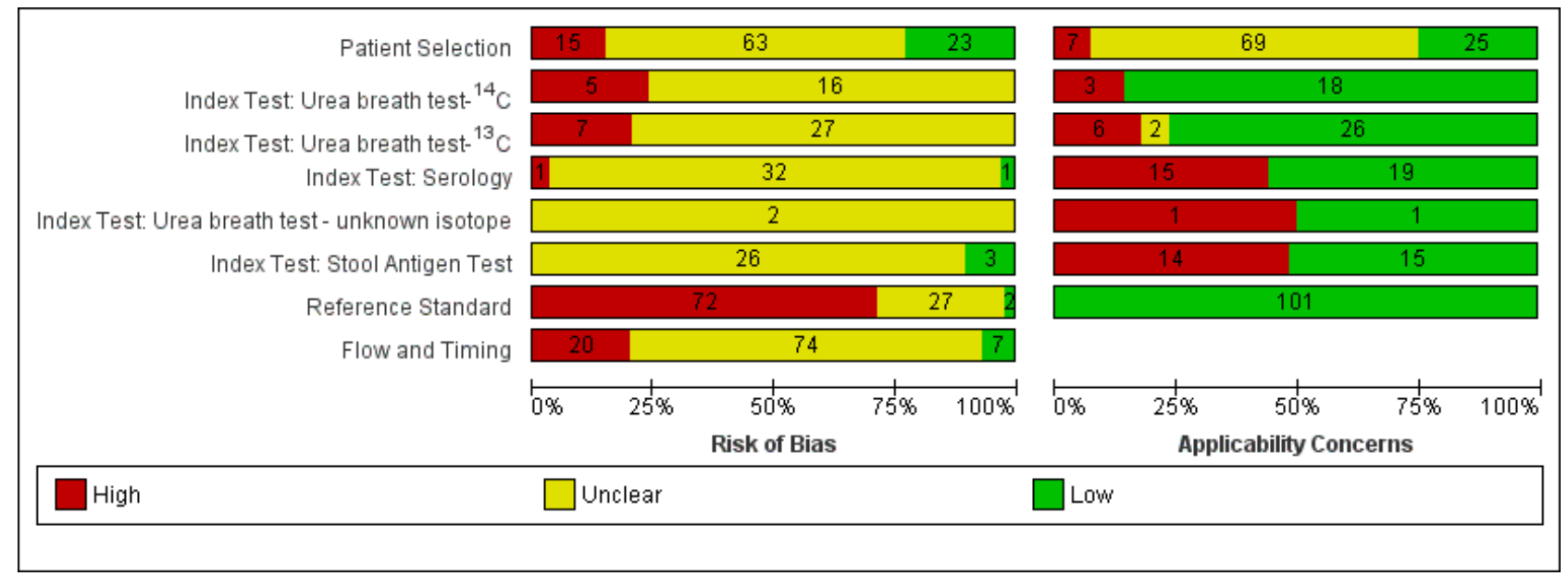

\section{Patient selection domain}

In the patient selection domain, 23, 15 and 63 studies were at low, high and unclear risk of bias, respectively. All 15 studies were at high risk of bias because they did not include a consecutive or random series of participants.

Twenty-five, seven and 69 studies were of low, high and unclear applicability concern. In the 69 studies of unclear applicability concern it was not clear whether participants similar to those seen in the clinical setting where the test is used were excluded, while the seven studies of high concern clearly excluded such participants. In these seven studies, only people who had undergone gastrectomy or those with atrophic gastritis were included.

\section{Index test domain}

In the index test domain, studies generally had an unclear risk of bias because it was unclear whether the index test results were interpreted without the knowledge of the results of the reference standard, and/or it was unclear whether a threshold was prespecified.

\section{Urea breath test}

None of the studies that evaluated the urea breath test $\left({ }^{13} \mathrm{C},{ }^{14} \mathrm{C}\right.$ or unknown isotope) were at low risk of bias. The risk of bias was unclear in the two studies that did not report the type of isotope (Han 2012; Lombardo 2003). Of the 34 studies that evaluated urea breath test- ${ }^{13} \mathrm{C}$, seven (21\%) had a high risk of bias while $27(79 \%)$ had unclear risk of bias. There were 21 studies of urea breath test- ${ }^{14} \mathrm{C}, 16(76 \%)$ of which had unclear risk of bias while five $(24 \%)$ had high risk of bias.

For the two studies with unknown isotope, applicability concern was high in one study and low in the other. Of the 34 urea breath test- ${ }^{13} \mathrm{C}$ studies, applicability concerns were unclear for two (6\%) studies, high for six (18\%) studies and low for $26(76 \%)$ studies. For urea breath test-14C, applicability concerns were generally low $(18 / 21 ; 86 \%)$ with only three studies having high applicability concerns (Selcukcan 2011; Surveyor 1989; Yu 1999).

\section{Serology}

One study (Ladas 2002a), had a low risk of bias.and another study (Rathbone 1986), had a high risk of bias. The risk of bias for the remaining $32(94 \%)$ studies was unclear. Applicability concerns were low in 19 (56\%) studies and high in 15 (44\%) studies. 


\section{Stool antigen test}

None of the 29 studies had a high risk of bias. Most of the studies (26/29; 90\%) had an unclear risk of bias; three studies (Islam 2005; Kuloglu 2008; Sharbatdaran 2013), had a low risk of bias. All the studies were of low applicability concern.

\section{Reference standard domain}

Two studies were at low risk of bias in the reference standard domain (Fallone 1995; Ladas 2002a). For 27 studies, the risk of bias was unclear because it was not clear whether reference standard results were interpreted without knowledge of the results of the index tests. The remaining 72 studies were at high risk of bias because the reference standard was endoscopic biopsy with $\mathrm{H}$ \& $\mathrm{E}$ stain in some or all participants.

All the studies were of low applicability concern.

\section{Flow and timing domain}

Seven studies were at low risk of bias in the flow and timing domain. The risk of bias was unclear for 74 studies because the interval between the index test and reference standard was unclear or it was unclear whether all participants were included in the analysis.
The remaining 20 studies were at high risk of bias because some participants were clearly excluded from the analysis. These studies did not report the reference standard results for the excluded participants. None of the studies reported indeterminate results (i.e. there were no indeterminate index test results in studies which provided a clear participant flow and none of the exclusions were due to indeterminate index test results).

\section{Findings}

\section{Urea breath test-13C}

The 34 studies of urea breath test- ${ }^{13} \mathrm{C}$ included 3139 participants, of whom 1526 had $H$ pylori infection (Figure 4). The threshold used in six studies was either unknown (Eggers 1990; Monteiro 2001a), or unclear (Sheu 1998a; Sheu 1998b; Vandenplas 1992; Wardi 2012). At the most commonly reported threshold of delta over baseline $>4 \%$ (30 minutes after administration of urea), the summary sensitivity (95\% confidence interval $(\mathrm{Cl}))$ and specificity $(95 \% \mathrm{Cl})$ from 10 studies (958 participants) were 0.95 ( $95 \% \mathrm{Cl} 0.79$ to $0.99)$ and 0.95 ( $95 \% \mathrm{Cl} 0.87$ to 0.98$)$. Other thresholds were used by a limited number of studies (Figure 5; Appendix 9). When possible we performed meta-analysis to estimate summary sensitivities and specificities at these common thresholds. The results are presented in Table 1.

Figure 4. Forest plot of urea breath test-13C.FN = false negative; $F P=$ false positive; $T N=$ true negative; $T P=$ true positive. The forest plot shows an estimate of sensitivity and specificity from each study and the threshold used. Studies are sorted by threshold, sensitivity and specificity. For threshold, the number of minutes in brackets is the time after administration of urea.

Study
Mion 1994
Ogata 2001
Epple 1997
Logan 1991a
Kim 2016
Yu 2001
Yoshimura 2001
Mana 2001a
Delvin 1999
Salles-Montaudon 2002
Czerwionka-Szaflarska 2007
Hafeez 2007
Adamopoulos 2009b
Schilling 2001
Korstanje 2006
Bosso 2000
D'Elios 2000
Germana 2001
Fallone 1995
Adamopoulos 2009a
Lahner 2004
Jordaan 2008
Duan 1999
Eltumi 1999
Behrens 1999
Inelmen 2004
Lottspeich 2007
Lee 1998
Sheu 1998b
Wardi 2012
Vandenplas 1992
Sheu 1998a
Monteiro 2001a
Eggers 1990

$\begin{array}{rrrr}\text { TP } & \text { FP } & \text { FN } & \text { TN } \\ 32 & 6 & 1 & 56 \\ 22 & 8 & 1 & 16 \\ 74 & 7 & 3 & 42 \\ 31 & 0 & 3 & 16 \\ 54 & 18 & 4 & 31 \\ 12 & 3 & 4 & 13 \\ 42 & 3 & 2 & 25 \\ 84 & 6 & 0 & 92 \\ 12 & 0 & 0 & 67 \\ 18 & 19 & 6 & 64 \\ 21 & 5 & 10 & 64 \\ 31 & 8 & 3 & 12 \\ 6 & 0 & 9 & 16 \\ 13 & 3 & 12 & 40 \\ 5 & 3 & 1 & 11 \\ 32 & 6 & 1 & 56 \\ 113 & 2 & 3 & 138 \\ 54 & 1 & 1 & 44 \\ 23 & 1 & 0 & 26 \\ 43 & 1 & 0 & 29 \\ 5 & 3 & 5 & 14 \\ 55 & 3 & 5 & 40 \\ 96 & 5 & 7 & 41 \\ 17 & 3 & 2 & 28 \\ 129 & 7 & 7 & 98 \\ 41 & 7 & 13 & 61 \\ 41 & 0 & 0 & 15 \\ 46 & 1 & 1 & 23 \\ 20 & 0 & 14 & 32 \\ 9 & 6 & 5 & 56 \\ 24 & 5 & 3 & 63 \\ 106 & 1 & 2 & 26 \\ 43 & 2 & 3 & 56 \\ 41 & 31 & 0 & 28 \\ & & \end{array}$

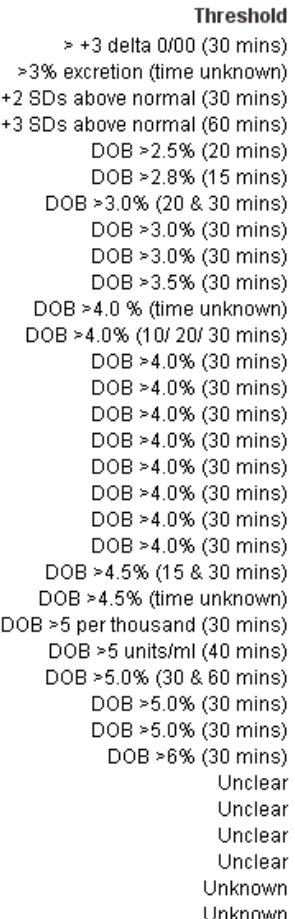

Sensitivity $(95 \% \mathrm{Cl})$
$0.97[0.84,1.00]$
$0.96[0.78,1.00]$
$0.96[0.89,0.99]$
$0.91[0.76,0.98]$
$0.93[0.83,0.98]$
$0.75[0.48,0.93]$
$0.95[0.85,0.99]$
$1.00[0.96,1.00]$
$1.00[0.74,1.00]$
$0.75[0.53,0.90]$
$0.68[0.49,0.83]$
$0.91[0.76,0.98]$
$0.40[0.16,0.68]$
$0.52[0.31,0.72]$
$0.83[0.36,1.00]$
$0.97[0.84,1.00]$
$0.97[0.93,0.99]$
$0.98[0.90,1.00]$
$1.00[0.85,1.00]$
$1.00[0.92,1.00]$
$0.50[0.19,0.81]$
$0.92[0.82,0.97]$
$0.93[0.86,0.97]$
$0.89[0.67,0.99]$
$0.95[0.90,0.98]$
$0.76[0.62,0.87]$
$1.00[0.91,1.00]$
$0.98[0.89,1.00]$
$0.59[0.41,0.75]$
$0.64[0.35,0.87]$
$0.89[0.71,0.98]$
$0.98[0.93,1.00]$
$0.93[0.82,0.99]$
$1.00[0.91,1.00]$
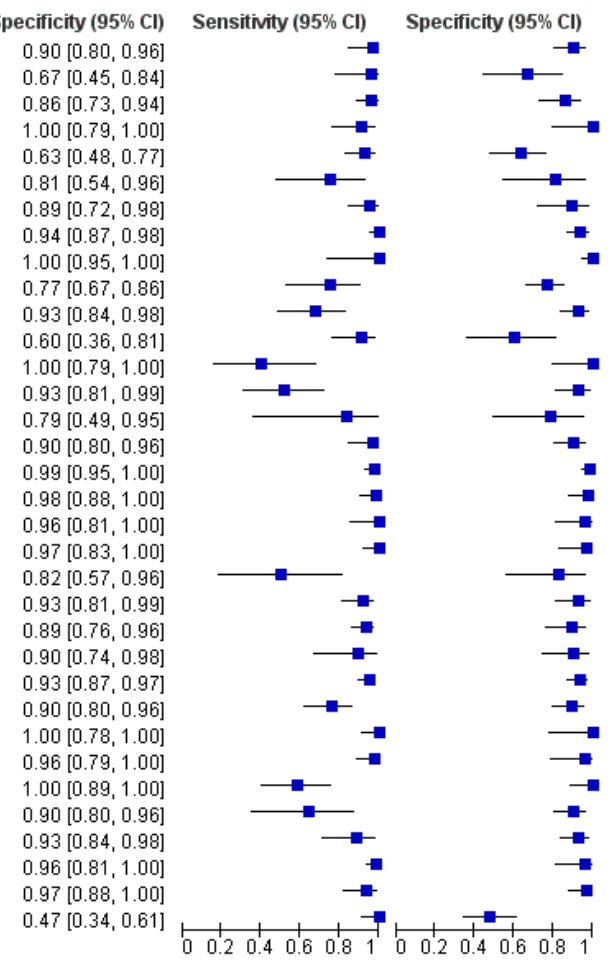
Figure 5. Forest plot of urea breath test-13C at commonly reported thresholds. $F N=$ false negative; $F P=f a l s e$ positive; TN = true negative; TP = true positive. Thresholds are shown in brackets and the number of minutes in brackets is the time after administration of urea.

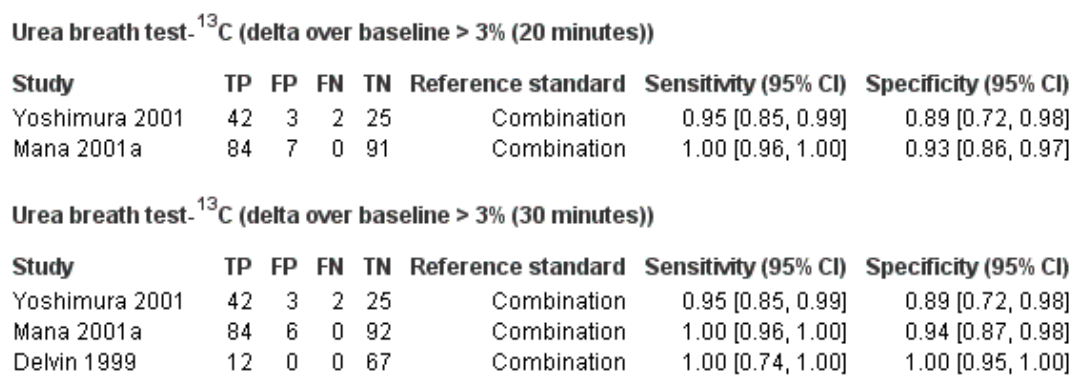

Urea breath test- ${ }^{13} \mathrm{C}$ (delta over baseline $>3.5 \%$ (30 minutes))

Study

TP FP FN TN Reference standard S

Salles-Montaudon $2002 \quad 18 \quad 19 \quad 6 \quad 64$

$\begin{array}{lllll}\text { Mana 2001a } & 84 & 5 & 0 & 93\end{array}$

Delvin 1999

$\begin{array}{llll}12 & 0 & 0 & 67\end{array}$

Combination

Combination

Combination
$0.75[0.53,0.90]$

$1.00[0.96,1.00]$

$1.00[0.74,1.00]$

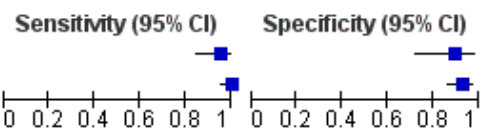

Sensitivity $(95 \% \mathrm{Cl}) \quad$ Specificity $(\mathbf{9 5} \% \mathrm{Cl})$

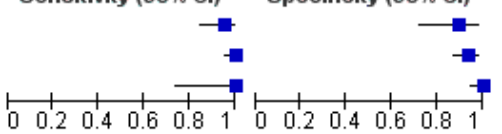

Urea breath test- ${ }^{13} \mathrm{C}$ (delta over baseline $>4 \%$ (10 minutes))

$\begin{array}{lrrrrrrr}\text { Study } & \text { TP } & \text { FP } & \text { FN } & \text { TN } & \text { Reference standard } & \text { Sensitivity }(95 \% \text { Cl) } & \text { Specificity }(95 \% \text { Cl) } \\ \text { Mana 2001a } & 84 & 5 & 0 & 93 & \text { Combination } & 1.00[0.96,1.00] & 0.95[0.88,0.98]\end{array}$

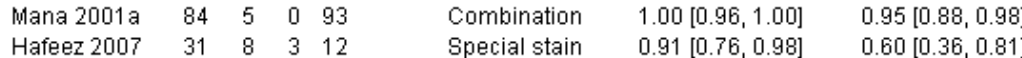

Urea breath test- ${ }^{13} \mathrm{C}$ (delta over baseline $>4 \%(20$ minutes))

Study TP FP FN TN Reference standard Sensitivity $(95 \% \mathrm{Cl})$ Specificity $(95 \% \mathrm{Cl})$

Mana 2001a $84 \quad 4 \quad 0 \quad 94 \quad$ Combination $1.00[0.96,1.00] \quad 0.96[0.90,0.99]$

Hafeez $2007 \quad 31 \quad 8 \quad 3 \quad 12 \quad$ Special stain $0.91[0.76,0.98] \quad 0.60[0.36,0.81]$

Urea breath test- ${ }^{13} \mathrm{C}$ (delta over baseline $>4 \%(30$ minutes))

Study TP FP FN TN Reference standard Sensitivity $(\mathbf{9 5} \% \mathrm{Cl})$ Specificity $(\mathbf{9 5} \% \mathrm{Cl})$ $\begin{array}{lllllllr}\text { Adamopoulos 2009b } & 6 & 0 & 9 & 16 & \text { Combination } & 0.40[0.16,0.68] & 1.00[0.79,1.00]\end{array}$ Korstanje $2006 \quad 5 \quad 3 \quad 1 \quad 11 \quad$ Combination $\quad 0.83[0.36,1.00] \quad 0.79[0.49,0.95]$ $0.98[0.90,1.00]$ Mana 2001a $\quad 83 \quad 4 \quad 1 \quad 94 \quad$ Combination $0.99[0.94,1.00]$ Adamopoulos 2009a $\quad 43 \quad 1 \quad 0 \quad 29 \quad$ Combination $1.00[0.92,1.00]$ Delvin $1999 \quad 12 \quad 0 \quad 0 \quad 67$ D'Elios $2000 \quad 113 \quad 2 \quad 3 \quad 138$

Bosso 2000

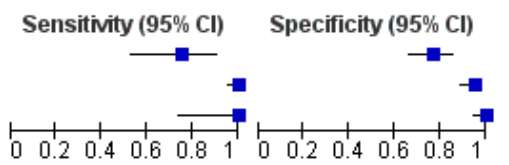

Urea breath test- ${ }^{13} \mathrm{C}$ (delta over baseline $>4.5 \%$ (30 minutes))

$\begin{array}{lrrrrrrr}\text { Study } & \text { TP } & \text { FP } & \text { FN } & \text { TN } & \text { Reference standard } & \text { Sensitivity (95\% Cl) } & \text { Specificity (95\% Cl) } \\ \text { Mana 2001a } & 81 & 4 & 3 & 94 & \text { Combination } & 0.96[0.90,0.99] & 0.96[0.90,0.99] \\ \text { Delvin 1999 } & 12 & 0 & 0 & 67 & \text { Combination } & 1.00[0.74,1.00] & 1.00[0.95,1.00] \\ \text { Lahner 2004 } & 5 & 3 & 5 & 14 & \text { Special stain } & 0.50[0.19,0.81] & 0.82[0.57,0.96]\end{array}$

$\begin{array}{llllllll}\text { Lahner } 2004 & 5 & 3 & 5 & 14 & \text { Special stain } & 0.50[0.19,0.81] & 0.82[0.57,0.96]\end{array}$

Urea breath test- ${ }^{13} \mathrm{C}$ (delta over baseline $>5 \%$ (30 minutes))

Study TP FP FN TN Reference standard Sensitivity $(95 \% \mathrm{Cl})$ Specificity $(\mathbf{9 5} \% \mathrm{Cl})$

$\begin{array}{llllllll}\text { Inelmen } 2004 & 41 & 7 & 13 & 61 & \text { Combination } & 0.76[0.62,0.87] & 0.90[0.80,0.96]\end{array}$

$\begin{array}{llllllll}\text { Mana 2001a } & 81 & 4 & 3 & 94 & \text { Combination } 0.96[0.90,0.99] & 0.96[0.90,0.99]\end{array}$

Lottspeich $2007 \quad 41 \quad 0 \quad 0 \quad 15 \quad$ Combination $\quad 1.00[0.91,1.00] \quad 1.00[0.78,1.00]$

$\begin{array}{lrlllrlr}\text { Behrens } 1999 & 129 & 7 & 7 & 98 & \text { H\&E stain } & 0.95[0.90,0.98] & 0.93[0.87,0.97]\end{array}$
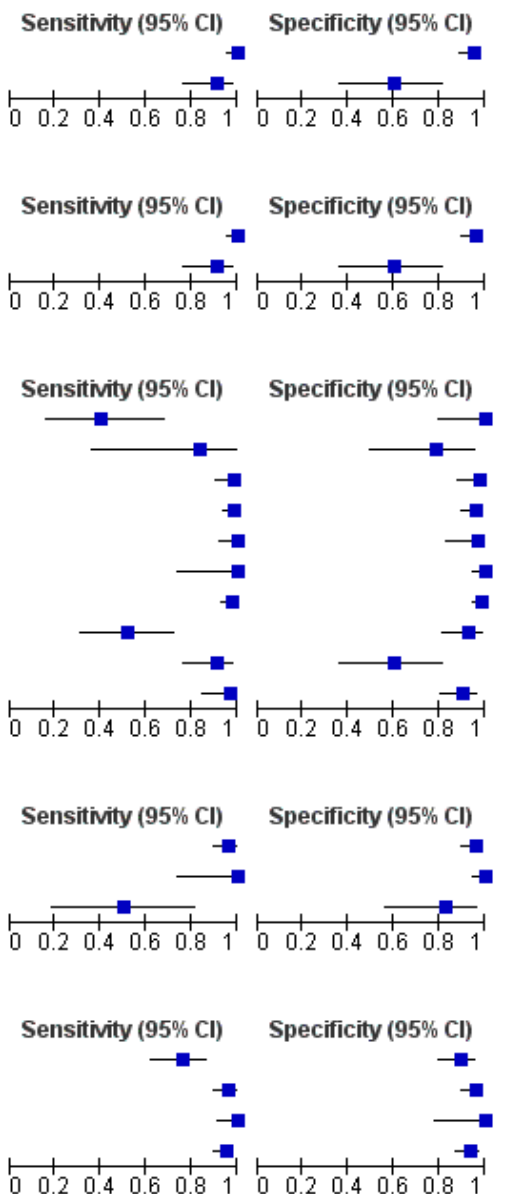

\section{Urea breath test-14C}

Figure 6 shows the 21 studies of urea breath test- ${ }^{14} \mathrm{C}$. The studies included 1810 participants (involving $1018 \mathrm{H}$ pylori cases). Three studies did not state the thresholds used (Selcukcan 2011; Surveyor 1989; Yu 1999). The two most commonly used thresholds were counts per minute $>50$ (10 minutes after administration of urea) in six studies (471 participants) and disintegrations per minute $>$ 
200 (10 minutes) in four studies (296 participants) (Table 1). Test accuracy results for other thresholds are shown in Appendix 9. The summary sensitivity $(95 \% \mathrm{Cl})$ and specificity $(95 \% \mathrm{Cl})$ at the counts per minute $>50$ threshold were $0.89(95 \% \mathrm{Cl} 0.55$ to 0.98$)$ and
0.91 ( $95 \% \mathrm{Cl} 0.79$ to 0.96$)$. For the disintegrations per minute $>200$ threshold, the summary sensitivity $(95 \% \mathrm{Cl})$ and specificity $(95 \% \mathrm{Cl})$ were 0.95 ( $95 \% \mathrm{Cl} 0.33$ to 1.00 ) and 0.95 (95\% $\mathrm{Cl} 0.80$ to 0.99$)$.

Figure 6. Forest plot of urea breath test-14C. $\mathrm{FN}=$ false negative; $\mathrm{FP}=$ false positive; $\mathrm{TN}=$ true negative; $\mathrm{TP}=\mathrm{true}$ positive. The forest plot shows an estimate of sensitivity and specificity from each study and the threshold used. Studies are sorted by threshold, sensitivity and specificity. For threshold, the number of minutes in brackets is the time after administration of urea.

Study
Noguera 1998
Novis 1991
Al-Fadda 2000
Dede 2015
Gurbuz 2005
Atli 2012
Rasool 2007
Kuloglu 2008
Ozturk 2003
Mansour-Ghanaei 2011
Villalobos 1992
Tiwari 2014
Aguilar 2007
Peura 1996
Jensen 1998
Allardyce 1997
Debongnie 1991
Selcukcan 2011
Surveyor 1989
Yu 1999
Morales 1995

\begin{tabular}{rrrr}
\multicolumn{1}{r}{ TP } & FP & FN & TN \\
19 & 3 & 3 & 13 \\
19 & 2 & 7 & 13 \\
54 & 2 & \\
29 & 9 & 5 & 21 \\
2 & 0 & 5 & 23 \\
26 & 3 & 8 & 28 \\
32 & 3 & 4 & 61 \\
61 & 2 & 5 & 26 \\
37 & 10 & 3 & 59 \\
48 & 6 & 0 & 19 \\
65 & 2 & 4 & 54 \\
75 & 6 & 1 & 23 \\
19 & 0 & 8 & 3 \\
23 & 0 & 1 & 7 \\
63 & 7 & 2 & 128 \\
16 & 2 & 0 & 17 \\
24 & 2 & 0 & 37 \\
119 & 9 & 8 & 92 \\
79 & 5 & 13 & 3 \\
30 & 2 & 2 & 25 \\
44 & 2 & 0 & 35 \\
62 & 5 & 12 & 25
\end{tabular}

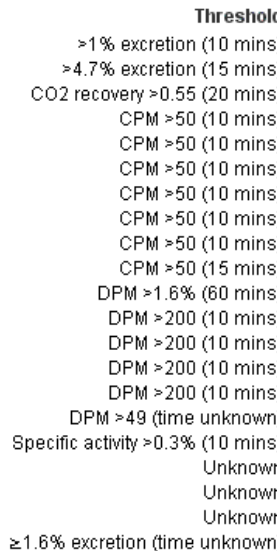

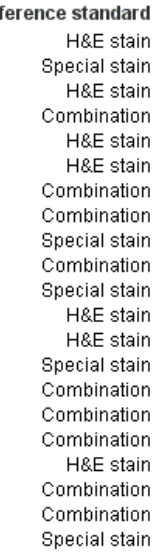

Sensitivity $(95 \% \mathrm{Cl})$
$0.86[0.65,0.97]$
$0.89[0.78,0.95]$
$0.85[0.69,0.95]$
$0.29[0.04,0.71]$
$0.76[0.59,0.89]$
$0.89[0.74,0.97]$
$0.92[0.83,0.97]$
$0.93[0.80,0.98]$
$1.00[0.93,1.00]$
$0.94[0.86,0.98]$
$0.99[0.93,1.00]$
$0.70[0.50,0.86]$
$0.96[0.79,1.00]$
$0.97[0.89,1.00]$
$1.00[0.79,1.00]$
$1.00[0.86,1.00]$
$0.94[0.88,0.97]$
$0.86[0.77,0.92]$
$0.94[0.79,0.99]$
$1.00[0.92,1.00]$
$0.84[0.73,0.91]$

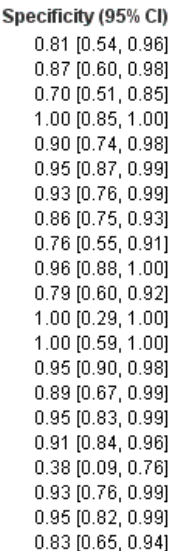

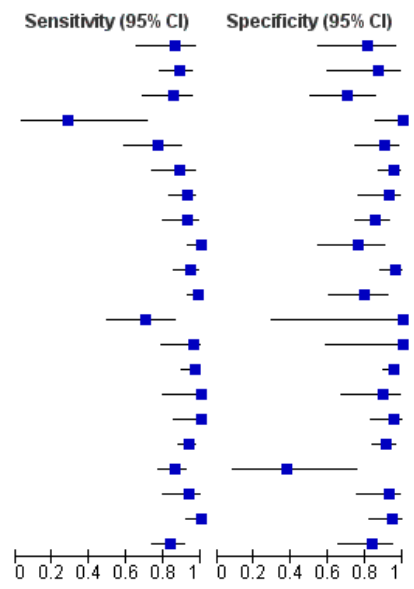

\section{Serology}

Serology was evaluated in 34 studies with a total of 4242 participants, of whom 2477 had $H$ pylori infection (Figure 7). There was considerable variation in the thresholds used but $14(41 \%)$ studies did not state the thresholds used. A threshold of $>7$ units/ $\mathrm{ml}$ was used in two studies (Iqbal 2013; Ogata 2001), involving
97 participants, and two studies involving 234 participants (Ladas 2002a; Monteiro 2001a) used a threshold of $\geq 300$ units (Table 1 ). The summary sensitivity $(95 \% \mathrm{Cl})$ and specificity $(95 \% \mathrm{Cl})$ at the $>7$ units $/ \mathrm{mL}$ threshold were 0.98 ( $95 \% \mathrm{Cl} 0.74$ to 1.00$)$ and $0.71(95 \% \mathrm{Cl}$ 0.51 to 0.86 ), and 0.91 ( $95 \% \mathrm{Cl} 0.82$ to 0.96$)$ and $0.86(95 \% \mathrm{Cl} 0.72$ to 0.93 ) for the $\geq 300$ units threshold. 
Figure 7. Forest plot of serology. FN = false negative; $F P=$ false positive; $S D=$ standard deviation; $T N=$ true negative; TP = true positive. The forest plot shows an estimate of sensitivity and specificity from each study and the threshold used. Studies are sorted by threshold, sensitivity and specificity. Other threshold is staining of a 120kDa protein (CagA) gel band and/or at least two of five proteins between 28-33 kDa.

$\begin{array}{lrrrr}\text { Study } & \text { TP } & \text { FP } & \text { FN } & \text { TN } \\ \text { El-Mekki 2011 } & 38 & 2 & 4 & 11 \\ \text { Safe 1993 } & 53 & 3 & 6 & 38 \\ \text { Mansour-Ghanaei 2011 } & 65 & 22 & 4 & 34 \\ \text { Thobani 1995 } & 14 & 0 & 2 & 10 \\ \text { Salles-Montaudon 2002 } & 21 & 8 & 3 & 75 \\ \text { Kalach 1998a } & 37 & 7 & 7 & 49 \\ \text { Iqbal 2013 } & 24 & 6 & 1 & 19 \\ \text { Ogata 2001 } & 23 & 8 & 0 & 16 \\ \text { Rathbone 1986 } & 39 & 1 & 3 & 30 \\ \text { Vandenplas 1992 } & 24 & 3 & 3 & 65 \\ \text { Korstanje 2006 } & 6 & 6 & 0 & 8 \\ \text { Shin 2009 } & 449 & 80 & 25 & 97 \\ \text { Chen 1991 } & 51 & 12 & 24 & 9 \\ \text { Ekesbo 2006 } & 67 & 1 & 24 & 34 \\ \text { Graham 1996a } & 67 & 0 & 0 & 8 \\ \text { Chey 1998 } & 115 & 25 & 16 & 131 \\ \text { Fallone 1996 } & 35 & 9 & 18 & 44 \\ \text { Wang 2008 } & 76 & 5 & 39 & 3 \\ \text { Ferrara 1998 } & 44 & 10 & 16 & 30 \\ \text { Soomro 2012 } & 66 & 2 & 24 & 8 \\ \text { Peitz 2001 } & 77 & 9 & 20 & 39 \\ \text { vanova 2010 } & 19 & 5 & 4 & 5 \\ \text { Dinler 1999 } & 48 & 11 & 10 & 8 \\ \text { El-Din 2013 } & 16 & 1 & 2 & 0 \\ \text { Misawa 1998 } & 79 & 1 & 5 & 29 \\ \text { Eltumi 1999 } & 18 & 6 & 1 & 25 \\ \text { Luthra 1998 } & 107 & 45 & 5 & 83 \\ \text { Mohammadian 2007 } & 72 & 32 & 3 & 72 \\ \text { Weiss 1994 } & 48 & 3 & 2 & 42 \\ \text { Gramley 1999 } & 11 & 0 & 0 & 11 \\ \text { Yoshimura 2001 } & 41 & 3 & 3 & 25 \\ \text { Formichella 2013 } & 205 & 11 & 5 & 279 \\ \text { Ladas 2002a } & 86 & 8 & 11 & 25 \\ \text { Monteiro 2001a } & 44 & 5 & 2 & 53 \\ & & & & \end{array}$

\begin{tabular}{|c|c|}
\hline Threshold & Sensitivity ( $95 \% \mathrm{Cl})$ \\
\hline$>1$ unitsiml & $0.90[0.77,0.97]$ \\
\hline$>10$ unitsiml & $0.90[0.79,0.96]$ \\
\hline$\Rightarrow 11 \mathrm{IU}$ & $0.94[0.86,0.98]$ \\
\hline$>2$ units & $0.88[0.62,0.98]$ \\
\hline$>300$ Units & $0.88[0.68,0.97]$ \\
\hline$>6 \mathrm{IU} / \mathrm{ml}$ & $0.84[0.70,0.93]$ \\
\hline$>7$ unitsiml & $0.96[0.80,1.00]$ \\
\hline$>7$ unitsiml & $1.00[0.85,1.00]$ \\
\hline -Mean +2 SDs above normal & $0.93[0.81,0.99]$ \\
\hline$>$ Mean +3 SDs above normal & $0.89[0.71,0.98]$ \\
\hline bsorbance (WL unknown) $>0.320$ & $1.00[0.54,1.00]$ \\
\hline Absorbance $450 \mathrm{~nm}>0.406$ & $0.95[0.92,0.97]$ \\
\hline Agglutination (within 3 minutes) & $0.68[0.56,0.78]$ \\
\hline Other & $0.74[0.63,0.82]$ \\
\hline Pink line & $1.00[0.95,1.00]$ \\
\hline Two red lines & $0.88[0.81,0.93]$ \\
\hline Unknown & $0.66[0.52,0.78]$ \\
\hline Unknown & $0.66[0.57,0.75]$ \\
\hline Unknown & $0.73[0.60,0.84]$ \\
\hline Unknown & $0.73[0.63,0.82]$ \\
\hline Unknown & $0.79[0.70,0.87]$ \\
\hline Unknown & $0.83[0.61,0.95]$ \\
\hline Unknown & $0.83[0.71,0.91]$ \\
\hline Unknown & $0.89[0.65,0.99]$ \\
\hline Unknown & $0.94[0.87,0.98]$ \\
\hline Unknown & $0.95[0.74,1.00]$ \\
\hline Unknown & $0.96[0.90,0.99]$ \\
\hline Unknown & $0.96[0.89,0.99]$ \\
\hline Unknown & $0.96[0.86,1.00]$ \\
\hline Unknown & $1.00[0.72,1.00]$ \\
\hline$\geq 1.8$ units & $0.93[0.81,0.99]$ \\
\hline$\succeq 2$ or more antigens & $0.98[0.95,0.99]$ \\
\hline$\geq 300$ units & $0.89[0.81,0.94]$ \\
\hline$\succeq 300$ units & $0.96[0.85,0.99]$ \\
\hline
\end{tabular}
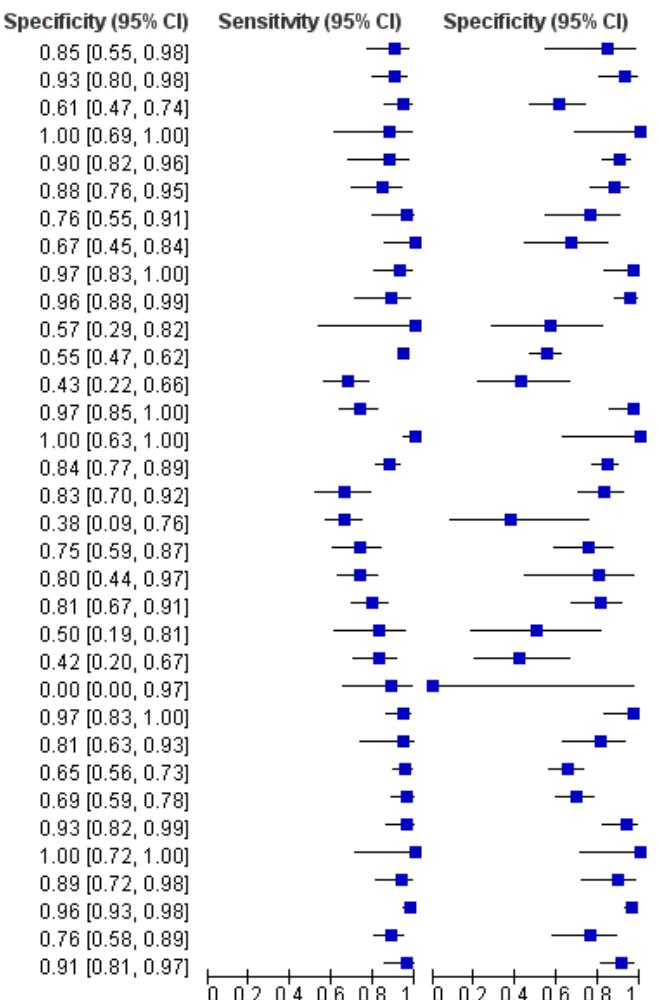

\section{Stool antigen test}

Twenty-nine studies assessed the stool antigen test in 2988 participants (including $1311 \mathrm{H}$ pylori cases) (Figure 8). The threshold used was unknown in almost half of the studies (14/29, 48\%). None of the thresholds reported were used by more than one study. Summary estimates of sensitivity and specificity were therefore not obtained at a common threshold. 
Figure 8. Forest plot of stool antigen test. $F N=$ false negative; $F P=$ false positive; $T N=$ true negative; $T P=$ true positive; $W L=$ wavelength. The forest plot shows an estimate of sensitivity and specificity from each study and the threshold used. Studies are sorted by threshold, sensitivity and specificity.

\begin{tabular}{|c|c|c|c|c|c|c|c|c|c|}
\hline Study & TP & FP & FN & TN & Threshold & Sensitivity (95\% Cl) & Specificity (95\% Cl) & Sensitivity (95\% Cl) & Specificity ( $95 \% \mathrm{Cl})$ \\
\hline Jekarl 2013 & 71 & 30 & 2 & 106 & Absence of yellow & $0.97[0.90,1.00]$ & $0.78[0.70,0.85]$ & & 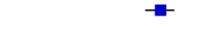 \\
\hline Salles-Montaudon 2002 & 18 & 3 & 6 & 80 & Absorbance (WL unknown) $>0.160$ & $0.75[0.53,0.90]$ & $0.96[0.90,0.99]$ & & \\
\hline Monteiro 2001a & 42 & 6 & 4 & 52 & Absorbance (WL unknown) $\geq 0.160$ & $0.91[0.79,0.98]$ & $0.90[0.79,0.96]$ & & \\
\hline Sharbatdaran 2013 & 25 & 2 & 13 & 21 & Absorbance $450 \mathrm{~nm}>+0.1$ of negative control & $0.66[0.49,0.80]$ & $0.91[0.72,0.99]$ & & \\
\hline Yu 2001 & 15 & 4 & 1 & 12 & Absorbance $450 \mathrm{~nm}>0.140$ & $0.94[0.70,1.00]$ & $0.75[0.48,0.93]$ & & \\
\hline Lahner 2004 & 4 & 0 & 6 & 17 & Absorbance $450 \mathrm{~nm} \succeq 0.160$ & $0.40[0.12,0.74]$ & $1.00[0.80,1.00]$ & & \\
\hline Trevisani 2005 & 52 & 1 & 7 & 44 & Absorbance $450 \mathrm{~nm} \geq 0.190$ & $0.88[0.77,0.95]$ & $0.98[0.88,1.00]$ & $=$ & \\
\hline Lottspeich 2007 & 44 & 0 & 2 & 54 & Absorbance $450 / 620 \mathrm{~nm}$ to $650 \mathrm{~nm} \geq 0.150$ & $0.96[0.85,0.99]$ & $1.00[0.93,1.00]$ & $\rightarrow$ & \\
\hline Puspok 1999 & 16 & 1 & 4 & 51 & Absorbance $450 / 620 \mathrm{~nm} \geq 0.100$ & $0.80[0.56,0.94]$ & $0.98[0.90,1.00]$ & & \\
\hline Islam 2005 & 15 & 7 & 5 & 85 & Absorbance $450 / 630 \mathrm{~nm}>0.120$ & $0.75[0.51,0.91]$ & $0.92[0.85,0.97]$ & & \\
\hline Yan 2003 & 18 & 4 & 1 & 8 & Absorbance $450 / 630 \mathrm{~nm}>0.120$ & $0.95[0.74,1.00]$ & $0.67[0.35,0.90]$ & & \\
\hline Fanti 1999 & 54 & 1 & 2 & 27 & Absorbance $450 / 630 \mathrm{~nm}>0.150$ & $0.96[0.88,1.00]$ & $0.96[0.82,1.00]$ & $\rightarrow$ & \\
\hline Inelmen 2004 & 39 & 9 & 15 & 59 & Definite yellow colour & $0.72[0.58,0.84]$ & $0.87[0.76,0.94]$ & & \\
\hline Qadeer 2009 & 39 & 6 & 3 & 52 & Pink-red band (time unknown) & $0.93[0.81,0.99]$ & $0.90[0.79,0.96]$ & & \\
\hline Kuloglu 2008 & 26 & 5 & 14 & 64 & Pink-red band (within 10 mins) & $0.65[0.48,0.79]$ & $0.93[0.84,0.98]$ & & \\
\hline Soomro 2012 & 47 & 1 & 43 & 9 & Unknown & $0.52[0.41,0.63]$ & $0.90[0.55,1.00]$ & $\rightarrow$ & \\
\hline Rafeey 2007 & 34 & 7 & 28 & 27 & Unknown & $0.55[0.42,0.68]$ & $0.79[0.62,0.91]$ & $\rightarrow$ & -- \\
\hline Segamwenge 2014 & 30 & 29 & 24 & 84 & Unknown & $0.56[0.41,0.69]$ & $0.74[0.65,0.82]$ & $\rightarrow-$ & - \\
\hline El-Nasr 2003 & 15 & 1 & 11 & 23 & Unknown & $0.58[0.37,0.77]$ & $0.96[0.79,1.00]$ & $\rightarrow$ & \\
\hline Argentieri 2007 & 37 & 10 & 27 & 141 & Unknown & $0.58[0.45,0.70]$ & $0.93[0.88,0.97]$ & $\rightarrow-$ & \\
\hline Ceken 2011 & 42 & 0 & 19 & 39 & Unknown & $0.69[0.56,0.80]$ & $1.00[0.91,1.00]$ & & \\
\hline Dede 2015 & 5 & 1 & 2 & 22 & Unknown & $0.71[0.29,0.96]$ & $0.96[0.78,1.00]$ & . & \\
\hline El-Din 2013 & 13 & 1 & 5 & 0 & Unknown & $0.72[0.47,0.90]$ & $0.00[0.00,0.97]$ & & \\
\hline Kamel 2011 & 18 & 22 & 4 & 11 & Unknown & $0.82[0.60,0.95]$ & $0.33[0.18,0.52]$ & $=-$ & $\rightarrow-$ \\
\hline Hafeez 2007 & 30 & 9 & 4 & 11 & Unknown & $0.88[0.73,0.97]$ & $0.55[0.32,0.77]$ & $\longrightarrow$ & \\
\hline Arikan 2004 & 74 & 3 & 8 & 15 & Unknown & $0.90[0.82,0.96]$ & $0.83[0.59,0.96]$ & $\rightarrow$ & \\
\hline Scuderi 2000 & 113 & 24 & 12 & 101 & Unknown & $0.90[0.84,0.95]$ & $0.81[0.73,0.87]$ & & - \\
\hline Faruqui 2007 & 27 & 1 & 2 & 20 & Unknown & $0.93[0.77,0.99]$ & $0.95[0.76,1.00]$ & $\rightarrow$ & \\
\hline Guo 2011 & 70 & 8 & 4 & 246 & Unknown & $0.95[0.87,0.99]$ & $0.97[0.94,0.99]$ & & \\
\hline
\end{tabular}

\section{Comparative accuracy of non-invasive tests for $\mathrm{H}$ pylori} infection

\section{Comparison based on all studies (Indirect test comparison)}

Across the four tests (urea breath test- ${ }^{13} \mathrm{C}$, urea breath test- ${ }^{14} \mathrm{C}$, serology and stool antigen test) 99 studies (5694 cases; 10799 participants) were included in this comparative meta-analysis (Figure 9). Preliminary assessment of each test separately indicated there was no significant association between test accuracy and threshold, and so a symmetric SROC curve is plausible for each test. Based on these preliminary assessments, and likelihood ratio tests comparing different HSROC meta-regression models with covariate terms for test type and examination of the variance parameters in these models, the final model we fitted allowed for differences in accuracy and threshold as random effects (i.e. unequal variances for the random effects) with symmetric SROC curves for the tests. Overall, there was statistical evidence of a difference in accuracy ( $P$ $=0.024)$. The DORs $(95 \% \mathrm{Cl})$ for urea breath test- $13 \mathrm{C}$, urea breath test- ${ }^{14} \mathrm{C}$, serology and stool antigen test were $153(95 \% \mathrm{Cl} 73.7$ to 316$), 105$ (95\% Cl 74.0 to 150), 47.4 (95\% Cl 25.5 to 88.1) and 45.1 ( $95 \% \mathrm{Cl} 24.2$ to 84.1 ) respectively (Table 2$)$. The accuracy of urea breath tests $\left({ }^{13} \mathrm{C}\right.$ and $\left.{ }^{14} \mathrm{C}\right)$ was significantly higher than that of serology and stool antigen test. For example, the ratio of DORs (95\%) for urea breath test-13C compared to serology was 3.22 (95\% $\mathrm{Cl} 1.24$ to 8.37$), \mathrm{P}=0.017$. 
Figure 9. Summary ROC plot of non-invasive tests for $H$ pylori infection. The SROC curves for the four tests are parallel. The curve for each test is drawn within the range of estimates of specificity from the studies included for the test.

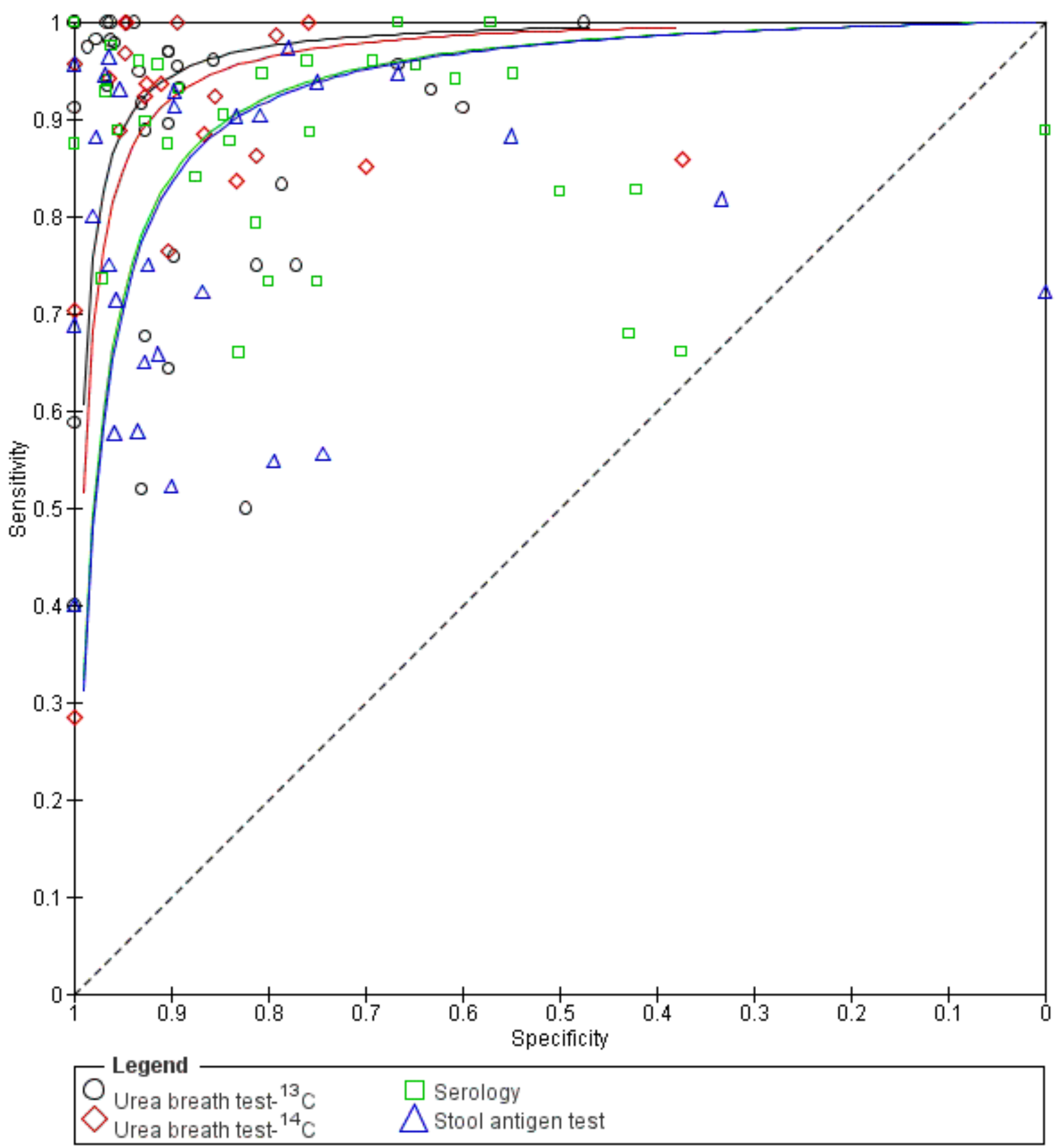

Table 3 shows the clinical implications of using each of the four tests in a hypothetical cohort of 1000 people with different levels of prevalence of $H$ pylori infection. For example, given a prevalence of $53.7 \%$ and a specificity of $0.90,46$ people who do not have $H$ pylori infection will be treated and urea breath test-13C, urea breath test- ${ }^{14} \mathrm{C}$, serology and stool antigen test will miss $30,42,86$ and 89 people respectively who have $H$ pylori infection.

\section{Direct comparisons (restricted to comparative studies)}

Direct comparisons were based on few studies. Table 4 shows the number of studies $(N)$ for each pairwise comparison and, where meta-analysis was possible, the ratio of DORs with $95 \% \mathrm{Cls}$ and $\mathrm{P}$ value. There were no comparative studies of urea breath test-13C and urea breath test-14C. All other comparisons were based on seven or fewer studies. Each pair of tests were evaluated as follows: 
- Urea breath test-13C versus serology (Figure 10): seven studies (Eltumi 1999; Korstanje 2006; Monteiro 2001a; Ogata 2001; Salles-Montaudon 2002; Vandenplas 1992; Yoshimura 2001).

- Urea breath test-13C versus stool antigen test (Figure 11): seven studies (Hafeez 2007; Inelmen 2004; Lahner 2004; Lottspeich 2007; Monteiro 2001a; Salles-Montaudon 2002; Yu 2001).
- Urea breath test- ${ }^{14} \mathrm{C}$ versus serology: two studies (Dede 2015; Kuloglu 2008).

- Urea breath test-14C versus serology: one study (MansourGhanaei 2011).

- Serology versus stool antigen test: four studies (El-Din 2013; Monteiro 2001a; Salles-Montaudon 2002; Soomro 2012).

Figure 10. Summary ROC plot of direct comparisons of urea breath test-13C and serology. Each summary curve was drawn restricted to the range of specificities for each test. The size of each symbol was scaled according to the precision of sensitivity and specificity in the study. A dotted line joins the pair of points for the two tests from each study.

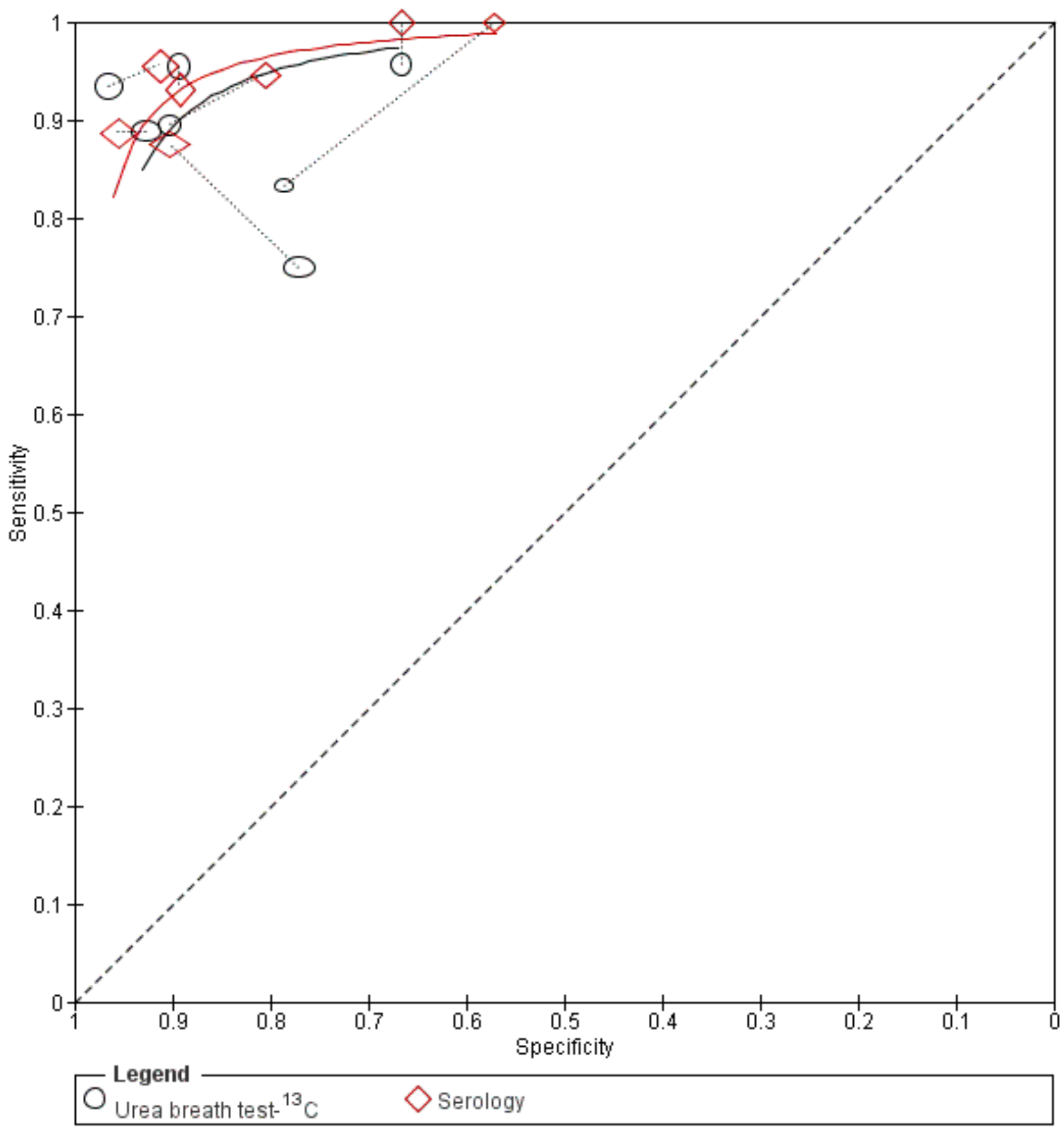


Figure 11. Summary ROC plot of direct comparisons of urea breath test-13C and stool antigen test. Each summary curve was drawn restricted to the range of specificities for each test. The size of each symbol was scaled according to the precision of sensitivity and specificity in the study. A dotted line joins the pair of points for the two tests from each study.

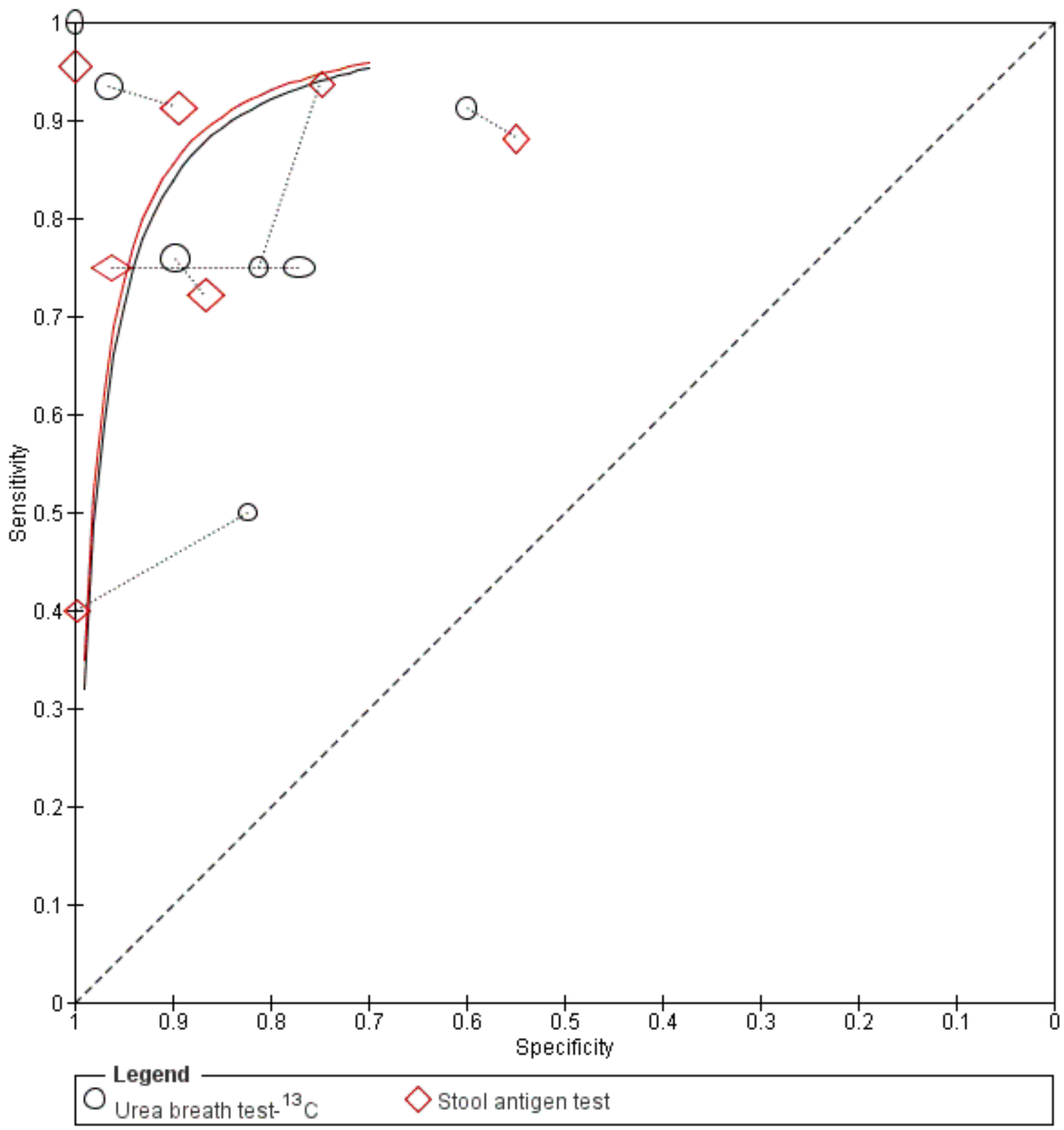

The ratios of DORs ( $95 \% \mathrm{Cl}$; $\mathrm{P}$ value) were $0.68(95 \% \mathrm{Cl} 0.12$ to $3.70 ; \mathrm{P}=0.56)$ for urea breath test- $13 \mathrm{C}$ versus serology, and 0.88 $(95 \% \mathrm{Cl} 0.14$ to $5.56 ; \mathrm{P}=0.84)$ for urea breath test-13C versus stool antigen test. Due to paucity of data and substantial heterogeneity observed in ROC space which precluded the use of simpler metaanalytic models, meta-analyses were not possible for the other two test comparisons that had more than one study. For the single study of urea breath test-14C versus serology (Mansour-Ghanaei 2011), both tests had similar sensitivity, but specificity was higher for urea breath test- ${ }^{14} \mathrm{C}$ than for serology. 


\section{Investigation of heterogeneity}

We were unable to investigate subtype of tests because most of the serological tests were ELISA (17/20 (85\%) studies that provided the type of serology test) and most studies (24/29 (83\%) studies) did not report whether monoclonal or polyclonal antibodies were used for stool antigen tests. Studies did not report the precise interval between index test and reference standard (unless they were performed on the same day), i.e. many studies did not report the interval at all, while some reported that the tests were performed within a few days of each other without stating the exact time interval. Of those that reported the interval, only two studies had an interval of more than two weeks (Dede 2015; Lombardo 2003). For each of the four tests, Appendix 10 shows the number of studies in each subgroup of other factors we had planned to investigate. Given the availability of data, we were only able to perform meta-regression to investigate the effect of reference standard on the accuracy of each test. Of the 99 studies, $42(42 \%)$ used a combination of stains and there were few data for Immunohistochemical stains (2/99;2\%). The analyses were therefore limited to comparisons of $H$ \& $E$ stain versus special stain for each test (Appendix 11). Although the effect of reference standard was not consistent across tests, there was no statistical evidence of a difference in test accuracy for any of the tests. For urea breath test- ${ }^{14} \mathrm{C}$, the DOR for special stain was higher than for $\mathrm{H}$ \& $\mathrm{E}$ stain, while for the other tests the DOR of both types of stain were similar or higher for $\mathrm{H}$ \& $\mathrm{E}$ (Appendix 11).

\section{DISCUSSION}

\section{Summary of main results}

We included 101 studies (11,003 participants) that evaluated the diagnostic accuracy of different non-invasive methods for the diagnosis of $H$ pylori. Of these 11,003 participants, 5839 participants (53.1\%) had $H$ pylori infection. The prevalence of $H$ pylori infection ranged from $15.2 \%$ to $94.7 \%$. The median prevalence was $53.7 \%$ (lower quartile: $42.0 \%$ and upper quartile: $66.5 \%$ ).

The summary of results for urea breath test- ${ }^{13} \mathrm{C}$, urea breath test- ${ }^{14} \mathrm{C}$, serology and stool antigen test is given in Summary of findings 1 . The studies used different thresholds and reference standards. As a result, there were few data for pooling sensitivities and specificities at specific thresholds, and we mainly estimated and compared SROC curves. The test comparison based on all available data (99 studies) for the four tests showed a statistically significant difference in diagnostic accuracy between the test $(P$ $=0.024)$. There was no statistical evidence of a difference in diagnostic accuracy between urea breath test- ${ }^{13} \mathrm{C}$ and urea breath test- ${ }^{14} \mathrm{C}$, while serology and stool antigen test were inferior to both urea breath tests. Direct comparisons are more reliable than indirect comparisons, due to the potential for confounding in indirect comparisons (Takwoingi 2013). However, we found few head-to-head studies and meta-analysis was possible for only two pairwise comparisons (urea breath test- ${ }^{13} \mathrm{C}$ versus serology, seven studies; and urea breath test-13C versus stool antigen test, seven studies).

Most of the tests that used visual assessment (for example, appearance of a pink-red line) were stool antigen tests, although some serology tests also used visual assessment. Some serology and stool antigen tests are therefore easy to use (stool antigen test is easier to use as described below), but low diagnostic accuracy is a disadvantage when compared to urea breath tests. Urea breath test is a cumbersome test and involves the use of radioisotopes; however, urea breath test- ${ }^{13} \mathrm{C}$ may be the most accurate test among the non-invasive tests. This has implications in the screening of individuals for $\mathrm{H}$ pylori as a decision has to be made regarding the use of a cumbersome and relatively costly test but with good diagnostic accuracy versus cheap tests that can be performed easily but with lower diagnostic accuracy. A further decision to make if one opts for easy-to-use tests is the threshold at which the test should be used. For example, one can use a threshold that provides higher sensitivity (at the cost of lower specificity, necessitating endoscopic biopsy confirmation or treatment) or a threshold that provides higher specificity (at the cost of lower sensitivity, resulting in people with $H$ pylori not being treated). Although at first sight it appears that the treatment for $\mathrm{H}$ pylori is relatively harmless and one would prefer a threshold at which the test has higher sensitivity rather than higher specificity, the decision to give antibiotics is not a straightforward one, because of the association between unnecessary antibiotic use and development of antimicrobial resistance (Llor 2014). Serology and stool antigen test have similar diagnostic test accuracy and the choice between the two may be made based on ease of carrying out the tests. Only one study included in this review used whole blood for performing serology (Chey 1998). Even this test required a laboratory technician to interpret the test result (Chey 1998). So, there are no bedside tests available for serology testing. On the other hand, bedside kits with easy interpretation by colour changes are available for stool antigen tests, making them easy to administer (Inelmen 2004; Jekarl 2013; Kuloglu 2008; Qadeer 2009; Trevisani 2005). A costeffectiveness study may clarify the most cost-effective non-invasive test in people with suspected $H$ pylori, but it is difficult to factor in the price of antimicrobial resistance to an individual as the price of antimicrobial resistance is paid by future generations (through increased mortality and decreased productivity), rather than the individual for whom the treatment decision has to be made (Taylor 2014).

\section{Strengths and weaknesses of the review}

We conducted a thorough literature search and included full-text publications and abstracts without any language restrictions. There are currently no reliable search strategies to identify diagnostic test accuracy studies (Beynon 2013). We did not use any diagnostic filter in our search strategy, thereby ensuring that studies on the topic were identified. Two review authors independently identified and extracted data from the studies, potentially decreasing errors related to single data extraction. PCR methodology is not standardised across laboratories and it is an unreliable reference standard (Chey 2007). Endoscopic biopsy followed by rapid urease testing has poor sensitivity following treatment with proton pump inhibitors, and endoscopic biopsy with culture has high specificity but poor sensitivity (Chey 2007). We used a strict reference standard (histology) which is likely to diagnose the target condition with a high degree of accuracy. These are the major strengths of the review.

A major limitation was the diversity of thresholds used in the studies. As a result, data were sparse for each threshold, which limited estimation of summary sensitivities and specificities. Therefore there is insufficient evidence to recommend specific thresholds for each of the tests. Nonetheless, we were able to estimate and compare SROC curves by including studies with 
different thresholds. There was a high proportion of studies at high risk of bias and with high concern regarding applicability in all the four domains of the QUADAS-2 tool. This makes the validity and applicability of the results questionable. The major concerns were lack of reporting of the threshold used or when the thresholds were reported, there was no information to judge whether the thresholds were prespecified. Despite the lack of statistical evidence of an effect of type of reference standard on test accuracy, as there were few studies for each subgroup and other differences between studies, we cannot conclude that diagnostic accuracy does not depend on type of reference standard.

\section{Comparison with other systematic reviews}

We identified several relevant systematic reviews (Ferwana 2015; Gisbert 2001; Gisbert 2004a; Loy 1996; Zhou 2014; Zhou 2017). The findings from this review support those of Zhou 2017, and Ferwana 2015 , that urea breath test has high diagnostic accuracy and that there was significant heterogeneity in the diagnostic accuracy of the urea breath test (Zhou 2017). Our findings agree with those of Zhou 2014 that stool antigen test has only modest diagnostic test accuracy. The review findings are contrary to those of Gisbert 2001, and Gisbert 2004a, which suggested that stool antigen tests are highly accurate. This difference may be due to the strict reference standards that we used in this review and how we handled the issue of heterogeneity in thresholds. In agreement with the findings of Loy 1996, the role of serology in clinical practice is uncertain, as stool antigen tests provide equivalent diagnostic accuracy to serology and are easier to interpret.

\section{Applicability of findings to the review question}

This review included adults and children who underwent noninvasive tests for the diagnosis of $H$ pylori. Most of the studies included only symptomatic people and so the findings of this review are applicable only to people with symptoms. Most studies excluded people who had previous gastrectomy and those who had recent antibiotics or proton pump inhibitors. Hence, the findings of this review are not applicable in these populations.

\section{AUTHORS' CONCLUSIONS}

\section{Implications for practice}

In people with no history of gastrectomy and those who have not recently had antibiotics or proton pump inhibitors, urea breath tests had high diagnostic accuracy while serology and stool antigen tests had lower accuracy to detect $H$ pylori infection. Although susceptible to bias due to confounding, this conclusion is based on evidence from indirect test comparisons, as evidence from direct comparisons was based on few studies or was unavailable. There was high or unclear risk of bias for many studies with respect to the selection of participants, and the conduct and interpretation of the index tests and reference standard. The thresholds used for these tests were highly variable, thus there is insufficient evidence to identify specific thresholds that might be useful in clinical practice.

\section{Implications for research}

Further comparative studies of high methodological quality are necessary to obtain more reliable evidence of accuracy between the tests (urea breath tests, serology, and stool antigen tests) in people with upper gastrointestinal symptoms and people without any symptoms suggestive of $H$ pylori. Such studies should be conducted prospectively in a representative spectrum of participants, and be clearly reported to ensure low risk of bias. Most importantly, studies should pre-specify and clearly report the thresholds used, should apply appropriate reference standards such as endoscopic biopsy with special stains, and should avoid inappropriate exclusions.

\section{ACK N O WLEDGEMENTS}

We thank the Cochrane Upper Gastrointestinal and Pancreatic Diseases (UGPD) Group, and the DTA editorial team for their advice in the preparation of this review. We thank the copy editors for improving the readability of the review. 


\section{RE F E R E N C E S}

\section{References to studies included in this review}

\section{Adamopoulos 2009a \{published data only\}}

Adamopoulos AB, Stergiou GS, Saklzlis GN, Tiniakos DG, Nasothimiou EG, Sioutis DK, et al. Diagnostic value of rapid urease test and urea breath test for Helicobacter pylori detection in patients with Billroth ii gastrectomy: A prospective controlled trial. Digestive and Liver Disease 2009;41(1):4-8.

\section{Adamopoulos 2009b \{published data only\}}

Adamopoulos AB, Stergiou GS, Saklzlis GN, Tiniakos DG, Nasothimiou EG, Sioutis DK, et al. Diagnostic value of rapid urease test and urea breath test for Helicobacter pylori detection in patients with Billroth ii gastrectomy: A prospective controlled trial. Digestive and Liver Disease 2009;41(1):4-8.

\section{Aguilar 2007 \{published data only\}}

Aguilar RC, Saavedra SP, Mendoza PG, Bussalleu RA, Cok GJ, Martinez MF, et al. Study of urease test or breath test (BT) and correlation with gastric biopsy to detect Helicobacter pylori (hp) in dyspeptic patients at "Hospital Nacional Cayetano Heredia hospital" (HNCH)--Lima. Revista de Gastroenterologia del Peru 2007;27(2):172-6.

\section{Al-Fadda 2000 \{published data only\}}

Al-Fadda M, Powe J, Rezeig M, Al Nazer M, Alrajhi AA, Baynton R. Comparison of carbon-14-urea breath test and rapid urease test with gastric biopsy for identification of Helicobacter pylori. Annals of Saudi Medicine 2000;20(2):170-2.

\section{Allardyce 1997 \{published data only\}}

Allardyce RA, Chapman BA, Tie ABM, Burt MJ, Yeo KJ, Keenan JI, et al. $37 \mathrm{KBQ}$ C-14-urea breath test and gastric biopsy analyses of H-pylori infection. Australian and New Zealand Journal of Surgery 1997;67(1):31-4.

\section{Argentieri 2007 \{published data only\}}

Argentieri M, Sabbi T, Pansani L, Torroni F, Francalanci P, De Angelis $\mathrm{P}$, et al. Helicobacter pylori infection in children: Utility of culture in diagnosis and study of resistance to metronidazole, clarithromycin and amoxicillin. Journal of Pediatric Infectious Diseases 2007;2(3):135-9.

\section{Arikan 2004 \{published data only\}}

Arikan S, Kocakusak A, Barut G, Sengoz G, Yucel AF, Gokturk K. Helicobacter pylori stool antigen test: Results of a prospective study. Surgery Today 2004;34(4):318-22.

\section{Atli 2012 \{published data only\}}

Atli T, Sahin S, Arslan BU, Varli M, Yalcin AE, Aras S. Comparison of the $\mathrm{C} 14$ urea breath test and histopathology in the diagnosis of Helicobacter pylori in the elderly. Journal of the Pakistan Medical Association 2012;62(10):1061-5

\section{Behrens 1999 \{published data only\}}

* Behrens R, Lang T, Keller KM, Bindl L, Becker M, Rodeck B, et al. Dual versus triple therapy of Helicobacter pylori infection: Results of a multicentre trial. Archives of Disease in Childhood 1999;81(1):68-70.
Behrens R, Lang T, Keller KM, Bindl L, Becker M, Rodeck B, et al. Helicobacter pylori infection in children and adolescents. Diagnosis and treatment. [German]. Tagliche Praxis 2001;42(3):473-83.

\section{Bosso 2000 \{published data only\}}

Bosso S, Balbo L, Lerro P, Kuvidi M, Musso A, Ansaldi N. Antigen detection in stools as a first choice for laboratory diagnosis of Helicobacter pylori disease. Minerva Gastroenterologica e Dietologica 2000;46(1):15-8.

\section{Ceken 2011 \{published data only\}}

Ceken N, Yurtsever SG, Baran N, Alper E, Buyrac Z, Unsal B. Comparison of Helicobacter pylori antibody detection in stool with other diagnostic tests for infection. Asian Pacific Journal of Cancer Prevention 2011;12(4):1077-81.

\section{Chen 1991 \{published data only\}}

Chen CF, Lee MH, Ng JL, Lin CY, Yeh HW, Huang TW. A rapid latex test for the serological diagnosis of Helicobacter pylori. Chinese Journal of Gastroenterology 1991;8(4):266-70.

\section{Chey 1998 \{published data only\}}

Chey WD, Murthy UK, Linscheer W, Barish C, Riff D, Rubin H, et al. The ChemTrak Hp Chek fingerstick whole blood serology test for the detection of Helicobacter pylori infection. American Journal of Gastroenterology 1998;93(1):16-9.

\section{Czerwionka-Szaflarska 2007 \{published data only\}}

Czerwionka-Szaflarska M, Brazowski J, Kupczyk W. Value of urease breath test in Helicobacter pylori infection diagnostics among children and youth. Medycyna Wieku Rozwojowego 2007;11(2 Pt 1):97-101.

D'Elios 2000 \{published data only\}

D'Elios MM, Amedei A, Benagiano M, Azzurri A, Del Prete G. Usefulness of $13 \mathrm{C}$-urea breath test in the diagnosis of gastric Helicobacter pylori infection. International Journal of Immunopathology and Pharmacology 2000;13(1):27-30.

\section{Debongnie 1991 \{published data only\}}

Debongnie JC, Pauwels S, Raat A, De Meeus Y, Haot J, Mainguet P. Quantification of Helicobacter pylori infection in gastritis and ulcer disease using a simple and rapid carbon-14urea breath test. Journal of Nuclear Medicine 1991;32(6):1192-8.

\section{Dede 2015 \{published data only\}}

Dede F, Civen H, Dane F, Aliustaoglu M, Turhal S, Turoglu HT, et al. Carbon-14 urea breath test: Does it work in patients with partial gastric resection?. Annals of Nuclear Medicine 2015;29(9):786-91.

\section{Delvin 1999 \{published data only\}}

Delvin EE, Brazier JL, Deslandres C, Alvarez F, Russo P, Seidman E. Accuracy of the [13C]-urea breath test in diagnosing Helicobacter pylori gastritis in pediatric patients. Journal of Pediatric Gastroenterology and Nutrition 1999;28(1):59-62. 
Dinler 1999 \{published data only\}

Dinler G, Ozen H, Kocak N, Yuce A, Gurakan F. Detection of Helicobacter pylori infection. American Journal of Gastroenterology 1999;94(4):1118.

\section{Duan 1999 \{published data only\}}

Duan L, Duan X, Ye S, Wang J, Jin Z, Wang Z. The diagnostic value of $13 \mathrm{C}$-urea breath test in Helicobacter pylori colonization density and the severity of gastritis. Zhonghua Nei Ke za Zhi [Chinese Journal of Internal Medicine] 1999;38(12):824-6.

\section{Eggers 1990 \{published data only\}}

Eggers RH, Kulp A, Tegeler R, Ludtke FE, Lepsien G, Meyer B, et al. A methodological analysis of the $\mathrm{C}$-13-urea breath test for detection of Helicobacter-pylori infections - high-sensitivity and specificity within 30-min using 75-mg of c-13-urea. European Journal of Gastroenterology \& Hepatology 1990;2(6):437-44.

\section{Ekesbo 2006 \{published data only\}}

Ekesbo R, Toth E, Fork FT, Held M, Nilsson I, Wadstrom T, et al. Chronic Helicobacter pylori infection in a population in southern Sweden analysed by histopathology, immunoblot and ELISA serology. European Journal of Gastroenterology \& Hepatology 2006;18(6):589-93.

\section{El-Din 2013 \{published data only\}}

El-Din HMA, Hashem AGM, Ragab YM, Hussein IL, Mohamed DB, Mohamed EB. Evaluation of noninvasive versus invasive techniques for the diagnosis of Helicobacter pylori infection. Applied Immunohistochemistry \& Molecular Morphology 2013;21(4):326-33.

\section{El-Mekki 2011 \{published data only\}}

El-Mekki A, Kumar A, Alknawy B, Al-Ammari O, Moosa R, Quli S, et al. Comparison of enzyme immunoassays detecting Helicobacter pylori specific IgG in serum and saliva with endoscopic and biopsy findings in patients with dyspepsia. Indian Journal of Medical Microbiology 2011;29(2):136-40.

\section{El-Nasr 2003 \{published data only\}}

El-Nasr MS, Elibiary SA, Bastawi MB, Hassan A, Shahin Y, Hassan L, et al. Evaluation of a new enzyme immunoassay for the detection of Helicobacter pylori in stool specimens. Journal of the Egyptian Society of Parasitology 2003;33(3):905-15.

Eltumi 1999 \{published data only\}

Eltumi M, Brueton MJ, Francis N. Diagnosis of Helicobacter pylori gastritis in children using the $13 \mathrm{C}$ urea breath test. Journal of Clinical Gastroenterology 1999;28(3):238-40.

\section{Epple 1997 \{published data only\}}

Epple HJ, Kirstein FW, Bojarski C, Frege J, Fromm M, Riecken EO, et al. 13C-urea breath test in Helicobacter pylori diagnosis and eradication. Correlation to histology, origin of 'false' results, and influence of food intake. Scandinavian Journal of Gastroenterology 1997;32(4):308-14.

\section{Fallone 1995 \{published data only\}}

Fallone CA, Mitchell A, Paterson WG. Determination of the test performance of less costly methods of Helicobacter pylori detection. Clinical and Investigative Medicine. Medecine Clinique et Experimentale 1995;18(3):177-85.

Fallone 1996 \{published data only\}

Fallone CA, Elizov M, Cleland P, Thompson JA, Wild GE, Lough J, et al. Detection of Helicobacter pylori infection by saliva IgG testing. American Journal of Gastroenterology 1996;91(6):1145-9.

\section{Fanti 1999 \{published data only\}}

Fanti L, Mezzi G, Cavallero A, Gesu G, Bonato C, Masci E. A new simple immunoassay for detecting Helicobacter pylori infection: Antigen in stool specimens. Digestion 1999;60(5):456-60.

\section{Faruqui 2007 \{published data only\}}

Faruqui AN, Majid U, Ahmed L, Khalil M, ul Hassan M. Helicobacter pylori stool antigen test (HpSA) for the diagnosis of gastric infection. Journal of the College of Physicians and Surgeons Pakistan 2007;17(6):316-9.

\section{Ferrara 1998 \{published data only\}}

Ferrara M, Apuzzo M, Bazuro ME, Tammaro GF, Pippa G. Serology screening for Helicobacter pylori in dyspeptic patients. Giornale Italiano di Endoscopia Digestiva 1998;21(1):15-22.

\section{Formichella 2013 \{published data only\}}

* Formichella L, Romberg L, Bolz C, Vieth M, Geppert M, Gottner $\mathrm{G}$, et al. A novel line immunoassay based on recombinant virulence factors enables highly specific and sensitive serologic diagnosis of Helicobacter pylori infection. Clinical \& Vaccine Immunology: CVI 2013;20(11):1703-10.

Gholi MK, Kalali B, Formichella L, Gottner G, Shamsipour F, Zarnani AH, et al. Helicobacter pylori FliD protein is a highly sensitive and specific marker for serologic diagnosis of $\mathrm{H}$. pylori infection. International Journal of Medical Microbiology 2013;303(8):618-23.

\section{Germana 2001 \{published data only\}}

* Germana B, Galliani E, Lecis P, Costan F. Diagnosis of Helicobacter pylori infections using isotope-selective non dispersive infrared spectrometry with 13C-urea breath test. Recenti Progressi in Medicina 2001;92(2):113-6.

Germana B, Galliani EA, Lecis PE, Doglioni C, Costan F. Isotopeselective non dispersive infrared spectrometry for detection of Helicobacter-pylori infection with c-13-urea breath test. Gut 1999;45(Suppl 3):A130.

\section{Graham 1996a \{published data only\}}

Graham DY, Evans DJ Jr, Peacock J, Baker JT, Schrier WH. Comparison of rapid serological tests (Flexsure $\mathrm{Hp}$ and Quickvue) with conventional ELISA for detection of Helicobacter pylori infection. American Journal of Gastroenterology 1996;91(5):942-8.

\section{Gramley 1999 \{published data only\}}

Gramley WA, Asghar A, Frierson HF Jr, Powell SM. Detection of Helicobacter pylori DNA in fecal samples from infected individuals. Journal of Clinical Microbiology 1999;37(7):2236-40. 


\section{Guo 2011 \{published data only\}}

Guo JX, Han J, Chen L, Xu J, Liu J, Zhao J, et al. Evaluation of the Helicobacter pylori stool antigen test. Zhonghua Shi Yan He Lin Chuang Bing du Xue za Zhi [Chinese Journal of Experimental and Clinical Virology] 2011;25(6):495-6.

Gurbuz 2005 \{published data only\}

Gurbuz AK, Ozel AM, Narin Y, Yazgan Y, Baloglu H, Demirturk L. Is the remarkable contradiction between histology and c-14 urea breath test in the detection of Helicobacter pylori due to false-negative histology or false-positive c-14 urea breath test?. Journal of International Medical Research 2005;33(6):632-40.

\section{Hafeez 2007 \{published data only\}}

Hafeez A, Bilal R, Haseeb HA, Khan UF, Latif Z, Hassan M. Comparison of diagnostic accuracy of non-invasive tests for Helicobacter pylori infection in children. Journal of the College of Physicians and Surgeons--Pakistan : JCPSP 2007;17(5):261-4.

\section{Han 2012 \{published data only\}}

Han H, Lee S, Hwang T. The significance of positive giemsa stain cases in negative UBT (urea breath test) patients. Helicobacter 2012;17:117.

Inelmen 2004 \{published data only\}

Inelmen EM, Gasparini G, Sergi G, Enzi G. Evaluation of Helicobacter pylori with a stool antigen assay in frail, elderly patients. Scandinavian Journal of Gastroenterology 2005;40(7):794-9.

* Inelmen EM, Maccari T, Enzi G, Gasparini G, Fuson F, Davanzo B, et al. Helicobacter pylori infection diagnosis in hospitalised elderly patients: The stool antigen test (HpSA) in comparison with other methods. Aging-Clinical \& Experimental Research 2004;16(5):349-55.

\section{Iqbal 2013 \{published data only\}}

Iqbal S, Fatima S, Raheem A, Khan AH. Agreement between serology and histology for detection of Helicobacter pylori infection. Journal of the College of Physicians and Surgeons-Pakistan : JCPSP 2013;23(10):784-6.

Islam 2005 \{published data only\}

Islam S, Weilert F, Babington R, Dickson G, Smith AC. Stool antigen testing for the diagnosis and confirmation of eradication of Helicobacter pylori infection: A prospective blinded trial. Internal Medicine Journal 2005;35(9):526-9.

\section{Ivanova 2010 \{published data only\}}

Ivanova K, Marina M, Vladimirov B, Churchev J, Tersiev I. Comparison of different methods for detection of Helicobacter pylori infection. Problems of Infectious and Parasitic Diseases 2010;38(1):25-7.

\section{Jekarl 2013 \{published data only\}}

Jekarl DW, An YJ, Lee S, Lee J, Kim Y, Park YJ, et al. Evaluation of a newly developed rapid stool antigen test using an immunochromatographic assay to detect Helicobacter pylori. Japanese Journal of Infectious Diseases 2013;66(1):60-4.

\section{Jensen 1998 \{published data only\}}

Jensen G, Friedenberg F, Levine G, Zaeri N, Braitman LE, Tran HD, et al. Accuracy and clinical utility of the mini-dose c-14-urea breath test in the evaluation of Helicobacter pylori infection. Nuclear Medicine Communications 1998;19(8):771-5.

Jordaan 2008 \{published data only\}

Jordaan M, Laurens JB. Diagnosis of Helicobacter pylori infection with the c-13-urea breath test by means of GC-MS analysis. Journal of Separation Science 2008;31(2):329-35.

\section{Kalach 1998a \{published data only\}}

Kalach N, Briet F, Raymond J, Benhamou PH, Barbet P, Bergeret $\mathrm{M}$, et al. The $13 \mathrm{Carbon}$ urea breath test for the noninvasive detection of Helicobacter pylori in children: Comparison with culture and determination of minimum analysis requirements. Journal of Pediatric Gastroenterology \& Nutrition 1998;26(3):291-6.

\section{Kamel 2011 \{published data only\}}

Kamel HY, Abd-Al-Atty MF, El-Banoby MH, El-Baz AA, Sakr MA, Ahmed NS, et al. Stool antigen test in diagnosis of Helicobacter pylori in older adults with dyspepsia. Journal of the American Geriatrics Society 2011;59(9):1769-70.

Kim 2016 \{published data only\}

Kim DH, Kim HD, Park H, Choi S, Beom JW, Kim WJ, et al. New monoclonal antibody-based test for Helicobacter pylori urease in gastric tissue. Korean Journal of Internal Medicine 2016;31(1):40-5

\section{Korstanje 2006 \{published data only\}}

Korstanje A, Van Eeden S, Offerhaus GJ, Sabbe LJ, Den Hartog G, Biemond I, et al. The 13Carbon urea breath test for the diagnosis of Helicobacter pylori infection in subjects with atrophic gastritis: Evaluation in a primary care setting. Alimentary Pharmacology \& Therapeutics 2006;24(4):643-50.

\section{Kuloglu 2008 \{published data only\}}

Kuloglu Z, Kansu A, Kirsaclioglu CT, Ustundag G, Aysev D, Ensari $A$, et al. A rapid lateral flow stool antigen immunoassay and (14)C-urea breath test for the diagnosis and eradication of Helicobacter pylori infection in children. Diagnostic Microbiology \& Infectious Disease 2008;62(4):351-6.

Ladas 2002a \{published data only\}

Ladas SD, Malamou H, Triantafyllou K, Varzakakos I, Georgopoulos S, Giota G, et al. Performance of two immunosorbent assay kits for the detection of serum immunoglobulin $\mathrm{G}$ to Helicobacter pylori in untreated Greek patients. Scandinavian Journal of Gastroenterology 2002;37(5):512-6.

\section{Lahner 2004 \{published data only\}}

Lahner E, Vaira D, Figura N, Pilozzi E, Pasquali A, Severi C, et al. Role of noninvasive tests (c-13-urea breath test and stool antigen test) as additional tools in diagnosis of Helicobacter pylori infection in patients with atrophic body gastritis. Helicobacter 2004;9(5):436-42. 


\section{Lee 1998 \{published data only\}}

Lee HS, Gwee KA, Teng LY, Kang JY, Yeoh KG, Wee A, et al. Validation of [13C] urea breath test for Helicobacter pylori using a simple gas chromatograph-mass selective detector. European Journal of Gastroenterology \& Hepatology 1998;10(7):569-72.

\section{Logan 1991a \{published data only\}}

Logan RP, Polson RJ, Misiewicz JJ, Rao G, Karim NQ, Newell D, et al. Simplified single sample 13Carbon urea breath test for Helicobacter pylori: Comparison with histology, culture, and ELISA serology. Gut 1991;32(12):1461-4.

\section{Lombardo 2003 \{published data only\}}

Lombardo L, Masoero G, Della Monica P, Crocella L, Ruggia O, Ravarino N, et al. Multiple sampling 13C-urea breath test: Improvement of diagnosis in postgastrectomy patients. Minerva Gastroenterologica e Dietologica 2003;49(3):181-6.

\section{Lottspeich 2007 \{published data only\}}

Lottspeich C, Schwarzer A, Panthel M, Koletzko S, Russmann H. Evaluation of the novel Helicobacter pylori ClariRes real-time PCR assay for detection and clarithromycin susceptibility testing of $h$.pylori in stool specimens from symptomatic children. Journal of Clinical Microbiology 2007;45(6):1718-22.

\section{Luthra 1998 \{published data only\}}

Luthra GK, DiNuzzo AR, Gourley WK, Crowe SE. Comparison of biopsy and serological methods of diagnosis of Helicobacter pylori infection and the potential role of antibiotics. American Journal of Gastroenterology 1998;93(8):1291-6.

\section{Mana 2001a \{published data only\}}

* Mana F, Franken PR, Ham HR, Urbain D. Cut-off point, timing and pitfalls of the c-13-urea breath test as measured by infrared spectrometry. Digestive and Liver Disease 2001;33(1):30-5.

Mana F, Fried M, Ham HR, Lacor P, Vandenplas Y, Urbain D. Evaluation of a 10 minute c-13-urea breath test for the diagnosis of Helicobacter pylori infection, as measured by infrared spectrometry. Gastroenterology 2000;118(4 Part 1):A508.

\section{Mansour-Ghanaei 2011 \{published data only\}}

Mansour-Ghanaei F, Sanaei O, Joukar F. Clinical validation of an office-based C-14-UBT (Heliprobe) for H. Pylori diagnosis in Iranian dyspeptic patients. Gastroenterology Research and Practice 2011 Jun 22 [Epub ahead of print]. [DOI: $10.1155 / 2011 / 930941]$

\section{Mion 1994 \{published data only\}}

Mion F, Delecluse HJ, Rousseau M, Berger F, Brazier JL, Minaire Y. 13C-urea breath test for the diagnosis of Helicobacter infection. Comparison with histology. Gastroenterologie Clinique et Biologique 1994;18(12):1106-11.

\section{Misawa 1998 \{published data only\}}

Misawa K, Kumagai T, Shimizu T, Furihata K, Ota H, Akamatsu T, et al. A new histological procedure for re-evaluation of the serological test for Helicobacter pylori. European Journal of Clinical Microbiology \& Infectious Diseases 1998;17(1):14-9.

\section{Mohammadian 2007 \{published data only\}}

Mohammadian T, Hagh-Zare M, Aria H, Doosti M, Paknejad M, Siavoshi F, et al. Comparison of serologic ELISA and histopathologic findings in diagnosis of Helicobacter pylori infection in Iran. Helicobacter 2007;12(4):446.

Monteiro 2001a \{published data only\}

Monteiro L, De Mascarel A, Sarrasqueta AM, Bergey B, Barberis C, Talby P, et al. Diagnosis of Helicobacter pylori infection: Noninvasive methods compared to invasive methods and evaluation of two new tests. American Journal of Gastroenterology 2001;96(2):353-8.

Morales 1995 \{published data only\}

Morales EOS, Vorackova FV, Perez JDV, Alonso SS, Angeles AA, Rivera JE, et al. Optimization of the c-14 urea breath test for the detection of Helicobacter-pylori in dyspeptic patients. Revista De Investigacion Clinica 1995;47(2):109-16.

\section{Noguera 1998 \{published data only\}}

Noguera ECA, Hames W, Bertola S, Mothe G. Helicobacter pylori: $\mathrm{C}$-14 urea breath test in clinical practice in a general hospital. Medicina-Buenos Aires 1998;58(1):45-50.

Novis 1991 \{published data only\}

Novis BH, Gabay G, Leichtmann G, Peri M, Bernheim J, Pomeranz IS. Two point analysis 15-minute 14c-urea breath test for diagnosing Helicobacter pylori infection. Digestion 1991;50(1):16-21.

\section{Ogata 2001 \{published data only\}}

Ogata SK, Kawakami E, Patricio FR, Pedroso MZ, Santos AM. Evaluation of invasive and non-invasive methods for the diagnosis of Helicobacter pylori infection in symptomatic children and adolescents. Sao Paulo Medical Journal 2001;119(2):67-71.

\section{Ozturk 2003 \{published data only\}}

Ozturk E, Yesilova Z, Ilgan S, Arslan N, Erdil A, Celasun B, et al. A new, practical, low-dose 14c-urea breath test for the diagnosis of Helicobacter pylori infection: Clinical validation and comparison with the standard method. European Journal of Nuclear Medicine \& Molecular Imaging 2003;30(11):1457-62.

\section{Peitz 2001 \{published data only\}}

Peitz U, Baumann M, Tillenburg B, Borsch G, Stolte M, Malfertheiner $P$, et al. Insufficient validity of a rapid blood test for diagnosis of Helicobacter pylori infection. Medizinische Klinik 2001;96(12):703-7.

\section{Peura 1996 \{published data only\}}

Peura DA, Pambianco DJ, Dye KR, Lind C, Frierson HF, Hoffman SR, et al. Microdose c-14-urea breath test offers diagnosis of Helicobacter pylori in 10 minutes. American Journal of Gastroenterology 1996;91(2):233-8.

Puspok 1999 \{published data only\}

Puspok A, Bakos S, Oberhuber G. A new, non-invasive method for detection of Helicobacter pylori: Validity in the routine clinical setting. European Journal of Gastroenterology \& Hepatology 1999;11(10):1139-42. 
Qadeer 2009 \{published data only\}

Qadeer AS, Kharal SA, Baig MF, Badvi JA, Durrani MA. Detection of Helicobacter pylori antigen in stool. Journal of the Liaquat University of Medical and Health Sciences 2009;8(2):126-30.

\section{Rafeey 2007 \{published data only\}}

Rafeey M, Nikvash S. Detection of Helicobacter pylori antigen in stool samples for diagnosis of infection in children. Eastern Mediterranean Health Journal 2007;13(5):1067-72.

\section{Rasool 2007 \{published data only\}}

* Rasool S, Abid S, Jafri W. Validity and cost comparison of 14 carbon urea breath test for diagnosis of $\mathrm{H}$ pylori in dyspeptic patients. World Journal of Gastroenterology 2007;13(6):925-9.

Rasool S, Abid S, Mumtaz K, Shah HA, Hamid S, Islam M, et al. $\mathrm{C}$-14-urea breath test: A reliable and practical test in officebased diagnosis of Helicobacter pylori infection. Helicobacter 2005;10(5):525.

\section{Rathbone 1986 \{published data only\}}

Rathbone BJ, Wyatt J, Tompkins D, Heatley RV, Losowsky MS. Diagnostic IgG ELISA for gastric campylobacter-pyloridis infection using serum samples. Gut 1986;27(5):A607.

\section{Safe 1993 \{published data only\}}

Safe AF, Warren B, Corfield A, McNulty CA, Watson B, Mountford RA, et al. Helicobacter-pylori infection in elderly people - correlation between histology and serology. Age and Ageing 1993;22(3):215-20.

\section{Salles-Montaudon 2002 \{published data only\}}

Salles-Montaudon N, Dertheil S, Broutet N, Gras N, Monteiro L, De Mascarel A, et al. Detecting Helicobacter pylori infection in hospitalized frail older patients: The challenge. Journal of the American Geriatrics Society 2002;50(10):1674-80.

\section{Schilling 2001 \{published data only\}}

Schilling D, Jakobs R, Peitz U, Sugilla M, Stolte M, Riemann JF, et al. The diagnostic accuracy of (13)COurea breath test in diagnosis of Helicobacter pylori (hp) infection in patients with partial gastric resection due to peptic ulcer disease. Gastroenterology 1999;116(4 suppl):A304.

* Schilling D, Jakobs R, Peitz U, Sulliga M, Stolte M, Riemann JF, et al. Diagnostic accuracy of c-13-urea breath test in the diagnosis of Helicobacter pylori infection in patients with partial gastric resection due to peptic ulcer disease - a prospective multicenter study. Digestion 2001;63(1):8-13.

\section{Scuderi 2000 \{published data only\}}

Scuderi G, Celi D, Romagnolo M, Lupi A, Alecci L, Dramissino I, et al. Helicobacter pylori: Use of a stool antigen detection test and a six-day triple therapy [2]. Digestive and Liver Disease 2000;32(1):71-3.

\section{Segamwenge 2014 \{published data only\}}

Segamwenge IL, Kagimu M, Ocama P, Opio K. The utility of the Helicobacter pylori stool antigen test in managing dyspepsia: An experience from a low resource setting. African Health Sciences 2014;14(4):829-34.

\section{Selcukcan 2011 \{published data only\}}

Selcukcan Aydin F, Demirkiran Urganci N, Uzum Yenici FU. Comparison of methods in diagnosis of gastritis originated from Helicobacter pylori in pediatric age, and use of urea breath test as a noninvasive technique in post-treatment follow-up of the patient. Duzce Medical Journal 2011;13(1):6-14.

\section{Sharbatdaran 2013 \{published data only\}}

Sharbatdaran M, Kashifard M, Shefaee S, Siadati S, Jahed B, Asgari S. Comparison of stool antigen test with gastric biopsy for the detection of Helicobacter pylori infection. Pakistan Journal of Medical Sciences 2013;29(1):68-71.

\section{Sheu 1998a \{published data only\}}

Sheu BS, Lee SC, Lin PW, Chang YC, Yang SB, Lin XZ. Diagnostic efficacy of carbon 13 urea breath test to detect $H$. pylori in patients after gastrectomy. Gut 1998;43(Suppl 2):A57.

\section{Sheu 1998b \{published data only\}}

Sheu BS, Lee SC, Lin PW, Chang YC, Yang SB, Lin XZ. Diagnostic efficacy of carbon 13 urea breath test to detect $H$. pylori in patients after gastrectomy. Gut 1998;43(Suppl 2):A57.

Shin 2009 \{published data only\}

Shin CM, Kim N, Lee HS, Lee HE, Lee SH, Park YS, et al. Validation of diagnostic tests for Helicobacter pylori with regard to grade of atrophic gastritis and/or intestinal metaplasia. Helicobacter 2009;14(6):512-9.

\section{Soomro 2012 \{published data only\}}

* Soomro RA, Abro AK, Ujjan ID, Ibraheem Z, Farooq M. Comparison of two diagnostic methods for detection of H.pylori i.e., gastric biopsy by H\&E \& Giemsa and serum anti H.pylori antibodies. Pakistan Journal of Medical and Health Sciences 2012;6(3):552-4.

Soomro RA, Sheikh TA, Memon Al, Pathan NA, Qazi N. Two easy and early methods for the diagnosis of H.pylori i.e.: serum anti H.pylori antibodies and stool antigen. Journal of the Liaquat University of Medical and Health Sciences 2013;12(2):87-90.

\section{Surveyor 1989 \{published data only\}}

Surveyor I, Goodwin CS, Mullan BP, Geelhoed E, Warren JR, Murray RN, et al. The c-14-urea breath-test for the detection of gastric campylobacter-pylori infection. Medical Journal of Australia 1989;151(8):435-9.

\section{Thobani 1995 \{published data only\}}

Thobani S, Jafri SMW, Ferrell L, Perezperez GI, Hasan SH, Blaser MJ, et al. Detection of Helicobacter-pylori gastritis in Pakistan - efficacy of an IgG ELISA based on a United-States population. Gastroenterology 1995;108(4 suppl):A241.

\section{Tiwari 2014 \{published data only\}}

Tiwari BP, Nistala S, Patil SP, Kalgutkar DP, Jaychandran N, $\mathrm{Chander} \mathrm{H}$, et al. Evaluation of the c-14-urea breath test using indigenously produced c-14-urea capsules and a modified technique for trapping exhaled breath: A pilot study. Nuclear Medicine Communications 2014;35(3):325-30. 
Trevisani 2005 \{published data only\}

Trevisani L, Sartori S, Rossi MR, Ruina M, Matarese V, Gullini S, et al. Evaluation of a new rapid immunoassay for the detection of Helicobacter pylori in faeces: A prospective pilot study. Alimentary Pharmacology \& Therapeutics 2005;21(4):485-9.

Vandenplas 1992 \{published data only\}

Vandenplas Y, Blecker U, Devreker T, Keppens E, Nijs J, Cadranel S, et al. Contribution of the 13C-urea breath test to the detection of Helicobacter pylori gastritis in children. Pediatrics 1992;90(4):608-11.

\section{Villalobos 1992 \{published data only\}}

Villalobos Perez JJ, Sanchez Morales EO, Vargas Vorackova F, Sixtos Alonso S, Angeles Angeles A, Elizondo Rivera J, et al. Usefulness of the 14c-urea marked test in the detection of Helicobacter pylori in patients with dyspepsia. Revista de Gastroenterologia de Mexico 1992;57(3):167-71.

\section{Wang 2008 \{published data only\}}

Wang XY, Yang Y, Shi RH, Ho B, Wang HD, Zhang GX. An evaluation of a serologic test with a current infection marker of Helicobacter pylori before and after eradication therapy in Chinese. Helicobacter 2008;13(1):49-55.

\section{Wardi 2012 \{published data only\}}

Wardi J, Shalev T, Shevah O, Boaz M, Avni Y, Shirin H. A rapid continuous-real-time c-13-urea breath test for the detection of Helicobacter pylori in patients after partial gastrectomy. Journal of Clinical Gastroenterology 2012;46(4):293-6.

\section{Weiss 1994 \{published data only\}}

Weiss J, Mecca J, Da Silva E, Gassner D. Comparison of PCR and other diagnostic techniques for detection of Helicobacter pylori infection in dyspeptic patients. Journal of Clinical Microbiology 1994;32(7):1663-8.

\section{Yan 2003 \{published data only\}}

Yan S, Lin Q, Song Y, Wang S. Detection of Helicobacter pylori stool antigen by non-invasive enzyme immunoassay. Chinese Medical Sciences Journal 2003;18(4):218-21.

\section{Yoshimura 2001 \{published data only\}}

Yoshimura N, Tajiri H, Sawada A, Kozaiwa K, Ida S, Fujisawa T, et al. A c-13-urea breath test in children with Helicobacter pylori infection: Assessment of eradication therapy and follow-up after treatment. Journal of Gastroenterology 2001;36(9):606-11.

\section{Yu 1999 \{published data only\}}

Yu WK, Chow PKH, Tan SY, Ng EH, Goh ASW, Soo KC, et al. Five micro-curie urea breath test for the diagnosis of Helicobacter pylori infection: Evaluation in a south-east Asian population. Australian and New Zealand Journal of Surgery 1999;69(1):37-40.

\section{Yu 2001 \{published data only\}}

Yu FJ, Wu DC, Kuo CH, Lu CY, Su YC, Lee YC, et al. Diagnosis of Helicobacter pylori infection by stool antigen test in southern Taiwan. Kaohsiung Journal of Medical Sciences 2001;17(7):344-50.

\section{References to studies awaiting assessment}

Buhigas-Garcia 2008 \{published data only\}

Buhigas-Garcia I, Herrero-Alonso MC, BarrioMerino A. From laboratory to clinic: $13-\mathrm{c}$ urea breath test [Test de urea marcada con carbono 13]. Anales de Pediatria Continuada 2008;6(3):155-8.

[appswl.elsevier.es/watermark/ctl_servlet?_f=10\&pident articulo $=80000328 \&$ pident_usuario $=0 \&$ pcontactid $=\&$ pident revista $=51 \&$ ty $=30 \& a c c i o n=L \&$ origen $=a p c c o n t i n u a d a \& w e b=w w w . a p c o n t i n u$ publi_pdf]

\section{Fazeli 2004 \{published data only\}}

Fazeli A, Safaei HG, Tamizifar H, Rashidi N, Medimond. Diagnosis of Helicobacter pylori infection by salivary immunoglobulin g. Immunology 2004: Immunodeficiency, Infectious Diseases, Immunomodulation, and Vaccines. 12th Annual International Congress of Immunology/4th Annual Conference of the Federation-of-Clinical-Immunology-Societies (FOCIS); $2004 \mathrm{Jul}$ 18-23; Montreal. 2004:79-82.

\section{Fuke 2009 \{published data only\}}

Fuke A, Kunita S, Goto K, Sugiyama F, Yagami K. Diagnosis method based on sandwich ELISA using Helicobacter hepaticusspecific monoclonal antibody. Journal of the American Association for Laboratory Animal Science 2009;48(5):634-5.

\section{Glupczynski 1991 \{published data only\}}

Glupczynski Y, Bourdeaux L, Vantricht L, Depre M, Balegamire B, Devos D, et al. C-14-urea breath test (ubt), an efficacious tool for studying Helicobacter-pylori (hp) epidemiology in developingcountries - a study in Zaire. Nuclear Medicine 1991;27:253-5.

\section{Karczewska 1997 \{published data only\}}

Karczewska E, Kacka K, Bielanski W, Plonka M, Zarzycki D, Konturek SJ, et al. The seroprevalence of IgG antibodies to hpylori caga protein in asymptomatic children assessed by helico blot 2.0 and ELISA methods. Gut 1997;41:A70.

\section{Kushch 2014 \{published data only\}}

Kushch I, Korenev N, Kamarchuk L, Pospelov A, Alexandrov Y, Kamarchuk G, et al. New possibilities in diagnosing Helicobacter pylori infection by the non-urease products of its activity. 8th World Congress of the World Society for Pediatric Infectious Diseases (WSPID); 2013 Nov 20-23; Cape Town. Bologna: MEDIMOND International, 2014:89-92.

\section{Lappas 1997 \{published data only\}}

Lappas A, Bogdanos D, Konstantinou G, Bokolas G, loannidis K, Boura $P$, et al. The value of the saliva-dental plaque urease test in the diagnosis and treatment of Helicobacter pylori infection associated with peptic ulcer disease. Archives of Hellenic Medicine 1997;14(3):330-4.

\section{Lee 1999a \{published data only\}}

Lee G, Chun HJ, Lee SJ, Kim KH, Jeen YT, Song CW, et al. Significance of c-13-urea breath test results: Delta(co2)-c-13 as a predictor of Helicobacter pylori density and activity of gastritis in gastric body. Gastrointestinal Endoscopy 1999;49(4):AB191$\mathrm{AB}$. 
Martin-de-Argila 1997 \{published data only\}

Martin-de-Argila C, Boixeda D, Canton R, Valdezate S, Mir N, De Rafael $\mathrm{L}$, et al. Usefulness of the combined igg and iga antibody determinations for serodiagnosis of Helicobacter pylori infection. European Journal of Gastroenterology \& Hepatology 1997;9(12):1191-6.

\section{Mason 1997 \{published data only\}}

Mason CL, Wong WW. The urea breath test for Helicobacter pylori: A direct application of stable isotope mass spectrometry. Abstracts of Papers of the American Chemical Society 1997;213:274-CHED.

\section{Thong-Ngam 2011 \{published data only\}}

Thong-Ngam D, Chayanupatkul M, Vongchampa P, Hanvivatvong $O$. An evaluation of a new in-house serum and urine ELISA test for detection of Helicobacter pylori infection in Thai population. Journal of the Medical Association of Thailand 2011;94(8):985-90.

\section{Tokunaga 2005a \{published data only\}}

Tokunaga K, Tanaka A, Takahashi S. Evaluation of diagnostic method for Helicobacter pylori infection. Nippon Rinsho [Japanese Journal of Clinical Medicine] 2005;63 Suppl 11:403-8.

\section{Xu 1995 \{published data only\}}

$\mathrm{Xu} \mathrm{C}, \mathrm{Xu} \mathrm{H}$, Cheng S. 14c-urea breath test in the diagnosis of Helicobacter pylori infection in the stomach. Zhonghua Nei Ke Za Zhi [Chinese Journal of Internal Medicine] 1995;34(4):239-42.

\section{Additional references}

\section{Abadi 2011}

Abadi ATB, Taghvaei T, Wolfram L. Inefficiency of rapid urease test for confirmation of Helicobacter pylori. Saudi Journal of Gastroenterology 2011;17(1):84-5.

\section{Abdullah 1997a}

Abdullah AM, Gad el Rab MO, al Ayed I, Kambal AM, al Sohaibani M, al Mazyad AL. Helicobacter pylori infection in children in Saudi Arabia. Tropical Gastroenterology 1997;18(2):63-5.

\section{Abdullah 1997b}

Abdullah AM, Gad el Rab MO, al Ayed I, al Mazyad AS, al Sanie A. Comparison of Helicobacter pylori antibody levels in children in Riyadh. Tropical Gastroenterology 1997;18(2):65-6.

\section{Abdulqawi 2012}

Abdulqawi K, El-Mahalaway AM, Abdelhameed A, Abdelwahab AA. Correlation of serum antibody titres with invasive methods for rapid detection of Helicobacter pylori infections in symptomatic children. International Journal of Experimental Pathology 2012;93(4):295-304.

\section{Abu 2015}

Abu Shady MM, Fathy HA, Ali A, Galal EM, Fathy GA, Sibaii H. Comparison of serum IgG antibody test with gastric biopsy for the detection of Helicobacter pylori infection among
Egyptian children. Macedonian Journal of Medical Sciences 2015;3(2):303-6.

\section{Abu-Sbeih 2014}

Abu-Sbeih RS, Hawari AD, Hassawi DS, Al-Daghistani HI. Isolation and detection of Helicobacter pylori from patients suffering from peptic ulcer using biochemical tests and molecular techniques. American Journal of Biochemistry and Biotechnology 2014;10(1):58-68.

\section{Abukhadir 1998}

Abukhadir BA, Heneghan MA, Kearns M, Little CL, McCarthy CF. Evaluation of a 20 minute $\mathrm{C}-14$ urea breath test for the diagnosis of Helicobacter pylori infection. Irish Medical Journal 1998;91(1):23-5.

\section{Abut 2006}

Abut E, Guveli H, Kurdas OO. Diagnostic tests used for the detection of Helicobacter pylori. Sendrom 2006;18(3):53-9.

\section{Aceti 1989}

Aceti A, Pennica A, Leri O, Caferro M, Grilli A, Celestino D, et al. Time-resolved fluoroimmunoassay for campylobacter pylori antibodies. Lancet 1989;2(8661):505.

\section{Adachi 2002}

Adachi K, Kawamura A, Ono M, Masuzaki K, Takashima T, Yuki M, et al. Comparative evaluation of urine-based and other minimally invasive methods for the diagnosis of Helicobacter pylori infection. Journal of Gastroenterology 2002;37(9):703-8.

\section{Adamczyk 2013}

Adamczyk M, Peczek Ł, Rudnicki C, Nawrot B, Stec-Michalska K. The clinical significance of GastroPanel in diagnostics of Helicobacter pylori eradication efficiency in patients with dyspepsia with correlation of family history of gastric cancer. Polski Merkuriusz Lekarski 2013;35(207):141-7.

\section{Adamek 1994}

Adamek RJ, Freitag M, Labenz J, Opferkuch W, Ruhl GH, Aygen S, et al. Modified 13C-urea breath test in the detection of Helicobacter pylori in the gastric mucosa. Deutsche Medizinische Wochenschrift 1994;119(46):1569-72.

\section{Adamek 1995}

Adamek RJ, Wegener M, Labenz J. C-12 urea breath test in Helicobacter-pylori infection of the gastric-mucosa - reply. Deutsche Medizinische Wochenschrift 1995;120(25-26):941-2.

\section{Adamsson 2000}

Adamsson I, Edlund C, Nord CE. Microbial ecology and treatment of Helicobacter pylori infections: Review. Journal of Chemotherapy 2000;12(1):5-16.

\section{Adiloglu 2003}

Adiloglu AK, Nazli C, Cicioglu-Aridogan B, Kinay O, Can R, Ergene O. Gastroduodenal Helicobacter pylori infection diagnosed by Helicobacter pylori stool antigen is related to atherosclerosis. Acta Cardiologica 2003;58(4):335-9. 


\section{Adiloglu 2007}

Adiloglu AK, Isler M, Goren I, Candir O, Senol A, Onal S, et al. Quantitative correlation of Helicobacter pylori stool antigen (HpSA) test with the severity of $\mathrm{H}$. pylori-related gastritis. Tohoku Journal of Experimental Medicine 2007;212(2):159-67.

\section{Agha-Amiri 1999a}

Agha-Amiri K, Mainz D, Peitz U, Kahl S, Leodolter A, Malfertheiner P. Evaluation of an enzyme immunoassay for detecting Helicobacter pylori antigens in human stool samples. Zeitschrift Fur Gastroenterologie 1999;37(12):1145-9.

\section{Agha-Amiri 1999b}

Agha-Amiri K, Leodolter A, Peitz U, Malfertheiner P. How does the Helicobacter pylori antigen concentration in stool correlate with the urease activity in c-13-urea breath test?. Gut 1999;45(Suppl 3):A132.

\section{Agha-Amiri 2001}

Agha-Amiri K, Peitz U, Mainz D, Kahl S, Leodolter A, Malfertheiner P. A novel immunoassay based on monoclonal antibodies for the detection of Helicobacter pylori antigens in human stool. Zeitschrift Fur Gastroenterologie 2001;39(8):555-60.

\section{Agudo 2009a}

Agudo S, Alarcón T, Urruzuno P, Lopez-Brea M. Evaluation of two monoclonal-based antigen in stool enzyme immunoassay for diagnosis of H.pylori infection in Spanish children. Helicobacter 2009;14(4):341-2.

\section{Agudo 2009b}

Agudo S, Alarcón T, Urruzuno P, Somodevilla A, Lopez-Brea M. Evaluation of a monoclonal-based antigen in stool enzyme immunoassay for diagnosis of Helicobacter pylori infection in Spanish children. Clinical Microbiology and Infection 2009;15:S315.

\section{Aguemon 2004}

Aguemon B, Struelens M, Deviere J, Denis O, Golstein P, Nagy N, et al. Evaluation of stool antigen detection for diagnosis of Helicobacter pylori infection in adults. Acta Clinica Belgica 2004;59(5):246-50.

\section{Aguemon 2005}

Aguemon B, Struelens M, Deviere J, Denis O, Golstein P, Salmon I, et al. Primary antibiotic resistance and effectiveness of Helicobacter pylori triple therapy in ulcero-inflammatory pathologies of the upper digestive tract. Acta Gastroenterologica Belgica 2005;68(3):287-93.

\section{Aguilar-Soto 2004}

Aguilar-Soto O, Majalca-Martńez C, León-Espinosa F, Avila-Vargas G, Sánchez-Medina R, Figueroa SA, et al. Comparative study between rapid urease test, imprint and histopathological study for Helicobacter pylori diagnosis. Revista de Gastroenterologia de Mexico 2004;69(3):136-42.

\section{Ahmed 2005}

Ahmed F, Murthy UK, Chey WD, Toskes PP, Wagner DA. Evaluation of the Ez-HBT Helicobacter blood test to establish
Helicobacter pylori eradication. Alimentary Pharmacology \& Therapeutics 2005;22(9):875-80.

\section{Ahuja 1998}

Ahuja V, Bal CS, Sharma MP. Can the c-14 urea breath test replace follow-up endoscopic biopsies in patients treated for Helicobacter pylori infection?. Clinical Nuclear Medicine 1998;23(12):815-9.

\section{Aje 2010}

Aje AO, Otegbayo JA, Odaibo GN, Bojuwoye BJ. Comparative study of stool antigen test and serology for Helicobacter pylori among Nigerian dyspeptic patients: a pilot study. Nigerian Journal of Clinical Practice 2010;13(2):120-4.

\section{Aksoy 2003}

Aksoy DY, Aybar M, Ozaslan E, Kav T, Engin D, Ercis S, et al. Evaluation of the Helicobacter pylori stool antigen test (HpSA) for the detection of Helicobacter pylori infection and comparison with other methods. Hepato-Gastroenterology 2003;50(52):1047-9.

\section{Aktepe 2011}

Aktepe OC, Ciftci IH, Safak B, Uslan I, Dilek FH. Five methods for detection of Helicobacter pylori in the Turkish population. World Journal of Gastroenterology 2011;17(47):5172-6.

\section{Al-Assi 1999}

Al-Assi MT, Miki K, Walsh JH, Graham DP, Asaka M, Graham DY. Noninvasive evaluation of Helicobacter pylori therapy: role of fasting or postprandial gastrin, pepsinogen i, pepsinogen ii, or serum IgG antibodies. American Journal of Gastroenterology 1999;94(9):2367-72.

\section{Al-Humayed 2008}

Al-Humayed SM, Ahmed MEK, Bello CS, Tayyar MA. Comparison of 4 laboratory methods for detection of Helicobacter pylori. Saudi Medical Journal 2008;29(4):530-2.

\section{Alam 2013}

Alam El-Din HM, Hashem AGM, Ragab YM, Hussein IL, Mohamed DB, Mohamed ECB. Evaluation of noninvasive versus invasive techniques for the diagnosis of Helicobacter pylori infection. Applied Immunohistochemistry and Molecular Morphology 2013;21(4):326-33.

\section{Alan 2014}

Alan Selcuk N, Toklu T, Karaaslan I. Evaluation of sensitivity of post-therapeutic i-131 whole body scan on detecting Helicobacter pylori. European Journal of Nuclear Medicine and Molecular Imaging 2014;41:S594.

\section{Alarcón-Rivera 2011}

Alarcón-Rivera G, Vázquez-Jiménez G, De la Cruz-Patiño E, Abarca M, Leyva E, Delgado F, et al. Comparative analysis between breath test, serological immunoassay and rapidurease test for detection of Helicobacter pylori infection in Mexican patients with non-investigated dyspepsia. Revista de Gastroenterologia de Mexico 2011;76(4):322-9. 


\section{Alavi 1996a}

Alavi A, Kroser JA, Faigel DO, Childs M, Furth EE, Alavi A, et al. Can quantitative urea breath test for Helicobacter pylori (hp) replace endoscopic biopsy?. Journal of Nuclear Medicine 1996;37(5 Suppl):246 (abstract 1104).

\section{Alavi 1996b}

Alavi A, Faigel DO, Childs M, Furth EE, Goin J, Metz DC. Comparison of 14-urea breath test for the diagnosis of Helicobacter pylori gastritis with standard techniques. Journal of Nuclear Medicine 1996;37(5 Suppl):114 (abstract 448).

\section{Albrecht 2012}

Albrecht P, Kotowska M, Misko E, lazowska-Przeorek I, Karolewska-Bochenek K, Banaszkiewicz A, et al. Agreement of monoclonal fecal test (amplified IDEA ${ }^{\mathrm{TM}} \mathrm{hp}$ star $^{\mathrm{TM}}$ ) with the urease breath test, before and after the eradication treatment of H. pylori in children. Pediatria Wspolczesna 2012;14(2):79-82.

\section{Alcalde 1994}

Alcalde M, Perez Garcia JI, Sanchez P, Lancho A, Carpintero P, Pajares JM. Usefulness of the breath test with urea-13C in the diagnosis of Helicobacter pylori infection. Medicina Clinica 1994;103(10):371-3.

\section{Alem 2002}

Alem M, Alem N, Cohen H, England T, Hamedi N, Moussazadeh M, et al. Diagnostic value of detection of IgM antibodies to Helicobacter pylori. Experimental \& Molecular Pathology 2002;72(1):77-83.

\section{Alemohammad 1993}

Alemohammad MM, Foley TJ, Cohen H. Detection of immunoglobulin $\mathrm{g}$ antibodies to Helicobacter pylori in urine by an enzyme immunoassay method. Journal of Clinical Microbiology 1993;31(8):2174-7.

\section{Ali 1997}

Ali A, Vaira D, Stanghellini V, Menegatti M, Salardi S, Landi F, et al. C-13 urea-breath test (UBT) with and without a citric acid test meal for Helicobacter pylori (hp) detection in adults and children. Gastroenterology 1997;112(4 suppl):A56.

\section{Ali 1998}

Ali A, Vaira D, Stanghellini V, Menegatti M, Landi F, Ricci C, et al. $\mathrm{C}-13$ vs c-14 urea breath test (UBT) for Helicobacter pylori (hp) detection. Gut 1998;43(Suppl 2):A55-A6.

\section{Allerberger 1996}

Allerberger F, Oberhuber G, Wrba F, Puspok A, Dejaco C, Dierich MP. Detection of Helicobacter pylori infection using single serum specimens: Comparison of five commercial serological tests. Hepato-Gastroenterology 1996;43(12):1656-9.

\section{Alpert 1989}

Alpert LC, Graham DY, Evans DJ, Yoshimura HH, Hazell SL, Evans DG, et al. Diagnostic possibilities for campylobacter pylori infection. European Journal of Gastroenterology \& Hepatology $1989 ; 1(1): 17-26$

\section{Altindis 2002a}

Altindis M, Dilek ON. Usefulness of the Helicobacter pylori stool antigen test for detection Helicobacter pylori infection. Acta Gastro-Enterologica Belgica 2002;65(2):74-6.

\section{Altindis 2002b}

Altindis M, Dilek ON. Erratum: Usefullness of the Helicobacter pylori stool antigen test for detection Helicobacter pylori infection (Acta Gastro-Enterologica Belgica 2002;65:2:74-6). Acta Gastro-Enterologica Belgica 2002;65(4):246.

\section{Altindis 2003}

Altindis M, Dilek ON. Erratum: Usefullness of the Helicobacter pylori stool antigen test for detection Helicobacter pylori infection (Acta Gastro-Enterologica Beljica 2002;65(2):74-6). Acta Gastro-Enterologica Belgica 2003;66(2):195.

\section{Amendola 2002}

Amendola R, Doweck J, Katz J, Racca J, Menendez G, Schenone $L$, et al. A new method for detection and eradication of Helicobacter pylori infection by stool antigens test. Acta Gastroenterologica Latinoamericana 2002;32(2):83-5.

\section{Anania 2007}

Anania C, Labalestra V, Neaga M, Ferrara E, Borrelli O, Cirulli M, et al. Evaluation of a polyclonal Helicobacter pylori stool antigen test (HpSA) for the detection of Helicobacter pylori infection in children. Digestive and Liver Disease 2007;39(10):A62.

\section{Anania 2008}

Anania C, Pacifico L, Olivero G, Osborn JF, Bonaiuto E, Chiesa C. Breath tests in pediatrics. Clinica Chimica Acta 2008;397(1-2):1-12.

\section{Andersen 1989}

Andersen LP. Campylobacter pylori antibodies measured by indirect ELISA using O-antigen. Gastroduodenal pathology and Campylobacter pylori: European Campylobacter Pylori Study Group ICS847. 1989:201-3.

\section{Andersen 1998}

Andersen LP, Kiilerick S, Pedersen G, Thoreson AC, Jorgensen F, Rath J, et al. An analysis of seven different methods to diagnose Helicobacter pylori infections. Scandinavian Journal of Gastroenterology 1998;33(1):24-30.

\section{Anderson 1993}

Anderson G, Alemohammad MM, Foley TJ, Colletti A, Patel A, Dooley CP. Rapid test for detection of antibodies to Helicobacter pylori. Clinical Infectious Diseases 1993;16(SUPPL. 4):S416-S7.

\section{Andrews 2003}

Andrews J, Marsden B, Brown D, Wong VS, Wood E, Kelsey M. Comparison of three stool antigen tests for Helicobocter pylori detection. Journal of Clinical Pathology 2003;56(10):769-71.

\section{Ang 2007a}

Ang CW, Krogfelt K, Herbrink P, Keijser J, Van Pelt W, Dalby T, et al. Validation of an enzyme-linked immunosorbent assay for the diagnosis of recent campylobacter infections in guillain- 
barre and reactive arthritis patients. Zoonoses and Public Health 2007;54:50.

\section{Ang 2007b}

Ang CW, Krogfelt K, Herbrink P, Keijser J, Van Pelt W, Dalby T, et al. Validation of an ELISA for the diagnosis of recent campylobacter infections in guillain-barre and reactive arthritis patients. Clinical Microbiology \& Infection 2007;13(9):915-22.

\section{Anonymous 1989}

Anonymous. 14c-urea breath test for $C$ pylori. Gut 1989;30(11):1656-7.

\section{Anonymous 1996}

Anonymous. Breath test for Helicobacter pylori. WHO Drug Information 1996;10(4):187.

\section{Anonymous 1997}

Anonymous. Technical annex: Tests used to assess Helicobacter pylori infection. Working party of the European Helicobacter pylori study group. Gut 1997;41 Suppl 2:S10-8.

\section{Anonymous 2000}

Anonymous. A stool test for H. pylori. Hospital Practice 2000;35(4):140.

\section{Anonymous 2002a}

Anonymous. The stool antigen test for detection of Helicobacter pylori after eradication therapy - commentary. Annals of Internal Medicine 2002;136(4):286-7.

\section{Anonymous 2002b}

Anonymous. H. pylori breath test effective. Pharmaceutical Journal 2002;268(7196):601.

\section{Anonymous 2004}

Anonymous. Which test for Helicobacter pylori in primary care?. Drug and Therapeutics Bulletin 2004;42(9):71-2.

\section{Antico 2010}

Antico A, Tozzoli R, Villalta D, Tonutti E, Tampoia M, Bizzaro N. Diagnostic efficacy of a specific serological profile for the diagnosis of chronic autoimmune gastritis. Rivista Italiana della Medicina di Laboratorio 2010;6(3):198-204.

\section{Antoine 1995}

Antoine C, Lozniewski A, De Korwin JD, Conroy MC, Feldmann L, Duprez A, et al. Comparative study of four commercial serological tests for the diagnosis of Helicobacter pylori infection. Gastroenterologie Clinique et Biologique 1995;19(2):182-8.

\section{Antos 2005}

Antos D, Crone J, Konstantopoulos N, Koletzko S. Evaluation of a novel rapid one-step immunochromatographic assay for detection of monoclonal Helicobacter pylori antigen in stool samples from children. Journal of Clinical Microbiology 2005;43(6):2598-601.

\section{Anwar 2012}

Anwar MM, Youssef Al, Sheta MI, Zaki A, Bernaba NR, elToukhi MA. Evaluation of specific biochemical indicators of Helicobacter pylori-associated gastric cancer in Egypt. Eastern Mediterranean Health Journal 2012;18(5):501-7.

\section{Arboleda 2013}

Arboleda RN, Schneider BG, Bravo LE, Romero-Gallo J, Peek RM Jr, Mera RM, et al. Use of the noninvasive enterotest in the detection of Helicobacter pylori in children in an endemic area in Colombia. Journal of Pediatric Gastroenterology \& Nutrition 2013;57(2):192-6.

\section{Archimandritis 2001}

Archimandritis A, Giontzis A, Kourtesas D, Tzivras M, Smilakou S, Davaris P. Diagnosis of Helicobacter pylori infection with a stool assay: Is it useful after eradication treatment?. American Journal of Gastroenterology 2001;96(4):1298-9.

\section{Arents 2001}

Arents NL, Van Zwet AA, Thijs JC, De Jong A, Pool MO, Kleibeuker JH. The accuracy of the Helicobacter pylori stool antigen test in diagnosing $H$. pylori in treated and untreated patients. European Journal of Gastroenterology \& Hepatology 2001;13(4):383-6.

\section{Arents 2002}

Arents NL, Van Zwet AA, Thijs JC, De Jong A, Pool MO, Kleibeuker JH. The accuracy of the Helicobacter pylori stool antigen test in diagnosing $\mathrm{H}$. pylori in treated patients reply. European Journal of Gastroenterology \& Hepatology 2002;14(1):89-90.

\section{Arinton 2011}

Arinton IG. Adjustment of cut-off values in ELISA for detection of Helicobacter pylori infection. Acta Medica Indonesiana 2011;43(2):88-91.

\section{Arita 1982}

Arita K, Yamauchi E, Mizuno S, Maki S. Serological response to campylobacter jejuni infection: Enzyme-linked immunosorbent assay (ELISA) for detection of antibodies to campylobacter jejuni. Kansenshogaku Zasshi [The Journal of the Japanese Association for Infectious Diseases] 1982;56(7):566-73.

\section{Arj 2012}

Arj A, Ehteram H, Razavizadeh M. Efficacy of stool ag test for the non-invasive diagnosis of Helicobacter pylori infection in dyspeptic patients. Journal of Gastroenterology and Hepatology 2012;27:420.

\section{Arora 2003}

Arora U, Aggarwal A, Singh K. Comparative evaluation of conventional methods and ELISA based IgG antibodies detection for diagnosis of Helicobacter pylori infection in cases of dyspepsia. Indian Journal of Medical Microbiology 2003;21(1):46-8.

\section{Artiko 2004}

Artiko V, Obradovic V, Petrovic N, Davidovic B, Vlajkovic M, Petrovic M, et al. Breath test (c-14-urea) in the detection of 
Helicobacter pylori infection. European Journal of Nuclear Medicine and Molecular Imaging 2004;31:S216-S7.

\section{Asaka 1988}

Asaka M, Mitani S, Yoshida J, Saito M, Meguro T. Clinical significance of ELISA for campylobacter pylori. Nihon Shokakibyo Gakkai Zasshi [Japanese Journal of Gastroenterology] 1988;85(4):950.

\section{Asaki 1996}

Asaki S, Yamagami H, Noda A, Tachikawa T, Osumi T, Hirao Y, et al. Phase i clinical trial of 13C-urea breath test (c-13ubt). Japanese Journal of Clinical Pharmacology and Therapeutics 1996;27(3):607-16.

\section{Asante 1998}

Asante MA, Mendall MA, Finlayson C, Ballam L, Northfield T. Screening dyspeptic patients for Helicobacter pylori prior to endoscopy: Laboratory or near-patient testing?. European Journal of Gastroenterology \& Hepatology 1998;10(10):843-6.

\section{Asfeldt 2004}

Asfeldt AM, Lochen ML, Straume B, Steigen SE, Florholmen J, Goll R, et al. Accuracy of a monoclonal antibody-based stool antigen test in the diagnosis of Helicobacter pylori infection. Scandinavian Journal of Gastroenterology 2004;39(11):1073-7.

\section{Ashraf 1999}

Ashraf P, UI Haq M, Amjad R. Assessment of $13 \mathrm{C}$ urea breath test's usefulness in the diagnosis of Helicobacter pylori infection. Journal of the College of Physicians and Surgeons Pakistan 1999;9(2):75-7.

\section{Atherton 1992}

Atherton JC, Hymantaylor P, Hawkey CJ, Spiller RC. Direct comparison of $\mathrm{c}-13$ and low-dose $\mathrm{c}-14$ as isotopic markers in the urea breath test for Helicobacter-pylori. Gut 1992;33(2):S5-S.

\section{Atherton 1994}

Atherton JC, Spiller RC. The urea breath test for Helicobacter pylori. Gut 1994;35(6):723-5.

\section{Attallah 2004}

Attallah AM, Ismail H, Ibrahim GG, Abdel-Raouf M, El-Waseef AM, Abdel-Wahab M. Use of a novel enzyme immunoassay based on detection of circulating antigen in serum for diagnosis of Helicobacter pylori infection. Clinical \& Diagnostic Laboratory Immunology 2004;11(4):775-9.

\section{Attumi 2011}

Attumi TA, Graham DY. Follow-up testing after treatment of Helicobacter pylori infections: Cautions, caveats, and recommendations. Clinical Gastroenterology and Hepatology 2011;9(5):373-5.

\section{Aucher 1998}

Aucher P, Petit ML, Mannant PR, Pezennec L, Babin P, Fauchere JL. Use of immunoblot assay to define serum antibody patterns associated with Helicobacter pylori infection and with h. Pylori-related ulcers. Journal of Clinical Microbiology 1998;36(4):931-6.

\section{Aulia 2009}

Aulia D, Manz GO, Simadibrata M. Pepsinogen i concentration in organic dyspepsia patients at Gastroenterology Division, Department of Internal Medicine, Cipto Mangunkusumo Hospital. Acta Medica Indonesiana 2009;41(3):107-14.

\section{Auroux 1998}

Auroux J, Lamarque D, Tankovic J, Benamouzig R, Mahe S, Chaumette MT, et al. Comparison of Helicobacter pylori gastric density by culture, histology and c-13 urea breath test. Gastroenterologie Clinique et Biologique 1998;22(4):407-12.

\section{Aziz 2014}

Aziz F, Sherwani SK, Akhtar SS, Kazmi SU. Development of an inhouse enzyme-linked immunosorbent assay based on surface whole cell antigen for diagnosis of Helicobacter pylori infection in patients with gastroduodenal ulcer disease. World Journal of Microbiology \& Biotechnology 2014;30(1):305-15.

\section{Bakka 2002}

Bakka AS, El-Gariani AB, AbouGhrara FM, Salih BA. Frequency of Helicobacter pylori infection in dyspeptic patients in Libya. Saudi Medical Journal 2002;23(10):1261-5.

\section{Balcilar 2012}

Balcilar E, Karsidag T, Tuzun S. Relaibility of Helicobacter antigen in stool for screening. Medical Bulletin of Haseki 2012;50(3):89-92.

\section{Ballam 1998}

Ballam L, Mendall MA, Morris J, Strachan D, Whincup P, Cook D. Western blotting ( $w b$ ) is useful in the salivary diagnosis of $h-$ pylori infection. Gastroenterology 1998;114(4 suppl):A64.

\section{Ballam 2000a}

Ballam LD, Mendall MA, Asante M, Morris J, Strachan DP, Whincup $\mathrm{PH}$, et al. Western blotting is useful in the salivary diagnosis of Helicobacter pylori infection. [Erratum appears in J Clin Pathol 2000;53(9):725]. Journal of Clinical Pathology 2000;53(4):314-7.

\section{Ballam 2000b}

Ballam LD, Mendall MA, Asante. Erratum: Western blotting is useful in the salivary diagnosis of Helicobacter pylori infection (Journal of clinical pathology 2000;53:314-7). Journal of Clinical Pathology 2000;53(9):725.

\section{Balon 1997}

Balon HR, Roff E, Dworkin HJ. Capsule-based c-14 urea breath test for Helicobacter pylori: Early experience and comparison with liquid-based test. Journal of Nuclear Medicine 1997;38(5 Suppl):Abstract 1092.

\section{Baqai 2003}

Baqai R, Qureshi H, Arian G, Mehdi I. Diagnostic efficacy of stool antigen test (HPSA), clo test and serology for the detection of Helicobacter pylori infection. Journal of Ayub Medical College, Abbottabad: JAMC 2003;15(4):34-6. 


\section{Baranskaia 2006}

Baranskaia EK, Ivashkin VT, Lapshin AV, Stepanov EV, Zyrianov PV. The diagnostic significance of laser 13C-urea breath test in various Helicobacter pylori-associated diseases. Klinicheskaia Meditsina 2006;84(8):47-50.

\section{Barbosa 2003}

Barbosa J, Dinis-Ribeiro M, Guilherme M, Filipe T, LombaViana R, Guimaraes MA, et al. Use of Helicobacter pylorispecific antibodies in the evaluation of intestinal metaplasia and gastric dysplasia. British Journal of Biomedical Science 2003;60(4):175-9.

\section{Barthel 1990}

Barthel JS, Everett ED. Diagnosis of campylobacter pylori infections: The "gold standard" and the alternatives. Reviews of Infectious Diseases 1990;12 Suppl 1:S107-14.

\section{Baryshnikova 2009}

Baryshnikova NV. Actual problems of Helicobacteriosis diagnostics. Eksperimental'naia i Klinicheskaia Gastroenterologiia [Experimental \& Clinical Gastroenterology] 2009;2:50-6.

\section{Baryshnikova 2012}

Baryshnikova NV, Uspenskiy YP, Smirnova AS, Dmitrienko MA, Bykov SE. Helicobacter pylori in oral cavity in patients with chronic gastritis. Helicobacter 2012;17:90.

\section{Baryshnikova 2013}

Baryshnikova NV, Belousova LN, Smirnova AS, Tsopanova EE, Loeva IA, Orlov OY, et al. Breath ammonium test in diagnostic of Helicobacter pylori infection. Helicobacter 2013;18:124.

\section{Baryshnikova 2014}

Baryshnikova NV, Belousova LN, Loeva IA, Kudryavtseva AS, Shehman AV, Yakovleva JS. Comparative analysis of efficacy of noninvasive ammonium "helic-test" and histological method in diagnostic of Helicobacter pylori infection. Helicobacter 2014;19:122.

\section{Basinska 2005}

Basinska T, Wisniewska M, Chmiela M. Principle of a new immunoassay based on electrophoretic mobility of poly(styrene/alpha-tert-butoxy-omega-vinylbenzylpolyglycidol) microspheres: Application for the determination of Helicobacter pylori igg in blood serum. Macromolecular Bioscience 2005;5(1):70-7.

\section{Bassler 1992}

Bassler HMS, Dreher RM, Wolf K. Isolation of h. Pylori proteins and their availability in serological tests. Immunitat und Infektion 1992;20(3):103-6.

\section{Basso 1999}

Basso D, Stefani A, Brigato L, Navaglia F, Greco E, Zambon CF, et al. Serum antibodies anti-h. Pylori and anti-caga: A comparison between four different assays. Journal of Clinical Laboratory Analysis 1999;13(4):194-8.

\section{Bateson 1991}

Bateson MC, Ching CK, Loffeld RJLF, Arends JW, Stobberingh E. Screening for Helicobacter pylori in dyspepsia [comment]. Lancet 1991;338(8763):393-4.

\section{Bateson 2001}

Bateson MC. Quadruple therapy for symptomatic spontaneous duodenal ulcer disease. Postgraduate Medical Journal 2001;77(909):447-50.

\section{Bathe 1996}

Bathe OF, Rae AJ, Zetler P, Cleator IGM. Validation of a new saliva test for Helicobacter pylori infection. Canadian Journal of Gastroenterology 1996;10(2):93-6.

\section{Bauernfeind 1989}

Bauernfeind A, Przyklenk B, Horl G, Otto U. Representative campylobacter pylori antigen for IgG-ELISA and diagnostic significance of antibody titres. Gastroduodenal pathology and Campylobacter pylori. The first meeting of the European Campylobacter Pylori Study Group ICS847; 1989. 1989:185-8.

\section{Bazaz 2005}

Bazaz RD, Khalaj A, Beiki D, Eftekhari M, Hosein MHAS, Khoshayand MR. Microdose $14 \mathrm{C}$ urea breath test for the diagnosis of Helicobacter pylori: A survey in Iranian population. Daru 2005;13(1):6-10.

\section{Bazzoli 1994}

Bazzoli F, Zagari RM, Pozzato P, Fossi S, Alampi G, Sottili S, et al. C-13-urea breath test to quantify Helicobacter-pylori colonization of gastric-mucosa and association with severity of inflammation. Gastroenterology 1994;106(4 suppl):A48.

\section{Bazzoli 1995}

Bazzoli F, Zagari RM, Pozzato P, Fossi S, Simoni P, Roda A, et al. The c-13-urea breath test to evaluate the effect of antisecretory drugs on Helicobacter-pylori. Gastroenterology 1995;108(4 suppl):A57.

\section{Bazzoli 1996}

Bazzoli F, Cecchini L, Corvaglia L, Antonia MD, Libera MD, DeGiacomo C, et al. The c-13-urea breath test for the diagnosis of Helicobacter pylori infection in children. Gastroenterology 1996;110(4 Suppl):A60.

\section{Bazzoli 1997a}

Bazzoli F, Zagari RM, Festi D, Palli D, Pozzato P, Sottili S, et al. A population based study of Helicobacter pylori infection .2. Uprevalence by c-13-urea breath test and association with family history of peptic ulcer and gastric cancer. Gut 1997;41(Suppl):A106.

\section{Bazzoli 1997b}

Bazzoli F, Zagari M, Fossi S, Pozzato P, Ricciardiello L, Mwangemi $\mathrm{C}$, et al. Urea breath tests for the detection of Helicobacter pylori infection. Helicobacter 1997;2 Suppl 1:S34-7. 


\section{Bazzoli 1998}

Bazzoli F, Zagari M, Pozzato P, Fossi S, Ricciardiello GL, Nicolini G, et al. Diagnosis of Helicobacter pylori infection: Noninvasive diagnostic tests. Italian Journal of Gastroenterology \& Hepatology 1998;30(suppl 3):S313-4.

\section{Bazzoli 1999}

Bazzoli F, Zagari RM, Pozzato P, Fossi S, Ricciardiello L, De Luca L, et al. Helicobacter pylori: Optimum diagnosis and test of cure. Journal of Chemotherapy 1999;11(6):601-5.

\section{Bazzoli 2000}

Bazzoli F, Cecchini L, Corvaglia L, Dall'Antonia M, De Giacomo C, Fossi S, et al. Validation of the 13C-urea breath test for the diagnosis of Helicobacter pylori infection in children: $\mathrm{A}$ multicenter study. American Journal of Gastroenterology 2000;95(3):646-50.

\section{Befrits 1993}

Befrits R, Granstrom M, Rylander M, Rubio C. Helicobacter pylori in 205 consecutive endoscopy patients. Scandinavian Journal of Infectious Diseases 1993;25(2):185-91.

\section{Beiki 2005}

Beiki D, Khalaj A, Dowlatabadi R, Eftekhari M, Hossein MHAS, Fard A, et al. Validation of 13C-urea breath test with non dispersive isotope selective infrared spectroscopy for the diagnosis of Helicobacter pylori infection: A survey in Iranian population. Daru 2005;13(2):52-5.

\section{Bekmen 2008}

Bekmen N, Demiray E, Gonen C, Dolek D, Soyturk M, Sagol O, et al. Determination of $H$. pylori antigenic frequency by western blot technique in adult patients with dyspepsia. Helicobacter 2008;13(5):452.

\section{Bell 1987}

Bell GD, Weil J, Harrison G, Morden A, Jones PH, Gant PW, et al. 14c-urea breath analysis, a non-invasive test for campylobacter pylori in the stomach. Lancet 1987;1(8546):1367-8.

\section{Bell 1991}

Bell GD, Powell K, Weil J, Harrison G, Brookes S, Prosser S. 13C-urea breath test for Helicobacter pylori infection. Gut 1991;32(5):551-2.

\section{Bellon 2004}

Bellon M. The urea breath test. ANZ Nuclear Medicine 2004;35(2):104-7.

\section{Bener 2002}

Bener A, Uduman SA, Ameen A, Alwash R, Pasha MA, Usmani MA, et al. Prevalence of Helicobacter pylori infection among low socio-economic workers. Journal of Communicable Diseases 2002;34(3):179-84

\section{Benito 1999}

Benito LM, Sara S, Gisbert JP, Vasquez MA, Jimenez I, Pajares JM. C-13-urea breath test for the diagnosis of $\mathrm{H}$-pylori infection: Are basal samples necessary?. Gut 1999;45(Suppl 3):A125-A6

\section{Benjamin 2012}

Benjamin YC, Feng Z, Ho KY, Christopher K, Lim LG, So JB, et al. Risk stratification for gastric cancer using serum pepsinogen and Helicobacter pylori serology in a Chinese population. Gastroenterology 2012;142(5 (Suppl)):S631.

\section{Bennedsen 1998}

Bennedsen M, Lehn N, Morgner A, Bayerdorffer E, Andersen LP. Development of a Helicobacter heilmanii specific ELISA. Gut 1998;43(Suppl 2):A115-A6.

\section{Bennett 2006}

Bennett K, Feely J, Thornton O, Dobson M, O'Morain CA, O'Connor HJ. Impact of Helicobacter pylori on the management of dyspepsia in primary care. Alimentary Pharmacology \& Therapeutics 2006;24(4):637-41.

\section{Berger 2002}

Berger A. Helicobacter pylori breath tests. BMJ 2002;324(7348):1263.

\section{Bergey 2003}

Bergey B, Marchildon P, Peacock J, Megraud F. What is the role of serology in assessing Helicobacter pylori eradication?. Alimentary Pharmacology \& Therapeutics 2003;18(6):635-9.

\section{Bergmann 1997}

Bergmann WL. Diagnosis and therapy ofHelicobacter pylori infections in adults. Deutsche Medizinische Wochenschrift 1997;122(11):348-9.

\section{Berker 2003}

Berker B, Soylemez F, Cengiz SD, Kose SK. Serologic assay of Helicobacter pylori infection - is it useful in hyperemesis gravidarum?. Journal of Reproductive Medicine 2003;48(10):809-12.

\section{Bermejo 2000a}

Bermejo San Jose F, Boixeda de Miguel D, Gisbert JP, Martin de Argila de Prados C, Sanz Sacristan JM, Defarges Pons V, et al. Efficacy of four widely used techniques of the diagnosis of Helicobacter pylori infection in gastric ulcer disease. Revista Clinica Española 2000;200(9):475-9.

\section{Bermejo 2000b}

Bermejo F, Boixeda D, Gisbert JP, Sanz JM, Canton R, Defarges V, et al. Concordance between noninvasive tests in detecting Helicobacter pylori and potential use of serology for monitoring eradication in gastric ulcer. Journal of Clinical Gastroenterology 2000;31(2):137-41.

\section{Bermejo 2002}

Bermejo F, Boixeda D, Gisbert JP, Defarges V, Sanz JM, Redondo C, et al. Rapid urease test utility for Helicobacter pylori infection diagnosis in gastric ulcer disease. HepatoGastroenterology 2002;49(44):572-5.

\section{Berning 2009}

Berning M, Krasz S, Schneider-Brachert W, Madisch A, Laass MW, $\mathrm{Knoth} \mathrm{H}$, et al. Randomized multicenter study of esomeprazole, moxifloxacin and amoxicillin for second-line or rescue 
treatment of Helicobacter pylori infection - impact of treatment duration. Gastroenterology 2009;136(5 (suppl)):A150.

\section{Bertschinger 1992}

Bertschinger P, Brunner J, Flury R, Lammer F, Jost R, Hacki WH. Comparison of effectiveness of omeprazole/bismuth subcitrate and triple therapy in Helicobacter pylori gastritis. Schweizerische Medizinische Wochenschrift 1992;122(39):1446-51.

\section{Besherdas 2000}

Besherdas K, Oben JA, Beck ER, Vicary FR, Wong VS. What proportion of dyspeptic patients having $H$. pylori breath test subsequently undergo endoscopy?. Gut 2000;46(Suppl 2):A52.

\section{Bessede 2011}

Bessede E, Delcamp A, Sifre E, Buissonniere A, Megraud F. New methods for detection of campylobacters in stool samples in comparison to culture. Journal of Clinical Microbiology 2011;49(3):941-4.

\section{Best 1992}

Best LM, Van Zanten SJOV, Bezanson GS, Haldane DJM, Malatjalian DA. Serological detection of Helicobacter pylori by a flow microsphere immunofluorescence assay. Journal of Clinical Microbiology 1992;30(9):2311-7.

\section{Best 1994}

Best LM, Van Zanten SJOV, Sherman PM, Bezanson GS. Serological detection of Helicobacter pylori antibodies in children and their parents. Journal of Clinical Microbiology 1994;32(5):1193-6.

\section{Beynon 2013}

Beynon R, Leeflang MM, McDonald S, Eisinga A, Mitchell RL, Whiting $P$, et al. Search strategies to identify diagnostic accuracy studies in MEDLINE and EMBASE. Cochrane Database of Systematic Reviews 2013, Issue 9. [DOI: 10.1002/14651858.MR000022.pub3]

\section{Bhewa 2007}

Bhewa Y, Hilmi I, Cheah PL, Navaratnam P, Goh KL. Evaluation of the monoclonal stool antigen test for Helicobacter pylori in an asian population with dyspepsia. Journal of Digestive Diseases 2007;8(4):207-10.

\section{Bielanski 1996a}

Bielanski W, Konturek SJ, Dobrzanska MJ, Pytko-Polonczyk J, Sito E, Marshall BJ. Microdose 14c-urea breath test in detection of Helicobacter pylori. Journal of Physiology \& Pharmacology 1996;47(1):91-100.

\section{Bielanski 1996b}

Bielanski W, Pytko J, Konturek SJ, Sito E, Marshall J. Usefulness of c-14-urea breath test in detection of Helicobacter pylori associated gastric diseases. Gastroenterology 1996;110(4 (suppl)):A65.

\section{Bielanski 1996c}

Bielanski W, Konturek SJ. New approach to 13C-urea breath test: Capsule-based modification with low-dose of 13C-urea in the diagnosis of Helicobacter pylori infection. Journal of Physiology \& Pharmacology 1996;47(3):545-53.

\section{Bielanski 1997a}

Bielanski W, Plonka M, Dobrzanska M, Kaminska A, Konturek SJ. Screening of $H$-pylori (HP) infection in adult population of Krakow, Poland using modified capsulated urea breath test. Gut 1997;41(Suppl):A37-A8.

\section{Bielanski 1997b}

Bielanski W, Dobrzanska J, Kaminska A, Plonka M, Sito E, Konturek SJ. Validation of new low dose and low cost c-13urea breath test in the diagnosis for Helicobacter pylori. Gastroenterology 1997;112(4 (suppl)):A72.

\section{Bielanski 1998}

Bielanski W, Bobrzynski A, Kostarczyk W, Karczewska E, Gedliczka O, Konturek SJ. Usefulness of capsulated low dose c-13-urea breath test in diagnosing h-pylori infection in patients with upper gastrointestinal bleeding. Gut 1998;43(Suppl 2):A54A5.

\section{Bielanski 1999}

Bielanski W, Dobrzanska M, Jakuszewska B, Kaminska A, Plonka M, Konturek SJ. Ethanol as confounding factor in detection of Helicobacter pylori (HP) by c-13-urea breath test. Gastroenterology 1999;116(4 (suppl)):A123.

\section{Bielanski 2000}

Bielanski W, Loster BW, Plonka M, Dobrzanska M, Kaminska A Majewski S, et al. Incidence of $H$-pylori (HP) infection in Polish endoscopists and dentists: Results of field survey with capsulated c-13-urea breath test (ubt). Gut 2000;47(Suppl 1):A50.

\section{Biemond 1997}

Biemond I, Veenendaal RA, Lamers C. Rapid diagnostic test for antibodies to Helicobacter pylori in comparison with the ELISA technique. Gut 1997;41(suppl):A159.

\section{Bilal 2007}

Bilal R, Khaar B, Qureshi TZ, Mirza SA, Ahmad T, Latif Z, et al. Accuracy of non-invasive 13C-urea breath test compared to invasive tests for Helicobacter pylori detection. Journal of the College of Physicians \& Surgeons - Pakistan 2007;17(2):84-8.

\section{Bilardi 2002}

Bilardi C, Biagini R, Dulbecco P, liritano E, Gambaro C, Mele MR, et al. Stool antigen assay (HPSA) is less reliable than urea breath test for post-treatment diagnosis of Helicobacter pylori infection. Alimentary Pharmacology \& Therapeutics 2002;16(10):1733-8.

\section{Billaud 1996}

Billaud N, Morali A, Conroy MJ, Floquet J. Helicobacter pylori infection in pediatric patients. A review of twenty-three cases. Annales De Pediatrie 1996;43(4):281-7. 


\section{Bindayna 2006}

Bindayna K, Al Baker W, Botta G. Detection of Helicobacter pylori caga gene in gastric biopsies, clinical isolates and faeces. Indian Journal of Medical Microbiology 2006;24(3):195-200.

\section{Birkenfeld 2004}

Birkenfeld S, Keter D, Dikman R, Shevah O, Shirin H, Niv Y. Prevalence of Helicobacter pylori infection in health-care personnel of primary care and gastroenterology clinics. Journal of Clinical Gastroenterology 2004;38(1):19-23.

\section{Bjorneklett 1989}

Bjorneklett A, Fausa O, Nedenskovsorensen P, Bukholm G, Aase $\mathrm{S}$. The c-14 urea breath test in the diagnosis of Campylobacter-pylori infection. Gastroduodenal Pathology and Camphylobacter pylori 1989;847:65-8.

\section{Blairon 2009}

Blairon L, Souayah H, Moens C, Dediste A, Vandenberg O. Comparison of 6 rapid assays for detection of Helicobacter pylori antigen in stool in children with recurrent abdominal pain - preliminary data. Clinical Microbiology and Infection 2009;15:S315.

\section{Blancas 2004}

Blancas Valencia JM. Importance of Helicobacter pylori diagnosis. Revista de Gastroenterologia de Mexico 2004;69(3):186-7.

\section{Blanco 2008}

Blanco S, Forne M, Lacoma A, Prat C, Cuesta MA, Latorre I, et al. Comparison of stool antigen immunoassay methods for detecting Helicobacter pylori infection before and after eradication treatment. Diagnostic Microbiology \& Infectious Disease 2008;61(2):150-5.

\section{Blanco 2009}

Blanco S, Forne M, Lacoma A, Prat C, Cuesta MA, Fuenzalida L, et al. Evaluation of a latex agglutination test (pylogen) for the detection of Helicobacter pylori in stool specimens. Diagnostic Microbiology \& Infectious Disease 2009;63(4):349-53.

\section{Blashenkov 2013}

Blashenkov NM, Sheshenya ES, Solov'ev SM, Sachenko VD, Gall LN, Zarutskii IV, et al. A specialized isotope mass spectrometer for noninvasive diagnostics of Helicobacter pylori infection in human beings. Technical Physics Letters 2013;39(5):431-4.

\section{Bleau 1998}

Bleau BL, Van Zanten SV, Best L, Hutchison D, Blevins J, Thee D. Determination of eradication of Helicobacter pylori (HP) by the HP stool antigen test (HPSAT). Gut 1998;43(Suppl 2):A50.

\section{Blecker 1992a}

Blecker U, Vandenplas Y. Helicobacter pylori seropositivity in symptom-free children. Lancet 1992;339(8808):1537.

\section{Blecker 1992b}

Blecker U, Lanciers S, Peeters S, Vandenplas Y. Helicobacter pylori infections in children. Tijdschrift voor Kindergeneeskunde 1992;60(2):35-9.

\section{Blecker 1993a}

Blecker U, Keymolen K, Levy J, Vandenplas Y. Low prevalence of Helicobacter pylori in the acquired immunodeficiency syndrome. American Journal of Gastroenterology 1993;88(8):1294.

\section{Blecker 1993b}

Blecker U, Lanciers S, Hauser B. Validation of a new serologic test for the detection of Helicobacter pylori. Acta Gastroenterologica Belgica 1993;56(5-6):309-14.

\section{Blecker $1993 \mathrm{C}$}

Blecker U, Lanciers S, Hauser B, Vandenplas Y. Diagnosis of Helicobacter pylori infection in adults and children by using the malakit Helicobacter pylori, a commercially available enzymelinked immunosorbent assay. Journal of Clinical Microbiology 1993;31(7):1770-3.

\section{Blecker 1993d}

Blecker U, Lanciers S, Hauser B, Vandenplas Y. Positive and negative titres of a new serologic test for the detection of Helicobacter pylori. European Journal of Gastroenterology \& Hepatology 1993;5(8):631-4.

\section{Blecker 1993e}

Blecker U, Vandenplas Y. Helicobacter pylori serology. Journal of Clinical Microbiology 1993;31(1):173.

\section{Blecker $1993 f$}

Blecker U, Vandenplas Y, Taha AS, Russell RI. Serological diagnosis of Helicobacter pylori. Gut 1993;34(10):1467.

\section{Blecker 1993g}

Blecker U, Hauser B, Lanciers S, Peeters S, Suys B, Vandenplas Y. The prevalence of Helicobacter pylori-positive serology in asymptomatic children. Journal of Pediatric Gastroenterology and Nutrition 1993;16(3):252-6.

\section{Blecker 1994a}

Blecker U, Lanciers S, Mehta DI, Vandenplas Y. The sensitivity and specificity of a recent generation serum ELISA test for the detection of Helicobacter-pylori specific IgG antibodies compared to the c-13-urea breath test. Gastroenterology 1994;106(4 (suppl)):A54.

\section{Blecker 1994b}

Blecker U, Vandenplas Y. Usefulness of specific IgM in the diagnosis of Helicobacter pylori infection. Pediatrics 1994;93(2):342-3.

\section{Blecker 1994c}

Blecker U, Vandenplas Y, Blecker U, Lanciers S, Mehta DI. Concordance between serology and 13C-urea breath test in the diagnosis of Helicobacter pylori infection. American Journal of Gastroenterology 1994;89(3):459. 


\section{Blecker 1994d}

Blecker U, Keymolen K, Lanciers S, Bahwere P, Souayah $\mathrm{H}$, Levy J, et al. The prevalence of Helicobacter pylori positivity in human immunodeficiency virus-infected children. Journal of Pediatric Gastroenterology \& Nutrition 1994;19(4):417-20.

\section{Blecker 1995a}

Blecker U, Lanciers S, Hauser B, Mehta DI, Vandenplas Y. Serology as a valid screening test for Helicobacter pylori infection in asymptomatic subjects. Archives of Pathology \& Laboratory Medicine 1995;119(1):30-2.

\section{Blecker 1995b}

Blecker U, Lanciers S, Hauser B, De Pont SM, Vandenplas Y. The contribution of specific immunoglobulin $\mathrm{m}$ antibodies to the diagnosis of Helicobacter pylori infection in children. European Journal of Gastroenterology \& Hepatology 1995;7(10):979-83.

\section{Blum 1997}

Blum AL, Bayerdorffer E, Borsch G, Classen M, Creutzfeldt W, Hotz J, et al. The Helicobacter revolution .2. Diagnosis and therapy. Leber Magen Darm 1997;27(4):241-6.

\section{Bode 1998}

Bode G, Rothenbacher D, Brenner H, Adler G. Variation in the 13C-urea breath test value by nationality in Helicobacter pyloriinfected children. Scandinavian Journal of Gastroenterology 1998;33(5):468-72.

\section{Bode 2000}

Bode G, Hoffmeister A, Koenig W, Brenner H, Rothenbacher D. Extent and determinants of differences in Helicobacter pylori serology and c-13-urea breath test in an asymptomatic sample of blood donors. Gut 2000;47(Suppl 1):A121.

\section{Bode 2001}

Bode G, Hoffmeister A, Koenig W, Brenner H, Rothenbacher D. Characteristics of differences in Helicobacter pylori serology and c-13-urea breath-testing in an asymptomatic sample of blood donors. Scandinavian Journal of Clinical \& Laboratory Investigation 2001;61(8):603-8.

\section{Bode 2002}

Bode G, Marchildon P, Peacock J, Brenner H, Rothenbacher D. Diagnosis of Helicobacter pylori infection in children: Comparison of a salivary immunoglobulin g antibody test with the c-13 urea breath test. Clinical and Diagnostic Laboratory Immunology 2002;9(2):493-5.

\section{Bodger 1999}

Bodger K, Wyatt JI, Heatley RV. Serologic screening before endoscopy: The value of Helicobacter pylori serology, serum recognition of the caga and vaca proteins, and serum pepsinogen i. Scandinavian Journal of Gastroenterology 1999;34(9):856-63.

\section{Bodhidatta 1993}

Bodhidatta L, Hoge CW, Churnratanakul S, Nirdnoy W, Sampathanukul P, Tungtaem C, et al. Diagnosis of Helicobacter pylori infection in a developing country: Comparison of two
ELISAs and a seroprevalence study. Journal of Infectious Diseases 1993;168(6):1549-53.

\section{Bohn 1994}

Bohn I, Teufel M, Niessen KH. Helicobacter pylori causing chronical stomach-ache in childhood. Monatsschrift fur Kinderheilkunde 1994;142(4):269-71.

\section{Bojko 1997}

Bojko JB, Braden B, Lembcke B, Stolte M, Burlage M, Folsch UR, et al. C-13-urea breath test correlates with the hp corpus colonization score in Helicobacter pylori - infected patients. Gastroenterology 1997;112(4 (suppl)):A75.

\section{Bolton 1989a}

Bolton FJ, Hutchinson DN, Hinchiliffe PM, Holt AV. Distribution in various clinical groups of antibody to $C$. pylori detected by enzyme-linked immunosorbent assay, complement fixation and microagglutination tests. Serodiagnosis and Immunotherapy in Infectious Disease 1989;3(1):41-50.

\section{Bolton 1989b}

Bolton FJ, Hutchinson DN. Evaluation of three Campylobacter pylori antigen preparations for screening sera from patients undergoing endoscopy. Journal of Clinical Pathology 1989;42(7):723-6.

\section{Bolton 1997}

Bolton FJ, Wareing DRA, Sails AD. Comparison of a novel microaerobic system with three other gas-generating systems for the recovery of Campylobacter species from human faecal samples. European Journal of Clinical Microbiology and Infectious Diseases 1997;16(11):839-42.

\section{Bommelaer 2001}

Bommelaer G, Des Varannes SB, Flejou JF, Matysiak T, Poynard T, Richard A, et al. Caga status and virulence of Helicobacter pylori strains. Results of a French multicentric prospective study. Gastroenterologie Clinique et Biologique 2001;25(12):1084-9.

\section{Bonamico 2004}

Bonamico M, Strappini PM, Bonci E, Ferri M, Crisogianni M, Guido M, et al. Evaluation of stool antigen test, PCR on oral samples and serology for the noninvasive detection of Helicobacter pylori infection in children. Helicobacter 2004;9(1):69-76.

\section{Bongermino 2010}

Bongermino MP, Ruggero V, Cristallo V, Bonfrate L, Santantonio M, Mola A, et al. Evaluation of non-invasive methods for the diagnosis of Helicobacter pylori infection. European Journal of Clinical Investigation 2010;40:67.

\section{Booka 2005}

Booka M, Okuda M, Shin K, Miyashiro E, Hayashi H, Yamauchi K, et al. Polymerase chain reaction-restriction fragment length polymorphism analysis of clarithromycin-resistant Helicobacter pylori infection in children using stool sample. Helicobacter 2005;10(3):205-13. 


\section{Bordin 2013}

Bordin DS, Berezina OI, Kim VA, Orobey YA, Patrushev NB. Diagnosis of $H$. pylori infection in routine clinical practice in Russia. Helicobacter 2013;18:122.

\section{Bornschein 2011}

Bornschein J, Selgrad M, Malfertheiner P. Helicobacter pylori - diagnosis and treatment. MMW-Fortschritte der Medizin 2011;153(38):58-61.

\section{Borody 2012}

Borody T, Wettstein A, Finlayson S, Torres M, Campbell J, Nowak A. Diagnostic value of fundic red spots in Helicobacter pylori (HP) infection. American Journal of Gastroenterology 2012;107:S59.

\section{Borody 2013}

Borody TJ, Wettstein AR, Benstock S, Nowak A, Finlayson SJ, Campbell J. Superior diagnosis of $H$. pylori infection with 14Curea helicaptm capsules versus standard pytest capsules. Gastroenterology 2013;144(5 (suppl 1)):S214-S5.

\section{Boudjella 2009}

Boudjella MEA, Matougui N, Tebaibia A, Oumnia N, Lahcene M, Mouffok F, et al. Evaluation of C-13-urea breath test in determining $H$. pylori status after treatment: About 197 cases. Helicobacter 2009;14(4):343.

\section{Boukthir 2005}

Boukthir S, Mazigh S, Fendri C, Kalach N, Barsaoui S. Evaluation of a non-invasive test for detection of Helicobacter pylori antigen in stool from children. Archives de Pediatrie 2005;12(1):85-7.

\section{Boyanova 2003}

Boyanova L, Koumanova R, Lazarova E, Jelev C. Helicobacter pylori and Helicobacter heilmannii in children. A Bulgarian study. Diagnostic Microbiology \& Infectious Disease 2003;46(4):249-52.

\section{Boyanova 2013}

Boyanova L, Ilieva Y, Vladimirov B, Gergova G, Nikolov R, Spasova Z, et al. The rate of Helicobacter pylori in adult patients with the 13C urea breath test. General Medicine 2013;15(4):22-5.

\section{Braden 1991}

Braden B, Lembcke B, Caspary WF. Stable isotopes in diagnosis and research. Deutsche Medizinische Wochenschrift 1991;116(45):1721-7.

\section{Braden 1992}

Braden B, Lembcke B, Caspary WF. Diagnosis of Helicobacterpylori. Innere Medizin 1992;19(3):103-7.

\section{Braden 1993}

Braden B, Klutz M, Lembcke B, Caspary WF. C-13 urea breath test for Helicobacter-pylori - optimal timing of breath sample collection. Gastroenterology 1993;104(4 (suppl)):A45.

\section{Braden 1994a}

Braden B, Haisch M, Duan LP, Lembcke B, Caspary WF, Hering P. Clinically feasible stable isotope technique at a reasonable price: Analysis of $13 \mathrm{Co} 2 / 12 \mathrm{co} 2$-abundance in breath samples with a new isotope selective-nondispersive infrared spectrometer. Zeitschrift fur Gastroenterologie 1994;32(12):675-8.

\section{Braden 1994b}

Braden B, Duan LP, Caspary WF, Lembcke B. More convenient 13C-urea breath test modifications still meet the criteria for valid diagnosis of Helicobacter pylori infection. Zeitschrift fur Gastroenterologie 1994;32(4):198-202.

\section{Braden 1996}

Braden B, Schafer F, Caspary WF, Lembcke B. Nondispersive isotope-selective infrared spectroscopy: A new analytical method for 13C-urea breath tests. Scandinavian Journal of Gastroenterology 1996;31(5):442-5.

\section{Braden 1997}

Braden B, Duan LP, Caspary WF, Lembcke B. Endoscopy is not a risk factor for Helicobacter pylori infection - but medical practice is. Gastrointestinal Endoscopy 1997;46(4):305-10.

\section{Braden 1999}

Braden B, Caspary WF, Lembcke B. Nondispersive infrared spectrometry for (co2)-c-13/(co2)-c-12-measurements: A clinically feasible analyzer for stable isotope breath tests in gastroenterology. Zeitschrift fur Gastroenterologie 1999;37(6):477-81.

\section{Braden 2000a}

Braden B. New faecal antigen test noninvasively detects Helicobacter pylori infection. Biomedicine and Pharmacotherapy 2000;54(7):416-7.

\section{Braden 2000b}

Braden B, Posselt HG, Ahrens P, Kitz R, Dietrich CF, Caspary WF. New immunoassay in stool provides an accurate noninvasive diagnostic method for Helicobacter pylori screening in children. Pediatrics 2000;106(1 Pt 1):115-7.

\section{Braden 2000c}

Braden B, Teuber G, Dietrich CF, Caspary WF, Lembcke B. Comparison of new faecal antigen test with c-13-urea breath test for detecting Helicobacter pylori infection and monitoring eradication treatment: Prospective clinical evaluation. BMJ 2000;320(7228):148.

\section{Braden 2001a}

Braden B, Gelbmann C, Dietrich CF, Caspary WF, Scholmerich J, Lock G. Qualitative and quantitative clinical evaluation of the laser-assisted ratio analyser for detection of Helicobacter pylori infection by c-13-urea breath tests. European Journal of Gastroenterology \& Hepatology 2001;13(7):807-10.

\section{Braden 2001b}

Braden B, Caspary WF. Detection of Helicobacter pylori infection: When to perform which test?. Annals of Medicine 2001;33(2):91-7. 


\section{Braden 2007}

Braden B, Lembcke B, Kuker W, Caspary WF. 13C-breath tests: Current state of the art and future directions. Digestive \& Liver Disease 2007;39(9):795-805.

\section{Braden 2012}

Braden B. Diagnosis of Helicobacter pylori infection. BMJ 2012;344:e828.

\section{Brandi 2006}

Brandi G, Biavati B, Calabrese C, Granata M, Nannetti A, Mattarelli P, et al. Urease-positive bacteria other than Helicobacter pylori in human gastric juice and mucosa. American Journal of Gastroenterology 2006;101(8):1756-61.

\section{Bravo 1999}

Bravo LE, Realpe JL, Campo C, Mera R, Correa P. Effects of acid suppression and bismuth medications on the performance of diagnostic tests for Helicobacter pylori infection. American Journal of Gastroenterology 1999;94(9):2380-3.

\section{Bravos 2000}

Bravos ED, Gilman RH. Accurate diagnosis of Helicobacter pylori other tests. Gastroenterology Clinics of North America 2000;29(4):925-9.

\section{Brennan 1991}

Brennan DP, Kennedy NP, Keeling PWN. Serum IgG response to Campylobacter-pylori antigens as measured by western blotting. Irish Journal of Medical Science 1991;160(2):64-5.

\section{Brennan 2015a}

Brennan D, Smith SM, Omorogbe JA, Holleran G, Hall B, Hussey M, et al. Detection of Helicobacter pylori and antibiotic resistance using a molecular genetics-based approach in human faecal samples. Gastroenterology 2015;148(4 (suppl)):S420.

\section{Brennan 2015b}

Brennan D, Omorogbe J, Holleran G, Hussey M, O'Morain C, Smith S, et al. A comparison of the prevalence of Helicobacter pylori infection and rates of antibiotic resistance in patients undergoing gastroscopy versus the urea breath test. Helicobacter 2015;20:100-1.

\section{Breslin 1997}

Breslin NP, Omorain CA. Noninvasive diagnosis of Helicobacter pylori infection: A review. Helicobacter 1997;2(3):111-7.

\section{Breslin 1998}

Breslin NP, Lee J, Buckley M, O'Morain C. Screening for Helicobacter pylori in young dyspeptic patients referred for investigation - endoscopy for those who test negative. Alimentary Pharmacology and Therapeutics 1998;12(6):577-82.

\section{Breslin 2000}

Breslin NP, Lee JM, Buckley MJ, Balbirnie E, Rice D, O'Morain CA. Validation of serological tests for Helicobacter pylori infection in an Irish population. Irish Journal of Medical Science 2000;169(3):190-4.

\section{Bretagne 1998}

Bretagne JF, Caekaert A, Barthelemy P, Hepysode. Long-term follow-up of Helicobacter pylori (HP) serology after successful eradication: A cohort of 203 patients tested by ELISA and heliSAL (TM) rapid blood tests. Gastroenterology 1998;114(4 (suppl)):A80.

\section{Briedigkeit 1992}

Briedigkeit H, Montag T, Spiridonow PS, Sielaff F, Wack R, Held C, et al. Detection of Helicobacter pylori infections by antibody determination. Zeitschrift fur Arztliche Fortbildung (Jena) 1992;86(17):869-72.

\section{Britto 2002}

Britto Gomes AT, Coelho LK, Secaf M, Pimenta Modena JL, De Almeida Troncon LE, De Oliveira RB. Accuracy of the 14Curea breath test for the diagnosis of Helicobacter pylori. Sao Paulo Medical Journal 2002;120(3):68-71.

\section{Brmbolic 1997}

Brmbolic B, Zerjav S, Bogdanov M, Dordevic M, Radivojevic M, Stojsic Z, et al. The value of serum IgG and IgA antibodies in the diagnosis of Helicobacter pylori infection in dyspeptic patients. Archives of Gastroenterohepatology 1997;16(1):12-5.

\section{Brown 1993}

Brown KE, Peura DA. Diagnosis of Helicobacter pylori infection. Gastroenterology Clinics of North America 1993;22(1):105-15.

\section{Bruce 2005}

Bruce M, Parkinson A, Gessner B. Does delayed testing of urea breath test samples effect results?. Digestion 2005;71(4):261.

\section{Bruden 2011}

Bruden DL, Bruce MG, Miernyk KM, Morris J, Hurlburt D, Hennessy TW, et al. Diagnostic accuracy of tests for Helicobacter pylori in an Alaska native population. World Journal of Gastroenterology 2011;17(42):4682-8.

\section{Bruning 2002}

Bruning A, Reimann FM, Homann N, Hussein ZE, Konecny E, Ludwig D. A novel continuous 13C-urea breath test for detection of $H$. pylori infection. Gastrointestinal Endoscopy 2002;55(5):AB190-AB.

\section{Brunner 1989}

Brunner H, Markt B, Mittermayer H, Binder L. C-14 urea breath test (UBT) for the detection and follow-up of Campylobacterpylori infection. Gastroduodenal Pathology and Camphylobacter pylori 1989;847:69-71.

\section{Buchan 2013}

Buchan BW, Olson WJ, Pezewski M, Marcon MJ, Novicki T, Uphoff TS, et al. Clinical evaluation of a real-time PCR assay for identification of Salmonella, Shigella, Campylobacter (Campylobacter jejuni and C. coli), and shiga toxin-producing Escherichia coli isolates in stool specimens. Journal of Clinical Microbiology 2013;51(12):4001-7. 


\section{Buchvald 1993}

Buchvald D, Buchvaldova D. Antigens for the ELISA test for serodiagnosis of Helicobacter pylori infection. Ceskoslovenska Epidemiologie, Mikrobiologie, Imunologie 1993;42(1):16-21.

\section{Buhling 2004}

Buhling F, Koch G, Wex T, Heimburg A, Vieth M, Leodolter A, et al. Simultaneous detection and differentiation of anti-Helicobacter pylori antibodies by flow microparticle immunofluorescence assay. Clinical \& Diagnostic Laboratory Immunology 2004;11(1):131-6.

\section{Bures 2000}

Bures J, Palicka V, Kopacova M, Vorisek V, Rejchrt S, Zivny P. Diagnosis of Helicobacter pylori with the 13C-labeled urea breath test: Study methodology. Casopis Lekaru Ceskych 2000;139(24):776-8.

\section{Burucoa 2013}

Burucoa C, Delchier JC, Courillon-Mallet A, De Korwin JD, Megraud F, Zerbib F, et al. Comparative evaluation of 29 commercial Helicobacter pylori serological kits. Helicobacter 2013;18(3):169-79.

\section{Busro 2013}

Busro VO, Bakry F, Farida A, Yuwono. Sensitivity and specificity value of saliva Helicobacter pylori examination in chronic gastritis patients. Hepatology International 2013;7:S753-S4.

\section{Butler 2000}

Butler AK, Brennan SA, Neal K, Logan RPH. A multi-centre study of the prevalence of $H$-pylori in urban Nottinghamshire children using the HpSA(r) stool antigen test. Gut 2000;47(Suppl 1):A45A6.

\section{Buyukbaba-Boral 2005}

Buyukbaba-Boral O, Kucuker-Ang M, Aktas G, Issever H, Ang O. HpSA fecoprevalence in patients suspected to have Helicobacter pylori infection in Istanbul, Turkey. International Journal of Infectious Diseases 2005;9(1):21-6.

\section{Buzas 2001}

Buzas GM, Illyes G, Szekely E, Szeles I. Six regimens for the eradication of Helicobacter pylori (HP) in duodenal ulcer patients: Three consecutive trials (1995-1999). Journal of Physiology, Paris 2001;95(1-6):437-41.

\section{Buzas 2008}

Buzas GM, Szeles I. Interpretation of the 13C-urea breath test in the choice of second- and third-line eradication of Helicobacter pylori infection. Journal of Gastroenterology 2008;43(2):108-14.

\section{Cacoullis 1991}

Cacoullis F, Batten JJ, Logan R, Karim QN, Walker M, Baron JH. Quantifying the extent of Helicobacter-pylori infection with the C-13 urea breath test. Gut 1991;32(5):A565.

\section{Cadranel 1998}

Cadranel S, Corvaglia L, Bontems P, Deprez C, Glupczynski Y, Van Riet A, et al. Detection of Helicobacter pylori infection in children with a standardized and simplified C-13-urea breath test. Journal of Pediatric Gastroenterology and Nutrition 1998;27(3):275-80.

\section{Cagdas 2012}

Cagdas U, Otag F, Tezcan S, Sezgin O, Aslan G, Emekdas G. Detection of Helicobacter pylori and antimicrobial resistance in gastric biopsy specimens. Mikrobiyoloji Bulteni 2012;46(3):398-409.

\section{Caglar 1999}

Caglar M, Belzberg AS, Spruston B, Sexsmith G. Time-optimized carbon-14 breath test for Helicobacter pylori contamination of the stomach. Clinical Nuclear Medicine 1999;24(9):674-7.

\section{Cai 2010}

Cai J, Olafsson S. Helicobacter pylori breath test in an open access system has a high rate of potentially false negative results. Negative result should be considered false negative until proven otherwise. Gastroenterology 2010;138(5 (suppl 1)):S336.

\section{Calam 1994}

Calam J. Helicobacter-pylori. European Journal of Clinical Investigation 1994;24(8):501-10.

\section{Calvet 1999}

Calvet X, Feu F, Forne M, Montserrat A, Elizalde JI, Viver JM, et al. The evaluation of a new immunoenzyme analysis for the detection of Helicobacter pylori infection in stool samples. [Spanish]. Gastroenterologia Y Hepatologia 1999;22(6):270-2.

\section{Calvet 2002a}

Calvet X, Salceda F, Sanfeliu I, Montserrat A, Brullet E, Real J, et al. Testing a new in-office test for determination of faecal Helicobacter pylori antigen. Medicina Clinica 2002;118(4):126-9.

\section{Calvet 2002b}

Calvet X, Sanfeliu I, Musulen E, Mas P, Dalmau B, Gil M, et al. Evaluation of Helicobacter pylori diagnostic methods in patients with liver cirrhosis. Alimentary Pharmacology \& Therapeutics 2002;16(7):1283-9.

\section{Calvet 2002c}

Calvet X, Rosello M, Quesada M, Sanfeliu I, Salcerda F, Montserrat A, et al. Diagnosis of Helicobacter pylori infection in dyspectic patients by stool antigen detection. Usefulness of a new monoclonal ELISA test. Gastroenterology 2002;122(4 (suppl)):A205-A6.

\section{Calvet 2003}

Calvet X, Quesada M, Rosello M, Salceda F, Sanfeliu I, Dalmau B, et al. Stool antigen for the diagnosis of Helicobacter pylori infection in cirrhosis: Comparative usefulness of three different methods. Alimentary Pharmacology \& Therapeutics 2003;17(5):727-31.

\section{Calvet 2005}

Calvet X, Quesada M, Calvet V, Choat T, Sanfeliu I, Segura F. Usefulness of RAPID HP StAR (TM), a new immunochomatographic, monoclonal antigen-based fecal 
test for diagnosing Helicobacter pylori infection in dyspeptic patients. Helicobacter 2005;10(5):524.

\section{Calvet 2009}

Calvet X, SaDelgado J, Montserrat A, Lario S, RamirezLazaro MJ, Quesada M, et al. Accuracy of diagnostic tests for Helicobacter pylori: A reappraisal. Clinical Infectious Diseases 2009;48(10):1385-91.

\section{Calvet 2010a}

Calvet X, Lario S, Ramirez-Lazaro MJ, Montserrat A, Quesada M, Reeves $\mathrm{L}$, et al. Comparative accuracy of 3 monoclonal stool tests for diagnosis of Helicobacter pylori infection among patients with dyspepsia. Clinical Infectious Diseases 2010;50(3):323-8.

\section{Calvet 2010b}

Calvet X, Lario S, Ramirez-Lazaro MJ, Montserrat A, Quesada M, Reeves $L$, et al. Accuracy of monoclonal stool tests for determining cure of Helicobacter pylori infection after treatment. Helicobacter 2010;15(3):201-5.

\section{Calvet 2015}

Calvet X. Diagnosis of Helicobacter pylori infection in the proton pump inhibitor era. Gastroenterology Clinics of North America 2015;44(3):507-18.

\section{Calvo 2013}

Calvo XC, Ramirez-Lazaro M, Lario S, Sanchez-Delgado J, Montserrat A, Casalots A, et al. C13-urea breath test skipping citric acid has low specificity for diagnosing $H$. pylori infection. Helicobacter 2013;18:119-20.

\section{Camargos 2003}

Camargos Rocha AM, Aguiar Rocha G, Santos A, De Oliveira CA, Magalhaes Queiroz DM. Accuracy of a commercial enzymelinked immunosorbent assay for CagA in patients from Brazil with and without gastric carcinoma. Journal of Clinical Microbiology 2003;41(1):447-8.

\section{Camorlinga-Ponce 1998}

Camorlinga-Ponce M, Torres J, Perez-Perez G, Leal-Herrera Y, Gonzalez-Ortiz B, Madrazo de la Garza A, et al. Validation of a serologic test for the diagnosis of Helicobacter pylori infection and the immune response to urease and CagA in children. American Journal of Gastroenterology 1998;93(8):1264-70.

\section{Campuzano-Maya 2007}

Campuzano-Maya G. An optimized C-13-urea breath test for the diagnosis of H. pylori infection. World Journal of Gastroenterology 2007;13(41):5454-64.

\section{Canard 2003}

Canard JM, Ponchon T, Napoleon B, Boyer J, Dalbies P, Escourrou J, et al. Specific roles of endoscopy and respiratory test in the diagnosis and eradication control of Helicobacter pylori. Acta Endoscopica 2003;33(5):810-2.

\section{Canete 2002}

Canete A, Abunaji Y, Alvarez-Calatayud G, De-Vicente M, Gonzalez-Holguera J, Leralta M, et al. 13C-urea breath test with $50 \mathrm{mg}$ of urea: An accurate method for the diagnosis of H. pylori infection in children. Gastroenterology 2002;122(4 (Suppl)):A207.

\section{Canete 2003}

Canete A, Abunaji Y, Alvarez-Calatayud G, DeVicente M, Gonzalez-Holguera JA, Leralta M, et al. Breath test using a single 50-mg dose of C-13-urea to detect Helicobacter pylori infection in children. Journal of Pediatric Gastroenterology and Nutrition 2003;36(1):105-11.

\section{Cao 2012}

Cao X, Jiang J, Jia ZF, Jin MS. Serum levels of pepsinogen ii are a useful biomarker of Helicobacter pylori-infected gastric cancer than pepsinogen i. Journal of Gastroenterology and Hepatology 2012;27:24.

\section{Caporali 2003}

Caporali R, Epis O, Negrini R, Scire CA, Solcia E, Montecucco C. Salivary gland lymphocytic infiltrates and Helicobacter pylori serology in anti-SSA/Ro positive patients in Italy. Clinical and Experimental Rheumatology 2003;21(2):266-7.

\section{Capurso 2006}

Capurso G, Carnuccio A, Lahner E, Panzuto F, Baccini F, Fave GD, et al. Corpus-predominant gastritis as a risk factor for falsenegative C-13-urea breath test results. Alimentary Pharmacology \& Therapeutics 2006;24(10):1453-60.

\section{Cardenas 2006}

Cardenas VM, Dominguez DC, Puentes F, Aragaki CC, Goodman KJ, Graham DY, et al. Rapid stool antigen test for diagnosis of $\mathrm{H}$-pylori infection in asymptomatic children. Gastroenterology 2006;130(4 (suppl)):A570.

\section{Cardenas 2008}

Cardenas VM, Dominguez DC, Puentes FA, Aragaki CC, Goodman KJ, Graham DY, et al. Evaluation of a novel stool native catalase antigen test for Helicobacter pylori infection in asymptomatic North American children. Journal of Pediatric Gastroenterology \& Nutrition 2008;46(4):399-402.

\section{Cardinali 2003}

Cardinali LDC, Rocha GA, Rocha AMC, De Moura SB, Soares TD, Esteves AMB, et al. Evaluation of C-13 urea breath test and Helicobacter pylori stool antigen test for diagnosis of $\mathrm{H}$-pylori infection in children from a developing country. Journal of Clinical Microbiology 2003;41(7):3334-5.

\section{Carrasco 1998}

Carrasco MAV, Alonso IJ, Canto JLG, Baruque LL, Molini PS, Gisbert JP, et al. Is fasting required to perform C-13-urea breath test in the diagnosis of $H$-pylori infection?. Gut 1998;43(Suppl 2):A54.

\section{Casellas 1999}

Casellas F, Lopez J, Borruel N, Saperas E, Vergara M, De Torres I, et al. The impact of delaying gastric emptying by either meal substrate or drug on the C-13 -urea breath test. American Journal of Gastroenterology 1999;94(2):369-73. 


\section{Caselli 1999}

Caselli M, Zaffoni E, Trevisani L, Sartori S, Alvisi V, Plebani M, et al. Diagnosis of Helicobacter pylori infection by HPSA test. Lancet 1999;354(9185):1209-11.

\section{Caspary 1995}

Caspary WF. 13C-urea breath test. Patient-friendly gold standard in the diagnosis of Helicobacter pylori infection with long term cost control potential. Deutsche Medizinische Wochenschrift 1995;120(27):976-8.

\section{Casswall 1999}

Casswall TH, Nilsson HO, Bergstrom M, Aleljung P, Wadstrom T, Dahlstrom AK, et al. Evaluation of serology, 13C-urea breath test, and polymerase chain reaction of stool samples to detect Helicobacter pylori in Bangladeshi children. Journal of Pediatric Gastroenterology \& Nutrition 1999;28(1):31-6.

\section{Castro 2004}

Castro Fernández M, Sánchez Muñoz D, García Díaz E, Galán Jurado MV, Rodríguez Alonso C. Diagnosis of Helicobacter pylori infection using urease rapid test in patients with bleeding duodenal ulcer: Influence of endoscopic signs and simultaneous corporal and antral biopsies. Revista Espanola De Enfermedades Digestivas 2004;96(9):599-602; 605.

\section{Castro-Fernandez 2004}

Castro-Fernández M, Sanchez-Muñoz D, García-Díaz E, MirallesSanchiz J, Vargas-Romero J. Diagnosis of Helicobacter pylori infection in patients with bleeding ulcer disease: Rapid urease test and histology. Revista Espanola De Enfermedades Digestivas 2004;96(6):395-8; 398-401.

\section{Cave 1999}

Cave DR, Zanten SV, Carter E, Halpern EF, Klein S, Prather C, et al. A multicentre evaluation of the laser assisted ratio analyser (LARA): A novel device for measurement of $13 \mathrm{CO} 2$ in the 13C-urea breath test for the detection of Helicobacter pylori infection. Alimentary Pharmacology \& Therapeutics 1999;13(6):747-52.

\section{Cevrioglu 2004}

Cevrioglu AS, Altindis M, Yilmazer M, Fenkci IV, Ellidokuz E, Kose S. Efficient and non-invasive method for investigating Helicobacter pylori in gravida with hyperemesis gravidarum: Helicobacter pylori stool antigen test. Journal of Obstetrics \& Gynaecology Research 2004;30(2):136-41.

\section{Chacon 1995}

Chacon EP, Correnti M, Salma N, Serrano N, Pinero R, Cavazza ME, et al. Immunoenzymatic assay for serodiagnosis of Helicobacter pylori infections. GEN 1995;49(3):208-11.

\section{Chalkias 2011}

Chalkias A, Nikotian G, Koutsovasilis A, Bramis J, Manouras A, Mystrioti $D$, et al. Patients with colorectal cancer are characterized by increased concentration of fecal $\mathrm{Hb}-\mathrm{Hp}$ complex, myeloperoxidase, and secretory IgA. American Journal of Clinical Oncology: Cancer Clinical Trials 2011;34(6):561-6.

\section{Chang 1999}

Chang MC, Wu MS, Wang HH, Wang HP, Lin JT. Helicobacter pylori stool antigen (HPSA) test - a simple, accurate and noninvasive test for detection of Helicobacter pylori infection. Hepato-Gastroenterology 1999;46(25):299-302.

\section{Chang 2000}

Chang YW, Kim KJ, Min SK, Dong SH, Kim HJ, Kim BH, et al. Quantitative result of $\mathrm{C}$-13-urea breath test does not correlate with Helicobacter pylori density in the stomach by assessing histopathology and grade of phenol red staining. Gastroenterology 2000;118(4):A1221.

\section{Chang 2002}

Chang MC, Chang YT, Sun CT, Wu MS, Wang HP, Lin JT. Quantitative correlation of Helicobacter pylori stool antigen (HPSA) test with C-13-urea breath test (C-13-UBT) by the updated Sydney Grading System of gastritis. HepatoGastroenterology 2002;49(44):576-9.

\section{Chang 2003}

Chang YW, Min SK, Kim KJ, Han YS, Lee JH, Dong SH, et al. Delta (13)C-urea breath test value is a useful indicator for Helicobacter pylori eradication in patients with functional dyspepsia. Journal of Gastroenterology \& Hepatology 2003;18(6):726-31.

\section{Chang 2012}

Chang WT, Lin CC, Lin YH, Wang CC, Wang SH, Liu YW, et al. The potential role of using $\mathrm{C}-13$ urea breath test as a routine perioperative evaluation of Helicobacter pylori infection in living-related liver donors. Liver Transplantation 2012;18:S205S.

\section{Chang 2013}

Chang C, Xie H, Ni Y, Ting Q, Bo Z. The clinical studies to the diagnostic value of serum pepsinogen levels in gastric cancer. Journal of Gastroenterology and Hepatology 2013;28:742.

\section{Chattopadhyay 2002}

Chattopadhyay UK. Coagglutination test for rapid noncultural diagnosis of human campylobacteriosis. European Review for Medical and Pharmacological Sciences 2002;6(1):9-11.

\section{Chattopadhyay 2004}

Chattopadhyay S, Patra R, Ramamurthy T, Chowdhury A, Santra A, Dhali GK, et al. Multiplex PCR assay for rapid detection and genotyping of Helicobacter pylori directly from biopsy specimens. Journal of Clinical Microbiology 2004;42(6):2821-4.

\section{Checchi 2000}

Checchi L, Felice P, Acciardi C, Ricci C, Gatta L, Polacci R, et al. Absence of Helicobacter pylori in dental plaque assessed by stool test. American Journal of Gastroenterology 2000;95(10):3005-6.

\section{Chehter 2013}

Chehter EZ, Bacci MR, Fonseca FLA, Goncalves JAC, Buchalla G, Shiraichi SAR, et al. Diagnosis of the infection by the Helicobacter pylori through stool examination: Method standardization in adults. Clinical Biochemistry 2013;46(15):1622-4. 


\section{Chen 1994}

Chen JJ, Changchien CS, Tai DI, Chiou SS, Lee CM, Kuo CH. Role of Helicobacter pylori in cirrhotic patients with peptic ulcer. A serological study. Digestive Diseases \& Sciences 1994;39(7):1565-8.

\section{Chen 1996}

Chen JJ, Yang ZX, Jiang XG. A comparison of purified urease antigen and whole cell antigen of Helicobacter pylori by ELISA test--study on the application and serum diagnoses of Helicobacter pylori urease diagnostic reagent. Zhonghua Liu Xing Bing Xue Za Zhi = Zhonghua Liuxingbingxue Zazhi 1996;17(1):44-6.

\section{Chen 1997}

Chen TS, Chang FY, Lee SD. Serodiagnosis of Helicobacter pylori infection: Comparison and correlation between enzyme-linked immunosorbent assay and rapid serological test results. Journal of Clinical Microbiology 1997;35(1):184-6.

\section{Chen 2000}

Chen X, Haruma K, Kamada T, Mihara M, Komoto K, Yoshihara M, et al. Factors that affect results of the $\mathrm{C}-13$ urea breath test in Japanese patients. Helicobacter 2000;5(2):98-103.

\section{Chen 2001a}

Chen X, Haruma K, Kamada T, Hartori N, Yoshihara M, Kitadai Y, et al. A low 13C-urea breath test value is associated with increased risk of gastric cancer. Journal of Gastroenterology 2001;36(9):601-5.

\section{Chen 2001b}

Chen TS, Chang FY, Lee SD. Extending the reading time increases the accuracy of rapid whole blood test for diagnosis of Helicobacter pylori infection. Journal of Gastroenterology \& Hepatology 2001;16(12):1341-5.

\section{Chen 2002a}

Chen TS, Li FY, Chang FY, Lee SD. Immunoglobulin G antibody against Helicobacter pylori: Clinical implications of levels found in serum. Clinical \& Diagnostic Laboratory Immunology 2002;9(5):1044-8.

\section{Chen 2002b}

Chen TS, Chang FY, Lee SD. No difference of accuracy between capillary and venous blood in rapid whole blood test for diagnosis of Helicobacter pylori infection. Digestive Diseases \& Sciences 2002;47(11):2519-22.

\section{Chen 2003}

Chen TS, Chang FY, Chen PC, Huang TW, Ou JT, Tsai MH, et al. Simplified C-13-urea breath test with a new infrared spectrometer for diagnosis of Helicobacter pylori infection. Journal of Gastroenterology and Hepatology 2003;18(11):1237-43.

\section{Chen 2009a}

Chen CC, Liou JM, Hsu YC, Fang JY, Wang HP, Wu MS. Rabeprazole therapeutic trial in patients with uninvestigated dyspepsia. Journal of Gastroenterology and Hepatology 2009;24:A45.

\section{Chen 2009b}

Chen LW, Chang JJ, Chiu CJ, Fang KM, Chien RN, Chang LC, et al. $14 \mathrm{C}$ urea breath test in patients with peptic ulcer: The correlations with clinical factors, histology, rapid urease test and endoscopic findings. Journal of Gastroenterology and Hepatology 2009;24:A86.

\section{Cheng 2004}

Cheng H, Hu FL. The value of Helicobacter pylori stool antigen immunocard stat in diagnosis of HP infection and assessing of eradication of HP. Zhonghua Yi Xue Za Zhi 2004;84(14):1166-70.

\section{Cherian 2008}

Cherian S, Burgner DP, Carson CF, Sanfilippo FM, Cook AG, Forbes DA. Diagnosis of Helicobacter pylori infection in a highprevalence pediatric population: A comparison of 2 fecal antigen testing methods and serology. Journal of Pediatric Gastroenterology and Nutrition 2008;47(2):130-5.

\section{Chey 1997a}

Chey WD, Woods M, Scheiman JM, Nostrant TT, DelValle J. Lansoprazole and ranitidine affect the accuracy of the C-14-urea breath test by a $\mathrm{pH}$-dependent mechanism. American Journal of Gastroenterology 1997;92(3):446-50.

\section{Chey 1997b}

Chey WD. Proton pump inhibitors and the urea breath test: How long is long enough?. American Journal of Gastroenterology 1997;92(4):720-1.

\section{Chey 1999a}

Chey WD, Shaw S, Montague J, Jones M, Murthy U. Appropriate timing of the C-14-urea breath test to establish eradication of $H$-pylori infection: An interim analysis. Gastroenterology 1999;116(4 (suppl)):A136.

\section{Chey 1999b}

Chey WD, Murthy U, Toskes P, Carpenter S, Laine L. The 13Curea blood test accurately detects active Helicobacter pylori infection: A United States, multicenter trial. American Journal of Gastroenterology 1999;94(6):1522-4.

\section{Chey 2000a}

Chey WD, Metz DC, Shaw S, Kearney D, Montague J, Murthy U. Appropriate timing of the C-14-urea breath test to establish eradication of Helicobacter pylori infection. American Journal of Gastroenterology 2000;95(5):1171-4.

\section{Chey 2000b}

Chey WD. Accurate diagnosis of Helicobacter pylori - C-14urea breath test. Gastroenterology Clinics of North America 2000;29(4):895.

\section{Chey 2007}

Chey WD, Wong BC. American College of Gastroenterology guideline on the management of Helicobacter pylori infection. American Journal of Gastroenterology 2007;102(8):1808-25.

\section{Chiang 2010}

Chiang TH, Tu CH, Lee YC, Wu MS. Clinical predictors of significant esophagogastroduodenoscopy findings for 
asymptomatic subjects with positive immunochemical fecal occult blood test and negative colonoscopy. Gastrointestinal Endoscopy 2010;71 (5):AB357.

\section{Chiba 1999}

Chiba N, Veldhuyzen Van Zanten SJ. 13C-urea breath tests are the noninvasive method of choice for Helicobacter pylori detection. Canadian Journal of Gastroenterology 1999;13(8):681-3.

\section{Ching 1991a}

Ching CK, Thompson S, Buxton C, Holgate C, Hill P, Freeman JG, et al. Evaluation of the new Helico-G ELISA for serological diagnosis of Helicobacter-pylori infection. Gut 1991;32(5):A570.

\section{Ching 1991b}

Ching CK. A simplified diagnostic approach to Helicobacter pylori infection--is it adequate?. American Journal of Gastroenterology 1991;86(9):1276-8.

\section{Ching 1993}

Ching CK, Thompson S, Buxton C, Holgate C, Holmes GKT. Evaluation of a commercial enzyme-linked immunosorbent assay (ELISA) kit for serological diagnosis of Helicobacter pylori infection in a group of non-ulcer dyspepsia sufferers. Postgraduate Medical Journal 1993;69(812):456-60.

\section{Chisholm 2004}

Chisholm SA, Watson CL, Teare ELS, Saverymuttu S, Owen RJ. Non-invasive diagnosis of Helicobacter pylori infection in adult dyspeptic patients by stool antigen detection: Does the rapid immunochromatography test provide a reliable alternative to conventional ELISA kits?. Journal of Medical Microbiology 2004;53(7):623-7.

\section{Chmiela 2003}

Chmiela M, Wisniewska M, Bak-Romaniszyn L, Rechcinski T, Planeta-Malecka I, Bielanski W, et al. Serological differentiation of Helicobacter pylori CagA(+) and CagA(-) infections. Archivum Immunologiae et Therapiae Experimentalis 2003;51(2):131-6.

\section{Cho 2000}

Cho HS, Kang DH, Kim EA, Park DK, Park HC, Choi DJ, et al. The usefulness of C-13-urea breath test for the diagnosis of Helicobacter pylori infection in operative stomach. Gastroenterology 2000;118(4):A505.

\section{Cho 2003}

Cho YS, Kim SS, Chae HS, Han SW, Lee CD, Chung IS. The correlation between the DOB30 value of $13 \mathrm{C}$-urea breath test and the staining pattern of endoscopic phenol red test in the diagnosis of Helicobacter pylori infection. Gastroenterology 2003;124(4 (Suppl)):A176.

\section{Cho 2008}

Cho YS, Chae HS, Jang SN, Kim JS, Son HS, Kim HK, et al. Comparison of the 13C-urea breath test and the endoscopic phenol red mucosal $\mathrm{pH}$ test in the quantification of Helicobacter pylori infection loading. Korean Journal of Internal Medicine 2008;23(3):134-9.

\section{Choi 2010}

Choi J, Kim D, Park M. A prospective evaluation of new stool antigen test for detection of $\mathrm{H}$-pylori, in comparison with histology, rapid urease test, $\mathrm{C}$-13-urea breath test, and serology. Helicobacter 2010;15(4):359.

\section{Choi 2011}

Choi J, Kim CH, Kim D, Chung SJ, Song JH, Kang JM, et al. Prospective evaluation of a new stool antigen test for the detection of Helicobacter pylori, in comparison with histology, rapid urease test, $13 \mathrm{C}$-urea breath test, and serology. Journal of Gastroenterology and Hepatology (Australia) 2011;26(6):1053-9.

\section{Chong 1994}

Chong J, Marshall BJ, Barkin JS, McCallum RW, Reiner DK, Hoffman SR, et al. Occupational exposure to Helicobacter pylori for the endoscopy professional: A sera epidemiological study. American Journal of Gastroenterology 1994;89(11):1987-92.

\section{Chong 1995}

Chong SK, Lou Q, Asnicar MA, Zimmerman SE, Croffie JM, Lee $\mathrm{CH}$, et al. Helicobacter pylori infection in recurrent abdominal pain in childhood: Comparison of diagnostic tests and therapy. Pediatrics 1995;96(2 Pt 1):211-5.

\section{Chou 1997}

Chou CH, Sheu BS, Yang HB, Cheng PN, Shin JS, Chen CY, et al. Clinical assessment of the bacterial load of Helicobacter pylori on gastric mucosa by a new multi-scaled rapid urease test. Journal of Gastroenterology and Hepatology 1997;12(1):1-6.

\section{Christensen 1992}

Christensen AH, Gjorup T, Hilden J, Fenger C, Henriksen B, Vyberg M, et al. Observer homogeneity in the histologic diagnosis of Helicobacter-pylori - latent class analysis, kappacoefficient, and repeat frequency. Scandinavian Journal of Gastroenterology 1992;27(11):933-9.

\section{Christie 1996}

Christie JM, McNulty CA, Shepherd NA, Valori RM. Is saliva serology useful for the diagnosis of Helicobacter pylori?. Gut 1996;39(1):27-30.

\section{Chua 2002}

Chua TS, Fock KM, Teo EK, Ng TM. Validation of 13C-urea breathtest for the diagnosis of Helicobacter pylori infection in the Singapore population. Singapore Medical Journal 2002;43(8):408-11.

\section{Chung 2001a}

Chung IK, Hong SJ, Kim EJ, Cho JY, Kim HS, Park SH, et al. What is the best method to diagnose Helicobacter infection in bleeding peptic ulcers?: A prospective trial. Korean Journal of Internal Medicine 2001;16(3):147-52.

\section{Chung 2001b}

Chung AYF, Chow PKH, Yu WK, Ho JMS, Chan HS, Wong WK, et al. Prevalence of Helicobacter pylori in gastric cancer in a SouthEast Asian population by C-14-urea breath test. ANZ Journal of Surgery 2001;71(10):574-6. 


\section{Churchill 1998}

Churchill RD, Hill PG, Holmes GK. Management of dyspepsia in primary care. Breath test is better than near patient blood tests. BMJ 1998;316(7141):1389.

\section{Chvalova 1990}

Chvalova M, Sedlackova M, Souckova A, Soucek A, Jirasek A. Assessment of antibodies against Campylobacter-pylori in children and adolescents with gastroduodenal complaints. Sbornik Lekarsky 1990;92(11-12):343-8.

\section{Cinar 2004}

Cinar K, Soykan I, Ozden A. The effect of Helicobacter pylori eradication in patients with functional dyspepsia: Assessment of different diagnostic tests. Turkish Journal of Gastroenterology 2004;15(3):159-63.

\section{Ciok 2003}

Ciok J, Tacikowski T, Bujko J, Dzieniszewski J. Urea breath test (UBT) in the diagnosis of Helicobacter pylori infection. Gastroenterologia Polska 2003;10(3):241-6.

\section{Cirak 2007}

Cirak MY, Akyon Y, Megraud F. Diagnosis of Helicobacter pylori. Helicobacter 2007;12 Suppl 1:4-9.

\section{Clancy 1994}

Clancy RL, Cripps AW, Taylor DC, McShane LA, Webster VJ. Detection of antibody against Helicobacter pylori in the saliva of patients with dyspepsia. Canadian Journal of Gastroenterology 1994;8(7):408-12.

\section{Clayton 1992}

Clayton CL, Kleanthous H, Coates PJ, Morgan DD, Tabaqchali S. Sensitive detection of Helicobacter-pylori by using polymerase chain-reaction. Journal of Clinical Microbiology 1992;30(1):192-200.

\section{Cockburn 2001}

Cockburn M, Collett J, Cox B. Validation of the saliva-based $H$. pylori test, helisal, and its use in prevalence surveys. Epidemiology \& Infection 2001;126(2):191-6.

\section{Coelho 1990}

Coelho LGV, Chausson Y, Passos MCF, Sadala RU, Costa EL, Sabino CVS, et al. C-14 urea breath test as a noninvasive method to detect gastric Helicobacter-pylori colonization. Gastroenterologie Clinique et Biologique 1990;14(11):801-5.

\section{Coelho 1997}

Coelho LGV, Passos MCF, Chausson Y, Simal CJR, Aguiar ROA, Gallo MA, et al. Standard-dose (5-mu Ci) vs mini-dose (1-mu Ci) 14c-urea breath test for H-pylori detection. Gastroenterology 1997;112(4 (suppl)):A92.

\section{Coelho 1999}

Coelho LG, Reber M, Passos MC, Aguiar RO, Casaes PE, Bueno ML, et al. Application of isotope-selective non-dispersive infrared spectrometry for the evaluation of the 13C-urea breath test: Comparison with three concordant methods. Brazilian Journal of Medical \& Biological Research 1999;32(12):1493-7.

\section{Coelho 2003}

Coelho LGV, Rocha Z, Boechat LC, Aguiar ROA, Aragao ALA, Dias EES, et al. 13C-urea breath test for $\mathrm{H}$-pylori detection in children: Determination of the cutoff value by graphic method, independent of gold standard comparison. Gastroenterology 2003;124(4 (suppl)):A177.

\section{Coelho 2009a}

Coelho LGV, Coelho MCF, Oliveira SM, Santa-Cecilia EV, Moreira MR, Bomfim IM, et al. Does low dosage of 13C-urea keep good accuracy for diagnosis of $H$. pylori infection?. Helicobacter 2009;14 (4):340.

\section{Coelho 2009b}

Coelho LG, Silva-Junior AE, Coelho MC, Santa-Cecilia EV, Ferreira RO, Bomfim IM, et al. Does low dosage of 13C-urea keep good accuracy for diagnosis of Helicobacter pylori infection. Gastroenterology 2009;136(5 (Suppl)):A345.

\section{Coelho 2011}

Coelho LG, Silva AE Jr, Coelho MC, Penna FG, Ferreira RO, SantaCecilia EV. Does low dose (13)C-urea breath test maintain a satisfactory accuracy in diagnosing Helicobacter pylori infection?. Arquivos de Gastroenterologia 2011;48(2):104-8.

\section{Cohen 1999}

Cohen H, Rose S, Lewin DN, Retama B, Naritoku W, Johnson C, et al. Accuracy of four commercially available serologic tests, including two office-based tests and a commercially available C-13 urea breath test, for diagnosis of Helicobacter pylori. Helicobacter 1999;4(1):49-53.

\section{Colaiocco 1999}

Colaiocco Ferrante L, Papponetti M, Marcuccitti J, Neri M, Festi D. 13C-urea breath test for Helicobacter pylori infection: Stability of samples over time. Scandinavian Journal of Gastroenterology 1999;34(9):942-3.

\section{Collins 1992}

Collins JSA, Bamford KB, Sloan JM, Collins BJ, Moorehead RJ, Love AHG. Screening for Helicobacter pylori antibody could reduce endoscopy workload in young dyspeptic patients. European Journal of Gastroenterology and Hepatology 1992;4(12):991-3.

\section{Con 2007}

Con SA, Con-Wong R, Con-Chin GR, Con-Chin VG, Takeuchi H, Valerin AL, et al. Serum pepsinogen levels, Helicobacter pylori CagA status, and cytokine gene polymorphisms associated with gastric premalignant lesions in Costa Rica. Cancer Epidemiology, Biomarkers \& Prevention 2007;16(12):2631-6.

\section{Connor 1999}

Connor SJ, Seow F, Ngu MC, Katelaris PH. The effect of dosing with omeprazole on the accuracy of the C-13-urea breath test in Helicobacter pylori-infected subjects. Alimentary Pharmacology \& Therapeutics 1999;13(10):1287-93.

\section{Conti-Nibali 1990}

Conti-Nibali S, Baldari S, Vitulo F, Sferlazzas C, Russo E, Tedeschi A, et al. The 14CO2 urea breath test for Helicobacter 
pylori infection. Journal of Pediatric Gastroenterology \& Nutrition 1990;11(2):284-5.

\section{Continibali 1991}

Continibali S, Sferlazzas C, Fera MT, Saitta G, Tedeschi A, Magazzu G. A simplified diagnostic-approach to Helicobacterpylori infection - is it adequate - reply. American Journal of Gastroenterology 1991;86(9):1277-8.

\section{Contreras 2006}

Contreras M, Amado MAG, Rodriguez MJ, Landaez PB, Zambrano Y, Alvarez $\mathrm{M}$, et al. Validation of a fast immunochroniatographic test for $\mathrm{H}$. pylori detection in stool. Interciencia 2006;31(2):136-9.

\section{Coombs 2001}

Coombs GW, Foster NM, Pearman JW, Forbes GM. Detection of Helicobacter pylori antigen in faeces by enzyme immunoassay. Pathology 2001;33(4):496-7.

\section{Cooreman 1990}

Cooreman M, Hengels KJ, Krausgrill P, Strohmeyer G. 13C-urea breath test as a noninvasive means of diagnosing the presence of Helicobacter (Campylobacter) pylori. Deutsche Medizinische Wochenschrift 1990;115(10):367-71.

\section{Corti 2007}

Corti RE. The accuracy of the breath test with C-urea to diagnose Helicobacter pylori infection. Salud I Ciencia 2007;15(5):914.

\section{Corvaglia 1997}

Corvaglia L, Bontems P, Keppens E, Vandenborre C, DePrez C. $\mathrm{HP}$ infection in children: Comparison of results with serology and C-13-urea breath test. Gut 1997;41(suppl):A68.

\section{Corvaglia 1999}

Corvaglia L, Bontems P, Devaster JM, Heimann P, Glupczynski Y, Keppens E, et al. Accuracy of serology and C-13-urea breath test for detection of Helicobacter pylori in children. Pediatric Infectious Disease Journal 1999;18(11):976-9.

\section{Costa 2001}

Costa F, Mumolo MG, Bellini M, Romano MR, Manghetti M, Paci A, et al. Post-treatment diagnostic accuracy of a new enzyme immunoassay to detect Helicobacter pylori in stools. Alimentary Pharmacology \& Therapeutics 2001;15(3):395-401.

\section{Couturier 2014}

Couturier MR, Marshall BJ, Goodman KJ, Megraud F. Helicobacter pylori diagnostics and treatment: Could a lack of universal consensus be the best consensus?. Clinical Chemistry 2014;60(4):589-94.

\section{Crabtree 1990}

Crabtree JE, Shallcross TM, Wyatt JI, Heatley RV. Validation of a commercial ELISA for serodiagnosis of Helicobacter-pylori infection. Gut 1990;31(10):A1176.

\section{Crabtree 1991a}

Crabtree JE, Taylor JD, Shallcross TM, Wyatt JI, Rathbone BJ, Heatley RV. Western blotting analysis of mucosal and systemic immune-responses to Helicobacter-pylori. Gut 1991;32(5):A564.

\section{Crabtree 1991b}

Crabtree JE, Shallcross TM, Heatley RV, Wyatt JI. Evaluation of a commercial ELISA for serodiagnosis of Helicobacter pylori infection. Journal of Clinical Pathology 1991;44(4):326-8.

\section{Cremonini 2000}

Cremonini F, Zocco MA, Armuzzi A, Bartolozzi F, Santarelli L, Ojetti V, et al. C-13 urea breath test for predicting resistance to therapy in Helicobacter pylori infection. Gut 2000;47(Suppl 1):A117.

\section{Cremonini 2005}

Cremonini F, Bartolozzi F, Armuzzi A, Zocco MA, Santarelli L, Gabrielli M, et al. Can $13 \mathrm{C}$ urea breath test predict resistance to therapy in Helicobacter pylori infection?. HepatoGastroenterology 2005;52(64):1119-21.

\section{Crespo 2009}

Crespo Medina M, Sanchez Sanchez C, Morales JL, Huber LB, Mendiola I. Valuation of non-invasive tests to detect Helicobacter pylori infection in children. Acta Pediatrica Espanola 2009;67(7):319-24.

\section{Crispino 2013}

Crispino P, Colarusso D, Minervini G, Schiava A, Tripodi B, Cimmino G, et al. Diagnosis of Helicobacter pylori infection: Comparison between invasive and non invasive tests. Italian Journal of Medicine 2013;7(2S):33.

\section{Cullen 1992}

Cullen DJ, Cullen KJ, Collins BJ, Christiansen KJ, Epis J. Serological assessment of Helicobacter pylori eradication. Lancet 1992;340(8828):1161-2.

\section{Cullen 2002}

Cullen KP, Broderick BM, Jayaram J, Flynn B, O'Connor HJ. Evaluation of the Helicobacter pylori stool antigen (HPSA) test in routine clinical practice--is it patient-friendly?. Irish Medical Journal 2002;95(10):305-6.

\section{Cunningham 2010}

Cunningham SA, Sloan LM, Nyre LM, Vetter EA, Mandrekar J, Patel R. Three-hour molecular detection of Campylobacter, Salmonella, Yersinia, and Shigella species in feces with accuracy as high as that of culture. Journal of Clinical Microbiology 2010;48(8):2929-33.

\section{Cutler 1993}

Cutler A, Schubert A, Schubert T. Role of Helicobacter pylori serology in evaluating treatment success. Digestive Diseases \& Sciences 1993;38(12):2262-6.

\section{Cutler 1995a}

Cutler AF, Havstad S, Ma CK, Blaser MJ, Perez-Perez GI, Schubert TT. Accuracy of invasive and noninvasive tests to 
diagnose Helicobacter pylori infection. Gastroenterology 1995;109(1):136-41.

\section{Cutler 1995b}

Cutler AF. Re - C-13 urea breath test - response. American Journal of Gastroenterology 1995;90(11):2070.

\section{Cutler 1996}

Cutler AF, Prasad VM. Long-term follow-up of Helicobacter pylori serology after successful eradication. American Journal of Gastroenterology 1996;91(1):85-8.

\section{Cutler 1997}

Cutler AF. Diagnostic tests for $H$. pylori: A prospective evaluation of their accuracy, without selecting a single test as the gold standard. American Journal of Gastroenterology 1997;92(3):538-9.

\section{Cutler 1998}

Cutler AF, Miller S. Comparison of C-13 urea blood test to C-13 urea breath test for diagnosis of H-pylori. Gastroenterology 1998;114(4 (suppl)):A97.

\section{Cutler 1999}

Cutler AF, Toskes P. Comparison of 13C-urea blood test to 13C-urea breath test for the diagnosis of Helicobacter pylori. American Journal of Gastroenterology 1999;94(4):959-61.

\section{Czinn 1991}

Czinn SJ, Carr HS, Speck WT. Diagnosis of gastritis caused by Helicobacter pylori in children by means of an ELISA. Reviews of Infectious Diseases 1991;13 Suppl 8:S700-3.

\section{Czkwianianc 1997}

Czkwianianc E, Chmiela M, Lawnik M, Planeta-Malecka I, Rudnicka W. Serodiagnosis of Helicobacter pylori in children with gastroduodenitis. Central-European Journal of Immunology 1997;22(4):240-7.

\section{Da Silva 2010}

Da Silva JMK, Villares CA, Monteiro MS, Colauto C, Dos Santos AF, Mattar R. Validation of a rapid stool antigen test for diagnosis of Helicobacter pylori infection. Revista Do Instituto De Medicina Tropical De Sao Paulo 2010;52(3):125-8.

\section{Dahlberg 1998}

Dahlberg M, Schjonsby H. 13C-urea breath test as diagnostic method in Helicobacter pylori infection. Tidsskrift for Den Norske Laegeforening 1998;118(24):3762-5.

\section{Daino 2015}

Daino DF, Soifer L, Pedesta J, Rome J. Pilot test for Helicobacter pylori detection with ammonia breath test. Acta Gastroenterologica Latinoamericana 2015;45(1):12-7.

\section{Dan 2013}

Dan W, Jing W, Libo W, Hong X. Detection and analysis of Helicobacter pylori antibodies by protein chip technology. Journal of Gastroenterology and Hepatology 2013;28:541.

\section{Danielli 1993}

Danielli E. A fluorometric enzyme-linked-immunosorbentassay for serological diagnosis of Helicobacter-pylori infection. European Journal of Gastroenterology \& Hepatology 1993;5:S57S59.

\section{Datta 2003}

Datta D, Gazzard B, Stebbing J. The diagnostic yield of stool analysis in $525 \mathrm{HIV}$-1-infected individuals. Aids 2003;17(11):1711-3.

\section{Datta 2005}

Datta S, Chattopadhyay S, Chowdhury A, Santra A, Saha DR, Ramamurthy T, et al. Diagnosis and genotyping of Helicobacter pylori by polymerase chain reaction of bacterial DNA from gastric juice. Journal of Gastroenterology and Hepatology 2005;20(8):1253-9.

\section{Day 2002}

Day AS, Sherman PM. Accuracy of office-based immunoassays for the diagnosis of Helicobacter pylori infection in children. Helicobacter 2002;7(3):205-9.

\section{Day 2003}

Day AS, Veldhuyzen van Zanten S, Otley AR, Best L, Griffiths A, Sherman PM. Use of LARA-urea breath test in the diagnosis of Helicobacter pylori infection in children and adolescents: A preliminary study. Canadian Journal of Gastroenterology 2003;17(12):701-6.

\section{De Angelis 2007}

De Angelis GL, Cavallaro LG, Maffini V, Moussa AM, Fornaroli F, Liatopoulou $S$, et al. Usefulness of a serological panel test in the assessment of gastritis in symptomatic children. Digestive Diseases 2007;25(3):206-13.

\section{De Argila 2001}

de Argila CM, Boixeda D. Practical considerations for the diagnosis of Helicobacter pylori infection. Medicina Clinica 2001;117(10):386-91.

\section{De Arruda 2001}

De Arruda SMB, Passaro DJ, Yang S, Parsonnet J. Variability of serologic testing for $H$. pylori using U.S. and Peruvian antigens. Gastroenterology 2001;120(1):325-6.

\section{De Boer 1995}

De Boer WA. Re: $13 C$ urea breath test. American Journal of Gastroenterology 1995;90(11):2069-70.

\section{De Bustillo 1998}

De Bustillo EM, Tomero JAS, Sanz JC, Moreno JA, Jimenez I, Lopez-Brea M, et al. Eradication and follow-up of Helicobacter pylori infection in hemodialysis patients. Nephron 1998;79(1):55-60.

\section{De Carvalho 2003}

De Carvalho Costa Cardinali L, Rocha GA, Rocha AM, De Moura SB, De Figueiredo Soares T, Esteves AM, et al. Evaluation of $13 \mathrm{C}$ urea breath test and Helicobacter pylori stool antigen test for diagnosis of $H$. pylori infection in children 
from a developing country. Journal of Clinical Microbiology 2003;41(7):3334-5.

\section{De Giacomo 1991}

De Giacomo C, Lisato L, Negrini R, Licardi G, Maggiore G. Serum immune response to Helicobacter pylori in children: Epidemiologic and clinical applications. Journal of Pediatrics 1991;119(2):205-10.

\section{De Laat 2001}

De Laat LE, De Boer WA, Megraud F. The CLO test as a reference method for Helicobacter pylori infection. European Journal of Gastroenterology \& Hepatology 2001;13(10):1269-70.

\section{De Oliveira 1999}

De Oliveira AMR, Rocha GA, De Magalhaes Queiroz DM, Mendes EN, De Carvalho AST, Ferrari TCA, et al. Evaluation of enzyme-linked immunosorbent assay for the diagnosis of Helicobacter pylori infection in children from different age groups with and without duodenal ulcer. Journal of Pediatric Gastroenterology and Nutrition 1999;28(2):157-61.

\section{De Pascalis 1999}

De Pascalis R, Del Pezzo M, Nardone G, Budillon G, Lavitola A. Performance characteristics of an enzymelinked immunosorbent assay for determining salivary immunoglobulin G response to Helicobacter pylori. Journal of Clinical Microbiology 1999;37(2):430-2.

\section{Deankanob 2006}

Deankanob W, Chomvarin C, Hahnvajanawong C, Intapan PM, Wongwajana S, Mairiang P, et al. Enzyme-linked immunosorbent assay for serodiagnosis of Helicobacter pylori in dyspeptic patients and volunteer blood donors. Southeast Asian Journal of Tropical Medicine \& Public Health 2006;37(5):958-65.

\section{Debongnie 1993}

Debongnie JC, Durez P, Luyasu V. Validation of a commercial serologic test in the diagnosis of Helicobacter-pylori infection - clinical and epidemiologic use. Gastroenterologie Clinique et Biologique 1993;17(2):98-102.

\section{Dediste 2003}

Dediste A, Vandenberg O, Vlaes L, Ebraert A, Douat N, Bahwere $P$, et al. Evaluation of the prospect microplate assay for detection of Campylobacter: A routine laboratory perspective. Clinical Microbiology \& Infection 2003;9(11):1085-90.

\section{Deguchi 2009}

Deguchi R, Matsushima M, Suzuki T, Mine T, Fukuda R, Nishina M, et al. Comparison of a monoclonal with a polyclonal antibody-based enzyme immunoassay stool test in diagnosing Helicobacter pylori infection after eradication therapy. Journal of Gastroenterology 2009;44(7):713-6.

\section{Del Pozo Garcia 2006}

Del Pozo Garcia AJ, Gisbert JP. Is the string test a useful alternative to gastroscopy with biopsy for $H$. pylori identification?. Revista Espanola De Enfermedades Digestivas 2006;98(7):542-9.

\section{Del Zompo 2014}

Del Zompo F, Feliciani D, Mangiola F, D'Angelo G, Di Rienzo T, Vanella G, et al. Gas production during lactulose breath test is associated with Helicobacter pylori infection. Helicobacter 2014;19:82.

\section{Delaney 2003}

Delaney BC, Holder RL, Allan TF, Kenkre JE, Hobbs FDR. A comparison of Bayesian and maximum likelihood methods to determine the performance of a point of care test for Helicobacter pylori in the office setting. Medical Decision Making 2003;23(1):21-30.

\section{Demir 2001}

Demir H, Ercis S, Kocak N, Hascelik G, Ozen H, Yuce A, et al. Detection of Helicobacter pylori with stool antigen test in children with gastroesophageal reflux disease. American Journal of Gastroenterology 2001;96(6):1944.

\section{Demiray 2006}

Demiray E, Yilmaz O, Sarkis C, Soyturk M, Simsek I. Comparison of invasive methods and two different stool antigen tests for diagnosis of $\mathrm{H}$-pylori infection in patients with gastric bleeding. World Journal of Gastroenterology 2006;12(26):4206-10.

\section{Demiray 2012}

Demiray Gurbuz E, Gonen C, Bekmen N, Dolek D, Soyturk M, Sagol O, et al. The diagnostic accuracy of urine IgG antibody tests for the detection of Helicobacter pylori infection in Turkish dyspeptic patients. Turkish Journal of Gastroenterology 2012;23(6):753-8.

\section{Demiray-Gurbuz 2012}

Demiray-Gurbuz E, Bekmen N, Erci T, Dotan Y, Yilmaz O. Evaluation of Helicobacter pylori stool antigen test results required from different outpatient clinics at university hospital. Helicobacter 2012;17:87-8.

\section{Demirturk 2003}

Demirturk L, Yazgan Y, Tarcin O, Ozel M, Diler M, Oncul O, et al. Does $\mathrm{N}$-acetyl cysteine affect the sensitivity and specificity of Helicobacter pylori stool antigen test?. Helicobacter 2003;8(2):120-3.

\section{Desroches 1997}

Desroches JJ, Lahaie RG, Picard M, Morais J, Dumont A, Gaudreau C, et al. Methodological validation and clinical usefulness of carbon-14-urea breath test for documentation of presence and eradication of Helicobacter pylori infection. Journal of Nuclear Medicine 1997;38(7):1141-5.

\section{Devenish 2005}

Devenish J, Brooks B, Perry K, Milnes D, Burke T, McCabe D, et al. Validation of a monoclonal antibody-based capture enzyme-linked immunosorbent assay for detection of Campylobacter fetus. Clinical and Diagnostic Laboratory Immunology 2005;12(11):1261-8. 


\section{Dewan 2000}

Dewan R, Sachdev GK. Diagnosis of Helicobacter pylori infection in primary and tertiary care centers. Indian Journal of Gastroenterology 2000;19 Suppl 1:S11-4; discussion S5.

\section{Dhar 1998}

Dhar R, Mustafa AS, Dhar PM, Khan MS, Al-Rashidi FJS, Al-Shamali AAA, et al. Evaluation and comparison of two immunodiagnostic assays for Helicobacter pylori antibodies with culture results. Diagnostic Microbiology and Infectious Disease 1998;30(1):1-6.

\section{Dhesi 2015}

Dhesi E, White B, Chitembwe A, Alisa A, Musa S, Besherdas K. Is there any value in performing a CLO test at endoscopy in patients previously having a stool antigen test?. Gut 2015;64:A78

\section{Di Fulvio 2003}

Di Fulvio A, lerfone N, Standoli M, Trancassini M, Giordano A, Magni A, et al. Study of fecal antigens against Helicobacter pylori as non-invasive test compared with the 13C-urea breath-test. Personal experience. /l Giornale di Chirurgia 2003;24(8-9):312-4.

\section{Di Mario 2009}

Di Mario F, Gatta L, Franze A, Rugge M, Scarpignato C, Dal Bo N, et al. Effects of $H$. pylori eradication on serum pepsinogen $\mathrm{i}$, ii, ratio and gastrin-17 in Italian and immigrant patients. Helicobacter 2009;14 (4):408.

\section{Di Mario 2010}

Di Mario F. Diagnostic accuracy of serum pepsinogens and gastrin to follow-up H. pylori infection. Helicobacter 2010;15(4):350.

\section{Di Rienzo 2013}

Di Rienzo TA, D'Angelo G, Ojetti V, Campanale MC, Tortora A, Cesario V, et al. 13C-urea breath test for the diagnosis of Helicobacter pylori infection. European Review for Medical \& Pharmacological Sciences 2013;17 Suppl 2:51-8.

\section{Di Silvio 1998}

Di Silvio M, Larisch J, Dibildox M, Almaguer I, Gitler R, Dehesa M, et al. Breath tests as a noninvasive diagnostic method in Helicobacter pylori infection. Revista de Gastroenterologia de Mexico 1998;63(3):135-42.

\section{Dietz 2001}

Dietz J, Sekine S, Segal F, Kulczynski JMU, Chaves ALH, Costa JD, et al. "Helicobacter pylori" diagnosis: Comparison between invasive methods. Gastrenterologia Endoscopia Digestiva 2001;20(2):36-40.

\section{Dill 1989}

Dill S, Paynejames JJ, McSwiggan D, Scrimgeour CM, Rennie MJ, Misiewicz JJ. Sensitivity and specificity of the C-13 urea breath test in detecting Campylobacter-pylori. Gut 1989;30(5):A752.

\section{Dill 1990}

Dill S, Payne-James JJ, Misiewicz JJ, Grimble GK, McSwiggan D, Pathak K, et al. Evaluation of 13C-urea breath test in the detection of Helicobacter pylori and in monitoring the effect of tripotassium dicitratobismuthate in non-ulcer dyspepsia. Gut 1990;31(11):1237-41.

\section{Ding 1993}

Ding SZ, Jia BQ, Liu XG. An urease enzyme linked immunosorbent assay for detection of Helicobacter pylori infection. Zhonghua Nei Ke Za Zhi [Chinese Journal of Internal Medicine] 1993;32(5):298-301.

\section{Ding 2000}

Ding SL, Ring JA, Hebbard GS, Morcom JM, Young GP. Lansoprazole but not ranitidine interferes with $\mathrm{C}-13$ urea breath test detection of Helicobacter pylori infection. Gastroenterology 2000;118(4):A1228.

\section{Djurasinovic 2014}

Djurasinovic MZ, Sokic-Milutinovic A, Filipovic B, Basara S, Krstic M, Milosavljevic T. The role of non-invasive assessment of the secretory function of the gastric mucosa in dyspepsia. Helicobacter 2014;19:112.

\section{Dmitrienko 2009}

Dmitrienko M, Bykov S. Method of breath sampling for noninvasive H. pylori analysis. Helicobacter 2009;14 (4):341.

\section{Dmitrienko 2011}

Dmitrienko M, Bykov S, Parolova N, Karaseva G. Ammonia breath test - transportation way of ammonia. Helicobacter 2011;16:115.

\section{Dolek 2007}

Dolek D, Soyturk M, Bekmen N, Yilmaz O, Demiray E, Sarioglu S, et al. Urine-based ELISA testing for the diagnosis and confirmation of eradication of Helicobacter pylori infection. Helicobacter 2007;12(4):444.

\section{Dominguez 2006}

Dominguez J, Forne M, Blanco S, Prat C, Gali N, Latorre I, et al. Comparison of a monoclonal with a polyclonal antibody-based enzyme immunoassay stool test in diagnosing Helicobacter pylori infection before and after eradication therapy. Alimentary Pharmacology \& Therapeutics 2006;23(12):1735-40.

\section{Dominguezmunoz 1995}

Dominguezmunoz JE, Linke A, Sauerbruch T, Malfertheiner P. How to improve the C-13-urea breath test (UBT) for the diagnosis of Helicobacter-pylori infection. Gastroenterology 1995;108(4 (suppl)):A84.

\section{Domínguez-Muñoz 1997}

Domínguez-Muñoz JE, Leodolter A, Sauerbruch T, Malfertheiner P. A citric acid solution is an optimal test drink in the 13C-urea breath test for the diagnosis of Helicobacter pylori infection. Gut 1997;40(4):459-62.

\section{Donati 1997}

Donati M, Moreno S, Storni E, Tuccia A, Poli L, Sambri V, et al. Study of anti-Helicobacter pylori antibodies with use of latex agglutination test. Microbiologia Medica 1997;12(3):130-1. 


\section{Donati 2000}

Donati M, Sambri V, Ranucci L, De Orsi D, Tucci A, Poli L, et al. Recombinant CagA enzyme-linked immunosorbent assay and western immunoblot for the detection of serum antibodies to Helicobacter pylori. Clinical Microbiology \& Infection 2000;6(3):164-6.

\section{Dondi 2006}

Dondi E, Rapa A, Boldorini R, Fonio P, Zanetta S, Oderda G. High accuracy of noninvasive tests to diagnose Helicobacter pylori infection in very young children. Journal of Pediatrics 2006;149(6):817-21.

\section{Dong 2015}

Dong FY, Ji DN, Huang RX, Zhang F, Huang YQ, Xiang P, et al. Multiple genetic analysis system-based antibiotic susceptibility testing in Helicobacter pylori and high eradication rate with phenotypic resistance-guided quadruple therapy. Medicine 2015 [Epub ahead of print]; Vol. 94, issue 47. [DOI: 10.1097/ MD.0000000000002056]

\section{Dore 1997}

Dore SP, Krupadas S, Borgonha S, Kurpad AV. The $13 \mathrm{C}$ urea breath test to assess Helicobacter pylori infection in school children. National Medical Journal of India 1997;10(2):57-60.

\section{Dore 2003}

Dore MP, Realdi G, Sepulveda AR, Graham DY. Detection of genomic Helicobacter pylori DNA in the blood of patients positive for the infection. Digestive and Liver Disease 2003;35(11):839-40.

\section{Dore 2004}

Dore MP, Negrini R, Tadeu V, Marras L, Maragkoudakis E, Nieddu S, et al. Novel monoclonal antibody-based Helicobacter pylori stool antigen test. Helicobacter 2004;9(3):228-32.

\section{Dorta 2005}

Dorta G. Helicobacter pylori detection revisited. Endoscopy 2005;37(6):579-80; author reply 581-2.

\section{Dou 2008}

Dou YC, Wang JB. Detection of $H$. pylori infection in patients with pancreatic cancer and clinical significance. Journal of Jilin University Medicine Edition 2008;34(2):317-9.

\section{Douraghi 2013}

Douraghi M, Rostami MN, Goudarzi H, Ghalavand Z. Comparison of stool antigen immunoassay and serology for screening for Helicobacter pylori infection in intellectually disabled children. Microbiology and Immunology 2013;57(11):772-7.

\section{Doweck 1997}

Doweck J, Quintana C, Barrios A, Monastra L, Lopetegui G, Zerbo $\mathrm{O}$, et al. Evaluation of sensitivity, specificity and predictive value of six qualitative serological methods for the detection of Helicobacter pylori antibodies. Acta Gastroenterologica Latinoamericana 1997;27(4):259-61.

\section{Dowlatshahi 2002}

Dowlatshahi S. Effect of gastrointestinal bleeding on the sensitivity of diagnostic tests for Helicobacter pylori infection. Archives of Iranian Medicine 2002;5(3):201-2.

\section{Drew 1988}

Drew H, Lafrance ND, Mertz H, Hernandez J, Ravich W, Milligan F, et al. C-14 urea breath test in Campylobacter pyloridis gastric disorders - comparison with biopsy with comparison and sensitivity of 20, 40,60 and 120 minute sampling. Clinical Nuclear Medicine 1988;13(5):394.

\section{Drumm 1999}

Drumm B, Rowland M, Imrie C. Sensitivity of urease-based test on diagnosis of Helicobacter pylori in children and the elderly. Gastroenterology 1999;116(6):1506.

\section{Drzymala-Czy 2014}

Drzymala-Czy S, Stawinska-Witoszynska B, Madry E, Krzywinska-Wiewiorowska M, Szczepanik M, Walkowiak J, et al. Non-invasive detection of Helicobacter pylori in cystic fibrosis - the fecal test vs. the urea breath test. European Review for Medical and Pharmacological Sciences 2014;18(16):2343-8.

\section{Du 2004}

Du JX, Watkins T, Bravo LE, Fontham ET, Camargo MC, Correa P, et al. 13C-urea breath test for Helicobacter pylori in young children: Cut-off point determination by finite mixture model. Statistics in Medicine 2004;23(13):2049-60.

\section{Duan 1994}

Duan LP, Braden B, Lembcke B, Caspary WF. C-13-urea breath test after breakfast still meets the criteria for valid diagnosis of Helicobacter-pylori. Gastroenterology 1994;106(4 (suppl)):A71.

\section{DuBois 2005}

DuBois S, Kearney DJ. Iron-deficiency anemia and Helicobacter pylori infection: a review of the evidence. American Journal of Gastroenterology 2005;100(2):453-9.

\section{Duggan 1998}

Duggan AE, Hardy E, Hawkey CJ. Evaluation of a new near patient test for the detection of Helicobacter pylori. European Journal of Gastroenterology \& Hepatology 1998;10(2):133-6.

\section{Duggan 1999}

Duggan AE, Elliott C, Logan RFA. Testing for Helicobacter pylori infection: Validation and diagnostic yield of a near patient test in primary care. BMJ 1999;319(7219):1236-9.

\section{Dulbecco 2001}

Dulbecco P, Gambaro C, Zentilin P, Bilardi C, Biagini R, Savarino $V$. The impact of long-term ranitidine and pantoprazole on the precision of C-13-urea breath test (UBT) in subjects infected with Helicobacter pylori. Gastroenterology 2001;120(5 (suppl)):A578.

\section{Dulbecco 2003}

Dulbecco P, Gambaro C, Bilardi C, Zentilin P, Mele MR, Mansi C, et al. Impact of long-term ranitidine and pantoprazole on 
accuracy of $13 \mathrm{C}$ urea breath test. Digestive Diseases \& Sciences 2003;48(2):315-21.

\section{Dumont 1989}

Dumont A, Abramovici J, Muller C, Trolin C, Barbier P. Diagnostic efficiency of the $14 C$-urea breath test in the detection of antral Campylobacter pylori infection. Gastroduodenal pathology and Campylobacter pylori: European Campylobacter Pylori Study Group ICS847. 1989:73-5.

\section{Dun 2001}

Dun CDR, Blac M, Cowell DC, Penaul C, Ratcliffe NM, Spence R, et al. Ammonia vapour in the mouth as a diagnostic marker for Helicobacter pylori infection: Preliminary 'proof of principle' pharmacological investigations. British Journal of Biomedical Science 2001;58(2):66-75.

\section{Durdal 2002}

Durdal US, Engin D, Hascelik G. Evaluation of western blot method for the serological diagnosis of Helicobacter pylori infections. Mikrobiyoloji Bulteni 2002;36(2):153-60.

\section{Dy-Limquiaco 2006}

Dy-Limquiaco LA, Florendo WO, Labio ME, Banez V, Daez ML. Validation of the new 14-carbon urea breath test (14-C UBT) in the diagnosis of Helicobacter pylori infection. Journal of Gastroenterology and Hepatology 2006;21:A505.

\section{Dyrla 2015}

Dyrla P, Gil J, Wojtun S, Korszun K, Kasinska E, Mackiewicz A. Helicobacter pylori infection. Diagnosis and treatment. Pediatria i Medycyna Rodzinna 2015;11(1):68-74.

\section{Ebara 2000}

Ebara S, Aoyama N, Sakai T, Ikemura T, Shirasaka D, Sakashita M, et al. A study of gastric emptying in $\mathrm{H}$-pylori negative healthy volunteers using the $\mathrm{C}$-13-octanoic acid breath test. Gastroenterology 2000;118(4):A1169.

\section{Ebell 1998}

Ebell MH. Breath test and serologic testing for Helicobacter pylori. Journal of the American Board of Family Practice 1998;11(2):170-1.

\section{Edwards 1997}

Edwards CN, Douglin CP, Prussia PR, Garriques SA, Levett PN. Epidemiology of Helicobacter pylori infection in Barbados. West Indian Medical Journal 1997;46(1):3-7.

\section{El-Nujumi 1996}

El-Nujumi A, Hilditch TE, McColl KEL. Effect of omeprazole therapy on determination of Helicobacter pylori status by C-14 urea breath test. Gastroenterology 1996;110(4 (suppl)):A102.

\section{El-Nujumi 1998}

El-Nujumi A, Hilditch TE, Williams C, McColl KE. Current or recent proton pump inhibitor therapy markedly impairs the accuracy of the $14 \mathrm{C}$ urea breath test. European Journal of Gastroenterology \& Hepatology 1998;10(9):759-64.

\section{El-Zaatari 1995}

El-Zaatari FA, Nguyen AM, Genta RM, Klein PD, Graham DY. Determination of Helicobacter pylori status by reverse transcription-polymerase chain reaction. Comparison with urea breath test. Digestive Diseases \& Sciences 1995;40(1):109-13.

\section{El-Zimaity 1998}

El-Zimaity HMT, Segura AM, Genta RM, Graham DY. Histologic assessment of Helicobacter pylori status after therapy: Comparison of Giemsa, Diff-Quik, and Genta stains. Modern Pathology 1998;11(3):288-91.

\section{Elbast 1999}

Elbast W, Brazier JL. Nondispersive infrared spectroscopy, an alternative to isotope ratio mass spectrometry: Case of the C-13 urea breath test. Analusis 1999;27(3):228-31.

\section{Elitsur 1997}

Elitsur Y, Neace C, Triest WE. Comparison between a rapid officebased and ELISA serologic test in screening for Helicobacter pylori in children. Helicobacter 1997;2(4):180-4.

\section{Elitsur 1999a}

Elitsur Y, Neace C, Werthammer MC, Triest WE. Prevalence of CagA, VacA antibodies in symptomatic and asymptomatic children with Helicobacter pylori infection. Helicobacter 1999;4(2):100-5.

\section{Elitsur 1999b}

Elitsur Y, Neace C. Detection of Helicobacter pylori organisms by HP-Fast in children. Digestive Diseases and Sciences 1999;44(6):1169-72.

\section{Elitsur 2000}

Elitsur Y, Aflak R, Neace C, Triest WE. Helicobacter pylori serology and the diagnosis of $H$. pylori infection in children. West Virginia Medical Journal 2000;96(5):564-6.

\section{Elitsur 2004}

Elitsur Y, Lawrence Z, Hill I. Stool antigen test for diagnosis of Helicobacter pylori infection in children with symptomatic disease: A prospective study. Journal of Pediatric Gastroenterology \& Nutrition 2004;39(1):64-7.

\section{Elitsur 2005}

Elitsur Y. Helicobacter pylori diagnostic tools: Is it in the stool?. Journal of Pediatrics 2005;146(2):164-7.

\section{Elitsur 2009}

Elitsur Y, Tolia V, Gilger MA, Reeves-Garcia J, SchmidtSommerfeld E, Opekun AR, et al. Urea breath test in children: The United States prospective, multicenter study. Helicobacter 2009;14(2):134-40.

\section{Ellenrieder 1997}

Ellenrieder V, Glasbrenner B, Stoffels C, Weiler S, Bode G, Moller $P$, et al. Qualitative and semi-quantitative value of a modified 13C-urea breath test for identification of Helicobacter pylori infection. European Journal of Gastroenterology \& Hepatology 1997;9(11):1085-9. 


\section{Elnujumi 1991}

Elnujumi AM, Rowe P, Dorrian CA, McColl KEL. Value of C-14 urea breath test and urease slide test (CLO test) to diagnose Helicobacter-pylori in uremic patients. Gut 1991;32(10):A1220.

\section{Eloubeidi 2001}

Eloubeidi MA, Wade SB, Provenzale D. Factors associated with acceptance and full publication of $\mathrm{GI}$ endoscopic research originally published in abstract form. Gastrointestinal Endoscopy 2001;53(3):275-82.

\section{Endtz 2000}

Endtz HP, Ang CW, Van den Braak N, Luijendijk A, Jacobs BC, De Man P, et al. Evaluation of a new commercial immunoassay for rapid detection of Campylobacter jejuni in stool samples. European Journal of Clinical Microbiology and Infectious Diseases 2000;19(10):794-7.

\section{Engberg 2003}

Engberg JH, Strid MA, Molbak K, Krogfelt KA. Antibody response following infection with Campylobacter determined by enzymelinked immunosorbent assay (ELISA). Ugeskrift for Laeger 2003;165(24):2485-6.

\section{Engstrand 1992}

Engstrand L, Nguyen AM, Graham DY, el-Zaatari FA. Reverse transcription and polymerase chain reaction amplification of rRNA for detection of Helicobacter species. Journal of Clinical Microbiology 1992;30(9):2295-301.

\section{Enroth 1997a}

Enroth H, Rigo R, Hulten K, Engstrand L. Diagnostic accuracy of a rapid whole-blood test for detection of Helicobacter pylori. Journal of Clinical Microbiology 1997;35(10):2695-7.

\section{Enroth 1997b}

Enroth H, Engstrand L. Rapid detection of Helicobacter pylori infection in serum and whole-blood samples. APMIS 1997;105(12):951-5.

\section{Enroth 2002}

Enroth H, Kraaz W, Rohan T, Nyren O, Engstrand L. Does the method of Helicobacter pylori detection influence the association with gastric cancer risk?. Scandinavian Journal of Gastroenterology 2002;37(8):884-90.

\section{Erzin 2004}

Erzin Y, Altun S, Dobrucali A, Aslan M, Erdamar S, Dirican A, et al. Comparison of two different stool antigen tests for the primary diagnosis of Helicobacter pylori infection in Turkish patients with dyspepsia. Helicobacter 2004;9(6):657-62.

\section{Erzin 2005}

Erzin Y, Altun S, Dobrucali A, Aslan M, Erdamar S, Dirican A, et al. Evaluation of two enzyme immunoassays for detecting Helicobacter pylori in stool specimens of dyspeptic patients after eradication therapy. Journal of Medical Microbiology 2005;54(Pt 9):863-6.

\section{Evans 1989}

Evans DJ Jr, Evans DG, Graham DY, Klein PD. A sensitive and specific serologic test for detection of Campylobacter pylori infection. Gastroenterology 1989;96(4):1004-8.

\section{Everts 1996}

Everts B, Hamlet A, Pettersson A. A 10 minutes solid dosage C-13-urea breath test for diagnosis of Helicobacter pylori infection. Gastroenterology 1996;110(4 suppl):A105.

\section{Faigel 1996a}

Faigel DO, Furth EE, Childs M, Goin J, Metz DC. Histological predictors of active Helicobacter pylori infection. Digestive Diseases \& Sciences 1996;41(5):937-43.

\section{Faigel 1996b}

Faigel DO, Childs M, Furth EE, Alavi A, Metz DC. New noninvasive tests for Helicobacter pylori gastritis - comparison with tissue-based gold standard. Digestive Diseases and Sciences 1996;41(4):740-8.

\section{Faigel 2000}

Faigel DO, Magaret N, Corless C, Lieberman DA, Fennerty MB. Evaluation of rapid antibody tests for the diagnosis of Helicobacter pylori infection. American Journal of Gastroenterology 2000;95(1):72-7.

\section{Faigel 2001}

Faigel DO, Hahn M. Urea breath test for the diagnosis of Helicobacter pylori - response. Gastrointestinal Endoscopy 2001;53(6):700-1.

\section{Fakhrjou 2011}

Fakhrjou A, Somi MH, Fattahi E, Koohbanani SS, Shadravan S. Rapid urease test, touch cytology and histopathologic assessment in determining infection by Helicobacter pylori in outpatient setting. Pakistan Journal of Biological Sciences 2011;14(12):698-702.

\section{Falaknazi 2010}

Falaknazi K, Jalalzadeh M, Vafaeimanesh J. Noninvasive stool antigen assay for screening of Helicobacter pylori infection and assessing success of eradication therapy in patients on hemodialysis. Iranian Journal of Kidney Diseases 2010;4(4):317-21.

\section{Falk 1997}

Falk GW. Best tests for detecting Helicobacter pylori. Consultant 1997;37(7):1765.

\section{Fallone 1998}

Fallone CA, Loo VG, Barkun AN. Utility of serology in determining Helicobacter pylori eradication after therapy. Canadian Journal of Gastroenterology 1998;12(2):117-24.

\section{Fallone 2000}

Fallone CA, Veldhuyzen van Zanten SJ, Chiba N. The urea breath test for Helicobacter pylori infection: Taking the wind out of the sails of endoscopy. CMAJ Canadian Medical Association Journal 2000;162(3):371-2. 


\section{Falsafi 2005}

Falsafi T, Valizadeh N, Sepehr S, Najafi M. Application of a stool antigen test to evaluate the incidence of Helicobacter pylori infection in children and adolescents from Tehran, Iran. Clinical \& Diagnostic Laboratory Immunology 2005;12(9):1094-7.

\section{Falsafi 2009}

Falsafi T, Favaedi R, Mahjoub F, Najafi M. Application of stoolPCR test for diagnosis of Helicobacter pylori infection in children. World Journal of Gastroenterology 2009;15(4):484-8

\section{Falsafi 2014}

Falsafi T, Lavasani P, Basardeh I, Massarrat S, Landarani Z. Evaluation of an Iranian home Helicobacter pylori stool antigen ELISA kit. Jundishapur Journal of Microbiology 2014; Vol. 7, issue 6:e10629. [DOI: 10.5812/jjm.10629]

\section{Fanti 2001}

Fanti L, leri R, Mezzi G, Testoni PA, Passaretti S, Guslandi M. Long-term follow-up and serologic assessment after triple therapy with omeprazole or lansoprazole of Helicobacterassociated duodenal ulcer. Journal of Clinical Gastroenterology 2001;32(1):45-8.

\section{Farkkila 1996}

Farkkila M. Active Campylobacter pylori infection diagnosed by the urea breath test. Duodecim; Laaketieteellinen Aikakauskirja 1996;112(5):349-50.

\section{Faulde 1991}

Faulde M, Putzker M, Mertes T, Sobe D. Evaluation of an immunofluorescence assay for specific detection of immunoglobulin-G antibodies directed against Helicobacterpylori, and antigenic cross-reactivity between Helicobacterpylori and Campylobacter-jejuni. Journal of Clinical Microbiology 1991;29(2):323-7.

\section{Fayaz 2014}

Fayaz F, Gachkar L, Roodsari SR, Pourkaveh B. Prevalence of Helicobacter pylori infection in patients with down syndrome and mental retardation. Archives of Clinical Infectious Diseases 2014 Sep 25 [Epub ahead of print]; Vol. 9, issue 4. [ 10.5812/ archcid.22064]

\section{Fayed 2008}

Fayed SB, Aref MI, Fathy HM, El Dayem SMA, Emara NA, Maklof A, et al. Prevalence of celiac disease, Helicobacter pylori and gastroesophageal reflux in patients with refractory iron deficiency anemia. Journal of Tropical Pediatrics 2008;54(1):43-53.

\section{Fazulzyanova 2012}

Fazulzyanova A, Isaeva G, Ivanovskaya K. Evaluation of effectiveness of different methods of Helicobacter pylori detection in patients with chronic HCV-infection. Helicobacter 2012;17:95.

\section{Fazzio 1995}

Fazzio S, Vazquez G, Ardao G, Blanco J, Vivero E, Gualco G, et al. Helicobacter pylori: Comparative study of different diagnostic techniques. Acta Gastroenterologica Latinoamericana 1995;25(5):269-76.

\section{Feldman 1995}

Feldman RA, Deeks JJ, Evans SJW. Multilaboratory comparison of 8 commercially available Helicobacter-pylori serology kits. European Journal of Clinical Microbiology \& Infectious Diseases 1995;14(5):428-33.

\section{Felz 1997}

Felz MW, Burke GJ, Schuman BM. Breath test diagnosis of Helicobacter pylori in peptic ulcer disease: A noninvasive primary care option. Journal of the American Board of Family Practice 1997;10(6):385-9.

\section{Ferrante 1999}

Ferrante LC, Papponetti M, Marcuccitti J, Neri M, Festi D. C-13urea breath test for Helicobacter pylori infection: Stability of samples over time. Scandinavian Journal of Gastroenterology 1999;34(9):942-3.

\section{Ferwana 2015}

Ferwana M, Abdulmajeed I, Alhajiahmed A, Madani W, Firwana B, Hasan R, et al. Accuracy of urea breath test in Helicobacter pylori infection: Meta-analysis. World Journal of Gastroenterology 2015;21(4):1305-14.

\section{Festi 1999}

Festi D, Marcuccitti J, Papponetti M, Colaiocco-Ferrante L, Bonitatibua A, Di Ilio C, et al. C-13-urea breath test for Helicobacter pylori infection: A repeatability study. Gastroenterology 1999;116(4 (suppl)):A162.

\section{Feteih 2009}

Feteih R, Abdel-Salam M, Jamjoom H, Akbar H. Salivary anti-Helicobacter pylori positivity among endoscopy patients with chronic liver disease. Eastern Mediterranean Health Journal 2009;15(6):1371-8.

\section{Feydt-Schmidt 2002}

Feydt-Schmidt A, Russmann H, Lehn N, Fischer A, Antoni I, Stork D, et al. Fluorescence in situ hybridization vs. Epsilometer test for detection of clarithromycin-susceptible and clarithromycin-resistant Helicobacter pylori strains in gastric biopsies from children. Alimentary Pharmacology \& Therapeutics 2002;16(12):2073-9.

\section{Figura 1994}

Figura N, Oderda G, Verdiani S. Evaluation of a commercial ELISA kit for the serological diagnosis of Helicobacter pylori infection. New Microbiologica 1994;17(4):319-25.

\section{Figura 2005}

Figura N, Santucci A, Lahner E, Mini R, Bernardini G, Vaira D, et al. Western blotting for the diagnosis of Helicobacter pylori infection in patients with atrophic body gastritis. Helicobacter 2005;10(5):521. 


\section{Figura 2014}

Figura N, Marini L, Macchiarelli R, Moretti E. Latex agglutination test for detection of $H$. pylori in gastric biopsies. Helicobacter 2014;19:125.

\section{Finderle 2013}

Finderle P, Suhadolc K, Osredkar J. Determination of Helicobacter pylori antigen in stool in comparison to breath test. Biochimica Clinica 2013;37:S665.

\section{Floch 2012}

Floch P, Goret J, Bessede E, Lehours P, Megraud F. Evaluation of the positive predictive value of a rapid immunochromatographic test to detect Campylobacter in stools. Gut Pathogens 2012 Dec 4; Vol. 4, issue 1:17. [10.1186/1757-4749-4-17]

\section{Foertsch 2010}

Foertsch S, Neumann H, Vieth M, Guldi DM, Neurath MF, Kuth R. Development of a new electrochemical device for rapid Helicobacter pylori detection. Gastroenterology 2010;138(5 (suppl 1)):S512.

\section{Folwaczny 1999}

Folwaczny C, Reichardt B, Klauser A, Klose J, Blendinger C, Wiebecke B, et al. Accuracy of C-13-urea breath test for diagnosis of Helicobacter pylori infection in clinical routine. Gastroenterology 1999;116(4 (suppl)):A164.

\section{Fontana 2000}

Fontana C, Pietroiusti A, Mastino A, Pistoia ES, Marino D, Magrini A, et al. Comparison of an enzyme immunoassay versus a rapid latex test for serodiagnosis of Helicobacter pylori infection. European Journal of Clinical Microbiology \& Infectious Diseases 2000;19(3):239-40.

\section{Ford 2014}

Ford AC, Forman D, Hunt RH, Yuan Y, Moayyedi P. Helicobacter pylori eradication therapy to prevent gastric cancer in healthy asymptomatic infected individuals: systematic review and meta-analysis of randomised controlled trials. BMJ 2014;348:g3174.

\section{Formichella 2012}

Formichella L, Romberg L, Bolz C, Vieth M, Geppert M, Gottner $\mathrm{G}$, et al. A novel line blot system to detect an infection with pathogenic H. pylori. International Journal of Medical Microbiology 2012;302:6.

\section{Forne 2000}

Forne M, Dominguez J, Fernandez-Banares F, Lite J, Esteve M, Gali N, et al. Accuracy of an enzyme immunoassay for the detection of Helicobacter pylori in stool specimens in the diagnosis of infection and posttreatment check-up. American Journal of Gastroenterology 2000;95(9):2200-5.

\section{Fowora 2012}

Fowora MA, Breithaupt U, Otegbayo JA, Akere A, Onyekwere CA, Ndububa D, et al. Molecular characterization of Helicobacter pylori infections in Nigeria. Helicobacter 2012;17:88.

\section{Fox 1989}

Fox JG, Correa P, Taylor NS, Zavala D, Fontham E, Janney F, et al. Campylobacter pylori-associated gastritis and immune response in a population at increased risk of gastric carcinoma. American Journal of Gastroenterology 1989;84(7):775-81.

\section{Fradkin 1997}

Fradkin A, Yahav Y, DiverHaber A, Weisselberg B, Jonas A. The value of anti-Helicobacter pylori IgG antibodies in establishing eradication of infection in children. Israel Journal of Medical Sciences 1997;33(2):87-92.

\section{Franceschi 1999}

Franceschi F, Armuzzi A, Maniccia E, Ojetti V, Torre ES, Candelli M, et al. Delta(CO2)-C-13 excretion and prevalence of gastrointestinal symptoms in subjects evaluated for $\mathrm{H}$-pylori infection through C-13-urea breath test. Gastroenterology 1999;116(4 (suppl)):A164.

\section{Franchini 2007}

Franchini M, Cruciani M, Mengoli C, Pizzolo G, Veneri D. Effect of Helicobacter pylori eradication on platelet count in idiopathic thrombocytopenic purpura: a systematic review and meta-analysis. Journal of Antimicrobial Chemotherapy 2007;60(2):237-46.

\section{Fraser 1996a}

Fraser AG, Moore L, Rafiq Ali M, Chua LE, Hollis B, Little SV. An audit of low dose triple therapy for eradication of Helicobacter pylori. New Zealand Medical Journal 1996;109(1027):290-2.

\section{Fraser 1996b}

Fraser AG, Ali MR, McCullough S, Yeates NJ, Haystead A. Diagnostic tests for Helicobacter pylori - can they help select patients for endoscopy. New Zealand Medical Journal 1996;109(1018):95-8.

\section{Fraser 1997}

Fraser AG, McIntosh C, Berry S, Moore L. The urea breath test (UBT) for H-pylori (HP) in the initial assessment of dyspepsia in primary care. Gut 1997;41(suppl):A77-A8.

\section{Fraser 1998}

Fraser AG, McIntosh C, Berry S, Moore L. Can the urea breath test for $H$. pylori replace endoscopy for the assessment of dyspepsia in primary care?. New Zealand Medical Journal 1998;111(1058):11-4.

\section{Fraser 2003}

Fraser A, Williamson S, Lane M, Hollis B. Nurse-led dyspepsia clinic using the urea breath test for Helicobacter pylori. New Zealand Medical Journal 2003;116(1176):U479.

\section{Frenck 2006}

Frenck RW Jr, Fathy HM, Sherif M, Mohran Z, El Mohammedy H, Francis W, et al. Sensitivity and specificity of various tests for the diagnosis of Helicobacter pylori in Egyptian children. Pediatrics 2006;118(4):e1195-e202. 


\section{Fruehauf 2003}

Fruehauf H, Lindenmann N, Volkart K, Bauerfeind P, Ben-Oren I, Fried $M$. The gastroscopic $C$-13-urea breath test: $A$ new rapid online test for Helicobacter pylori (HP) detection during routine upper endoscopy. Gastroenterology 2003;124(4 (suppl)):A176.

\section{Fry 2005}

Fry LC, Curioso WH, Rickes S, Horton G, Hirschowitz BI, Monkemuller K. Comparison of $13 \mathrm{C}$ - urea blood test to 13C-breath test and rapid urease test for the diagnosis of Helicobacter pylori infection. Acta Gastroenterologica Latinoamericana 2005;35(4):225-9.

\section{Fujisawa 2001}

Fujisawa T, Kaneko T, Kumagai T, Akamatsu T, Katsuyama T, Kiyosawa K, et al. Evaluation of urinary rapid test for Helicobacter pylori in general practice. Journal of Clinical Laboratory Analysis 2001;15(3):154-9.

\section{Fukuda 1996}

Fukuda Y, Fukuda S, Munakata A, Yoshida Y, Shimoyama T. Validity of various diagnostic tests to evaluate cure of Helicobacter pylori infection. Journal of Gastroenterology 1996;31(2):171-4.

\section{Fukuda 2002}

Fukuda Y, Yoshida K, Ezaki H, Tomita T, Kosaka T, Hori K, et al. Diagnosis of Helicobacter pylori infection. Nihon Rinsho [Japanese Journal of Clinical Medicine] 2002;60(8):1543-8.

\section{Fukuda 2003a}

Fukuda Y, Tamura K, Tomita T, Hori K, Tanida N, Shimoyama T. Validation of the accuracy of the $\mathrm{H}$. pylori stool antigen test (HPSA) in the Japanese population. Digestive and Liver Disease 2003;35(1):62-3.

\section{Fukuda 2003b}

Fukuda Y, Hori K, Sakagami T, Shimoyama T. Suitable diagnostic methods for $H$. pylori infection after eradication therapy. Nihon Rinsho [Japanese Journal of Clinical Medicine] 2003;61(1):102-8.

\section{Fukuda 2005}

Fukuda S, Tanaka M, Shimoyama T, Sato M, Takahashi R, Munakata A. Applicability of a Helicobacter pylori stool antigen test to determine the results of eradication therapy. Helicobacter 2005;10(5):524.

\section{Fukuda 2006}

Fukuda S, Shimoyama T, Nishiya D, Munakata A. Applicability of a Helicobacter pylori stool antigen test to determine the results of eradication therapy. Gastroenterology 2006;130(4 (suppl)):A571.

\section{Fukuda 2007}

Fukuda Y, Shimoyama T, Takahashi R, Nakabayashi N, Koizuka $\mathrm{H}$, Abe D, et al. Evaluation of a new monoclonal antibody (HRII-51)-antigen capture ELISA with high specificity for Helicobacter hepaticus using sera from mice inoculated with Helicobacter species. Helicobacter 2007;12(4):388-9.

\section{Fukuda 2009}

Fukuda Y, Shimoyama T, Ohmura T, Sano Y, Nakabayashi N, Takahashi R, et al. Characterization and application of a new monoclonal antibody with high specificity for Helicobacter hepaticus. Helicobacter 2009;14(1):66-71.

\section{Fusconi 1997}

Fusconi M, Farinelli S, Menegatti M, Figura N, Landi F, Quan S, et al. Western immunoblotting (WB) and a recombinant immunoblotting assay (RIBA(TM)) for detection of $H$-pylori (HP) anti Cag-A reactivity (anti-HP Cag-A). Gut 1997;41(suppl):A73A4.

\section{Fusconi 1999}

Fusconi M, Vaira D, Menegatti M, Farinelli S, Figura N, Holton J, et al. Anti-caga reactivity in Helicobacter pylori-negative subjects - a comparison of three different methods. Digestive Diseases and Sciences 1999;44(8):1691-5.

\section{Galleguillos 1998}

Galleguillos C, Gonzalez P, Massardo T, Morales A, Pimentel C, Gil C, et al. Low specificity of carbon-14-urea breath test is the gold standard adequate for Helicobacter pylori infection C. Journal of Nuclear Medicine 1998;39(5 Suppl):57P-8P.

\section{Gallo 2001}

Gallo N, Basso D, Zambon CF, Navaglia F, Di Mario F, Rugge M, et al. Diagnosis of Helicobacter pylori infection: Comparison of techniques. Recenti Progressi in Medicina 2001;92(5):332-5.

\section{Ganga-Zandzou 2001}

Ganga-Zandzou PS, Vincent P, Michaud L, Guimber D, Turck D, Gottrand F. C-13-urea breath test in children with Helicobacter pylori infection: Validity of the use of a mask to collect exhaled breath samples. Acta Paediatrica 2001;90(2):232-3.

\section{Gangaidzo 1995}

Gangaidzo I, Mason PR, Kiire CF, Bak-Jensen E, Willen R, Lelwala-Guruge J, et al. Helicobacter pylori in endoscopy patients in Zimbabwe: Value of enzyme-linked immunosorbent assay and a rapid urease test. Transactions of the Royal Society of Tropical Medicine \& Hygiene 1995;89(5):502-5.

\section{Gao 2015}

Gao F, Li W. Investigation on causes of false-negative 14C-urea breath test. Chinese Journal of Gastroenterology 2015;20(3):151-4.

\section{Garces 2012}

Garces HRH, Gonzalez VVC, Fabian LG, Velazquez MI, Pena K, Sierra YA. Chromoendoscopy with red phenol in the diagnosis of Helicobacter pylori infection. Revista Espanola De Enfermedades Digestivas 2012;104(1):4-9.

\section{Garcia 1996}

Garcia JIP, Garcia JMP, Alonso IJ. C13 urea breath test for Helicobacter pylori. Validation of the method. Revista Espanola De Enfermedades Digestivas 1996;88(3):202-8. 


\section{Garcia 2000}

Garcia Valriberas R, Gisbert JP, Hermida C, Cabrera MM, Diaz Blasco J, Pajares JM. Antibodies against Helicobacter pylori in saliva. Study of their validity versus breath test and its agreement with serology. Atencion Primaria / Sociedad Espanola de Medicina de Familia y Comunitaria 2000;25(6):390-4.

\section{Garcia 2006}

Garcia AJD, Gisbert JP. Is the string test a useful alternative to gastroscopy with biopsy for h-pylori identification?. Revista Espanola De Enfermedades Digestivas 2006;98(7):542-6.

\section{Garcia-Diaz 2002}

Garcia-Diaz E, Castro-Fernandez M, Romero-Gomez M, VargasRomero J. The effectiveness of (IgG-ELISA) serology as an alternative diagnostic method for detecting Helicobacter pylori infection in patients with gastro-intestinal bleeding due to gastro-duodenal ulcer. Revista Espanola De Enfermedades Digestivas 2002;94(12):725-36.

\section{Garza-Gonzalez 2002}

Garza-Gonzalez E, Perez-Perez GI, Tijerina-Menchaca R, Maldonado-Garza HJ, Bosques-Padilla FJ. Helicobacter pylori genotypes and their association with host's immune response. Revista de Gastroenterologia de Mexico 2002;67(3):155-60.

\section{Garza-Gonzalez 2003}

Garza-Gonzalez E, Bosques-Padilla FJ, Tijerina-Menchaca R, Flores-Gutierrez JP, Maldonado-Garza HJ, Perez-Perez GI. Comparison of endoscopy-based and serum-based methods for the diagnosis of Helicobacter pylori. Canadian Journal of Gastroenterology 2003;17(2):101-6.

\section{Gatta 2003a}

Gatta L, Ricci C, Tampieri A. Noninvasive tests to diagnose Helicobacter pylori infection. Current Gastroenterology Reports 2003;5(5):351-2.

\section{Gatta 2003b}

Gatta L, Vakil N, Ricci C, Osborn JF, Tampieri A, Perna F, et al. A rapid, low-dose, c-13-urea tablet for the detection of Helicobacter pylori infection before and after treatment. Alimentary Pharmacology \& Therapeutics 2003;17(6):793-8.

\section{Gatta 2003c}

Gatta L, Vakil N, Tampieri A, Ricci C, Perna F, Miglioli M, et al. Effects of proton pump inhibitor therapy (ppi) on $13 \mathrm{C}$ breath test (ubt) \& stool antigen test (st) in h pylori (hp): Effects of citric acid \& orange juice. Gastroenterology 2003;124(4 (suppl)):A58.

\section{Gatta 2003d}

Gatta L, Ricci C, Stanghellini V, Ali A, Menegatti M, Labate AMM, et al. Best cut-off values for c-14 -urea breath tests for Helicobacter pylori detection. Scandinavian Journal of Gastroenterology 2003;38(11):1144-8.

\section{Gatta 2004a}

Gatta L, Vakil N, Ricci C, Osborn JF, Tampieri A, Perna F, et al. Effect of proton pump inhibitors and antacid therapy on $13 \mathrm{C}$ urea breath tests and stool test for Helicobacter pylori infection. American Journal of Gastroenterology 2004;99(5):823-9.

\section{Gatta 2004b}

Gatta L, Perna F, Ricci C, Osborn JF, Tampieri A, Bernabucci V, et al. A rapid immunochromatographic assay for Helicobacter pylori in stool before and after treatment. Alimentary Pharmacology \& Therapeutics 2004;20(4):469-74.

\section{Gatta 2006}

Gatta L, Ricci C, Tampieri A, Osborn J, Perna F, Bernabucci V, et al. Accuracy of breath tests using low doses of 13C-urea to diagnose Helicobacter pylori infection: A randomised controlled trial. Gut 2006;55(4):457-62.

\section{Gatta 2010a}

Gatta L, Vaira D, Scarpignato C, Mario P, Cavestro G, Cavallaro L, et al. Diagnostic accuracy of serum pepsinogens and gastrin in the follow-up of Helicobacter pylori infection: A pilot study. Digestive and Liver Disease 2010;42:S112.

\section{Gatta 2010b}

Gatta L, Di Mario F, Vaira D, Rugge M, Scarpignato C, Malfertheiner $P$, et al. Diagnostic accuracy of serum pepsinogens and gastrin to follow-up Helicobacter pylori infection: A pilot study. Gastroenterology 2010;138(5 (suppl 1)):S340.

\section{Gatta 2011}

Gatta L, Di Mario F, Vaira D, Rugge M, Franze A, Plebani M, et al. Quantification of serum levels of pepsinogens and gastrin to assess eradication of Helicobacter pylori. Clinical Gastroenterology \& Hepatology 2011;9(5):440-2.

\section{Geletneky 1996}

Geletneky JV, Meineke I, Ludtke FE, Schauer A, Bauer FE. Longterm investigation using the $13 \mathrm{C}$-urea breath test (13C-UBT) for the noninvasive semiquantitative assessment of the extent of the mucosal lesion. Verdauungskrankheiten 1996;14(4):125-32.

\section{Gemignani 2013}

Gemignani L, Savarino E, Corbo M, Dulbecco P, Giacchino M, Giambruno E, et al. The diagnostic value of narrow-band imaging with magnifying endoscopy in the detection of gastric intestinal metaplasia: A prospective study in an unselected population. Digestive and Liver Disease 2013;45:S206.

\section{Gene 2000}

Gene E, Calvet X, Azagra R. Diagnosis of Helicobacter pylori after triple therapy in uncomplicated duodenal ulcers--a costeffectiveness analysis. Alimentary Pharmacology \& Therapeutics 2000;14(4):433-42.

\section{Gerards 1999}

Gerards C, Leodolter A, Nilius M, Peitz U, Malfertheiner P. Should we rely on serology or c-13-urea breath test (c-13-ubt) for therapy decision in h. Pylori infection?. Gut 1999;45(Suppl 3):A129.

\section{Gerstenecker 1992}

Gerstenecker B, Eschweiler B, Vogele H, Koch HK, Hellerich U, Kist M. Serodiagnosis of Helicobacter pylori infections with an enzyme immunoassay using the chromatographically purified 
120 kilodalton protein. European Journal of Clinical Microbiology \& Infectious Diseases 1992;11(7):595-601.

\section{Ghasemian 2005}

Ghasemian Safaei H, Fazeli A, Tamizifar H, Rashidi N. Comparison of salivary anti Helicobacter pylori IgG with serum IgG and bacteriological tests in detecting Helicobacter pylori infections. Journal of Research in Medical Sciences 2005;10(1):1-5

\section{Ghosh 2014}

Ghosh R, Uppal B, Aggarwal P, Chakravarti A, Jha AK, Dubey AP. A comparative study of conventional and molecular techniques in diagnosis of campylobacter gastroenteritis in children. Annals of Clinical and Laboratory Science 2014;44(1):42-8.

\section{Ghoshal 2010}

Ghoshal UC, Kumar S, Krishnani N, Chourasia D, Tripathi S. Evaluation of utility of pepsinogen (pg)-i, pg-ii and gastrin-17 serum levels in diagnosis of cancer-associated gastric mucosal lesions like intestinal metaplasia in patients with h. Pylori infection in india. Indian Journal of Gastroenterology 2010;29(1 Suppl):A25-A6.

\section{Gilger 2002}

Gilger MA, Tolia V, Johnson A, Rabinowitz S, Jibaly R, Elitsur Y, et al. The use of an oral fluid immunoglobulin g ELISA for the detection of Helicobacter pylori infection in children. Helicobacter 2002;7(2):105-10.

\section{Gill 2007}

Gill P, Amini M, Ghaemi A, Shokouhizadeh L, Abdul-Tehrani H, Karami A, et al. Detection of Helicobacter pylori by enzymelinked immunosorbent assay of thermophilic helicasedependent isothermal DNA amplification. Diagnostic Microbiology \& Infectious Disease 2007;59(3):243-9.

\section{Girdalidze 2013}

Girdalidze AM, Elisabedashvili GV, Sharvadze LG, Dzhorbenadze TA. Comparative diagnostic value of Helicobacter pylori infection testing methods. Georgian Medical News 2013;225:53-60.

\section{Gisbert 1996}

Gisbert JP, Boixeda D, Redondo C, Alvarez Baleriola I, Jimenez I, Perez Garcia JI, et al. Breath test in the diagnosis of Helicobacter pylori infection: concordance with histological methods and correlation with anatomopathological lesions of the gastric mucosa. Revista Espanola de Enfermedades Digestivas 1996;88(4):259-64.

\section{Gisbert 1997}

Gisbert JP, Boixeda D, deArgila CM, Barba M, Bermejo F, Plaza AG, et al. Long-term follow-up after h-pylori eradication: Reinfection incidence and evolution of urea breath test. Gut 1997;41(suppl):A78.

\section{Gisbert 1999a}

Gisbert JP, Vazquez MA, Jimenez I, Carpio D, Cruzado AI, Del Castillo E, et al. C-13-urea breath test for the diagnosis of h-pylori infection: Is citric acid necessary?. Gut 1999;45(Suppl 3):A129.

\section{Gisbert 1999b}

Gisbert JP, Vazquez MA, Jimenez I, Del Castillo E, Martin MJ, Morales A, et al. C-13-urea breath test for the diagnosis of $h$ pylori infection: Is citric acid necessary?. Gastroenterology 1999;116(4 (suppl)):A171.

\section{Gisbert 1999c}

Gisbert JP, Boixeda D, Al-Mostafa A, Vila T, De Rafael L, Baleriola IA, et al. Basal and stimulated gastrin and pepsinogen levels after eradication of Helicobacter pylori: A 1-year followup study. European Journal of Gastroenterology \& Hepatology 1999;11(2):189-200.

\section{Gisbert 2000a}

Gisbert J, Gonzalez L, De Pedro A, Vaibuena M, Prieto B, Llorca I, et al. C-13-urea breath test for the diagnosis of h-pylori infection: Are basal samples necessary?. Gastroenterology 2000;118(4):A1238.

\section{Gisbert 2000b}

Gisbert JP. Diagnosis of Helicobacter pylori infection. Revista Clinica Espanola 2000;200(7):370-2.

\section{Gisbert 2000c}

Gisbert JP, Benito LM, Lara S, Vazquez A, Jimenez I, Pajares JM. C-13-urea breath test for the diagnosis of Helicobacter pylori infection: Are basal samples necessary?. European Journal of Gastroenterology \& Hepatology 2000;12(11):1201-5.

\section{Gisbert 2000d}

Gisbert JP, Blanco M, Benito LM, Pajares JM. Value of quantitative serology for confirmation of Helicobacter pylori eradication: An 18-month follow-up study. Clinical Infectious Diseases 2000;30(6):976-80.

\section{Gisbert 2000e}

Gisbert JP, Cruzado Al, Cabrera MM, Carpio D, Benito LM, Perez Poveda JJ, et al. "Rapid" serology for the diagnosis of Helicobacter pylori infection. Evaluation of its accuracy compared with a gold-standard and its concordance with "classic" serology. Gastroenterologia Y Hepatologia 2000;23(4):159-64.

\section{Gisbert $2000 f$}

Gisbert JP, Vazquez MA, Jimenez I, Cruzado AI, Carpio D, Del Castillo E, et al. 13C-urea breath test for the diagnosis of Helicobacter pylori infection before treatment: Is citric acid necessary?. Digestive \& Liver Disease 2000;32(1):20-4.

\section{Gisbert 2000g}

Gisbert J, Cruzado A, Cabrera M, Carpio D, Benito L, PerezPoveda J, et al. Rapid whole blood test for diagnosing $H$. pylori infection. Validation against a gold standard and study of its concordance with ELISA serology. Gastroenterology 2000;118(4):A1238. 


\section{Gisbert 2001}

Gisbert JP, Pajares JM. Diagnosis of Helicobacter pylori infection by stool antigen determination: A systematic review. American Journal of Gastroenterology 2001;96(10):2829-38.

\section{Gisbert 2002a}

Gisbert JP, Ducons J, Gomollon F, Dominguez-Muñoz E, Borda F, Mino G, et al. Validation of c-13-urea breath test for the initial diagnosis of Helicobacter pylori infection and for the confirmation of its eradication after treatment. Gut 2002;51(Suppl):A109.

\section{Gisbert 2002b}

Gisbert JP, Gomollon F, Dominguez-Muñoz E, Borda F, Jimenez I, Vazquez MA, et al. Isotope ratio mass spectrometry (irms) versus nondispersive infrared spectrometry (ndirs) c-13-urea breath test for the diagnosis of Helicobacter pylori infection. Gut 2002;51(Suppl):A111.

\section{Gisbert 2002C}

Gisbert JP, Vazquez MA, Cantero J, Pajares JM. Study of the validity of <<rapid >> serology in diagnosing Helicobacter pylori infection. Atencion Primaria 2002;30(8):501-6.

\section{Gisbert 2002d}

Gisbert JP, Cabrera Md Mdel M, Pajares JM. Stool antigen test for initial Helicobacter pylori diagnosis and for confirmation of eradication after therapy. Medicina Clinica 2002;118(11):401-4.

\section{Gisbert 2003a}

Gisbert JP, Gomollon F, Dominguez-Muñoz JE, Borda F, Jimenez I, Vazquez MA, et al. Comparison between two 13C-urea breath tests for the diagnosis of Helicobacter pylori infection: Isotope ratio mass spectrometer versus infrared spectrometer. Gastroenterologia Y Hepatologia 2003;26(3):141-6.

\section{Gisbert 2003b}

Gisbert JP, Ducons J, Gomollon F, Dominguez-Muñoz JE, Borda F, Mino G, et al. Validation of the c-13-urea breath test for the initial diagnosis of Helicobacter pylori infection and to confirm eradication after treatment. Revista Espanola De Enfermedades Digestivas 2003;95(2):121-6.

\section{Gisbert 2004a}

Gisbert JP, Pajares JM. Stool antigen test for the diagnosis of Helicobacter pylori infection: A systematic review. Helicobacter 2004;9(4):347-68.

\section{Gisbert 2004b}

Gisbert JP, Khorrami S, Carballo F, Calvet X, Gene E, DominguezMuñoz E. Meta-analysis: Helicobacter pylori eradication therapy vs. antisecretory non-eradication therapy for the prevention of recurrent bleeding from peptic ulcer. Alimentary Pharmacology and Therapeutics 2004;19(6):617-29.

\section{Gisbert 2005}

Gisbert JP, Trapero M, Pajares JM. Evaluation of 3 different tests for the detection of stool antigens to confirm Helicobacter pylori eradication after treatment. A pilot study. Gastroenterologia $Y$ Hepatologia 2005;28(10):615-8.

\section{Gisbert 2006a}

Gisbert JP, Abraira V. Accuracy of Helicobacter pylori diagnostic tests in patients with bleeding peptic ulcer: A systematic review and meta-analysis. American Journal of Gastroenterology 2006;101(4):848-63.

\section{Gisbert 2006b}

Gisbert JP, De la Morena F, Abraira V. Accuracy of monoclonal stool antigen test for the diagnosis of Helicobacter pylori infection: A systematic review and meta-analysis. Helicobacter 2006;11(4):380.

\section{Gisbert 2006c}

Gisbert JP, Esteban C, Jimenez I, Moreno-Otero R, Pajares JM. $\mathrm{C}$-13-urea breath test during hospitalization for the diagnosis of Helicobacter pylori infection in peptic ulcer bleeding. Helicobacter 2006;11(4):382.

\section{Gisbert 2006d}

Gisbert JP, Olivares D, Jimenez I, Pajares JM. Is there any correlation between 13C-urea breath test values and response to first-line and rescue Helicobacter pylori eradication therapies?. Digestive \& Liver Disease 2006;38(4):254-9.

\section{Gisbert 2006e}

Gisbert JP, Olivares D, Jimenez I, Pajares JM. Is there any correlation between c-13-urea breath test values and response to first-line and rescue Helicobacter pylori eradication therapies?. Helicobacter 2006;11(4):380-1.

\section{Gisbert 2006f}

Gisbert JP, Olivares D, Jimenez I, Pajares JM. Long-term follow-up of 13C-urea breath test results after Helicobacter pylori eradication: Frequency and significance of borderline delta13Co2 values. Alimentary Pharmacology \& Therapeutics 2006;23(2):275-80.

\section{Gisbert 2006g}

Gisbert JR, De la Morena F, Abraira V. Accuracy of monoclonal stool antigen test for the diagnosis of h-pylori infection: $A$ systematic review and meta-analysis. American Journal of Gastroenterology 2006;101(8):1921-30.

\section{Gisbert 2006h}

Gisbert JP. Breath test with c-13-urea for h. Pylori infection diagnosis by means of mass spectrometry and infrared spectrophotometry. Salud I Ciencia 2006;15(1):461-3.

\section{Gisbert 2007}

Gisbert JP, Esteban C, Jimenez I, Moreno-Otero R. 13Curea breath test during hospitalization for the diagnosis of Helicobacter pylori infection in peptic ulcer bleeding. Helicobacter 2007;12(3):231-7.

\section{Glassman 1990}

Glassman MS, Dallal S, Berezin SH, Bostwick HE, Newman LJ, Perez-Perez GI, et al. Helicobacter pylori-related gastroduodenal disease in children. Diagnostic utility of enzyme-linked immunosorbent assay. Digestive Diseases \& Sciences 1990;35(8):993-7. 


\section{Glupczynski 1992}

Glupczynski Y, Bourdeaux L, Verhas M, DePrez C, DeVos D, Devreker T. Use of a urea breath test versus invasive methods to determine the prevalence of Helicobacter pylori in Zaire. European Journal of Clinical Microbiology \& Infectious Diseases 1992;11(4):322-7.

\section{Gobert 1988}

Gobert B, Bene MC, Faure G, Dekorwin JD, Conroy MC, Mole C, et al. Detection of antibodies to campylobacter pyloridis by immunoprint and by quantitative ELISA test. Annales De Biologie Clinique 1988;46(7):523.

\section{Gobert 1989}

Gobert B, Bene MC, Faure G, Denis JJ, De Korwin JD, Conroy MC, et al. IgG, IgA and IgM antibodies to campylobacter pylori detected by dot-ELISA and ELISA. Gastroduodenal pathology and Campylobacter pylori: European Campylobacter Pylori Study Group ICS847. 1989:219-22.

\section{Goel 2003}

Goel N, Sherwal BL, Patwari AK, Bajaj P, Choudhury M. Evaluation of invasive and non-invasive diagnostic modalities for Helicobacter pylori infection in children. Indian Pediatrics 2003;40(2):141-6.

\section{Goettner 2012}

Goettner G, Formicella L, Romberg L, Bolz C, Nolting C, Soutschek E, et al. Novel immuno-line system to detect infections with pathogenic h. Pylori. Helicobacter 2012;17:70.

\section{Goh 1995}

Goh KL, Parasakthi N, Peh SC, Ong KK. 14c-urea breath test: A useful non-invasive test in the diagnosis of Helicobacter pylori infection. Medical Journal of Malaysia 1995;50(3):208-11.

\section{Goji 2015}

Goji S, Tamura Y, Sasaki M, Nakamura M, Matsui H, Yamagata Murayama S, et al. Helicobacter suis-infected nodular gastritis and a review of diagnostic sensitivity for Helicobacter heilmannii-like organisms. Case Reports in Gastroenterology 2015;9:179-87.

\section{Gold 2000}

Gold BD, Colletti RB, Abbott M, Czinn SJ, Elitsur Y, Hassall E, et al. Helicobacter pylori infection in children: Recommendations for diagnosis and treatment. Journal of Pediatric Gastroenterology and Nutrition 2000;31(5):490-7.

\section{Gold 2014}

Gold BD, Elfant AB. Helicobacter pylori detection and eradication in pediatric and adult patients. Gastroenterology and Hepatology 2014;10(7):447-50.

\section{Gomes 2002}

Gomes AT, Coelho LK, Secaf M, Modena JL, Troncon LE, Oliveira RB. Accuracy of the 14c-urea breath test for the diagnosis of Helicobacter pylori. Sao Paulo Medical Journal [Revista Paulista de Medicina] 2002;120(3):68-71.

\section{Gomes 2005}

Gomes CAR Jr, Catapani WR, Mader AMAA, Locatelli A, Silva CBP, Waisberg J. Antral exfoliative cytology for the detection of Helicobacter pylori in the stomach. World Journal of Gastroenterology 2005;11(18):2784-8.

\section{Gomez 2000}

Gomez MR, Vargas J, Grande L, Otero MA, Bernal S, Fernandez MC. Usefulness of Helicobacter pylori antigens detection in stools for infection diagnosis and confirming eradication. Medicina Clinica 2000;114(15):571-3.

\section{Gomez 2011}

Gomez PP, Rodriguez CG, Meleiro JI, Rodriguez MM, Sanchez FM. Helicobacter pylori infection in children diagnosed via the urea breath test. Helicobacter 2011;16:111.

\section{Gomez-Camarasa 2014}

Gomez-Camarasa C, Gutierrez-Fernandez J, RodriguezGranger JM, Sampedro-Martinez A, Sorlozano-Puerto A, Navarro-Mari JM. Evaluation of the rapid ridaquick campylobacter test in a general hospital. Diagnostic Microbiology and Infectious Disease 2014;78(2):101-4.

\section{Gomollon 2003}

Gomollon F, Ducons JA, Santolaria S, Omiste IL, Guirao R, Ferrero A, et al. Breath test is very reliable for diagnosis of Helicobacter pylori infection in real clinical practice. Digestive and Liver Disease 2003;35(9):612-8.

\section{Gong 2010}

Gong YH, Sun LP, Jin SG, Yuan Y. Comparative study of serology and histology based detection of Helicobacter pylori infections: A large population-based study of 7,241 subjects from China. European Journal of Clinical Microbiology \& Infectious Diseases 2010;29(7):907-11.

\section{Gong 2014}

Gong YH, Wei W, Yuan Y. Association between abnormal gastric function risk and Helicobacter pylori infection assessed by ELISA and C-14-urea breath test. Diagnostic Microbiology and Infectious Disease 2014;80(4):316-20.

\section{Gonzalez 2003}

Gonzalez P, Galleguillos C, Massardo T, Rivera M, Morales A, Smok G, et al. Could the [14c] urea breath test be proposed as a 'gold standard' for detection of Helicobacter pylori infection?. Medical Science Monitor 2003;9(8):CR363-8.

\section{Gonzalez 2004}

Gonzalez P. 14c-urea breath test as a 'gold standard' for detection of Helicobacter pylori infection - in reply. Medical Science Monitor 2004;10(9):LE17-LE8.

\section{Gonzalez 2007}

Gonzalez FCG, Serrano C, Harris PR. Diagnosis of Helicobacter pylori infection in children based on stool antigen test. Revista Medica De Chile 2007;135(2):182-8. 


\section{Gonzalez 2012}

Gonzalez CA, Megraud F, Buissonniere A, Lujan Barroso L, Agudo A, Duell EJ, et al. Helicobacter pylori infection assessed by ELISA and by immunoblot and noncardia gastric cancer risk in a prospective study: The eurgast-epic project. Annals of Oncology 2012;23(5):1320-4.

\section{Gonzalez 2013}

Gonzalez L, Marrero K, Reyes O, Rodriguez E, Martinez L, Rodriguez BL. Cloning and expression of a recombinant caga -gene fragment of Helicobacter pylori and its preliminary evaluation in serodiagnosis. Biomedica 2013;33(4):546-53.

\section{Gonzalez-Cuevas 2001}

Gonzalez-Cuevas A, Juncosa T, Jene M, Varea V, Gene A, Muñoz C, et al. Helicobacter pylori infections: Antigen detection in stool samples. Enfermedades Infecciosas Y Microbiologia Clinica 2001;19(2):49-52.

\section{Good 1991}

Good DJ, Dill S, Mossi S, Frey R, Beglinger C, Stalder GA, et al. Sensitivity and specificity of a simplified, standardized 13Curea breath test for the demonstration of Helicobacter pylori. Schweizerische Medizinische Wochenschrift Journal Suisse de Medecine 1991;121(20):764-6.

\section{Goodwin 1987}

Goodwin CS, Blincow E, Peterson G. Enzyme-linked immunosorbent assay for campylobacter pyloridis: Correlation with presence of $c$. Pyloridis in the gastric mucosa. Journal of Infectious Diseases 1987;155(3):488-94.

\section{Gosciniak 1993}

Gosciniak G, Matysiak-Budnik T, Przondo-Mordarska A. Evaluation of three serological tests for the detection of Helicobacter pylori associated infection. Archivum Immunologiae et Therapiae Experimentalis 1993;41(5-6):315-9.

\section{Gosciniak 1996}

Gosciniak G, Poniewierka E, Iwanczak B, Grzeszek T. Iga antibodies against Helicobacter pylori in serum and saliva of patients with upper gastrointestinal tract diseases. Gastroenterologia Polska 1996;3(2):119-24.

\section{Gosciniak 2000}

Gosciniak G, Przondo-Mordarska A, Iwanczak B, Poniewierka E. Neutralisation of vacuolating activity of cytotoxin by serum antibodies of Helicobacter pylori infected patients. Acta Microbiologica Polonica 2000;49(2):113-20.

\section{Gosciniak 2002}

Gosciniak G, Przondo-Mordarska A, Iwanczak B, Blitek A. Detection of Helicobacter pylori antigen in stool specimens taken from children with chronic gastritis. Polski Merkuriusz Lekarski 2002;12(68):104-7.

\section{Gosciniak 2003}

Gosciniak G, Przondo-Mordarska A, Iwanczak B, Blitek A. Helicobacter pylori antigens in stool specimens of gastritis children before and after treatment. Journal of Pediatric Gastroenterology \& Nutrition 2003;36(3):376-80.

\section{Goto 1995}

Goto Y, Ogihara Y, Taniguchi Y, Satoh K, Kimura K, Takatori K, et al. Simple rapid and inexpensive diagnosis of Helicobacterpylori infection in c-13-urea breath test - ir spectrometric analysis. Gastroenterology 1995;108(4 (suppl)):A103.

\section{Goto 1998}

Goto A, Fujimori K, Kaneko T, Akamatsu T. Diagnosis of Helicobacter infections by serodiagnosis, analysis of serum pepsinogen, and urea breath tests. Nihon Naika Gakkai Zasshi [Journal of the Japanese Society of Internal Medicine] 1998;87(5):863-7.

\section{Gotoh 1997}

Gotoh T, Nishizono A, Mifune K, Fujioka T, Nasu M, Azumi J. Validity of the new ELISA system of serodiagnosis for eradication of Helicobacter pylori infection. Gastroenterology 1997;112(4 (suppl)):A131.

\section{Gottrand 2001}

Gottrand F. Diagnostic tests and treatment of helicopter pylori gastritis in children. Archives De Pediatrie 2001;8:396S-8S.

\section{Graham 1986}

Graham DY, Klein PD, Evans DG, Opekun AR, Evans DG, Alpert LC, et al. Rapid noninvasive diagnosis of gastric campylobacter by a c-13 urea breath test. Gastroenterology 1986;90(5):1435.

\section{Graham 1987}

Graham DY, Evans DJ, Alpert LC, Klein PD, Evans DG, Opekun AR, et al. Campylobacter-pylori detected noninvasively by the $\mathrm{c}-13$ urea breath test. Lancet 1987;1(8543):1174-7.

\section{Graham 1991}

Graham DY, Malaty HM, Evans DG, Evans DJ Jr, Klein PD, Adam E. Epidemiology of Helicobacter pylori in an asymptomatic population in the United States. Effect of age, race, and socioeconomic status. Gastroenterology 1991;100(6):1495-501.

\section{Graham 1996b}

Graham DY, Malaty HM, ElZimaity HM, Genta RM, Yousfi MM, Klein PD. 20 minute fasting version of the us c-13-urea breath test for the diagnosis of h-pylori infection. Gastroenterology 1996;110(4 (suppl)):A122.

\section{Graham 2000}

Graham DY, Klein PD. Accurate diagnosis of Helicobacter pylori c-13-urea breath test. Gastroenterology Clinics of North America 2000;29(4):885.

\section{Graham 2001a}

Graham DY, Malaty HM, Cole RA, Martin RF, Klein PD. Simplified 13C-urea breath test for detection of Helicobacter pylori infection. American Journal of Gastroenterology 2001;96(6):1741-5.

\section{Graham 2001b}

Graham DY, Reddy S. Rapid detection of anti-Helicobacter pylori igg in urine using immunochromatography. Alimentary Pharmacology \& Therapeutics 2001;15(5):699-702. 


\section{Graham 2001c}

Graham DY. An alternate explanation of the effect of citric acid on proton pump inhibitor-associated false negative urea breath tests. American Journal of Gastroenterology 2001;96(10):3037-9.

\section{Graham 2010}

Graham DY. Monoclonal stool antigen testing for diagnosing Helicobacter pylori in young children: Revisited. Journal of Pediatric Gastroenterology and Nutrition 2010;51(3):373.

\section{Granberg 1993}

Granberg C, Mansikka A, Lehtonen OP, Kujari H, Gronfors R, Nurmi $\mathrm{H}$, et al. Diagnosis of Helicobacter pylori infection by using Pyloriset EIA-G and EIA-A for detection of serum immunoglobulin $\mathrm{G}$ (IgG) and IgA antibodies. Journal of Clinical Microbiology 1993;31(6):1450-3.

\section{Grino 2001}

Grino P, Pascual S, Such J, Casellas JA, Niveiro M, Andreu M, et al. Comparison of diagnostic methods for Helicobacter pylori infection in patients with upper gastrointestinal bleeding. Scandinavian Journal of Gastroenterology 2001;36(12):1254-8.

\section{Grino 2003}

Grino P, Pascual S, Such J, Casellas JA, Niveiro M, Andreu M, et al. Comparison of stool immunoassay with standard methods for detection of Helicobacter pylori infection in patients with upper-gastrointestinal bleeding of peptic origin. European Journal of Gastroenterology \& Hepatology 2003;15(5):525-9.

\section{Grossi 2000}

Grossi C, Mombelli B, Capurso G, Martino G, Gismondo M, Lahner E, et al. Low sensitivity of c-13-urea breath test (ubt) in the diagnosis of $h$-pylori infection in atrophic body gastritis patients (abg). Gut 2000;47(Suppl 1):A117.

\section{Grossi 2012}

Grossi L, Di Tullio AM, Pagliaro M, Tavani R, Cocciolillo S, Ciccaglione AF, et al. Relationship between Helicobacter pylori infection and gerd symptoms. Digestive and Liver Disease 2012;44:S152.

\section{Grotowski 1998}

Grotowski M, Winnicki L, Trawinski J, Gancarz A, Domaniecki J. Prevalence of Helicobacter pylori infection after surgery of gastric or duodenal peptic ulcer. Gastroenterologia Polska 1998;5(6):525-30.

\section{Groves 1997}

Groves FD, Zhang L, Li JY, You WC, Chang YS, Zhao L, et al. Comparison of two enzyme-linked immunosorbent assay tests for diagnosis of Helicobacter pylori infection in China. Cancer Epidemiology, Biomarkers \& Prevention 1997;6(7):551-2.

\section{Groves 2002}

Groves FD, Perez-Perez G, Zhang L, You WC, Lipsitz SR, Gail MH, et al. Serum antibodies to Helicobacter pylori and the caga antigen do not explain differences in the prevalence of precancerous gastric lesions in two Chinese populations with contrasting gastric cancer rates. Cancer Epidemiology Biomarkers and Prevention 2002;11(10 I):1091-4.

\section{Guducuoglu 2010}

Guducuoglu H, Berktas M, Bozkurt H, Toka Ozer T, Bulut G, Ozturk $\mathrm{O}$, et al. Evaluation of western blot method for the detection of antibodies to Helicobacter pylori antigens in patients with gastric carcinoma and cases with epigastric complaints. Mikrobiyoloji Bulteni 2010;44(1):21-8.

\section{Guell 2006}

Guell M, Artigau E, Esteve V, Sanchez-Delgado J, Junquera F, Calvet $X$. Usefulness of a delayed test for the diagnosis of Helicobacter pylori infection in bleeding peptic ulcer. Alimentary Pharmacology \& Therapeutics 2006;23(1):53-9.

\section{Guja 1999}

Guja M, Lombardo L, Andrini L, Della Monica P, Vicari S, Sallio F, et al. Is Helicobacter pylori stool antigen assay comparable to urea breath test in the diagnosis of h-pylori infection?. Gastroenterology 1999;116(4 (suppl)):A178.

\section{Gulcan 2005}

Gulcan EM, Varol A, Kutlu T, Cullu F, Erkan T, Adal E, et al. Helicobacter pylori stool antigen test. Indian Journal of Pediatrics 2005;72(8):675-8.

\section{Gunay 2009}

Gunay EC, Yengel E, Ucblek E, Altintas E, Sezgin O. C-14 urea breath test values do not correlate with the degree of colonization by Helicobacter pylori in adults. European Journal of Nuclear Medicine and Molecular Imaging 2009;36:S442.

\section{Guo 2005}

Guo YY, Zhang ST, Peng XX, Zhan SY. A systematic review of diagnosis of Helicobacter pylori infection by Helicobacter pylori stool antigen test.. National Medical Journal of China 2005;85(22):1564-7.

\section{Gupta 2003}

Gupta P, Pandey LB, Behra RN, Rai MK, Chandra R. Role of ELISA in $\mathrm{H}$. pylori detection and its correlation with urease test. Indian Journal of Pathology \& Microbiology 2003;46(3):511-4.

\section{Gurbuz 2009}

Gurbuz ED, Soyturk M, Yilmaz O, Bekmen N, Guvenir M, Ellidokuz $\mathrm{H}$, et al. The importance of stool antigen test for the diagnosis of Helicobacter pylori infection and eradication follow-up. Clinical Microbiology and Infection 2009;15:S316.

\section{Guslandi 2000}

Guslandi M. Stool immunoassay for Helicobacter pylori is not specific enough. BMJ 2000;320(7248):1541.

\section{Gutierrez 1999}

Gutierrez A, Celdran MT, Bonilla F, Vazquez N, Royo G, Sillero C. Use of Helicobacter pylori (hp) antigen test in stool samples to detect hp infection. Gastroenterologia y Hepatologia 1999;22(10):533.

\section{Gutierrez 2005}

Gutierrez S, Chacon-Petrola M, Flores M, Pinto A, Pacheco M. Evaluation of infection by Helicobacter pylori in hiv 
positive patients trough enzyme immunoassay and specific amplification of DNA. Investigacion Clinica 2005;46(1):43-52.

\section{Guven 2011}

Guven MA, Ertas IE, Coskun A, Ciragil P. Serologic and stool antigen assay of Helicobacter pylori infection in hyperemesis gravidarum: Which test is useful during early pregnancy?. Taiwanese Journal of Obstetrics \& Gynecology 2011;50(1):37-41.

\section{Hackelsberger 1998}

Hackelsberger A, Schultze V, Peitz U, Gunther T, Nilius M, Diete $U$, et al. Performance of a rapid whole blood test for Helicobacter pylori in primary care: A German multicenter study. Helicobacter 1998;3(3):179-83.

\section{Haggerty 2005}

Haggerty TD, Perry S, Sanchez L, Perez-Perez G, Parsonnet J. Significance of transiently positive enzyme-linked immunosorbent assay results in detection of Helicobacter pylori in stool samples from children. Journal of Clinical Microbiology 2005;43(5):2220-3.

\section{Hahn 2000}

Hahn M, Fennerty MB, Corless CL, Magaret N, Lieberman DA, Faigel DO. Noninvasive tests as a substitute for histology in the diagnosis of Helicobacter pylori infection. Gastrointestinal Endoscopy 2000;52(1):20-6.

\section{Hamlet 1995}

Hamlet AK, Erlandsson KIM, Olbe L, Svennerholm AM, Backman VEM, Pettersson AB. A simple, rapid, and highly reliable capsule-based ${ }^{14} \mathrm{C}$ urea breath test for diagnosis of Helicobacter pylori infection. Scandinavian Journal of Gastroenterology 1995;30(11):1058-63.

\section{Hamlet 1999}

Hamlet A, Stage L, Lonroth H, Cahlin C, Nystrom C, Pettersson A. A novel tablet-based c-13 urea breath test for Helicobacter pylori with enhanced performance during acid suppression therapy. Scandinavian Journal of Gastroenterology 1999;34(4):367-74.

\section{Han 2006}

Han FC, Li XJ, Jiang H, Qin LP, Li D, Guo YH, et al. Detection of h. Pylori antibody profile in serum by protein array. World Journal of Gastroenterology 2006;12(25):4044-8.

\section{Hanvivatvong 2004}

Hanvivatvong $\mathrm{O}$, Pongpanich A, Thong-Ngam D, Thammacharoenrach N, Kullavanijaya P. Evaluation of commercial immunoassays for detection of antibody against Helicobacter pylori in thai dyspeptic patients. Clinical and Diagnostic Laboratory Immunology 2004;11(3):618-20.

\section{Hanvivatvong 2006}

Hanvivatvong O, Thong-Ngam D, Kuakarn S, Mahachai V. Evaluation of Helicobacter pylori stool antigen test in Thai patients with upper gastrointestinal bleeding. Journal of the Medical Association of Thailand 2006;89 Suppl 3:S98-103.

\section{Harde 2008}

Harde H, Dressler M, Helmrich G, Wolff M, Groninga H. New optical analyzer for c-13-breath test. Biophotonics: photonic solutions for better health care. Progress in biomedical optics and imaging; 2008 April 8-10; Strasbourg. Bellingham (DC): SPIE, 2008; Vol. 6691:69910T. [DOI: 10.1117/12.781271; 69910T]

\section{Harde 2010}

Harde H, Helmrich G, Wolff M. Optoacoustic c-13-breath test analyzer. Photons plus ultrasound: imaging and sensing 2010. International Society for Optical Engineering; 2010 Jan 24-26; San Francisco (CA). Bellingham (WA): SPIE, 2010; Vol. 7564:75641E. [DOI: 10.1117/12.841660]

\section{Harries 1992}

Harries AD, Stewart M, Deegan KM, Mughogho GK, Wirima JJ, Hommel M, et al. Helicobacter pyrlori in Malawi, central africa. Journal of Infection 1992;24(3):269-76.

\section{Harris 1995}

Harris AW. Helicobacter pylori testing at home. European Journal of Gastroenterology \& Hepatology 1995;7(7):595-6.

\section{Harris 1998}

Harris AW. Helicobacter pylori and urea breath testing. Can the breath test result predict the outcome of treatment?. Italian Journal of Gastroenterology \& Hepatology 1998;30(2):151-2.

\section{Harrison 1998}

Harrison JR, Bevan J, Furth EE, Metz DC. Accustat whole blood fingerstick test for Helicobacter pylori infection - a reliable screening method. Journal of Clinical Gastroenterology 1998;27(1):50-3.

\section{Hart 1999}

Hart GC, Avison MP. 13C-urea versus 14c-urea breath test: Is there still a need for 14c-urea?. Nuclear Medicine Communications 1999;20(5):495-6.

\section{Hartman 1992}

Hartman NG, Jay M, Hill DB, Bera RK, Nickl NJ, Ryo UY. Noninvasive detection of Helicobacter pylori colonization in stomach using ${ }^{11} \mathrm{C}$-urea. Digestive Diseases and Sciences 1992;37(4):618-21.

\section{Hartmann 2003}

Hartmann D, Schilling D, Riemann JF. New nondispersive infrared spectrometry in c-13-urea breath tests. Deutsche Medizinische Wochenschrift 2003;128(31-32):1645-8.

\section{Hashemi 2008}

Hashemi MR, Rahnavardi M, Bikdeli B, Zahedani MD, Iranmanesh F. Touch cytology in diagnosing Helicobacter pylori: Comparison of four staining methods. Cytopathology 2008;19(3):179-84

\section{Hassan 2013}

Hassan K, Haq M. To study the frequency of $h$ pylori in patients presenting with functional dyspepsia using stool antigen test and its comparison with serology. Journal of Gastroenterology and Hepatology 2013;28:547. 


\section{Hauser 2006}

Hauser B, Wybo I, Tshibuabua G, Pierard D, Vandenplas Y. Multiple-step polyclonal versus one-step monoclonal enzyme immunoassay in the detection of Helicobacter pylori antigen in the stools of children. Acta Paediatrica 2006;95(3):297-301.

\section{Havlasova 1998}

Havlasova J, Bures J, Rejchrt S, Voxova B, Krejsek J. Helicobacter pylori caga antigen antibodies. Casopis Lekaru Ceskych 1998;137(13):404-9.

\section{Hawthorne 1999}

Hawthorne Barney A, Morgan S, Westmoreland D, Stenson R, Thomas GAO, Newcombe RG. A comparison of two rapid whole-blood tests and laboratory serology, in the diagnosis of Helicobacter pylori infection. European Journal of Gastroenterology \& Hepatology 1999;11(8):863-5.

\section{Hawtin 1999}

Hawtin PR. Serology and urea breath test in the diagnosis of hpylori infection. Molecular Biotechnology 1999;11(1):85-92.

\section{Hayashi 2003}

Hayashi T, Karasawa T, Nagase H, Kinami S, Fujimura T, Miwa K, et al. Timing of sampling in endoscopic ${ }^{13} \mathrm{C}$-urea breath test for H. pylori infection. Japanese Pharmacology and Therapeutics 2003;31(8):667-70.

\section{He 1997}

He YN, Chen HY, Zheng JJ, Zhang GY, Chen ZL. Differential pulse voltammetric enzyme-linked immunoassay for the determination of Helicobacter pylori specific immunoglobulin $g$ (igg) antibody. Talanta 1997;44(5):823-30.

\section{Heaney 1998}

Heaney A, Collins JS, Watson RG, McFarland RJ, Bamford KB. Rapid serological diagnosis of Helicobacter pylori: A need for caution and re-evaluation. Irish Journal of Medical Science 1998;167(3):152-4.

\section{Heanhean 2013}

Heanhean $\mathrm{Ng}$ T, Rosaida R. Evaluation of serology and urea breath test as reliable diagnostic test for h.Pylori infection. Journal of Gastroenterology and Hepatology 2013;28:97.

\section{Heenan 1989}

Heenan A. Breath tester. Nursing Times 1989;85(36):23.

\section{Hegedus 2001a}

Hegedus O, Rehnberg AS, Bengtsson C, Befrits R, Granstrom M, Hellstrom PM. Refinement and development of a "dry" novel 14c-urea breath test (heliprobe (tm)) for detection of Helicobacter pylori. Gastroenterology 2001;120(5 (suppl)):A653.

\section{Hegedus 2001b}

Hegedus O, Mjornell U, Prior C, Ryden J, Hellstrom PM. Rapid urea breath test (heliprobe) for detection of Helicobacter pylori by use of encapsulated acidified solid c-14-urea: Validation of test accuracy. Gut 2001;49(Suppl):A101.

\section{Hegedus 2002}

Hegedus O, Ryden J, Rehnberg AS, Nilsson S, Hellstrom PM. Validated accuracy of a novel urea breath test for rapid Helicobacter pylori detection and in-office analysis. European Journal of Gastroenterology \& Hepatology 2002;14(5):513-20.

\section{Helvaci 1993}

Helvaci S, Akdis C, Gulten M, Yerci O. Evaluation of the ELISA method for the diagnosis of Helicobacter pylori. Mikrobiyoloji Bulteni 1993;27(4):294-8.

\section{Henze 1988}

Henze $\mathrm{E}$, Malfertheiner $\mathrm{P}$, Burkhardt $\mathrm{H}$, Clausen M, Adam WE. The $\mathrm{c}-14$ urea breath test for detecting colonization of campylobacter pylori invivo. European Journal of Nuclear Medicine 1988;14(5-6):245.

\section{Henze 1989}

Henze E, Malfertheiner P, Clausen M, Lietzenmaier R, Burkhardt $\mathrm{H}$, Adam WE. Diagnostic accuracy of a ${ }^{14} \mathrm{C}$-urea breath test for detecting campylobacter pylori infection. Gastroduodenal pathology and Campylobacter pylori: European Campylobacter Pylori Study Group ICS847. 1989:85-8.

\section{Henze 1990}

Henze E, Malfertheiner P, Clausen M, Burkhardt H, Adam WE. Validation of a simplified carbon-14-urea breath test for routine use for detecting Helicobacter [correction of heliobacter] pylori noninvasively. Journal of Nuclear Medicine 1990;31(12):1940-4.

\section{Herbrink 1988}

Herbrink P, Vandenmunckhof HAM, Bumkens M, Lindeman J, Vandijk WC. Human-serum antibody-response in campylobacter-jejuni enteritis as measured by enzymelinked immunosorbent-assay. European Journal of Clinical Microbiology \& Infectious Diseases 1988;7(3):388-93.

\section{Herold 2002}

Herold R, Becker M. 13C-urea breath test threshold calculation and evaluation for the detection of Helicobacter pylori infection in children. BMC Gastroenterology 2002;2:12.

\section{Hidaka 2010}

Hidaka N, Nakayama Y, Horiuchi A, Kato S, Sano K. Endoscopic identification of Helicobacter pylori gastritis in children. Digestive Endoscopy 2010;22(2):90-4.

\section{Higazy 2000}

Higazy E, Al-Saeedi F, Loutfi I, Heiba S, Kalaoui M, Al-Nakib B, et al. The impact of brushing teeth on carbon-14 urea breath test results. Journal of Nuclear Medicine Technology 2000;28(3):162-4

\section{Hildebrand 1997}

Hildebrand P, Beglinger C. Nondispersive infrared spectrometry: A new method for the detection of Helicobacter pylori infection with the c-13-urea breath test. Clinical Infectious Diseases 1997;25(5):1003-5. 


\section{Hilker 1994}

Hilker E, Stoll R, Domschke W. Quantitative assessment of Helicobacter-pylori (hp) colonization of the gastric-mucosa by c-13-urea breath test. Gastroenterology 1994;106(4 (suppl)):A93.

\section{Hilker 1996}

Hilker E, Domschke W, Stoll R. C-13-urea breath test for detection of Helicobacter pylori and its correlation with endoscopic and histologic findings. Journal of Physiology and Pharmacology 1996;47(1):79-90.

\section{Hino 2004}

Hino B, Eliakim T, Levine A, Sprecher H, Berkowitz D, Hartman $\mathrm{C}$, et al. Comparison of invasive and non-invasive tests diagnosis and monitoring of Helicobacter pylori infection in children. Journal of Pediatric Gastroenterology and Nutrition 2004;39(5):519-23.

\section{Hirschl 1990}

Hirschl AM, Rathbone BJ, Wyatt JI, Berger J, Rotter ML. Comparison of ELISA antigen preparations alone or in combination for serodiagnosing Helicobacter pylori infections. Journal of Clinical Pathology 1990;43(6):511-3.

\section{Hirschl 1991}

Hirschl AM, Hirschl MM, Berger J, Rotter ML. Evaluation of a commercial latex test for serological diagnosis of Helicobacter pylori infection in treated and untreated patients. European Journal of Clinical Microbiology \& Infectious Diseases 1991;10(11):971-4.

\section{Hirschl 1993}

Hirschl AM, Brandstatter G, Dragosics B, Hentschel E, Kundi M, Rotter ML, et al. Kinetics of specific igg antibodies for monitoring the effect of anti-Helicobacter pylori chemotherapy. Journal of Infectious Diseases 1993;168(3):763-6.

\section{Hirschl 1996}

Hirschl AM, Rotter ML. Serological tests for monitoring Helicobacter pylori eradication treatment. Journal of Gastroenterology 1996;31 Suppl 9:33-6.

\section{Hirschl 2005}

Hirschl AM, Makristathis A. Non-invasive Helicobacter pylori diagnosis: Stool or breath tests?. Digestive \& Liver Disease 2005;37(10):732-4.

\section{Ho 1996}

Ho AS, Young TH, Shyu RY, Yeh C, Tseng HH, Lee SC, et al. The accuracy of the rapid urease test and $13 \mathrm{C}$-urea breath test in the diagnosis of Helicobacter pylori infection. Chung Hua i Hsueh Tsa Chih [Chinese Medical Journal] 1996;58(6):400-6.

\section{Ho 2000}

Ho B, Marshall BJ. Accurate diagnosis of Helicobacter pylori - serologic testing. Gastroenterology Clinics of North America 2000;29(4):853.

\section{Ho 2004}

Ho CY, Chen TS, Chang FY, Lee SD. Rapid urease test from nonulcer part of stomach is superior to histology from ulcer in detection of Helicobacter pylori infection in patients with gastric ulcer. Hepato-Gastroenterology 2004;51(60):1877-80.

\section{Hoang 2006}

Hoang TT, Rehnberg AS, Wheeldon TU, Bengtsson C, Phung DC, Befrits $\mathrm{R}$, et al. Comparison of the performance of serological kits for Helicobacter pylori infection with european and asian study populations. Clinical Microbiology \& Infection 2006;12(11):1112-7.

\section{Hoek 1992}

Hoek FJ, Noach LA, Rauws EAJ, Tytgat GNJ. Evaluation of the performance of commercial test kits for detection of Helicobacter pylori antibodies in serum. Journal of Clinical Microbiology 1992;30(6):1525-8.

\section{Hollenz 1999}

Hollenz M, Stolte M, Labenz J. Helicobacter pylori screening in a general practice. Deutsche Medizinische Wochenschrift 1999;124(7):171-5.

\section{Hong 2008}

Hong WD, Zhu QH, Chen XR. Study on the value of helieobacter pylori (h. Pylori) stool antigen immunocard stat in the diagnosis of h. Pylori infection: A meta-analysis.. Zhonghua Liu Xing Bing Xue Za Zhi 2008;29(1):71-4.

\section{Hooton 2006}

Hooton C, Keohane J, Clair J, Azam M, O'Mahony S, Crosbie O, et al. Comparison of three stool antigen assays with the c-13urea breath test for the primary diagnosis of Helicobacter pylori infection and monitoring treatment outcome. European Journal of Gastroenterology \& Hepatology 2006;18(6):595-9.

\section{Hoshiya 2001}

Hoshiya S, Tokunaga K, Tanaka A, Takahashi S. Serological diagnosis of Helicobacter pylori infection. Nihon Rinsho [Japanese Journal of Clinical Medicine] 2001;59(2):259-64.

\section{Houben 1998}

Houben M, Hensen EF, Stam P, Van't Hoff BWM, Van der Hulst RWM, Van der Ende A, et al. Post-eradication evaluation of h-pylori (hp) status: The c-13 urea laser assisted ratio analyzer (lara) breath test. Gastroenterology 1998;114(4 (suppl)):A153.

\section{Houben 1999}

Houben M, Vaira D, Lam K, Hensen EF, Stam P, Van 't Hoff BWM, et al. Usefulness of the c-13 lara (tm) urea breath test in confirming eradication of Helicobacter pylori (hp). Gastroenterology 1999;116(4 (suppl)):A190.

\section{Hsu 2010}

Hsu PI. Application of serology in the diagnosis of Helicobacter pylori infection in patients with atrophic gastritis. Journal of the Chinese Medical Association 2010;73(11):561-2.

\section{Hu 1995}

Hu P, Cui Y, Chen M. Application of serology and 14c-urea breath test to monitoring of the effect of anti-Helicobacter pylori 
chemotheraphy.. Zhonghua Nei Ke Za Zhi [Chinese journal of internal medicine] 1995;34(12):819-22.

\section{Hu 2000}

Hu F, Cheng H, Li J. Evaluation and comparison of the Helicobacter pylori stool antigen test and the gastric mucosal antigen test.. Zhonghua Yi Xue Za Zhi 2000;80(11):820-2.

\section{Hu 2007}

Hu HM, Kuo CH, Lo YC, Wu MT, Wu IC, Lu CY, et al. Evaluation of the two immunochromatographic methods for detecting urine and serum igg antibodies to Helicobacter pylori and comparison of accuracy and clinical utility. HepatoGastroenterology 2007;54(73):119-23.

\section{Hu 2011}

Hu FL. Performance of current infection marker test for the diagnosis of Helicobacter pylori current infection: A multicenter clinical trial. National Medical Journal of China 2011;91(27):1891-4.

\section{Huang 1993}

Huang CK, Chen GH, Kao CH, Wang SJ, Leu JF, Shir JM, et al. A 10-minute carbon-14 urea breath test for the detection of Helicobacter pylori. Chinese Journal of Gastroenterology 1993;10(3):212-20.

\section{Huang 1996}

Huang MS, Wang WM, Wu DC, Chen LT, Jan CM, Chen CY, et al. Utility of brushing cytology in the diagnosis of Helicobacter pylori infection. Acta Cytologica 1996;40(4):714-8.

\section{Huang 1998}

Huang JQ, Sridhar S, Chen Y, Hunt RH. Meta-analysis of the relationship between Helicobacter pylori seropositivity and gastric cancer. Gastroenterology 1998;114(6):1169-79.

\section{Huang 2000}

Huang JJ, Huang CJ, Ruaan MK, Chen KW, Yen TS, Sheu BS. Diagnostic efficacy of (13)c-urea breath test for Helicobacter pylori infection in hemodialysis patients. American Journal of Kidney Diseases 2000;36(1):124-9.

\section{Huang 2002}

Huang JQ, Sridhar S, Hunt RH. Role of Helicobacter pylori infection and non-steroidal anti-inflammatory drugs in pepticulcer disease: a meta-analysis. Lancet 2002;359(9300):14-22.

\section{Huang 2003}

Huang JQ, Zheng GF, Sumanac K, Irvine EJ, Hunt RH. Metaanalysis of the relationship between cagA seropositivity and gastric cancer. Gastroenterology 2003;125(6):1636-44.

\section{Huelin 1996}

Huelin J, Sanchez-Galdon S, Cardenas A, Ibanez J, Espana P, De la Cruz J, et al. Comparative study of Helisal ${ }^{\mathrm{TM}}$ rapid blood and ELISA, Jatrox and pathologic anatomy in the diagnosis of Helicobacter pylori infection [Spanish]. Revista Espanola de Enfermedades Digestivas 1996;88(12):825-7.

\section{Huijsdens 2004}

Huijsdens XW, Linskens RK, Koppes J, Tang YL, Meuwissen SGM, Vandenbroucke-Grauls CMJE, et al. Detection of Helicobacter species DNA by quantitative PCR in the gastrointestinal tract of healthy individuals and of patients with inflammatory bowel disease. FEMS Immunology and Medical Microbiology 2004;41(1):79-84.

\section{Hung 2002}

Hung CT, Leung WK, Chan FKL, Sung JJY. Comparison of two new rapid serology tests for diagnosis of Helicobacter pylori infection in Chinese patients. Digestive and Liver Disease 2002;34(2):111-5

\section{Hung 2010}

Hung HH, Chen TS, Lin HC. Immunoglobulin g antibody against Helicobacter pylori is an accurate test for atrophic gastritis. Journal of the Chinese Medical Association 2010;73(7):355-9.

\section{Husson 2000}

Husson MO, Rolland C, Gottrand F, Guimber D, Kalach N, Spyckerelle C, et al. Evaluation of a Helicobacter pylori stool antigen test for the diagnosis and follow-up of infections in children. European Journal of Clinical Microbiology \& Infectious Diseases 2000;19(10):787-9.

\section{Hynes 1998}

Hynes SO, Moran AP. Comparison of enzyme-linked immunosorbent assay, immunodot and western blot techniques for detecting lewis antigen expression on Helicobacter pylori clinical isolates. Gut 1998;43(Suppl 2):A20.

\section{Hynes 2000}

Hynes SO, Moran AP. Comparison of three serological methods for detection of lewis antigens on the surface of Helicobacter pylori. FEMS Microbiology Letters 2000;190(1):67-72.

\section{Ibrahim 2012}

Ibrahim NH, Gomaa AA, Abu-Sief MA, Hifnawy TM, Tohamy MAE. The use of different laboratory methods in diagnosis of Helicobacter pylori infection; a comparative study. Life Science Journal-Acta Zhengzhou University Overseas Edition 2012;9(4):249-59.

\section{Ichinose 1998}

Ichinose $\mathrm{Y}$, Kanai E, Yamasawa F, Nishi I, Toyama $\mathrm{K}$ Simultaneous continuous $13 \mathrm{C}, 12 \mathrm{c}$ analysis of expired gas in the $13 \mathrm{C}$ breath test. Respirology 1998;3(1):21-4.

\section{lerardi 2002}

lerardi E, Margiotta M, Monno R, De Francesco V, Minenna MF, Burattini $O$, et al. A new semiquantitative method of quantifying Helicobacter pylori in antigen stools. Journal of Clinical Gastroenterology 2002;35(5):375-8.

\section{lerfone 2003}

lerfone N, Di Fulvio A, Standoli M, Pontone S, Tonda M, Pontone P. Breath test as non-invasive assessment for the initial screening of non-ulcerous dyspepsia. Giornale di Chirurgia 2003;24(10):357-63. 


\section{Ignys 2006}

Ignys I, Klincewicz B, Malewski W, Cichy W. The non-invasive diagnostic test for detection of Helicobacter pylori infection in children - the value of Helicobacter pylori stool antigen test. Pediatria Wspolczesna 2006;8(4):234-6.

\section{lijima 1998}

lijima K, Ohara S, Sekine H, Moriyama S, Kato K, Koike T, et al. Correlation between 13C-urea breath test and gastric histological findings in Helicobacter pylori positive patients. Nippon Shokakibyo Gakkai Zasshi [Japanese Journal of Gastroenterology] 1998;95(1):18-25.

\section{Ilan 1998}

Ilan Y, Israelit YY, Bar Meir S, Yudchack S, Goldin E. A novel method \& device for Helicobacter pylori detection: Continuous, fast c-13-urea breath test. Gastroenterology 1998;114(4):A157.

\section{Ilga 2008}

Ilga U, Ozyurt M, Yildirim S, Ergunay K, Ardic N, Demirturk L, et al. Helicobacter pylori isolation, serology and caga, cage and virb11 detection in patients with non-ulcer dyspepsia from Turkey: Correlation with histopathologic findings. Central European Journal of Medicine 2008;3(1):41-6.

\section{Imperiale 1996}

Imperiale TF, McCullough AJ. C-13 urea breath test for Helicobacter pylori infection. American Journal of Gastroenterology 1996;91(1):175-6.

\section{Imrie 2001}

Imrie C, Rowland M, Bourke B, Drumm B. Limitations to carbon 13-labeled urea breath testing for Helicobacter pylori in infants. Journal of Pediatrics 2001;139(5):734-7.

\section{Inaba 2002}

Inaba T, Mizuno M, Kawai K, Takaguchi K, Yoshida Y, Kita K, et al. Effect of antiulcer agents on the urea breath test - comparison between rebamipide and ecabet sodium. Japanese Journal of Gastroenterology 2002;99(1):27-33.

\section{Iranikhah 2013}

Iranikhah A, Ghadir MR, Sarkeshikian S, Saneian H, Heidari A, Mahvari M. Stool antigen tests for the detection of Helicobacter pylori in children. Iranian Journal of Pediatrics 2013;23(2):138-42.

\section{Ishihara 2000}

Ishihara S, Kaji T, Kawamura A, Rumi MAK, Sato H, Okuyama T, et al. Diagnostic accuracy of a new non-invasive enzyme immunoassay for detecting Helicobacter pylori in stools after eradication therapy. Alimentary Pharmacology and Therapeutics 2000;14(5):611-4.

\section{Ishizuka 1999}

Ishizuka J. Clinical evaluation of Helicobacter pylori stool antigen (HPSA) assay for assessment of diagnosis and eradication. Japanese Journal of Gastroenterology 1999;96(10):1196.

\section{Islami 2008}

Islami F, Kamangar F. Helicobacter pylori and esophageal cancer risk: a meta-analysis. Cancer Prevention Research 2008;1(5):329-38.

\section{Ismail 2016}

Ismail H, Morgan C, Griffiths P, Williams J, Jenkins G. A newly developed nested PCR assay for the detection of Helicobacter pylori in the oral cavity. Journal of Clinical Gastroenterology 2016;50(1):17-22.

\section{Isomoto 2002}

Isomoto H, Inoue K, Shikuwa S, Furusu H, Nishiyama T, Omagari $\mathrm{K}$, et al. Five minute endoscopic urea breath test with $25 \mathrm{mg}$ of c-13-urea in the management of Helicobacter pylori infection. European Journal of Gastroenterology \& Hepatology 2002;14(10):1093-100.

\section{Isomoto 2003}

Isomoto H, Inoue KI, Mizuta Y, Nakazato M, Kanazawa Y, Nishiyama $\mathrm{H}$, et al. Validation of endoscopic ${ }^{13} \mathrm{C}$-urea breath test with nondispersive infrared spectrometric analysis in the management of Helicobacter pylori infection. HepatoGastroenterology 2003;50(50):422-5.

\section{Isomoto 2006}

Isomoto H, Kawazoe K, Inoue K, Kohno S. Usefulness of the immunological rapid urease test for detection of Helicobacter pylori in patients who are reluctant to undergo endoscopic biopsies. Digestive Diseases \& Sciences 2006;51(12):2302-5.

\section{Israeli 2003}

Israeli E, Ilan Y, Meir SB, Buenavida C, Goldin E. A novel 13Curea breath test device for the diagnosis of Helicobacter pylori infection: Continuous online measurements allow for faster test results with high accuracy. Journal of Clinical Gastroenterology 2003;37(2):139-41.

\section{Ito 2002}

Ito M, Haruma K, Kaya S, Kamada T, Kim S, Sasaki A, et al. Role of anti-parietal cell antibody in Helicobacter pylori-associated atrophic gastritis: Evaluation in a country of high prevalence of atrophic gastritis. Scandinavian Journal of Gastroenterology 2002;37(3):287-93.

\section{Ito 2005}

Ito M, Tanaka S, Kim SJ, Tahara K, Kawamura Y, Sumii M, et al. A combination of the Helicobacter pylori stool antigen test and urea breath test is useful for clinical evaluation of eradication therapy: A multicenter study. Journal of Gastroenterology and Hepatology 2005;20(8):1241-5.

\section{Iwanczak 2005}

Iwanczak F, Pytrus T, Iwanczak B, Gosciniak G, WitkowskaVogtt E, Dzierzanowska D, et al. Assessment of selected tests in diagnostics of Helicobacter pylori infections. Polski Merkuriusz Lekarski 2005;19(109):52-6.

\section{Jaakkimainen 1999}

Jaakkimainen RL, Boyle E, Tudiver F. Is Helicobacter pylori associated with non-ulcer dyspepsia and will 
eradication improve symptoms? A meta-analysis. BMJ 1999;319(7216):1040-4.

\section{Jabbari 2009}

Jabbari Moghaddam Y, Rafeey M, Radfar R. Comparative assessment of Helicobacter pylori colonization in children tonsillar tissues. International Journal of Pediatric Otorhinolaryngology 2009;73(9):1199-201.

\section{Jadresin 2000}

Jadresin O, Kolacek S, Percl M, Tambic A, Dasovic I, Grguric J. Detection of Helicobacter pylori antigen in stools - an alternative method of verifying hp infection in children. Paediatria Croatica 2000;44(4):141-4.

\section{Jaff 2011}

Jaff MS. Relation between ABO blood groups and Helicobacter pylori infection in symptomatic patients. Clinical and Experimental Gastroenterology 2011;4(1):221-6.

\section{Jafri 2010}

Jafri W, Yakoob J, Abid S, Siddiqui S, Awan S, Nizami SQ. Helicobacter pylori infection in children: Population-based agespecific prevalence and risk factors in a developing country. Acta Paediatrica 2010;99(2):279-82.

\section{Jaime 2013}

Jaime F, Villagran A, Serrano C, Cerda J, Harris PR. Frequency of Helicobacter pylori infection in 144 school age Chilean children. Revista Medica de Chile 2013;141(10):1249-54.

\section{Jain 1999}

Jain A, Buddhiraja S, Khurana B, Singhal R, Nair D, Arora P, et al. Risk factors for duodenal ulcer in north India. Tropical Gastroenterology 1999;20(1):36-9.

\section{Jalali 1988}

Jalali S, Hollingsworth J, Vanzanten SV, Tytgat K, Goldie J, Bowen B, et al. C-14 urea breath test for the detection of $C$ pylori (cp) infections. Gastroenterology 1988;94(5):A205.

\section{Jane 1999}

Jane Santamaria M, Varea Calderon V, Camacho E. Concordance between breath test and histologic damage in Helicobacter pylori associated infections in infancy. Revista Espanola De Enfermedades Digestivas 1999;91(10):703-10.

\section{Janjetic 2010}

Janjetic MA, Goldman CG, Balcarce NE, Rua EC, Gonzalez AB, Fuda JA, et al. Iron, zinc, and copper nutritional status in children infected with Helicobacter pylori. Journal of Pediatric Gastroenterology \& Nutrition 2010;51(1):85-9.

\section{Janjetic 2011}

Janjetic MA, Goldman CG, Barrado DA, Rua EC, Balcarce N, Mantero $P$, et al. Decreasing trend of Helicobacter pylori infection in children with gastrointestinal symptoms from Buenos Aires, Argentina. Helicobacter 2011;16(4):316-9.

\section{Janjetic 2015}

Janjetic MA, Mantero P, Rua EC, Balcarce N, De Palma GZ, Catalano M, et al. Dietary and anthropometric indicators of nutritional status in relation to Helicobacter pylori infection in a paediatric population. British Journal of Nutrition 2015;113(7):1113-9.

\section{Janssen 2001}

Janssen K. Diagnostic series. Helicobacter pylori infections rapidly recognized. MMW Fortschritte der Medizin 2001;143(13):41-2.

\section{Janulaityte 1998}

Janulaityte D, Kupcinskas L, Pavilonis A, Wadstrom T, Andersen L. Western blot analysis of Helicobacter pylori infection in patients with and without gastric cancer. Gut 1998;43(Suppl 2):A69.

\section{Janus 1991}

Janus G, Hammermeister I, Prignet JM, Saccharin C, Kist M, Koch HK. Helicobacter pylori: A serological study of young soldiers with endoscopic. Microbiologic and histologic study of ten cases with positive serology. Medecine et Maladies Infectieuses 1991;21(5):308-12.

\section{Jarbol 2006}

Jarbol DE, Kragstrup J, Stovring H, Havelund T, Schaffalitzky de Muckadell OB. Proton pump inhibitor or testing for Helicobacter pylori as the first step for patients presenting with dyspepsia? A cluster-randomized trial. American Journal of Gastroenterology 2006;101(6):1200-8.

\section{Jensen 1993}

Jensen AKV, Andersen LP, Wachmann CH. Evaluation of eight commercial kits for Helicobacter pylori IgG antibody detection. APMIS 1993;101(10):795-801.

\section{Ji 1993}

Ji J, Li XM, Jiang GH. Diagnosis of Helicobacter pylori infection by $13 \mathrm{C}$-urea breath test. Zhonghua Nei Ke za Zhi [Chinese Journal of Internal Medicine] 1993;32(3):170-2.

\section{Jiang 2004}

Jiang Z, Huang AL, Tao XH, Wang PL. Diagnosis of Helicobacter pylori infection and diseases associated with Helicobacter pylori by Helicobacter pylori outer membrane proteins. World Journal of Gastroenterology 2004;10(23):3464-9.

\section{Jo 2008}

Jo Y, Chung M, Lim C, Son B, Jun D, Kim S, et al. Urea breath test is the most reliable $h$. Pylori diagnostic test in patients with upper gastrointestinal bleeding in high h. Pylori prevalent population. Helicobacter 2008;13(5):451.

\section{Jo 2014}

Jo Y, Lee J, Kim J, Kim T. Urea breath test and serological test have equivalent accuracy to detect Helicobacter pylori in patients with gastroduodenal ulcer bleeding. Helicobacter 2014;19:124. 


\section{Johansen 2004}

Johansen JK, Sehested A, Myrhoj T, Ladefoged K, Krogfelt KA. Helicobacter pylori infection in Greenlandic patients with dyspepsia. International Journal of Circumpolar Health 2004;63 Suppl 2:219-20.

\section{Johnston 1998}

Johnston BJ, Gruer N, Johnson P. Effect of patient position on the performance of the c-13-urea breath test for the detection of Helicobacter pylori. Gut 1998;43(Suppl 2):A57.

\section{Jolley 2007}

Jolley CD, Wagner DA. Comparison of the c-13-urea blood test to histology and rapid urease testing in the diagnosis of Helicobacter pylori infection in children. Journal of Pediatric Gastroenterology and Nutrition 2007;44(1):68-70.

\section{Jonaitis 2007}

Jonaitis LV, Kiudelis G, Kupcinskas L. Evaluation of a novel c-14urea breath test "heliprobe" in diagnosis of Helicobacter pylori infection. Medicina-Lithuania 2007;43(1):32-5.

\section{Jones 1997a}

Jones R, Phillips I, Felix G, Tait C. An evaluation of near-patient testing for Helicobacter pylori in general practice. Alimentary Pharmacology \& Therapeutics 1997;11(1):101-5.

\section{Jones 1997b}

Jones NL, Bourke B, Sherman PM. Breath testing for Helicobacter pylori infection in children: A breath of fresh air?. Journal of Pediatrics 1997;131(6):791-3.

\section{Jones 2007}

Jones RT, Darboe MK, Doherty CP, MacKay WG, Weaver LT, Campbell DI, et al. Evaluation of c-13-urea breath test and fecal antigen immunoassay to detect Helicobacter pylori infection in Gambian infants. Journal of Pediatric Gastroenterology and Nutrition 2007;44(5):650-2.

\section{Juhasz 2000}

Juhasz M, Pronai L, Zagoni T, Nemeth A, Herszenyi L, Schandl L, et al. Comparison of various methods in the detection of Helicobacter pylori infection. Orvosi Hetilap 2000;141(17):911-4.

\section{Juncal 1998}

Juncal AR, Garea MT, Cid A, Penalver MD, Vazquez R, Montero E, et al. Evaluation of four commercial enzyme immunoassays for the serologic diagnosis of infection by Helicobacter pylori. Enfermedades Infecciosas y Microbiologia Clinica 1998;16(4):185-9.

\section{Jung 2002}

Jung A, Wasilewska-Radwanska M, Kopanski Z. Semiempirical model for diagnostication Helicobacter pylori infection by use of c-14 labelled urea. Nukleonika 2002;47(3):95-9.

\section{Jung 2013}

Jung H, Moon J, Park K, Kwon M, Jeong S, Park Y, et al. Detection rates of clarithromycin resistance and eradication rates of Helicobacter pylori infection: efficacy of Panplex ${ }^{\mathrm{TM}} \mathrm{Clar}-\mathrm{H}$. pylori detection. Helicobacter 2013;18:132.

\section{Kabir 2001}

Kabir S. Detection of Helicobacter pylori in faeces by culture, PCR and enzyme immunoassay. Journal of Medical Microbiology 2001;50(12):1021-9.

\section{Kajiwara 1997}

Kajiwara M, lida K, Takatori K, Taniguchi Y, Kimura K. Validity of the c-13-urea breath test for the diagnosis of Helicobacter pylori infection. Chemical \& Pharmaceutical Bulletin 1997;45(4):741-3.

\section{Kajiwara 1998}

Kajiwara M, lida K, Takatori K, Taniguchi Y, Kimura K. Validity of the c-13-urea breath test for the diagnosis of Helicobacter pylori infection. In: Heys JR, Melillo DG editor(s). Synthesis and Applications of Isotopically Labelled Compounds 1997. 1st Edition. Chichester: John Wiley \& Sons, 1998:627-31.

\section{Kakinoki 2001}

Kakinoki K, Takemori Y, Noda Y. Efficacy of the urine antibody test for detection of Helicobacter pylori: Comparison with serum antibody tests. Japanese Journal of Gastroenterology 2001;98(8):935-41.

\section{Kaklikkaya 2006}

Kaklikkaya N, Akdogan RA, Ozgur O, Uzun DY, Cobanoglu U, Dinc $U$, et al. Evaluation of a new rapid lateral flow chromatography test for the diagnosis of Helicobacter pylori. Saudi Medical Journal 2006;27(6):799-803.

\section{Kalach 1996}

Kalach N, Briet F, Raymond J, Benhamou P, Senouci L, Bergert $\mathrm{M}$, et al. Time course analysis and simplification of the c-13-urea breath test (c-13-ubt) in the detection of Helicobacter pylori infection (h-pylori) in children. Gastroenterology 1996;110(4 (suppl)):A148.

\section{Kalach 1998b}

Kalach N, Benhamou PH, Briet F, Raymond J, Dupont C. The urea-c-13 breath test in the course of Helicobacter pylori gastric infection in children. Archives De Pediatrie 1998;5(12):1359-65.

\section{Kalach 2005}

Kalach N, Nguyen V, Bergeret M, Boutros N, Dupont C, Raymond J. Usefulness and influence of age of a novel rapid monoclonal enzyme immunoassay stool antigen for the diagnosis of Helicobacter pylori infection in children. Diagnostic Microbiology and Infectious Disease 2005;52(2):157-60.

\section{Kalach 2009}

Kalach N, Dehecq E, Gosset P, Decoster A, Bergeret M, Dupont C, et al. Usefulness and influence of age of a novel rapid $\mathrm{Hpstar}^{\mathrm{TM}}$ stool antigen for the diagnosis of Helicobacter pylori infection in children. Diagnostic Microbiology and Infectious Disease 2009;65(4):450-3.

\section{Kalem 2010}

Kalem F, Ozdemir M, Baysal B. Investigation of the presence of Helicobacter pylori by different methods in patients with dyspeptic complaints. Mikrobiyoloji Bulteni 2010;44(1):29-34. 


\section{Kang 1999}

Kang G, Rajan DP, Patra S, Chacko A, Mathan MM. Use of serology, the urease test \& histology in diagnosis of Helicobacter pylori infection in symptomatic \& asymptomatic Indians. Indian Journal of Medical Research 1999;110:86-90.

\section{Kannath 2007}

Kannath A, Rutt HN. Development of low cost instrumentation for non-invasive detection of Helicobacter pylori - art. No. 643001 . Advanced Biomedical and Clinical Diagnostic Systems 2007;6430:L4300.

\section{Kao 1993}

Kao CH, Huang CK, Wang SJ, Hsu CY, Lin WY, Chen GH. Accuracy of a rapid 10-minute carbon-14 urea breath test for the diagnosis of Helicobacter pylori-associated peptic ulcer disease. European Journal of Nuclear Medicine 1993;20(8):708-11.

\section{Kaore 2012}

Kaore NM, Nagdeo NV, Thombare VR. Comparative evaluation of the diagnostic tests for Helicobacter pylori and dietary influence for its acquisition in dyspeptic patients: a rural hospital based study in central India. Journal of Clinical and Diagnostic Research 2012;6(4 SUPPL 2):636-41.

\section{Kaptan 2009}

Kaptan ZK, Emir H, Uzunkulaoglu H, Yucel M, Karakoc E, Koca G, et al. Determination of Helicobacter pylori in patients with chronic nonspecific pharyngitis. Laryngoscope 2009;119(8):1479-83.

\section{Karakus 2013}

Karakus C, Salih BA. Comparison of the lateral flow immunoassays (LFIA) for the diagnosis of Helicobacter pylori infection. Journal of Immunological Methods 2013;396(1-2):8-14.

\section{Karsligil 2010}

Karsligil T, Mehli M, Koruk M, Eksi F. Urea breath test and specific IgA in Helicobacter pylori infection. Nobel Medicus 2010;6(3):46-50.

\section{Kasho 1996}

Kasho VN, Cheng S, Jensen DM, Ajie H, Lee WNP, Faller LD. Feasibility of analysing c-13 urea breath tests for Helicobacter pylori by gas chromatography-mass spectrometry in the selected ion monitoring mode. Alimentary Pharmacology \& Therapeutics 1996;10(6):985-95.

\section{Kassa 1996}

Kassa E, Tsega E, Gebre W. Comparison of diagnostic methods for detection of Helicobacter pylori. East African Medical Journal 1996;73(4):239-41.

\section{Katelaris 1997}

Katelaris PH, Jones DB. Testing for Helicobacter pylori infection after antibiotic treatment. American Journal of Gastroenterology 1997;92(8):1245-7.

\section{Katelaris 1998}

Katelaris PH, Connor SJ, Seow F, Huntley S, Ngu MC. The effect of short term omeprazole use on the accuracy of the c-13- urea breath test in Helicobacter pylori infected subjects. Gut 1998;43(Suppl 2):A53.

\section{Kato 1997}

Kato M, Ohara S, Asaka M, Toyota T. New, on-the-spot infrared analyzer for C-13-urea breath test: A simple, easy-to-use method for detecting Helicobacter pylori in the physician's office. Gastroenterology 1997;112(4 (suppl)):A169.

\section{Kato 1998}

Kato M, Kobayashi T, Ishizuka J, Kudo T, Katagiri M, Komatsu Y, et al. Detection of h-pylori infections by urine-based enzyme-linked immunosorbent assay. Gastroenterology 1998;114(4):A169.

\section{Kato 1999}

Kato M, Asaka M, Saito M, Ohara S, Toyota T, Akamatsu T, et al. Clinical usefulness of a urine-based ELISA for detection of anti-Helicobacter pylori antibody. Gastroenterology 1999;116(4 (suppl)):A206-A7.

\section{Kato 2000a}

Kato M, Hokari K, Ishizuka J, Mizushima T, Sukegawa M, Komatsu Y, et al. Assessment of Helicobacter pylori eradication using a urine-based ELISA of anti-Helicobacter pylori antibody. Gastroenterology 2000;118(4 Part 1):A505.

\section{Kato 2000b}

Kato S, Tachikawa T, Ozawa K, Konno M, Oyake Y, Nakazato Y, et al. Usefulness of urine-based ELISA for detection of IgG antibodies to Helicobacter pylori in children. Gastroenterology 2000;118(4):A506.

\section{Kato 2000c}

Kato M, Asaka M, Saito M, Sekine H, Ohara S, Toyota T, et al. Clinical usefulness of urine-based enzyme-linked immunosorbent assay for detection of antibody to Helicobacter pylori: A collaborative study in nine medical institutions in Japan. Helicobacter 2000;5(2):109-19.

\section{Kato 2001a}

Kato M. Evaluation of a new ${ }^{13} \mathrm{CO}_{2}$ infrared analyzer (ubit-ir300) for ${ }^{13} \mathrm{C}$-urea breath test. Japanese Journal of Gastroenterology 2001;98(7):853.

\section{Kato 2001b}

Kato S, Tachikawa T, Ozawa K, Konno M, Okuda M, Fujisawa T, et al. Urine-based enzyme-linked immunosorbent assay for the detection of Helicobacter pylori infection in children. Pediatrics 2001;107(6):E87.

\section{Kato 2001c}

Kato C, Yamaguchi T, Yusa K, Sasaki H, Suzuki K, Sato K, et al. 13C-urea breath test. Nippon Rinsho [Japanese Journal of Clinical Medicine] 2001;59(2):267-71.

\section{Kato 2002a}

Kato M, Iwasaki T, Miyazaki H, Ohira K, Oizumi S, Kawarazaki M, et al. Urea breath test for diagnosis of Helicobacter pylori infection. Nippon Rinsho [Japanese Journal of Clinical Medicine] 2002;60(Suppl 2):332-8. 


\section{Kato 2002b}

Kato S, Ozawa K, Konno M, Kagimoto S, Okuda M, Fujisawa T, et al. Usefulness of the stool antigen test (HPSA) for diagnosis of Helicobacter pylori infection in Japanese children: $A$ multicenter study. Gastroenterology 2002;122(4 (suppl)):A202A3.

\section{Kato 2002c}

Kato S, Ozawa K, Konno M, Tajiri H, Yoshimura N, Shimizu T, et al. Diagnostic accuracy of the c-13-urea breath test for childhood Helicobacter pylori infection: A multicenter Japanese study. American Journal of Gastroenterology 2002;97(7):1668-73.

\section{Kato 2002d}

Kato S, Ozawa K, Minoura T, linuma K. A simplified c-13-urea breath test for diagnosis of Helicobacter pylori infection in children. Gastroenterology 2002;122(4 (Suppl)):A206.

\section{Kato 2002e}

Kato C, Kasugai S, Fukuda Y, Yusa K, Kudara N, Iwasaki M, et al. Diagnosis of Helicobacter pylori infection by the antigen analysis of stools. Nippon Rinsho [Japanese Journal of Clinical Medicine] 2002;60(Suppl 2):347-9.

\section{Kato 2003a}

Kato C, Sugiyama T, Sato K, Saito S, Kudara N, Abiko Y, et al. Appropriate cut-off value of $13 \mathrm{C}$-urea breath test after eradication of Helicobacter pylori infection in Japan. Journal of Gastroenterology \& Hepatology 2003;18(12):1379-83.

\section{Kato 2003b}

Kato S, Ozawa K, Okuda M, Fujisawa T, Kagimoto S, Konno M, et al. Accuracy of the stool antigen test for the diagnosis of childhood Helicobacter pylori infection: A multicenter Japanese study. American Journal of Gastroenterology 2003;98(2):296-300.

\section{Kato 2004a}

Kato S, Nakayama K, Minoura T, Konno M, Tajiri H, Matsuhisa T, et al. Comparison between the 13C-urea breath test and stool antigen test for the diagnosis of childhood Helicobacter pylori infection. Journal of Gastroenterology 2004;39(11):1045-50.

\section{Kato 2004b}

Kato S, Ozawa K, Okuda M, Nakayama Y, Yoshimura N, Konno M, et al. Multicenter comparison of rapid lateral flow stool antigen immunoassay and stool antigen enzyme immunoassay for the diagnosis of Helicobacter pylori infection in children. Helicobacter 2004;9(6):669-73.

\section{Kato 2004c}

Kato M, Saito M, Fukuda S, Kato C, Ohara S, Hamada S, et al. C-13-urea breath test, using a new compact nondispersive isotope-selective infrared spectrophotometer: Comparison with mass spectrometry. Journal of Gastroenterology 2004;39(7):629-34.

\section{Kato 2005a}

Kato M, Shimizu Y, Nakagawa S, Nakagawa M, Ono Y, Ono S, et al. Prevention of false-positive result of $13 \mathrm{C}$-urea breath test after eradication of h. Pylori using film-coated 13C-urea tablet. Gastroenterology 2005;128(4 (suppl)):A561.

\section{Kato 2005b}

Kato M, Shimizu Y, Shouji E, Takeda H, Asaka M. Problem of $13 \mathrm{C}$-urea breath test in the diagnosis of h. Pylori after eradication. Nippon Rinsho [Japanese Journal of Clinical Medicine] 2005;63(Suppl 11):221-5.

\section{Kato 2005c}

Kato M, Asaka M. Helicobacter pylori igg antibody, urea breath test, Helicobacter pylori antigen in the stool. Nippon Rinsho [Japanese Journal of Clinical Medicine] 2005;63(Suppl 7):175-9.

\section{Kato 2007}

Kato C, Sugiyama T, Horie A, Igarashi M, Takayanagi N, Tsuchida Y. Diagnostic accuracy of a novel Helicobacter pylori stool antigen test using monoclonal antibody after eradication therapy in Japanese population. Helicobacter 2007;12(4):442-3.

\section{Kato 2010}

Kato M, Asaka M. Helicobacter pylori (igg antibody test, urea breath test, stool antigen test). Nippon Rinsho [Japanese Journal of Clinical Medicine] 2010;68(Suppl 6):183-8.

\section{Katsuragi 1998}

Katsuragi K, Noda A, Tachikawa T, Azuma A, Mukai F, Murakami K, et al. Highly sensitive urine-based enzyme-linked immunosorbent assay for detection of antibody to Helicobacter pylori. Helicobacter 1998;3(4):289-95.

\section{Kaul 1998}

Kaul A, Bhasin DK, Pathak CM, Ray P, Vaiphei K, Sharma BC, et al. Normal limits of 14c-urea breath test. Tropical Gastroenterology 1998;19(3):110-3.

\section{Kawai 2008}

Kawai T, Kawakami K, Kataoka M, Itoi T, Takei K, Moriyasu F, et al. A study of the relationship between Helicobacter pylori microbial susceptibility, 13C-urea breath test values. HepatoGastroenterology 2008;55(82-83):786-90.

\section{Kawakami 2002}

Kawakami E, Machado RS, Reber M, Patricio FR. 13 c-urea breath test with infrared spectroscopy for diagnosing Helicobacter pylori infection in children and adolescents. Journal of Pediatric Gastroenterology \& Nutrition 2002;35(1):39-43.

\section{Kazemi 2011}

Kazemi S, Tavakkoli H, Habizadeh MR, Emami MH. Diagnostic values of Helicobacter pylori diagnostic tests: Stool antigen test, urea breath test, rapid urease test, serology and histology. Journal of Research in Medical Sciences 2011;16(9):1097-104.

\section{Kearney 1999}

Kearney DJ, Boes L, Peacock JS. Use of a dried plasma collection card for simplified diagnosis of Helicobacter pylori infection. Alimentary Pharmacology \& Therapeutics 1999;13(11):1531-4.

\section{Kearney 2002}

Kearney DJ, Hubbard T, Putnam D. Breath ammonia measurement in Helicobacter pylori infection. Digestive Diseases \& Sciences 2002;47(11):2523-30. 


\section{Ken 2013}

Ken Dror S, Barak M. Evaluation of the diasorin liaison automatic stool antigen test for the diagnosis of Helicobacter pylori infection. Biochimica Clinica 2013;37:S659.

\section{Kesli 2010}

Kesli R, Gokturk HS, Erbayrak M, Karabagli P, Terzi Y. Comparison of the diagnostic values of the 3 different stool antigen tests for the noninvasive diagnosis of Helicobacter pylori infection. Journal of Investigative Medicine 2010;58(8):982-6.

\section{Kessenich 2012}

Kessenich CR, Erigo-Backsman RC. Gastritis and noninvasive testing for Helicobacter pylori. Nurse Practitioner 2012;37(4):7-9.

\section{Khafri 2005}

Khafri A, Van yousefi J, Madani R, Pourdian M, Khaki P. Designing an ELISA technique for h.Pylori antibody detection using water extracted antigens. Iranian Journal of Public Health 2005;34(2):14-9.

\section{Khalifehgholi 2013}

Khalifehgholi M, Shamsipour F, Ajhdarkosh H, Daryani NE, Reza Pourmand M, Hosseini M, et al. Comparison of five diagnostic methods for Helicobacter pylori. Iranian Journal of Microbiology 2013;5(4):396-401.

\section{Kharchenko 2012}

Kharchenko N, Lopukh I, Janelidze D. Helicobacter pylori immediate detection with helic breath test: Diagnostic value comparison with c-13 breath test and PCR DNA in feces. Journal of Gastroenterology and Hepatology 2012;27:297-8.

\section{Khorovskaya 2003}

Khorovskaya LA, Kornienko EA, Dmitrienko MA, Nazhiganov ON. Experience of a modified non-isotopic, non-invasive breath test for Helicobacter pylori in pediatric practice. Clinical Chemistry 2003;49(6 (suppl)):A52.

\section{Kias 2011}

Kias F, Taleb F, Mouffok F, Matougui N, Boudjella M, Lamri A, et al. Helicobacter pylori: diagnosis of infection in adults in Algeria. Helicobacter 2011;16:116.

\section{Kikuchi 1999}

Kikuchi H, Ichinose Y, Ishii H, Mori M, Yamaguchi K, Igari K. Influence on diagnosis of Helicobacter pylori infection in $13 \mathrm{C}$ urea breath test of existence of dead space gas. Journal of Occupational Health 1999;41(6):183-9.

\section{Kim 1996}

Kim J, Bank S, Bailey B. Comparison of C14 breath test with clo test in detecting Helicobacter pylori. Gastroenterology 1996;110(4 (suppl)):A155.

\section{Kim 1997}

Kim MJ, Michener R, Triadafilopoulos G. Serum c-13bicarbonate assay for the diagnosis of gastric Helicobacter pylori infection and response to treatment. Gastroenterology 1997;113(1):31-7.

\section{Kim 1999}

Kim PS, Lee JW, Pai SH, Choe YH, Shin YW, Kim YS. Detection of H. pylori antigen in stool by ELISA. Gut 1999;45(Suppl 3):A133.

\section{Kim 2001}

Kim I, Kim P, Kwon K, Lee D, Kim H, Shin Y, et al. Comparison of urine-based enzyme-linked immunosorbent assay and c-14 ubt test for detection of Helicobacter pylori. Gut 2001;49(suppl):A102-A3.

\section{Kim 2002}

Kim PS, Lee J, Pai SH, Kim YB, Cho JK, Lee JW, et al. Detection of Helicobacter pylori antigen in stool by enzyme immunoassay. Yonsei Medical Journal 2002;43(1):7-13.

\section{Kim 2009}

Kim D. The detection of Helicobacter pylori in the terminal ileum and rectum from urea breath test positive healthy adults with culture and PCR during colonoscopy. American Journal of Gastroenterology 2009;104:S514.

\section{Kim 2012}

Kim WJ, Kim HD. The efficacy of monoclonal antibodybased test as addictive tool to detect h. Pylori. Journal of Gastroenterology and Hepatology 2012;27:65.

\section{Kim 2013}

Kim HD, Kim DH, Park H, Kim WJ, Ahn YS, Lee YJ, et al. Detection of Helicobacter pylori in gastric aspirates using a monoclonal antibody-based test. Gut and Liver 2013;7(1):30-4.

\section{Kim 2014}

Kim H, Choi S, Beom J. New monoclonal antibody-based test for Helicobacter pylori urease in gastric tissue. Journal of Gastroenterology and Hepatology (Australia) 2014;29:228-9.

\section{Kindermann 2000}

Kindermann A, Demmelmair H, Koletzko B, KraussEtschmann S, Wiebecke B, Koletzko S. Influence of age on $\mathrm{c}$-13-urea breath test results in children. Journal of Pediatric Gastroenterology and Nutrition 2000;30(1):85-91.

\section{Kindermann 2001a}

Kindermann A, Konstantopoulos N, Lehn N, Demmelmair H, Koletzko S. Evaluation of two commercial enzyme immunoassays, testing immunoglobulin $\mathrm{g}$ (igg) and iga responses, for diagnosis of Helicobacter priori infection in children. Journal of Clinical Microbiology 2001;39(10):3591-6.

\section{Kindermann 2001b}

Kindermann A, Faus-Kessler T, Ballauff A, Findeisen A, Laske G, Demmelmair $\mathrm{H}$, et al. Evaluation of a rapid whole blood test to detect Helicobacter pylori infection in children. Scandinavian Journal of Gastroenterology 2001;36(6):572-6.

\section{Kishkun 2002}

Kishkun AA, Sadokov VM, Arsenin SL, Budzinskii AA, Klimkova MA, Kuchin GA, et al. Significance of the operational test parameters in selection of a diagnostic test for Helicobacter infection. Eksperimental'naia i Klinicheskaia Gastroenterologiia [Experimental \& Clinical Gastroenterology] 2002;4:103-8, 34-35. 


\section{Kist 1999}

Kist M, Strobel S, Kirchner T, Dammann HG. Impact of ELISA and immunoblot as diagnostic tools one year after eradication of Helicobacter pylori in a multicentre treatment study. FEMS Immunology \& Medical Microbiology 1999;24(2):239-42.

\section{Klein 1996}

Klein PD, Malaty HM, Martin RF, Graham KS, Genta RM, Graham DY. Noninvasive detection of Helicobacter pylori infection in clinical practice: The c-13 urea breath test. American Journal of Gastroenterology 1996;91(4):690-4.

\section{Klein 1999}

Klein PD, Malaty HM, Czinn SJ, Emmons SC, Martin RF, Graham DY. Normalizing results of $13 \mathrm{C}$-urea breath testing for $\mathrm{CO} 2$ production rates in children. Journal of Pediatric Gastroenterology \& Nutrition 1999;29(3):297-301.

\section{Klyucharova 2013}

Klyucharova A, Garipova E, Skorohodkina O. Comparison of the urea breath test with bacteriological investigation in detecting of Helicobacter pylori in patients with chronic urticaria. Allergy: European Journal of Allergy and Clinical Immunology 2013;68:604-5.

\section{Kobayashi 2002}

Kobayashi D, Eishi Y, Ohkusa T, Ishige I, Suzuki T, Minami J, et al. Gastric mucosal density of Helicobacter pylori estimated by real-time PCR compared with results of urea breath test and histological grading. Journal of Medical Microbiology 2002;51(4):305-11.

\section{Koca 2005}

Koca G, Ozdemir E, Cakal E, Culha C, Turkolmez S, Korkmaz M, et al. Comparison of c-14 urea-breath test, Helicobacter pylori igg and cytotoxin associated gene a findings in diabetic patients with dyspeptic complaints. European Journal of Nuclear Medicine and Molecular Imaging 2005;32:S218.

\section{Kodama 2004}

Kodama M, Fujioka T, Okimoto T, Kagawa J, Murakami K, Sato R, et al. Evaluation of the Helicobacter pylori stool antigen (HPSA) assay for diagnosing infection and confirming eradication after treatment. Journal of Gastroenterology 2004;39(12):1219-20.

\section{Kodama 2012}

Kodama M, Murakami K, Okimoto T, Fukuda Y, Shimoyama T, Okuda M, et al. Infuence of proton pump inhibitor treatment on Helicobacter pylori stool antigen test. World Journal of Gastroenterology 2012;18(1):44-8.

\section{Koizumi 2003}

Koizumi W, Tanabe S, Imaizumi H, Hibi KI, Kida M, Ohida M, et al. Effect of anti-Helicobacter pylori igg antibody titer following eradication of Helicobacter pylori infection. HepatoGastroenterology 2003;50(49):293-6.

\section{Kokkola 1998}

Kokkola A, Puolakkainen P, Rautelin H, Sipponen P, Farkkila M, Haapiainen R, et al. Positive serology indicates an active hpylori infection in patients with atrophic gastritis in spite of negative histology and c-13-urea breath test. Gastroenterology 1998;114(4):A183.

\section{Kokkola 2000}

Kokkola A, Rautelin H, Puolakkainen P, Sipponen P, Farkkila M, Haapiainen R, et al. Diagnosis of Helicobacter pylori infection in patients with atrophic gastritis: Comparison of histology, c-13-urea breath test, and serology. Scandinavian Journal of Gastroenterology 2000;35(2):138-41.

\section{Koletzko 1995}

Koletzko S, Haisch M, Seeboth I, Braden B, Hengels K, Koletzko $B$, et al. Isotope-selective non-dispersive infrared spectrometry for detection of Helicobacter pylori infection with ${ }^{13}$ C-urea breath test. Lancet 1995;345(8955):961-2.

\section{Koletzko 2003}

Koletzko S, Konstantopoulos N, Bosman D, Feydt-Schmidt A, Van der Ende A, Kalach N, et al. Evaluation of a novel monoclonal enzyme immunoassay for detection of Helicobacter pylori antigen in stool from children. Gut 2003;52(6):804-6.

\section{Kolho 2002}

Kolho KL, Korhonen J, Verkasalo M, Lindahl H, Savilahti E, Rautelin H. Helicobacter pylori serology at diagnosis and followup of biopsy-verified infection in children. Scandinavian Journal of Infectious Diseases 2002;34(3):177-82.

\section{Kolho 2006}

Kolho KL, Klemola T, Koivusalo A, Rautelin H. Stool antigen tests for the detection of Helicobacter pylori in children. Diagnostic Microbiology and Infectious Disease 2006;55(4):269-73.

\section{Kolt 1997}

Kolt SD, Dow C, Elliott SL, Yeomans ND. Effect of omeprazole on the accuracy of the i mu ci c-14-urea breath test for h-pylori. Gastroenterology 1997;112(4 (suppl)):A180.

\section{Kolts 1993}

Kolts BE, Joseph B, Achem SR, Bianchi T, Monteiro C. Helicobacter-pylori detection - a quality and cost-analysis. American Journal of Gastroenterology 1993;88(5):650-5.

\section{Kondo 2000}

Kondo T, Mitsui T, Kitagawa M, Nakae Y. Association of fasting breath nitrous oxide concentration with gastric juice nitrate and nitrite concentrations and Helicobacter pylori infection. Digestive Diseases \& Sciences 2000;45(10):2054-7.

\section{Konorev 2013}

Konorev MR, Matveenko ME, Komleva EN. Comparative evaluation of efficiency of helic ammonia breath test for diagnostics of h. Pylori infection in gastric mucous. Helicobacter 2013;18:122.

\section{Konorev 2014}

Konorev MR, Komleva EN, Matveenko ME. Evaluation of efficiency of helic ammonia breath test for diagnostics of $h$. Pylori infection in stomach in rheumatoid arthritis patients taking nsaids. Helicobacter 2014;19:123. 


\section{Konstantopoulos 2001}

Konstantopoulos N, Russmann H, Tasch C, Sauerwald T, Demmelmair H, Autenrieth I, et al. Evaluation of the Helicobacter pylori stool antigen test (HPSA) for detection of Helicobacter pylori infection in children. American Journal of Gastroenterology 2001;96(3):677-83.

\section{Konturek 1999}

Konturek SJ, Bielanski W, Bobrzynski A, Rembiarz K, Winiarski M, Karczewska E, et al. Upper gastrointestinal bleeding does not interfere with the effectiveness of urea breath test in detecting of Helicobacter pylori in humans. Gastroenterology 1999;116(4 (suppl)):A220.

\section{Kopacova 1999}

Kopacova M, Bures J, Vorisek V, Konstacky M, Rejchrt S, Zivny P, et al. Detection of Helicobacter pylori by means of ${ }^{13} \mathrm{C}$ urea breath test: Clinical reproducibility of the test. Klinicka Biochemie a Metabolismus 1999;7(4):213-6.

\section{Kopacova 2005}

Kopacova M, Bures J, Vorisek V, Konstacky M, Rejchrt S, Zivny P, et al. Comparison of different protocols for $\mathrm{C}-13$-urea breath test for the diagnosis of Helicobacter pylori infection in healthy volunteers. Scandinavian Journal of Clinical \& Laboratory Investigation 2005;65(6):491-8.

\section{Kopanski 1993a}

Kopanski Z, Cienciata A. Serologic detection of Helicobacter pylori antibodies after surgery for stomach and duodenal ulcer. Wiener Klinische Wochenschrift 1993;105(14):408-11.

\section{Kopanski 1993b}

Kopanski Z, Cienciala A, Slowakiewicz E, Witkowska B, Ulatowski Z. Serological diagnosis of infection by Helicobacter pylori in chronic ulcer disease. Materia Medica Polona 1993;25(2):81-2.

\section{Kopanski 1996}

Kopanski Z, Schlegel-Zawadzka M, Witkowska B, Cienciala A, Szczerba J. Role of the enterotest in the diagnosis of the Helicobacter pylori infections. European Journal of Medical Research 1996;1(11):520-2.

\section{Kopanski 1997}

Kopanski Z, Niziol J, Micherdzinski J, Wasilewska-Radwanska H, Schlegel-Zawadzka M, Lasa J, et al. Significance of the 14c-urea breath test in the determination of the location infected by Helicobacter pylori in the alimentary canal. European Journal of Medical Research 1997;2(3):136-8.

\section{Kopanski 2002}

Kopanski Z, Jung A, Wasilewska-Radwanska M, Kuc T, SchlegelZawadzka M, Witkowska B. Comparative diagnostic value of the breath test and the urine test with ${ }^{14} \mathrm{C}$-urea in the detection of the Helicobacter pylori infection. Nuclear Medicine Review 2002;5(1):21-4

\section{Korkmaz 2013}

Korkmaz H, Kesli R, Karabagli P, Terzi Y. Comparison of the diagnostic accuracy of five different stool antigen tests for the diagnosis of Helicobacter pylori infection. Helicobacter 2013;18(5):384-91.

\section{Korkmaz 2015}

Korkmaz H, Findik D, Ugurluoglu C, Terzi Y. Reliability of stool antigen tests: Investigation of the diagnostic value of a new immunochromatographic Helicobacter pylori approach in dyspeptic patients. Asian Pacific Journal of Cancer Prevention: Apjcp 2015;16(2):657-60.

\section{Korzonek 1997}

Korzonek M. Diagnostic value of different methods applied for detecting Helicobacter pylori infection in gastric mucosa. Annales Academiae Medicae Stetinensis 1997;43:143-59.

\section{Koumi 2011}

Koumi A, Filippidis T, Leontara V, Makri L, Panos MZ. Detection of Helicobacter pylori: A faster urease test can save resources. World Journal of Gastroenterology 2011;17(3):349-53.

\section{Kountouras 1996}

Kountouras J, Boura P, Iliadis M, Giannouli P, Tsapas G. Saliva urease test and serological surveillance of Helicobacter pylori infection during treatment of peptic ulcer disease. Hellenic Journal of Gastroenterology 1996;9(1):67-71.

\section{Kowalski 1990}

Kowalski AJ, Cuan J, Chiang CS, Grove T, Perezperez G, Blaser M. Detection of antibodies to Helicobacter-pylori by ELISA. Clinical Chemistry 1990;36(6):1092.

\section{Kozaiwa 1997}

Kozaiwa K, Tajiri H, Sawada A, Miyoshi Y, Tada K, Etani Y, et al. Usefulness of $\mathrm{c}-13$ urea breath test in diagnosis and monitoring of Helicobacter pylori infection in children with recurrent abdominal pain. Gastroenterology 1997;112(4 (suppl)):A184.

\section{Kozlov 2006}

Kozlov AV, Evstratova lu S, Novikova VP, Tkachenko EI, Khochinskaia O. Gas analyzer "helicosense" as a new device for diagnosis of the Helicobacter infection. Meditsinskaia Tekhnika 2006;3:44-6.

\section{Krausse 2008}

Krausse R, Muller G, Doniec M. Evaluation of a rapid new stool antigen test for diagnosis of Helicobacter pylori infection in adult patients. Journal of Clinical Microbiology 2008;46(6):2062-5

\section{Kroser 1998}

Kroser JA, Faigel DO, Furth EE, Metz DC. Comparison of rapid office-based serology with formal laboratory-based ELISA testing for diagnosis of Helicobacter pylori gastritis. Digestive Diseases \& Sciences 1998;43(1):103-8.

\section{Krumbiegel 2000a}

Krumbiegel $P$, Muller DM. Helicobacter pylori in vivo diagnosis after food intake: Results of simultaneous $\mathrm{n}-15$ urea urine and c-13 acetate breath tests. Isotopes in Environmental and Health Studies 2000;36(2):99-110. 


\section{Krumbiegel 2000b}

Krumbiegel P, Herbarth O, Kiess W, Muller DM, Richter T. Diagnosis of Helicobacter pylori infection in children: Is the $\mathrm{n}-15$ urine test more reliable than the c-13 breath test?. Scandinavian Journal of Gastroenterology 2000;35(4):353-8.

\section{Kryvy 2012}

Kryvy V, Klyaryts'ka I. Modified 13C-urea breath test in the diagnosis of infection $\mathrm{h}$. Pylori in crimean population patients with gastritis. Helicobacter 2012;17:94.

\section{Kuang 1998}

Kuang A, Liang Z, Tan T, Chen D, Ma H, Si K, et al. Rapid microdose 14c-urea breath test for detection of Helicobacter pylori infection.. Hua Xi Yi Ke Da Xue Xue Bao [Journal of West China University of Medical Sciences] 1998;29(4):435-8.

\section{Kubo 2001}

Kubo Y, Matsui H, Ninomiya T, Mizukami Y, Onji M. Non-invasive approach for diagnosing atrophic gastritis using the c-13bicarbonate breath test. International Journal of Molecular Medicine 2001;7(4):381-4.

\section{Kubota 2002}

Kubota K, Shimoyama S, Shimizu N, Noguchi C, Mafune K, Kaminishi M, et al. Studies of c-13-urea breath test for diagnosis of Helicobacter pylori infection in patients after partial gastrectomy. Digestion 2002;65(2):82-6.

\section{Kubota 2003}

Kubota K, Hiki N, Shimizu N, Shimoyama S, Noguchi C, Tange T, et al. Utility of [13C] urea breath test for Helicobacter pylori detection in partial gastrectomy patients. Digestive Diseases \& Sciences 2003;48(11):2135-8.

\section{Kumbhari 2012}

Kumbhari V, Rahme N, Meredith CG. Evaluation of a novel office-based c-14 urea breath test 'heliprobe (r)' for the rapid detection of Helicobacter pylori. Journal of Gastroenterology and Hepatology 2012;27:58.

\section{Kumbhari 2013}

Kumbhari V, Rahme N, Meredith C. Evaluation of a novel office based 14c urea breath test, heliprobe, in patients undergoing endoscopy. Gastroenterology 2013;1:S334.

\section{Kuo 2002}

Kuo CH, Wu DC, Lu CY, Su YC, Yu FJ, Lee YC, et al. The media of rapid urease test influence the diagnosis of Helicobacter pylori. Hepato-Gastroenterology 2002;49(47):1191-4.

\section{Kuo 2005}

Kuo FC, Wang SW, Wu IC, Yu FJ, Yang YC, Wu JY, et al. Evaluation of urine ELISA test for detecting Helicobacter pylori infection in Taiwan: a prospective study. World Journal of Gastroenterology 2005;11(35):5545-8.

\section{Kushch 2009}

Kushch I, Korenev N, Kamarchuk L, Pospelov A, Alexandrov J, Kamarchuk G. Non-urease recognition of Helicobacter pylori infection using novel sensor technique for breath gas analysis. Scandinavian Journal of Gastroenterology 2009;44:25.

\section{Kwon 2004}

Kwon KT, Lee DS, Chung IK, Park MJ, Park CK, Cho CM, et al. The diagnostic validity of Helicobacter pylori stool antigen test in the pre- and post-eradication. Taehan Sohwagi Hakhoe C [Korean Journal of Gastroenterology] 2004;44(4):199-205.

\section{Kwon 2015}

Kwon YH, Kim N, Lee JY, Choi YJ, Yoon K, Hwang JJ, et al. The diagnostic validity of citric acid-free, high dose c-13-urea breath test after Helicobacter pylori eradication in Korea. Helicobacter 2015;20(3):159-68

\section{Kyrlagkitsis 2007}

Kyrlagkitsis I, Ladas SD, Mallass EG, Raptis S, Mentis A, Delliou E, et al. Evaluation of a conventional ELISA (Novitec) and a near patient immunochromatographic test (Stick H. pyl) for Helicobacter pylori antigen detection in stool. HepatoGastroenterology 2007;54(75):799-802.

\section{Labenz 1996}

Labenz J, Barsch G, Peitz U, Aygen S, Hennemann O, Tillenburg B, et al. Validity of a novel biopsy urease test (hut) and a simplified 13C-urea breath test for diagnosis of Helicobacter pylori infection and estimation of the severity of gastritis. Digestion 1996;57(6):391-7.

\section{Labenz 1997}

Labenz J, Peitz U, Aygen S, Hennemann O, Stolte M. Accuracy of rapid urease test and urea breath test for diagnosis of Helicobacter pylori infection after treatment - an investigator blind multicenter study. Gastroenterology 1997;112(4 (suppl)):A188.

\section{Ladas 2000}

Ladas SD, Malamou H, Giota G, Varzakakos I, Kitsanta P, Georgopoulos S, et al. Prospective evaluation of a wholeblood antibody test (flexpack hp) for in-office diagnosis of Helicobacter pylori infection in untreated patients. European Journal of Gastroenterology \& Hepatology 2000;12(7):727-31.

\section{Ladas 2002b}

Ladas SD, Varzakakos I, Malamou H, Georgopoulos S, Giota G, Triantafyllou K, et al. Evaluation of a single-step serological assay for laboratory diagnosis of Helicobacter pylori infection. European Journal of Clinical Microbiology \& Infectious Diseases 2002;21(1):56-9.

\section{Lahaie 1995}

Lahaie RG, Desroches J, Picard M, Lemoyne M, Poitras P, Gagnon M, et al. Value of one-step, 20 min c-14 urea breath test in diagnosis and proof of eradication of Helicobacter-pylori infection. Gastroenterology 1995;108(4):A141.

\section{Laheij 2006}

Laheij RJ. Assessment of a new rapid urease test (gut test) to diagnose Helicobacter pylori infection. Netherlands Journal of Medicine 2006;64(9):317-8. 


\section{Lai 1997}

Lai KC, Chu KM, Hui WM, Wong BCY, Lam SK. Non-invasive tests before endoscopy in area with high prevalence of gastric carcinoma - Helicobacter pylori serology or urea breath test? Gastroenterology 1997;112(4 (Suppl)):A599.

\section{Laine 1997}

Laine L, Lewin DN, Naritoku W, Cohen H. Prospective comparison of H\&E, Giemsa, and Genta stains for the diagnosis of Helicobacter pylori. Gastrointestinal Endoscopy 1997;45(6):463-7.

\section{Laine 1999}

Laine L, Knigge K, Faigel D, Margaret N, Marquis SP, Vartan G, et al. Fingerstick Helicobacter pylori antibody test: Better than laboratory serological testing?. American Journal of Gastroenterology 1999;94(12):3464-7.

\section{Lamarque 1996}

Lamarque D, Tankovic J, Benamouzig R, Mahe S, Chaumette MT, Auroux J, et al. Quantification of Helicobacter pylori (hp) infection in antrum: Comparison of culture, histological examination and c-13-urea breath test. Gastroenterology 1996;110(4 (suppl)):A169.

\section{Langhorst 2002}

Langhorst J, Heuer S, Drouven FU, Schwobel HD, Reichenberger S, Neuhaus H. Evaluation of a new immunochromatographic based whole blood near patient test for the diagnosis of Helicobacter pylori infection. Zeitschrift Fur Gastroenterologie 2002;40(6):389-93.

\section{Larras 2009}

Larras R, Moubri M, Berrah H, Mouffok F, Bouhadef A, Bouzid K, et al. Evaluation of a monoclonal stool antigen test for the diagnosis of $H$. pylori infection in preschool Algerian children. Helicobacter 2009;14(4):347.

\section{Lassnig 1988}

Lassnig C, Umlauft F, Schaber E, Stoffler G, Aigner F. The value of indirect immunofluorescence, ELISA and western blots for diagnosis and epidemiology of campylobacter pylori infections. Biological Chemistry Hoppe-Seyler 1988;369(9):862.

\section{Laszewicz 2014}

Laszewicz W, Iwanczak F, Iwanczak B, Task Force of the Polish Society of Gastroenterology. Seroprevalence of Helicobacter pylori infection in Polish children and adults depending on socioeconomic status and living conditions. Advances in Medical Sciences 2014;59(1):147-50.

\section{Lee 1999}

Lee CL, Lee SC, Wu CH, Chen TK. Diagnosis of h. Pylori infection by urea breath test: Comparison of $50 \mathrm{mg}$ vs $100 \mathrm{mg}$ of c-13 urea. Gut 1999;45(Suppl 3):A131.

\section{Lee 2000a}

Lee SC, Sheu BS, Huang JJ, Yang HB, Lin XZ. Diagnostic efficacy of c-13-urea breath test for Helicobacter pylori infection in hemodialysis patients. Gut 2000;47(Suppl 1):A120.

\section{Lee 2000b}

Lee JM, Breslin NP, Fallon C, O'Morain CA. Rapid urease tests lack sensitivity in Helicobacter pylori diagnosis when peptic ulcer disease presents with bleeding. American Journal of Gastroenterology 2000;95(5):1166-70.

\section{Lee 2003}

Lee YH, Lee SY, Kim YT, Park CK, Jo CM, Tak WY, et al. Diagnosis of Helicobacter pylori infection with urine and stool. Taehan Sohwagi Hakhoe Chi [Korean Journal of Gastroenterology] 2003;42(2):115-20.

\section{Lee 2013}

Lee YC, Chiu HM, Chiang TH, Yen AMF, Chiu SYH, Chen SLS, et al. Accuracy of faecal occult blood test and Helicobacter pylori stool antigen test for detection of upper gastrointestinal lesions. BMJ Open 2013; Vol. 3, issue 10:e003989. [DOI: 10.1136/ bmjopen-2013-003989]

\section{Lee 2014}

Lee YC, Tseng PH, Liou JM, Chen MJ, Chen CC, Tu CH, et al. Performance of a one-step fecal sample-based test for diagnosis of Helicobacter pylori infection in primary care and mass screening settings. Journal of the Formosan Medical Association 2014;113(12):899-907.

\section{Lee 2015a}

Lee SY, Moon HW, Hur M, Yun YM. Validation of western Helicobacter pylori igg antibody assays in Korean adults. Journal of Medical Microbiology 2015;64(Pt 5):513-8.

\section{Lee 2015b}

Lee JY, Kim N. Diagnosis of Helicobacter pylori by invasive test: histology. Annals of Translational Medicine 2015;3(1):10.

\section{Leja 2009}

Leja M, Kupcinskas L, Funka K, Sudraba A, Jonaitis L, Ivanauskas $A$, et al. The validity of a biomarker method for indirect detection of gastric mucosal atrophy versus standard histopathology. Digestive Diseases \& Sciences 2009;54(11):2377-84.

\section{Lelwala 1990}

Lelwala Guruge J, Schalen C, Nilsson I, Ljungh A, Tyskiewicz T, Wikander M, et al. Detection of antibodies to Helicobacter pylori cell surface antigens. Scandinavian Journal of Infectious Diseases 1990;22(4):457-65.

\section{Lemus 2004}

Lemus SMV, Acar MR, Ponce MC, Torres J, Rodriguez OO. Detection of antibodies against Helicobacter pylori and positivity to the 13 carbon urea breath test in patients with rosacea. Dermatologia Revista Mexicana 2004;48(4):189-96.

\section{Leodolter 1997}

Leodolter A, DominguezMunoz JE, Nilius M, VonArnim U, Malfertheiner P. Non-invasive primary diagnosis of h-pylori infection: 13C-urea breath test or serology?. Gastroenterology 1997;112(4 (suppl)):A197. 


\section{Leodolter 1998a}

Leodolter A, Dominguez-Muñoz JE, Von Arnim U, Manes G, Malfertheiner P. 13C-urea breath test for the diagnosis of Helicobacter pylori infection. A further simplification for clinical practice. Scandinavian Journal of Gastroenterology 1998;33(3):267-70

\section{Leodolter 1998b}

Leodolter A, Dominguez-Muñoz JE, Gerards C, Von Arnim U, Malfertheiner P. Validity of a modified c-13-urea breath test (c-13-ubt) for pre- and post-treatment diagnosis of Helicobacter pylori infection in clinical routine. Gut 1998;43(Suppl 2):A52.

\section{Leodolter 1999a}

Leodolter A, Dominguez-Muñoz JE, Von Arnim U, Malfertheiner P. Citric acid or orange juice for the c-13-urea breath test: The impact of ph and gastric emptying. Alimentary Pharmacology \& Therapeutics 1999;13(8):1057-62.

\section{Leodolter 1999b}

Leodolter A, Dominguez-Muñoz JE, Von Arnim U, Kahl S, Peitz U, Malfertheiner P. Validity of a modified c-13-urea breath test for pre- and posttreatment diagnosis of Helicobacter pylori infection in the routine clinical setting. American Journal of Gastroenterology 1999;94(8):2100-4.

\section{Leodolter 2000}

Leodolter A, Von Arnim U, Gerards C, Kahl S, Malfertheiner P. Pre- and post-treatment diagnosis of h-pylori infection by the c-13-urea breath test (13C-ubt): Validation of a new isotopeselective infrared spectrometer (isis). Gastroenterology 2000;118(4 Part 1):A506.

\section{Leodolter 2001a}

Leodolter A, Vaira D, Bazzoli F, Hirschl A, Megraud F, Malfertheiner P. European multicentre validation trial of two new non-invasive tests for detection of antibody to $H$. pylori: urine-based ELISA and rapid urine test. Gastroenterology 2001;120(5):A491.

\section{Leodolter 2001b}

Leodolter A, Ziegler K, Lehn N, Malfertheiner P. The h-pylori antigen stool test for determination of $h$-pylori status in general practice: Is unfrozen delivery of stool specimens sufficient using a regular postal service?. Gut 2001;49(suppl):A97.

\section{Leodolter 2001c}

Leodolter A, Agha-Amiri K, Peitz U, Gerards C, Ebert MP, Malfertheiner P. Validity of a Helicobacter pylori stool antigen assay for the assessment of $h$-pylori status following eradication therapy. European Journal of Gastroenterology \& Hepatology 2001;13(6):673-6.

\section{Leodolter 2002}

Leodolter A, Peitz U, Ebert MP, Agha-Amiri K, Malfertheiner P. Comparison of two enzyme immunoassays for the assessment of Helicobacter pylori status in stool specimens after eradication therapy. American Journal of Gastroenterology 2002;97(7):1682-6.

\section{Leodolter 2003a}

Leodolter A, Wolle K, Wex T, Peitz U, Malfertheiner P. Evaluation of a novel rapid $\mathrm{H}$. pylori stool antigen test: Is a reliable diagnosis now possible in the doctor's office?. Gastroenterology 2003;124(4):A58.

\section{Leodolter 2003b}

Leodolter A, Vaira D, Bazzoli F, Schutze K, Hirschl A, Megraud F, et al. European multicentre validation trial of two new non-invasive tests for the detection of Helicobacter pylori antibodies: urine-based ELISA and rapid urine test. Alimentary Pharmacology \& Therapeutics 2003;18(9):927-31.

\section{Leodolter 2004}

Leodolter A, Wolle K, Peitz U, Schaffranke A, Wex T, Malfertheiner P. Evaluation of a near-patient fecal antigen test for the assessment of Helicobacter pylori status. Diagnostic Microbiology \& Infectious Disease 2004;48(2):145-7.

\section{Leodolter 2005}

Leodolter A, Wolle K, Von Arnim U, Kahl S, Treiber G, Ebert MP, et al. Breath and string test: A diagnostic package for the identification of treatment failure and antibiotic resistance of Helicobacter pylori without the necessity of upper gastrointestinal endoscopy. World Journal of Gastroenterology 2005;11(4):584-6.

\section{Lepper 2004}

Lepper PM, Moricke A, Vogt K, Bode G, Trautmann M. Comparison of different criteria for interpretation of immunoglobulin g immunoblotting results for diagnosis of Helicobacter pylori infection. Clinical \& Diagnostic Laboratory Immunology 2004;11(3):569-76.

\section{Lerang 1998a}

Lerang F, Moum B, Mowinckel P, Haug JB, Ragnhildstveit E, Berge T, et al. Accuracy of seven different tests for the diagnosis of Helicobacter pylori infection and the impact of $\mathrm{H} 2$ receptor antagonists on test results. Scandinavian Journal of Gastroenterology 1998;33(4):364-9.

\section{Lerang 1998b}

Lerang F, Haug JB, Moum B, Mowinckel P, Berge T, Ragnhildstveit E, et al. Accuracy of IgG serology and other tests in confirming Helicobacter pylori eradication. Scandinavian Journal of Gastroenterology 1998;33(7):710-5.

\section{Leszczynska 2009}

Leszczynska K, Namiot DB, Namiot Z, Leszczynska JK, Jakoniuk P, Kemona A. Application of immunoassay for detection of Helicobacter pylori antigens in the dental plaque. Advances in Medical Sciences 2009;54(2):194-8.

\section{Leung 1998a}

Leung WK, Ng EKW, Sung JY. Performance of commercially available serological ELISA test for $\mathrm{H}$. pylori infection: discrepancy between east and west. Gastroenterology 1998;114(4 (suppl)):A201. 


\section{Leung 1998b}

Leung WK, Chan FKL, Falk MS, Suen R, Sung JJY. Comparison of two rapid whole-blood tests for Helicobacter pylori infection in Chinese patients. Journal of Clinical Microbiology 1998;36(11):3441-2.

\section{Leung 1999}

Leung WK, Ng EKW, Chan FKL, Chung SCS, Sung JJY. Evaluation of three commercial enzyme-linked immunosorbent assay kits for diagnosis of Helicobacter pylori in Chinese patients. Diagnostic Microbiology and Infectious Disease 1999;34(1):13-7.

\section{Leung 2001}

Leung WK, Chow TP, Ng EKW, Chan FKL, Chung SCS, Sung JJY. Validation of a new immunoblot assay for the diagnosis of Helicobacter pylori in the asian population. Alimentary Pharmacology and Therapeutics 2001;15(3):423-8.

\section{Leunk 1990}

Leunk RD, Ferguson MA, Morgan DR, Low DE, Simor AE. Antibody to cytotoxin in infection by Helicobacter pylori. Journal of Clinical Microbiology 1990;28(6):1181-4.

\section{Levine 2004a}

Levine A, Shevah O, Shabat-Sehayek V, Aeed H, Boaz M, Moss SF, et al. Masking of $\mathrm{c}-13$ urea breath test by proton pump inhibitors is dependent on type of medication: Comparison between omeprazole, pantoprazole, lansoprazole and esomeprazole. Alimentary Pharmacology \& Therapeutics 2004;20(1):117-22.

\section{Levine 2004b}

Levine A, Shevah O, Miloh T, Wine F, Niv Y, Bujanover Y, et al. Validation of a novel real time c-13 urea breath test for rapid evaluation of Helicobacter pylori in children and adolescents. Journal of Pediatrics 2004;145(1):112-4.

\section{Lew 1999}

Lew EA, Pisegna JR, Ohning GV, Faller LD, David S, Walsh JH, et al. Intragastric ph titration affects the accuracy of uc urea breath test in the diagnosis of Helicobacter pylori. Gastroenterology 1999;116(4 (suppl)):A235.

\section{Lewin-van 1999}

Lewin-van den Broek NT, Numans ME, Buskens E, De Wit NJ, Smout AJPM, Verheij TJM. Validation and value of an enzymelinked immunosorbent assay for Helicobacter pylori in primary care. Scandinavian Journal of Gastroenterology 1999;34(4):391-5.

\section{Lewis 1997}

Lewis JD, Kroser J, Bevan J, Furth EE, Metz DC. Urease-based tests for Helicobacter pylori gastritis - accurate for diagnosis but poor correlation with disease severity. Journal of Clinical Gastroenterology 1997;25(2):415-20.

\section{Li 1995}

Li C, Ha T, Ferguson DA, Zhao RG, Chi DS, Patel NR, et al. Comparison of PCR detection of Helicobacter-pylori infection using gastric biopsy, saliva and stool specimens with other established techniques (ELISA, culture and histology). Gastroenterology 1995;108(4):A147.

\section{Li 1996}

Li C, Ha T, Ferguson DA, Jr, Chi DS, Zhao R, et al. A newly developed PCR assay of h. Pylori in gastric biopsy, saliva, and feces. Evidence of high prevalence of $h$. Pylori in saliva supports oral transmission. Digestive Diseases \& Sciences 1996;41(11):2142-9.

\section{Li 2004}

Li YH, Guo H, Zhang PB, Zhao XY, Da SP. Clinical value of Helicobacter pylori stool antigen test, immunocard stat HPSA, for detecting h pylori infection. World Journal of Gastroenterology 2004;10(6):913-4.

\section{Liao 2002}

Liao CC, Lee CL, Chiang TC, Lee SC, Huang SH, Tu TC, et al. The c-13-urea breath test to detect Helicobacter pylori injection: A validated simple methodology with $50 \mathrm{mg}$ c-13-urea. Alimentary Pharmacology \& Therapeutics 2002;16(4):787-92.

\section{Liao 2003}

Liao CC, Lee CL, Lai YC, Huang SH, Lee SC, Wu CH, et al. Accuracy of three diagnostic tests used alone and in combination for detecting Helicobacter pylori infection in patients with bleeding gastric ulcers. Chinese Medical Journal 2003;116(12):1821-6.

\section{Lie 2012}

Lie MR, Ganesh S, Haringsma J, Francke J, Kuipers EJ. Analytical equivalence study of ndirs versus irms in breath test analysis. Gastroenterology 2012;142(5 (Suppl 1)):S487.

\section{$\operatorname{Lim} 2005$}

Lim LG, Yeoh KG, Ho B, Lim SG. Validation of four Helicobacter pylori rapid blood tests in a multi-ethnic asian population. World Journal of Gastroenterology 2005;11(42):6681-3.

\section{Lin 1992}

Lin SK, Lambert JR, Schembri M, Nicholson L, Finlay M, Wong $C$, et al. A comparison of diagnostic tests to determine Helicobacter pylori infection. Journal of Gastroenterology \& Hepatology 1992;7(2):203-9.

\section{Lin 2004a}

Lin HJ, Lo WC, Perng CL, Li AF, Tseng GY, Sun IC, et al. Helicobacter pylori stool antigen test in patients with bleeding peptic ulcers. Helicobacter 2004;9(6):663-8.

\section{Lin 2004b}

Lin HJ, Sun IC, Lo WC. Helicobacter pylori stool antigen test is not reliable in patients with bleeding peptic ulcers. Gastroenterology 2004;126(4 (Suppl)):A184.

\section{Lin 2004c}

Lin FY, Sabri M, Erickson D, Alirezaie J, Li D, Sherman PM. Development of a novel microfluidic immunoassay for the detection of Helicobacter pylori infection. Analyst 2004;129(9):823-8.

\section{Lin 2015}

Lin Z, Cheng SL, Yan Q, Liu XF, Zheng W, Hu XM, et al. Development of an immunochromatographic lateral flow 
device for rapid detection of Helicobacter pylori stool antigen. Clinical Biochemistry 2015;48(18):1298-303.

\section{Lindsetmo 2008}

Lindsetmo RO, Johnsen R, Eide TJ, Gutteberg T, Husum HH, Revhaug A. Accuracy of Helicobacter pylori serology in two peptic ulcer populations and in healthy controls. World Journal of Gastroenterology 2008;14(32):5039-45.

\section{Ling 2013}

Ling D. Carbon-13 urea breath test for Helicobacter pylori infection in patients with uninvestigated ulcer-like dyspepsia: An evidence-based analysis. Ontario Health Technology Assessment Series 2013;13(19):1-30.

\section{Liquornik 1998}

Liquornik KN, Liacouras CA, Ruchelli ED, Metz DC. The c13-urea breath test: An excellent noninvasive method for detection of h-pylori infection in pediatric patients. Gastroenterology 1998;114(4 (suppl)):A205.

\section{Liston 1996}

Liston R, Pitt MA, Banerjee AK. IgG ELISA antibodies and detection of Helicobacter pylori in elderly patients. Lancet 1996;347(8996):269.

\section{Liu 2002}

Liu W, Xiao S, Wang J, Zhao Z, Qian J, Hu F, et al. Evaluation of Helicobacter pylori stool antigen test for detection of Helicobacter pylori: A multicenter study. Chinese Journal of Gastroenterology 2002;7(3):136-9.

\section{Llor 2014}

Llor C, Bjerrum L. Antimicrobial resistance: risk associated with antibiotic overuse and initiatives to reduce the problem. Therapeutic Advances in Drug Safety 2014;5(6):229-41.

\section{Lo 2005}

Lo CC, Lai KH, Peng NJ, Lo GH, Tseng HH, Lin CK, et al. Polymerase chain reaction: A sensitive method for detecting Helicobacter pylori infection in bleeding peptic ulcers. World Journal of Gastroenterology 2005;11(25):3909-14.

\section{Locatelli 2004}

Locatelli A, Catapani WR, Gomes CR Jr, Silva CBP, Waisberg J. Detection of anti-Helicobacter pylori antibodies in serum and duodenal fluid in peptic gastroduodenal disease. World Journal of Gastroenterology 2004;10(20):2997-3000.

\section{Loeb 1997}

Loeb MB, Riddell RH, James C, Hunt R, Smaill FM. Evaluation of salivary antibodies to detect infection with Helicobacter pylori. Canadian Journal of Gastroenterology 1997;11(5):437-40.

\section{Loffeld 1989}

Loffeld RJ, Stobberingh E, Flendrig JA, Van Spreeuwel JP, Arends JW. Diagnostic value of an immunoassay to detect anti campylobacter pylori antibodies in non-ulcer dyspepsia. Lancet 1989;1(8648):1182-5.

\section{Loffeld 1993}

Loffeld RJLF, Vriese WTJ, Stobberingh EE. Usefulness of several commercial enzyme-linked; immunoassays for detection of Helicobacter pylori infection in clinical medicine. European Journal of Gastroenterology \& Hepatology 1993;5(5):333-7.

\section{Logan 1990}

Logan RPH, Dill S, Walker MM, Bauer FE, Rathbone BP, Johnson P, et al. Evaluation of European standard c-13 urea breath test for the detection of Helicobacter-pylori. Gut 1990;31(10):A1177.

\section{Logan 1991b}

Logan RPH, Dill S, Bauer FE, Walker MM, Hirschl AM, Gummett PA, et al. The European c-13-urea breath test for the detection of Helicobacter-pylori. European Journal of Gastroenterology \& Hepatology 1991;3(12):915-21.

\section{Lombardo 1999}

Lombardo L, Masoero G, Della Monica P, Taraglio S, Motta M, Ravarino N, et al. Six-time points c-13-urea breath test is a suitable method for Helicobacter pylori diagnosis in postgastrectomy patients. Gut 1999;45(Suppl 3):A131.

\section{Lopez 2001}

Lopez Penas D, Naranjo Rodriguez A, Munoz Molinero J, Rodriguez Lopez F, Galvez Calderon C, Chicano Gallardo M, et al. Efficacy of fecal detection of Helicobacter pylori with the HPSA technique in patients with upper digestive hemorrhage. Gastroenterologia y Hepatologia 2001;24(1):5-8.

\section{Lopez 2004}

Lopez T, Quesada M, Almirall J, Sanfeliu I, Segura F, Calvet X. Usefulness of non-invasive tests for diagnosing Helicobacter pylori infection in patients undergoing dialysis for chronic renal failure. Helicobacter 2004;9(6):674-80.

\section{Lopez-Brea 1998}

Lopez-Brea M, Alarcon T, Domingo D, Sanchez I, Martinez MJ, Sanz JC. Evaluation of a western-blot technique (helicoblot 2.0) for the detection of antibodies versus specific antigens of Helicobacter in children. Enfermedades Infecciosas $Y$ Microbiologia Clinica 1998;16(6):275-9.

\section{Lotterer 1991}

Lotterer E, Ramaker J, Ludtke FE, Tegeler R, Geletneky JV, Bauer FE. The simplified 13C-urea breath test--one point analysis for detection of Helicobacter pylori infection. Zeitschrift Fur Gastroenterologie 1991;29(11):590-4.

\section{Lotterer 1993a}

Lotterer E, Ludtke FE, Tegeler R, Lepsien G, Bauer FE. The 13C-urea breath test--detection of Helicobacter pylori infection in patients with partial gastrectomy. Zeitschrift Fur Gastroenterologie 1993;31(2):115-9.

\section{Lotterer 1993b}

Lotterer E, Ludtke FE, Tegeler R, Bauer FE. The c-13-urea breath test, Helicobacter-pylori infection, and the operated stomach. Journal of Clinical Gastroenterology 1993;16(1):82-3. 


\section{Loy 1996}

Loy CT, Irwig LM, Katelaris PH, Talley NJ. Do commercial serological kits for Helicobacter pylori infection differ in accuracy? A meta-analysis. American Journal of Gastroenterology 1996;91(6):1138-44.

\section{Lozniewski 1996}

Lozniewski A, DeKorwin JD, Conroy MC, Plenat F, Weber M. Evaluation of Pyloriset dry, a new rapid agglutination test for Helicobacter pylori antibody detection. Journal of Clinical Microbiology 1996;34(7):1773-5.

\section{Lu 2005}

Lu CY, Kuo CH, Lo YC, Chuang HY, Yang YC, Wu IC, et al. The best method of detecting prior Helicobacter pylori infection. World Journal of Gastroenterology 2005;11(36):5672-6.

\section{Lu 2006}

Lu CY, Kuo FC, Wang SW, Lo YC, Wu IC, Chang LL, et al. The clinical applications and accuracy of 2 rapid near-patient tests in detecting Helicobacter pylori infection. Diagnostic Microbiology \& Infectious Disease 2006;56(3):241-6.

\section{Lucio 1999}

Lucio L, Masoero G, Della Monica P, Taraglio S, Motta M, Ravarino N, et al. Six-time points c-13-urea breath test is a suitable method for Helicobacter pilory diagnosis in post-gastrectomy patients. Gastroenterology 1999;116(4 (suppl)):A240.

\section{Luzza 1995}

Luzza F, Maletta M, Imeneo M, Doldo P, Marasco R, Biancone L, et al. Salivary specific igg is a sensitive indicator of the humoral immune response to Helicobacter pylori. FEMS Immunology \& Medical Microbiology 1995;10(3-4):281-3.

\section{Luzza 1997}

Luzza F, Oderda G, Maletta M, Imeneo M, Mesuraca L, Chioboli E, et al. Salivary immunoglobulin g assay to diagnose Helicobacter pylori infection in children. Journal of Clinical Microbiology 1997;35(12):3358-60.

\section{Luzza 2000}

Luzza F, Imeneo M, Marasco A, Crotta S, lerardi E, Usai P, et al. Evaluation of a commercial serological kit for detection of salivary immunoglobulin g to Helicobacter pylori: A multicentre study. European Journal of Gastroenterology \& Hepatology 2000;12(10):1117-20.

\section{Ma 2006}

Ma YJ, Liu GQ, Zhang HD, Fang QB, Zhao HG. Feasibility of ammonia breath test in diagnosis of Helicobacter pylori infection.. World Chinese Journal of Digestology 2006;14(36):3504-8.

\section{Maaroos 2004}

Maaroos HI, Andreson H, Loivukene K, Hutt P, Kolk H, Kull I, et al. The diagnostic value of endoscopy and Helicobacter pylori tests for peptic ulcer patients in late post-treatment setting. BMC Gastroenterology 2004;4:27.

\section{Macaskill 2013}

Macaskill P, Gatsonis C, Deeks JJ, Harbord RM, Takwoingi Y, editor(s). Chapter 10: Analysing and Presenting Results. In: Deeks JJ, Bossuyt PM, Gatsonis C, editor(s). Cochrane Handbook for Systematic Reviews of Diagnostic Test Accuracy Version 1.0.0. The Cochrane Collaboration, 2013. Available from srdta.cochrane.org.

\section{Machado 2004}

Machado RS, Patricio FRD, Kawakami E. C-13-urea breath test to diagnose Helicobacter pylori infection in children aged up to 6 years. Helicobacter 2004;9(1):39-45.

\section{Machado 2006}

Machado RS, Kawakami E, Patricio FRD, Reber M. Urease activity does not reflect the degree of colonization by Helicobacter pylori in children. Pediatrics International 2006;48(4):398-402.

\section{MacKay 2003}

MacKay WG, Williams CL, McMillan M, Ndip RN, Shepherd AJ, Weaver LT. Evaluation of protocol using gene capture and PCR for detection of Helicobacter pylori DNA in feces. Journal of Clinical Microbiology 2003;41(10):4589-93.

\section{Madico 1995}

Madico G, Verastegui M. Serodiagnosis of Helicobacter pylori infection by enzyme-linked immunoelectrotransfer blot. Gastrointestinal physiology working group of Cayetano Heredia University. Journal of Diarrhoeal Diseases Research 1995;13(2):122-6.

\section{Mahmood 2010}

Mahmood S, Hamid A. Comparison between invasive and noninvasive tests in diagnosis of Helicobacter pylori infection. Pakistan Journal of Biological Sciences 2010;13(10):509-12.

\section{Mahony 1988}

Mahony MJ, Littlewood JM. Diagnosis of campylobacter pylori gastritis by IgG ELISA. Pediatric Research 1988;24(3):416.

\section{Maity 2014}

Maity A, Banik GD, Ghosh C, Som S, Chaudhuri S, Daschakraborty SB, et al. Residual gas analyzer mass spectrometry for human breath analysis: A new tool for the noninvasive diagnosis of Helicobacter pylori infection. Journal of Breath Research 2014;8(1):016005.

\section{Makristathis 1998}

Makristathis A, Pasching E, Schutze K, Wimmer M, Rotter ML, Hirschl AM. Detection of Helicobacter pylori in stool specimens by PCR and antigen enzyme immunoassay. Journal of Clinical Microbiology 1998;36(9):2772-4.

\section{Makristathis 2000}

Makristathis A, Barousch W, Pasching E, Binder C, Kuderna C, Apfalter $P$, et al. Two enzyme immunoassays and PCR for detection of Helicobacter pylori in stool specimens from pediatric patients before and after eradication therapy. Journal of Clinical Microbiology 2000;38(10):3710-4. 


\section{Malaty 1996}

Malaty HM, El-Zimaity HM, Genta RM, Klein PD, Graham DY. Twenty-minute fasting version of the us $13 \mathrm{C}$-urea breath test for the diagnosis of h. Pylori infection. Helicobacter 1996;1(3):165-7.

\section{Malaty 2000}

Malaty HM, Logan ND, Graham DY, Ramchatesingh JE, Reddy SG. Helicobacter pylori infection in asymptomatic children: Comparison of diagnostic tests. Helicobacter 2000;5(3):155-9.

\section{Malaty 2002}

Malaty HM, Haveman T, Graham DY, Fraley JK. Helicobacter pylori infection in asymptomatic children: Impact of epidemiologic factors on accuracy of diagnostic tests. Journal of Pediatric Gastroenterology \& Nutrition 2002;35(1):59-63.

\section{Malfertheiner 1988}

Malfertheiner P, Henze E, Stanescu A, Glasbrenner B, Schoetensack C, Ditschuneit H. C-14-breath-test to identify campylobacter-pylori colonization of the mucous-membrane of the stomach. Zeitschrift fur Gastroenterologie 1988;26(9):528.

\section{Malfertheiner 2002}

Malfertheiner P, Axon A, O'Morain C, Pajares-Garcia JM, Ekstrom P, Schutze K, et al. Evaluation of a new Helicobacter pylori catalase based stool antigen test (femtolab h. Pylori $\mathrm{cnx}$ ): A European multicenter study. Gastroenterology 2002;122(4 (Suppl)):A205.

\section{Malfertheiner 2005}

Malfertheiner P. 13C-urea breath test: Further modification towards an unrestricted use. Digestion 2005;71(4):206-7.

\section{Malfertheiner 2012}

Malfertheiner P, Megraud F, O'Morain CA, Atherton J, Axon AT, Bazzoli F, et al. Management of Helicobacter pylori infection - the Maastricht IV/ Florence Consensus Report. Gut 2012;61(5):646-64.

\section{Mana 2000a}

Mana F, Lacor P, Urbain D. ${ }^{13} \mathrm{C}$ urea breath test for the diagnosis of Helicobacter pylori infection: Contribution of an infrared spectrometer. Tijdschrift voor Geneeskunde 2000;56(17):1240-6.

\section{Mana 2000b}

Mana F, Franken PR, Ham HR, Reynaert H, Urbain D. C-13 urea breath test with nondispersive isotope-selective infrared spectrometry: Reproducibility and importance of the fasting status. Helicobacter 2000;5(2):104-8.

\section{Mana 2001b}

Mana F, Ham HR, Reynaert H, Franken P, Urbain D. Urea breath test for the diagnosis of Helicobacter pylori. Gastrointestinal Endoscopy 2001;53(6):700-1.

\section{Mana 2005}

Mana F, Van Laer W, Bossuyt A, Urbain D. The early effect of proton pump inhibitor therapy on the accuracy of the 13Curea breath test [erratum appears in Digestive \& Liver Disease 2009;41(8):613 note: Van laere, w [corrected to van laer, w]]. Digestive \& Liver Disease 2005;37(1):28-32.

\section{Manes 2000}

Manes G, Balzano A, laquinto G, Ricci C, Giardullo N, Lioniello M, et al. Accuracy of the h-pylori stool antigen test in the pre- and post-eradication assessment and in patients on omeprazole treatment. Gut 2000;47(Suppl 1):A113.

\section{Manes 2001}

Manes G, Balzano A, laquinto G, Ricci C, Piccirillo MM, Giardullo N, et al. Accuracy of the stool antigen test in the diagnosis of Helicobacter pylori infection before treatment and in patients on omeprazole therapy. Alimentary Pharmacology \& Therapeutics 2001;15(1):73-9.

\section{Manes 2005}

Manes G, Zanetti MV, Piccirillo MM, Lombardi G, Balzano A, Pieramico 0 . Accuracy of a new monoclonal stool antigen test in post-eradication assessment of Helicobacter pylori infection: Comparison with the polyclonal stool antigen test and urea breath test. Digestive \& Liver Disease 2005;37(10):751-5.

\section{Mansour-Ghanaei 2013}

Mansour-Ghanaei F, Joukar F, Sheykhian MR, Soati F, Rafatzand AM. Effect of gastric acidification on the c-14-ubt heliprobe ( $r$ ) accuracy during pantoprazole treatment in Helicobacter pylori positive patients. International Journal of Clinical and Experimental Medicine 2013;6(3):185-91.

\section{Marchildon 1996}

Marchildon PA, Ciota LM, Zamaniyan FZ, Peacock JS, Graham DY. Evaluation of three commercial enzyme immunoassays compared with the c-13 urea breath test for detection of Helicobacter pylori infection. Journal of Clinical Microbiology 1996;34(5):1147-52.

\section{Marchildon 1999}

Marchildon P, Balaban DH, Sue M, Charles C, Doobay R, Passaretti N, et al. Usefulness of serological igg antibody determinations for confirming eradication of Helicobacter pylori infection. American Journal of Gastroenterology 1999;94(8):2105-8.

\section{Marchildon 2003}

Marchildon PA, Sugiyama T, Fukuda Y, Peacock JS, Asaka M, Shimoyama T, et al. Evaluation of the effects of strain-specific antigen variation on the accuracy of serologic diagnosis of Helicobacter pylori infection [erratum appears in Journal of Clinical Microbiology 2003;41(7):3462 note: Fukada, y [corrected to fukuda, y]]. Journal of Clinical Microbiology 2003;41(4):1480-5.

\section{Marshall 1988a}

Marshall BJ, Surveyor I. Carbon-14 urea breath test for the diagnosis of campylobacter pylori associated gastritis. Journal of Nuclear Medicine 1988;29(1):11-6.

\section{Marshall 1988b}

Marshall BJ, Guerrant RL, Plankey MW, Dye KR, Barrett L, Frierson HF, et al. Comparison of c-14-urea breath test, microbiology and histology for the diagnosis of campylobacter pylori. Gastroenterology 1988;94(5):A284. 


\section{Marshall 1988c}

Marshall BJ, Plankey MW, Dye KR, Frierson H, Hoffman SR, Barrett $L$, et al. A rapid c-14 urea breath test for the diagnosis of c-pylori associated gastritis. Clinical Research 1988;36(1):A14.

\section{Marshall 1991}

Marshall BJ, Plankey MW, Hoffman SR, Boyd CL, Dye KR, Frierson HF Jr, et al. A 20-minute breath test for Helicobacter pylori. American Journal of Gastroenterology 1991;86(4):438-45.

\section{Marshall 1999}

Marshall JK, O'Brien BJ, Armstrong D. C-13-urea breath test or h-pylori serology for the initial evaluation of young patients with ulcer-like dyspepsia: A decision analysis. Gastroenterology 1999;116(4 (suppl)):A78.

\section{Marusic 2006}

Marusic M, Presecki V, Katicic M, Dominis M, Kalenic S. The place and role of serologic methods in detecting Helicobacter pylori infection. Collegium Antropologicum 2006;30(3):529-33.

\section{Masoero 2000}

Masoero G, Lombardo L, Della Monica P, Vicari S, Crocilla C, Duglio A, et al. Discrepancy between Helicobacter pylori stool antigen assay and urea breath test in the detection of Helicobacter pylori infection. Digestive \& Liver Disease 2000;32(4):285-90.

\section{Massarrat 2012}

Massarrat S, Sheykholeslami A. Serum pepsinogen ii as a good marker for mass screening and eradication of $h$. Pylori infection in populations at risk for gastric cancer. Archives of Iranian Medicine 2012;15(4):265-6.

\section{Matougui 2007}

Matougui N, Boudjella MA, Oumnia N, Lahcene M, Tebaibia A, Mouffok F, et al. Evaluation of pronto-dry test versus c-13 urea breath test in determining Helicobacter pylori status after treatment. Helicobacter 2007;12(4):445.

\section{Matsuda 2003a}

Matsuda M, Noda Y, Takemori Y. Utility and limitations of a method for detecting Helicobacter pylori-specific antigens in the stool. Journal of Gastroenterology 2003;38(3):222-8.

\section{Matsuda 2003b}

Matsuda M, Noda Y, Takemori Y. Novel diagnostic method of testing for Helicobacter pylori infection using the rapid leukocyte strip test, leukostix. Journal of Gastroenterology and Hepatology 2003;18(10):1196-201.

\section{Matsukura 1995}

Matsukura N, Onda M, Tokunaga A, Kato S, Yamashita K, Ohbayashi M. Detection of Helicobacter pylori DNA in gastric juice by the polymerase chain reaction: Comparison with findings in bacterial culture and the detection of tissue iga and serum igg antibodies against Helicobacter pylori. Journal of Gastroenterology 1995;30(6):689-95.

\section{Matsukura 2004}

Matsukura N, Tajiri T, Kato S, Togashi A, Masuda G, Tokunaga A, et al. Diagnostic value of culture, histology and PCR for Helicobacter pylori in the remnant stomach after surgery. Alimentary Pharmacology \& Therapeutics 2004;20 Suppl 1:33-8.

\section{Matsuo 2000}

Matsuo K, Hamajima N, Tominaga S, Suzuki T, Nakamura T, Matsuura A, et al. Helicobacter pylori igg antibody test established in the United States showed a substantially lower sensitivity for Japanese population. American Journal of Gastroenterology 2000;95(6):1597-8.

\section{Mattar 1999}

Mattar R, Silva FM, Alexandrino AM, Laudanna AA. Validation of 14c-urea breath test for diagnosis of Helicobacter pylori. Revista do Instituto de Medicina Tropical de Sao Paulo 1999;41(1):3-8.

\section{Mattar 2014}

Mattar R, Villares CA, Marostegam PF, Chaves CE, Pinto VB, Carrilho FJ. Low dose capsule based 13C-urea breath test compared with the conventional $13 \mathrm{C}$-urea breath test and invasive tests. Arquivos de Gastroenterologia 2014;51(2):133-8.

\section{Matthews 2000}

Matthews GM, Butler RN, Cummins AG, Lawrence A, Johnson B, Campbell F. The c-13-urea breath test reflects the severity of Helicobacter pylori associated antral inflammation. Gastroenterology 2000;118(4 (Part 2)):A1272.

\section{Matthews 2005}

Matthews GM, Cummins AG, Lawrence A, Johnson B, Campbell F, Butler RN. 13C-urea breath test: Reproducibility and association with the severity of Helicobacter pyloriassociated antral gastritis. Journal of Gastroenterology and Hepatology 2005;20(2):270-4.

\section{Mauro 2006a}

Mauro M, Radovic V, Zhou P, Wolfe M, Kamath M, Bercik P, et al. ${ }^{13} \mathrm{C}$ urea breath test for Helicobacter pylori: determination of the optimal cut-off point in a Canadian community population. Canadian Journal of Gastroenterology 2006;20(12):770-4.

\section{Mauro 2006b}

Mauro M, Radovic V, Wolfe M, Kamath M, Bercik P, Armstrong D. C-13 urea breath test for Helicobacter pylori: Evaluation of 10minute breath collection. Canadian Journal of Gastroenterology 2006;20(12):775-8.

\section{McColl 1997}

McColl KE, El-Nujumi A, Murray L, El-Omar E, Gillen D, Dickson A, et al. The Helicobacter pylori breath test: A surrogate marker for peptic ulcer disease in dyspeptic patients. Gut 1997;40(3):302-6.

\section{McColl 2003}

McColl KE, Murray LS, Gillen D, Delaney B. Noninvasive Helicobacter pylori testing was as effective as endoscopy for managing dyspepsia. Evidence-Based Medicine 2003;8(1):20-1. 


\section{McNamara 1999}

McNamara D, Whelan H, Hamilton H, Beattie S, O'Morain C. Hpsa: Assessment of a new non-invasive diagnostic assay for Helicobacter pylori infection in an Irish population. Irish Journal of Medical Science 1999;168(2):111-3.

\section{McNulty 1999}

McNulty CA, Nair P, Watson BE, Uff JS, Valori RM. A comparison of six commercial kits for Helicobacter pylori detection. Communicable Disease \& Public Health 1999;2(1):59-63.

\section{McNulty 2005}

McNulty C, Teare L, Owen R, Tompkins D, Hawtin P, McColl K. Test and treat for dyspepsia - but which test?. BMJ 2005;330(7483):105-6.

\section{Mediero 2007}

Mediero GG, Ramos JM, Garcia JI, Varela IO, Del Blanco T, Conde JAS. Evaluation of Helicobacter pylori stool antigen test for the detection of h-pylori infection in paediatric patients. International Journal of Antimicrobial Agents 2007;29:S641.

\section{Megraud 1988}

Megraud F. Comparison of different tests for campylobacter pylori. Scandinavian Journal of Gastroenterology - Supplement 1988;142:64-8.

\section{Megraud 2000}

Megraud F, Burette A, Glupczynski Y, Fiocca R, Logan R, Quina M, et al. Comparison of tests for assessment of Helicobacter pylori eradication: Results of a multi-centre study using centralized facility testing. European Journal of Gastroenterology \& Hepatology 2000;12(6):629-33.

\section{Megraud 2005}

Megraud F, European PTFonHp. Comparison of non-invasive tests to detect Helicobacter pylori infection in children and adolescents: Results of a multicenter European study. Journal of Pediatrics 2005;146(2):198-203.

\section{Mehrazma 2014}

Mehrazma M, Nakhaii S, Talachian E, Harahdashti AL. Diagnostic accuracy of Helicobacter pylori stool antigen test in iranian children. Infectious Diseases in Clinical Practice 2014;22(3):154-6.

\section{Meijer 1997}

Meijer BC, Thijs JC, Kleibeuker JH, Van Zwet AA, Berrelkamp RJP. Evaluation of eight enzyme immunoassays for detection of immunoglobulin g against Helicobacter pylori. Journal of Clinical Microbiology 1997;35(1):292-4.

\section{Meltzer 2013}

Meltzer AC, Pierce R, Cummings DAT, Pines JM, May L, Smith MA, et al. Rapid ${ }^{13} \mathrm{C}$ urea breath test to identify Helicobacter pylori infection in emergency department patients with upper abdominal pain. Western Journal of Emergency Medicine 2013;14(3):278-82.

\section{Mendall 1992}

Mendall MA, Goggin PM, Marrero JM, Molineaux N, Levy J, Badve S, et al. Role of Helicobacter pylori serology in screening prior to endoscopy. European Journal of Gastroenterology \& Hepatology 1992;4(9):713-7.

\section{Mendoza 2006}

Mendoza RB, Sio-Aguilar JO. The validity of Helicobacter pylori immunochromatographic stool antigen test and campylobacter urease test in the diagnosis of Helicobacter pylori infection among pediatric patients. Journal of Gastroenterology and Hepatology 2006;21:A392.

\section{Menegatti 1997a}

Menegatti M, Vaira D, Stanghellini V, Ali A, Landi F, Ricci C, et al. Comparison of c-13-vs c-14-urea breath test (ubt) for Helicobacter pylori (hp). Gastroenterology 1997;112(4 (suppl)):A218.

\section{Menegatti 1997b}

Menegatti M, Stanghellini V, Landi F, Farinelli S, Mucci F, Ali A, et al. C-13 with and without test meal vs C-14 urea breath test (ubt) to detect h-pylori before and after treatment. Gut 1997;41(Suppl):A162-A3.

\section{Metz 1998}

Metz DC, Furth EE, Faigel DO, Kroser JA, Alavi A, Barrett DM, et al. Realities of diagnosing Helicobacter pylori infection in clinical practice: A case for non-invasive indirect methodologies. Yale Journal of Biology \& Medicine 1998;71(2):81-90.

\section{Metz 2000}

Metz DC. Stool testing for Helicobacter pylori infection: Yet another noninvasive alternative. American Journal of Gastroenterology 2000;95(2):546-8.

\section{Midolo 1995}

Midolo PD, Lambert JR, Russell EG, Lin SK. A practical single sample dry latex agglutination test for Helicobacter pylori antibody detection. Journal of Clinical Pathology 1995;48(10):969-71.

\section{Miehlke 1996}

Miehlke S, Figura N, Kim JG, Small SM, Graham DY, Do MF. Western blotting for detection of Helicobacter pylori anti-caga antibodies strongly correlates with presence of the caga gene. Gastroenterology 1996;110(4 (suppl)):A197.

\section{Miftahussurur 2016}

Miftahussurur M, Yamaoka Y. Diagnostic methods of Helicobacter pylori infection for epidemiological studies: Critical importance of indirect test validation. BioMed Research International 2016; Vol. 2016:4819423. [DOI: $10.1155 / 2016 / 4819423]$

\section{Minoli 1998}

Minoli G, Prada A, Schuman R, Murnick D, Rigas B. A simplified urea breath test for the diagnosis of Helicobacter pylori infection using the lara system. Journal of Clinical Gastroenterology 1998;26(4):264-6. 


\section{Mion 1996}

Mion F, Rousseau M. Diagnostic tests to document Helicobacter pylori eradication. Gastroenterology 1996;110(1 (suppl)):324-5.

\section{Mion 1997a}

Mion F, Rosner G, Rousseau M, Minaire Y. 13C-urea breath test for Helicobacter pylori: Cut-off point determination by cluster analysis. Clinical Science 1997;93(1):3-6.

\section{Mion 1997b}

Mion F, Rosner G, Rousseau M, Brazier JL. C-13-urea breath test for Helicobacter pylori: Optimal cutoff point determination by roc curve and cluster analysis. Clinical Chemistry 1997;43(6 (Suppl 2)):17.

\section{Mion 2001}

Mion F, Ecochard R, Guitton J, Ponchon T. (co2)-c-13 breath tests: Comparison of isotope ratio mass spectrometry and nondispersive infrared spectrometry results. Gastroenterologie Clinique Et Biologique 2001;25(4):375-9.

\section{Mirbagheri 2005}

Mirbagheri SA, Sohrabpour AA, Hasibi M, Moghimi B, Mohamadnejad M. 14c-urea breath test in patients undergoing anti-tuberculosis therapy. World Journal of Gastroenterology 2005;11(11):1712-4.

\section{Mitchell 1988}

Mitchell HM, Lee A, Berkowicz J, Borody T. The use of serology to diagnose active campylobacter pylori infection. Medical Journal of Australia 1988;149(11-12):604-9.

\section{Miwa 1997}

Miwa H, Murai T, Ohkura R, Kawabe M, Tanaka H, Ogihara T, et al. Effect of fasting subjects' posture on c-13-urea breath test for detection of Helicobacter pylori infection. Helicobacter 1997;2(2):82-5.

\section{Miwa 1998a}

Miwa H, Ohkura R, Nagahara A, Murai T, Ogihara T, Watanabe S, et al. C-13 -urea breath test for assessment of cure of Helicobacter pylori infection at 1 month after treatment. Journal of Clinical Gastroenterology 1998;27:S150-S3.

\section{Miwa 1998b}

Miwa H, Murai T, Ohkura R, Nagahara A, Watanabe H, Terai T, et al. Usefulness of the c-13 -urea breath test for detection of Helicobacter pylori infection in fasting patients. Journal of Gastroenterology and Hepatology 1998;13(10):1039-43.

\section{Miwa 1999}

Miwa H, Hirose M, Kikuchi S, Terai T, Iwazaki R, Kobayashi O, et al. How useful is the detection kit for antibody to Helicobacter pylori in urine (urinelisa) in clinical practice?. American Journal of Gastroenterology 1999;94(12):3460-3.

\section{Miwa 2000}

Miwa H, Kikuchi S, Ohtaka K, Kobayashi O, Ogihara A, Hojo M, et al. Insufficient diagnostic accuracy of imported serological kits for Helicobacter pylori infection in Japanese population. Diagnostic Microbiology \& Infectious Disease 2000;36(2):95-9.

\section{Miwa 2001}

Miwa H, Akamatsu S, Tachikawa T, Sogabe T, Ohtaka K, Nagahara A, et al. On-site diagnosis of h-pylori infection by urine. Diagnostic Microbiology and Infectious Disease 2001;39(2):95-7.

\section{Mizukami 1994}

Mizukami T, Osawa T, Niwa M, Oya A, Masubuchi N, Takahashi S. An enzyme-linked immunosorbent assay for the detection of igg antibodies against urease of Helicobacter pylori. Rinsho Byori [Japanese Journal of Clinical Pathology] 1994;42(11):1188-93.

\section{Moayyedi 1997}

Moayyedi P, Braunholtz D, Heminbrough E, Clough M, Tompkins DS, Mapstone NP, et al. Do patients need to fast for a c-13-urea breath test?. European Journal of Gastroenterology \& Hepatology 1997;9(3):275-7.

\section{Mock 1999}

Mock T, Yatscoff R, Foster R, Hyun JH, Chung IS, Shim CS, et al. Clinical validation of the helikit ${ }^{\mathrm{TM}}$ : A c-13 urea breath test used for the diagnosis of Helicobacter pylori infection. Clinical Biochemistry 1999;32(1):59-63.

\section{Mohammadi 2008}

Mohammadi M, Talebkhan Y, Khalili G, Mahboudi F, Massarrat S, Zamaninia L, et al. Advantage of using a home-made ELISA kit for detection of Helicobacter pylori infection over commercially imported kits. Indian Journal of Medical Microbiology 2008;26(2):127-31.

\section{Moncayo 2006}

Moncayo JI, Santacruz JJ, Alvarez AL, Franco B, Lopez MA Angel A, et al. Comparison of methods in the diagnosis of Helicobacter pylori infection in Quindio, Colombia. Colombia Medica 2006;37(3):203-12.

\section{Monteiro 2001b}

Monteiro L, Gras N, Megraud F. Magnetic immuno-PCR assay with inhibitor removal for direct detection of Helicobacter pylori in human feces. Journal of Clinical Microbiology 2001;39(10):3778-80.

\section{Morales 2002}

Morales A, Hurtado C, Madrid AM, Pimentel C, Espinosa MN. An ELISA stool test to detect Helicobacter pylori infection. Revista Medica de Chile 2002;130(1):61-5.

\section{Moshkowitz 1993}

Moshkowitz M, Peled Y, Baratz M, Halpern Z, Tiomny E, Gilat T. $14 \mathrm{c}$-urea breath test--a simple, noninvasive method for the detection of Helicobacter pylori infection. Israel Journal of Medical Sciences 1993;29(2-3):94-7.

\section{Motta 2009}

Motta O, De Caro F, Quarto F, Proto A. New FTIR methodology for the evaluation of $(13) C /(12) C$ isotope ratio in Helicobacter pylori infection diagnosis. Journal of Infection 2009;59(2):90-4. 


\section{Moulton-Barrett 1993}

Moulton-Barrett R, Triadafilopoulos G, Michener R, Gologorsky D. Serum 13C-bicarbonate in the assessment of gastric Helicobacter pylori urease activity. American Journal of Gastroenterology 1993;88(3):369-74.

\section{Mowat 1997}

Mowat C, Murray L, Hilditch TE, Kelman A, Oien K, McColl KEl. Comparison of helisal test kit and c-14-urea breath test in determining h-pylori status and predicting ulcer disease in dyspeptic patients. Gastroenterology 1997;112(4 (suppl)):A226.

\section{Mowat 1998}

Mowat C, Murray L, Hilditch TE, Kelman A, Oien K, McColl KE. Comparison of helisal rapid blood test and 14c-urea breath test in determining Helicobacter pylori status and predicting ulcer disease in dyspeptic patients. American Journal of Gastroenterology 1998;93(1):20-5.

\section{Mrevlje 2012}

Mrevlje Z, Plut S, Jeverica S, Osredkar J, Stabuc B. Comparison of success rates of noninvasive and invasive methods in diagnosis of Helicobacter pylori infection. Helicobacter 2012;17:94.

\section{Muhsen 2006}

Muhsen K, Athamna A, Athamna M, Spungin-Bialik A, Cohen D. Evaluation of a urine-based enzyme-linked immunosorbent assay test for the detection of Helicobacter pylori infection among 3- to 5-year-old Israeli Arab healthy children. Journal of Pediatric Gastroenterology \& Nutrition 2006;43(3):398-401.

\section{Muhsen 2012}

Muhsen K, Jurban M, Goren S, Cohen D. Incidence, age of acquisition and risk factors of Helicobacter pylori infection among Israeli Arab infants. Journal of Tropical Pediatrics 2012;58(3):208-13.

\section{Munster 1993}

Munster DJ, Chapman BA, Burt MJ, Dobbs BR, Allardyce RA, Bagshaw PF, et al. The fate of ingested 14c-urea in the urea breath test for Helicobacter pylori infection. Scandinavian Journal of Gastroenterology 1993;28(8):661-6.

\section{Murakami 2003}

Murakami K, Sato R, Okimoto T, Watanabe K, Nasu M, Fujioka T, et al. Influence of anti-ulcer drugs used in Japan on the result of c-13-urea breath test for the diagnosis of Helicobacter pylori infection. Journal of Gastroenterology 2003;38(10):937-41.

\section{Murakami 2011}

Murakami K, Kamada T, Ishikawa H, Imamura H, Matsumoto H, Fujita M, et al. An evaluation of the performance of a novel sticktype kit for rapid detection of Helicobacter pylori antibodies in urine. Clinical Laboratory 2011;57(7-8):481-7.

\section{Murata 2002}

Murata Y, Kojyo A, Ikeda A, Yamanaka K. Study on the detection methods of Helicobacter pylori from clinical specimens. Rinsho Biseibutsu Jinsoku Shindan Kenkyukai Shi [JARMAM :
Journal of the Association for Rapid Method and Automation in Microbiology] 2002;12(2):105-19.

\section{Murphy 2015}

Murphy C, Yamaguchi D, Rainey PM. Helicobacter pylori c-13-urea breath test: The unique challenges of validating a clia-waived test. American Journal of Clinical Pathology 2015;143:A11.

\section{Murugesan 2011}

Murugesan SV, Steele I, Tiszlavicz L, Farragher T, Moore AR, Varro A, et al. Factors that determine the sensitivity of rapid urease tests for the detection of Helicobacter pylori infection. Gastroenterology 2011;140(5 (suppl)):S879.

\section{Muñoz 1998}

Muñoz E, Corcuera M, Roldán M, Gómez F, Picazo A, Baquero $\mathrm{M}$, et al. Comparative study of microbiological and histopathological techniques used for the detection of Helicobacter pylori. European Journal of Histochemistry 1998;42(4):297-302.

\section{Muñoz 1999}

Muñoz C, Jane M, Gonzalez-Cuevas A, Juncosa T, Gene A, Varea $V$, et al. Evaluation of a simple, rapid polymerase chain reaction (PCR) technique for the diagnosis of Helicobacter pylori infection in infancy. Enfermedades Infecciosas $Y$ Microbiologia Clinica 1999;17(3):119-25.

\section{Myllyniemi 2007}

Myllyniemi M, Linnala A, Paloheimo LI, Hendolin P, Engstrand L, Perez GP, et al. Improved specificity of Helicobacter pylori IgA/ IgG ELISA over other H. pylori tests. Helicobacter 2007;12(4):447.

\section{Myllyniemi 2008}

Myllyniemi M, Hendolin P, Telaranta-Keerie A, Nikulin M, Paloheimo LI, Engstrand L, et al. New specific H. pylori IgG ELISA test. Helicobacter 2008;13(5):472-3.

\section{Nagahara 2003}

Nagahara Y, Mizuno M, Maga T, Ishiki K, Okuno T, Yoshida T, et al. Outcome of patients with inconsistent results from c-13urea breath test and bacterial culture at the time of assessment of heliclobacter pylori eradication therapy in Japan. HepatoGastroenterology 2003;50(53):1700-3.

\section{Nair 1995}

Nair P, Stephens JC, Mackay EH, West K, Mayberry JF, Wicks ACB, et al. A simple 3-minute latex agglutination-test for rapid Helicobacter-pylori serodiagnosis. Gastroenterology 1995;108(4):A174.

\section{Nakagawa 1995}

Nakagawa T, Ohara H, Yamamoto M, Yoneshima M, Suzuki T, Murai S, et al. 13C-urea breath test for the detection of Helicobacter pylori infection and the assessment of therapeutic effect. Nippon Shokakibyo Gakkai Zasshi [Japanese Journal of Gastroenterology] 1995;92(3):264. 


\section{Nakata 1995}

Nakata H, Itoh H, Yokoya Y, Kawai J, Nishioka S, Miyamoto K, et al. Serum antibody against Helicobacter pylori assayed by a new capture ELISA. Journal of Gastroenterology 1995;30(3):295-300.

\section{Nakata 2004}

Nakata $\mathrm{H}$, Itoh $\mathrm{H}$, Ishiguchi T, Iwata T, Sato H, Higashimoto Y, et al. Immunological rapid urease test using monoclonal antibody for Helicobacter pylori. Journal of Gastroenterology and Hepatology 2004;19(9):970-4.

\section{Nakayama 2004}

Nakayama K, Konno M, Tajiri H, Matsuhisa T, Kato S, Minoura T, et al. Comparison between the ${ }^{13} \mathrm{C}$-urea breath test and stool antigen test for the diagnosis of childhood Helicobacter pylori infection. Journal of Gastroenterology 2004;39(11):1045-50.

\section{Naruki 1996}

Naruki Y, Koyama H, Kurita T, Nishino M, Higashi Y, Otsuka S, et al. Evaluation of $\mathrm{c}-13$ urea breath test in a diagnosis of Helicobacter pylori. Journal of Nuclear Medicine 1996;37(5 (suppl)):246 (abstract 1103).

\section{Navarro 1992}

Navarro F, Coll P, Sainz S, Mirelis B, Cardenosa N, Alonso C, et al. Evaluation of two different commercial kits for Helicobacter pylori specific antibodies detection in patients undergoing gastrointestinal endoscopic procedures. A seroprevalence study in asymptomatic population. Enfermedades Infecciosas $Y$ Microbiologia Clinica 1992;10(4):190-4.

\section{NCBI 2014}

NCBI. MeSH. NLM Controlled Vocabulary. Helicobacter pylori. www.ncbi.nlm.nih.gov/mesh/68016480 (accessed 3 August 2014).

\section{Negayama 1992}

Negayama K, Terada S, Kawanishi K. Clinical significance of antiHelicobacter pylori antibody in the diagnosis of Helicobacter pylori infection in chronic gastritis. Kansenshogaku Zasshi [Journal of the Japanese Association for Infectious Diseases] 1992;66(11):1597-8.

\section{Negrini 1992}

Negrini R, Zanella I, Savio A, Poiesi C, Verardi R, Ghielmi S, et al. Serodiagnosis of Helicobacter pylori-associated gastritis with a monoclonal antibody competitive enzymelinked immunosorbent assay. Scandinavian Journal of Gastroenterology 1992;27(7):599-605.

\section{Neri 1999}

Neri M, Angelucci D, Laterza F, Ricciuti M, Del Duca L, Di Matteo $S$, et al. False negativity of c-13 urea breath test in the presence of coccoid forms of h.Pylori: Effects on the sensitivity of the test. Gastroenterology 1999;116(4 (suppl)):A265.

\section{Neumann 2010}

Neumann H, Foertsch S, Vieth M, Mudter J, Kuth R, Neurath MF. Immediate detection of Helicobacter infection with a novel electrochemical system: Feasibility and comparison of diagnostic yield with immunohistochemistry, $13 \mathrm{C}$ urea breath test and Helicobacter urease test. Gastroenterology 2010;138(5 (suppl 1)):S114.

\section{Neumann 2011}

Neumann H, Foertsch S, Vieth M, Kuth R, Roll S, Neurath MF. A newly developed electrochemical device enables accurate and immediate detection of h. Pylori infection within 10 seconds. Gastroenterology 2011;140(5 (suppl)):S58.

\section{Neumann 2012}

Neumann H, Foertsch S, Ritter B, Vieth M, Kuth R, Neurath MF. Final data of a new electrochemical device that enables rapid and accurate detection of Helicobacter pylori infection. Gastroenterology 2012;142(5 (Suppl 1)):S484.

\section{Newell 1988}

Newell DG, Johnston BJ, Ali MH, Reed PI. An enzymelinked immunosorbent assay for the serodiagnosis of campylobacter pylori-associated gastritis. Scandinavian Journal of Gastroenterology - Supplement 1988;142:53-7.

\section{Newell 1989a}

Newell DG, Rathbone BJ. The serodiagnosis of campylobacter pylori infection. Serodiagnosis and Immunotherapy in Infectious Disease 1989;3(1):1-6.

\section{Newell 1989b}

Newell DG, Stacey A. Antigens for the serodiagnosis of campylobacter pylori infections. Gastroenterologie Clinique et Biologique 1989;13(1 Pt 1):37B-41B.

\section{Newell 1991}

Newell DG, Hawtin PR, Stacey AR, MacDougall MH, Ruddle AC. Estimation of prevalence of Helicobacter pylori infection in an asymptomatic elderly population comparing [14c] urea breath test and serology. Journal of Clinical Pathology 1991;44(5):385-7.

\section{$\mathrm{Ng} 2002$}

Ng FH, Lai KC, Wong BC, Wong WM, Wong SY, Chow KC, et al. [13C]-urea breath test without prior fasting and without test meal is accurate for the detection of Helicobacter pylori infection in Chinese. Journal of Gastroenterology and Hepatology 2002;17(8):834-8.

\section{$\mathrm{Ng} 2013$}

$\mathrm{Ng}$ TH, Rosaida R. Evaluation of serology and urea breath test as reliable diagnostic test for h.Pylori infection. Journal of Gastroenterology and Hepatology 2013;28:97.

\section{Nguyen 2008a}

Nguyen TV, Bengtsson C, Nguyen GK, Granstrom M. Evaluation of a novel monoclonal-based antigen-in-stool enzyme immunoassay (premier platinum HPSA plus) for diagnosis of Helicobacter pylori infection in Vietnamese children. Helicobacter 2008;13(4):269-73.

\section{Nguyen 2008b}

Nguyen TVH, Bengtsson C, Nguyen GK, Granstrom M. Evaluation of a novel monoclonal-based antigen-in-stool enzyme immunoassay (premier platinum HPSA plus) for diagnosis 
of Helicobacter pylori infection in Vietnamese children. Helicobacter 2008;13(4):269-73.

\section{Nguyen 2010}

Nguyen LT, Uchida T, Tsukamoto Y, Trinh TD, Ta L, Ho DQD, et al. Evaluation of rapid urine test for the detection of Helicobacter pylori infection in the Vietnamese population. Digestive Diseases and Sciences 2010;55(1):89-93.

\section{Nguyen 2012}

Nguyen VB, Nguyen GK, Ha Nguyen TV, Ha Hoang TT, Anh Le TL, Xuan Nguyen TA, et al. Helicobacter pylori (hp) infection in Vietnam: Epidemiology, symptomatology, diagnosis and treatment in children. Journal of Gastroenterology and Hepatology 2012;27:46.

\section{Nguyen 2013}

Nguyen B, Anhthi Nguyen V, Nguyen K, Anhthi Le L, Hathi Nguyen V, Hathi Hoang T, et al. Helicobacter pylori (hp) infection in Vietnam: Epidemiology, symptomatology, diagnosis and treatment in children. Journal of Gastroenterology and Hepatology 2013;28:550-1.

\section{Ni 2000}

$\mathrm{Ni}$ YH, Lin JT, Huang SF, Yang JC, Chang MH. Accurate diagnosis of Helicobacter pylori infection by stool antigen test and six other currently available tests in children. Gastroenterology 2000;118(4):A1283.

\section{Nightingale 1996}

Nightingale SL. Breath test for Helicobacter pylori collection kit approved. Journal of the American Medical Association 1996;276(21):1710.

\section{Nijevitch 2001}

Nijevitch AA, Sataev VU. The reliability of urease tests for Helicobacter pylori in childhood. Journal of Clinical Gastroenterology 2001;32(3):277-9.

\section{Nilius 2001}

Nilius M, Wex T, Muller-Dietz G, Leodolter A, Schilling D, Malfertheiner P. Comparative evaluation of two hemagglutination tests for the detection of anti-Helicobacter pylori antibodies. Diagnostic Microbiology \& Infectious Disease 2001;41(4):221-3.

\section{Nishi 1998}

Nishi I, Irie H, Watanabe N, Futami J, Suzuki H, Ichinose Y, et al. Urea breath test "breath by breath measurement" of (v)over$\operatorname{dot}(13) \operatorname{co}(2)$ and (v)over-dot(12)co(2): An approach to the quantitative evaluation for the therapeutic elimination of $h$ pylori. Gastroenterology 1998;114(4 (suppl)):A243.

\section{Nishikawa 1996}

Nishikawa K, Katagiri M, Kagaya H, Kudo M, Kato M, Takeda H, et al. Evaluation of rapid urease tests for Helicobacter pylori in biopsy specimens, compared with culture and c-13-urea breath test. Gastroenterology 1996;110(4 (suppl)):A212.

\section{Nishikawa 1999}

Nishikawa K, Kato M, Sugiyama T, Asaka M. Helicobacter pylori, serum igg antibody, urea breath test. Nippon Rinsho 1999;57(Suppl):154-6.

\section{Nishikawa 2000}

Nishikawa K, Sugiyama T, Kato M, Ishizuka J, Kagaya H, Hokari K, et al. A prospective evaluation of new rapid urease tests before and after eradication treatment of Helicobacter pylori, in comparison with histology, culture and c-13-urea breath test. Gastrointestinal Endoscopy 2000;51(2):164-8.

\section{Nishizono 1998}

Nishizono A, Gotoh T, Fujioka T, Murakami K, Kubota T, Nasu M, et al. Serological assessment of the early response to eradication therapy using an immunodominant outer membrane protein of Helicobacter pylori. Clinical \& Diagnostic Laboratory Immunology 1998;5(6):856-61.

\section{Niv 1998}

Niv Y, Sperber AD, Scapa E, Maoz E, Fraser G, Druzd T, et al. A comparison of new rapid urease tests for detection of Helicobacter pylori: Test characteristics and factors affecting positivity and time to positivity. Journal of Clinical Gastroenterology 1998;27(4):327-30.

\section{Niv 2000}

Niv Y, Abuksis G, Ben-Gur S, Koren K. 13C-urea breath test (13Cubt) for validation of successful Helicobacter pylori eradication. Evaluation of 1371 patients. Gastroenterology 2000;118(4 (part 2)):A1284.

\section{Niv 2003}

Niv Y, Abuksis G, Koren R. $13 \mathrm{C}$ urea breath test (13C ubt) for Helicobacter pylori (hp) diagnosis in geriatrics. Gastroenterology 2003;124(4 (suppl)):A625.

\section{Noguchi 2007}

Noguchi N, Rimbara E, Kato A, Tanaka A, Tokunaga K, Kawai T, et al. Detection of mixed clarithromycin-resistant and -susceptible Helicobacter pylori using nested PCR and direct sequencing of DNA extracted from faeces. Journal of Medical Microbiology 2007;56(9):1174-80.

\section{Notarnicola 1996}

Notarnicola M, Russo F, Cavallini A, Bianco M, Jirillo E, Pece S, et al. PCR identification of Helicobacter pylori DNA in faeces from patients with gastroduodenal pathology. Medical Science Research 1996;24(11):785-7.

\section{Nugalieva 2006}

Nugalieva ZZ, Opekun AR, Graham DY. Problem of distinguishing false-positive tests from acute or transient Helicobacter pylori infections. Helicobacter 2006;11(2):69-74.

\section{Nurgalieva 2003}

Nurgalieva Z, Goodman KJ, Wang C, Day RS, Campos A, de la Rosa J. Detection of Helicobacter pylori infection in children followed from birth: Correspondence of serology and the urea breath test. American Journal of Epidemiology 2003;157(11):S85-S. 


\section{Nurgalieva 2008}

Nurgalieva Z, Goodman KJ, Phillips CV, Fischbach L, de la Rosa JM, Gold BD. Correspondence between Helicobacter pylori antibodies and urea breath test results in a USMexico birth cohort. Paediatric and Perinatal Epidemiology 2008;22(3):302-12

\section{Nysaeter 1992}

Nysaeter G, Berstad K, Weberg R, Berstad A, Hardardottir H. Diagnosis of Helicobacter pylori infection. Rapid urease test, microscopy of smears and culture from ventricular biopsy compared with the 14c-urea breath test. Tidsskrift for Den Norske Laegeforening 1992;112(18):2356-8.

\section{O'Connor 2010}

O'Connor A, O'Morain NR, Dobson M, Qasim A, Ryan BM, Breslin N, et al. Helicobacter pylori eradication treatment is more successful when diagnosis is made after urea breath test than after rapid urease testing at endoscopy in patients with dyspepsia. Gastroenterology 2010;138(5 (suppl 1)):S340.

\section{Oak 2011}

Oak JH, Chung WC, Jung SH, Choi KH, Kim EJ, Kang BK, et al. Effect of acid pump antagonist (revaprazan, revanex(r)) on result of $13 \mathrm{C}$ urea breath test in patients with Helicobacter pylori associated peptic ulcer disease. Taehan Sohwagi Hakhoe Chi Korean Journal of Gastroenterology] 2011;57(1):8-13.

\section{Obata 2003}

Obata Y, Kikuchi S, Miwa H, Yagyu K, Lin YS, Ogihara A. Diagnostic accuracy of serological kits for Helicobacter pylori infection with the same assay system but different antigens in a Japanese patient population. Journal of Medical Microbiology 2003;52(10):889-92.

\section{Obradovic 2001}

Obradovic V, Artiko V, Petrovic M, Petrovic N, Davidovic B, Bosnjakovic V, et al. Detection of Helicobacter pylori infection using 14-c urea breath test. European Journal of Nuclear Medicine 2001;28(8):1188.

\section{Odaka 2002}

Odaka T, Yamaguchi T, Koyama H, Saisho H, Nomura F. Evaluation of the Helicobacter pylori stool antigen test for monitoring eradication therapy. American Journal of Gastroenterology 2002;97(3):594-9.

\section{Oderda 1989}

Oderda G, Vaira D, Holton J, Dowsett JF, Ansaldi N. Serum pepsinogen $\mathrm{i}$ and igg antibody to campylobacter pylori in nonspecific abdominal pain in childhood. Gut 1989;30(7):912-6.

\section{Oderda 1998a}

Oderda G, Garisio P, Harding M, Thomas JE. Use of the c-13 urea breath test for the diagnosis of Helicobacter pylori infection in childhood. Gut 1998;43:S11-S2.

\section{Oderda 1998b}

Oderda G, Harding M, Thomas JE, Coward WA, Bazzoli F, Zagari M, et al. The c-13 urea breath test to assess Helicobacter pylori eradication in childhood $\mathrm{h}$ pylori gastritis. Gut 1998;43(Suppl 3):S9-S10.

\section{Oderda 1999}

Oderda G, Rapa A, Ronchi B, Lerro P, Pastore M, Staiano A, et al. Evaluation of the Helicobacter pylori stool antigen test (HPSA) for detection of h-pylori infection in children. A multicentre Italian study. Gut 1999;45(Suppl 3):A93-A4.

\section{Oderda 2000}

Oderda G, Rapa A, Ronchi B, Lerro P, Pastore M, Staiano A, et al. Detection of Helicobacter pylori in stool specimens by noninvasive antigen enzyme immunoassay in children: Multicentre Italian study. BMJ 2000;320(7231):347-8.

\section{Oderda 2004}

Oderda G, Rapa A, Bona G. Diagnostic tests for childhood Helicobacter pylori infection: Invasive, noninvasive or both?. Journal of Pediatric Gastroenterology and Nutrition 2004;39(5):482-4.

\section{Ogunc 2003}

Ogunc D, Artan R, Ongut G, Gelen T, Colak D, Donmez L, et al. Evaluation of a western blot technique (helicoblot 2.1) for the diagnosis of Helicobacter pylori infection in children. Pathology 2003;35(2):157-60.

\section{Ohara 1995}

Ohara H, Suzuki T, Nakagawa T, Yoneshima M, Yamamoto M, Tsujino D, et al. 13C-ubt using an infrared spectrometer for detection of Helicobacter pylori and for monitoring the effects of lansoprazole. Journal of Clinical Gastroenterology 1995;20 Suppl 2:S115-7.

\section{Ohara 1996}

Ohara S, Sekine H, Moriyama S, Sugiyama K, Arikawa T, lijima K, et al. Methodological study of ${ }^{13} \mathrm{C}$ urea breath test for detection of Helicobacter pylori infection. Japanese Journal of Gastroenterology 1996;93(8):530-6.

\section{Ohara 1997}

Ohara S, Kato M, Asaka M, Toyota T. Cut-off vague and clinical utility of c-13-urea breath test for diagnosis of Helicobacter pylori infection. Gastroenterology 1997;112(4 (suppl)):A241.

\section{Ohara 1998a}

Ohara S, Kato M, Asaka M, Toyota T. Studies of 13C-urea breath test for diagnosis of Helicobacter pylori infection in Japan. Journal of Gastroenterology 1998;33(1):6-13.

\section{Ohara 1998b}

Ohara S, Kato M, Asaka M, Toyota T. The ubit-100 13Co2 infrared analyzer: Comparison between infrared spectrometric analysis and mass spectrometric analysis. Helicobacter 1998;3(1):49-53.

\section{Ohara 2004}

Ohara S, Kato M, Saito M, Fukuda S, Kato C, Hamada S, et al. Comparison between a new c-13-urea breath test, using a film-coated tablet, and the conventional c-13-urea breath test for the detection of Helicobacter pylori infection. Journal of Gastroenterology 2004;39(7):621-8. 


\section{Ohkura 1998}

Ohkura R. Usefulness of Helicobacter pylori stool antigen (HPSA) assay for detection of Helicobacter pylori infection. Japanese Journal of Gastroenterology 1998;95(12):1397.

\section{Ohkura 2000}

Ohkura R, Miwa H, Murai T, Nagahara A, Ohta K, Sato K, et al. Usefulness of a novel enzyme immunoassay for the detection of Helicobacter pylori in feces. Scandinavian Journal of Gastroenterology 2000;35(1):49-53.

\section{Oksanen 1997}

Oksanen A, Bergstrom M, Sjostedt S, Gad A, Hammarlund B, Seensalu R. Accurate detection of Helicobacter pylori infection with a simplified c-13 urea breath test. Scandinavian Journal of Clinical \& Laboratory Investigation 1997;57(8):689-94.

\section{Oksanen 1998}

Oksanen A, Veijola L, Sipponen P, Schauman KO, Rautelin H. Evaluation of Pyloriset screen, a rapid whole-blood diagnostic test for Helicobacter pylori infection. Journal of Clinical Microbiology 1998;36(4):955-7.

\section{Oksanen 2001}

Oksanen A, Sipponen P, Sarna S, Rautelin H. Serologic diagnosis of Helicobacter pylori infection in outpatients aged 45 years or less. European Journal of Clinical Microbiology \& Infectious Diseases 2001;20(8):554-7.

\section{Okuda 2002}

Okuda M, Miyashiro E, Koike M, Tanaka T, Bouoka M, Okuda S, et al. Serodiagnosis of Helicobacter pylori infection is not accurate for children aged below 10 . Pediatrics International 2002;44(4):387-90.

\section{Okuda 2004}

Okuda M, Nakazawa T, Booka M, Miyashiro E, Yosikawa N. Evaluation of a urine antibody test for Helicobacter pylori in Japanese children. Journal of Pediatrics 2004;144(2):196-9.

\section{Okuda 2005}

Okuda M, Sugiyama T, Fukunaga K, Kondou M, Miyashiro E, Nakazawa T. A strain-specific antigen in Japanese Helicobacter pylori recognized in sera of Japanese children. Clinical \& Diagnostic Laboratory Immunology 2005;12(11):1280-4.

\section{Okuda 2010}

Okuda M, Oomatsu H, Kotake J, Fukuda N, Yamamoto N, Sakaedani N, et al. Evaluation of urine antibody test for $h$. pylori in Japanese children. Helicobacter 2010;15(4):361.

\section{Okuda 2013}

Okuda M, Kamiya S, Booka M, Kikuchi S, Osaki T, Hiwatani T, et al. Diagnostic accuracy of urine-based kits for detection of Helicobacter pylori antibody in children. Pediatrics International 2013;55(3):337-41.

\section{Okuda 2014}

Okuda M, Osaki T, Kikuchi S, Ueda J, Lin YS, Yonezawa H, et al. Evaluation of a stool antigen test using a mab for native catalase for diagnosis of Helicobacter pylori infection in children and adults. Journal of Medical Microbiology 2014;63:1621-5.

\section{Olafsson 2012}

Olafsson S, Patel B, Jackson C, Cai J. Helicobacter pylori breath testing in an open access system has a high rate of potentially false negative results due to protocol violations. Helicobacter 2012;17(5):391-5.

\section{Oleastro 2000}

Oleastro M, Monteiro L, Matos R, Lopes Al, Cabral J, Cabrita J. Evaluation of a western blot test, helico blot 2.1, in the diagnosis of Helicobacter pylori infection in a Portuguese paediatric population. Gut 2000;47(Suppl 1):A98.

\section{Oleastro 2002}

Oleastro M, Matos R, Cabral J, Barros R, Lopes AI, Ramalho P, et al. Evaluation of a western blot test, helico blot 2.1, in the diagnosis of Helicobacter pylori infection in a pediatric population. Helicobacter 2002;7(3):210-5.

\section{Oliaro 2000}

Oliaro J, Johnson RD, Chen WX, Chadwick VS, Murray A. Identification of an immunogenic 18-kda protein of Helicobacter pylori by alkaline phosphatase gene fusions. Journal of Medical Microbiology 2000;49(7):643-50.

\section{Olsson 1993}

Olsson K, Wadstrom T, Tyskiewicz T. PCR identification of Helicobacter pylori in gastritis patients. Lancet 1993;341(8853):1155.

\section{Omorogbe 2015}

Omorogbe JA, Brennan D, Alsaffar M, Smith S, McNamara D, Trinity Acad Gastroenterology G. Comparison of non-invasive tests; stool HpSA ELISA and c13urea breath test in the diagnosis of Helicobacter pylori infection in a low prevalence cohort. Helicobacter 2015;20:89.

\section{Ong 1993}

Ong KK, Goh KL, Parasakthi N. C-14 urea breath test - a useful noninvasive test in the diagnosis of Helicobacter-pylori infection. Gastroenterology 1993;104(4 suppl):A165.

\section{Opekun 2002}

Opekun AR, Abdalla N, Sutton FM, Hammoud F, Kuo GM, Torres $\mathrm{E}$, et al. Urea breath testing and analysis in the primary care office. Journal of Family Practice 2002;51(12):1030-2.

\section{Opekun 2006}

Opekun AR, Luu P, Gotschall AB, Abdalla N, Torres E, Rudd SB, et al. Point-of-care Helicobacter pylori urine antibody detection in a multi-ethnic adult population in the United States. Translational Research: The Journal Of Laboratory \& Clinical Medicine 2006;148(1):13-8.

\section{Ormand 1990}

Ormand JE, Talley NJ, Carpenter HA, Shorter RG, Conley CR, Wilson WR, et al. [14c] urea breath test for diagnosis of Helicobacter pylori. Digestive Diseases \& Sciences 1990;35(7):879-84. 


\section{Ortiz-Olvera 2007}

Ortiz-Olvera Nayeli NX, Moran Villota S, Gallardo Wong I, Blancas Valencia JM, Cabrera Muñoz L. Validation of a simplified method of the ${ }^{13} \mathrm{C}$ urea breath test for diagnosis of Helicobacter pylori. Revista Espanola de Enfermedades Digestivas 2007;99(7):392-7.

\section{Osaki 2008}

Osaki T, Mabe K, Hanawa T, Kamiya S. Urease-positive bacteria in the stomach induce a false-positive reaction in a urea breath test for diagnosis of Helicobacter pylori infection. Journal of Medical Microbiology 2008;57(Pt 7):814-9.

\section{Osman 2014}

Osman HA, Hasan H, Suppian R, Bahar N, Hussin NSC, Rahim AA, et al. Evaluation of the atlas Helicobacter pylori stool antigen test for diagnosis of infection in adult patients. Asian Pacific Journal of Cancer Prevention 2014;15(13):5245-7.

\section{Osoba 2004}

Osoba AO, Ibrahim MB, Al-Shareef BA, Yassen AA, Hussein BA. Comparison of Helicobacter pylori stool antigen test with clo test in the diagnosis of Helicobacter pylori associated dyspepsia in a Saudi population. Saudi Medical Journal 2004;25(12):1906-8.

\section{Ou 2013}

Ou ZY, Xiong LY, Li DY, Geng LL, Li LX, Chen PY, et al. Evaluation of a new fluorescence quantitative PCR test for diagnosing Helicobacter pylori infection in children. BMC Gastroenterology 2013 Jan 14; Vol. 13:7. [DOI: 10.1186/1471-230X-13-7]

\section{Ozdemir 2008}

Ozdemir E, Karabacak NI, Degertekin B, Cirak M, Dursun A, Engin $D$, et al. Could the simplified ${ }^{14} \mathrm{C}$ urea breath test be a new standard in noninvasive diagnosis of Helicobacter pylori infection?. Annals of Nuclear Medicine 2008;22(7):611-6.

\section{Ozturk 2009}

Ozturk E, Yesilova Z, Ilgan S, Ozguven M, Dagalp K. Performance of acidified c-14-urea capsule breath test during pantoprazole and ranitidine treatment. Journal of Gastroenterology and Hepatology 2009;24(7):1248-51.

\section{Pacheco 2001}

Pacheco N, Mago V, Gomez I, Gueneau P, Guelrud M, Reyes N, et al. Comparison of PCR and common clinical tests for the diagnosis of h-pylori in dyspeptic patients. Diagnostic Microbiology and Infectious Disease 2001;39(4):207-10.

\section{Pacheco 2013}

Pacheco SLM, Ogata SK, Machado RS, Patricio FRDS, Pardo MLE, Kawakami E. Diagnosis of Helicobacter pylori infection by means of reduced-dose 13C-urea breath test and early sampling of exhaled breath. Journal of Pediatric Gastroenterology and Nutrition 2013;57(5):607-11.

\section{Paimela 2006}

Paimela HM, Oksala NK, Kaariainen IP, Carlson PJ, Kostiala AA, Sipponen PI. Faecal antigen tests in the confirmation of the effect of Helicobacter eradication therapy. Annals of Medicine 2006;38(5):352-6.

\section{Palka 2010}

Palka M, Tomasik T, Windak A, Margas G, Mach T, Bohonos A. The reliability of ELISA in predicting $H$. pylori infection in dyspeptic populations under age 45. Medical Science Monitor 2010;16(1):PH24-8.

\section{Pandya 2014}

Pandya HB, Patel JS, Agravat HH, Singh NKR. Non-invasive diagnosis of Helicobacter pylori: Evaluation of two enzyme immunoassays, testing serum igg and iga response in the Anand district of central Gujarat, india. Journal of Clinical and Diagnostic Research 2014;8(6):D12-D5.

\section{Pantoflickova 1999}

Pantoflickova D, Blum AL, Blackmon K, Dorta G. Optimization of c-13 urea breath test (ubt) for diagnosis of h-pylori (hp) infection. Gastroenterology 1999;116(4 (suppl)):A276.

\section{Pantoflickova 2000}

Pantoflickova D, Lew EA, Dorta G, Pisegna JR, Ohning GV, Faller LV, et al. Intragastric ph affects the results of the $\mathrm{c}$-13-urea breath test (ubt) in the diagnosis of h-pylori (hp). Gastroenterology 2000;118(4 (part 1)):A507.

\section{Pantoflickova 2003}

Pantoflickova D, Scott DR, Sachs G, Dorta G, Blum AL. 13C urea breath test (ubt) in the diagnosis of Helicobacter pylori: Why does it work better with acid test meals?. Gut 2003;52(7):933-7.

\section{Paoluzi 2001}

Paoluzi OA, Rossi P, Montesano C, Bernardi S, Carnieri E, Marchione OP, et al. Discrepancy between polymerase chain reaction assay and western blot analysis in the assessment of caga status in dyspeptic patients. Helicobacter 2001;6(2):130-5.

\section{Parejo 1998}

Parejo Carranza R, Olivares Miguel F, Escobar Castro H, Jimenez Alonso I, De Rafael Nerpell L, Camarero Salces C. Comparative analysis of diagnostic methods for Helicobacter pylori infection in children. Anales Espanoles de Pediatria 1998;49(3):257-63.

\section{Parente 2000a}

Parente F, Maconi G, Sainaghi M, Imbesi V, Vago L, Porro GB. Pretreatment c-13-urea breath test values but not h-pylori antigen levels in stool correlate well with bacterial density and gastritis activity in the gastric body. Gut 2000;47(Suppl 1):A114

\section{Parente 2000b}

Parente F, Sainaghi M, Maconi G, Imbesi V, Cucino C, Porro GB. Not all short-term proton pump inhibitors (ppi) impair the accuracy of c-13-urea breath test and h.Pylori stool antigen assay. Gut 2000;46(Suppl 2):A86.

\section{Parente 2001}

Parente F, Bianchi Porro G. The (13)c-urea breath test for noninvasive diagnosis of Helicobacter pylori infection: Which procedure and which measuring equipment?. European Journal of Gastroenterology \& Hepatology 2001;13(7):803-6. 


\section{Parente 2002a}

Parente F, Maconi G, Porro GB, Caselli M. Stool test with polyclonal antibodies for monitoring Helicobacter pylori eradication in adults: A critical reappraisal. Scandinavian Journal of Gastroenterology 2002;37(7):747-9.

\section{Parente 2002b}

Parente F, Sainaghi M, Sangaletti O, Imbesi V, Maconi G, Anderloni A, et al. Different effects of short-term omeprazole, lansoprazole or pantoprazole on the accuracy of the c-13urea breath test. Alimentary Pharmacology \& Therapeutics 2002;16(3):553-7.

\section{Park 2001}

Park D, Kang D, Jung M, Park H, Kim J. Patients factors, dob value of c-13-urea breath test and clinical diagnosis do not affect eradication of Helicobacter pylori with omeprazole based triple therapy. Gut 2001;49(suppl):A95.

\section{Park 2006}

Park YB. Diagnostic value of rapid urine test (Rapirun) compared with biopsy, C-13-UBT, and serum IgG-ELISA in Helicobacter pylori. Helicobacter 2006;11:40.

\section{Park 2009}

Park S, Park J, Kim Y, Seol S, Moon J, Jee S, et al. The clinical usefulness of the noninvasive rapid urine test to h. Pylori: Rapirun. Helicobacter 2009;14 (4):342-3.

\section{Park 2015}

Park YH, Kim N, Shim YK, Lee CM, Kyuahn B, Jaepark S, et al. The effect of pre-intake of citric acid on the delta value of the 13C-urea breath test. Journal of Gastroenterology and Hepatology 2015;30:120.

\section{Parolova 2012}

Parolova N, Dmitrienko M. The effectiveness of non-invasive tests in diagnosis of Helicobacter pylori infection in children. Helicobacter 2012;17:94.

\section{Patel 1994}

Patel P, Mendall MA, Khulusi S, Molineaux N, Levy J, Maxwell JD, et al. Salivary antibodies to Helicobacter pylori: Screening dyspeptic patients before endoscopy. Lancet 1994;344(8921):511-2

\section{Pathak 1992}

Pathak CM, Panigrahi D, Bhasin DK, Rana SV, Malik AK, Mehta SK. Advantage of use of dpm for ${ }^{14 C}$-urea breath test for the detection of Helicobacter pylori. American Journal of Gastroenterology 1992;87(12):1887-8.

\section{Pathak 1994}

Pathak CM, Bhasin DK, Panigrahi D, Goel RC. Evaluation of 14c-urinary excretion and its comparison with $14 \mathrm{co} 2$ in breath after 14c-urea administration in Helicobacter pylori infection. American Journal of Gastroenterology 1994;89(5):734-8.

\section{Pathak 2008}

Pathak CM, Avti PK, Bunger D, Khanduja KL. Kinetics of 14 carbon dioxide excretion from 14c-urea by oral commensal flora. Journal of Gastroenterology and Hepatology 2008;23(10):1603-7.

\section{Pathak 2011}

Pathak CM, Kaur B, Bhasin DK, Mittal BR, Sharma S, Khanduja KL. Comparative performance of capsulated vs noncapsulated 14c-urea breath test for the detection of Helicobacter pylori infection. Indian Journal of Nuclear Medicine 2011;26(Suppl 1):S20.

\section{Pathak 2012}

Pathak CM, Kaur B, Bhasin DK, Mittal BR, Sharma S, Khanduja KL, et al. Superiority of non-capsulated 14c-urea breath test over capsule based method for detection of Helicobacter pylori infection - a preliminary report. Tropical Gastroenterology 2012;33(2):123-8.

\section{Pathak 2013}

Pathak CM, Kaur B, Bhasin DK, Mittal BR, Sharma S, Khanduja KL, et al. Comparison of capsulated versus non-capsulated 14c-urea breath test for the detection of Helicobacter pylori infection: A scintigraphy study. Indian Journal of Gastroenterology 2013;32(1 SUPPL):A18-A9.

\section{Pathak 2014}

Pathak CM, Kaur B, Bhasin DK, Mittal BR, Sharma S, Khanduja KL, et al. Comparison of encapsulated versus nonencapsulated (14) c-urea breath test for the detection of Helicobacter pylori infection: A scintigraphy study. Helicobacter 2014;19(2):116-23.

\section{Pattison 1996}

Pattison CP, Marshall L. C-13-urea breath test for Helicobacter pylori: A second look analysis. American Journal of Gastroenterology 1996;91(11):2447.

\section{Pattison 1997}

Pattison CP, Kaczmarski DR, Bruggen JT, Oconnor MC. Comparison of c-14-urea breath test (c-14-ubt) and serology for detection of Helicobacter pylori in hiv positive patients. Gastroenterology 1997;112(4 (suppl)):A1060.

\section{Pavlitou 1998}

Pavlitou K, Pastore F, Moldovanidou K, Gioula G, Routsinas C, Polidorou F, et al. Rapid immunochromatographic assay for detection of Helicobacter pylori antibodies. Acta Microbiologica Hellenica 1998;43(3):267-70.

\section{Pavlitou 2000}

Pavlitou K, Pastore F, Konias A, Chrisohoidou S, Tsintarakis E, Polydorou $\mathrm{F}$, et al. Evaluation of a rapid serological test for the detection of igg antibodies to Helicobacter pylori. [greek]. Acta Microbiologica Hellenica 2000;45(3):293-7.

\section{Pawar 2014}

Pawar S, Reddy SR, Chelluri LK, Prasad CE. Detection of Helicobacter pylori infection in patients with obstructive airway diseases with sero techniques using highly specific igg antibodies for Helicobacter pylori antigen. Asian Pacific Journal of Tropical Disease 2014;4:S366-S72. 


\section{Payne 2006}

Payne I, Mold JW. What is the most sensitive non-invasive test for initial diagnosis of h. Pylori infection in adults?. Journal Oklahoma State Medical Association 2006;99(6):368-9.

\section{Peitz 2000}

Peitz U, Agha-Amiri K, Glasbrenner B, Leodolter A, Kahl S, Maertens D, et al. High specificity, but reduced sensitivity of h-pylori stool test in upper gastrointestinal bleeding. Gut 2000;47(Suppl 1):A121-A2.

\section{Peitz 2003}

Peitz U, Leodolter A, Kahl S, Agha-Amiri K, Wex T, Wolle K, et al. Antigen stool test for assessment of Helicobacter pylori infection in patients with upper gastrointestinal bleeding. Alimentary Pharmacology \& Therapeutics 2003;17(8):1075-84

\section{Peitz 2004}

Peitz U, Leodolter A, Wex T, Schutze D, Wolle K, Welte T, et al. Diagnostics of Helicobacter pylori infection in patients with peptic ulcer bleeding. Zeitschrift fur Gastroenterologie 2004;42(2):141-6.

\section{Peleteiro 2014}

Peleteiro B, Bastos A, Ferro A, Lunet N. Prevalence of Helicobacter pylori Infection worldwide: a systematic review of studies with national coverage. Digestive Diseases and Sciences 2014;59(8):1698-709.

\section{Pena 1989}

Pena AS, Endtz HP, Offerhaus GJ, Hoogenboom-Verdegaal A, Van Duijn W, De Vargas N, et al. Value of serology (ELISA and immunoblotting) for the diagnosis of campylobacter pylori infection. Digestion 1989;44(3):131-41.

\section{Peng 2000a}

Peng NJ, Hsu PI, Lee SC, Tseng HH, Huang WK, Tsay DG, et al. A 15-minute c-13-urea breath test for the diagnosis of Helicobacter pylori infection in patients with non-ulcer dyspepsia. Journal of Gastroenterology and Hepatology 2000;15(3):284-9.

\section{Peng 2000b}

Peng NJ, Hsu PI, Lee SC, Tsay DW, Lai KH, Lin LC, et al. Ultrarapid endoscopic c-13-urea breath test for the diagnosis of Helicobacter pylori infection. Journal of Nuclear Medicine 2000;41(5):317P.

\section{Peng 2001a}

Peng NJ, Lai KH, Liu RS, Lee SC, Tsay DG, Lo CC, et al. Clinical significance of oral urease in diagnosis of Helicobacter pylori infection by c- 13 urea breath test. Digestive Diseases and Sciences 2001;46(8):1772-8.

\section{Peng 2001b}

Peng NJ, Hsu PI, Lee SC, Tsay DG, Lai KH, Liu RS. Ultrarapid capsule-based c-13-urea breath test for the diagnosis of Helicobacter pylori infection. Journal of Nuclear Medicine 2001;42(5):329P.

\section{Peng 2002}

Peng NJ, Hsu PI, Lee SC, Tsay DG, Lai KH, Liu RS. Comparison of $100 \mathrm{mg}$ and $50 \mathrm{mg}$ endoscopic c-13-urea breath test for the diagnosis of Helicobacter pylori infection. Journal of Nuclear Medicine 2002;43(5):333P.

\section{Peng 2003}

Peng NJ, Lai KH, Liu RS, Lee SC, Tsay DG, Lo CC, et al. Endoscopic c-13-urea breath test for the diagnosis of Helicobacter pylori infection. Digestive and Liver Disease 2003;35(2):73-7.

\section{Peng 2005}

Peng NJ, Lai KH, Liu RS, Lee SC, Tsay DG, Lo CC, et al. Capsule 13C-urea breath test for the diagnosis of Helicobacter pylori infection. World Journal of Gastroenterology 2005;11(9):1361-4

\section{Peng 2009}

Peng NJ, Lai KH, Lo GH, Hsu PI. Comparison of noninvasive diagnostic tests for Helicobacter pylori infection. Medical Principles \& Practice 2009;18(1):57-61.

\section{Perets 2014}

Perets TT, Shporn E, Hamouda D, Niv Y, Dickman R. Can we achieve the same results from repetitive testing of $13 \mathrm{Co} 2$ breath samples for the diagnosis of Helicobacter pylori?. Gastroenterology 2014;146(5 (suppl)):S397-S8.

\section{Perets 2015}

Perets TT, Shporn E, Dickman R, Niv Y. Stability of $13 \mathrm{Co} 2$ breath tests samples over time in the diagnosis of Helicobacter pylori. Clinical Chemistry and Laboratory Medicine 2015;53:S1268.

\section{Perez 1996}

Perez Paramo M, Albillos Martinez A, Calleja Panero JL, Marin Rojas MC, Marcos Moreno ML, Freile Garcia I, et al. Effectiveness of the breath test with ${ }^{14} \mathrm{C}$-urea in the diagnosis of Helicobacter pylori infection. Revista Espanola de Medicina Nuclear 1996;15(1):15-20.

\section{Perez 1998}

Perez Paramo M, Albillos Martinez A, Ortiz Berrocal J. The breath test with labled urea for the diagnosis of Helicobacter pylori infection. Revista Espanola de Medicina Nuclear 1998;17(6):455-67.

\section{Perez-Perez 1997}

Perez-Perez GI, Cutler AF, Blaser MJ. Value of serology as a noninvasive method for evaluating the efficacy of treatment of Helicobacter pylori infection. Clinical Infectious Diseases 1997;25(5):1038-43.

\section{Perezperez 1994}

Perezperez GI, Brown WR, Cover TL, Dunn BE, Cao P, Blaser MJ. Correlation between serological and mucosal inflammatory responses to Helicobacter-pylori. Clinical and Diagnostic Laboratory Immunology 1994;1(3):325-9.

\section{Perna 2002}

Perna F, Tampieri A, Ricci C, Gatta L, Miglioli M, Vaira D. Evaluation of a new rapid one step stool antigen test 
for Helicobacter pylori (hp) infection diagnosis. Gut 2002;51(Suppl):A106

\section{Perna 2005}

Perna F, Ricci C, Gatta L, Bernabucci V, Cavina M, Miglioli M, et al. Diagnostic accuracy of a new rapid urease test (pronto dry) before and after treatment of Helicobacter pylori infection. Minerva Gastroenterologica e Dietologica 2005;51(3):247-54.

\section{Perri 1994}

Perri F, Ghoos Y, Maes B, Annese V, Geypens B, Hiele M, et al. Urea breath test in Helicobacter-pylori infected subjects is influenced by gastric-emptying rate. Gastroenterology 1994;106(4 (suppl)):A160.

\section{Perri 1995}

Perri F, Ghoos Y, Hiele M, Andriulli A, Rutgeerts P. The urea breath test: A non-invasive clinical tool for detecting Helicobacter pylori infection. Italian Journal of Gastroenterology 1995;27(2):55-63.

\section{Perri 1997a}

Perri F, Clemente R, Bisceglia M, Annese V, Niro G, Ghoos Y, et al. The c-13-urea breath test (ubt) predicts intragastric bacterial load and correlates with the depth of inflammation in h-pylori related gastritis. Gastroenterology 1997;112(4 (suppl)):A256.

\section{Perri 1997b}

Perri F, Clemente R, Bisceglia M, Quitadamo M, Festa V, Niro G, et al. The c-13-urea breath test (ubt) correlates with the bacterial load ansi the severity of inflammation in h-pylori (hp) gastritis. Gut 1997;41(Suppl):A80-A1.

\section{Perri 1998a}

Perri F, Clemente R, Pastore M, Quitadamo M, Festa V, Bisceglia M, et al. The c-13-urea breath test as a predictor of intragastric bacterial load and severity of Helicobacter pylori gastritis. Scandinavian Journal of Clinical \& Laboratory Investigation 1998;58(1):19-27.

\section{Perri 1998b}

Perri F, Clemente R, Festa V, Quitadamo M, Conoscitore P, Niro G, et al. Relationship between the results of pre-treatment urea breath test and efficacy of eradication of Helicobacter pylori infection. Italian Journal of Gastroenterology \& Hepatology 1998;30(2):146-50.

\section{Perri 1998c}

Perri F, Clemente R, Quitadamo M, Annese V, Andriulli A. C-13 urea breath test is a very accurate clinical tool in the diagnosis of intragastric Helicobacter pylori infection. Gut 1998;43(Suppl 3):S8-9.

\section{Perri 2000}

Perri F. Diagnosis of Helicobacter pylori infection: Which is the best test? The urea breath test. Digestive \& Liver Disease 2000;32 Suppl 3:S196-8.

\section{Perri 2002a}

Perri F, Manes G, Neri M, Vaira D, Nardone G. Helicobacter pylori antigen stool test and 13C-urea breath test in patients after eradication treatments. American Journal of Gastroenterology 2002;97(11):2756-62.

\section{Perri 2002b}

Perri F, Manes G, Nardone G, Neri M, Vaira D. Helicobacter pylori antigen stool test (HPSA) and 13C-urea breath test (ubt) in patients after eradicating treatments. Gastroenterology 2002;122(4 (suppl)):A206.

\section{Perri 2002c}

Perri F, Ricciardi R, Merla A, Piepoli A, Gasperi V, Quitadamo M, et al. Appropriateness of urea breath test: A prospective observational study based on maastricht 2000 guidelines. Alimentary Pharmacology \& Therapeutics 2002;16(8):1443-7.

\section{Perri 2005}

Perri F, Quitadamo M, Ricciardi R, Piepoli A, Cotugno R, Gentile A, et al. Comparison of a monoclonal antigen stool test (hp star) with the c-13-urea breath test (ubt) in monitoring Helicobacter pylori eradication therapy. World Journal of Gastroenterology 2005;11(37):5878-81.

\section{Perrone 2005}

Perrone M, Muñoz L, Camorlinga M, Correnti M, Cavazza ME, Lecuna V, et al. Importance of IgG anti-caga antibodies of Helicobacter pylori in Venezuelan patients with gastric diseases. Investigacion Clinica 2005;46(4):357-67.

\section{Petrovic 2011}

Petrovic M, Artiko V, Novosel S, Ille T, Sobic-Saranovic D, Pavlovic S, et al. Relationship between Helicobacter pylori infection estimated by c-14-urea breath test and gender, blood groups and rhesus factor. Hellenic Journal of Nuclear Medicine 2011;14(1):21-4.

\section{Pettersson 2001}

Pettersson A, Rasmusson M, Kyronpalo S, Sipponen P, Rautilin H, Farkkila M, et al. A 10 minutes tablet based 13Curea breath test for the diagnosis of Helicobacter pylori. Gastroenterology 2001;120(5 (suppl)):A579.

\section{Pianko 1999}

Pianko S, Petterson A, Lundqvist T, Stringer C, Sievert W, Korman M. Evaluation of a novel tablet based carbon 13 urea breath test for the rapid diagnosis of Helicobacter pylori infection. Gastroenterology 1999;116(4 (Suppl)):A282.

\section{Pilotto 1999}

Pilotto A, Franceschi M, Leandro G, Rassu M, Zagari RM, Bazzoli $F$, et al. The non-invasive diagnosis of $h$-pylori infection in older subjects: Comparison of c-13-urea breath test with serology. Gastroenterology 1999;116(4 (suppl)):A283.

\section{Pilotto 2000a}

Pilotto A, Franceschi M, Leandro G, Rassu M, Zagari RM, Bozzola L, et al. Noninvasive diagnosis of Helicobacter pylori infection in older subjects: Comparison of the c-13-urea breath test with serology. Journals of Gerontology Series A-Biological Sciences and Medical Sciences 2000;55(3):M163-M7. 


\section{Pilotto 2000b}

Pilotto A, Franceschi M, Rassu M, Novello R, Brusarosco G, Bozzola L, et al. Stool antigen test (HPSA) for detection of hpylori infection in elderly subjects: Comparison with serology and influence of concomitant treatments on diagnostic accuracy. Gut 2000;47(Suppl 1):A117-A8.

\section{Pilotto 2002}

Pilotto A, Franceschi M, Furlan F, Bozzola L, Fucito L, Rassu M, et al. The noninvasive diagnosis of $h$-pylori infection in geriatric subjects by the c-13-urea breath test (c-13-ubt) and the stool antigen test (HPSA): The role of disability and cognitive status. Gut 2002;51(Suppl):A108.

\section{Plebani 1999}

Plebani M, Basso D. Diagnosis of Helicobacter pylori infection by HPSA test. Lancet 1999;354(9185):1210.

\section{Ploier 1995}

Ploier R, Rezanka E, Emhofer J, Dorninger L, Feichtinger J, Haidinger R, et al. Predictive value of latex agglutination on Helicobacter pylori in children with recurrent abdominal pain. Klinische Padiatrie 1995;207(1):8-11.

\section{Ploier 1996}

Ploier R, Dorninger L, Emhofer J, Franz V, Feichtinger J. Predictive value of an ELISA for Helicobacter pylori infection in children. Monatsschrift fur Kinderheilkunde 1996;144(12):1326-9.

\section{Ploier 1997}

Ploier R, Doringer I, Emhofer J, Franz V, Feichtinger J. Predictive value of an ELISA for the detection of Helicobacter pylori infection in children - reply. Monatsschrift fur Kinderheilkunde 1997;145(10):1094.

\section{Polat 2010}

Polat TB, Urganci N, Selcukcan F, Yenici FN. Efficacy of noninvasive tests in the diagnosis and post-treatment follow-up of Helicobacter pylori infection in pediatric patients. Gazi Medical Journal 2010;21(1):17-22.

\section{Pons 2014}

Pons C, Maisterra S, Salord S, Pla A, Asensio D, Fernandez FJ, et al. Almagate interference in breath test results for the diagnosis of Helicobacter pylori infection. Revista Espanola De Enfermedades Digestivas 2014;106(7):448-51.

\section{Porter 2009a}

Porter V, Macdonald JC, Zahid MA, Mackie B, McNamara D. Validation of a low dose tablet formulation $13 \mathrm{C}$ urea and citric acid breath test employing an automated non dispersive isotope selective infrared spectroscopy analyser (helifan/fan as) for the diagnosis of Helicobacter pylori infection in a Scottish population. Gastroenterology 2009;136(5 (suppl )):A346.

\section{Porter 2009b}

Porter V, Zahid A, Mackie B, McNamara DA. Results of a prospective comparison pilot validation study of a lowdose tablet formulation c-13 urea and citric acid breath test employing a novel automated nondispersive isotope selective infrared spectroscopy analyser for the diagnosis of Helicobacter pylori infection. European Journal of Gastroenterology \& Hepatology 2009;21(11):1321-2.

\section{Portorreal 2002}

Portorreal A, Kawakami E. Evaluation of enzyme-linked immunosorbent assay for the diagnosis of Helicobacter pylori infection in children and adolescents. Arquivos de Gastroenterologia 2002;39(3):198-203.

\section{Posteraro 2006}

Posteraro P, Branca G, Sanguinetti M, Ranno S, Cammarota G, Rahimi S, et al. Rapid detection of clarithromycin resistance in Helicobacter pylori using a PCR-based denaturing hplc assay. Journal of Antimicrobial Chemotherapy 2006;57(1):71-8.

\section{Potashov 1996}

Potashov LV, Morozov VP, Kudrevatykh IP, Savranskii VM, Aurtiunian AA, Did-Zurabova ES, et al. The diagnosis of Helicobacter infections in patients with gastric and duodenal peptic ulcers. Zhurnal Mikrobiologii, Epidemiologii, $i$ Immunobiologii 1996;6:11-3.

\section{Pourakbari 2011a}

Pourakbari B, Mirsalehian A, Maleknejad P, Mamishi S, Azhdarkosh H, Daryani NE, et al. Evaluation of a new antigen for diagnosis of Helicobacter pylori infection in stool of adult and children. Helicobacter 2011;16(1):42-6.

\section{Pourakbari 2011b}

Pourakbari B, Mirsalehian A, Mamishi S, Najafi M, Kazemi B, Paknejad M, et al. Diagnosis of Helicobacter pylori infection by invasive and noninvasive methods. Tropical Medicine and International Health 2011;16:264-5.

\section{Pourakbari 2013}

Pourakbari B, Ghazi M, Mahmoudi S, Mamishi S, Azhdarkosh H, Najafi M, et al. Diagnosis of Helicobacter pylori infection by invasive and noninvasive tests. Brazilian Journal of Microbiology 2013;44(3):795-8.

\section{Prabakaran 1997}

Prabakaran K, Fernandes V, McDonald J, Jones RC. Single sample c-14 urea breath test for the diagnosis of Helicobacter pylori infection. Journal of Nuclear Medicine 1997;38(5 Suppl):Abstract 261.

\section{Prell 2009}

Prell C, Osterrieder S, Schwarzer A, Lottspeich C, Rusmann H, Ossiander $\mathrm{G}$, et al. Improved performance of a novel rapid onestep monoclonal chromatographic immunoassay for detection of Helicobacter pylori antigen in stool in children. Journal of Pediatric Gastroenterology and Nutrition 2009;48(Suppl 3):E47E8.

\section{Presecki 1997}

Presecki V, Katicic M, Kalenic S, Marusic M, Ticak M, Prskalo M, et al. Evaluation of commercial cf and ELISA tests for diagnosis of $H$-pylori infection in gastric carcinoma and non Hodgkin lymphoma patients. Gut 1997;41:A164. 


\section{Prieto 1994}

Prieto Bozano G. Clinical diagnosis of Helicobacter pylori infection in the child. Enfermedades Infecciosas Y Microbiologia Clinica 1994;12 Suppl 1:18-22.

\section{Pronovost 1994}

Pronovost AD, Rose SL, Pawlak JW, Robin H, Schneider R. Evaluation of a new immunodiagnostic assay for Helicobacter pylori antibody detection: Correlation with histopathological and microbiological results. Journal of Clinical Microbiology 1994;32(1):46-50.

\section{Przyklenk 1990}

Przyklenk B, Bauernfeind A, Bornschein W, Gabor M. Evaluation of an IgG-ELISA-kit for diagnosing Helicobacter pylori associated gastroduodenal disease. Serodiagnosis and Immunotherapy in Infectious Disease 1990;4(4):263-9.

\section{Pu 2005}

Pu XH, Guo XQ, Shi YL, An T, Qiu M, Qiu XX. Values of Helicobacter pylori stool antigen test in the etiological diagnosis of recurrent abdominal pain in children. Chinese Journal of Contemporary Pediatrics 2005;7(5):426-8.

\section{Puolakkainen 1997}

Puolakkainen P, Rautelin H, Sipponen P, Farkkila M, Kosunen T, Haapiainen R, et al. Comparison of histology, c-13 urea breath test (ubt) and serology for detecting h-pylori infection in patients with atrophic gastritis. Gastroenterology 1997;112(4 (suppl)):A262.

\section{Puz 2006}

Puz S, Kovach Z, Hirschl AM, Hafner M, Innerhofer A, Rotter M, et al. Evaluation of the novel Helicobacter pylori clarires realtime PCR assay for detection and clarithromycin susceptibility testing of h-pylori in stool specimens and gastric biopsies; comparison with the stool antigen test drug resistance. Helicobacter 2006;11(4):396.

\section{Puz 2008}

Puz S, Innerhofer A, Ramharter M, Haefner M, Hirschl AM, Kovach Z, et al. A novel noninvasive genotyping method of Helicobacter pylori using stool specimens. Gastroenterology 2008;135(5):1543-51.

\section{Qibi 2008}

Qibi EM, Abdulla ZA. Detection of Helicobacter pylori infection in dyspeptic patients by different sero-bacteriological methods. Qatar Medical Journal 2008;17(2):17-21.

\section{Quach 2014}

Quach DT, Hiyama T, Shimamoto F, Le QD, Ho LX, Vu NH, et al. Value of a new stick-type rapid urine test for the diagnosis of Helicobacter pylori infection in the Vietnamese population. World Journal of Gastroenterology 2014;20(17):5087-91.

\section{Queiroz 1999}

Queiroz DMM, Mendes EN, Rocha GA, Oliveira AMR, Oliveira CA, Cabral MMDA, et al. Serological and direct diagnosis of Helicobacter pylori in gastric carcinoma: A case-control study. Journal of Medical Microbiology 1999;48(5):501-6.

\section{Queiroz 2000}

Queiroz DMM, Rocha AMC, Rocha GA, Mendes EN, Carvalho AST, Nogueira AMF, et al. Validation of a commercial ELIS to detect anti-caga antibodies in children with $H$. pylori (hp) infection. Gut 2000;47(Suppl 1):A96.

\section{Queiroz 2013}

Queiroz DM, Saito M, Rocha GA, Rocha AM, Melo FF, Checkley W, et al. Helicobacter pylori infection in infants and toddlers in South America: concordance between [13C] urea breath test and monoclonal $H$. pylori stool antigen test. Journal of Clinical Microbiology 2013;51(11):3735-40.

\section{Queralt 2005}

Queralt N, Bartolome R, Araujo R. Detection of Helicobacter pylori DNA in human faeces and water with different levels of faecal pollution in the north-east of Spain. Journal of Applied Microbiology 2005;98(4):889-95.

\section{Quesada 2006a}

Quesada M, Calvet X, Dosal A, Calvet V, Sanfeliu I, Ribera L, et al. Evaluation of four different fecal tests for determination of cure after Helicobacter pylori treatment. Journal of Clinical Gastroenterology 2006;40(9):790-4.

\section{Quesada 2006b}

Quesada M, Calvet X, Calvet V, Choat T, Fallowfield B, Sanfeliu I, et al. Usefulness of rapid hp star, a new immumochromatographic, monoclonal antigen-based faecal test, for diagnosing Helicobacter pylori infection in dyspeptic patients. Gastroenterology 2006;130(4 (suppl)):A458.

\section{Rabbe 1988}

Rabbe MP, Megraud F. Anti-campylobacter-pylori antibody titer by ELISA. Gastroenterologie Clinique et Biologique 1988;12(6-7):587-8.

\section{Radke 1997}

Radke M. Predictive value of an ELISA for the detection of Helicobacter pylori infection in children. Monatsschrift fur Kinderheilkunde 1997;145(10):1093.

\section{Rae 1995}

Rae AJ, Belzberg A, Cleator IGM, Caglar M. Use of the c-14 breath test in the treatment of Helicobacter-pylori. Canadian Journal of Gastroenterology 1995;9(4):191-4.

\section{Raedsch 1992}

Raedsch R. Serological screening for Helicobacter pylori. Deutsche Medizinische Wochenschrift 1992;117(21):844-5.

\section{Raguza 2005}

Raguza D, Granato CFH, Kawakami E. Evaluation of the stool antigen test for Helicobacter pylori in children and adolescents. Digestive Diseases and Sciences 2005;50(3):453-7.

\section{Raguza 2010}

Raguza D, MacHado RS, Ogata SK, Granato CFH, Patricio FRS, Kawakami E. Validation of a monoclonal stool antigen test for diagnosing Helicobacter pylori infection in young 
children. Journal of Pediatric Gastroenterology and Nutrition 2010;50(4):400-3.

\section{Rahman 2008}

Rahman SHZ, Azam MG, Rahman MA, Arfin MS, Alam MM, Bhuiyan TM, et al. Non-invasive diagnosis of h pylori infection: Evaluation of serological tests with and without current infection marker cim. World Journal of Gastroenterology 2008;14(8):1231-6.

\section{Raju 1994}

Raju GS, Smith MJ, Morton D, Bardhan KD. Mini-dose (1-microci) 14c-urea breath test for the detection of Helicobacter pylori. American Journal of Gastroenterology 1994;89(7):1027-31.

\section{Ramírez-Lázaro 2011}

Ramírez-Lázaro MJ, Lario S, Casalots A, Sanfeliu E, Boix L, García-Iglesias P, et al. Real-time PCR improves Helicobacter pylori detection in patients with peptic ulcer bleeding. PLoS ONE 2011; Vol. 6, issue 5:e20009. [DOI: 10.1371/ journal.pone.002000]

\section{Ramírez-Lázaro 2015}

Ramírez-Lázaro MJ, Lario S, Calvet X, Sánchez-Delgado J, Montserrat A, Quilez EM, et al. Occult h-pylori infection partially explains "false-positive' results of c-13-urea breath test. United European Gastroenterology Journal 2015;3(5):437-42.

\section{Rao 2001}

Rao P, Sarkar A, Shivananda PG, Pai G. Comparison of ELISA for antibody detection and biopsy urease test against $\mathrm{h}$. Pylori in cases of gastroduodenal disorders. Indian Journal of Medical Sciences 2001;55(7):366-70.

\section{Rapoport 2014}

Rapoport SI, Shubina NA. 13-year period of application of the 13C-urease breath test for determining Helicobacter pylori in Russian clinical practice. Klinicheskaia Meditsina 2014;92(11):59-64.

\section{Rasheed 2014}

Rasheed F, Khalid A, Saadia A, Habib S, Khan SM, Saeed F, et al. Correlation of c-13 urea breath test values with Helicobacter pylori load among positive patients. Hepato-Gastroenterology 2014;61(129):125-8.

\section{Ratnaraj 2015}

Ratnaraj F, Hamdeh S, Salih M, Ayan M, Mansour G, Reddymasu S. Urea breath test (ubt) versus stool antigen test in post-treatment eradication of Helicobacter pylori infection: A meta-analysis. American Journal of Gastroenterology 2015;110:S1038.

\section{Rauws 1987}

Rauws EAJ, Langenberg W, Houthoff HJ, Tytgat GN. Histology, culture, breath test and therapeutic attempts in campylobacter pylori gastritis. Zeitschrift fur Gastroenterologie 1987;25(SUPPI. 4):24-8.

\section{Rauws 1989a}

Rauws EAJ. Detecting campylobacter-pylori with the c-13 urea and c-14-urea breath test. Scandinavian Journal of Gastroenterology 1989;24:25-6.

\section{Rauws 1989b}

Rauws EA, Van Royen EA, Tytgat GN. 14c-urea breath test as a method to detect campylobacter pylori colonization. Gastroenterologie Clinique et Biologique 1989;13(1 Pt 1):42B-3B.

\section{Rauws 1989c}

Rauws EAJ, Royen EAV, Langenberg W, Woensel JV, Vrij AA, Tytgat GN. ${ }^{14} \mathrm{C}$-urea breath test in $C$ pylori gastritis. Gut 1989;30(6):798-803.

\section{Raymond 1999}

Raymond J, Sauvestre C, Kalach N, De Korwin JD, Valverde V. Evaluation of a new serologic test for diagnosis of Helicobacter pylori infection in children. European Journal of Clinical Microbiology \& Infectious Diseases 1999;18(3):192-8.

\section{Raymond 2000}

Raymond J, Sauvestre C, Kalach N, Bergeret M, Dupont C. Immunoblotting and serology for diagnosis of Helicobacter pylori infection in children. Pediatric Infectious Disease Journal 2000;19(2):118-21.

\section{Razaghi 2010}

Razaghi M, Boutorabi SM, Mirjalili A, Norolahi S, Hashemi M, Jalalian M. Diagnosis of Helicobacter pylori infection by ELISA stool antigen and comparison with the other diagnostic methods. Healthmed 2010;4(3):545-51.

\section{Rechcinski 1997}

Rechcinski T, Chmiela M, Malecka-Panas E, Planeta-Malecka I, Rudnicka W. Serological indicators of Helicobacter pylori infection in adult dyspeptic patients and healthy blood donors. Microbiology \& Immunology 1997;41(5):387-93.

\section{Redéen 2011}

Redéen S, Petersson F, Törnkrantz E, Levander H, Mårdh E, Borch K. Reliability of diagnostic tests for Helicobacter pylori infection. Gastroenterology Research and Practice 2011; Vol. 2011:940650. [DOI: 10.1155/2011/940650]

\section{Rehnberg 2001}

Rehnberg AS, Bengtsson C, Befrits R, Granstrom M, Hellstrom PM. Refinement of the c-14-urea breath test for detection of Helicobacter pylori. Scandinavian Journal of Gastroenterology 2001;36(8):822-6.

\section{Reilly 1997}

Reilly TG, Poxon V, Sanders DSA, Elliott TSJ, Walt RP. Comparison of serum, salivary, and rapid whole blood diagnostic tests for Helicobacter pylori and their validation against endoscopy based tests. Gut 1997;40(4):454-8.

\section{Rejchrt 2004}

Rejchrt S, Havlasova J, Bures J, Siroky M, Kopacova M, Voxova B, et al. Evaluation of serum anti-Helicobacter pylori IgG antibodies against p120 antigen (caga) and investigation 
of specific antibody response against Helicobacter pylori by means of western blotting. Klinicka Biochemie a Metabolismus 2004;12(1):19-23.

\section{Ren 2005}

Ren Z, Borody T, Pang G, Dunkley M, Clancy R, Xia HHX, et al. Evaluation of anti-Helicobacter pylori igg2 antibody for the diagnosis of Helicobacter pylori infection in western and Chinese populations. Alimentary Pharmacology and Therapeutics 2005;21(1):83-9.

\section{Ren 2010}

Ren HT, Xu XW, Li AH. Diagnostic value of gene chip test for detection of h.Pylori infection and relationship between H.pylori virulence factors and the severity of gastroduodenal lesions. World Chinese Journal of Digestology 2010;18(26):2826-30.

\section{Reshetnikov 2007}

Reshetnikov OV, Kurilovich SA, Krotov SA, Krotova VA. Comparison of two ELISA kits for Helicobacter pylori detection in Siberian populations. Helicobacter 2007;12(4):441.

\section{Reynders 2012}

Reynders MBML, Deyi VYM, Dahma H, Scheper T, Hanke M, Decolvenaer M, et al. Performance of individual Helicobacter pylori antigens in the immunoblot-based detection of $h$. Pylori infection. FEMS Immunology and Medical Microbiology 2012;64(3):352-63.

\section{Riaz 2011}

Riaz S, Munir I, Nawaz MK, Bashir H, Muzahir S, Saadullah M, et al. C-14 - urea breath test in the diagnosis of Helicobacter pylori infection in Pakistani population. European Journal of Nuclear Medicine and Molecular Imaging 2011;38:S403.

\section{Ricci 2007}

Ricci C, Holton J, Vaira D. Diagnosis of Helicobacter pylori invasive and non-invasive tests. Best Practice \& Research: Clinical Gastroenterology 2007;21(2):299-313.

\section{Richter 2002}

Richter J, Stiborova I, Kral V, Jilek D. Direct evidence of the Helicobacter pylori antigen in faeces. Prakticky Lekar 2002;82(4):205-7.

\section{Riepl 2000}

Riepl RL, Folwaczny C, Otto B, Klauser A, Blendinger C, Wiebecke B, et al. Accuracy of c-13-urea breath test in clinical use for diagnosis of Helicobacter pylori infection. Zeitschrift fur Gastroenterologie 2000;38(1):13-9.

\section{Ritchie 2009}

Ritchie B, Brewster D, Tran CD, McNeil Y, Zacharakis B, Davidson GP, et al. Lack of diagnostic accuracy of the monoclonal stool antigen test for detection of Helicobacter pylori infection in young Australian aboriginal children. Pediatric Infectious Disease Journal 2009;28(4):287-9.

\section{Rocha 1998}

Rocha GA, Oliveira AM, Queiroz DM, Mendes EN, Moura SB, Oliveira CA, et al. Serodiagnosis of Helicobacter pylori infection by cobas core ELISA in adults from Minas Gerais, Brazil. Brazilian Journal of Medical \& Biological Research 1998;31(10):1263-8.

\section{Rocha 2002}

Rocha GA, Cardinali LCC, Queiroz DMM, Rocha AMC, Moura SB, Soares TF, et al. The performance of the c-13-urea breath test for the diagnosis of Helicobacter pylori infection in children from a developing country. Gut 2002;51(Suppl):A82.

\section{Rocha 2004}

Rocha AM, Rocha GA, Leite JL, Lisboa RL, Silva PV, Queiroz DM. Immunoblotting for the serodiagnosis of Helicobacter pylori infection in Brazilian patients with and without gastric carcinoma. Memorias do Instituto Oswaldo Cruz 2004;99(2):189-93.

\section{Rogge 1995}

Rogge JD, Wagner DR, Carrico RJ, Glowinski EA, Mahoney SJ, Boguslaski RC, et al. Evaluation of a new urease reagent strip for detection of Helicobacter-pylori in gastric biopsy specimens. American Journal of Gastroenterology 1995;90(11):1965-8.

\section{Roggero 2002}

Roggero P, Bonfiglio A, Luzzani S, Valade A, Cataliotti E, Corno G, et al. Helicobacter pylori stool antigen test: A method to confirm eradication in children. Journal of Pediatrics 2002;140(6):775-7.

\section{Rollan 1997}

Rollan A, Giancaspero R, Arrese M, Figueroa C, Vollrath V, Schultz $M$, et al. Accuracy of invasive and noninvasive tests to diagnose Helicobacter pylori infection after antibiotic treatment. American Journal of Gastroenterology 1997;92(8):1268-74.

\section{Roma-Giannikou 2010}

Roma-Giannikou E, Roubani A, Sgouras DN, Panayiotou J, VanVliet C, Polyzos A, et al. Endoscopic tests for the diagnosis of Helicobacter pylori infection in children: Validation of rapid urease test. Helicobacter 2010;15(3):227-32.

\section{Romaozinho 2011}

Romaozinho JGM, Donato MRSR, Ferreira J, Sofia C. Detection of Helicobacter pylori infection: clinical validation of ${ }^{14} \mathrm{C}(37 \mathrm{kbq})$ urea breath test. Helicobacter 2011;16:115.

\section{Roth 2001}

Roth DE, Taylor DN, Gilman RH, Meza R, Katz U, Bautista C, et al. Posttreatment follow-up of Helicobacter pylori infection using a stool antigen immunoassay. Clinical \& Diagnostic Laboratory Immunology 2001;8(4):718-23.

\section{Rothenbacher 2000a}

Rothenbacher D, Marchildon P, Peacock J, Bode G, Brenner H. Diagnosis of $h$-pylori infection in children: Comparison of a salivary igg antibody test with c-13-urea breath test. Gut 2000;47(Suppl 1):A116. 


\section{Rothenbacher 2000b}

Rothenbacher D, Bode G, Brenner H. Diagnosis of Helicobacter pylori infection with a novel stool antigen-based assay in children. Pediatric Infectious Disease Journal 2000;19(4):364-6.

\section{Rowland 1997a}

Rowland M, Lambert I, Gormally S, Thomas JE, Daly LE, Durnin M, et al. C-13-urea breath test for the diagnosis of Helicobacter pylori in children. Gastroenterology 1997;112(4 (suppl)):A272.

\section{Rowland 1997b}

Rowland M, Lambert I, Gormally S, Daly LE, Thomas JE, Hetherington C, et al. Carbon 13-labeled urea breath test for the diagnosis Helicobacter pylori infection in children. Journal of Pediatrics 1997;131(6):815-20.

\section{Rutter 2001}

Rutter CM, Gatsonis CA. A hierarchical regression approach to meta-analysis of diagnostic test accuracy evaluations. Statistics in Medicine 2001;20(19):2865-84.

\section{Sabbi 2005}

Sabbi T, De Angelis P, Colistro F, Dall'Oglio L, Di Abriola GF, Castro M. Efficacy of noninvasive tests in the diagnosis of Helicobacter pylori infection in pediatric patients. Archives of Pediatrics \& Adolescent Medicine 2005;159(3):238-41.

\section{Sadowski 1998}

Sadowski D, Cohen H, Laine L, Greenberg P, Goldstein J, Mihalov M, et al. Evaluation of the flexsure hp whole blood antibody test for diagnosis of Helicobacter pylori infection. American Journal of Gastroenterology 1998;93(11):2119-23.

\section{Saez 2012}

Saez J, Belda S, Santibanez M, Rodriguez JC, Sola-Vera J, Galiana A, et al. Real-time PCR for diagnosing Helicobacter pylori infection in patients with upper gastrointestinal bleeding: Comparison with other classical diagnostic methods. Journal of Clinical Microbiology 2012;50(10):3233-7.

\section{Saffari 2003}

Saffari M, Motavalii MA, Fazeli A. Immunoblot assay in determination of serum antibody profile of Helicobacter pylori infection. Iranian Journal of Medical Sciences 2003;28(2):90-2.

\section{Salama 1993}

Salama SM, Wefuan JN, Shiro-Koulla S, Mbakop A, TagniSartre M, Ndam EC, et al. Value of whole-cell antigen extracts for serologic detection of Helicobacter pylori. Journal of Clinical Microbiology 1993;31(12):3331-2.

\section{Salih 2013}

Salih BA, Karakus C, Ulupinar Z, Akbas F. A novel lateral flow test strip (Ifts) for the detection of Helicobacter pylori infection. Helicobacter 2013;18:124.

\section{Salles-Montaudon 2001}

Salles-Montaudon N, Dertheil S, Broutet N, Monteiro L, Gras N, Pereira E, et al. How should Helicobacter pylori infection be diagnosed in the elderly?. Revue de Medecine Interne 2001;22(4):339-47.

\section{Salomaa-Rasanen 2004}

Salomaa-Rasanen A, Kosunen TU, Mattila J, Sarna S, Rautelin H. Age-dependent accuracy of Helicobacter pylori antibody assays for adults, with special emphasis on atrophic gastritis. Clinical and Diagnostic Laboratory Immunology 2004;11(6):1185-8.

\section{Saltik 2001}

Saltik IN, Ercis S, Kocak N, Hascelik G, Ozen H, Yuce A, et al. Helicobacter pylori stool antigen ( $\mathrm{HpSA}$ ) test in children with recurrent abdominal pain. American Journal of Gastroenterology 2001;96(8):2514-5.

\section{Saltik 2003}

Saltik IN, Demir H, Kocak N, Ozen H, Gurakan F, Yuce A. Diagnostic accuracy of c-13-urea breath test for Turkish children with Helicobacter pylori infection. American Journal of Gastroenterology 2003;98(1):222-3.

\section{Sampson 2008}

Sampson M, Shojania KG, McGowan J, Daniel R, Rader T, lansavichene $\mathrm{AE}$, et al. Surveillance search techniques identified the need to update systematic reviews. Journal of Clinical Epidemiology 2008;61(8):755-62.

\section{Sanches 2013}

Sanches BSF, Martins GM, Pinto HAF, Meira ACD, Alves EJ, Trindade OR, et al. Evaluation of stool antigen test on initial diagnosis and control test of Helicobacter pylori eradication. Helicobacter 2013;18:122.

\section{Saneian 2013}

Saneian H, Rahimi H, Mahmoodi NS. Comparison of the sensitivity and specificity of available methods in Helicobacter pylori infection detection in children. Journal of Isfahan Medical School 2013; Vol. 30, issue 212.

\section{Sano 2004}

Sano N, Ohara S, Koike T, Sekine H, Imatani A, Kitagawa Y, et al. Influence of urease activity of the oral cavity and oropharynx on 13C-urea breath test. Japanese Journal of Gastroenterology 2004;101(12):1302-8.

\section{Santogade 1990}

Santogade PJ, Bokkenheuser VD, Faisal MA, Kotler DP, Scholes JV, Holt PR. Evaluation of methods for identification of campylobacter pyloris infection. New York State Journal of Medicine 1990;90(1):4-7.

\section{Sarker 2003}

Sarker SA, Bardhan PK, Rahaman M, Beglinger C, Gyr N. Usefulness of the Helicobacter pylori stool antigen test for detection of Helicobacter pylori infection in young Bangladeshi children. Gastroenterology 2003;124(4 suppl):A178.

\section{SAS [Computer program]}

SAS Institute Inc. SAS. Version 9.4. Cary, NC, USA: SAS Institute Inc, 2013. 


\section{Sastry 1997}

Sastry A, Flynn K, Mehra M. Development of an ELISA method for the measurement of $H$. pylori in human serum using a single reagent tmb system. Clinical Chemistry 1997;43(6 (Suppl 2)):628.

\section{Sato 2012}

Sato M, Shimoyama T, Takahashi R, Kajiyama H, Sano Y, Sakaedani N, et al. Characterization and usefulness of stool antigen tests using a monoclonal antibody to Helicobacter pylori catalase. Journal of Gastroenterology and Hepatology (Australia) 2012;27(SUPPL.3):23-8.

\section{Satoh 1993}

Satoh K, Yoshida Y, Taniguchi Y, Kimura K. Elisa tests for detection of Helicobacter pylori antibodies. Nihon Rinsho [Japanese Journal of Clinical Medicine] 1993;51(12):3201-4.

\section{Savarino 1999}

Savarino V, Mela GS, Zentilin P, Bisso G, Pivari M, Mansi C, et al. Comparison of isotope ratio mass spectrometry and nondispersive isotope-selective infrared spectroscopy for c-13-urea breath test. American Journal of Gastroenterology 1999;94(5):1203-8.

\section{Savarino 2000a}

Savarino V, Bisso G, Pivari M, Zentilin P, Bilardi C, Dulbecco P, et al. Effect of gastric acid suppression on C-13-urea breath test: Comparison of ranitidine with omeprazole. Alimentary Pharmacology \& Therapeutics 2000;14(3):291-7.

\section{Savarino 2000b}

Savarino V, Landi F, Dulbecco P, Ricci C, Tessieri L, Biagini R, et al. Isotope ratio mass spectrometry (irms) versus laser-assisted ratio analyzer (lara) - a comparative study using two doses of c-13 urea and two test meals for pre- and posttreatment diagnosis of Helicobacter pylori infection. Digestive Diseases and Sciences 2000;45(11):2168-74.

\section{Savarino 2001}

Savarino V, Tracci D, Dulbecco P, Mele MR, Zentilin P, Mansi C, et al. Negative effect of ranitidine on the results of urea breath test for the diagnosis of Helicobacter pylori. American Journal of Gastroenterology 2001;96(2):348-52.

\section{Savio 1999}

Savio A, Buffoli F, Landi F, Ricci C, Acciardi C, Gatta L, et al. The value of a new capture ELISA system for the diagnosis and the follow-up of Helicobacter pylori (hp) infection. Gut 1999;45(Suppl 3):A128.

\section{Sawada 2001}

Sawada A, Tajiri H, Yoshimura N, Kozaiwa K, Ida S, Fujisawa T, et al. A simplified C-13-urea breath test in children with Helicobacter pylori infection: Assessment of eradication therapy and follow-up after treatment. Gastroenterology 2001;120(5 suppl):A579.

\section{Sayed 2011}

Sayed MM, Ibrahim WA, Abdel-Bary SA, Abdelhakam SM, ElMasry SA, Ghoraba D. Salivary PCR detection of Helicobacter pylori DNA in Egyptian patients with dyspepsia. Egyptian Journal of Medical Human Genetics 2011;12(2):211-6.

\section{Schaefer 1999}

Schaefer R, Bugno M, Auer P, Ramp U, Gabbert HE, Erckenbrecht JF. Does quantitative c-13-urea breath test reflect intensity of gastric Helicobacter pylori colonization or mucosal inflammation?. Gastroenterology 1999;116(4 (suppl)):A304.

\section{Scherbakov 2001}

Scherbakov PL, Belousov B, Govorun VM, Filin VA, Isakov VA, Kaganov BS, et al. Diagnosis of Helicobacter pylori infection in children by PCR in stool: comparative study with antigen stool test. Gut 2001;49(suppl):A81.

\section{Schilling 2003}

Schilling D, Demel A, Adamek HE, Nusse T, Weidmann E, Riemann JF. A negative rapid urease test is unreliable for exclusion of Helicobacter pylori infection during acute phase of ulcer bleeding - a prospective case control study. Digestive and Liver Disease 2003;35(4):217-21.

\section{Schmitt 1996}

Schmitt B, Bartel J. Comparison of a new rapid blood assay for detection of antibodies to Helicobacter pylori (bm-test Helicobacter pylori rapid assay, boehringer mannheim) with an enzyme-linked immunosorbent assay (enzygnost, behringwerke marburg). Klinisches Labor 1996;42(7-8):601-6.

\section{Schuman 1995}

Schuman R, Rigas B, Prada A, Minoli G. Diagnosis of Helicobacter-pylori infection by the Lara ${ }^{\mathrm{TM}}$ system - towards a simplified breath test. Gastroenterology 1995;108(4 suppl):A215.

\section{Schumann 2006}

Schumann C, Triantafilou K, Rasche FM, Moricke A, Vogt K, Triantafilou $M$, et al. Serum antibody positivity for distinct Helicobacter pylori antigens in benign and malignant gastroduodenal disease. ljmm International Journal of Medical Microbiology 2006;296(4-5):223-8.

\section{Schwarzer 2007}

Schwarzer A, Lottspeich C, Russmann H, Ossiander G, Koletzko S. Evaluation of a novel rapid one-step monoclonal chromatographic immunoassay for detection of Helicobacter pylori in stool from children. European Journal of Clinical Microbiology \& Infectious Diseases 2007;26(7):475-80.

\section{Sedlackova 1992}

Sedlackova M, Soucek A, Mucksova J. Serologic detection of antibodies to Helicobacter pylori in children and adolescents using ELISA. Ceskoslovenska Pediatrie 1992;47(10):577-80.

\section{Sen 2005}

Sen N, Yilmaz O, Simsek I, Kupelioglu AA, Ellidokuz H. Detection of Helicobacter pylori DNA by a simple stool PCR method in adult dyspeptic patients. Helicobacter 2005;10(4):353-9.

\section{Sen 2011}

Sen N, Demiray-Gurbuz E, Yilmaz O, Kupeliotlu A, Simsek I. Comparing the accuracy of stool antigen tests for the detection 
of Helicobacter pylori infection in Turkish dyspeptic patients. Helicobacter 2011;16:114-5.

\section{Seo 2004}

Seo JK. Diagnostic validity of the Helicobacter pylori stool antigen test before and after eradication treatment. Taehan Sohwagi Hakhoe Chi [Korean Journal of Gastroenterology] 2004;44(4):229-35.

\section{Seo 2013}

Seo JH, Jun JS, Youn HS, Yeom JS, Park JS, Park CH, et al. Development of an ELISA for quantitative detection of immunoglobulin g (IgG) and IgA antibodies to Helicobacter pylori for use in Korean patients with $\mathrm{H}$. pylori-associated diseases. Gut and Liver 2013;7(4):437-42.

\section{Serrano 2008}

Serrano CA, Gonzalez CG, Rollan AR, Duarte I, Torres J, Pena AJ, et al. Lack of diagnostic utility of specific immunoglobulin $m$ in Helicobacter pylori infection in children. Journal of Pediatric Gastroenterology and Nutrition 2008;47(5):612-7.

\section{Sfarti 2009}

Sfarti C, Stanciu C, Cojocariu C, Trifan A. 13C-urea breath test for the diagnosis of Helicobacter pylori infection in bleeding duodenal ulcer. Revista Medico-Chirurgicala a Societatii de Medici si Naturalisti Din Lasi 2009;113(3):704-9.

\section{Shaikh 2005}

Shaikh S, Khaled MA, Islam A, Kurpad AV, Mahalanabis D. Evaluation of stool antigen test for Helicobacter pylori infection in asymptomatic children from a developing country using 13C-urea breath test as a standard. Journal of Pediatric Gastroenterology \& Nutrition 2005;40(5):552-4.

\section{Sharma 1995}

Sharma TK, Cutler AF. Relationship between the magnitude of c-13 urea breath test-results and endoscopic diagnoses in Helicobacter-pylori infected individuals. Gastroenterology 1995;108(4 (suppl)):A217.

\section{Sharma 1997}

Sharma TK, Young EL, Miller S, Cutler AF. Evaluation of a rapid, new method for detecting serum igg antibodies to Helicobacter pylori. Clinical Chemistry 1997;43(5):832-6.

\section{Sharma 1999}

Sharma BC, Bhasin DK, Pathak CM, Sinha SK, Ray P, Vaiphei K, et al. C-14 -urea breath test to confirm eradication of Helicobacter pylori. Journal of Gastroenterology and Hepatology 1999;14(4):309-12.

\section{Sharma 2015}

Sharma U, Rehmani B, Shirazi N, Mittal G. A study of Helicobacter pylori infection in perforated peptic ulcer disease. International Journal of Surgery 2015;23:S119-S20.

\section{She 2009}

She RC, Wilson AR, Litwin CM. Evaluation of Helicobacter pylori immunoglobulin g (igg), iga, and igm serologic testing compared to stool antigen testing. Clinical and Vaccine Immunology 2009;16(8):1253-5.

\section{Sheikhian 2007}

Sheikhian A, Hassan Zuhair M, Mostafaie A. Detection of Helicobacter pylori diagnostic antigens in the stool of infected patients. Iranian Journal of Medical Sciences 2007;32(4):198-204.

\section{Shepherd 2000}

Shepherd AJ, Williams CL, Doherty CP, Hossack M, Preston T, McColl KEL, et al. Comparison of an enzyme immunoassay for the detection of Helicobacter pylori antigens in the faeces with the urea breath test. Archives of Disease in Childhood 2000;83(3):268-70.

\section{Sheu 1997}

Sheu BS, Lee SC, Lin XZ. Quantitative result of c-13 urea breath test can predict the bacterial density of h-pylori. Gut 1997;41:A84.

\section{Sheu 1999a}

Sheu BS, Lee SC, Yang HB, Lin XZ. Quantitative result of c-13 urea breath test at 15 minutes may correlate with the bacterial density of h-pylori in the stomach. Hepato-Gastroenterology 1999;46(27):2057-62.

\section{Sheu 1999b}

Sheu BS, Lee SC, Wang YL, Shiesh SC, Yang HB, Lin XZ. A lower cut-off point of $\mathrm{c}-13$ urea breath test is more suitable to monitor the success of h-pylori eradication. Gut 1999;45(Suppl 3):A125.

\section{Sheu 2000a}

Sheu BS, Lee SC, Yang HB, Kuo AW, Wang YL, Shiesh SC, et al. Selection of lower cutoff point of c-13 urea breath test is helpful to monitor h-pylori eradication after proton pump inhibitor-based triple therapy. Digestive Diseases and Sciences 2000;45(7):1330-6.

\section{Sheu 2000b}

Sheu BS, Lee SC, Yang HB, Wu HW, Wu CS, Lin XZ, et al. Lowerdose c-13-urea breath test to detect Helicobacter pylori infection - comparison between infrared spectrometer and mass spectrometry analysis. Alimentary Pharmacology \& Therapeutics 2000;14(10):1359-63.

\section{Sheu $2000 c$}

Sheu BS, Lee SC, Lin PW, Wang ST, Chang YC, Yang HB, et al. (13)carbon urea breath test is not as accurate as endoscopy to detect Helicobacter pylori after gastrectomy. Gastrointestinal Endoscopy 2000;51(6):670-5.

\section{Sheu 2002}

Sheu BS, Yang HB, Wang YL, Kao AW, Chuang CH, Lin PW, et al. Stool antigen assay to screen $\mathrm{h}$-pylori infection and to assess the success of 3-day and 7-day eradication therapy in the patients with partial gastrectomy. Helicobacter 2002;7(3):199-204.

\section{Shiba 1998}

Shiba K. The rapid method in microbiology using chemical method and immunochemical method. Rinsho Biseibutsu 
Jinsoku Shindan Kenkyukai Shi [Journal of the Association for Rapid Method and Automation in Microbiology] 1998;9(2):73-81.

\section{Shimada 1994}

Shimada T, Ogura K, Ota S, Terano A, Takahashi M, Hamada E, et al. Identification of Helicobacter pylori in gastric specimens, gastric juice, saliva, and faeces of Japanese patients. Lancet 1994;343(8913):1636-7.

\section{Shimizu 2003a}

Shimizu T, Yarita Y, Haruna H, Kaneko K, Yamashiro Y, Gupta R, et al. Urine-based enzyme-linked immunosorbent assay for the detection of Helicobacter pylori antibodies in children. Journal of Paediatrics \& Child Health 2003;39(8):606-10.

\section{Shimizu 2003b}

Shimizu T, Fujii T, Haruna H, Shoji H, Kudo T, Yamashiro Y. Effects of stool dilution on the faecal Helicobacter pylori antigen test. Journal of Paediatrics and Child Health 2003;39(4):286-8.

\section{Shimoyama 1996}

Shimoyama T, Fukuda Y, Fukuda S, Munakata A, Yoshida Y, Shimoyama T. Validity of various diagnostic tests to evaluate cure of Helicobacter pylori infection. Journal of Gastroenterology 1996;31(2):171-4.

\section{Shimoyama 2009a}

Shimoyama T, Oyama T, Matsuzaka M, Danjo K, Nakaji S, Fukuda S. Comparison of a stool antigen test and serology for the diagnosis of Helicobacter pylori infection in mass survey. Helicobacter 2009;14(2):87-90.

\section{Shimoyama 2009b}

Shimoyama T, Kato C, Kodama M, Kobayashi I, Fukuda Y. Applicability of a monoclonal antibody-based stool antigen test to evaluate the results of Helicobacter pylori eradication therapy. Japanese Journal of Infectious Diseases 2009;62(3):225-7.

\section{Shimoyama 2010}

Shimoyama T, Kobayashi I, Kato C, Kodama M, Fukuda Y. Comparison of monoclonal antibody-based stool antigen tests to determine the results of Helicobacter pylori eradication therapy. Scandinavian Journal of Gastroenterology 2010;45(12):1431-4.

\section{Shimoyama 2011}

Shimoyama T, Sawaya M, Ishiguro A, Hanabata N, Yoshimura T, Fukuda S. Applicability of a rapid stool antigen test, using monoclonal antibody to catalase, for the management of Helicobacter pylori infection. Journal of Gastroenterology 2011;46(4):487-91.

\section{Shimoyama 2014}

Shimoyama T, Chinda D, Ebina T, Iwamura H, Fukuda S. Screening of Helicobacter pylori infection using stool antigen test for young adults in a Japanese population with high incidence of gastric cancer. Helicobacter 2014;19:121.

\section{Shimoyama 2015}

Shimoyama T, Sawada Y, Fukuda S. Accuracy of a stick-type kit and enzyme-linked immunosorbent assay for the detection of Helicobacter pylori antibodies in urine. American Journal of Gastroenterology 2015;110:S1020.

\section{Shirin 2001}

Shirin H, Kenet G, Shevah O, Wardi Y, Birkenfeld S, Shahmurov M, et al. Evaluation of a novel continuous real time c-13 urea breath analyser for Helicobacter pylori. Alimentary Pharmacology \& Therapeutics 2001;15(3):389-94.

\section{Shirin 2003}

Shirin H, Frenkel D, Shevah O, Levine A, Bruck R, Moss SF, et al. Effect of proton pump inhibitors on the continuous real time c-13-urea breath test. American Journal of Gastroenterology 2003;98(1):46-50.

\section{Shirin 2005}

Shirin H, Levine A, Shevah O, Shabat-Sehayek V, Aeed H, Wardi J, et al. Eradication of Helicobacter pylori can be accurately confirmed 14 days after termination of triple therapy using a high-dose citric acid-based c-13 urea breath test. Digestion 2005;71(4):208-12.

\section{Shmuely 2007}

Shmuely H, Yahav J, Samra Z, Chodick G, Ofek I. Elevated c-13 urea breath test values females infected with Helicobacter pylori. Digestive Diseases and Sciences 2007;52(2):402-4.

\section{Shuber 2002}

Shuber AP, Ascaño JJ, Boynton KA, Mitchell A, Frierson HF Jr, ElRifai W, et al. Accurate, noninvasive detection of Helicobacter pylori DNA from stool samples: Potential usefulness for monitoring treatment. Journal of Clinical Microbiology 2002;40(1):262-4.

\section{Shukla 2012}

Shukla S, Pujani M, Agarwal A, Pujani M, Rohtagi A. Correlation of serology with morphological changes in gastric biopsy in Helicobacter pylori infection and evaluation of immunohistochemistry for h. Pylori identification. Saudi Journal of Gastroenterology 2012;18(6):369-74.

\section{Sicinschi 2003a}

Sicinschi LA, Correa P, Schneider BG. Comparison of genotyping of Helicobacter pylori caga and vaca virulence genes from gastric biopsies and stool specimens. Helicobacter 2003;8(6):601-7.

\section{Sicinschi 2003b}

Sicinschi LA, Correa P, Bravo LE, Schneider BG. Detection and typing of Helicobacter pylori caga/vaca genes by radioactive, one-step polymerase chain reaction in stool samples from children. Journal of Microbiological Methods 2003;52(2):197-207.

\section{Siddiqui 2010}

Siddiqui AA, Ansari MA, Rahman RU, Jabeen R, Qureshi NR, Kashoob MB. Comparison between Helicobacter pylori fecal antigen detection and endoscopic gastric biopsy in diagnosis 
of h. Pylori infection in 50 adult cases. Journal of the Liaquat University of Medical and Health Sciences 2010;9(1):23-6.

\section{Silva 2009}

Silva DG, Stevens RH, Macedo JMB, Hirata R, Pinto AC, Alves LM, et al. Higher levels of salivary muc5b and muc7 in individuals with gastric diseases who harbor Helicobacter pylori. Archives of Oral Biology 2009;54(1):86-90.

\section{Sito 1994}

Sito E, Karczewska E, Szczeba J, Kaminski K, Oleksy J, NowakSadzikowska J, et al. Comparative evaluation of culture techniques and ELISA test in detection of Helicobacter pylori infection. Medycyna Doswiadczalna i Mikrobiologia 1994;46(4):301-4.

\section{Slade 1999}

Slade PE, Davidson AR, Steel A, Cox RA, Blackburn PA. Reducing the endoscopic workload: Does serological testing for Helicobacter pylori help?. European Journal of Gastroenterology \& Hepatology 1999;11(8):857-62.

\section{Slater 2004}

Slater C, Preston T, Weaver LT. Is there an advantage in normalising the results of the Helicobacter pylori c-13 urea breath test for $\mathrm{CO} 2$ production rate in children?. Isotopes in Environmental and Health Studies 2004;40(1):89-98.

\section{Slomianski 1994}

Slomianski A, Schubert T, Cutler AF. C-13 urea breath test to confirm eradication of Helicobacter-pylori. Gastroenterology 1994;106(4 (suppl)):A183.

\section{Slomianski 1995}

Slomianski A, Schubert T, Cutler AF. [13C]urea breath test to confirm eradication of Helicobacter pylori. American Journal of Gastroenterology 1995;90(2):224-6.

\section{Smith 2006}

Smith SI, Oyedeji KS, Odeniyi OAM, Arigbabu AO, Coker AO. Diagnosis of Helicobacter pylori infection among patients with dental caries by stool antigen test. British Journal of Biomedical Science 2006;63(3):144-5.

\section{Smith 2009}

Smith SI, Omonigbehin EA, Goodluck HA, Abdulkareem FB, Onyekwere CA, Agomo C, et al. The use of histology as a gold standard for diagnosis of $h$. Pylori in Nigeria. Helicobacter 2009;14(4):342.

\section{Smith 2010}

Smith SI, Fowora MA, Lesi OA, Agbebaku E, Abdulkareem FB, Contreras M, et al. Application of stool-PCR test for the diagnosis of h. Pylori in Nigeria. Helicobacter 2010;15(4):363.

\section{Smith 2011}

Smith SI, Oyedeji KS, Goodluck HA, Fowora MA, Anomneze E, Lesi OA. The use of Helicobacter pylori stool antigen test for the diagnosis of Helicobacter pylori in Lagos, Nigeria. West Indian Medical Journal 2011;60(1):33-5.

\section{Smith 2012}

Smith SI, Fowora MA, Lesi OA, Agbebaku E, Odeigah P, Abdulkareem FB, et al. Application of stool-PRC for the diagnosis of Helicobacter pylori from stool in Nigeria- a pilot study. Springerplus 2012;1(1):78. [DOI: 10.1186/2193-1801-1-78]

\section{Snyder 1999}

Snyder JD, Veldhuyzen Van Zanten S. Novel diagnostic tests to detect Helicobacter pylori infection: A pediatric perspective. Canadian Journal of Gastroenterology 1999;13(7):585-9.

\section{Sobala 1991}

Sobala GM, Crabtree JE, Pentith JA, Rathbone BJ, Shallcross TM, Wyatt JI, et al. Screening dyspepsia by serology to Helicobacter pylori. Lancet 1991;338(8759):94-6.

\section{Sokucu 2002}

Sokucu S, Suoglu OD, Turkkan E, Elkabes B, Ozden T, Saner G. Helicobacter pylori infection in turkish children with gastrointestinal symptoms and evaluation of serology. Turkish Journal of Pediatrics 2002;44(2):102-8.

\section{Song 2000}

Song Q, Lange T, Spahr A, Adler G, Bode G. Characteristic distribution pattern of Helicobacter pylori in dental plaque and saliva detected with nested PCR. Journal of Medical Microbiology 2000;49(4):349-53.

\section{Song 2014}

Song $\mathrm{Y}$, Jiang $\mathrm{K}$, Jin $\mathrm{H}$, Wang BM. The application of methane and hydrogen breath test in the diagnosis and treatment of Helicobacter pylori. Journal of Digestive Diseases 2014;15:116.

\section{Sonmezoglu 2005}

Sonmezoglu M, Baysal B, Ergen A, Barut SG. Detection and evaluation of salivary antibodies to Helicobacter pylori in dyspeptic patients. International Journal of Clinical Practice 2005;59(4):433-6.

\section{Sorberg 1997}

Sorberg M, Engstrand L, Strom M, Jonsson KA, Jorbeck H, Granstrom $M$. The diagnostic value of enzyme immunoassay and immunoblot in monitoring eradication of Helicobacter pylori. Scandinavian Journal of Infectious Diseases 1997;29(2):147-51.

\section{Steen 1995}

Steen T, Berstad K, Meling T, Berstad A. Reproducibility of the $14 \mathrm{c}$ urea breath test repeated after 1 week. American Journal of Gastroenterology 1995;90(12):2103-5.

\section{Stege 2010}

Stege PW, Raba J, Messina GA. Online immunoaffinity assayce using magnetic nanobeads for the determination of antiHelicobacter pylori IgG in human serum. Electrophoresis 2010;31(20):3475-81.

\section{Stermer 1997}

Stermer E, Levy N, Tabak M, Neeman I. Lanzoprazole and ranitidine affect the accuracy of the 14c-urea breath 
test by a ph-dependent mechanism. American Journal of Gastroenterology 1997;92(9):1575-6.

\section{Sternberg 1997}

Sternberg A, Coscas D, Wagner Y, Auslander L, Kaufshtein M, Fireman Z. Comparison of various Helicobacter pylori detection methods: Serology, histology and bacteriology. Israel Journal of Medical Sciences 1997;33(3):160-3.

\section{Stirling 1995}

Stirling N, McCallion W. Helicobacter pylori gastritis: Noninvasive diagnosis. Paediatric Nursing 1995;7(2):17-9.

\section{Stojkovic 2011}

Stojkovic M, Durutovic DR, Petrovic MN, Stojkovic MV, Petrovic NS, Antic AA, et al. Helicobacter pylori infection in various groups of patients studied, estimated by $14 \mathrm{c}$-urea breath test. Acta Chirurgica Iugoslavica 2011;58(1):95-8.

\section{Stone 1997}

Stone MA, Mayberry JF, Wicks ACB, Livsey SA, Stevens M, Swann RA, et al. Near patient testing for Helicobacter pylori: A detailed evaluation of the cortecs helisal rapid blood test. European Journal of Gastroenterology \& Hepatology 1997;9(3):257-60.

\section{Storskrubb 2005}

Storskrubb T, Aro P, Ronkainen J, Vieth M, Stolte M, Wreiber K, et al. A negative Helicobacter pylori serology test is more reliable for exclusion of premalignant gastric conditions than a negative test for current $h$. Pylori infection: A report on histology and $h$. Pylori detection in the general adult population. Scandinavian Journal of Gastroenterology 2005;40(3):302-11.

\section{Stray-Pedersen 2007}

Stray-Pedersen A, Gaustad P, Stray-Pedersen B, Rognum TO. Detection rate of Helicobacter pylori stool antigen in newborn infants and small children. Journal of Perinatal Medicine 2007;35(2):155-8.

\section{Stuppy 2010}

Stuppy W, Everitt M. Correlation of salivary antibody (HPSAigg) and stool antigen (hpstag) in Helicobacter pylori infection. American Journal of Gastroenterology 2010;105:S46.

\section{Stuppy 2011}

Stuppy W, El Khoury M. Pre- and post-treatment correlation of salivary antibody with stool antigen in Helicobacter pylori infection. American Journal of Gastroenterology 2011;106:S49.

\section{Sudraba 2010}

Sudraba A, Funka K, Tolmanis I, Vanags A, Daugule I, Janciauskas D, et al. Gastric biomarkers in h. Pylori positive and negative patients. Helicobacter 2010;15(4):353.

\section{Sudraba 2011}

Sudraba A, Daugule I, Rudzite D, Funka K, Tolmanis I, Engstrand L, et al. Performance of routine Helicobacter pylori tests in patients with atrophic gastritis. Journal of Gastrointestinal \& Liver Diseases 2011;20(4):349-54.

\section{Sue 1996}

Sue M, Peura D, Charles C, Doobay R, Reid H, Morris E, et al. Comparison of two treatment strategies for the eradication of h-pylori utilizing a screening antibody serum blot test and confirmatory c 14 breath test. Gastroenterology 1996;110(4 (suppl)):A266.

\section{Sugiyama 1991}

Sugiyama T, Imai K, Yoshida H, Takayama Y, Yabana T, Yokota K et al. A novel enzyme immunoassay for serodiagnosis of Helicobacter pylori infection. Gastroenterology 1991;101(1):77-83.

\section{Sujatha 2013}

Sujatha R, Arunagiri D, Singh DN, Hariomsharan. Diagnosis of Helicobacter pylori associated acid peptic disease by serology and rapid urease test. Journal of Pure and Applied Microbiology 2013;7(1):691-5.

\section{Sukhanov 2011}

Sukhanov AV, Pikerskii IE, Saifutdinov RG, Makarov AA, Frolov SV. Comparison of various diagnostic methods of Helicobacter infection. Eksperimental'naia i Klinicheskaia Gastroenterologiia [Experimental \& Clinical Gastroenterology] 2011;5:8-15.

\section{Sumona 2009}

Sumona AA, Hossain MA, Musa AK, Shamsuzzaman AK, Mahmud MC, Khan MS, et al. Anti h.Pylori igm in symptomatic and asymptomatic population. Mymensingh Medical Journal: MMJ 2009;18(1):18-20.

\section{Sunnerstam 1999}

Sunnerstam B, Kjerstadius T, Jansson L, Giesecke J, Bergstrom M, Ejderhamn J. Detection of Helicobacter pylori antibodies in a pediatric population: Comparison of three commercially available serological tests and one in-house enzyme immunoassay. Journal of Clinical Microbiology 1999;37(10):3328-31.

\section{Surveyor 1988}

Surveyor I, Goodwin CS, Warren JR, Geelhoed E, Murray RN, Waters TE. Further experience of the c-14 urea breath test for the detection of c-pylori infection. Australian and New Zealand Journal of Medicine 1988;18(3):505.

\section{Suto 1997a}

Suto H, Azuma T, Ito S, Ito Y, Miyaji H, Yamazaki Y, et al. Evaluation of the endoscopic c-13-urea breath test: A new accurate diagnostic test of Helicobacter pylori infection. Gastroenterology 1997;112(4 (suppl)):A301.

\section{Suto 1997b}

Suto H, Azuma T, Ito S, Ito Y, Miyaji H, Yamazaki Y, et al. A trial of ${ }^{13} \mathrm{C}$-urea breath test combined with endoscopic phenol red test for detection of Helicobacter pylori infection. Digestive Endoscopy 1997;9(4):283-9.

\section{Suto 1999}

Suto H, Azuma T, Ito S, Ito Y, Miyaji H, Yamazaki Y, et al. Evaluation of endoscopic c-13-urea breath test for assessment 
of Helicobacter pylori eradication. Journal of Gastroenterology 1999;34(Suppl 11):67-71.

\section{Suto 2000a}

Suto H, Azuma T, Ito S, Ito Y, Miyaji H, Yamazaki Y, et al. Endoscopic ${ }^{13} \mathrm{C}$-urea breath test for quantification of Helicobacter pylori infection. Journal of Gastroenterology and Hepatology (Australia) 2000;15(2):161-7.

\section{Suto $2000 b$}

Suto G, Vincze A, Pakodi F, Hunyady B, Karadi O, Garamszegi M, et al. C-13-urea breath test is superior in sensitivity to detect Helicobacter pylori infection than either antral histology or rapid urease test. Journal of Physiology-Paris 2000;94(2):153-6.

\section{Suzuki 2010}

Suzuki K, Shimoyama T, Kobayashi I, Kato C, Kodama M, Fukuda Y. Comparison of monoclonal antibody-based stool antigen tests to determine the results of $h$. Pylori eradication therapy. Helicobacter 2010;15 (4):358.

\section{Syam 2005}

Syam AF, Rani AA, Abdullah M, Manan C, Makmun D, Simadibrata M, et al. Accuracy of Helicobacter pylori stool antigen for the detection of Helicobacter pylori infection in dyspeptic patients. World Journal of Gastroenterology 2005;11(3):386-8.

\section{Sykora 2002}

Sykora J, Valeckova K, Hejda V, Varvarovska J, Stozicky F. Accurate noninvasive diagnosis of Helicobacter pylori infection using antigen determination in the feces in the pediatric population. Casopis Lekaru Ceskych 2002;141(13):425-7.

\section{Sykora 2003}

Sykora J, Valeckova K, Stozicky F, Schwarz J, Varvarovska J. Revealing of the Helicobacter pylori infection in children by detection of stool antigen by a novel enzyme immunoassay using monoclonal antibodies (hpstar). Casopis Lekaru Ceskych 2003;142(11):687-90.

\section{Taha 1992}

Taha AS, Boothman P, Nakshabendi I, Reid J, Morran C, Gemmell CG, et al. Diagnostic tests for Helicobacter pylori: Comparison and influence of non-steroidal anti-inflammatory drugs. Journal of Clinical Pathology 1992;45(8):709-12.

\section{Taha 1993}

Taha AS, Reid J, Boothmann P, Gemmell CG, Lee FD, Sturrock RD, et al. Serological diagnosis of Helicobacter pylori-evaluation of four tests in the presence or absence of nonsteroidal anti-inflammatory drugs. Gut 1993;34(4):461-5.

\section{Takagi 1993}

Takagi A, Suyama T, Kida M, Matsuda M, Matsumoto H, Kojima K, et al. Comparison between ELISA and culture method for detection of Helicobacter pylori. Rinsho Byori [Japanese Journal of Clinical Pathology] 1993;41(12):1333-7.

\section{Takagi 2002}

Takagi A, Mine T. Serodiagnosis of Helicobacter pylori infection. Nihon Rinsho [Japanese Journal of Clinical Medicine] 2002;60(Suppl 2):324-7.

\section{Takagi 2003}

Takagi A. Detection of $h$. Pylori by serum and urine-based ELISA. Nihon Rinsho [Japanese Journal of Clinical Medicine] 2003;61(1):88-91.

\section{Takahashi 2010}

Takahashi R, Shimoyama T, Abe D, Nakabayashi N, Okuda M, Fukuda Y. Determining cut-off values for serodiagnosis of Helicobacter hepaticus infection by hrii-51-hh-15 capture enzyme-linked immunosorbent assay. Helicobacter 2010;15(4):362.

\section{Takwoingi 2013}

Takwoingi Y, Leeflang MM, Deeks JJ. Empirical evidence of the importance of comparative studies of diagnostic test accuracy. Annals of internal medicine 2013;158(7):544-54. [PUBMED: 23546566]

\section{Takwoingi 2017}

Takwoingi Y, Guo B, Riley RD, Deeks JJ. Performance of methods for meta-analysis of diagnostic test accuracy with few studies or sparse data. Statistical Methods in Medical Research 2017; Vol. 26 , issue 4:1896-911.

\section{Talebkhan 2009}

Talebkhan Y, Ebrahimzadeh F, Esmaeili M, Oghalaie A, Sadeghi M, Mohammadi M. H. Pylori immunoreactive antigens and their screening applications. Helicobacter 2009;14 (4):338.

\section{Talebkhan 2010}

Talebkhan Y, Esmaili M, Hassanpour P, Morakabati A, Rakhshani N, Mohagheghi M, et al. Comparison of routinely used invasive and non invasive approaches in diagnosis of $h$. Pylori infection. Helicobacter 2010;15(4):358-9.

\section{Talley 1991}

Talley NJ, Newell DG, Ormand JE, Carpenter HA, Wilson WR, Zinsmeister AR, et al. Serodiagnosis of Helicobacter pylori: Comparison of enzyme-linked immunosorbent assays. Journal of Clinical Microbiology 1991;29(8):1635-9.

\section{Talley 1992}

Talley NJ, Kost L, Haddad A, Zinsmeister AR. Comparison of commercial serological tests for detection of Helicobacter pylori antibodies. Journal of Clinical Microbiology 1992;30(12):3146-50.

\section{Talley 1998}

Talley NJ, Lambert JR, Howell S, Xia HH, Lin SK, Agreus L. An evaluation of whole blood testing for Helicobacter pylori in general practice. Alimentary Pharmacology \& Therapeutics 1998;12(7):641-5.

\section{Talley 2008}

Talley NJ, Fock KM, Moayyedi P. Gastric Cancer Consensus conference recommends Helicobacter pylori screening and treatment in asymptomatic persons from high-risk populations 
to prevent gastric cancer. American Journal of Gastroenterology 2008;103(3):510-4.

\section{Tamura 2001}

Tamura S, Yokoyama Y, Morita T, Tadokoro T, Higashidani Y, Onishi S. Stool test for Helicobacter pylori. American Journal of Gastroenterology 2001;96(6):1936-8.

\section{Tanahashi 1998}

Tanahashi T, Kodama T, Yamaoka Y, Sawai N, Tatsumi Y, Kashima K, et al. Analysis of the c-13-urea breath test for detection of Helicobacter pylori infection based on the kinetics of delta-(co2)-c-13 using laser spectroscopy. Journal of Gastroenterology and Hepatology 1998;13(7):732-7.

\section{Tanaka 2001}

Tanaka A, Watanabe K, Tokunaga K, Hoshiya S, Imase K, Sugano $\mathrm{H}$, et al. Evaluation of Helicobacter pylori stool antigen test before and after eradication therapy. Gut 2001;49(suppl):A101.

\section{Tanaka 2003}

Tanaka A, Watanabe K, Tokunaga K, Hoshiya S, Imase K, Sugano $\mathrm{H}$, et al. Evaluation of Helicobacter pylori stool antigen test before and after eradication therapy. Journal of Gastroenterology \& Hepatology 2003;18(6):732-8.

\section{Tanaka 2004}

Tanaka A, Takahashi S. Helicobacter pylori stool antigen test. Nihon Rinsho [Japanese Journal of Clinical Medicine] 2004;62(3):464-9.

\section{Tanaka 2005}

Tanaka A, Tokunaga K, Imase K, Sugano H, Ishida H, Takahashi S. Evaluation of rapid h-pylori stool antigen test before and after eradication therapy. American Journal of Gastroenterology 2005;100(9):S69-70.

\section{Tanigawa 1996}

Tanigawa T, Mizo-oku Y, Moriguchi K, Suzuki T, Osumi T, Odomi M. Simple and rapid quantitative assay of $13 \mathrm{C}$ labelled urea in human serum using liquid chromatographyatmospheric pressure chemical ionization mass spectrometry. Journal of Chromatography B: Biomedical Applications 1996;683(2):135-42.

\section{Taniguchi 1995}

Taniguchi Y, Kimura K, Satoh K, Kawada H, Sohara H, Yamamoto $\mathrm{H}$, et al. Substitute, inexpensive diagnosis of Helicobacter-pylori infection by infrared (ir) spectrophotometer in c-13-urea breath test. Gastroenterology 1995;108(4 (Suppl)):A235.

\section{Taylor 1987}

Taylor DE, Chang N. Immunoblot and enzyme-linked immunosorbent assays of campylobacter major outermembrane protein and application to the differentiation of campylobacter species. Molecular \& Cellular Probes 1987;1(3):261-74.

\section{Taylor 2014}

Taylor J, Hafner M, Yerushalmi E, Smith R, Bellasio J, Vardavas R, et al. Estimating the economic costs of antimicrobial resistance. Model and Results. www.rand.org/pubs/research_reports/ RR911.html 2014 (accessed 15 December 2016).

\section{Teich 1997}

Teich M, Bohn I, Niessen KH. Validation of a children's c-13-urea breath test for diagnosis of Helicobacter pylori. Monatsschrift Kinderheilkunde 1997;145(3):242-8.

\section{Temelli 2011}

Temelli B, Velipasaoglu Z, Akdemir E, Bozkurt MF. Efficacy of carbon-14 urea breath test in the diagnosis of Helicobacter pylori infection in children: Comparison among different tests to find out the best. European Journal of Nuclear Medicine and Molecular Imaging 2011;38:S190-S1.

\section{Teo 1997}

Teo EK, Fock KM, Ng TM, Khor CJL, Lee YM, Sim CS. 13 carbon-urea breath test for detection of h-pylori infection. Gastroenterology 1997;112(4 suppl):A311.

\section{Tepes 2015}

Tepes B, Malfertheiner P, Labenz J, Aygen S. The accuracy of a new c-13 urea breath test meal (refex ( $r)$ ) for Helicobacter pylori in patients taking proton pump inhibitors. Helicobacter 2015;20:81

\section{Tereshchenko 2014}

Tereshchenko S, Gorbacheva N, Anisimova E, Babushkin V. The diagnostic accuracy of Helicobacter pylori antigen detection in duodenal juice. Helicobacter 2014;19:125-6.

\section{Tewari 2001}

Tewari V, Nath G, Gupta H, Dixit VK, Jain AK. 14c-urea breath test for assessment of gastric Helicobacter pylori colonization and eradication. Indian Journal of Gastroenterology 2001;20(4):140-3.

\section{Tham 1993}

Tham TCK, McLaughlin N, Hughes DF, Ferguson M, Crosbie JJ, Madden M, et al. Evaluation of a commercial ELISA for the serodiagnosis of Helicobacter-pylori infection. Gastroenterology 1993;104(4 suppl):A210.

\section{Tham 1994}

Tham TCK, McLaughlin M, Hughes DF, Ferguson M, Crosbie JJ, Madden $\mathrm{M}$, et al. Possible role of Helicobacter pylori serology in reducing endoscopy workload. Postgraduate Medical Journal 1994;70(829):809-12.

\section{Thijs 1994}

Thijs JC, Van Zwet AA, Meyer BC, Berrelkamp RJP. Serology to monitor the efficacy of anti-Helicobacter pylori treatment. European Journal of Gastroenterology \& Hepatology 1994;6(7):579-83.

\section{Thijs 1995a}

Thijs WJ, Thijs JC, Kleibeuker JH, Elzinga H, Stellaard F. Evaluation of clinical and home performance of the $13 \mathrm{C}$-urea 
breath test for the detection of Helicobacter pylori. European Journal of Gastroenterology \& Hepatology 1995;7(7):603-7.

\section{Thijs 1995b}

Thijs WJ, Thijs JC, Kleibeuker JH, Elzinga H, Stellaard F. The c-13-urea breath test for the detection of Helicobacter-pylori - an analysis of the test performed clinically and at home. Gastroenterology 1995;108(4 (suppl)):A241.

\section{Thijs 1996}

Thijs JC, Van Zwei AA, Thijs WJ, Oey HB, Karrenbeld A, Stellaard F, et al. Diagnostic tests for Helicobacter pylori: A prospective evaluation of their accuracy, without selecting a single test as the gold standard. American Journal of Gastroenterology 1996;91(10):2125-9.

\section{Thillainayagam 1991}

Thillainayagam AV, Arvind AS, Cook RS, Harrison IG, Tabaqchali S, Farthing MJG. Diagnostic efficiency of an ultrarapid endoscopy room test for Helicobacter-pylori. Gut 1991;32(5):467-9.

\section{Thomas 1990}

Thomas JE, Whatmore AM, Barer MR, Eastham EJ, Kehoe MA. Serodiagnosis of Helicobacter pylori infection in childhood. Journal of Clinical Microbiology 1990;28(12):2641-6.

\section{Thomas 1999}

Thomas JE, Dale A, Harding M, Coward WA, Cole TJ, Sullivan PB, et al. Interpreting the c-13-urea breath test among a large population of young children from a developing country. Pediatric Research 1999;46(2):147-51.

\section{Thongbai 2007}

Thongbai T, Thong-Ngam D, Mahachai V, Kullavanijaya P. Effect of antiulcer drugs used on the detection of Helicobacter pylori using urea breath test. Helicobacter 2007;12(4):443.

\section{Tindberg 2001}

Tindberg Y, Bengtsson C, Bergstrom M, Granstrom M. Phe accuracy of serologic diagnosis of Helicobacter pylori infection in school-aged children of mixed ethnicity. Helicobacter 2001;6(1):24-30.

\section{Tinnert 1998}

Tinnert A, Hamlet A, Svennerholm AM. Antibodies against Helicobacter pylori in feces and saliva before and after eradication therapy. Clinical Microbiology and Infection 1998;4(11):634-43.

\section{Tiryaki 2010}

Tiryaki Z, Yilmaz-Ciftdogan D, Kasirga E. Diagnostic value of stool antigen and antibody tests for Helicobacter pylori infection in Turkish children with upper gastrointestinal complaints before and after eradication. Turkish Journal of Pediatrics 2010;52(5):505-11.

\section{Togashi 2006}

Togashi A, Matsukura N, Kato S, Masuda G, Ohkawa K, Tokunaga A, et al. Simple and accurate c-13-urea breath test for detection of Helicobacter pylori in the remnant stomach after surgery. Journal of Gastroenterology 2006;41(2):127-32.

\section{Tokunaga 1998}

Tokunaga Y, Shirahase H, Yamamoto E, Gouda Y, Kanaji K, Ohsumi K. Semiquantitative evaluation for diagnosis of Helicobacter pylori infection in relation to histological changes. American Journal of Gastroenterology 1998;93(1):26-9.

\section{Tokunaga 2000}

Tokunaga Y, Shirahase H, Yamamoto E, Inao R, Hamaguchi S, Kanaji K, et al. Modified rapid urease test for Helicobacter pylori detection in relation to an immunohistochemical stain. Journal of Gastroenterology and Hepatology 2000;15(6):617-21.

\section{Tokunaga 2005}

Tokunaga K, Watanabe K, Tanaka A, Sugano H, Imase K, Ishida $\mathrm{H}$, et al. Evaluation of ${ }^{13} \mathrm{C}$-urea breath test to confirm eradication of Helicobacter pylori. Japanese Journal of Gastroenterology 2005;102(2):176-82.

\section{Toporowska-Kowalska 2005}

Toporowska-Kowalska E, Wasowska-Krolikowska K, Kurnatowski M, Gebora-Kowalska B. Clinical applicability of non-invasive testing of Helicobacter pylori infection in children - stool antygen (HPSA) and urea breath test. Pediatria Wspolczesna 2005;7(3):177-9.

\section{Tormo 2013}

Tormo R. Urea c-13 test is not enough to diagnose a Helicobacter pylori infection. Journal of Pediatric Gastroenterology and Nutrition 2013;56(6):e53.

\section{Torres 2001}

Torres J, Camorlinga M, Perez-Perez G, Gonzalez G, Muñoz O. Validation of the string test for the recovery of Helicobacter pylori from gastric secretions and correlation of its results with urea breath test results, serology, and gastric ph levels. Journal of Clinical Microbiology 2001;39(4):1650-1.

\section{Toyama 1999}

Toyama J, Kato C, Sato K, Sato S. The 13C-urea breath test efficacy in determining Helicobacter pylori eradication. Nihon Rinsho [Japanese Journal of Clinical Medicine] 1999;57(1):93-6.

\section{Trautmann 1994}

Trautmann M, Moldrzyk M, Vogt K, Korber J, Held T, Marre R. Use of a receiver operating characteristic in the evaluation of two commercial enzyme immunoassays for detection of Helicobacter pylori infection. European Journal of Clinical Microbiology \& Infectious Diseases 1994;13(10):812-9.

\section{Treiber 2000}

Treiber G, Malfertheiner P. Usefulness of serology for diagnosis and follow-up of h.pylori infection - comparison of third vs. second generation ELISA. Gastroenterology 2000;118(4 Part 2):A1316.

\section{Trevisani 1998}

Trevisani L, Sartori S, Galvani F, Rossi MR, Ruina M, Caselli M. Detection of Helicobacter pylori in faeces with a new enzyme 
immunoassay method: Preliminary results. Scandinavian Journal of Gastroenterology 1998;33(8):893-4.

\section{Trevisani 1999a}

Trevisani L, Sartori S, Ruina M, Caselli M, Rossi MR, Costa F, et al. Helicobacter pylori stool antigen test - clinical evaluation and cost analysis of a new enzyme immunoassay. Digestive Diseases and Sciences 1999;44(11):2303-6.

\section{Trevisani 1999b}

Trevisani L, Sartori S, Galvani F, Rossi MR, Ruina M, Chiamenti C, et al. Evaluation of a new enzyme immunoassay for detecting Helicobacter pylori in feces: A prospective pilot study. American Journal of Gastroenterology 1999;94(7):1830-3.

\section{Trevisani 2002}

Trevisani L, Sartori S. The accuracy of the Helicobacter pylori stool antigen test in diagnosing h-pylori in treated patients. European Journal of Gastroenterology \& Hepatology 2002;14(1):89.

\section{Tseng 2005}

Tseng CA, Wang WM, Wu DC. Comparison of the clinical feasibility of three rapid urease tests in the diagnosis of Helicobacter pylori infection. Digestive Diseases and Sciences 2005;50(3):449-52.

\section{Tu 1999}

Tu TC, Lee CL, Wu CH, Chen TK, Chan CC, Huang SH, et al. Comparison of invasive and noninvasive tests for detecting Helicobacter pylori infection in bleeding peptic ulcers. Gastrointestinal Endoscopy 1999;49(3 I):302-6.

\section{Tucci 1996}

Tucci A, Poli L, Donati M, Mazzoni C, Cevenini R, Sambri V, et al. Value of serology (ELISA) for the diagnosis of Helicobacter pylori infection: evaluation in patients attending endoscopy and in those with fundic atrophic gastritis. Italian Journal of Gastroenterology 1996;28(7):371-6.

\section{Tummala 2007}

Tummala S, Sheth SG, Goldsmith JD, Goldar-Najafi A, Murphy CK, Osburne MS, et al. Quantifying gastric Helicobacter pylori infection: A comparison of quantitative culture, urease breath testing, and histology. Digestive Diseases \& Sciences 2007;52(2):396-401.

\section{Uchida 2011}

Uchida T, Vilaichone R, Ratanachu-Ek T, Mahachai V, Tshering L, Fujioka T, et al. Evaluation of diagnostic tests for h. Pylori infection in the Bhutanese population. Helicobacter 2011;16:114

\section{Ueda 2014}

Ueda J, Okuda M, Nishiyama T, Lin YS, Fukuda Y, Kikuchi S. Diagnostic accuracy of the e-plate serum antibody test kit in detecting Helicobacter pylori infection among Japanese children. Journal of Epidemiology 2014;24(1):47-51.

\section{Uematsu 2002}

Uematsu T, Matsuno H, Tanba M, Kozawa O, Ikei N, Kawasaki J, et al. Clinical pharmacology study of c-13 ubt tablet for the in vivo diagnosis of Helicobacter pylori infection. Japanese Journal of Clinical Pharmacology and Therapeutics 2002;33(3):81-4.

\section{Urita 2000}

Urita Y, Miki K. Endoscopic ${ }^{13} \mathrm{C}$-urea breath test. Digestive Endoscopy 2000;12(1):29-32.

\section{Urita 2002}

Urita Y, Torii N, Hike K, Kikuchi Y, Kanda E, Sasajima M, et al. Proteinuria reduces the diagnostic accuracy of urine-based enzyme-linked immunosorbent assay for detection of antibody to Helicobacter pylori. American Journal of Gastroenterology 2002;97(9):S49.

\section{Urita 2004a}

Urita Y, Hike K, Torii N, Kikuchi Y, Kurakata H, Kanda E, et al. Comparison of serum iga and igg antibodies for detecting Helicobacter pylori infection. Internal Medicine 2004;43(7):548-52.

\section{Urita 2004b}

Urita Y, Kikuchi Y, Hike K, Torii N, Kanda E, Kurakata H, et al. Endoscopic 13C-urea breath test for detection of Helicobacter pylori infection after partial gastrectomy. Gastrointestinal Endoscopy 2004;59(5):AB153.

\section{Urita 2004c}

Urita Y, Hike K, Torii N, Kikuchi Y, Kanda E, Kurakata H, et al. Breath sample collection through the nostril reduces falsepositive results of $\mathrm{c}$-13-urea breath test for the diagnosis of Helicobacter pylori infection. Digestive and Liver Disease 2004;36(10):661-5.

\section{Urita 2006}

Urita Y, Hike K, Torii N, Kikuchi Y, Kanda E, Kurakata H, et al. Influence of urease activity in the intestinal tract on the results of c-13-urea breath test. Journal of Gastroenterology and Hepatology 2006;21(4):744-7.

\section{Urita 2007a}

Urita Y, Maeda T, Ishihara S, Sugimoto M, Watanabe T, Domon K, et al. Endoscopic c-13-urea breath test for detection of Helicobacter pylori infection after partial gastrectomy. HepatoGastroenterology 2007;54(78):1891-4.

\section{Urita 2007b}

Urita Y, Hike K, Torii N, Kikuchi Y, Watanabe T, Kurakata H, et al. Ten-second endoscopic breath test using a 20-mg dose of c-13-urea to detect Helicobacter pylori infection. HepatoGastroenterology 2007;54(75):951-4.

\section{Us 2002}

Us D, Engin D, Hascelik G. Evaluation of western blot methods for serologic diagnosis of Helicobacter pylori infections. Mikrobiyoloji Bulteni 2002;36(2):153-60. 


\section{Uyub 1994}

Uyub AM, Anuar AK, Aiyar S. Reliability of two commercial serological kits for serodiagnosing Helicobacter pylori infection. Southeast Asian Journal of Tropical Medicine \& Public Health 1994;25(2):316-20.

\section{Vafaeimanesh 2014}

Vafaeimanesh J, Bagherzadeh M. Noninvasive stool antigen assay for screening of Helicobacter pylori infection and assessing success of eradication therapy in patients on hemodialysis. Journal of Gastroenterology and Hepatology (Australia) 2014;29:236.

\section{Vaira 1989}

Vaira D, Holton J. Serum immunoglobulin g antibody levels for campylobacter pylori diagnosis. Gastroenterology 1989;97(4):1069-70.

\section{Vaira 1996}

Vaira D, Stanghellini V, Miglioli M, Corinaldesi R. IgG ELISA antibodies and detection of Helicobacter pylori in elderly patients. Italian Helicobacter pylori Study Group. Lancet 1996;347(8996):269-70.

\section{Vaira 1999a}

Vaira D, Malfertheiner P, Megraud F, Axon AT. Diagnosis of Helicobacter pylori infection by HPSA test. European Helicobacter pylori HPSA study group. Lancet 1999;354(9191):1732.

\section{Vaira 1999b}

Vaira D, Malfertheiner P, Megraud F, Axon AT, Deltenre M, Hirschl AM, et al. Diagnosis of Helicobacter pylori infection with a new non-invasive antigen-based assay. Hpsa European Study Group. Lancet 1999;354(9172):30-3.

\section{Vaira 1999c}

Vaira D, Malferteiner P, Megraud F, Moayyedi P, Axon ATR, Deltenre M, et al. Accuracy of a new antigen based stool test for Helicobacter pylori (hp) in 117 endoscoped patients before and after treatment. European Multicentre Study. Gut 1999;44(Suppl 3):A96.

\section{Vaira 2000a}

Vaira D, Menegatti M, Ricci C, Gatta L, Berardi S, Miglioli M. Accurate diagnosis of Helicobacter pylori stool tests. Gastroenterology Clinics of North America 2000;29(4):917-23.

\section{Vaira 2000b}

Vaira D, Ricci C, Menegatti M, Gatta L, Geminiani A, Miglioli M. Clinical role of fecal antigen determination in the diagnosis of Helicobacter pylori infection. Clinical Laboratory 2000;46(9-10):487-91.

\section{Vaira 2000c}

Vaira D, Malfertheiner P, Megraud F, Axon AT, Deltenre M, Gasbarrini G, et al. Noninvasive antigen-based assay for assessing Helicobacter pylori eradication: A European multicenter study. The European Helicobacter pylori HPSA Study Group. American Journal of Gastroenterology 2000;95(4):925-9.

\section{Vaira 2002}

Vaira D, Vakil N, Menegatti M, Van't Hoff B, Ricci C, Gatta L, et al. The stool antigen test for detection of Helicobacter pylori after eradication therapy [summary for patients in Annals of Internal Medicine. feb 19 2002;136(4):I36; pmid: 11848739]. Annals of Internal Medicine 2002;136(4):280-7.

\section{Vaira 2009}

Vaira D, Gatta L, Ricci C, Di Mario F, Lanzini A. Accuracy of urea breath tests tablets after 10 minutes compared with standard 30 minutes to diagnose and monitoring Helicobacter pylori infection: A randomized controlled trial. Journal of Clinical Gastroenterology 2009;43(7):693-4.

\section{Vaira 2010a}

Vaira D, Vakil N, Gatta L, Ricci C, Perna F, Saracino I, et al. Accuracy of a new ultrafast rapid urease test to diagnose Helicobacter pylori infection in 1000 consecutive dyspeptic patients. Alimentary Pharmacology \& Therapeutics 2010;31(2):331-8.

\section{Vaira 2010b}

Vaira D, Gatta L, Ricci C, Perna F, Saracino I, Fiorini G, et al. A comparison amongst three rapid urease tests to diagnose Helicobacter pylori infection in 375 consecutive dyspeptic. Internal \& Emergency Medicine 2010;5(1):41-7.

\section{Vakil 1999}

Vakil N, Affi A, Sundaram M, Robinson J, Dunn B, Phadnis S. Prospective, blinded evaluation of the accuracy of a stool test for the detection of h-pylori. Gastroenterology 1999;116(4 (suppl)):A342.

\section{Vakil 2000a}

Vakil N, Affi A, Robinson J, Sundaram M, Phadnis S. Prospective blinded trial of a fecal antigen test for the detection of Helicobacter pylori infection. American Journal of Gastroenterology 2000;95(7):1699-701.

\section{Vakil 2000b}

Vakil N. Is the stool test out of breath?. Digestive \& Liver Disease 2000;32(4):291-3.

\section{Valdeperez 2003}

Valdeperez J, Vicente R, Novella MP, Valle L, Sicilia B, Yus $\mathrm{C}$, et al. Is the breath test reliable in primary care diagnosis of Helicobacter pylori infection?. Atencion Primaria 2003;31(2):93-7.

\section{Valentine 1991}

Valentine JL, Arthur RR, Mobley HLT, Dick JD. Detection of Helicobacter-pylori by using the polymerase chain-reaction. Journal of Clinical Microbiology 1991;29(4):689-95.

\section{Valle 1997}

Valle J, Vazquez MA, Zomeno M, FernandezSalazar L, JimenezAlonso I, Lara S, et al. Direct correlation between the c-13-urea breath test values and the density of Helicobacter pylori in antrum biopsies. Gut 1997;41:A87. 


\section{Valle 2013}

Valle PC, Breckan RK, Mortensen L, Amin A, Kildahl-Andersen O, Paulssen EJ. Managing dyspepsia in the young adult patient: Effects of different tests for Helicobacter pylori in a "test-andscope" approach. Scandinavian Journal of Gastroenterology 2013;48(8):913-20.

\section{Van Bohemen 1988}

Van Bohemen CG, Langenberg ML, Rauws EAJ, Weterings E, Zanen HC. Assay-igg to campylobacter pylori in histological chronic and biopsy campylobacter positive gastritis. FEMS Microbiology Letters 1988;55(3):321-6.

\section{Van Bohemen 1989}

Van Bohemen CG, Langenberg ML, Rauws EAJ, Oudbier J, Weterings E, Zanen HC. Rapidly decreased serum igg to campylobacter pylori following elimination of campylobacter in histological chronic biopsy campylobacter-positive gastritis. Immunology Letters 1989;20(1):59-61.

\section{Van de Wouw 1995}

Van de Wouw BA, De Boer WA, Jansz AR, Staals AP, Roymans RT. Serodiagnosis of Helicobacter pylori infection: an evaluation of a commercially available ELISA-IgG. Netherlands Journal of Medicine 1995;47(6):272-7.

\section{Van de Wouw 1996}

Van de Wouw BA, De Boer WA, Jansz AR, Roymans RT, Staals AP. Comparison of three commercially available enzyme-linked immunosorbent assays and biopsy-dependent diagnosis for detecting Helicobacter pylori infection. Journal of Clinical Microbiology 1996;34(1):94-7.

\section{Van de Wouw 1997}

Van de Wouw BA, De Boer WA, Hermsen HW, Valkenburg JG, Geuskens LM, Tytgat GN. Usefulness of the 14c urea breath test as a semi-quantitative monitoring instrument after therapy for Helicobacter pylori infection. Scandinavian Journal of Gastroenterology 1997;32(2):112-7.

\section{Van Den 1991}

Van Den Oever HLA, Loffeld RJLF, Stobberingh EE. Usefulness of a new serological test (bio-rad) to diagnose Helicobacter pylori-associated gastritis. Journal of Clinical Microbiology 1991;29(2):283-6.

\section{Van Der Ende 1999}

Van Der Ende A, Van Der Hulst RWM, Roorda P, Tytgat GNJ, Dankert J. Evaluation of three commercial serological tests with different methodologies to assess Helicobacter pylori infection. Journal of Clinical Microbiology 1999;37(12):4150-2.

\section{Van der Est 1990}

Van der Est MMC, Veenendaal RA, Pena AS, Van Duijn W, Kuiper I, Lamers CBHW. ELISA analysis of IgA subclass antibodies to Helicobacter pylori. Elevated serum IgA1 antibodies in Helicobacter pylori infected patients. Journal of Clinical Nutrition and Gastroenterology 1990;5(1):185-90.

\section{Van Der Hulst 1999}

Van Der Hulst RWM, Lamouliatte H, Megraud F, Pounder RE, Stolte M, Vaira D, et al. Laser assisted ratio analyser ${ }^{13} \mathrm{C}$-urea breath testing, for the detection of $\mathrm{H}$. pylori: $\mathrm{A}$ prospective diagnostic European multicentre study. Alimentary Pharmacology \& Therapeutics 1999;13(9):1171-7.

\section{Van der Hulst 1999}

Van der Hulst RW, Hensen EF, Van der Ende A, Kruizinga SP, Homan A, Tytgat GN. Laser-assisted 13C-urea breath test; a new noninvasive detection method for Helicobacter pylori infection. Nederlands Tijdschrift voor Geneeskunde 1999;143(8):400-4.

\section{Van der Voort 1998}

Van der Voort PHJ, Van der Hulst RWM, Zandstra DF, Geraedts AAM, Tytgat GNJ. Detection of h-pylori in mechanically ventilated intensive care patients using the lara-c-13-urea breath test. Gastroenterology 1998;114(4 (suppl)):A319.

\section{Van der Voort 1999}

Van der Voort PHJ, Van der Hulst RWM, Zandstra DF, Van der Ende A, Geraedts AAM, Tytgat GNJ. Detection of Helicobacter pylori in mechanically ventilated patients: The lara-13C-urea breath test and serology. Clinical Intensive Care 1999;10(3):91-5.

\section{Van der Wouden 1999}

Van der Wouden ET, Thijs JC, Van Zwet AA, Oey HB, Kleibeuker JH. Reliability of biopsy-based diagnostic tests for Helicobacter pylori after treatment aimed at its eradication. European Journal of Gastroenterology \& Hepatology 1999;11(11):1255-8.

\section{Van Doorn 2000}

Van Doorn LJ, Henskens Y, Nouhan N, Verschuuren A, Vreede R, Herbink $P$, et al. The efficacy of laboratory diagnosis of Helicobacter pylori infections in gastric biopsy specimens is related to bacterial density and vacA, cagA, and iceA genotypes. Journal of Clinical Microbiology 2000;38(1):13-7.

\section{Van Doorn 2001}

Van Doorn OJ, Bosman DK, Van THBW, Taminiau JA, Ten Kate FJ, Van der Ende A. Helicobacter pylori stool antigen test: A reliable non-invasive test for the diagnosis of Helicobacter pylori infection in children. European Journal of Gastroenterology \& Hepatology 2001;13(9):1061-5.

\section{Van Leerdam 2002}

Van Leerdam ME, Van der Ende A, Ten Kate F, Rauws EAJ, Tytgat GNJ. Lack of accuracy of the non-invasive Helicobacter pylori stool antigen test in patients with gastroduodenal ulcer bleeding. Gastroenterology 2002;122(4 (suppl)):A46.

\section{Van Leerdam 2003}

Van Leerdam ME, Van der Ende A, Ten Kate FJW, Rauws EAJ, Tytgat GNJ. Lack of accuracy of the noninvasive Helicobacter pylori stool antigen test in patients with gastroduodenal ulcer bleeding. American Journal of Gastroenterology 2003;98(4):798-801. 


\section{Van Zanten 1998}

Van Zanten SV, Bleau BL, Best L, Hutchison D, Blevins J, Thee D. Use of the Helicobacter pylori stool antigen test (HPSAt) for detection of h-pylori (hp) infection. Gut 1998;43(Suppl 2):A49.

\section{Van Zanten 1999}

Van Zanten S, Bleau BL, Best LM, Hutchison DM, Blevins J, Thee D. Helicobacter pylori stool antigen test (HPSA): Use for detection of infection and eradication. Gastroenterology 1999;116(4 (suppl)):A837.

\section{Van Zwet 1992}

Van Zwet AA, Meyer BC, Berrelkamp RJ, Thijs JC. Serological tests to monitor treatment of Helicobacter pylori. Lancet 1992;340(8810):51.

\section{Van Zwet 1994}

Van Zwet AA, Thijs JC, Kooistra-Smid AMD, Schirm J, Snijder JAM. Use of PCR with feces for detection of Helicobacter pylori infections in patients. Journal of Clinical Microbiology 1994;32(5):1346-8.

\section{Van't Hoff 2000}

Van't Hoff BW, Vaira D, Vakil NB, Gasbarrini G, Quina M, Garcia JMP, et al. Early diagnosis of failed Helicobacter pylori (hp) eradication using a stool antigen test. Gastroenterology 2000;118(4):A697.

\section{Vannella 2009}

Vannella L, Gianni D, Lahner E, Amato A, Grossi E, Delle Fave G, et al. Pre-endoscopic screening for Helicobacter pylori and celiac disease in young anemic women. World Journal of Gastroenterology 2009;15(22):2748-53.

\section{Vargas 2013}

Vargas J, Lopez-Sanchez M, Pabon M, Lamas E, Parra M, CastroFernandez M. Evaluation of a novel chemiluminiscent inmunoassay for the detection of Helicobacter pylori antigen and their correlation with immunochromatographic rapid test in stools samples from adults patients. Helicobacter 2013;18:121.

\section{Vaz Coelho 2005}

Vaz Coelho LG, De Castro Boechat L, Rocha Z, Almeida Aguiar RO, Andrade Aragao AL, Silva Dias EE, et al. ${ }^{13} \mathrm{C}$-urea breath test for the detection of h. pylori infection in children: determination of the cut-off point by a graphic method not depending on the gold standard. Gastroenterologia Endoscopia Digestiva 2005;24(1):15-20.

\section{Vecsei 2010}

Vecsei A, Innerhofer A, Binder C, Gizci H, Hammer K, Bruckdorfer A, et al. Stool polymerase chain reaction for Helicobacter pylori detection and clarithromycin susceptibility testing in children. Clinical Gastroenterology \& Hepatology 2010;8(3):309-12.

\section{Veenendaal 1995}

Veenendaal RA, Gotz JM, Schroijen V, Kurban F, Bernards AT, Veselic M, et al. Diagnosis of Helicobacter pylori infection by specific gastric mucosal iga and igg pylori antibodies. Journal of Clinical Pathology 1995;48(11):990-3.

\section{Veijola 2005a}

Veijola L, Myllyluoma E, Korpela R, Rautelin H. Stool antigen tests in the diagnosis of Helicobacter pylori infection before and after eradication therapy. World Journal of Gastroenterology 2005;11(46):7340-4.

\section{Veijola 2005b}

Veijola L, Oksanen A, Lofgren T, Sipponen P, Karvonen AL, Rautelin H. Comparison of three stool antigen tests in confirming Helicobacter pylori eradication in adults. Scandinavian Journal of Gastroenterology 2005;40(4):395-401.

\section{Veijola 2008}

Veijola L, Oksanen A, Sipponen P, Rautelin H. Evaluation of a commercial immunoblot, helicoblot 2.1, for diagnosis of Helicobacter pylori infection. Clinical \& Vaccine Immunology: CVI 2008;15(11):1705-10.

\section{Velayos 2012}

Velayos B, Fernandez-Salazar L, Pons-Renedo F, Muñoz MF, Almaraz A, Aller R, et al. Accuracy of urea breath test performed immediately after emergency endoscopy in peptic ulcer bleeding. Digestive Diseases \& Sciences 2012;57(7):1880-6.

\section{Veldhuyzen 1990}

Veldhuyzen van Zanten SJO, Tytgat KMAJ, Hollingsworth J, Jalali S, Rashid FA, Bowen BM, et al. ${ }^{14} \mathrm{C}$-urea breath test for the detection of Helicobacter pylori. American Journal of Gastroenterology 1990;85(4):399-403.

\section{Veldhuyzen 1991}

Veldhuyzen van Zanten SJO, Tytgat DeGara KMAJCJ, Goldie J, Rashid FA, Bowen BM, Cook RJ, et al. A prospective comparison of symptoms and five diagnostic tests in patients with Helicobacter pylori positive and negative dyspepsia. European Journal of Gastroenterology \& Hepatology 1991;3(6):463-8.

\section{Vesna 2005}

Vesna Vukadinovic M, Prohaska Potocnik C. Specific igg decline after successful treatment of Helicobacter pylori infection according to treatment protocol with azithromycin. Infektoloski Glasnik 2005;25(4):137-42.

\section{Vincent 1999}

Vincent P, Michaud L, Martin de Lasalle E, Benon B, Turck D, Gottrand F. 13C-urea breath test and gastric mucosal colonization by Helicobacter pylori in children: Quantitative relation and usefulness for diagnosis of infection. Helicobacter 1999;4(4):233-7.

\section{Vinette 2004}

Vinette KMB, Gibney KM, Proujansky R, Fawcett PT. Comparison of PCR and clinical laboratory tests for diagnosing h-pylori infection in pediatric patients. BMC Microbiology 2004;4:5.

\section{Vivas 1993}

Vivas J, Contreras M, Mathew C, Peraza S, Maury de Tami I, Oliver W, et al. The use of urea carbon 14 in breath tests as 
diagnostic method for Helicobacter pylori infections. GEN 1993;47(3):150-6.

\section{Von Wulffen 1988a}

Von Wulffen H, Grote HJ, Laufs R. Serodiagnosis of campylobacter pylori-related antrum gastritis by ELISA and immunoblot methods. Zentralblatt fur Bakteriologie, Mikrobiologie, und Hygiene. Series A, Medical Microbiology, Infectious Diseases, Virology, Parasitology 1988;268(4):499.

\section{Von Wulffen 1988b}

Von Wulffen H, Grote HJ. Enzyme-linked immunosorbent assay for detection of immunoglobulin a and $\mathrm{g}$ antibodies to campylobacter pylori. European Journal of Clinical Microbiology \& Infectious Diseases 1988;7(4):559-65.

\section{Von Wulffen 1989}

Von Wulffen H, Grote HJ. Serodiagnosis of campylobacter pylori infection using an enzyme-linked immunosorbent assay. Gastroduodenal pathology and Campylobacter pylori: European Campylobacter Pylori Study Group ICS847. 1989:231-6.

\section{Von Wulffen 1993}

Von Wulffen H, Gatermann S, Windler E, Gabbe E, Heinrich HC. Performance of Helicobacter pylori acid extract and urease enzyme-linked immunosorbent assays in relation to 14c-urea breath test. Zentralblatt fur Bakteriologie 1993;280(1-2):203-13.

\section{Vorobjova 1991}

Vorobjova T, Maaroos HI, Uibo R, Wadstrom T, Wood WG, Sipponen P. Helicobacter pylori: Histological and serological study on gastric and duodenal ulcer patients in Estonia. Scandinavian Journal of Gastroenterology - Supplement 1991;186:84-9.

\section{Vyas 1994}

Vyas SK, Sharpstone D, Treasure J, Fine D, Hawtin PR. Preendoscopy screening using serodiagnosis of Helicobacter pylori infection. European Journal of Gastroenterology \& Hepatology 1994;6(9):783-5.

\section{Wadstrom 1994}

Wadstrom T, Bolin I, Fandriks L, Gad A, Carling L. Diagnosis of Helicobacter pylori infection. Lakartidningen 1994;91(19):1926-7.

\section{Wallace 2006}

Wallace RA, Schluter P, Webb P. Stool antigen testing for the diagnosis and confirmation of eradication of Helicobacter pylori infection. Internal Medicine Journal 2006;36(2):139-41.

\section{Wang 1998}

Wang WM, Lee SC, Ding HJ, Jan CM, Chen LT, Wu DC, et al. Quantification of Helicobacter pylori infection: Simple and rapid c-13-urea breath test in Taiwan. Journal of Gastroenterology 1998;33(3):330-5.

\section{Wang 2000}

Wang WM, Lee SC, Wu DC, Chen LT, Liu CS, Peng CF, et al. Simplified 13C-urea breath test for the diagnosis of Helicobacter pylori infection--the availability of without fasting and without test meal. Kaohsiung Journal of Medical Sciences 2000;16(12):607-13.

\section{Wang 2001}

Wang YL, Sheu BS, Huang JJ, Yang HB. Noninvasive stool antigen assay can effectively screen Helicobacter pylori infection and assess success of eradication therapy in hemodialysis patients. American Journal of Kidney Diseases 2001;38(1):98-103.

\section{Wang 2002}

Wang L, Zhou L, Tian R. Helicobacter pylori antigen and its igg, iga-type specific immunocomplexes in sera from patients with Helicobacter pylori infection. Chinese Medical Journal 2002;115(3):381-3.

\section{Wang 2003}

Wang SW, Yu FJ, Lo YC, Yang YC, Wu MT, Wu IC, et al. The clinical utility of string-PCR test in diagnosing Helicobacter pylori infection. Hepato-Gastroenterology 2003;50(53):1208-13.

\section{Wang 2015a}

Wang $\mathrm{H}$, Zou WJ. Comparison of different methods for detecting Helicobacter pylori.. World Chinese Journal of Digestology 2015;23(3):525-9.

\section{Wang 2015b}

Wang Z, Xie L, Liu C, Zhao H. Reliability of stool antigen test for clinical diagnosis of Helicobacter pylori infection.. Chinese Journal of Gastroenterology 2015;20(2):78-80.

\section{Watanabe 2001}

Watanabe K, Joh T, Seno K, Sasaki M, Todoroki I, Miyashita M, et al. Development and clinical application of an immunoassay using intact Helicobacter pylori attached to a solid phase as an antigen. Clinical Biochemistry 2001;34(4):291-5.

\section{Watanabe 2013}

Watanabe K, Nagata N, Shimbo T, Nakashima R, Furuhata E, Sakurai T, et al. Accuracy of endoscopic diagnosis of Helicobacter pylori infection according to level of endoscopic experience and the effect of training. BMC Gastroenterology 2013;13:128.

\section{Weijnen 2001a}

Weijnen CF, De Wit NJ, Numans ME, Kuipers EJ, Hoes AW, Verheij TJM. Helicobacter pylori testing in the primary care setting: Which diagnostic test should be used?. Alimentary Pharmacology and Therapeutics 2001;15(8):1205-10.

\section{Weijnen 2001b}

Weijnen CF, Hendriks HA, Hoes AW, Verweij WM, Verheij TJM, De Wit NJ. New immunoassay for the detection of Helicobacter pylori infection compared with urease test, $\mathrm{c}-13$ breath test and histology: Validation in the primary care setting. Journal of Microbiological Methods 2001;46(3):235-40.

\section{Weingart 2003}

Weingart V, Ruessmann H, Koletzko S, Weingart J, Hoechter W, Sackmann M. A novel monoclonal stool antigen test for the 
detection of h. Pylori before and after eradication therapy: A prospective study in outpatients. Gastroenterology 2003;124(4 (suppl)):A177.

\section{Weingart 2004}

Weingart V, Russmann H, Koletzko S, Weingart J, Hochter W, Sackmann M. Sensitivity of a novel stool antigen test for detection of Helicobacter pylori in adult outpatients before and after eradication therapy. Journal of Clinical Microbiology 2004;42(3):1319-21.

\section{Werdmuller 1998}

Werdmuller BFM, Van der Putten A, Veenendaal RA, Lamers C, Loffeld R. Can screening for igg antibodies against Helicobacter pylori be used in clinical practice? Omit endoscopy in seropositive or seronegative patients?. Digestive Diseases and Sciences 1998;43(10):2296-300.

\section{Westblom 1992}

Westblom TU, Madan E, Gudipati S, Midkiff BR, Czinn SJ. Diagnosis of Helicobacter pylori infection in adult and pediatric patients by using Pyloriset, a rapid latex agglutination test. Journal of Clinical Microbiology 1992;30(1):96-8.

\section{Westblom 1999}

Westblom TU, Bhatt BD. Diagnosis of Helicobacter pylori infection. Current Topics in Microbiology \& Immunology 1999;241:215-35.

\section{Whiting 2006}

Whiting PF, Weswood ME, Rutjes AW, Reitsma JB, Bossuyt PN, Kleijnen J. Evaluation of QUADAS, a tool for the quality assessment of diagnostic accuracy studies. BMC Medical Research Methodology 2006;6:9.

\section{Whiting 2011}

Whiting PF, Rutjes AW, Westwood ME, Mallett S, Deeks JJ, Reitsma JB, et al. QUADAS-2: a revised tool for the quality assessment of diagnostic accuracy studies. Annals of Internal Medicine 2011;155(8):529-36.

\section{Wilcox 1996}

Wilcox MH, Dent THS, Hunter JO, Gray JJ, Brown DFJ, Wight DGD, et al. Accuracy of serology for the diagnosis of Helicobacter pylori infection - a comparison of eight kits. Journal of Clinical Pathology 1996;49(5):373-6.

\section{Wildgrube 1995}

Wildgrube HJ. C-12 urea breath test in Helicobacter-pylori infection of the gastric-mucosa. Deutsche Medizinische Wochenschrift 1995;120(25-26):940-1.

\section{Wildner-Christensen 2002}

Wildner-Christensen M, Lassen AT, Lindebjerg J, Schaffalitzky De Muckadell OB. Diagnosis of Helicobacter pylori in bleeding peptic ulcer patients, evaluation of urea-based tests. Digestion 2002;66(1):9-13.

\section{Wilson 2008}

Wilson RB, Lam VWT, Trinh LK. Clo test in Helicobacter gastritis. ANZ Journal of Surgery 2008;78(8):722.

\section{Winiarski 2003a}

Winiarski M, Bielanski W, Plonka M, Dobrzanska M, Kaminska A, Bobrzynski A, et al. The usefulness of capsulated 13C-urea breath test in diagnosis of Helicobacter pylori infection in patients with upper gastrointestinal bleeding.[erratum appears in Journal of Clinical Gastroenterology 2003;37(2):198]. Journal of Clinical Gastroenterology 2003;37(1):34-8.

\section{Winiarski 2003b}

Winiarski M, Bielanski W, Plonka M, Dobrzanska M, Kaminska A, Bobrzynski A, et al. Erratum: The usefulness of capsulated ${ }^{13} \mathrm{C}$ urea breath test in diagnosis of Helicobacter pylori infection in patients with upper gastrointestinal bleeding (Journal of Clinical Gastroenterology (2003) 37 (34-38)). Journal of Clinical Gastroenterology 2003;37(2):198.

\section{Wirtheim 2001}

Wirtheim E, Yahav J, Maoz E, Dickman R, Braun M, Fraser GM, et al. Evaluation of novel enzyme immunoassay for detection of Helicobacter pylori antigen in stool. European Journal of Clinical Microbiology and Infectious Diseases 2001;20(4):293-4.

\section{Wisniewska 2002a}

Wisniewska M, Bak-Romaniszyn L, Planeta-Malecka I, Rechcinski T, Plonka M, Bielanski W, et al. The detection of Helicobacter pylori antigens in stool with premier platinum HPSA test. Pediatria Wspolczesna 2002;4(3):373-6.

\section{Wisniewska 2002b}

Wisniewska M, Nilsson HO, Bak-Romaniszyn L, Rechcinski T, Bielanski W, Planeta-Malecka I, et al. Detection of specific Helicobacter pylori DNA and antigens in stool samples in dyspeptic patients and healthy subjects. Microbiology \& Immunology 2002;46(10):657-65.

\section{Wisniewska 2006}

Wisniewska M, Grebowska A, Rechcinski T, Bak-Romaniszyn L, Czkwianianc E, Planeta-Malecka I, et al. Usefulness of selected noninvasive tests in detection of Helicobacter pylori infections. Gastroenterologia Polska 2006;13(4):265-8.

\section{Witt 1990}

Witt CS, Anderson J, McShane LA, Montgomery JM, Stiel D, Clancy RL, et al. False positive with campylobacter-pylori antibody ELISA. Advances in mucosal immunology. Fifth international congress of mucosal immunology; July 1989; London. Dordrecht: Kluwer Academic, 1990:793-4. [250]

\section{Wong 1999}

Wong CY, Wong KW, Lam SK, Lai KC, Hu WHC, Lau GKK, et al. A simplified c13-urea breath test for detection of Helicobacter pylori (hp) infection. Gastroenterology 1999;116(4 (suppl)):A356A7.

\section{Wong 2000a}

Wong WM, Wong BC, Wong KW, Fung FM, Lai KC, Hu WH, et al. (13)c-urea breath test without a test meal is highly accurate for the detection of Helicobacter pylori infection in Chinese. Alimentary Pharmacology \& Therapeutics 2000;14(10):1353-8. 


\section{Wong 2000b}

Wong BC, Wong W, Tang VS, Lai K, Yuen S, Hu WH, et al. An evaluation of whole blood testing for Helicobacter pylori infection in the Chinese population. Alimentary Pharmacology \& Therapeutics 2000;14(3):331-5.

\section{Wong 2000c}

Wong WM, Wong BCY, Wong KW, Fung FMY, Lai KC, Hu WHC, et al. C-13-urea breath test without a test meal is highly accurate for the detection of Helicobacter pylori infection in Chinese. Alimentary Pharmacology \& Therapeutics 2000;14(10):1353-8.

\section{Wong 2001a}

Wong BC, Wong WM, Wang WH, Tang VS, Young J, Lai KC, et al. An evaluation of invasive and non-invasive tests for the diagnosis of Helicobacter pylori infection in Chinese. Alimentary Pharmacology \& Therapeutics 2001;15(4):505-11.

\section{Wong 2001b}

Wong WM, Wong BCY, Li TM, Wong KW, Cheung KL, Fung FMY, et al. Twenty-minute $50 \mathrm{mg}$ c-13-urea breath test without test meal for the diagnosis of Helicobacter pylori infection in Chinese. Alimentary Pharmacology \& Therapeutics 2001;15(9):1499-504.

\section{Wong 2003a}

Wong WM, Lam SK, Lai KC, Chu KM, Xia HHX, Wong KW, et al. A rapid-release 50-mg tablet-based c-13-urea breath test for the diagnosis of Helicobacter pylori infection. Alimentary Pharmacology \& Therapeutics 2003;17(2):253-7.

\section{Wong 2003b}

Wong BCY, Xia HHX, Cheung HKL, Ng FH, Wong SY, Chow KC, et al. Evaluation of two stool antigen tests for the detection of Helicobacter pylori infection in the Chinese population. Journal of Gastroenterology and Hepatology (Australia) 2003;18(1):26-31.

\section{Wong 2003c}

Wong WM, Lam SK, Tong TSM, Cheung KL, Tang VSY, Xia HHX, et al. Evaluation of a rapid stool antigen test for the diagnosis of Helicobacter pylori infection in Chinese patients. Chinese Journal of Digestive Diseases 2003;4(3):132-5.

\section{Wu 1992}

Wu JC, Liu GL, Zhang ZH, Mou YL, Chen Q, Wu JC, et al. (nh4+)-n-15 excretion test - a new method for detection of Helicobacter-pylori infection. Journal of Clinical Microbiology 1992;30(1):181-4.

\section{Wu 2001a}

Wu DC, Kuo CH, Lu CY, Su YC, Yu FJ, Lee YC, et al. Evaluation of an office-based urine test for detecting Helicobacter pylori: A prospective pilot study. Hepato-Gastroenterology 2001;48(39):614-7.

\section{Wu 2001b}

Wu S, Gao Q, Zhang D, Xiao S. 13C-urea breath test with infrared heterodyne ratiometry in the diagnosis of Helicobacter pylori infection. Chinese Journal of Gastroenterology 2001;6(4):206-8.

\section{Wu 2003}

Wu IC, Ke HL, Lo YC, Yang YC, Chuang CH, Yu FJ, et al. Evaluation of a newly developed office-based stool test for detecting Helicobacter pylori: An extensive pilot study. HepatoGastroenterology 2003;50(54):1761-5.

\section{Wu 2004}

Wu IC, Wu DC, Lu CY, Kuo CH, Su YC, Yu FJ, et al. Comparison of serum and urine ELISA methods for the diagnosis of Helicobacter pylori - a prospective pilot study. HepatoGastroenterology 2004;51(60):1736-41.

\section{Wu 2006a}

Wu DC, Wu IC, Wang SW, Lu CY, Ke HL, Yuan SSF, et al. Comparison of stool enzyme immunoassay and immunochromatographic method for detecting Helicobacter pylori antigens before and after eradication. Diagnostic Microbiology and Infectious Disease 2006;56(4):373-8.

\section{Wu 2006b}

Wu IC, Wang SW, Yang YC, Yu FJ, Kuo CH, Chuang CH, et al. Comparison of a new office-based stool immunoassay and c-13ubt in the diagnosis of current Helicobacter pylori infection. Journal of Laboratory and Clinical Medicine 2006;147(3):145-9.

\section{Wu 2013}

Wu Q, Yang ZP, Xu P, Gao LC, Fan DM. Association between Helicobacter pylori infection and the risk of colorectal neoplasia: a systematic review and meta-analysis. Colorectal Disease 2013;15(7):e352-64.

\section{Xia 2000a}

Xia HH, Kalantar JS, Wyatt JM, Adams S, Cheung K, Eslick GD, et al. High sensitivity and specificity of a laboratory-based serological test, pylori dtect ELISA, for detection of Helicobacter pylori infection. Diagnostic Microbiology \& Infectious Disease 2000;36(2):69-74.

\section{Xia 2000b}

Xia HHX, Kalantar JS, Mitchell HM, Talley NJ. Can Helicobacter pylori serology still be applied as a surrogate marker to identify peptic ulcer disease in dyspepsia?. Alimentary Pharmacology and Therapeutics 2000;14(5):615-24.

\section{Xia 2002}

Xia HHX, Wong BCY, Wong WM, Tang VSY, Cheung HKL, Sham FNF, et al. Optimal serological tests for the detection of Helicobacter pylori infection in the Chinese population. Alimentary Pharmacology and Therapeutics 2002;16(3):521-6.

\section{Xiao 1991}

Xiao SD, Pan ZJ, Zhang ZH, Jiang SJ. Enzyme-linked immunosorbent assay for detection of immunoglobulin $\mathrm{g}$ antibody against Helicobacter pylori. Chinese Medical Journal 1991;104(11):904-8.

\section{Xiao 2013}

Xiao M, Wang Y, Gao Y. Association between Helicobacter pylori infection and pancreatic cancer development: a meta-analysis. PloS One 2013;8(9):e75559. 


\section{Xie 2008a}

Xie F, Luo N, Blackhouse G, Goeree R, Lee HP. Cost-effectiveness analysis of Helicobacter pylori screening in prevention of gastric cancer in Chinese. International Journal of Technology Assessment in Health Care 2008;24(1):87-95.

\section{Xie 2008b}

Xie F, Luo N, Lee HP. Cost effectiveness analysis of populationbased serology screening and 13C-urea breath test of Helicobacter pylori to prevent gastric cancer: A Markov model. World Journal of Gastroenterology 2008;14(19):3021-7.

\section{Xue 2001}

Xue FB, Xu YY, Wan Y, Pan BR, Ren J, Fan DM. Association of H. pylori infection with gastric carcinoma: a meta analysis. World Journal of Gastroenterology 2001;7(6):801-4.

\section{Yachi 1991}

Yachi A, Yabana T, Imai K, Sugiyama T, Takayama Y, Yoshida H, et al. Novel ELISA for serodiagnosis of Helicobacter-pylori (campylobacter-pylori) infection-associated gastritis. Frontiers of Mucosal Immunology 1991;939:697-700.

\section{Yakoob 2008}

Yakoob J, Jafri W, Abbas Z, Abid S, Islam M, Ahmed Z. The diagnostic yield of various tests for Helicobacter pylori infection in patients on acid-reducing drugs. Digestive Diseases and Sciences 2008;53(1):95-100.

\section{Yakoob 2014}

Yakoob J, Abbas Z. Agreement between serology and histology for detection of Helicobacter pylori infection. Journal of the College of Physicians \& Surgeons - Pakistan 2014;24(10):779-80.

\section{Yamakawa 1993}

Yamakawa O, Takemori Y, Noda Y, Ohta G. Availability of determination of serum anti-Helicobacter pylori igg antibody in diagnosis of Helicobacter pylori infection. Japanese Journal of Gastroenterology 1993;90(9):2090-6.

\section{Yamamoto 1995}

Yamamoto Y, Kouda M, Abe K, Sakurabayashi S, Sezai S, Hirano M, et al. Detection of Helicobacter pylori by culture and the 13C-urea breath test using an automated breath $13 \mathrm{C}$ analyzer. Japanese Journal of Gastroenterology 1995;92(11):1839-45.

\section{Yamamoto 1996}

Yamamoto Y, Koda M, Abe K, Sakurabayashi M, Sezai H, Hirano M, et al. The detection of Helicobacter pylori by the 13C-urea breath test (13C-ubt) using automated breath $13 \mathrm{C}$ analyser. Nippon Shokakibyo Gakkai Zasshi [Japanese Journal of Gastroenterology] 1996;93(1):68.

\section{Yamamoto 2000}

Yamamoto S, Uemura N, Okamoto S, Yamaguchi S, Mashiba $\mathrm{H}$, Tachikawa T. A new rapid test for detecting antiHelicobacter pylori antibody excreted into urine. Helicobacter 2000;5(3):160-4.

\section{Yamamoto 2003}

Yamamoto T, Tamura M, Ishii T, Anjiki H, Hattori K, Saitoh M, et al. Urinary antibody titers to Helicobacter pylori and an impact of clinical characteristics. Journal of Clinical Gastroenterology 2003;36(4):329-31.

\section{Yamamoto 2005}

Yamamoto T, Ishii T, Kawakami T, Sase Y, Horikawa C, Aoki N, et al. Reliability of urinary tests for antibody to Helicobacter pylori in patients with pulmonary tuberculosis. World Journal of Gastroenterology 2005;11(3):412-4.

\section{Yamamoto 2008}

Yamamoto T, Ishii T, Sanaka M, Kuyama Y. Diagnosis of Helicobacter pylori infection using rapirun h. Pylori antibody detection kit. Expert Review of Molecular Diagnostics 2008;8(5):565-9.

\section{Yamaoka 1998}

Yamaoka Y, Kodama T, Graham DY, Kashima K. Comparison of four serological tests to determine the caga or vaca status of Helicobacter pylori strains. Journal of Clinical Microbiology 1998;36(11):3433-4.

\section{Yamasaki 2004}

Yamasaki T, Kume K, Yamasaki M, Yoshikawa I, Otsuki M. Light meal decreased false-positive in the 13C-urea breath test for the diagnosis of Helicobacter pylori infection. Gastroenterology 2004;126(4 (suppl)):A187.

\section{Yamashiro 1995}

Yamashiro Y, Oguchi S, Otsuka Y, Nagata S, Shioya T, Shimizu T. Helicobacter pylori colonization in children with peptic ulcer disease iii. Diagnostic value of the 13C-urea breath test to detect gastric h. Pylori colonization. Acta Paediatrica Japonica (Overseas Edition) 1995;37(1):12-6.

\section{Yan 2010}

Yan J, Yamaguchi T, Odaka T, Suzuki T, Ohyama N, Hara T, et al. Stool antigen test is a reliable method to detect Helicobacter pylori in the gastric remnant after distal gastrectomy for gastric cancer. Journal of Clinical Gastroenterology 2010;44(1):73-4.

\section{Yanez 2000}

Yanez P, Madrazo-de la Graz A, Perez-Perez G, Cabrera L, Muñoz $\mathrm{O}$, Torres J. Comparison of invasive and noninvasive methods for the diagnosis and evaluation of eradication of Helicobacter pylori infection in children. Archives of Medical Research 2000;31(4):415-21.

\section{Yang 2005}

Yang HR, Seo JK. Diagnostic accuracy of the c-13-urea breath test in children: Adjustment of the cut-off value according to age. Journal of Gastroenterology and Hepatology 2005;20(2):264-9.

\section{Yang 2007}

Yang YJ, Sheu BS, Lee SC, Wu JJ. More economic $25 \mathrm{mg}$ c-13-urea breath test can be effective in detecting primary Helicobacter pylori infection in children. Journal of Gastroenterology and Hepatology 2007;22(3):335-9. 


\section{Yang 2008a}

Yang HR, Seo JK. Helicobacter pylori stool antigen (HpSA) tests in children before and after eradication therapy: comparison of rapid immunochromatographic assay and HpSA ELISA. Digestive Diseases \& Sciences 2008;53(8):2053-8.

\section{Yang 2008b}

Yang HR, Ko JS, Seo JK. Does the diagnostic accuracy of the $13 \mathrm{C}$-urea breath test vary with age even after the application of urea hydrolysis rate?. Helicobacter 2008;13(4):239-44.

\section{Yang 2015}

Yang BL, Yeh C, Kwong WG, Lee SD. A novel one-step Helicobacter pylori saliva antigen test. Journal of the Chinese Medical Association 2015;78(2):96-100.

\section{Yasuda 2009}

Yasuda A, Uchida T, Nguyen LT, Kawazato H, Tanigawa M, Murakami K, et al. A novel diagnostic monoclonal antibody specific for Helicobacter pylori caga of east Asian type. APMIS; Acta Pathologica, Microbiologica, et Immunologica Scandinavica 2009;117(12):893-9.

\section{Ye 2005}

Ye WM, Held M, Enroth H, Kraaz W, Engstrand L, Nyren O. Histology and culture results among subjects with antibodies to caga but no evidence of Helicobacter pylori infection with IgG ELISA. Scandinavian Journal of Gastroenterology 2005;40(3):312-8.

\section{Ye 2014}

Ye CL, Liao GP, He S, Pan YN, Kang YB, Zhang ZY. Levofloxacin and proton pump inhibitor-based triple therapy versus standard triple first-line therapy for Helicobacter pylori eradication. Pharmacoepidemiology and Drug Safety 2014;23(5):443-55.

\section{Yee 2002}

Yee YK, Yip KT, Que TL, Chang KK, Li KF, Lee CK, et al. Efficacy of enzyme immunoassay for the detection of Helicobacter pylori antigens in frozen stool specimens: Local validation. Alimentary Pharmacology and Therapeutics 2002;16(10):1739-42.

\section{Yilmaz 2006}

Yilmaz O, Sen N, Kupelioglu AA, Simsel I. Detection of $h$ pylori infection by ELISA and western blot techniques and evaluation of anti caga seropositivity in adult Turkish dyspeptic patients. World Journal of Gastroenterology 2006;12(33):5375-8.

\section{Yin 2015}

Yin SM, Zhang F, Shi DM, Xiang P, Xiao L, Huang YQ, et al. Effect of posture on c-13-urea breath test in partial gastrectomy patients. World Journal of Gastroenterology 2015;21(45):12888-95.

\section{Yokota 1990}

Yokota K, Oguma K, Yoshida H, Takayama Y, Sugiyama T, Yabana T, et al. Comparison of three methods for detecting campylobacter pylori and measurement of human antibody titers against the whole organisms. Kansenshogaku Zasshi [Journal of the Japanese Association for Infectious Diseases] 1990;64(5):597-603.

\section{Yong 2006}

Yong CS, Kim YI, Park SM, Kwon R, Han HH, Park JG, et al. Trials of novel c-13-urea-containing capsule for more economic and sensitive diagnosis of Helicobacter pylori infection in human subjects. Archives of Pharmacal Research 2006;29(10):879-83.

\section{Yoo 2007}

Yoo JY, Kim N, Park YS, Hwang JH, Kim JW, Jeong SH, et al. Detection rate of Helicobacter pylori against a background of atrophic gastritis and/or intestinal metaplasia. Journal of Clinical Gastroenterology 2007;41(8):751-5.

\section{Yoshida 1993}

Yoshida J, Asaka M. 13C-urea breath test. Nippon Rinsho [Japanese Journal of Clinical Medicine] 1993;51(12):3196-200.

\section{Yoshida 2000}

Yoshida H, Hirota K, Ogura K, Maeda S, Shiratori Y, Sasaki Y, et al. Determination of the optimal cut-off value for the $c-13$ -urea breath test based on a Helicobacter pylori-specific polymerase chain reaction assay. Journal of Gastroenterology and Hepatology 2000;15(2):155-60.

\section{Young 1995}

Young EL, Cutler AF. Use of the c-13 urea breath test to evaluate a new rapid urease test for Helicobacter-pylori. Gastroenterology 1995;108(4 (suppl)):A265.

\section{Young 1996}

Young EL, Sharma TK, Cutler AF. Prospective evaluation of a new urea-membrane test for the detection of Helicobacter pylori in gastric antral tissue. Gastrointestinal Endoscopy 1996;44(5):527-31.

\section{Zagari 1998}

Zagari RM, Pozzato P, Bazzoli F, Fossi S, Ricciardiello L, Nicolini G, et al. A comparative trial to optimize the protocol of the c-13 urea breath test for the diagnosis of Helicobacter pylori infection. Gastroenterology 1998;114(4):A344.

\section{Zagari 2003}

Zagari RM, Bazzoli F. Helicobacter pylori testing in patients with peptic ulcer bleeding. Digestive \& Liver Disease 2003;35(4):215-6.

\section{Zagari 2005}

Zagari RM, Pozzato P, Martuzzi C, Fuccio L, Martinelli G, Roda E, et al. C-13-urea breath test to assess Helicobacter pylori bacterial load. Helicobacter 2005;10(6):615-9.

\section{Zagari 2012}

Zagari RM, Eusebi LH, Rabitti S, Bazzoli F. 13C-urea breathid system for the real-time diagnosis of Helicobacter pylori infection. Digestive and Liver Disease 2012;44:S208.

\section{Zalabska 2010}

Zalabska E. The evidence of Helicobacter pylori in gastric biopsy and stool samples. Klinicka Mikrobiologie a Infekcni Lekarstvi 2010;16(6):203-5. 


\section{Zambon 2004}

Zambon CF, Basso D, Navaglia F, Mazza S, Razetti M, Fogar P, et al. Non-invasive diagnosis of Helicobacter pylori infection: Simplified c-13-urea breath test, stool antigen testing, or DNA PCR in human feces in a clinical laboratory setting?. Clinical Biochemistry 2004;37(4):261-7.

\section{Zanetti 2002}

Zanetti M, Vendramin R, Pieramico O. Stool antigen test for non-invasive post-treatment assessment of Helicobacter pylori infection: A comparative study between immunoenzymatic and immunochromatographic tests. Gut 2002;51(Suppl):A111.

\section{Zaremba 1995}

Zaremba M, Rozkiewicz M, Pydzinska J, Stasiewicz J, Szalaj W, Musiatowicz B, et al. Diagnostic value of the latex test (Pyloriset) for detection of Helicobacter pylori antibodies in adult patients with upper digestive tract diseases. Medycyna Doswiadczalna $i$ Mikrobiologia 1995;47(1-2):11-6.

\section{Zawadzka-Gralec 2009}

Zawadzka-Gralec A, Wroblewska M, Szaflarska PA, Mierzwa G, Parzecka M, Bala G, et al. The analysis of usefulness different diagnostic methods in children and adolescents with Helicobacter pylori infection. Polski Merkuriusz Lekarski 2009;26(151):24-8

\section{Zhang 1990}

Zhang QB, Zhang SJ, Jia BQ. Enzyme-linked immunosorbent assay for the serodiagnosis of campylobacter pylori infection. Zhonghua Nei Ke Za Zhi [Chinese Journal of Internal Medicine] 1990;29(8):457-60, 509.

\section{Zhang 2002}

Zhang WD, Xu ZM. Immunophenotyping of Helicobacter pylori. World Chinese Journal of Digestology 2002;10(5):509-12.

\section{Zhang 2006}

Zhang C, Guan Y, Yuan Z, Wu Y, Yamada N, Wen M, et al. Analysis of histological detection of Helicobacter pylori before and after eradication therapy: Compared with the results of 13C-urea breath test. Chinese Journal of Gastroenterology 2006;11(4):215-8.

\section{Zhang 2007}

Zhang L, Zhang JZ. Analysis of different diagnostic methods of Helicobacter pylori infection in China. World Chinese Journal of Digestology 2007;15(6):649-54.

\section{Zhelezova 2006}

Zhelezova GZ, Boyanova L. Stool antigen test for diagnosis of Helicobacter pylori infection. Problems of Infectious and Parasitic Diseases 2006;34(2):16-8.

\section{Zheng 2004}

Zheng Q, Chen X, Pan Y, Shi Y. Comparison of reliability of 13C-urea breath tests using two different reagents for clinical diagnosis of Helicobacter pylori infection. Chinese Journal of Gastroenterology 2004;9(4):210-2.

\section{Zhou 1996}

Zhou DY, Xu KQ, Yang HT, Hoffman S, Marshall B. Microdose c-14urea breath test for the detection of h-pylori in Chinese patients. Gastroenterology 1996;110(4 (suppl)):A307.

\section{Zhou 2000}

Zhou H, Chan KL, Chu KM, Tam PKH. Intrafamilial spread of Helicobacter pylori: A prospective study using urea breath test. Journal of Pediatric Surgery 2000;35(11):1672-5.

\section{Zhou 2014}

Zhou XY, Su J, Xu GX, Zhang GX. Accuracy of stool antigen test for the diagnosis of Helicobacter pylori infection in children: A meta-analysis. Clinics and Research in Hepatology and Gastroenterology 2014;38(5):629-38.

\section{Zhou 2017}

Zhou Q, Li L, Ai Y, Pan Z, Guo M, Han J. Diagnostic accuracy of the 14c-urea breath test in Helicobacter pylori infections: $A$ meta-analysis. Wiener Klinische Wochenschrift 2017; Vol. 129, issue 1-2:38-45. [DOI: 10.1007/s00508-016-1117-3]

\section{Zhu 2002a}

Zhu Y, Lin J, Li D, Du Q, Qian K, Wu Q, et al. Helicobacter pylori antigen and its igg, iga -type specific immunocomplexes in sera from patients with Helicobacter pylori infection. Chinese Medical Journal 2002;115(3):381-3.

\section{Zhu 2002b}

Zhu YY, Wu JC, Zhang ZH. Emissive spectral analysis applied in $\mathrm{n}-15$ excretion test of Helicobacter pylori. Society of Photooptical Instrumentation Engineers (SPIE): Optics in health care and biomedical optics: Diagnostics and treatment 2002;4916:194-6.

\section{Zhukhovitskii 2005}

Zhukhovitskii VG, Gorbacheva AP, Golovkin BA, Gidaiatova LA. Serological diagnosis of Helicobacter infection: Comparison of the analytical capacities of three test systems for enzyme immunoassay. Klinicheskaia Laboratornaia Diagnostika 2005;11:12-4.

\section{Zhuo 2008}

Zhuo XL, Wang Y, Zhuo WL, Zhang XY. Possible association of Helicobacter pylori infection with laryngeal cancer risk: an evidence-based meta-analysis. Archives of Medical Research 2008;39(6):625-8.

\section{Zipser 2000}

Zipser RD, Parikh MV. Is repeat testing needed for Helicobacter pylori?. Journal of the American Board of Family Practice 2000;13(6):449-50.

\section{Zubillaga 1997}

Zubillaga M, Oliveri P, Calcagno ML, Goldman C, Caro R, Mitta A, et al. Min 14c ubt: A combination of gastric basal transit and 14c-urea breath test for the detection of Helicobacter pylori infection in human beings. Nuclear Medicine \& Biology 1997;24(6):565-9. 


\section{Zubillaga 1999}

Zubillaga M, Oliveri P, Panarello H, Buzurro M, Adami J, Goldman C, et al. Stable isotope techniques for the detection of Helicobacter pylori infection in clinical practice. $13 \mathrm{C}$ urea breath test in different experimental conditions. Acta Physiologica, Pharmacologica et Therapeutica Latinoamericana 1999;49(2):101-7.

\section{References to other published versions of this review \\ Gurusamy 2016}

Gurusamy KS, Yaghoobi M, Davidson BR. Non-invasive diagnostic tests for Helicobacter pylori infection. Cochrane Database of Systematic Reviews 2016, Issue 2. [DOI: 10.1002/14651858.CD012080]

* Indicates the major publication for the study

CHARACTERISTICS OF STUDIES

Characteristics of included studies [ordered by study ID]

Adamopoulos 2009a

\section{Study characteristics}

\section{Patient sampling}

Patient characteristics and setting
Type of study: prospective study

Consecutive or random sample: consecutive patients

Sample size: 73

Female: 24 (33\%)

Age: 63 years

Presentation:

1. People who had undergone endoscopy (for various indications)

Setting: secondary care, Greece
Index test: urea breath test $-13 \mathrm{C}$

Further details:

Technical specifications: manufacturer - Infai Institut für Biomedizinische;

Analytik \& NMR-Imaging GmbH, Bochum

Performed by: not stated

Criteria for positive diagnosis: delta over baseline $>4.0 \%$ (30 minutes)

\footnotetext{
Target condition and reference standard(s)
}

\section{Target condition: $H$ pylori infection}

Reference standard: endoscopic biopsy with H \& E stain and Giemsa stain Further details:

Technical specifications: not stated

Performed by: endoscopist and histopathologist

Criteria for positive diagnosis: presence of $H$ pylori in biopsy

Flow and timing

Number of indeterminates for whom the results of reference standard was available: not stated

Number of patients who were excluded from the analysis: 0 (0\%)

\section{Comparative}

Notes

\section{Methodological quality}

\begin{tabular}{llll}
\hline Item & Authors' judgement & Risk of bias & $\begin{array}{l}\text { Applicability con- } \\
\text { cerns }\end{array}$ \\
\hline
\end{tabular}

\section{DOMAIN 1: Patient Selection}

Was a consecutive or random sample of patients en- Yes rolled? 
Adamopoulos 2009a (Continued)

Was a case-control design avoided?

Yes

Did the study avoid inappropriate exclusions? Yes

Low

Low

\section{DOMAIN 2: Index Test Urea breath test-13C}

Were the index test results interpreted without knowl- Unclear

edge of the results of the reference standard?

If a threshold was used, was it pre-specified? Unclear

\begin{tabular}{lll}
\hline & Unclear & Unclear \\
\hline DOMAIN 3: Reference Standard & &
\end{tabular}

Is the reference standards likely to correctly classify Yes

the target condition?

Were the reference standard results interpreted with- Unclear out knowledge of the results of the index tests?

\begin{tabular}{llll}
\hline & Unclear & Low \\
\hline DOMAIN 4: Flow and Timing & & \\
\hline $\begin{array}{l}\text { Was there an appropriate interval between index test } \\
\text { and reference standard? }\end{array}$ & Yes \\
\hline Did all patients receive the same reference standard? & Yes \\
\hline Were all patients included in the analysis? & Yes \\
\hline
\end{tabular}

Low

\section{Adamopoulos 2009b}

\section{Study characteristics}

\begin{tabular}{ll}
\hline Patient sampling & $\begin{array}{l}\text { Type of study: prospective study } \\
\text { Consecutive or random sample: consecutive patients }\end{array}$ \\
\hline Patient characteristics and setting & Sample size: 31 \\
& Female: $8(25.8 \%)$ \\
& Age: 71 years \\
& Presentation: \\
& 1. People who had undergone Billroth II gastrectomy and endoscopy (for \\
& various indications) \\
& Setting: secondary, Greece \\
& Index test: urea breath test-13C \\
& Further details: \\
Index tests & Technical specifications: manufacturer - Infai Institut für Biomedizinische; \\
& Analytik \& NMR-Imaging GmbH, Bochum
\end{tabular}


Adamopoulos 2009b (Continued)

Performed by: not stated

Criteria for positive diagnosis: delta over baseline $>4.0 \%$ (30 minutes)

Target condition and reference standard(s)

\section{Target condition: $H$ pylori infection}

Reference standard: endoscopic biopsy with H \& E stain and Giemsa stain

Further details:

Technical specifications: not stated

Performed by: endoscopist and histopathologist

Criteria for positive diagnosis: presence of $H$ pylori in biopsy

Flow and timing

Number of indeterminates for whom the results of reference standard was available: not stated

Number of patients who were excluded from the analysis: $0(0 \%)$

\section{Comparative}

\section{Notes}

\section{Methodological quality}

\begin{tabular}{llll}
\hline Item & Authors' judgement & Risk of bias & $\begin{array}{l}\text { Applicability con- } \\
\text { cerns }\end{array}$
\end{tabular}

\section{DOMAIN 1: Patient Selection}

Was a consecutive or random sample of patients en- Yes rolled?

\begin{tabular}{llll}
\hline Was a case-control design avoided? & Yes & \\
\hline Did the study avoid inappropriate exclusions? & Yes & Low & High \\
\hline
\end{tabular}

\section{DOMAIN 2: Index Test Urea breath test-13C}

\section{Were the index test results interpreted without Unclear}

knowledge of the results of the reference standard?

\begin{tabular}{llll}
\hline If a threshold was used, was it pre-specified? Unclear & & Unclear \\
\hline
\end{tabular}

\section{DOMAIN 3: Reference Standard}

Is the reference standards likely to correctly classify Yes the target condition?

Were the reference standard results interpreted without knowledge of the results of the index tests?

\begin{tabular}{lll}
\hline & Unclear & Low \\
\hline DOMAIN 4: Flow and Timing & &
\end{tabular}

Was there an appropriate interval between index Yes test and reference standard? 
Adamopoulos 2009b (Continued)

Did all patients receive the same reference stan- Yes dard?

Were all patients included in the analysis?

Yes

\section{Study characteristics}

$\begin{array}{ll}\text { Patient sampling } & \begin{array}{l}\text { Type of study: unclear whether prospective or retrospective study } \\ \text { Consecutive or random sample: unclear sampling process }\end{array}\end{array}$

\begin{tabular}{ll}
\hline Patient characteristics and setting & Sample size: 31 \\
& Female: $5(16.1 \%)$ \\
& Age: not stated \\
Presentation: & 1. Dyspepsia \\
& Setting: secondary care, Peru
\end{tabular}

$\begin{array}{ll}\text { Index tests } & \text { Index test: urea breath test- }{ }^{14} \mathrm{C} \\ & \text { Further details: } \\ & \text { Technical specifications: Not stated } \\ & \text { Performed by: Not stated } \\ \text { Criteria for positive diagnosis: disintegrations per minute }>200 \text { (10 min- } \\ \text { utes) }\end{array}$

Target condition and reference standard(s)

Target condition: $H$ pylori infection

Reference standard: endoscopic biopsy with H \& E stain

Further details:

Technical specifications: Not stated

Performed by: endoscopist and pathologist

Criteria for positive diagnosis: presence of $H$ pylori in biopsy

Flow and timing

Number of indeterminates for whom the results of reference standard was available: not stated

Number of patients who were excluded from the analysis: not stated

\section{Comparative}

$$
\text { Notes }
$$

\section{Methodological quality}

$\begin{array}{llll}\text { Item } & \text { Authors' judgement } & \text { Risk of bias } & \begin{array}{l}\text { Applicability con- } \\ \text { cerns }\end{array}\end{array}$

\section{DOMAIN 1: Patient Selection}

Was a consecutive or random sample of patients en- Unclear rolled? 
Aguilar 2007 (Continued)

Did the study avoid inappropriate exclusions? Unclear

Unclear Low

DOMAIN 2: Index Test Urea breath test-14C

Were the index test results interpreted without knowl- Unclear edge of the results of the reference standard?

\begin{tabular}{llll}
\hline If a threshold was used, was it pre-specified? & Unclear & Low & Unclear \\
\hline
\end{tabular}

\section{DOMAIN 3: Reference Standard}

Is the reference standards likely to correctly classify the No target condition?

Were the reference standard results interpreted without Unclear knowledge of the results of the index tests?

High Low

\section{DOMAIN 4: Flow and Timing}

Was there an appropriate interval between index test Unclear
and reference standard?

Did all patients receive the same reference standard? Yes

Were all patients included in the analysis? Unclear

\begin{tabular}{ll}
\hline Unclear \\
\hline
\end{tabular}

\section{Al-Fadda 2000}

\section{Study characteristics}

\begin{tabular}{|c|c|}
\hline Patient sampling & $\begin{array}{l}\text { Type of study: prospective study } \\
\text { Consecutive or random sample: unclear sampling process }\end{array}$ \\
\hline Patient characteristics and setting & $\begin{array}{l}\text { Sample size: } 64 \\
\text { Female: not stated } \\
\text { Age: not stated } \\
\text { Presentation: } \\
\text { 1. Patients with upper gastroinstestinal symptoms } \\
\text { Setting: secondary care, Peru }\end{array}$ \\
\hline Index tests & $\begin{array}{l}\text { Index test: urea breath test- }{ }^{14} \mathrm{C} \\
\text { Further details: } \\
\text { Technical specifications: Not stated } \\
\text { Performed by: Not stated } \\
\text { Criteria for positive diagnosis: } \mathrm{CO}^{2} \text { recovery >0.55 (20 minutes) }\end{array}$ \\
\hline Target condition and reference standard(s) & Target condition: H pylori infection \\
\hline
\end{tabular}


Al-Fadda 2000 (Continued)

Reference standard: endoscopic biopsy with H \& E stain

Further details:

Technical specifications: Not stated

Performed by: endoscopist and pathologist

Criteria for positive diagnosis: presence of $H$ pylori in biopsy

Flow and timing

Number of indeterminates for whom the results of reference standard was available: not stated

Number of patients who were excluded from the analysis: not stated

\section{Comparative}

$$
\text { Notes }
$$

\section{Methodological quality}

\begin{tabular}{llcl}
\hline Item Authors' judgement & Risk of bias & $\begin{array}{l}\text { Applicability con- } \\
\text { cerns }\end{array}$ \\
\hline
\end{tabular}

\section{DOMAIN 1: Patient Selection}

Was a consecutive or random sample of patients en- Unclear

rolled?

\begin{tabular}{llll}
\hline Was a case-control design avoided? & Yes & \\
\hline Did the study avoid inappropriate exclusions? & Unclear & Unclear & Low \\
\hline
\end{tabular}

\section{DOMAIN 2: Index Test Urea breath test-14C}

\section{Were the index test results interpreted without knowl- Unclear}

edge of the results of the reference standard?

If a threshold was used, was it pre-specified? Yes

Unclear

Low

\section{DOMAIN 3: Reference Standard}

Is the reference standards likely to correctly classify the No

target condition?

Were the reference standard results interpreted without Unclear

knowledge of the results of the index tests?

High

Low

\section{DOMAIN 4: Flow and Timing}

Was there an appropriate interval between index test Unclear
and reference standard?
and reference standard?

\begin{tabular}{ll}
\hline Did all patients receive the same reference standard? & Yes \\
\hline Were all patients included in the analysis? & Unclear \\
\hline
\end{tabular}




\section{Study characteristics}

\begin{tabular}{ll}
\hline Patient sampling & $\begin{array}{l}\text { Type of study: unclear whether prospective or retrospective study } \\
\text { Consecutive or random sample: unclear sampling process }\end{array}$ \\
\hline Patient characteristics and setting & Sample size: 63 \\
& Female: $26(41.3 \%)$ \\
& Age: not stated \\
& Presentation: \\
& 1. Dyspepsia \\
& Setting: secondary care, New Zealand \\
\hline \multirow{2}{*}{ Index tests } & Index test: urea breath test-14C \\
& Further details: \\
& Technical specifications: Not stated \\
& $\begin{array}{l}\text { Performed by: Not stated } \\
\text { Criteria for positive diagnosis: disintegrations per minute }>49 \text { (time not } \\
\text { stated) }\end{array}$ \\
\hline \multirow{2}{*}{ Target condition and reference standard(s) } & Target condition: $H$ pylori infection \\
& Reference standard: endoscopic biopsy with $\mathrm{H} \& \mathrm{E}$ stain and Giemsa \\
stain & Further details: \\
Technical specifications: Not stated & Performed by: endoscopist and pathologist \\
Criteria for positive diagnosis: presence of $H$ pylori in biopsy
\end{tabular}

Flow and timing Number of indeterminates for whom the results of reference standard was available: not stated

Number of patients who were excluded from the analysis: not stated

\section{Comparative}

\section{Notes}

\section{Methodological quality}

\begin{tabular}{llll}
\hline Item & Authors' judgement & Risk of bias & $\begin{array}{l}\text { Applicability con- } \\
\text { cerns }\end{array}$
\end{tabular}

\section{DOMAIN 1: Patient Selection}
Was a consecutive or random sample of patients en-
Unclear rolled?

\begin{tabular}{lll}
\hline Was a case-control design avoided? & Yes & \\
\hline Did the study avoid inappropriate exclusions? & Unclear & Lnclear \\
\hline
\end{tabular}


Allardyce 1997 (Continued)

DOMAIN 2: Index Test Urea breath test-14C

Were the index test results interpreted without knowl- Unclear edge of the results of the reference standard?

\begin{tabular}{lll}
\hline If a threshold was used, was it pre-specified? & Unclear & \\
\hline & Unclear & Low \\
\hline
\end{tabular}

\section{DOMAIN 3: Reference Standard}

Is the reference standards likely to correctly classify the No target condition?

Were the reference standard results interpreted without No knowledge of the results of the index tests?

High Low

\section{DOMAIN 4: Flow and Timing}

Was there an appropriate interval between index test Unclear
and reference standard?

Did all patients receive the same reference standard? Yes

Were all patients included in the analysis? Unclear

Unclear

\section{Argentieri 2007 \\ Study characteristics}

\begin{tabular}{|c|c|}
\hline Patient sampling & $\begin{array}{l}\text { Type of study: unclear whether prospective or retrospective study } \\
\text { Consecutive or random sample: unclear sampling process }\end{array}$ \\
\hline Patient characteristics and setting & $\begin{array}{l}\text { Sample size: } 215 \\
\text { Female: not stated } \\
\text { Age: not stated } \\
\text { Presentation: } \\
\text { 1. Children undergoing upper gastrointestinal endoscopy } \\
\text { Exclusion: } \\
\text { 1. Recent } H \text { pylori treatment } \\
\text { Setting: secondary care, Italy }\end{array}$ \\
\hline Index tests & $\begin{array}{l}\text { Index test: stool antigen test } \\
\text { Further details: } \\
\text { Technical specifications: Premier Platinum HpSA } \\
\text { Performed by: Not stated } \\
\text { Criteria for positive diagnosis: Not stated }\end{array}$ \\
\hline Target condition and reference standard(s) & $\begin{array}{l}\text { Target condition: } H \text { pylori infection } \\
\text { Reference standard: endoscopic biopsy with Giemsa stain } \\
\text { Further details: } \\
\text { Technical specifications: Not stated }\end{array}$ \\
\hline
\end{tabular}


Argentieri 2007 (Continued)

Performed by: endoscopist and pathologist

Criteria for positive diagnosis: presence of $H$ pylori in biopsy

Flow and timing

Number of indeterminates for whom the results of reference standard was available: not stated

Number of patients who were excluded from the analysis: not stated

\section{Comparative}

Notes

\section{Methodological quality}

\begin{tabular}{llll}
\hline Item & Authors' judgement & Risk of bias & \multicolumn{1}{c}{$\begin{array}{l}\text { Applicability con- } \\
\text { cerns }\end{array}$} \\
\hline
\end{tabular}

\section{DOMAIN 1: Patient Selection}

Was a consecutive or random sample of patients en- Unclear rolled?

\begin{tabular}{llll}
\hline Was a case-control design avoided? & Yes & \\
\hline Did the study avoid inappropriate exclusions? & Unclear & Unclear & Unclear \\
\hline
\end{tabular}

\section{DOMAIN 2: Index Test Stool Antigen Test}

Were the index test results interpreted without Unclear
knowledge of the results of the reference standard?

knowledge of the results of the reference standard?

If a threshold was used, was it pre-specified? Unclear

\begin{tabular}{lll}
\hline & Unclear & High \\
\hline DOMAIN 3: Reference Standard & &
\end{tabular}

Is the reference standards likely to correctly classify Yes the target condition?

Were the reference standard results interpreted Unclear without knowledge of the results of the index tests?

\begin{tabular}{ll}
\hline & Unclear \\
\hline DOMAIN 4: Flow and Timing & \\
\hline $\begin{array}{l}\text { Was there an appropriate interval between index } \\
\text { test and reference standard? }\end{array}$ & Unclear \\
\hline $\begin{array}{l}\text { Did all patients receive the same reference stan- } \\
\text { dard? }\end{array}$ & Yes \\
\hline Were all patients included in the analysis? & Unclear
\end{tabular}

\section{Unclear}


Arikan 2004

\section{Study characteristics}

\begin{tabular}{ll}
\hline Patient sampling & $\begin{array}{l}\text { Type of study: prospective study } \\
\text { Consecutive or random sample: unclear sampling process }\end{array}$ \\
\hline Patient characteristics and setting & Sample size: 100 \\
& Female: not stated \\
Age: not stated & Presentation: \\
1. Patients undergoing endoscopy & Exclusion: \\
1. Malignancy & 2. Taken antibiotics or proton pump inhibitors in last 2 weeks \\
& Setting: secondary care Turkey
\end{tabular}

Setting: secondary care, Turkey

$\begin{array}{ll}\text { Index tests } & \text { Index test: stool antigen test } \\ & \text { Further details: } \\ & \text { Technical specifications: Premier Platinum HpSA } \\ & \text { Performed by: Not stated } \\ & \text { Criteria for positive diagnosis: Not stated }\end{array}$

Target condition and reference standard(s)

Target condition: H pylori infection

Reference standard: endoscopic biopsy with $\mathrm{H}$ \& E stain

Further details:

Technical specifications: Not stated

Performed by: endoscopist and pathologist

Criteria for positive diagnosis: presence of $H$ pylori in biopsy

Flow and timing

Number of indeterminates for whom the results of reference standard was available: not stated

Number of patients who were excluded from the analysis: not stated

\section{Comparative}

Notes

\section{Methodological quality}

\begin{tabular}{llll}
\hline Item Authors' judgement & Risk of bias & $\begin{array}{l}\text { Applicability con- } \\
\text { cerns }\end{array}$
\end{tabular}

\section{DOMAIN 1: Patient Selection}

\section{Was a consecutive or random sample of patients en- Unclear} rolled?

\begin{tabular}{llll}
\hline Was a case-control design avoided? & Yes & \\
\hline Did the study avoid inappropriate exclusions? & Unclear & Unclear \\
\hline
\end{tabular}

\section{DOMAIN 2: Index Test Stool Antigen Test}


Arikan 2004 (Continued)

Were the index test results interpreted without

Unclear knowledge of the results of the reference standard?

If a threshold was used, was it pre-specified? Unclear

Unclear

High

\section{DOMAIN 3: Reference Standard}

Is the reference standards likely to correctly classify No

the target condition?

Were the reference standard results interpreted

Unclear

without knowledge of the results of the index tests?

\begin{tabular}{lll}
\hline & High & Low \\
\hline DOMAIN 4: Flow and Timing & &
\end{tabular}

Was there an appropriate interval between index Unclear
test and reference standard?

Did all patients receive the same reference stan-
dard?
dard?
Were all patients included in the analysis?
Unclear

Unclear

\section{Atli 2012}

\section{Study characteristics}

\begin{tabular}{ll}
\hline Patient sampling & $\begin{array}{l}\text { Type of study: unclear whether prospective or retrospective study } \\
\text { Consecutive or random sample: unclear sampling process }\end{array}$ \\
\hline Patient characteristics and setting & Sample size: 100 \\
& Female: $57(57 \%)$ \\
& Age: 71 years \\
& Presentation: \\
& 1. Patients with dyspepsia and symptoms or signs related to peptic ulcer $>65$ \\
& years of age \\
& Exclusion: \\
& 1. Patients who had taken antibiotics or anti-ulcer treatment in the past 2 weeks \\
& 2. Advanced dementia \\
& 3. Cerbrovascular disease \\
& 4. Advanced respiratory problems \\
& 5 . Alarm symptoms for malignancy \\
& Setting: secondary setting, Turkey \\
Index tests & Index test: urea breath test- $14 \mathrm{C}$ \\
& Further details: \\
Technical specifications: not stated & Performed by: not stated \\
Criteria for positive diagnosis: counts per minute $>50(10$ minutes $)$
\end{tabular}


Atli 2012 (Continued)

Target condition and reference standard(s)

Flow and timing

Comparative

Notes

\section{Methodological quality}

\begin{tabular}{llll}
\hline Item & Authors' judgement & Risk of bias & Applicability concerns \\
\hline
\end{tabular}

\section{DOMAIN 1: Patient Selection}

Was a consecutive or random sample of patients Unclear enrolled?

\begin{tabular}{ll}
\hline Was a case-control design avoided? & Yes \\
\hline Did the study avoid inappropriate exclusions? & Unclear
\end{tabular}

\begin{tabular}{lll}
\hline Unclear & Unclear \\
\hline
\end{tabular}

DOMAIN 2: Index Test Urea breath test-14C

Were the index test results interpreted without Unclear knowledge of the results of the reference standard?

If a threshold was used, was it pre-specified? Unclear

\begin{tabular}{lll}
\hline Unclear & Low \\
\hline
\end{tabular}

\section{DOMAIN 3: Reference Standard}

Is the reference standards likely to correctly No
classify the target condition?

Were the reference standard results interpret- Unclear ed without knowledge of the results of the index tests?

\begin{tabular}{llll}
\hline Ligh & Low \\
\hline
\end{tabular}

\section{DOMAIN 4: Flow and Timing}

Was there an appropriate interval between index Unclear test and reference standard? 
Atli 2012 (Continued)

Did all patients receive the same reference stan- Yes dard?

Were all patients included in the analysis?

Unclear

\section{Unclear}

\section{Behrens 1999}

\section{Study characteristics}

$\begin{array}{ll}\text { Patient sampling } & \begin{array}{l}\text { Type of study: unclear whether prospective or retrospective study } \\ \text { Consecutive or random sample: unclear sampling process }\end{array}\end{array}$

\begin{tabular}{ll}
\hline Patient characteristics and setting & Sample size: 252 \\
& Female: not stated \\
& Age: not stated \\
& Presentation: \\
& 1. Children ( 3 years to 18 years) with abdominal pain, nausea, or vomiting \\
& Exclusion criteria: \\
& 1. Previous treatment with antibiotics or proton pump inhibitors \\
& 2. WBC $<3500 /$ microlitre or platelets $<100,000 /$ microlitre \\
& Setting: secondary setting, Germany
\end{tabular}

Index tests

Index test: urea breath test $-13 \mathrm{C}$

Further details:

Technical specifications: Promochem, Wesel

Performed by: not stated

Criteria for positive diagnosis: delta over baseline $>5.0 \%$ (30 minutes and 60 minutes)

\section{Target condition and reference standard(s)}

Target condition: $H$ pylori infection Reference standard: endoscopic biopsy with $\mathrm{H}$ \& E stain

Further details:

Technical specifications: not stated

Performed by: endoscopist and pathologist

Criteria for positive diagnosis: presence of $H$ pylori in biopsy

Flow and timing

Number of indeterminates for whom the results of reference standard was available: not stated

Number of patients who were excluded from the analysis: not stated

Comparative

\section{Notes}

\section{Methodological quality}

\begin{tabular}{llll}
\hline Item & Authors' judgement & Risk of bias & Applicability concerns \\
\hline
\end{tabular}

DOMAIN 1: Patient Selection

Was a consecutive or random sample of patients Unclear enrolled? 
Behrens 1999 (Continued)

Was a case-control design avoided?

Yes

Did the study avoid inappropriate exclusions? Unclear

Unclear

Unclear

\section{DOMAIN 2: Index Test Urea breath test-13C}

Were the index test results interpreted without

Unclear

knowledge of the results of the reference stan-

dard?

If a threshold was used, was it pre-specified? Unclear

Unclear

Low

\section{DOMAIN 3: Reference Standard}

Is the reference standards likely to correctly No

classify the target condition?

Were the reference standard results interpret- Unclear ed without knowledge of the results of the index tests?

\begin{tabular}{lll}
\hline Ligh & Low \\
\hline
\end{tabular}

\section{DOMAIN 4: Flow and Timing}

Was there an appropriate interval between index Unclear test and reference standard?

Did all patients receive the same reference stan- Yes

dard?

Were all patients included in the analysis? Unclear

Unclear

Bosso 2000

\section{Study characteristics}

\section{Patient sampling}

Patient characteristics and setting
Type of study: retrospective study

Consecutive or random sample: unclear sampling process

Sample size: 95

Female: not stated

Age: not stated

Presentation:

1. Patients with upper abdominal symptoms

Exclusion:

1. Patients with previous gastric surgery

Setting: secondary care, France 


\section{Bosso 2000 (Continued)}

Index tests
Index test: urea breath test $-13 \mathrm{C}$

Further details:

Technical specifications: not stated

Performed by: not stated

Criteria for positive diagnosis: delta over baseline $>4.0 \%$ (30 minutes)
Target condition and reference standard(s)

Flow and timing

\section{Target condition: H pylori infection}

Reference standard: endoscopic biopsy with Warthin-Starry stain

Further details:

Technical specifications: not stated

Performed by: endoscopist and pathologist

Criteria for positive diagnosis: presence of $H$ pylori in biopsy

Number of indeterminates for whom the results of reference standard was available: not stated

Number of patients who were excluded from the analysis: not stated

\section{Comparative}

Notes

\section{Methodological quality}

\begin{tabular}{llll}
\hline Item & Authors' judgement & Risk of bias & $\begin{array}{c}\text { Applicability con- } \\
\text { cerns }\end{array}$ \\
\hline DOMAIN 1: Patient Selection & & \\
\hline $\begin{array}{l}\text { Was a consecutive or random sample of patients en- } \\
\text { rolled? }\end{array}$ & Unclear & \\
\hline Was a case-control design avoided? & Yes & Unclear \\
\hline Did the study avoid inappropriate exclusions? & Unclear & Unclear \\
\hline
\end{tabular}

DOMAIN 2: Index Test Urea breath test-13C

Were the index test results interpreted without knowl- Unclear

edge of the results of the reference standard?

If a threshold was used, was it pre-specified?

No

High Low

\section{DOMAIN 3: Reference Standard}

Is the reference standards likely to correctly classify Yes the target condition?

Were the reference standard results interpreted with- Unclear out knowledge of the results of the index tests?

\section{DOMAIN 4: Flow and Timing}


Bosso 2000 (Continued)

Was there an appropriate interval between index test Yes and reference standard?

Did all patients receive the same reference standard? Yes

Were all patients included in the analysis? Unclear

Unclear

\section{Ceken 2011}

\section{Study characteristics}

\begin{tabular}{|c|c|}
\hline Patient sampling & $\begin{array}{l}\text { Type of study: unclear whether prospective or retrospective study } \\
\text { Consecutive or random sample: unclear sampling process }\end{array}$ \\
\hline Patient characteristics and setting & $\begin{array}{l}\text { Sample size: } 100 \\
\text { Female: } 67(67 \%) \\
\text { Age: } 48 \text { years } \\
\text { Presentation: } \\
\text { 1. Patients with dyspepsia } \\
\text { Exclusion: } \\
\text { 1. Antibiotics or anti-ulcer treatment within last } 4 \text { weeks } \\
\text { 2. Gastric surgery } \\
\text { Setting: secondary care, France }\end{array}$ \\
\hline Index tests & $\begin{array}{l}\text { Index test: stool antigen test } \\
\text { Further details: } \\
\text { Technical specifications: Helicobacter Antigen Quick Castte } \\
\text { Performed by: not stated } \\
\text { Criteria for positive diagnosis: not stated }\end{array}$ \\
\hline Target condition and reference standard(s) & $\begin{array}{l}\text { Target condition: } H \text { pylori infection } \\
\text { Reference standard: endoscopic biopsy (staining not reported, probably } \mathrm{H} \& \\
\text { E) } \\
\text { Further details: } \\
\text { Technical specifications: not stated } \\
\text { Performed by: endoscopist and pathologist } \\
\text { Criteria for positive diagnosis: presence of } H \text { pylori in biopsy }\end{array}$ \\
\hline
\end{tabular}

Flow and timing

Number of indeterminates for whom the results of reference standard was available: not stated

Number of patients who were excluded from the analysis: not stated

Comparative

Notes

\section{Methodological quality}

Item Authors' judgement $\quad$ Risk of bias $\begin{aligned} & \text { Applicability con- } \\ & \text { cerns }\end{aligned}$

DOMAIN 1: Patient Selection 
Ceken 2011 (Continued)

Was a consecutive or random sample of patients en- Unclear rolled?

\begin{tabular}{llll}
\hline Was a case-control design avoided? & Yes & Unclear & Unclear \\
\hline Did the study avoid inappropriate exclusions? & Unclear & & \\
\hline DOMAIN 2: Index Test Stool Antigen Test & Unclear & \\
\hline $\begin{array}{l}\text { Were the index test results interpreted without } \\
\text { knowledge of the results of the reference standard? }\end{array}$ & Unclear & Unclear \\
\hline If a threshold was used, was it pre-specified? & & High
\end{tabular}

\section{DOMAIN 3: Reference Standard}

Is the reference standards likely to correctly classify No the target condition?

Were the reference standard results interpreted Unclear without knowledge of the results of the index tests?

\begin{tabular}{lll}
\hline DOMAIN 4: Flow and Timing & High & \\
\hline $\begin{array}{l}\text { Was there an appropriate interval between index } \\
\text { test and reference standard? }\end{array}$ & Unclear & \\
\hline $\begin{array}{l}\text { Did all patients receive the same reference stan- } \\
\text { dard? }\end{array}$ & Yes & Unclear \\
\hline Were all patients included in the analysis? & & Unclear \\
\hline
\end{tabular}

\section{Chen 1991}

\section{Study characteristics}

Patient sampling

Patient characteristics and setting
Type of study: unclear whether prospective or retrospective study Consecutive or random sample: consecutive patients

\author{
Sample size: 96 \\ Female: not stated \\ Age: not stated \\ Presentation: \\ 1. Adult patients with dyspepsia \\ Setting: secondary care, China
}

Index test: serology 
Chen 1991 (Continued)

Further details:

Technical specifications: Pyloriset

Performed by: not stated

Criteria for positive diagnosis: presence of agglutination (within 3 minutes)

Target condition and reference standard(s)
Target condition: H pylori infection

Reference standard: endoscopic biopsy with H \& E stain

Further details:

Technical specifications: not stated

Performed by: endoscopist and pathologist

Criteria for positive diagnosis: presence of $H$ pylori in biopsy

Flow and timing

Number of indeterminates for whom the results of reference standard was available: not stated

Number of patients who were excluded from the analysis: $0(0 \%)$

\section{Comparative}

Notes

\section{Methodological quality}

\begin{tabular}{llll}
\hline Item & Authors' judgement & Risk of bias & $\begin{array}{l}\text { Applicability con- } \\
\text { cerns }\end{array}$ \\
\hline
\end{tabular}

\section{DOMAIN 1: Patient Selection}

Was a consecutive or random sample of patients en- Yes rolled?

\begin{tabular}{llll}
\hline Was a case-control design avoided? & Yes & \\
\hline Did the study avoid inappropriate exclusions? & Yes & Low Low \\
\hline
\end{tabular}

\section{DOMAIN 2: Index Test Serology}

Were the index test results interpreted without knowl- Unclear edge of the results of the reference standard?

\begin{tabular}{llll}
\hline If a threshold was used, was it pre-specified? & Unclear & \\
\hline & Unclear & Low \\
\hline
\end{tabular}

\section{DOMAIN 3: Reference Standard}

Is the reference standards likely to correctly classify the No target condition?

Were the reference standard results interpreted without Unclear knowledge of the results of the index tests?

High

Low

\section{DOMAIN 4: Flow and Timing}


Chen 1991 (Continued)

Was there an appropriate interval between index test Unclear and reference standard?

Did all patients receive the same reference standard?

Yes

Were all patients included in the analysis?

Yes

\section{Unclear}

\section{Chey 1998}

\section{Study characteristics}

\begin{tabular}{ll}
\hline Patient sampling & $\begin{array}{l}\text { Type of study: unclear whether prospective or retrospective } \\
\text { Consecutive or random sample: unclear sampling process }\end{array}$ \\
\hline Patient characteristics and setting & Sample size: 287 \\
& Female: $140(48.8 \%)$ \\
& Age: 53 years \\
& Presentation: \\
& 1. People undergoing endoscopy \\
& Exclusion: \\
& 1. Recent treatment for $H$ pylori or anti-ulcer treatment \\
Setting: Variable settings, USA
\end{tabular}

Setting: Variable settings, USA

Index tests

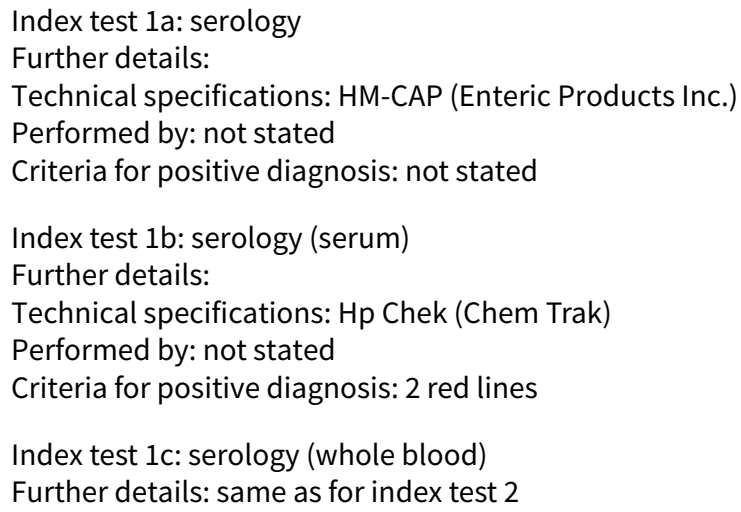

Flow and timing

Number of indeterminates for whom the results of reference standard was available: not stated

Number of patients who were excluded from the analysis: not stated

\section{Comparative}

\section{Notes}

\section{Methodological quality}


Chey 1998 (Continued)

\begin{tabular}{llll} 
Item & Authors' judgement & Risk of bias & Applicability concerns \\
\hline
\end{tabular}

\section{DOMAIN 1: Patient Selection}

Was a consecutive or random sample of pa- Unclear tients enrolled?

\begin{tabular}{ll}
\hline Was a case-control design avoided? & Yes \\
\hline Did the study avoid inappropriate exclusions? & Unclear \\
\hline
\end{tabular}

\begin{tabular}{llll}
\hline DOMAIN 2: Index Test Serology & Unclear & Unclear \\
\hline $\begin{array}{l}\text { Were the index test results interpreted with- } \\
\text { out knowledge of the results of the reference } \\
\text { standard? }\end{array}$ & & \\
\hline $\begin{array}{l}\text { If a threshold was used, was it pre-specified? } \\
\text { Yes }\end{array}$ & Unclear & Low \\
\hline
\end{tabular}

\section{DOMAIN 3: Reference Standard}

\section{Is the reference standards likely to correctly No} classify the target condition?

Were the reference standard results interpret- Unclear ed without knowledge of the results of the index tests?

\begin{tabular}{lcc}
\hline Ligh & Low \\
\hline DOMAIN 4: Flow and Timing & \\
\hline
\end{tabular}

\section{Was there an appropriate interval between in- Unclear dex test and reference standard?}

Did all patients receive the same reference Yes standard?

Were all patients included in the analysis? Yes

Unclear

\section{Czerwionka-Szaflarska 2007}

\section{Study characteristics}

$$
\text { Patient sampling }
$$

Patient characteristics and setting
Type of study: retrospective study

Consecutive or random sample: unclear sampling process

Sample size: 100

Female: 66 (66\%) 
Czerwionka-Szaflarska 2007 (Continued)

\begin{tabular}{|c|c|c|c|}
\hline & \multicolumn{3}{|c|}{$\begin{array}{l}\text { Age: } 13 \text { years } \\
\text { Presentation: } \\
\text { 1. Children with gastrointestinal disorders } \\
\text { Setting: secondary care, Poland }\end{array}$} \\
\hline Index tests & \multicolumn{3}{|c|}{$\begin{array}{l}\text { Index test: urea breath test- } 13 \mathrm{C} \\
\text { Further details: } \\
\text { Technical specifications: not stated } \\
\text { Performed by: not stated } \\
\text { Criteria for positive diagnosis: delta over baseline }>4.0 \% \text { (time not stat- } \\
\text { ed) }\end{array}$} \\
\hline Target condition and reference standard(s) & \multicolumn{3}{|c|}{$\begin{array}{l}\text { Target condition: } H \text { pylori infection } \\
\text { Reference standard: endoscopic biopsy with } H \text { \& E stain } \\
\text { Further details: } \\
\text { Technical specifications: not stated } \\
\text { Performed by: endoscopist and pathologist } \\
\text { Criteria for positive diagnosis: presence of } H \text { pylori in biopsy }\end{array}$} \\
\hline Flow and timing & \multicolumn{3}{|c|}{$\begin{array}{l}\text { Number of indeterminates for whom the results of reference standard } \\
\text { was available: not stated } \\
\text { Number of patients who were excluded from the analysis: not stated }\end{array}$} \\
\hline \multicolumn{4}{|l|}{ Comparative } \\
\hline \multicolumn{4}{|l|}{ Notes } \\
\hline \multicolumn{4}{|l|}{ Methodological quality } \\
\hline Item & Authors' judgement & Risk of bias & $\begin{array}{l}\text { Applicability con- } \\
\text { cerns }\end{array}$ \\
\hline \multicolumn{4}{|l|}{ DOMAIN 1: Patient Selection } \\
\hline $\begin{array}{l}\text { Was a consecutive or random sample of patients en- } \\
\text { rolled? }\end{array}$ & Unclear & & \\
\hline Was a case-control design avoided? & Yes & & \\
\hline \multirow[t]{2}{*}{ Did the study avoid inappropriate exclusions? } & Unclear & & \\
\hline & & Unclear & Unclear \\
\hline
\end{tabular}

DOMAIN 2: Index Test Urea breath test-13C

\section{Were the index test results interpreted without knowl- Unclear}

edge of the results of the reference standard?

\begin{tabular}{lll}
\hline If a threshold was used, was it pre-specified? & Unclear & \\
\hline & Unclear & Low \\
\hline
\end{tabular}

\section{DOMAIN 3: Reference Standard}

Is the reference standards likely to correctly classify the No target condition? 


\section{Czerwionka-Szaflarska 2007 (Continued)}

Were the reference standard results interpreted without Unclear knowledge of the results of the index tests?

High

Low

\section{DOMAIN 4: Flow and Timing}

Was there an appropriate interval between index test Unclear and reference standard?

Did all patients receive the same reference standard? Yes

Were all patients included in the analysis? Unclear

Unclear

\section{D'Elios 2000}

\section{Study characteristics}

\begin{tabular}{ll} 
Patient sampling & $\begin{array}{l}\text { Type of study: unclear whether prospective } \\
\text { Consecutive or random sample: consecutive }\end{array}$ \\
\hline Patient characteristics and setting & Sample size: 256 \\
& Female: not stated \\
Age: not stated & Presentation: \\
1. Patients with dyspepsia \\
Exlusion: \\
1. Gastric surgery \\
2. Recent treatment for ulcer or $H$ pylori \\
3. Pulmonary failure \\
Setting: secondary care, Italy
\end{tabular}

Index tests Index test: urea breath test- ${ }^{13 \mathrm{C}}$

Further details:

Technical specifications: AB Analitica

Performed by: not stated

Criteria for positive diagnosis: delta over baseline $>4.0 \%$ (30 minutes)

Target condition and reference standard(s)

\section{Target condition: H pylori infection}

Reference standard: endoscopic biopsy (staining not reported, probably $\mathrm{H}$ \& E)

Further details:

Technical specifications: not stated

Performed by: endoscopist and pathologist

Criteria for positive diagnosis: presence of $H$ pylori in biopsy

\section{Flow and timing}

Number of indeterminates for whom the results of reference standard was available: not stated

Number of patients who were excluded from the analysis: $0(0 \%)$

\section{Comparative}

\section{Notes}


D'Elios 2000 (Continued)

Methodological quality

\begin{tabular}{llcl}
\hline Item & Authors' judgement & Risk of bias & $\begin{array}{l}\text { Applicability con- } \\
\text { cerns }\end{array}$ \\
\hline
\end{tabular}

\section{DOMAIN 1: Patient Selection}

Was a consecutive or random sample of patients en- Yes rolled?

\begin{tabular}{lcc}
\hline Was a case-control design avoided? & Yes & \\
\hline Did the study avoid inappropriate exclusions? & Yes & Low \\
\hline
\end{tabular}

\section{DOMAIN 2: Index Test Urea breath test-13C}

Were the index test results interpreted without
knowledge of the results of the reference standard?

knowledge of the results of the reference standard?

If a threshold was used, was it pre-specified? Yes

\begin{tabular}{lll}
\hline & Unclear & Low \\
\hline DOMAIN 3: Reference Standard & &
\end{tabular}

Is the reference standards likely to correctly classify No
the target condition?

the target condition?

\section{Were the reference standard results interpreted Unclear}

without knowledge of the results of the index tests?

\begin{tabular}{lll}
\hline High & Low \\
\hline
\end{tabular}

\section{DOMAIN 4: Flow and Timing}

Was there an appropriate interval between index Unclear
test and reference standard?
test and reference standard?

Did all patients receive the same reference stan-
dard?
dard?

Were all patients included in the analysis? Yes

\section{Unclear}

\section{Debongnie 1991}

\section{Study characteristics}

$$
\text { Patient sampling }
$$

Type of study: unclear whether prospective or retrospective study Consecutive or random sample: neither - patients with previous gastric surgery excluded 
Debongnie 1991 (Continued)

$\begin{array}{ll}\text { Patient characteristics and setting } & \text { Sample size: } 230 \\ & \text { Female: not stated } \\ & \text { Age: not stated } \\ \text { Presentation: } & \text { 1. Patients referred for upper gastrointestinal surgery } \\ & \text { Excluded: } \\ \text { 1. Gastric surgery } \\ \text { 2. Haematologic disease } \\ \text { 3. Immunodeficiency } \\ \text { 4. Gastric cancer } \\ \text { 5. Recent treatment for ulcer or } H \text { pylori } \\ \text { 6. Atrophic gastritis } \\ \text { Setting: secondary care, Belgium }\end{array}$

Index tests

Index test: urea breath test- ${ }^{14} \mathrm{C}$

Further details:

Technical specifications: not stated

Performed by: not stated

Criteria for positive diagnosis: specific activity $>0.3 \%$ (10 minutes)

Target condition and reference standard(s)
Target condition: $H$ pylori infection

Reference standard: endoscopic biopsy with H \& E stain and Cresyl Violet stain

Further details:

Technical specifications: not stated

Performed by: endoscopist and pathologist

Criteria for positive diagnosis: presence of $H$ pylori in biopsy

Flow and timing

Number of indeterminates for whom the results of reference standard was

available: not stated

Number of patients who were excluded from the analysis: 27 (11.7\%)

\section{Comparative}

Notes

\section{Methodological quality}

\begin{tabular}{llll}
\hline Item & Authors' judgement & Risk of bias & Applicability concerns \\
\hline DOMAIN 1: Patient Selection & & \\
\hline $\begin{array}{l}\text { Was a consecutive or random sample of patients } \\
\text { enrolled? }\end{array}$ & No & \\
\hline Was a case-control design avoided? & Yes & Unclear
\end{tabular}

\section{DOMAIN 2: Index Test Urea breath test-14C}

Were the index test results interpreted without knowledge of the results of the reference standard?
Unclear

\footnotetext{
No

If a threshold was used, was it pre-specified?
} 
Debongnie 1991 (Continued)

High

Low

\section{DOMAIN 3: Reference Standard}

Is the reference standards likely to correctly clas- No

sify the target condition?

Were the reference standard results interpret-

Unclear

ed without knowledge of the results of the index

tests?

\section{High}

Low

\section{DOMAIN 4: Flow and Timing}

Was there an appropriate interval between index Yes

test and reference standard?

Did all patients receive the same reference stan- Yes

dard?

Were all patients included in the analysis?

No

High

\section{Dede 2015}

\section{Study characteristics}

$\begin{array}{ll}\text { Patient sampling } & \text { Type of study: prospective study } \\ \text { Consecutive or random sample: unclear sampling process }\end{array}$

Patient characteristics and setting Sample size: 30

Female: 8 (26.7\%)

Age: 55 years

Presentation:

1. Patients who had undergone partial gastrectomy

Setting: secondary care, Turkey

Index tests

Index test 1: stool antigen test

Further details:

Technical specifications: not stated

Performed by: not stated

Criteria for positive diagnosis: not stated

Index test 2: urea breath test- ${ }^{14} \mathrm{C}$

Further details:

Technical specifications: Heliprobe System, Kibion AB

Performed by: not stated

Different criteria for positive diagnosis:

- Counts per minute $>23$ (10 minutes)

- Counts per minute $>29$ (30 minutes)

- Counts per minute $>35$ (20 minutes)

- Counts per minute $>50$ (10 minutes) 
Dede 2015 (Continued)

- Counts per minute $>50$ (20 minutes)

- Counts per minute $>50$ (30 minutes)

Target condition and reference standard(s)

Target condition: $H$ pylori infection

Reference standard: endoscopic biopsy with $\mathrm{H} \& \mathrm{E}$ stain and modified Giemsa

stain

Further details:

Technical specifications: not stated

Performed by: endoscopist and pathologist

Criteria for positive diagnosis: presence of $H$ pylori in biopsy

Flow and timing

Number of indeterminates for whom the results of reference standard was

available: not stated

Number of patients who were excluded from the analysis: not stated

Comparative

Notes

\section{Methodological quality}

\begin{tabular}{llll}
\hline Item & Authors' judgement & Risk of bias & Applicability concerns \\
\hline DOMAIN 1: Patient Selection & & \\
\hline $\begin{array}{l}\text { Was a consecutive or random sample of patients } \\
\text { enrolled? }\end{array}$ & Unclear & \\
\hline Was a case-control design avoided? & Yes & \\
\hline Did the study avoid inappropriate exclusions? & Unclear & Unclear & Unclear \\
\hline
\end{tabular}

DOMAIN 2: Index Test Urea breath test-14C

Were the index test results interpreted without

Unclear knowledge of the results of the reference standard?

If a threshold was used, was it pre-specified?

No

High

Low

\section{DOMAIN 2: Index Test Stool Antigen Test}

Were the index test results interpreted without knowledge of the results of the reference standard?

If a threshold was used, was it pre-specified? Yes

\begin{tabular}{lll}
\hline Unclear & High \\
\hline
\end{tabular}

\section{DOMAIN 3: Reference Standard}


Dede 2015 (Continued)

Is the reference standards likely to correctly clas- No sify the target condition?

Were the reference standard results interpret-

Unclear

ed without knowledge of the results of the index

tests?

\section{High}

Low

\section{DOMAIN 4: Flow and Timing}

Was there an appropriate interval between index No

test and reference standard?

Did all patients receive the same reference stan- Yes

dard?

Were all patients included in the analysis?

Unclear

High

\section{Delvin 1999}

\section{Study characteristics}

$\begin{array}{ll}\text { Patient sampling } & \begin{array}{l}\text { Type of study: prospective study } \\ \text { Consecutive or random sample: consecutive patients }\end{array}\end{array}$

\begin{tabular}{ll}
\hline Patient characteristics and setting & Sample size: 79 \\
& Female: not stated \\
& Age: not stated \\
Presentation: \\
1. Children with gastrointestinal symptoms \\
Exclusion: \\
1. Chilren with functional abdominal pain \\
2. Anti-ulcer or $H$ pylori treatment in last 6 weeks \\
Setting: secondary care, Canada
\end{tabular}

Index tests Index test 1 : urea breath test- ${ }^{13} \mathrm{C}$

Further details:

Technical specifications: Dia 13-Helico; Dianatec iso

Performed by: not stated

Different criteria for positive diagnosis:

- Delta over baseline $>2.0 \%$ (30 minutes)

- Delta over baseline $>2.5 \%$ (30 minutes)

- Delta over baseline $>3.0 \%$ (30 minutes)

- Delta over baseline $>3.5 \%$ (30 minutes)

- Delta over baseline $>4.0 \%$ (30 minutes)

- Delta over baseline $>4.5 \%$ (30 minutes)

\footnotetext{
Target condition and reference standard(s)

Target condition: $H$ pylori infection

Reference standard: endoscopic biopsy with $\mathrm{H}$ \& E stain and Warthin-Starry stain Further details:

Technical specifications: not stated
} 
Delvin 1999 (Continued)

Performed by: endoscopist and pathologist

Criteria for positive diagnosis: presence of $H$ pylori in biopsy

Flow and timing
Number of indeterminates for whom the results of reference standard was available: not stated

Number of patients who were excluded from the analysis: 0 (0\%)

Comparative

Notes

Methodological quality

\begin{tabular}{llll}
\hline Item & Authors' judgement & Risk of bias & Applicability concerns \\
\hline DOMAIN 1: Patient Selection & &
\end{tabular}

Was a consecutive or random sample of pa- Yes tients enrolled?

\begin{tabular}{llll}
\hline Was a case-control design avoided? & Yes & Low & Low \\
\hline Did the study avoid inappropriate exclusions? & Yes & Low \\
\hline DOMAIN 2: Index Test Urea breath test-13C &
\end{tabular}

Were the index test results interpreted with- Yes
out knowledge of the results of the reference out knowledge of the results of the reference standard?

If a threshold was used, was it pre-specified? No

\begin{tabular}{lll}
\hline Ligh & How \\
\hline
\end{tabular}

\section{DOMAIN 3: Reference Standard}

Is the reference standards likely to correctly No classify the target condition?

Were the reference standard results interpret- Unclear ed without knowledge of the results of the in-

dex tests?

\begin{tabular}{lll}
\hline DOMAIN 4: Flow and Timing & High \\
\hline $\begin{array}{l}\text { Was there an appropriate interval between in- } \\
\text { dex test and reference standard? }\end{array}$ & Unclear \\
\hline $\begin{array}{l}\text { Did all patients receive the same reference } \\
\text { standard? }\end{array}$ & Yes \\
\hline Were all patients included in the analysis? & Yes \\
\hline
\end{tabular}


Delvin 1999 (Continued)

Unclear

Dinler 1999

\section{Study characteristics}

\begin{tabular}{ll}
\hline Patient sampling & Type of study: unclear whether prospective or retrospective study \\
& Consecutive or random sample: unclear sampling process \\
\hline Patient characteristics and setting & Sample size: 77 \\
& Female: $48(62.3 \%)$ \\
& Age: 13 years \\
& Presentation: \\
& 1. Children with recurrent abdominal pain \\
& Setting: secondary care, Turkey \\
\hline Index tests & Index test: serology \\
& Further details: \\
& Technical specifications: not stated \\
& Performed by: not stated \\
& Criteria for positive diagnosis: not stated \\
\hline Target condition and reference standard(s) & Target condition: $H$ pylori infection \\
& Reference standard: endoscopic biopsy (staining not reported, probably \\
& H \& E) \\
& Further details: \\
Technical specifications: not stated \\
Performed by: endoscopist and pathologist \\
Criteria for positive diagnosis: presence of $H$ pylori in biopsy
\end{tabular}

Flow and timing

Number of indeterminates for whom the results of reference standard was available: not stated

Number of patients who were excluded from the analysis: not stated

\section{Comparative}

Notes

\section{Methodological quality}

\begin{tabular}{llll}
\hline Item Authors' judgement & Risk of bias & $\begin{array}{l}\text { Applicability con- } \\
\text { cerns }\end{array}$
\end{tabular}

\section{DOMAIN 1: Patient Selection}

\begin{tabular}{lll}
\hline $\begin{array}{l}\text { Was a consecutive or random sample of patients en- } \\
\text { rolled? }\end{array}$ & Unclear \\
\hline Was a case-control design avoided? & Yes & Unclear \\
\hline Did the study avoid inappropriate exclusions? & & Unclear \\
\hline
\end{tabular}

\section{DOMAIN 2: Index Test Serology}


Dinler 1999 (Continued)

Were the index test results interpreted without knowl- Unclear edge of the results of the reference standard?

If a threshold was used, was it pre-specified? Unclear

\section{DOMAIN 3: Reference Standard}

Is the reference standards likely to correctly classify the No target condition?

Were the reference standard results interpreted without Unclear knowledge of the results of the index tests?

High Low

\section{DOMAIN 4: Flow and Timing}

Was there an appropriate interval between index test Unclear and reference standard?

Did all patients receive the same reference standard? Yes

Were all patients included in the analysis? Unclear

Unclear

\section{Duan 1999}

\section{Study characteristics}

\begin{tabular}{|c|c|}
\hline Patient sampling & $\begin{array}{l}\text { Type of study: unclear whether prospective or retrospective study } \\
\text { Consecutive or random sample: unclear sampling process }\end{array}$ \\
\hline Patient characteristics and setting & $\begin{array}{l}\text { Sample size: } 149 \\
\text { Female: } 35(23.5 \%) \\
\text { Age: } 44 \text { years } \\
\text { Presentation: } \\
\text { 1. Patients with gastritis or gastric ulcer } \\
\text { Exclusion: } \\
\text { 1. Treatment with antibiotics or bismuth in the previous } 2 \text { months } \\
\text { 2. Previous gastric surgery or gastric cancer } \\
\text { Setting: secondary care, China }\end{array}$ \\
\hline Index tests & $\begin{array}{l}\text { Index test: urea breath test- }{ }^{13} \mathrm{C} \\
\text { Further details: } \\
\text { Technical specifications: Finniga, MAT-252, USA } \\
\text { Performed by: not stated } \\
\text { Criteria for positive diagnosis: delta over baseline }>5 \text { per thousand ( } 30 \text { minutes) }\end{array}$ \\
\hline Target condition and reference standard(s) & $\begin{array}{l}\text { Target condition: H pylori infection } \\
\text { Reference standard: endoscopic biopsy with H \& E stain and Warthin-Starry } \\
\text { stain } \\
\text { Further details: } \\
\text { Technical specifications: not stated }\end{array}$ \\
\hline
\end{tabular}


Duan 1999 (Continued)

Performed by: endoscopist and pathologist

Criteria for positive diagnosis: presence of $H$ pylori in biopsy

Flow and timing

Number of indeterminates for whom the results of reference standard was available: not stated

Number of patients who were excluded from the analysis: not stated

\section{Comparative}

\section{Notes}

\section{Methodological quality}

\begin{tabular}{llll}
\hline Item & Authors' judgement & Risk of bias & Applicability concerns \\
\hline
\end{tabular}

DOMAIN 1: Patient Selection

Was a consecutive or random sample of patients Unclear
enrolled?
enrolled?

\begin{tabular}{ll}
\hline Was a case-control design avoided? & Yes \\
\hline Did the study avoid inappropriate exclusions? & Unclear \\
\hline DOMAlear & Unclear
\end{tabular}

Were the index test results interpreted without Unclear
knowledge of the results of the reference stan-
dard?

If a threshold was used, was it pre-specified? Unclear

\begin{tabular}{lll}
\hline & Unclear & Low \\
\hline DOMAIN 3: Reference Standard & &
\end{tabular}

\section{DOMAIN 3: Reference Standard}

Is the reference standards likely to correctly clas- No sify the target condition?

Were the reference standard results interpret- Unclear ed without knowledge of the results of the index tests?

\begin{tabular}{ll}
\hline DOMAIN 4: Flow and Timing & High \\
\hline $\begin{array}{l}\text { Was there an appropriate interval between index } \\
\text { test and reference standard? }\end{array}$ \\
\hline $\begin{array}{l}\text { Did all patients receive the same reference stan- } \\
\text { dard? }\end{array}$ \\
\hline Were all patients included in the analysis? & Unclear \\
\hline
\end{tabular}


Duan 1999 (Continued)

\section{Unclear}

\section{Eggers 1990}

\section{Study characteristics}

\begin{tabular}{ll}
\hline Patient sampling & $\begin{array}{l}\text { Type of study: unclear whether prospective or retrospective study } \\
\text { Consecutive or random sample: unclear sampling process }\end{array}$ \\
\hline Patient characteristics and setting & Sample size: 100 \\
& Female: not stated \\
Age: not stated & Presentation: \\
& 1. Patients undergoing endoscopy \\
& Setting: secondary care, Germany \\
\hline Index tests & Index test: urea breath test-13C \\
& Further details: \\
& Technical specifications: not stated \\
& Performed by: not stated \\
& Criteria for positive diagnosis: not stated \\
\hline \multirow{2}{*}{ Target condition and reference standard(s) } & Target condition: $H$ pylori infection \\
& Reference standard: endoscopic biopsy (staining not reported, probably \\
H \& E) & Further details: \\
Technical specifications: not stated \\
Performed by: endoscopist and pathologist \\
Criteria for positive diagnosis: presence of $H$ pylori in biopsy
\end{tabular}

Flow and timing

Number of indeterminates for whom the results of reference standard was available: not stated

Number of patients who were excluded from the analysis: 8 (7.4\%)

\section{Comparative}

Notes

\section{Methodological quality}

\begin{tabular}{llll}
\hline Item Authors' judgement & Risk of bias & \multicolumn{1}{l}{$\begin{array}{l}\text { Applicability con- } \\
\text { cerns }\end{array}$}
\end{tabular}

DOMAIN 1: Patient Selection

\begin{tabular}{llll}
$\begin{array}{l}\text { Was a consecutive or random sample of patients en- } \\
\text { rolled? }\end{array}$ & Unclear \\
\hline Was a case-control design avoided? & Yes & Unclear & Unclear \\
\hline Did the study avoid inappropriate exclusions? & & Unclear
\end{tabular}

\section{DOMAIN 2: Index Test Urea breath test-13C}


Eggers 1990 (Continued)

Were the index test results interpreted without knowl- Yes edge of the results of the reference standard?

If a threshold was used, was it pre-specified? Unclear

Unclear

High

\section{DOMAIN 3: Reference Standard}

Is the reference standards likely to correctly classify the No target condition?

Were the reference standard results interpreted without Yes

knowledge of the results of the index tests?

High Low

\section{DOMAIN 4: Flow and Timing}

Was there an appropriate interval between index test Unclear and reference standard?

Did all patients receive the same reference standard? Yes

Were all patients included in the analysis? No

High

Ekesbo 2006

\section{Study characteristics}

\begin{tabular}{ll}
\hline Patient sampling & Type of study: unclear whether prospective or retrospective study \\
& Consecutive or random sample: neither - patients with previous gastric \\
surgery excluded & \\
\hline Patient characteristics and setting & Sample size: 126 \\
& Female: not stated \\
& Age: not stated \\
& Presentation: \\
& 1. Patients undergoing gastroscopy for dyspepsia or gastrointestinal bleed- \\
& ing \\
& Setting: primary care, Sweden \\
\hline Index tests & Index test: serology \\
& Further details: \\
& Technical specifications: not stated \\
& Performed by: not stated \\
Criteria for positive diagnosis: staining of a 120 kilodalton protein gel band & and/or at least 2 of 5 proteins between $28-33$ kilodaltons \\
& Target condition: $H$ pylori infection \\
Target condition and reference standard(s) & Reference standard: endoscopic biopsy with immunostaining \\
& Further details: \\
Technical specifications: not stated & Performed by: endoscopist and pathologist \\
\hline
\end{tabular}


Ekesbo 2006 (Continued)

Criteria for positive diagnosis: presence of $H$ pylori in biopsy

Flow and timing

Number of indeterminates for whom the results of reference standard was available: not stated

Number of patients who were excluded from the analysis: 40 (24.1\%)

Comparative

Notes

\section{Methodological quality}

\begin{tabular}{llll}
\hline Item Authors' judgement & Risk of bias & $\begin{array}{l}\text { Applicability con- } \\
\text { cerns }\end{array}$
\end{tabular}

\section{DOMAIN 1: Patient Selection}

Was a consecutive or random sample of patients en- No rolled?

\begin{tabular}{llll}
\hline Was a case-control design avoided? & Yes & \\
\hline Did the study avoid inappropriate exclusions? & Unclear & High & Unclear \\
\hline
\end{tabular}

\section{DOMAIN 2: Index Test Serology}

Were the index test results interpreted without Unclear knowledge of the results of the reference standard?

If a threshold was used, was it pre-specified? Unclear

\begin{tabular}{l}
\hline Unclear \\
Low
\end{tabular}

\section{DOMAIN 3: Reference Standard}

Is the reference standards likely to correctly classify Yes the target condition?

Were the reference standard results interpreted Unclear without knowledge of the results of the index tests?

Unclear Low

\section{DOMAIN 4: Flow and Timing}

Was there an appropriate interval between index Unclear
test and reference standard?

Did all patients receive the same reference stan- Yes dard?

Were all patients included in the analysis?

No

\section{High}


El-Din 2013

\section{Study characteristics}

$\begin{array}{ll}\text { Patient sampling } & \begin{array}{l}\text { Type of study: unclear whether prospective or retrospective study } \\ \text { Consecutive or random sample: neither - patients without pathologic } \\ \text { data excluded }\end{array}\end{array}$

$\begin{array}{ll}\text { Patient characteristics and setting } & \text { Sample size: } 19 \\ & \text { Female: } 6(31.6 \%) \\ \text { Age: } 47 \text { years } & \text { Presentation: } \\ & \text { 1. Patients with upper gastrointestinal disorders } \\ & \text { Setting: secondary care, Egypt }\end{array}$

\begin{tabular}{ll}
\hline Index tests & Index test 1: serology \\
& Further details: \\
& Technical specifications: Ridascreen \\
& Performed by: not stated \\
& Criteria for positive diagnosis: not stated \\
& Index test 2: stool antigen test \\
& Further details: \\
& Technical specifications: Immunodiagnostik AG \\
& Performed by: not stated \\
& Criteria for positive diagnosis: not stated \\
\end{tabular}

Target condition and reference standard(s)

Target condition: H pylori infection

Reference standard: endoscopic biopsy with Giemsa stain

Further details:

Technical specifications: not stated

Performed by: endoscopist and pathologist

Criteria for positive diagnosis: presence of $H$ pylori in biopsy

Flow and timing

Number of indeterminates for whom the results of reference standard was available: not stated

Number of patients who were excluded from the analysis: 33 (63.5\%)

\section{Comparative}

Notes

\section{Methodological quality}

\begin{tabular}{llll}
\hline Item Authors' judgement & Risk of bias & \multicolumn{1}{l}{$\begin{array}{l}\text { Applicability con- } \\
\text { cerns }\end{array}$}
\end{tabular}

\section{DOMAIN 1: Patient Selection}

Was a consecutive or random sample of patients en- No rolled?

\begin{tabular}{lll}
\hline Was a case-control design avoided? & Yes & \\
\hline Did the study avoid inappropriate exclusions? & Unclear & High \\
\hline
\end{tabular}


El-Din 2013 (Continued)

\section{DOMAIN 2: Index Test Stool Antigen Test}

Were the index test results interpreted without knowl- Unclear edge of the results of the reference standard?

If a threshold was used, was it pre-specified? Unclear

\begin{tabular}{llll}
\hline DOMAIN 2: Index Test Serology & Unclear & High \\
\hline $\begin{array}{l}\text { Were the index test results interpreted without knowl- } \\
\text { edge of the results of the reference standard? }\end{array}$ & Unclear & \\
\hline $\begin{array}{l}\text { If a threshold was used, was it pre-specified? } \\
\text { Unclear }\end{array}$ & Unclear & High
\end{tabular}

\section{DOMAIN 3: Reference Standard}

Is the reference standards likely to correctly classify the Yes target condition?

Were the reference standard results interpreted without Unclear knowledge of the results of the index tests?

Unclear

Low

\section{DOMAIN 4: Flow and Timing} Was there an appropriate interval between index test Unclear
and reference standard?

Did all patients receive the same reference standard? Yes

Were all patients included in the analysis? No

High

\section{El-Mekki 2011}

\section{Study characteristics}

\begin{tabular}{ll}
\hline Patient sampling & $\begin{array}{l}\text { Type of study: unclear whether prospective or retrospective study } \\
\text { Consecutive or random sample: consecutive patients }\end{array}$ \\
\hline Patient characteristics and setting & Sample size: 55 \\
& Female: $35(63.6 \%)$ \\
& Age: 37 years \\
& Presentation: \\
& 1. Patients with dyspepsia \\
& Setting: secondary care, Saudi Arabia \\
\hline Index tests & Index test: serology \\
& Further details:
\end{tabular}


El-Mekki 2011 (Continued)

Technical specifications: HeliSAL TM serum

Performed by: not stated

Criteria for positive diagnosis: > 1 units $/ \mathrm{ml}$

Target condition and reference standard(s)

Target condition: $H$ pylori infection

Reference standard: endoscopic biopsy with H \& E stain and Giemsa

stain

Further details:

Technical specifications: not stated

Performed by: endoscopist and pathologist

Criteria for positive diagnosis: presence of $H$ pylori in biopsy

Flow and timing

Number of indeterminates for whom the results of reference standard was available: not stated

Number of patients who were excluded from the analysis: 0 (0\%)

\section{Comparative}

\section{Notes}

\section{Methodological quality}

\begin{tabular}{llll}
\hline Item & Authors' judgement & Risk of bias & $\begin{array}{l}\text { Applicability con- } \\
\text { cerns }\end{array}$ \\
\hline
\end{tabular}

\section{DOMAIN 1: Patient Selection}

Was a consecutive or random sample of patients en- Yes rolled?

\begin{tabular}{llll}
\hline Was a case-control design avoided? & Yes & \\
\hline Did the study avoid inappropriate exclusions? & Yes & Low \\
\hline
\end{tabular}

\section{DOMAIN 2: Index Test Serology}

\section{Were the index test results interpreted without knowl- Unclear}

edge of the results of the reference standard?

\begin{tabular}{llll}
\hline If a threshold was used, was it pre-specified? & Unclear & \\
\hline & Unclear & Low \\
\hline
\end{tabular}

\section{DOMAIN 3: Reference Standard}

Is the reference standards likely to correctly classify the No target condition?

Were the reference standard results interpreted without Unclear knowledge of the results of the index tests?

\begin{tabular}{lll}
\hline Low & High & Low \\
\hline
\end{tabular}

\section{DOMAIN 4: Flow and Timing}


El-Mekki 2011 (Continued) Was there an appropriate interval between index test Unclear
and reference standard?

Did all patients receive the same reference standard?

Yes

Were all patients included in the analysis?

Yes

\section{Unclear}

\section{El-Nasr 2003}

\section{Study characteristics}

\begin{tabular}{ll}
\hline Patient sampling & $\begin{array}{l}\text { Type of study: unclear whether prospective or retrospective study } \\
\text { Consecutive or random sample: unclear sampling process }\end{array}$ \\
\hline Patient characteristics and setting & Sample size: 50 \\
& Female: $16(32 \%)$ \\
& Age: 36 years \\
& Presentation: \\
& 1. Patients with dyspepsia \\
& Setting: secondary care, Egypt \\
\hline Index tests & Index test: stool antigen test \\
& Further details: \\
& Technical specifications: Premier Platinum HpSA, Meridien Diagnostics \\
& Performed by: not stated \\
& Criteria for positive diagnosis: not stated \\
\hline \multirow{2}{*}{ Target condition and reference standard(s) } & Target condition: $H$ pylori infection \\
& Reference standard: endoscopic biopsy (staining not reported, probably $H$ \\
\&E) & Further details: \\
Technical specifications: not stated \\
Performed by: endoscopist and pathologist \\
Criteria for positive diagnosis: presence of $H$ pylori in biopsy
\end{tabular}

Flow and timing

Number of indeterminates for whom the results of reference standard was available: not stated

Number of patients who were excluded from the analysis: not stated

\section{Comparative}

\section{Notes}

\section{Methodological quality}

\begin{tabular}{llll}
\hline Item Authors' judgement & Risk of bias & \multicolumn{1}{|l}{$\begin{array}{l}\text { Applicability con- } \\
\text { cerns }\end{array}$}
\end{tabular}

\section{DOMAIN 1: Patient Selection}

Was a consecutive or random sample of patients en- Unclear
rolled?
rolled? 
El-Nasr 2003 (Continued)

Was a case-control design avoided? Yes

Did the study avoid inappropriate exclusions? Unclear

Unclear

Unclear

\section{DOMAIN 2: Index Test Stool Antigen Test}

Were the index test results interpreted without knowl- Unclear

edge of the results of the reference standard?

If a threshold was used, was it pre-specified? Unclear

Unclear

High

\section{DOMAIN 3: Reference Standard}

Is the reference standards likely to correctly classify the No target condition?

Were the reference standard results interpreted with- Unclear out knowledge of the results of the index tests?

High Low

\section{DOMAIN 4: Flow and Timing}

Was there an appropriate interval between index test Unclear and reference standard?

Did all patients receive the same reference standard? Yes

Were all patients included in the analysis? Unclear

Unclear

Eltumi 1999

\section{Study characteristics}

\begin{tabular}{ll}
\hline Patient sampling & $\begin{array}{l}\text { Type of study: prospective study } \\
\text { Consecutive or random sample: unclear sampling process }\end{array}$ \\
\hline Patient characteristics and setting & Sample size: 50 \\
& Female: $17(34 \%)$ \\
& Age: 11 years \\
& Presentation: \\
& 1. Children referred for endoscopy \\
& Exclusion: \\
& 1. Recent treatment for H pylori \\
& Setting: Tertiary care, UK \\
\hline Index tests & Index test 1: urea breath test-13C \\
& Further details: \\
Technical specifications: not stated
\end{tabular}


Eltumi 1999 (Continued)

Performed by: not stated

Criteria for positive diagnosis: delta over baseline $>5$ units $/ \mathrm{ml}$ (40 minutes)

Index test 2: serology

Further details:

Technical specifications: not stated

Performed by: not stated

Criteria for positive diagnosis: not stated

Target condition and reference standard(s)
Target condition: $H$ pylori infection

Reference standard: endoscopic biopsy with H \& E stain and Warthin-Star-

ry stain

Further details:

Technical specifications: not stated

Performed by: endoscopist and pathologist

Criteria for positive diagnosis: presence of $H$ pylori in biopsy

Flow and timing

Number of indeterminates for whom the results of reference standard was available: not stated

Number of patients who were excluded from the analysis: not stated

\section{Comparative}

Notes

\section{Methodological quality}

\begin{tabular}{llll}
\hline Item Authors' judgement & Risk of bias & \multicolumn{1}{c}{$\begin{array}{l}\text { Applicability con- } \\
\text { cerns }\end{array}$} \\
\hline
\end{tabular}

\section{DOMAIN 1: Patient Selection}

Was a consecutive or random sample of patients en- Unclear rolled?

\begin{tabular}{lll}
\hline Was a case-control design avoided? & Yes & Unclear \\
\hline Did the study avoid inappropriate exclusions? & Unclear & \\
\hline DOMAIN 2: Index Test Urea breath test-13C & & \\
\hline $\begin{array}{l}\text { Were the index test results interpreted without knowl- } \\
\text { edge of the results of the reference standard? }\end{array}$ & Unclear & \\
\hline If a threshold was used, was it pre-specified? & & Unclear \\
\hline
\end{tabular}

\section{DOMAIN 2: Index Test Serology}

Were the index test results interpreted without knowl- Unclear edge of the results of the reference standard?

If a threshold was used, was it pre-specified? Unclear 
Eltumi 1999 (Continued)

Unclear

High

\title{
DOMAIN 3: Reference Standard
}

Is the reference standards likely to correctly classify the No

target condition?

Were the reference standard results interpreted with- Unclear

out knowledge of the results of the index tests?

High

Low

\section{DOMAIN 4: Flow and Timing}

Was there an appropriate interval between index test Unclear and reference standard?

\begin{tabular}{ll}
\hline Did all patients receive the same reference standard? & Yes \\
\hline Were all patients included in the analysis? & Unclear \\
\hline
\end{tabular}

Unclear

Epple 1997

\section{Study characteristics}

$\begin{array}{ll}\text { Patient sampling } & \begin{array}{l}\text { Type of study: unclear whether prospective or retrospective study } \\ \text { Consecutive or random sample: consecutive patients }\end{array}\end{array}$

$\begin{array}{ll}\text { Patient characteristics and setting } & \text { Sample size: } 126 \\ & \text { Female: } 70(55.6 \%) \\ \text { Age: } 48 \text { years } \\ \text { Presentation: } \\ \text { 1. Patients undergoing routine endoscopy } \\ \text { Exclusion: } \\ \text { 1. Gastric cancer } \\ \text { 2. Previous gastric surgery } \\ \text { Setting: secondary care, Germany }\end{array}$

Index tests Index test: urea breath test-13C

Further details:

Technical specifications: not stated

Performed by: not stated

Criteria for positive diagnosis: > Mean +2 standard deviations above normal level (30 minutes)

\footnotetext{
Target condition and reference standard(s)
}

\author{
Target condition: $H$ pylori infection \\ Reference standard: endoscopic biopsy with H \& E stain and Warthin-Starry \\ stain \\ Further details: \\ Technical specifications: not stated \\ Performed by: endoscopist and pathologist \\ Criteria for positive diagnosis: presence of $H$ pylori in biopsy
}


Epple 1997 (Continued)

Flow and timing

Number of indeterminates for whom the results of reference standard was available: not stated

Number of patients who were excluded from the analysis: $0(0 \%)$

\section{Comparative}

\section{Notes}

\section{Methodological quality}

\begin{tabular}{llll}
\hline Item Authors' judgement & Risk of bias & $\begin{array}{l}\text { Applicability con- } \\
\text { cerns }\end{array}$
\end{tabular}

\section{DOMAIN 1: Patient Selection}

Was a consecutive or random sample of patients en- Yes rolled?

\begin{tabular}{ll}
\hline Was a case-control design avoided? & Yes \\
\hline Did the study avoid inappropriate exclusions? & Yes
\end{tabular}

\begin{tabular}{lll}
\hline Low & Low \\
\hline
\end{tabular}

\section{DOMAIN 2: Index Test Urea breath test-13C}

Were the index test results interpreted without knowl- Unclear

edge of the results of the reference standard?

\begin{tabular}{lll}
\hline If a threshold was used, was it pre-specified? & No & High \\
\hline
\end{tabular}

\section{DOMAIN 3: Reference Standard}

Is the reference standards likely to correctly classify No the target condition?

Were the reference standard results interpreted with- Unclear out knowledge of the results of the index tests?

\begin{tabular}{llll}
\hline DOMAIN 4: Flow and Timing & High & Low \\
\hline $\begin{array}{l}\text { Was there an appropriate interval between index test } \\
\text { and reference standard? }\end{array}$ & Yes & \\
\hline Did all patients receive the same reference standard? & Yes \\
\hline Were all patients included in the analysis? & Yes & Low \\
\hline
\end{tabular}




\section{Fallone 1995}

\section{Study characteristics}

\begin{tabular}{ll} 
Patient sampling & $\begin{array}{l}\text { Type of study: prospective study } \\
\text { Consecutive or random sample: consecutive patients }\end{array}$ \\
\hline Patient characteristics and setting & Sample size: 50 \\
& Female: not stated \\
Age: not stated & Presentation: \\
& 1. Patients undergoing endoscopy \\
Exclusion & 1. Conditions that would make gastric biopsy dangerous \\
& 2. Lactating \\
3. Pregnant or women of child-bearing potential who were not using ade- & quate control \\
Setting: secondary care, Canada
\end{tabular}

\begin{tabular}{|c|c|}
\hline Index tests & $\begin{array}{l}\text { Index test: urea breath test- } 13 \mathrm{C} \\
\text { Further details: } \\
\text { Technical specifications: not stated } \\
\text { Performed by: not stated } \\
\text { Criteria for positive diagnosis: > 1.5\% excretion ( } 15 \text { minutes) }\end{array}$ \\
\hline Target condition and reference standard(s) & $\begin{array}{l}\text { Target condition: } H \text { pylori infection } \\
\text { Reference standard: endoscopic biopsy with Silver stain } \\
\text { Further details: } \\
\text { Technical specifications: not stated } \\
\text { Performed by: endoscopist and pathologist } \\
\text { Criteria for positive diagnosis: presence of } H \text { pylori in biopsy }\end{array}$ \\
\hline Flow and timing & $\begin{array}{l}\text { Number of indeterminates for whom the results of reference standard was } \\
\text { available: not stated } \\
\text { Number of patients who were excluded from the analysis: } 4(7.4 \%)\end{array}$ \\
\hline
\end{tabular}

\section{Comparative}

Notes

\section{Methodological quality}

\begin{tabular}{llll}
\hline Item Authors' judgement & Risk of bias & $\begin{array}{l}\text { Applicability con- } \\
\text { cerns }\end{array}$ \\
\hline
\end{tabular}

\section{DOMAIN 1: Patient Selection}

Was a consecutive or random sample of patients en- Yes rolled?

\begin{tabular}{llll}
\hline Was a case-control design avoided? & Yes & \\
\hline Did the study avoid inappropriate exclusions? & Unclear & Unclear \\
\hline
\end{tabular}

DOMAIN 2: Index Test Urea breath test-13C 


\section{Fallone 1995 (Continued)}

Were the index test results interpreted without knowl- Yes edge of the results of the reference standard?

\begin{tabular}{lll}
\hline If a threshold was used, was it pre-specified? & Unclear & \\
\hline & Unclear & Low \\
\hline
\end{tabular}

\section{DOMAIN 3: Reference Standard}

Is the reference standards likely to correctly classify Yes the target condition?

Were the reference standard results interpreted with- Yes out knowledge of the results of the index tests?

\section{DOMAIN 4: Flow and Timing}

Was there an appropriate interval between index test Yes and reference standard?

Did all patients receive the same reference standard? Yes

Were all patients included in the analysis? No

High

Fallone 1996

\section{Study characteristics}

\section{Patient sampling}

\section{Patient characteristics and setting}

Type of study: unclear whether prospective or retrospective study Consecutive or random sample: consecutive patients

\author{
Sample size: 106 \\ Female: 51 (48.1\%) \\ Age: 54 years \\ Presentation: \\ 1. Patients undergoing endoscopy \\ Exclusion: \\ 1. Recent treatment for $\mathrm{H}$ pylori \\ Setting: secondary care, Canada
}

\begin{tabular}{ll}
\hline Index tests & Index test: serology \\
& Further details: \\
& Technical specifications: HeliSAL TM serum \\
& Performed by: not stated \\
& Criteria for positive diagnosis: not stated
\end{tabular}

Target condition and reference standard(s)
Target condition: $H$ pylori infection Reference standard: endoscopic biopsy with $\mathrm{H}$ \& E stain

Further details:

Technical specifications: not stated

Performed by: endoscopist and pathologist 
Fallone 1996 (Continued)

Criteria for positive diagnosis: presence of $H$ pylori in biopsy

Flow and timing

Number of indeterminates for whom the results of reference standard was available: not stated

Number of patients who were excluded from the analysis: $0(0 \%)$

Comparative

Notes

\section{Methodological quality}

\begin{tabular}{llll}
\hline Item & Authors' judgement & Risk of bias & $\begin{array}{l}\text { Applicability con- } \\
\text { cerns }\end{array}$
\end{tabular}

DOMAIN 1: Patient Selection

Was a consecutive or random sample of patients en- Yes rolled?

\begin{tabular}{llll}
\hline Was a case-control design avoided? & Yes & \\
\hline Did the study avoid inappropriate exclusions? & Yes & Low & Low \\
\hline
\end{tabular}

\section{DOMAIN 2: Index Test Serology}

Were the index test results interpreted without knowl- Unclear edge of the results of the reference standard?

If a threshold was used, was it pre-specified? Unclear

Unclear

High

\section{DOMAIN 3: Reference Standard}

Is the reference standards likely to correctly classify the No target condition?

Were the reference standard results interpreted without Unclear knowledge of the results of the index tests?

High Low

\section{DOMAIN 4: Flow and Timing}

Was there an appropriate interval between index test Yes and reference standard?

Did all patients receive the same reference standard? Yes

Were all patients included in the analysis? Yes 
Fanti 1999

\section{Study characteristics}

\begin{tabular}{ll}
\hline Patient sampling & $\begin{array}{l}\text { Type of study: unclear whether prospective or ret } \\
\text { Consecutive or random sample: unclear sampling }\end{array}$ \\
\hline Patient characteristics and setting & Sample size: 84 \\
& Female: $45(53.6 \%)$ \\
& Age: 50 years \\
& Presentation: \\
1. Patients with dyspepsia & 2. Not on current treatment for $H$ pylori or ulcers \\
& Setting: secondary care, Italy
\end{tabular}

Index tests

Index test: stool antigen test

Further details:

Technical specifications: Premier Platinum HpSA (Meridian Diagnostics)

Performed by: not stated

Criteria for positive diagnosis: Absorbance 450/630 nm >0.150

$\begin{array}{ll}\text { Target condition and reference standard(s) } & \text { Target condition: } H \text { pylori infection } \\ & \text { Reference standard: endoscopic biopsy with H \& E stain and Giemsa stain } \\ & \text { Further details: } \\ & \text { Technical specifications: not stated } \\ & \text { Performed by: endoscopist and pathologist } \\ & \text { Criteria for positive diagnosis: presence of } H \text { pylori in biopsy }\end{array}$

Flow and timing

Number of indeterminates for whom the results of reference standard was available: not stated

Number of patients who were excluded from the analysis: not stated

\begin{tabular}{llll}
\hline Comparative & & \\
\hline Notes & Authors' judgement & Risk of bias & Applicability con- \\
\hline Methodological quality & & cerns \\
\hline Item & Unclear & \\
\hline DomalN 1: Patient Selection & Yes & \\
\hline $\begin{array}{l}\text { Was a consecutive or random sample of patients en- } \\
\text { rolled? }\end{array}$ & Unclear & Unclear \\
\hline Was a case-control design avoided? & & \\
\hline Did the study avoid inappropriate exclusions? & & \\
\hline
\end{tabular}

\section{DOMAIN 2: Index Test Stool Antigen Test}

Were the index test results interpreted without Unclear
knowledge of the results of the reference standard?

knowledge of the results of the reference standard?

If a threshold was used, was it pre-specified? Unclear 
Fanti 1999 (Continued)

Unclear

Low

\section{DOMAIN 3: Reference Standard}

Is the reference standards likely to correctly classify No

the target condition?

Were the reference standard results interpreted Unclear

without knowledge of the results of the index tests?

High $\quad$ Low L H

\section{DOMAIN 4: Flow and Timing}

Was there an appropriate interval between index Unclear test and reference standard?

Did all patients receive the same reference stan- Yes
dard?

Were all patients included in the analysis? Unclear

Unclear

\section{Faruqui 2007}

\section{Study characteristics}

Patient sampling

Patient characteristics and setting
Type of study: unclear whether prospective or retrospective study

Consecutive or random sample: unclear sampling process

\section{Sample size: 50}

Female: $26(52 \%)$

Age: 36 years

Presentation:

1. Patients with dyspepsia despite anti-ulcer treatment

Exclusion:

1. Myocardial infarction in the last 6 months

2. Cardiac failure

3. Bleeding diathesis

Setting: secondary care, Pakistan
Index test: stool antigen test

Further details:

Technical specifications: not stated

Performed by: not stated

Criteria for positive diagnosis: not stated
Target condition and reference standard(s)
Target condition: H pylori infection
Reference standard: endoscopic biopsy (staining not reported, probably H \& E)
Further details:
Technical specifications: not stated
Performed by: endoscopist and pathologist
Criteria for positive diagnosis: presence of $H$ pylori in biopsy 


\section{Faruqui 2007 (Continued)}

Flow and timing
Number of indeterminates for whom the results of reference standard was available: not stated

Number of patients who were excluded from the analysis: not stated

\section{Comparative}

\section{Notes}

\section{Methodological quality}

\begin{tabular}{llll}
\hline Item & Authors' judgement & Risk of bias & $\begin{array}{l}\text { Applicability con- } \\
\text { cerns }\end{array}$
\end{tabular}

\section{DOMAIN 1: Patient Selection}

Was a consecutive or random sample of patients en- Unclear rolled?

\begin{tabular}{ll}
\hline Was a case-control design avoided? & Yes \\
\hline Did the study avoid inappropriate exclusions? & Unclear
\end{tabular}

\begin{tabular}{llll}
\hline \multicolumn{1}{l}{ Unclear } & Unclear \\
\hline $\begin{array}{l}\text { Were the index test results interpreted without } \\
\text { knowledge of the results of the reference standard? }\end{array}$ & Unclear & \\
\hline $\begin{array}{l}\text { If a threshold was used, was it pre-specified? } \\
\text { Unclear }\end{array}$ & Unclear & High \\
\hline
\end{tabular}

\section{DOMAIN 3: Reference Standard}

Is the reference standards likely to correctly classify No the target condition?

Were the reference standard results interpreted without knowledge of the results of the index tests?

\begin{tabular}{ll}
\hline DOMAIN 4: Flow and Timing & High \\
\hline $\begin{array}{l}\text { Was there an appropriate interval between index } \\
\text { test and reference standard? }\end{array}$ \\
\hline $\begin{array}{l}\text { Did all patients receive the same reference stan- } \\
\text { dard? }\end{array}$ \\
\hline Were all patients included in the analysis? & Unclear \\
\hline
\end{tabular}

\section{Unclear}


Ferrara 1998

\section{Study characteristics}

\section{Patient sampling}

\section{Patient characteristics and setting}

Type of study: unclear whether prospective or retrospective study Consecutive or random sample: unclear sampling process

\begin{tabular}{ll} 
Index tests & Index test: serology \\
& Further details: \\
& Technical specifications: not stated \\
& Performed by: not stated \\
Criteria for positive diagnosis: not stated & \\
& Target condition: $H$ pylori infection \\
\hline Target condition and reference standard(s) & Reference standard: endoscopic biopsy with H \& E stain and Giemsa \\
stain & Further details: \\
& Technical specifications: not stated \\
& Performed by: endoscopist and pathologist \\
& Criteria for positive diagnosis: presence of $H$ pylori in biopsy
\end{tabular}

Flow and timing Number of indeterminates for whom the results of reference standard was available: not stated

Number of patients who were excluded from the analysis: not stated

\begin{tabular}{llll}
\hline Comparative & & \\
\hline Notes & & & \\
\hline Methodological quality & Authors' judgement & Risk of bias & $\begin{array}{l}\text { Applicability con- } \\
\text { cerns }\end{array}$
\end{tabular}

\section{DOMAIN 1: Patient Selection}
Was a consecutive or random sample of patients en-
Unclear
rolled?

\begin{tabular}{llll}
\hline Was a case-control design avoided? & Yes & \\
\hline Did the study avoid inappropriate exclusions? & Unclear & Unclear & Unclear \\
\hline
\end{tabular}

\section{DOMAIN 2: Index Test Serology}

Were the index test results interpreted without knowl-

edge of the results of the reference standard?

Unclear

$$
\text { cof }
$$


Ferrara 1998 (Continued)

If a threshold was used, was it pre-specified?

Unclear

Unclear

High

DOMAIN 3: Reference Standard

Is the reference standards likely to correctly classify the No target condition?

Were the reference standard results interpreted without Unclear

knowledge of the results of the index tests?

High Low

\section{DOMAIN 4: Flow and Timing}

Was there an appropriate interval between index test Unclear and reference standard?

Did all patients receive the same reference standard? Yes

Were all patients included in the analysis? Unclear

Unclear

\section{Formichella 2013}

\section{Study characteristics}

Patient sampling

Type of study: unclear whether prospective or retrospective study

Consecutive or random sample: unclear sampling process

Patient characteristics and setting

Sample size: 500

Female: 263 (52.6\%)

Age: 50 years

Presentation:

1. Patients undergoing routine endoscopy

Exclusion:

1. Undergone $H$ pylori eradication therapy

2. Active immunosuppressive therapy

3. Suffering from malignant diseases

Setting: secondary care, Germany

Index tests

Index test 1a: serology

Further details:

Technical specifications: recomWell ELISA (Mikrogen)

Performed by: not stated

Criteria for positive diagnosis: not stated

Index test $1 \mathrm{~b}$ : serology

Further details:

Technical specifications: not stated

Performed by: not stated

Criteria for positive diagnosis: 2 or more antigens

Index test 1c: serology 
Formichella 2013 (Continued)

Further details:

Technical specifications: Immunoblot Helicobacter (Mikrogen)

Performed by: not stated

Criteria for positive diagnosis: not stated

Target condition and reference stan$\operatorname{dard}(\mathrm{s})$
Target condition: $H$ pylori infection

Reference standard: endoscopic biopsy with $\mathrm{H} \& \mathrm{E}$ stain, Warthin-Starry stain, and

Giemsa stain

Further details:

Technical specifications: not stated

Performed by: endoscopist and pathologist

Criteria for positive diagnosis: presence of $H$ pylori in biopsy

Number of indeterminates for whom the results of reference standard was available: not stated

Number of patients who were excluded from the analysis: not stated

\section{Comparative}

Notes

\section{Methodological quality}

\begin{tabular}{llll}
\hline Item & Authors' judgement & Risk of bias & Applicability concerns \\
\hline
\end{tabular}

DOMAIN 1: Patient Selection

Was a consecutive or random sample of Unclear
patients enrolled?
patients enrolled?

\begin{tabular}{llll}
\hline Was a case-control design avoided? & Yes & \\
\hline $\begin{array}{l}\text { Did the study avoid inappropriate exclu- } \\
\text { sions? }\end{array}$ & Unclear & Unclear & Unclear
\end{tabular}

\section{DOMAIN 2: Index Test Serology}

Were the index test results interpreted

Unclear without knowledge of the results of the reference standard?

If a threshold was used, was it pre-speci- Unclear fied?

\section{Unclear}

High

\section{DOMAIN 3: Reference Standard}

Is the reference standards likely to cor-

No

rectly classify the target condition?

Were the reference standard results inter- Unclear preted without knowledge of the results of the index tests? 
Formichella 2013 (Continued)

DOMAIN 4: Flow and Timing

Was there an appropriate interval be- Yes

tween index test and reference standard?

Did all patients receive the same refer- Yes

ence standard?

Were all patients included in the analysis? Unclear

\section{Unclear}

\section{Germana 2001}

\section{Study characteristics}

$\begin{array}{ll}\text { Patient sampling } & \text { Type of study: unclear whether prospective or retrospective study } \\ \text { Consecutive or random sample: unclear sampling process }\end{array}$

$\begin{array}{ll}\text { Patient characteristics and setting } & \text { Sample size: } 100 \\ & \text { Female: } 52(52 \%) \\ & \text { Age: } 51 \text { years } \\ \text { Presentation: } & \text { 1. Patients with dyspepsia } \\ \text { 2. Not on current treatment for H pylori } \\ \text { Setting: secondary care, Italy }\end{array}$

Index tests Index test: urea breath test- ${ }^{13} \mathrm{C}$

Further details:

Technical specifications: Wagner Analysen - Tecturik

Performed by: not stated

Criteria for positive diagnosis: delta over baseline $>4.0 \%$ (30 minutes)

Target condition and reference standard(s)

\section{Target condition: $H$ pylori infection}

Reference standard: endoscopic biopsy with H \& E stain and immunohistochemical stain

Further details:

Technical specifications: not stated

Performed by: endoscopist and pathologist

Criteria for positive diagnosis: presence of $H$ pylori in biopsy
Number of indeterminates for whom the results of reference standard was available: not stated

Number of patients who were excluded from the analysis: not stated

\section{Comparative}

\section{Notes}

\section{Methodological quality}

\begin{tabular}{llll}
\hline Item Authors' judgement & Risk of bias & $\begin{array}{l}\text { Applicability con- } \\
\text { cerns }\end{array}$
\end{tabular}

\section{DOMAIN 1: Patient Selection}


Germana 2001 (Continued)

Was a consecutive or random sample of patients en- Unclear rolled?

\begin{tabular}{ll}
\hline Was a case-control design avoided? & Yes \\
\hline Did the study avoid inappropriate exclusions? & Unclear
\end{tabular}

\begin{tabular}{llll}
\hline DOMAIN 2: Index Test Urea breath test-13C & Unclear & Unclear \\
\hline $\begin{array}{l}\text { Were the index test results interpreted without } \\
\text { knowledge of the results of the reference standard? }\end{array}$ & & \\
\hline If a threshold was used, was it pre-specified? & Unclear & Unclear & Low \\
\hline
\end{tabular}

\section{DOMAIN 3: Reference Standard}

Is the reference standards likely to correctly classify No the target condition?

Were the reference standard results interpreted Unclear without knowledge of the results of the index tests?

\begin{tabular}{lll}
\hline DOMAIN 4: Flow and Timing & High & \\
\hline $\begin{array}{l}\text { Was there an appropriate interval between index } \\
\text { test and reference standard? }\end{array}$ & Unclear & \\
\hline $\begin{array}{l}\text { Did all patients receive the same reference stan- } \\
\text { dard? }\end{array}$ & Yes Unclear & Unclear \\
\hline Were all patients included in the analysis? & & \\
\hline
\end{tabular}

Graham 1996a

\section{Study characteristics}

Patient sampling

Patient characteristics and setting
Type of study: retrospective study

Consecutive or random sample: unclear sampling process

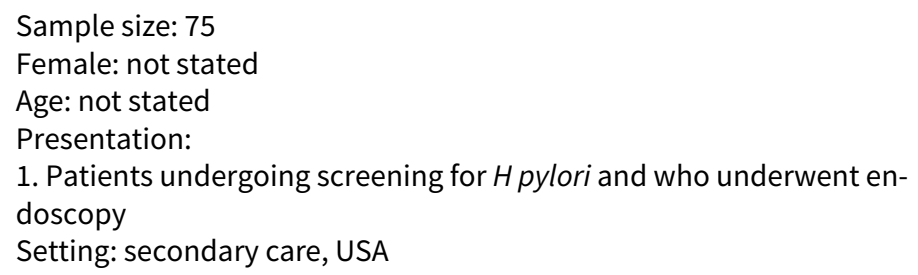


Graham 1996a (Continued)

$\begin{array}{ll}\text { Index tests } & \text { Index test: serology } \\ & \text { Further details: } \\ & \text { Technical specifications: FlexSure HP } \\ & \text { Performed by: not stated } \\ & \text { Criteria for positive diagnosis: pink line }\end{array}$

Target condition and reference standard(s)

Target condition: $H$ pylori infection

Reference standard: endoscopic biopsy (staining not reported, probably

$\mathrm{H} \& \mathrm{E})$

Further details:

Technical specifications: not stated

Performed by: endoscopist and pathologist

Criteria for positive diagnosis: presence of $H$ pylori in biopsy

Flow and timing

Number of indeterminates for whom the results of reference standard was available: not stated

Number of patients who were excluded from the analysis: $476(86.4 \%)$

\section{Comparative}

\section{Notes}

\section{Methodological quality}

\begin{tabular}{llll}
\hline Item Authors' judgement & Risk of bias $\begin{array}{l}\text { Applicability con- } \\
\text { cerns }\end{array}$
\end{tabular}

\section{DOMAIN 1: Patient Selection}

\begin{tabular}{lll}
\hline $\begin{array}{l}\text { Was a consecutive or random sample of patients en- } \\
\text { rolled? }\end{array}$ & Unclear \\
\hline Was a case-control design avoided? & Yes & Unclear \\
\hline Did the study avoid inappropriate exclusions? & & Unclear \\
\hline
\end{tabular}

\section{DOMAIN 2: Index Test Serology}

\section{Were the index test results interpreted without knowl- Unclear} edge of the results of the reference standard?

If a threshold was used, was it pre-specified? Yes

Unclear

Low

\section{DOMAIN 3: Reference Standard}

Is the reference standards likely to correctly classify the No target condition?

Were the reference standard results interpreted without Unclear knowledge of the results of the index tests? 
Graham 1996a (Continued)

\section{DOMAIN 4: Flow and Timing}

\section{Was there an appropriate interval between index test Unclear} and reference standard?

Did all patients receive the same reference standard? Yes

Were all patients included in the analysis? No

High

\section{Gramley 1999}

\section{Study characteristics}

\begin{tabular}{ll}
\hline Patient sampling & $\begin{array}{l}\text { Type of study: unclear whether prospective or retrospective study } \\
\text { Consecutive or random sample: consecutive patients }\end{array}$
\end{tabular}

Patient characteristics and setting

Sample size: 22

Female: not stated

Age: not stated

Presentation:

1. Patients undergoing endoscopy

Setting: secondary care, USA

$\begin{array}{ll}\text { Index tests } & \text { Index test: serology } \\ & \text { Further details: } \\ & \text { Technical specifications: not stated } \\ & \text { Performed by: not stated } \\ & \text { Criteria for positive diagnosis: not stated }\end{array}$

Target condition and reference standard(s)

Target condition: $H$ pylori infection

Reference standard: endoscopic biopsy (staining not reported, probably

$H \& E)$

Further details:

Technical specifications: not stated

Performed by: endoscopist and pathologist

Criteria for positive diagnosis: presence of $H$ pylori in biopsy

Flow and timing

Number of indeterminates for whom the results of reference standard was available: not stated

Number of patients who were excluded from the analysis: $0(0 \%)$

Comparative

Notes

Methodological quality

\begin{tabular}{llll}
\hline Item & Authors' judgement & Risk of bias & $\begin{array}{l}\text { Applicability con- } \\
\text { cerns }\end{array}$ \\
\hline
\end{tabular}

DOMAIN 1: Patient Selection 
Gramley 1999 (Continued)

Was a consecutive or random sample of patients en- Yes rolled?

\begin{tabular}{lc}
\hline Was a case-control design avoided? & Yes \\
\hline Did the study avoid inappropriate exclusions? & Yes \\
\hline
\end{tabular}

Low

Low

\section{DOMAIN 2: Index Test Serology}

Were the index test results interpreted without knowl- Unclear edge of the results of the reference standard?

\begin{tabular}{llll}
\hline If a threshold was used, was it pre-specified? & Unclear & & High \\
\hline
\end{tabular}

\section{DOMAIN 3: Reference Standard}

Is the reference standards likely to correctly classify the No target condition?

Were the reference standard results interpreted without Unclear knowledge of the results of the index tests?

High Low

\section{DOMAIN 4: Flow and Timing}

\begin{tabular}{l}
$\begin{array}{l}\text { Was there an appropriate interval between index test } \\
\text { and reference standard? }\end{array}$ \\
\begin{tabular}{ll} 
Did all patients receive the same reference standard? & Yes \\
\hline Were all patients included in the analysis? & Yes
\end{tabular} \\
\hline
\end{tabular}

Unclear

\section{Guo 2011}

\section{Study characteristics}

\begin{tabular}{ll}
\hline Patient sampling & $\begin{array}{l}\text { Type of study: unclear whether prospective or retrospective study } \\
\text { Consecutive or random sample: unclear sampling process }\end{array}$ \\
\hline Patient characteristics and setting & Sample size: 328 \\
& Female: $90(27.4 \%)$ \\
& Age: 47 years \\
& Presentation: \\
& 1. Patients with gastrointestinal symptoms \\
& 2. No previous treatment or stopped treatment for $H$ pylori \\
& Setting: secondary care, China \\
\hline Index tests & Index test: stool antigen test
\end{tabular}


Guo 2011 (Continued)

Further details:

Technical specifications: Kyowa pharmaceutical

Performed by: not stated

Criteria for positive diagnosis: not stated

Target condition and reference standard(s)

Target condition: $H$ pylori infection

Reference standard: endoscopic biopsy with silver stain

Further details:

Technical specifications: not stated

Performed by: endoscopist and pathologist

Criteria for positive diagnosis: presence of $H$ pylori in biopsy

Flow and timing

Number of indeterminates for whom the results of reference standard was available: not stated

Number of patients who were excluded from the analysis: not stated

\section{Comparative}

\section{Notes}

\section{Methodological quality}

\begin{tabular}{llcl}
\hline Item & Authors' judgement & Risk of bias & $\begin{array}{l}\text { Applicability con- } \\
\text { cerns }\end{array}$ \\
\hline
\end{tabular}

\section{DOMAIN 1: Patient Selection}

Was a consecutive or random sample of patients en- Unclear rolled?

\begin{tabular}{llll}
\hline Was a case-control design avoided? & Yes & \\
\hline Did the study avoid inappropriate exclusions? & Unclear & Unclear & Unclear \\
\hline
\end{tabular}

\section{DOMAIN 2: Index Test Stool Antigen Test}

\section{Were the index test results interpreted without Unclear}

knowledge of the results of the reference standard?

\begin{tabular}{llll}
\hline If a threshold was used, was it pre-specified? & Unclear & & High \\
\hline
\end{tabular}

\section{DOMAIN 3: Reference Standard}

Is the reference standards likely to correctly classify Yes the target condition?

Were the reference standard results interpreted without knowledge of the results of the index tests?

Unclear

Unclear Low

\section{DOMAIN 4: Flow and Timing}


Guo 2011 (Continued)

Was there an appropriate interval between index Unclear test and reference standard?

Did all patients receive the same reference stan- $\quad$ Yes dard?

\section{Gurbuz 2005}

\section{Study characteristics}

$\begin{array}{ll}\text { Patient sampling } & \begin{array}{l}\text { Type of study: unclear whether prospective or retrospective study } \\ \text { Consecutive or random sample: neither - patients with previous gastric } \\ \text { surgery excluded }\end{array}\end{array}$

$\begin{array}{ll}\text { Patient characteristics and setting } & \text { Sample size: } 65 \\ & \text { Female: } 45(69.2 \%) \\ & \text { Age: not stated } \\ & \text { Presentation: } \\ & \text { 1. Patients undergoing routine endoscopy } \\ & \text { Exclusion: } \\ & \text { 1. Undergone } H \text { pylori eradication therapy } \\ \text { 2. Pregnancy or lactation } & \text { 3. Prior gastric surgery } \\ \text { Setting: secondary care, Turkey }\end{array}$

Index tests

Index test: urea breath test-14C

Further details:

Technical specifications: Heliprobe system

Performed by: not stated

Criteria for positive diagnosis: Counts per minute $>50$ (10 minutes)

\section{Target condition and reference standard(s)}

\author{
Target condition: $H$ pylori infection \\ Reference standard: endoscopic biopsy with H \& E stain \\ Further details: \\ Technical specifications: not stated \\ Performed by: endoscopist and pathologist \\ Criteria for positive diagnosis: presence of $H$ pylori in biopsy
}

Flow and timing

Number of indeterminates for whom the results of reference standard was available: not stated

Number of patients who were excluded from the analysis: 3 (4.4\%)

\section{Comparative}

\section{Notes}

\section{Methodological quality}

\begin{tabular}{llll}
\hline Item & Authors' judgement & Risk of bias & Applicability concerns \\
\hline
\end{tabular}

DOMAIN 1: Patient Selection 
Gurbuz 2005 (Continued)

Was a consecutive or random sample of patients No
enrolled?

Was a case-control design avoided? Yes

\begin{tabular}{ll} 
Was a case-control design avoided? & Yes \\
\hline Did the study avoid inappropriate exclusions? & Unclear
\end{tabular}

High Unclear

\title{
DOMAIN 2: Index Test Urea breath test-14C
}

\begin{abstract}
Were the index test results interpreted without Unclear
knowledge of the results of the reference standard?
\end{abstract}

\begin{tabular}{llll}
\hline If a threshold was used, was it pre-specified? & Unclear & & Low Unclear \\
\hline
\end{tabular}

\section{DOMAIN 3: Reference Standard}

Is the reference standards likely to correctly classi- No

fy the target condition?

Were the reference standard results interpreted Unclear

without knowledge of the results of the index tests?

\begin{tabular}{llll}
\hline DOMAIN 4: Flow and Timing & High & Low \\
\hline $\begin{array}{l}\text { Was there an appropriate interval between index } \\
\text { test and reference standard? }\end{array}$ & Yes & \\
\hline $\begin{array}{l}\text { Did all patients receive the same reference stan- } \\
\text { dard? }\end{array}$ & Yes & High \\
\hline Were all patients included in the analysis? & & No \\
\hline
\end{tabular}

Hafeez 2007

\section{Study characteristics}

Patient sampling

Type of study: unclear whether prospective or retrospective study

Consecutive or random sample: neither - patients with inadequate breath samples excluded

Patient characteristics and setting

Sample size: 60

Female: not stated

Age: not stated

Presentation:

1. Children with gastrointestinal symptoms

Setting: secondary care, Pakistan 
Hafeez 2007 (Continued)

Index tests
Index test 1: urea breath test-13C

Further details:

Technical specifications: not stated

Performed by: not stated

Criteria for positive diagnosis: delta over baseline $>4.0 \%$ (10 minutes, 20 minutes, and 30 minutes)

Index test 2: stool antigen test

Further details:

Technical specifications: not stated

Performed by: not stated

Criteria for positive diagnosis: not stated

\section{Target condition and reference standard(s)}

\section{Target condition: $H$ pylori infection} Reference standard: endoscopic biopsy with Giemsa stain

Further details:

Technical specifications: not stated

Performed by: endoscopist and pathologist

Criteria for positive diagnosis: presence of $H$ pylori in biopsy

Flow and timing

Number of indeterminates for whom the results of reference standard was available: not stated

Number of patients who were excluded from the analysis: 6 (10\%)

\section{Comparative}

$$
\text { Notes }
$$

\section{Methodological quality}

\begin{tabular}{llll}
\hline Item & Authors' judgement & Risk of bias & $\begin{array}{l}\text { Applicability con- } \\
\text { cerns }\end{array}$ \\
\hline
\end{tabular}

\section{DOMAIN 1: Patient Selection}

Was a consecutive or random sample of patients en- No

rolled?

\begin{tabular}{ll}
\hline Was a case-control design avoided? & Yes \\
\hline
\end{tabular}

Did the study avoid inappropriate exclusions? Unclear

High

Unclear

\section{DOMAIN 2: Index Test Urea breath test-13C}

Were the index test results interpreted without knowl- Unclear

edge of the results of the reference standard?

\begin{tabular}{lll}
\hline If a threshold was used, was it pre-specified? & Unclear & \\
\hline & Unclear & Low \\
\hline
\end{tabular}

\section{DOMAIN 2: Index Test Stool Antigen Test}

Were the index test results interpreted without knowl- Unclear edge of the results of the reference standard? 
Hafeez 2007 (Continued)

\begin{tabular}{lll}
\hline Unclear & High \\
\hline
\end{tabular}

DOMAIN 3: Reference Standard

Is the reference standards likely to correctly classify Yes the target condition?

Were the reference standard results interpreted with- Unclear out knowledge of the results of the index tests?

Unclear

Low

\title{
DOMAIN 4: Flow and Timing
}

Was there an appropriate interval between index test Yes and reference standard?

\begin{tabular}{ll}
\hline Did all patients receive the same reference standard? & Yes \\
\hline Were all patients included in the analysis? & No
\end{tabular}

High

Han 2012

\section{Study characteristics}

Patient sampling

Patient characteristics and setting
Type of study: unclear whether prospective or retrospective study

Consecutive or random sample: unclear sampling process
Target condition and reference standard(s)

\author{
Sample size: 99 \\ Female: not stated \\ Age: not stated \\ Presentation: \\ 1. Patients who had undergone urea breath tests and endoscopy \\ Setting: secondary care, South Korea
}

Index test: urea breath test - unknown isotope

Further details:

Technical specifications: not stated

Performed by: not stated

Criteria for positive diagnosis: not stated

\begin{abstract}
Targetcondition and reference standard(s)
\end{abstract}
Target condition: $H$ pylori infection

Reference standard: endoscopic biopsy with Giemsa stain

Further details:

Technical specifications: not stated

Performed by: endoscopist and pathologist

Criteria for positive diagnosis: presence of $H$ pylori in biopsy

Flow and timing

Number of indeterminates for whom the results of reference standard was available: not stated

Number of patients who were excluded from the analysis: not stated 
Han 2012 (Continued)

Comparative

$$
\text { Notes }
$$

\section{Methodological quality}

\begin{tabular}{llcl}
\hline Item Authors' judgement & Risk of bias & $\begin{array}{l}\text { Applicability con- } \\
\text { cerns }\end{array}$ \\
\hline
\end{tabular}

\section{DOMAIN 1: Patient Selection}

Was a consecutive or random sample of patients en- Unclear rolled?

\begin{tabular}{lll}
\hline Was a case-control design avoided? & Yes \\
\hline Did the study avoid inappropriate exclusions? & Unclear & Unclear \\
\hline
\end{tabular}

\section{DOMAIN 2: Index Test Urea breath test - unknown isotope}

Were the index test results interpreted without knowl- Unclear edge of the results of the reference standard?

\begin{tabular}{llll}
\hline If a threshold was used, was it pre-specified? & Unclear & & High \\
\hline DOMAIN 3: Reference Standard & Unclear & \\
\hline
\end{tabular}
Is the reference standards likely to correctly classify Yes
the target condition?

Were the reference standard results interpreted with- Unclear out knowledge of the results of the index tests?

\begin{tabular}{ll}
\hline DOMAIN 4: Flow and Timing & Unclear \\
\hline $\begin{array}{l}\text { Was there an appropriate interval between index test } \\
\text { and reference standard? }\end{array}$ \\
\hline Did all patients receive the same reference standard? & Yes \\
\hline Were all patients included in the analysis? & Unclear \\
\hline
\end{tabular}

\section{Unclear}

\section{Inelmen 2004}

\section{Study characteristics}


Inelmen 2004 (Continued)

Consecutive or random sample: consecutive patients

$\begin{array}{ll}\text { Patient characteristics and setting } & \text { Sample size: } 122 \\ & \text { Female: } 81(66.4 \%) \\ & \text { Age: } 80 \text { years } \\ & \text { Presentation: } \\ & \text { 1. Patients undergoing upper gastrointestinal endoscopy } \\ & \text { Setting: secondary care, Italy }\end{array}$

Index tests

Index test 1: urea breath test- $13 \mathrm{C}$

Further details:

Technical specifications: BreathQuality-UBT 13C-Urea Kit, Zeta Farmaceutici

SpA

Performed by: not stated

Criteria for positive diagnosis: delta over baseline $>5.0 \%$ (30 minutes)

Index test 2: stool antigen test

Further details:

Technical specifications: Premier Platinum HpSA (Meridian Diagnostics)

Performed by: not stated

Criteria for positive diagnosis: definite yellow colour

$\begin{array}{ll}\text { Target condition and reference standard(s) } & \text { Target condition: } H \text { pylori infection } \\ & \text { Reference standard: endoscopic biopsy with H \& E stain and Giemsa stain } \\ & \text { Further details: } \\ & \text { Technical specifications: not stated } \\ & \text { Performed by: endoscopist and pathologist } \\ & \text { Criteria for positive diagnosis: presence of } H \text { pylori in biopsy }\end{array}$

Flow and timing

Number of indeterminates for whom the results of reference standard was available: not stated

Number of patients who were excluded from the analysis: 0 (0\%)

Comparative

\title{
Notes
}

\section{Methodological quality}

\begin{tabular}{llll}
\hline Item Authors' judgement & Risk of bias & $\begin{array}{l}\text { Applicability con- } \\
\text { cerns }\end{array}$
\end{tabular}

\section{DOMAIN 1: Patient Selection}

\begin{abstract}
Was a consecutive or random sample of patients en- Yes
\end{abstract} rolled?

\begin{tabular}{llll}
\hline Was a case-control design avoided? & Yes & \\
\hline Did the study avoid inappropriate exclusions? & Yes & Low & Low \\
\hline
\end{tabular}

DOMAIN 2: Index Test Urea breath test-13C

\footnotetext{
Were the index test results interpreted without Unclear

knowledge of the results of the reference standard?
} 
Inelmen 2004 (Continued)

If a threshold was used, was it pre-specified? Unclear

Unclear

Low

\section{DOMAIN 2: Index Test Stool Antigen Test}

Were the index test results interpreted without Unclear
knowledge of the results of the reference standard?

knowledge of the results of the reference standard?

If a threshold was used, was it pre-specified? Unclear

\begin{tabular}{llll}
\hline DOMAIN 3: Reference Standard & Unclear & Low \\
\hline $\begin{array}{l}\text { Is the reference standards likely to correctly classify } \\
\text { the target condition? }\end{array}$ & No & \\
\hline $\begin{array}{l}\text { Were the reference standard results interpreted } \\
\text { without knowledge of the results of the index tests? }\end{array}$ & Unclear & High \\
\hline
\end{tabular}

\section{DOMAIN 4: Flow and Timing}

Was there an appropriate interval between index Unclear
test and reference standard?

Did all patients receive the same reference stan- Yes
dard?

Were all patients included in the analysis?

Yes

\section{Unclear}

\section{Iqbal 2013}

\section{Study characteristics}

\begin{tabular}{ll}
\hline Patient sampling & $\begin{array}{l}\text { Type of study: retrospective study } \\
\text { Consecutive or random sample: unclear sampling process }\end{array}$ \\
\hline Patient characteristics and setting & Sample size: 50 \\
& Female: $19(38 \%)$ \\
& Age: 41 years \\
& Presentation: \\
& 1. Patients who underwent upper gastrointestinal endoscopy \\
& Setting: secondary care, Pakistan \\
\hline \multirow{2}{*}{ Index tests } & Index test: serology \\
& Further details: \\
& Technical specifications: HpG screen ELISA kit \\
Performed by: not stated & Criteria for positive diagnosis: $>7$ units/ml
\end{tabular}




\section{Iqbal 2013 (Continued)}

Target condition and reference standard(s)
Target condition: $H$ pylori infection

Reference standard: endoscopic biopsy (staining not reported, probably

$H \& E)$

Further details:

Technical specifications: not stated

Performed by: endoscopist and pathologist

Criteria for positive diagnosis: presence of $H$ pylori in biopsy

\section{Flow and timing}

Number of indeterminates for whom the results of reference standard was available: not stated

Number of patients who were excluded from the analysis: not stated

\section{Comparative}

\section{Notes}

\section{Methodological quality}

\begin{tabular}{llll}
\hline Item Authors' judgement & Risk of bias & $\begin{array}{l}\text { Applicability con- } \\
\text { cerns }\end{array}$
\end{tabular}

\section{DOMAIN 1: Patient Selection}

\section{Was a consecutive or random sample of patients en- Unclear rolled?}

\begin{tabular}{lll}
\hline Was a case-control design avoided? & Yes & \\
\hline Did the study avoid inappropriate exclusions? & Unclear & Unclear \\
\hline
\end{tabular}

\section{DOMAIN 2: Index Test Serology}

\section{Were the index test results interpreted without knowl- Unclear}

edge of the results of the reference standard?

\begin{tabular}{llll}
\hline If a threshold was used, was it pre-specified? & Yes & Low Unclear & Low \\
\hline
\end{tabular}

\section{DOMAIN 3: Reference Standard}

Is the reference standards likely to correctly classify the No target condition?

Were the reference standard results interpreted without Unclear knowledge of the results of the index tests?

\section{High}

Low

\section{DOMAIN 4: Flow and Timing}

\section{Was there an appropriate interval between index test Unclear and reference standard?}

\section{Did all patients receive the same reference standard? Yes}


Iqbal 2013 (Continued)

\section{Study characteristics}

\begin{tabular}{ll}
\hline Patient sampling & $\begin{array}{l}\text { Type of study: prospective study } \\
\text { Consecutive or random sample: neither - patients without stool samples } \\
\text { excluded }\end{array}$
\end{tabular}
excluded

\begin{tabular}{ll}
\hline Patient characteristics and setting & Sample size: 112 \\
& Female: not stated \\
Age: not stated & Presentation: \\
& 1. Patients undergoing upper gastrointestinal endoscopy \\
& Setting: secondary care, New Zealand \\
\hline Index tests & Index test: stool antigen test \\
& Further details: \\
& Technical specifications: Premier Platinum HpSA (Meridian Diagnostics) \\
& Performed by: pathologists \\
& Criteria for positive diagnosis: Absorbance $450 / 630 \mathrm{~nm}>0.120$
\end{tabular}

\footnotetext{
Target condition and reference standard(s)
}

\section{Target condition: H pylori infection}

Reference standard: endoscopic biopsy with H \& E stain and Immunoperox-

idase stain

Further details:

Technical specifications: not stated

Performed by: endoscopist and pathologist

Criteria for positive diagnosis: presence of $H$ pylori in biopsy

\section{Flow and timing}

Number of indeterminates for whom the results of reference standard was available: not stated

Number of patients who were excluded from the analysis: $15(11.8 \%)$

\section{Comparative}

\section{Notes}

\section{Methodological quality}

\begin{tabular}{llll}
\hline Item Authors' judgement & Risk of bias & $\begin{array}{l}\text { Applicability con- } \\
\text { cerns }\end{array}$
\end{tabular}

\section{DOMAIN 1: Patient Selection}

Was a consecutive or random sample of patients en- No rolled?

\begin{tabular}{ll}
\hline Was a case-control design avoided? & Yes \\
\hline Did the study avoid inappropriate exclusions? & Unclear \\
\hline
\end{tabular}


Islam 2005 (Continued)

High

Unclear

\section{DOMAIN 2: Index Test Stool Antigen Test}

Were the index test results interpreted without knowl- Yes

edge of the results of the reference standard?

If a threshold was used, was it pre-specified? Yes

\begin{tabular}{lll}
\hline Low & Low \\
\hline
\end{tabular}

DOMAIN 3: Reference Standard

Is the reference standards likely to correctly classify No

the target condition?

Were the reference standard results interpreted with- Yes out knowledge of the results of the index tests?

\begin{tabular}{lll}
\hline & High & Low \\
\hline DOMAIN 4: Flow and Timing & \\
\hline $\begin{array}{l}\text { Was there an appropriate interval between index test } \\
\text { and reference standard? }\end{array}$ & \\
\hline Did all patients receive the same reference standard? & Yes \\
\hline Were all patients included in the analysis? & No \\
\hline
\end{tabular}

High

Ivanova 2010

\section{Study characteristics}

\begin{tabular}{ll}
\hline Patient sampling & $\begin{array}{l}\text { Type of study: unclear whether prospective or retrospective study } \\
\text { Consecutive or random sample: unclear sampling process }\end{array}$ \\
\hline Patient characteristics and setting & Sample size: 33 \\
& Female: $16(48.5 \%)$ \\
& Age: 42 years \\
Presentation: & 1. Patients undergoing upper gastrointestinal endoscopy \\
& Setting: secondary care, Bulgaria \\
\hline Index tests & Index test: serology \\
& Further details: \\
& Technical specifications: Rapid HP, US Meds \\
& Performed by: not stated \\
Criteria for positive diagnosis: not stated \\
\hline Target condition and reference standard(s) & Target condition: $H$ pylori infection \\
& Reference standard: endoscopic biopsy with Giemsa stain \\
& Further details:
\end{tabular}


Ivanova 2010 (Continued)

Technical specifications: not stated

Performed by: endoscopist and pathologist

Criteria for positive diagnosis: presence of $\mathrm{H}$ pylori in biopsy

Flow and timing

Number of indeterminates for whom the results of reference standard was available: not stated

Number of patients who were excluded from the analysis: not stated

\section{Comparative}

Notes

\section{Methodological quality}

\begin{tabular}{llll}
\hline Item & Authors' judgement & Risk of bias & $\begin{array}{l}\text { Applicability con- } \\
\text { cerns }\end{array}$
\end{tabular}

\section{DOMAIN 1: Patient Selection}

Was a consecutive or random sample of patients en- Unclear rolled?

\begin{tabular}{lll}
\hline Was a case-control design avoided? & Yes \\
\hline Did the study avoid inappropriate exclusions? & Unclear & Unclear
\end{tabular}

\section{DOMAIN 2: Index Test Serology}

Were the index test results interpreted without knowl- Unclear edge of the results of the reference standard?

If a threshold was used, was it pre-specified? Unclear

\section{DOMAIN 3: Reference Standard}

Is the reference standards likely to correctly classify the Yes target condition?

Were the reference standard results interpreted without Unclear knowledge of the results of the index tests?

\section{DOMAIN 4: Flow and Timing}

Was there an appropriate interval between index test Unclear
and reference standard?

\begin{tabular}{ll}
\hline Did all patients receive the same reference standard? & Yes \\
\hline Were all patients included in the analysis? & Unclear
\end{tabular}

\begin{tabular}{ll}
\hline Unclear \\
\hline Non-invasive diagnostic tests for Helicobacter pylori infection (Review) \\
Copyright @ 2018 The Cochrane Collaboration. Published by John Wiley \& Sons, Ltd.
\end{tabular}




\section{Study characteristics}

$\begin{array}{ll}\text { Patient sampling } & \text { Type of study: unclear whether prospective or retrospective study } \\ \text { Consecutive or random sample: neither - patients with a recent antibiotic treat- } \\ \text { ment were excluded }\end{array}$

\begin{tabular}{|c|c|}
\hline Patient characteristics and setting & $\begin{array}{l}\text { Sample size: } 209 \\
\text { Female: } 85(40.7 \%) \\
\text { Age: not stated } \\
\text { Presentation: } \\
\text { 1. Patients undergoing routine health check-up and upper gastrointestinal en- } \\
\text { doscopy } \\
\text { Exclusion: } \\
\text { 1. Recent ulcer or } H \text { pylori treatment } \\
\text { 2. Previous gastric surgery } \\
\text { 3. Previous gastric cancer } \\
\text { Setting: secondary care, Korea }\end{array}$ \\
\hline Index tests & $\begin{array}{l}\text { Index test: stool antigen test } \\
\text { Further details: } \\
\text { Technical specifications: not stated } \\
\text { Performed by: not stated } \\
\text { Criteria for positive diagnosis: Absence of yellow }\end{array}$ \\
\hline Target condition and reference standard(s) & $\begin{array}{l}\text { Target condition: } H \text { pylori infection } \\
\text { Reference standard: endoscopic biopsy with H \& E stain and Warthin-Starry } \\
\text { stain } \\
\text { Further details: } \\
\text { Technical specifications: not stated } \\
\text { Performed by: endoscopist and pathologist } \\
\text { Criteria for positive diagnosis: presence of } H \text { pylori in biopsy }\end{array}$ \\
\hline
\end{tabular}

Flow and timing

Number of indeterminates for whom the results of reference standard was available: not stated

Number of patients who were excluded from the analysis: 57 (21.4\%)

\section{Comparative}

\section{Notes}

\section{Methodological quality}

\begin{tabular}{llll}
\hline Item & Authors' judgement & Risk of bias & Applicability concerns \\
\hline DOMAIN 1: Patient Selection & & \\
\hline $\begin{array}{l}\text { Was a consecutive or random sample of patients } \\
\text { enrolled? }\end{array}$ & No & \\
\hline Was a case-control design avoided? & Yes & Unclear \\
\hline Did the study avoid inappropriate exclusions? & Unclear & High \\
\hline
\end{tabular}

\section{DOMAIN 2: Index Test Stool Antigen Test}


Jekarl 2013 (Continued)

Were the index test results interpreted without knowledge of the results of the reference standard?

\begin{tabular}{llll}
\hline If a threshold was used, was it pre-specified? & Yes & Low Unclear & Unclear \\
\hline
\end{tabular}

\section{DOMAIN 3: Reference Standard}

Is the reference standards likely to correctly clas- No sify the target condition?

\section{Were the reference standard results interpret- Unclear} ed without knowledge of the results of the index tests?

\begin{tabular}{llll}
\hline DOMAIN 4: Flow and Timing & High & Low \\
\hline $\begin{array}{l}\text { Was there an appropriate interval between index } \\
\text { test and reference standard? }\end{array}$ & Unclear & \\
\hline $\begin{array}{l}\text { Did all patients receive the same reference stan- } \\
\text { dard? }\end{array}$ & Yes & No & High \\
\hline Were all patients included in the analysis? & &
\end{tabular}

\section{Jensen 1998}

\section{Study characteristics}

Patient sampling

Patient characteristics and setting
Type of study: unclear whether prospective or retrospective study

Consecutive or random sample: unclear

\begin{tabular}{ll}
\hline Index tests & Index test: urea breath test-14C \\
& Further details: \\
& Technical specifications: not stated \\
& Performed by: not stated \\
Criteria for positive diagnosis: disintegrations per minute $>$ 200 (10 min- & utes) \\
\hline Target condition and reference standard(s) & Target condition: $H$ pylori infection \\
& Reference standard: endoscopic biopsy with $\mathrm{H} \& \mathrm{E}$ stain and Giemsa stain
\end{tabular}


Jensen 1998 (Continued)

Further details:

Technical specifications: not stated

Performed by: endoscopist and pathologist

Criteria for positive diagnosis: presence of $H$ pylori in biopsy

Flow and timing

Number of indeterminates for whom the results of reference standard was available: not stated

Number of patients who were excluded from the analysis: 7 (16.7\%)

\section{Comparative}

Notes

\section{Methodological quality}

\begin{tabular}{llll}
\hline Item Authors' judgement & Risk of bias & $\begin{array}{l}\text { Applicability con- } \\
\text { cerns }\end{array}$
\end{tabular}

\section{DOMAIN 1: Patient Selection}

Was a consecutive or random sample of patients en- Unclear
rolled?

\begin{tabular}{llll}
\hline Was a case-control design avoided? & Yes & \\
\hline Did the study avoid inappropriate exclusions? & Unclear & Unclear \\
\hline
\end{tabular}

\section{DOMAIN 2: Index Test Urea breath test-14C}

Were the index test results interpreted without knowl- Unclear edge of the results of the reference standard?

\begin{tabular}{llll}
\hline If a threshold was used, was it pre-specified? & Unclear & \\
\hline & Unclear & Low \\
\hline
\end{tabular}

\section{DOMAIN 3: Reference Standard}

Is the reference standards likely to correctly classify No the target condition?

Were the reference standard results interpreted with- Yes out knowledge of the results of the index tests?

High Low

\section{DOMAIN 4: Flow and Timing}

Was there an appropriate interval between index test Unclear
and reference standard?

Did all patients receive the same reference standard? Yes

Were all patients included in the analysis?

No 
Jordaan 2008

\section{Study characteristics}

\begin{tabular}{ll}
\hline Patient sampling & Type of study: unclear whether prospective or retrospective study \\
Consecutive or random sample: neither - patients with previous gastrointesti- \\
nal surgery excluded
\end{tabular}

\begin{tabular}{ll}
\hline Patient characteristics and setting & Sample size: 103 \\
& Female: not stated \\
Age: not stated & Presentation: \\
1. Patients with dyspepsia \\
Exclusion criteria: \\
1. Recent $H$ pylori therapy \\
2. Major gastrointestinal surgery \\
Setting: secondary care, South Africa
\end{tabular}

Index tests Index test: urea breath test- ${ }^{13} \mathrm{C}$

Further details:

Technical specifications: not stated

Performed by: not stated

Criteria for positive diagnosis: delta over baseline $>4.5 \%$ (time not stated)

\begin{tabular}{ll}
\hline Target condition and reference standard(s) & Target condition: $H$ pylori infection \\
& Reference standard: endoscopic biopsy (staining not reported, probably $\mathrm{H} \&$ \\
& E) \\
& Further details: \\
& Technical specifications: not stated \\
& Performed by: endoscopist and pathologist \\
Criteria for positive diagnosis: presence of $H$ pylori in biopsy
\end{tabular}

Flow and timing

Number of indeterminates for whom the results of reference standard was available: not stated

Number of patients who were excluded from the analysis: 8 (7.2\%)

Comparative

Notes

Methodological quality

\begin{tabular}{|c|c|c|c|}
\hline Item & Authors' judgement & Risk of bias & Applicability concerns \\
\hline \multicolumn{4}{|l|}{ DOMAIN 1: Patient Selection } \\
\hline $\begin{array}{l}\text { Was a consecutive or random sample of patients } \\
\text { enrolled? }\end{array}$ & No & & \\
\hline Was a case-control design avoided? & Yes & & \\
\hline Did the study avoid inappropriate exclusions? & Unclear & & \\
\hline
\end{tabular}


Jordaan 2008 (Continued)

High

Unclear

\section{DOMAIN 2: Index Test Urea breath test-13C}

Were the index test results interpreted without

Unclear

knowledge of the results of the reference standard?

\begin{tabular}{llll}
\hline If a threshold was used, was it pre-specified? & Unclear & \\
\hline & Unclear & Low
\end{tabular}

\section{DOMAIN 3: Reference Standard}

Is the reference standards likely to correctly classi- No

fy the target condition?

Were the reference standard results interpreted Unclear

without knowledge of the results of the index tests?

\begin{tabular}{lll}
\hline Low High & Low \\
\hline DOMAIN 4: Flow and Timing &
\end{tabular}

Was there an appropriate interval between index Unclear test and reference standard?

Did all patients receive the same reference stan- $\quad$ Yes dard?

Were all patients included in the analysis?

No

High

Kalach 1998a

\section{Study characteristics}

Patient sampling

Type of study: prospective study

Consecutive or random sample: unclear sampling process

Patient characteristics and setting

Sample size: 100

Female: 35 (35\%)

Age: 11 years

Presentation:

1. Children undergoing upper gastrointestinal endoscopy for recurrent epi-

gastric pain or upper GI tract disorders

Exclusion:

1. Recent $H$ pylori treatment

Setting: secondary care, France

Index tests

Index test: serology

Further details:

Technical specifications: not stated

Performed by: not stated

Criteria for positive diagnosis: $>6 \mathrm{IU} / \mathrm{ml}$ 


\section{Kalach 1998a (Continued)}

Target condition and reference standard(s)
Target condition: H pylori infection

Reference standard: endoscopic biopsy with H \& E stain

Further details:

Technical specifications: not stated

Performed by: endoscopist and pathologist

Criteria for positive diagnosis: presence of $H$ pylori in biopsy

Number of indeterminates for whom the results of reference standard was available: not stated

Number of patients who were excluded from the analysis: not stated

Comparative

Notes

\section{Methodological quality}

\begin{tabular}{llll}
\hline Item Authors' judgement & Risk of bias & $\begin{array}{l}\text { Applicability con- } \\
\text { cerns }\end{array}$
\end{tabular}

\section{DOMAIN 1: Patient Selection}

Was a consecutive or random sample of patients en- Unclear rolled?

\begin{tabular}{llll}
\hline Was a case-control design avoided? & Yes & Unclear \\
\hline Did the study avoid inappropriate exclusions? & Unclear & Unclear & \\
\hline DOMAIN 2: Index Test Serology & & Unclear & Low \\
\hline $\begin{array}{l}\text { Were the index test results interpreted without } \\
\text { knowledge of the results of the reference standard? }\end{array}$ & Unclear & Unclear \\
\hline If a threshold was used, was it pre-specified? & & \\
\hline
\end{tabular}

\section{DOMAIN 3: Reference Standard}

Is the reference standards likely to correctly classify No the target condition?

Were the reference standard results interpreted Yes without knowledge of the results of the index tests?

High Low

\section{DOMAIN 4: Flow and Timing}

Was there an appropriate interval between index Unclear
test and reference standard?

Did all patients receive the same reference stan- $\quad$ Yes dard? 
Kalach 1998a (Continued)

Were all patients included in the analysis? Unclear

Unclear

\section{Kamel 2011}

\section{Study characteristics}

$\begin{array}{ll}\text { Patient sampling } & \begin{array}{l}\text { Type of study: unclear whether prospective or retrospective study } \\ \text { Consecutive or random sample: unclear sampling process }\end{array}\end{array}$

\begin{tabular}{ll}
\hline Patient characteristics and setting & Sample size: 55 \\
& Female: not stated \\
& Age: 67 years \\
Presentation: & 1. Older adults with dyspepsia and no gastrointestinal bleeding \\
& Setting: secondary care, Egypt
\end{tabular}

Index tests

Index test: stool antigen test

Further details:

Technical specifications: CerTest $H$ pylori Card

Performed by: not stated

Criteria for positive diagnosis: not stated

\section{Target condition and reference standard(s)}

\section{Target condition: $H$ pylori infection}

Reference standard: endoscopic biopsy with $\mathrm{H}$ \& E stain

Further details:

Technical specifications: not stated

Performed by: endoscopist and pathologist

Criteria for positive diagnosis: presence of $H$ pylori in biopsy

\section{Flow and timing}

Number of indeterminates for whom the results of reference standard was available: not stated

Number of patients who were excluded from the analysis: not stated

\section{Comparative}

\section{Notes}

\section{Methodological quality}

$\begin{array}{llll}\text { Item } & \text { Authors' judgement } & \text { Risk of bias } & \begin{array}{l}\text { Applicability con- } \\ \text { cerns }\end{array}\end{array}$

\section{DOMAIN 1: Patient Selection}

\section{Was a consecutive or random sample of patients en- Unclear} rolled?

\begin{tabular}{llll}
\hline Was a case-control design avoided? & Yes & \\
\hline Did the study avoid inappropriate exclusions? & Unclear & Unclear & Unclear \\
\hline
\end{tabular}


Kamel 2011 (Continued)

\section{DOMAIN 2: Index Test Stool Antigen Test}

\section{Were the index test results interpreted without knowl- Unclear} edge of the results of the reference standard?

If a threshold was used, was it pre-specified? Yes

Unclear

High

\section{DOMAIN 3: Reference Standard}

Is the reference standards likely to correctly classify the No target condition?

\section{Were the reference standard results interpreted without Unclear}

knowledge of the results of the index tests?

High Low

\section{DOMAIN 4: Flow and Timing}

Was there an appropriate interval between index test Unclear
and reference standard?

\begin{tabular}{lll}
\hline Did all patients receive the same reference standard? & Yes \\
\hline Were all patients included in the analysis? & Unclear & Unclear \\
\hline
\end{tabular}

\section{Kim 2016}

\section{Study characteristics}

\begin{tabular}{ll}
\hline Patient sampling & $\begin{array}{l}\text { Type of study: unclear whether prospective or retrospective study } \\
\text { Consecutive or random sample: unclear sampling process }\end{array}$ \\
\hline Patient characteristics and setting & Sample size: 107 \\
& Female: $56(52.3 \%)$ \\
& Age: 41 years \\
& Presentation: \\
& 1. Patients undergoing upper gastrointestinal endoscopy \\
& Exclusion: \\
& 1. Recent $H$ pylori treatment \\
& Setting: secondary care, South Korea \\
\hline Index tests & Index test: urea breath test-13C \\
& Further details: \\
& Technical specifications: UbiT-IR300 apparatus \\
& Performed by: not stated \\
Criteria for positive diagnosis: delta over baseline $>2.5 \%(20$ minutes $)$ & \\
\hline Target condition and reference standard(s) & Target condition: $H$ pylori infection \\
& Reference standard: endoscopic biopsy with Giemsa stain \\
& Further details: \\
Technical specifications: not stated
\end{tabular}


Kim 2016 (Continued)

Performed by: endoscopist and pathologist

Criteria for positive diagnosis: presence of $H$ pylori in biopsy

Flow and timing

Number of indeterminates for whom the results of reference standard was available: not stated

Number of patients who were excluded from the analysis: not stated

\section{Comparative}

\section{Notes}

\section{Methodological quality}

\begin{tabular}{llll}
\hline Item & Authors' judgement & Risk of bias & $\begin{array}{l}\text { Applicability con- } \\
\text { cerns }\end{array}$ \\
\hline
\end{tabular}

\section{DOMAIN 1: Patient Selection}

Was a consecutive or random sample of patients en- Unclear rolled?

\begin{tabular}{llll}
\hline Was a case-control design avoided? & Yes & \\
\hline Did the study avoid inappropriate exclusions? & Unclear & Unclear & Unclear \\
\hline
\end{tabular}

\section{DOMAIN 2: Index Test Urea breath test-13C}

Were the index test results interpreted without
knowledge of the results of the reference standard?

knowledge of the results of the reference standard?

If a threshold was used, was it pre-specified? Unclear

\begin{tabular}{llll}
\hline & Unclear & Low \\
\hline DOMAIN 3: Reference Standard & &
\end{tabular}

\section{DOMAIN 3: Reference Standard}

Is the reference standards likely to correctly classify Yes the target condition?

Were the reference standard results interpreted Unclear
without knowledge of the results of the index tests?

\begin{tabular}{l} 
\\
\hline Unclear \\
\hline
\end{tabular}

\section{DOMAIN 4: Flow and Timing}

\section{Was there an appropriate interval between index Unclear test and reference standard?}
Did all patients receive the same reference stan- Yes dard?

Were all patients included in the analysis? Unclear

\section{Unclear}


Korstanje 2006

\section{Study characteristics}

$\begin{array}{ll}\text { Patient sampling } & \begin{array}{l}\text { Type of study: unclear whether prospective or retrospective study } \\ \text { Consecutive or random sample: unclear sampling process }\end{array}\end{array}$

\begin{tabular}{ll}
\hline Patient characteristics and setting & Sample size: 20 \\
& Female: $9(45 \%)$ \\
& Age: 68 years \\
Presentation: & 1. Patients with atrophic gastritis \\
& Setting: primary care, Netherlands
\end{tabular}

Index tests Index test 1 : urea breath test-13 C

Further details:

Technical specifications: INFAI, Bochum, Germany

Performed by: not stated

Criteria for positive diagnosis: delta over baseline $>4.0 \%$ (30 minutes)

Index test 2: serology

Further details:

Technical specifications: not stated

Performed by: not stated

Criteria for positive diagnosis: Absorbance (wavelength not stated) $>0.320$

\section{Target condition and reference standard(s)}

Target condition: $H$ pylori infection

Reference standard: endoscopic biopsy with H \& E stain and Giemsa stain

Further details:

Technical specifications: not stated

Performed by: endoscopist and pathologist

Criteria for positive diagnosis: presence of $H$ pylori in biopsy

Flow and timing

Number of indeterminates for whom the results of reference standard was available: not stated

Number of patients who were excluded from the analysis: not stated

\section{Comparative}

Notes

Methodological quality

\begin{tabular}{llll}
\hline Item & Authors' judgement & Risk of bias & $\begin{array}{l}\text { Applicability con- } \\
\text { cerns }\end{array}$ \\
\hline
\end{tabular}

\section{DOMAIN 1: Patient Selection}

Was a consecutive or random sample of patients en- Unclear

rolled?

\begin{tabular}{llll}
\hline Was a case-control design avoided? & Yes & \\
\hline Did the study avoid inappropriate exclusions? & Unclear & Unclear & High \\
\hline
\end{tabular}

\section{DOMAIN 2: Index Test Urea breath test-13C}


Korstanje 2006 (Continued)

Were the index test results interpreted without knowl- Unclear edge of the results of the reference standard?

If a threshold was used, was it pre-specified? Unclear

Unclear

Low

\section{DOMAIN 2: Index Test Serology}

Were the index test results interpreted without knowl- Unclear edge of the results of the reference standard?

If a threshold was used, was it pre-specified? Unclear

\begin{tabular}{l}
\hline Unclear \\
Low
\end{tabular}

\section{DOMAIN 3: Reference Standard}

Is the reference standards likely to correctly classify No the target condition?

Were the reference standard results interpreted with- Unclear out knowledge of the results of the index tests?

High Low

\section{DOMAIN 4: Flow and Timing}

Was there an appropriate interval between index test Unclear and reference standard?

Did all patients receive the same reference standard? Yes

Were all patients included in the analysis? Unclear

\begin{tabular}{ll} 
Unclear \\
\hline
\end{tabular}

\section{Kuloglu 2008}

\section{Study characteristics}

$\begin{array}{ll}\text { Patient sampling } & \text { Type of study: prospective study } \\ \text { Consecutive or random sample: neither - patients without a either a stool } \\ \text { sample or a breath sample excluded }\end{array}$

Patient characteristics and setting Sample size: 109

Female: 58 (53.2\%)

Age: 12 years

Presentation:

1. Children with symptoms suggestive of $H$ pylori infection

Exclusion criteria:

1. Recent $H$ pylori treatment

Setting: secondary care, Turkey

Index test 1: urea breath test-14C 
Kuloglu 2008 (Continued)

Further details:

Technical specifications: Heliprobe BreathCard

Performed by: not stated

Criteria for positive diagnosis: Counts per minute $>50$ (10 minutes)

Index test 2: stool antigen test

Further details:

Technical specifications: Rapid HpSA test (LINEAR Chemical)

Performed by: not stated

Criteria for positive diagnosis: pinkish red band (within 10 minutes)

Target condition and reference standard(s)

Flow and timing

Comparative

Notes
Target condition: $H$ pylori infection

Reference standard: endoscopic biopsy with H \& E stain and Giemsa stain

Further details:

Technical specifications: not stated

Performed by: endoscopist and pathologist

Criteria for positive diagnosis: presence of $H$ pylori in biopsy

Number of indeterminates for whom the results of reference standard was available: not stated

Number of patients who were excluded from the analysis: 16 (12.8\%)

\section{Methodological quality}

\begin{tabular}{llll}
\hline Item & Authors' judgement & Risk of bias & \multicolumn{1}{c}{$\begin{array}{l}\text { Applicability con- } \\
\text { cerns }\end{array}$} \\
\hline
\end{tabular}

\section{DOMAIN 1: Patient Selection}

Was a consecutive or random sample of patients en- No rolled?

\begin{tabular}{|c|c|c|c|}
\hline Was a case-control design avoided? & Yes & & \\
\hline \multirow[t]{2}{*}{ Did the study avoid inappropriate exclusions? } & Unclear & & \\
\hline & & High & Unclear \\
\hline \multicolumn{4}{|l|}{ DOMAIN 2: Index Test Urea breath test-14C } \\
\hline $\begin{array}{l}\text { Were the index test results interpreted without } \\
\text { knowledge of the results of the reference standard? }\end{array}$ & Unclear & & \\
\hline \multirow[t]{2}{*}{ If a threshold was used, was it pre-specified? } & Unclear & & \\
\hline & & Unclear & Low \\
\hline
\end{tabular}

\section{DOMAIN 2: Index Test Stool Antigen Test}

\section{Were the index test results interpreted without Yes}

knowledge of the results of the reference standard?

If a threshold was used, was it pre-specified? Yes


Kuloglu 2008 (Continued)

Low

Low

\title{
DOMAIN 3: Reference Standard
}

Is the reference standards likely to correctly classify No

the target condition?

Were the reference standard results interpreted Yes

without knowledge of the results of the index tests?

High $\quad$ Low L H

\section{DOMAIN 4: Flow and Timing}

\section{Was there an appropriate interval between index Unclear} test and reference standard?

Did all patients receive the same reference stan- Yes
dard?

Were all patients included in the analysis? No

High

Ladas 2002a

\section{Study characteristics}

\section{Patient sampling}

Patient characteristics and setting
Type of study: unclear whether prospective or retrospective study

Consecutive or random sample: consecutive patients

\section{Index tests}

\author{
Index test 1a: serology \\ Further details: \\ Technical specifications: Pyloriset EIA-G \\ Performed by: not stated \\ Criteria for positive diagnosis: $\geq 300$ \\ Index test $1 \mathrm{~b}$ : serology \\ Further details: \\ Technical specifications: Milenia H Pylori IgG \\ Performed by: not stated \\ Criteria for positive diagnosis: $\geq 44$
}

Target condition and reference standard(s)

Target condition: H pylori infection 
Ladas 2002a (Continued)

Reference standard: endoscopic biopsy with Giemsa and Warthin-Starry stain

Further details:

Technical specifications: not stated

Performed by: endoscopist and pathologist

Criteria for positive diagnosis: presence of $H$ pylori in biopsy

Flow and timing

Number of indeterminates for whom the results of reference standard was available: not stated

Number of patients who were excluded from the analysis: 0 (0\%)

Comparative

Notes

Methodological quality

\begin{tabular}{llll}
\hline Item & Authors' judgement & Risk of bias & Applicability concerns \\
\hline
\end{tabular}

DOMAIN 1: Patient Selection

Was a consecutive or random sample of patients Yes enrolled?

\begin{tabular}{llll}
\hline Was a case-control design avoided? & Yes & \\
\hline Did the study avoid inappropriate exclusions? & Yes & Low & Low \\
\hline
\end{tabular}

\section{DOMAIN 2: Index Test Serology}

Were the index test results interpreted without dard?

\begin{tabular}{llll}
\hline If a threshold was used, was it pre-specified? & Yes & \\
\hline & Low & Low \\
\hline
\end{tabular}

\section{DOMAIN 3: Reference Standard}

Is the reference standards likely to correctly clas- Yes sify the target condition?

Were the reference standard results interpreted without knowledge of the results of the index tests?

\begin{tabular}{l}
\hline Low \\
\hline DOMAIN 4: Flow and Timing \\
\hline $\begin{array}{l}\text { Was there an appropriate interval between index } \\
\text { test and reference standard? }\end{array}$ \\
$\begin{array}{l}\text { Did all patients receive the same reference stan- } \\
\text { dard? }\end{array}$ \\
\hline
\end{tabular}


Ladas 2002a (Continued)

\section{Lahner 2004}

\section{Study characteristics}

$\begin{array}{ll}\text { Patient sampling } & \begin{array}{l}\text { Type of study: unclear whether prospective or retrospective study } \\ \text { Consecutive or random sample: consecutive patients }\end{array}\end{array}$

\begin{tabular}{ll}
\hline Patient characteristics and setting & Sample size: 27 \\
& Female: $19(70.4 \%)$ \\
& Age: 52 years \\
Presentation: & 1. Patients with atrophic gastritis \\
Exclusion criteria: & 1. Gastric surgery \\
2. Gastric malignancy \\
3. Recent $H$ pylori treatment \\
4. Diarrhoea \\
5. Constipation \\
Setting: not stated
\end{tabular}

Index tests Index test 1: urea breath test- ${ }^{13} \mathrm{C}$

Further details:

Technical specifications: not stated

Performed by: not stated

Criteria for positive diagnosis: delta over baseline $>4.5 \%$ (15 minutes and 30 minutes)

Index test 2: stool antigen test

Further details:

Technical specifications: HpSA, Meridian

Performed by: not stated

Criteria for positive diagnosis: Absorbance $450 \mathrm{~nm} \geq 0.160$

\section{Target condition and reference standard(s)}

Target condition: $H$ pylori infection

Reference standard: endoscopic biopsy with Giemsa stain

Further details:

Technical specifications: not stated

Performed by: endoscopist and pathologist

Criteria for positive diagnosis: presence of $H$ pylori in biopsy

Flow and timing

Number of indeterminates for whom the results of reference standard was available: not stated

Number of patients who were excluded from the analysis: 0 (0\%)

\section{Comparative}

\section{Notes}

\section{Methodological quality}

$\begin{array}{llll}\text { Item Authors' judgement } & \text { Risk of bias } & \begin{array}{l}\text { Applicability con- } \\ \text { cerns }\end{array}\end{array}$


Lahner 2004 (Continued)

\section{DOMAIN 1: Patient Selection}

Was a consecutive or random sample of patients en- Yes rolled?

\begin{tabular}{ll} 
Was a case-control design avoided? & Yes \\
\hline
\end{tabular}

Did the study avoid inappropriate exclusions?

Yes

Low Low

\section{DOMAIN 2: Index Test Urea breath test-13C}

Were the index test results interpreted without Unclear

knowledge of the results of the reference standard?

If a threshold was used, was it pre-specified? Unclear

\begin{tabular}{lll}
\hline Unclear & Low \\
\hline
\end{tabular}

\section{DOMAIN 2: Index Test Stool Antigen Test}

\section{Were the index test results interpreted without Unclear}

knowledge of the results of the reference standard?

If a threshold was used, was it pre-specified? Unclear

\begin{tabular}{llll}
\hline & Unclear & Low \\
\hline DOMAIN 3: Reference Standard & &
\end{tabular}

Is the reference standards likely to correctly classify Yes

the target condition?

Were the reference standard results interpreted Unclear

without knowledge of the results of the index tests?

\section{Unclear}

Low

\section{DOMAIN 4: Flow and Timing}

\section{Was there an appropriate interval between index Yes} test and reference standard? Did all patients receive the same reference stan- Yes
dard?

Were all patients included in the analysis? Yes

\section{Study characteristics}




\section{Lee 1998 (Continued)}

Patient sampling

Patient characteristics and setting
Type of study: unclear whether prospective or retrospective study Consecutive or random sample: consecutive patients

\section{Sample size: 71}

Female: not stated

Age: not stated

Presentation:

1. Patients undergoing endoscopy for duodenitis, gastritis, duodenal ulcer, gastric ulcer

Exclusion criteria:

1. Recent $H$ pylori treatment

Setting: secondary care, Singapore

Index tests

Index test: urea breath test- $13 \mathrm{C}$

Further details:

Technical specifications: not stated

Performed by: not stated

Criteria for positive diagnosis: delta over baseline $>6 \%$ (30 minutes)
Target condition: $H$ pylori infection

Reference standard: endoscopic biopsy with $\mathrm{H}$ \& E stain

Further details:

Technical specifications: not stated

Performed by: endoscopist and pathologist

Criteria for positive diagnosis: presence of $H$ pylori in biopsy

Number of indeterminates for whom the results of reference standard was available: not stated

Number of patients who were excluded from the analysis: $0(0 \%)$

Comparative

Notes

\section{Methodological quality}

\begin{tabular}{llll} 
Item Authors' judgement & Risk of bias & \multicolumn{1}{c}{$\begin{array}{l}\text { Applicability con- } \\
\text { cerns }\end{array}$}
\end{tabular}

DOMAIN 1: Patient Selection

Was a consecutive or random sample of patients en- Yes rolled?

\begin{tabular}{llll}
\hline Was a case-control design avoided? & Yes & \\
\hline Did the study avoid inappropriate exclusions? & Yes & Low & Low \\
\hline
\end{tabular}

\section{DOMAIN 2: Index Test Urea breath test-13C}

Were the index test results interpreted without knowl- Yes edge of the results of the reference standard? 
Lee 1998 (Continued)

Unclear

Low

\section{DOMAIN 3: Reference Standard}

Is the reference standards likely to correctly classify

No

the target condition?

Were the reference standard results interpreted with- Yes

out knowledge of the results of the index tests?

\begin{tabular}{llll}
\hline \multicolumn{1}{l}{ Low } & High \\
\hline DOMAIN 4: Flow and Timing & & \\
\hline $\begin{array}{l}\text { Was there an appropriate interval between index test } \\
\text { and reference standard? }\end{array}$ & Yes & \\
\hline Did all patients receive the same reference standard? & Yes \\
\hline Were all patients included in the analysis? & Yes & Low \\
\hline
\end{tabular}

Logan 1991a

\section{Study characteristics}

$\begin{array}{ll}\text { Patient sampling } & \begin{array}{l}\text { Type of study: unclear whether prospective or retrospective study } \\ \text { Consecutive or random sample: unclear sampling process }\end{array}\end{array}$

$\begin{array}{ll}\text { Patient characteristics and setting } & \text { Sample size: } 50 \\ & \text { Female: } 24(48 \%) \\ & \text { Age: } 51 \text { years } \\ & \text { Presentation: } \\ & \text { 1. Patients undergoing upper gastrointestinal endoscopy } \\ & \text { Exclusion criteria: } \\ & \text { 1. Recent } H \text { pylori infection } \\ \text { 2. Previous gastric surgery } & \text { Setting: secondary care, UK }\end{array}$

Index tests Index test: urea breath test- ${ }^{13} \mathrm{C}$

Further details:

Technical specifications: not stated

Performed by: not stated

Criteria for positive diagnosis: > Mean +3 standard deviations above normal level (60 minutes)

Target condition and reference standard(s)
Target condition: $H$ pylori infection

Reference standard: endoscopic biopsy with H \& E stain

Further details:

Technical specifications: not stated

Performed by: endoscopist and pathologist

Criteria for positive diagnosis: presence of $H$ pylori in biopsy
Number of indeterminates for whom the results of reference standard was available: not stated 
Logan 1991a (Continued)

Number of patients who were excluded from the analysis: not stated

Comparative

Notes

\section{Methodological quality}

\begin{tabular}{llll}
\hline Item & Authors' judgement & Risk of bias & $\begin{array}{l}\text { Applicability con- } \\
\text { cerns }\end{array}$
\end{tabular}

\section{DOMAIN 1: Patient Selection}

Was a consecutive or random sample of patients en- Unclear rolled?

\begin{tabular}{lll}
\hline Was a case-control design avoided? & Yes & Unclear \\
\hline Did the study avoid inappropriate exclusions? & Unclear & \\
\hline DOMAIN 2: Index Test Urea breath test-13C & No & High \\
\hline $\begin{array}{l}\text { Were the index test results interpreted without } \\
\text { knowledge of the results of the reference standard? }\end{array}$ & No & Low \\
\hline If a threshold was used, was it pre-specified?
\end{tabular}

\section{DOMAIN 3: Reference Standard}

Is the reference standards likely to correctly classify No the target condition?

Were the reference standard results interpreted without knowledge of the results of the index tests?

\section{Unclear}

\begin{tabular}{lll}
\hline DOMAIN 4: Flow and Timing & High & Low \\
\hline $\begin{array}{l}\text { Was there an appropriate interval between index } \\
\text { test and reference standard? }\end{array}$ & Yes & \\
\hline $\begin{array}{l}\text { Did all patients receive the same reference stan- } \\
\text { dard? }\end{array}$ & Yes & Unclear \\
\hline Were all patients included in the analysis? & & \\
\hline
\end{tabular}




\section{Lombardo 2003}

\section{Study characteristics}

$\begin{array}{ll}\text { Patient sampling } & \begin{array}{l}\text { Type of study: unclear whether prospective or retrospective study } \\ \text { Consecutive or random sample: neither - histology performed in a subset of } \\ \text { patients }\end{array}\end{array}$
patients

$\begin{array}{ll}\text { Patient characteristics and setting } & \text { Sample size: } 28 \\ & \text { Female: not stated } \\ & \text { Age: not stated } \\ \text { Presentation: } & 1 . \text { Patients who had undergone gastrectomy } \\ & \text { Setting: secondary care, Italy }\end{array}$

Index tests

Index test: urea breath test - unknown isotope

Further details:

Technical specifications: not stated

Performed by: not stated

Criteria for positive diagnosis: delta over baseline $>4$ per $\mathrm{ml}$ (at 5-minute intervals up to 30 minutes)

$\begin{array}{ll}\text { Target condition and reference standard(s) } & \text { Target condition: } H \text { pylori infection } \\ & \text { Reference standard: endoscopic biopsy with H \& E stain and Giemsa stain } \\ & \text { Further details: } \\ & \text { Technical specifications: not stated } \\ & \text { Performed by: endoscopist and pathologist } \\ & \text { Criteria for positive diagnosis: presence of } H \text { pylori in biopsy }\end{array}$

Flow and timing

Number of indeterminates for whom the results of reference standard was available: not stated

Number of patients who were excluded from the analysis: 72 (72\%)

\section{Comparative}

Notes

\section{Methodological quality}

\begin{tabular}{llll}
\hline Item Authors' judgement & Risk of bias & $\begin{array}{l}\text { Applicability con- } \\
\text { cerns }\end{array}$
\end{tabular}

\section{DOMAIN 1: Patient Selection}

Was a consecutive or random sample of patients en- No rolled?

\begin{tabular}{llll}
\hline Was a case-control design avoided? & Yes & \\
\hline Did the study avoid inappropriate exclusions? & Unclear & High \\
\hline
\end{tabular}

DOMAIN 2: Index Test Urea breath test - unknown isotope

Were the index test results interpreted without Unclear
knowledge of the results of the reference standard?

Were the index test results interpreted without
knowledge of the results of the reference standard?

If a threshold was used, was it pre-specified? Unclear 


\section{DOMAIN 3: Reference Standard}

Is the reference standards likely to correctly classify No the target condition?

Were the reference standard results interpreted Unclear without knowledge of the results of the index tests?

\begin{tabular}{lll}
\hline High & Low \\
\hline
\end{tabular}

\section{DOMAIN 4: Flow and Timing}

Was there an appropriate interval between index No test and reference standard?

Did all patients receive the same reference stan- Yes
dard?

Were all patients included in the analysis? No

\section{Lottspeich 2007}

\section{Study characteristics}

\begin{tabular}{ll}
\hline Patient sampling & Type of study: unclear whether prospective or retrospective study \\
Consecutive or random sample: neither - patients with recent antibiotic treat- \\
ment were excluded
\end{tabular}

\begin{tabular}{ll}
\hline Patient characteristics and setting & Sample size: 56 for urea breath test, 100 for stool antigen test \\
& Female: not stated \\
Age: 10 years & Presentation: \\
& 1. Children with abdominal symptoms undergoing endoscopy \\
& Exclusion criteria: \\
& 1. Recent $H$ pylori treatment \\
Setting: secondary care, Germany
\end{tabular}

Index tests

Index test 1: urea breath test-13C

Further details:

Technical specifications: not stated

Performed by: not stated

Criteria for positive diagnosis: delta over baseline $>5.0 \%$ (30 minutes)

Index test 2: stool antigen test

Further details:

Technical specifications: IDEIA HpStAR assay (DakoCytomation)

Performed by: not stated

Criteria for positive diagnosis: Absorbance $450 / 620 \mathrm{~nm}$ to $650 \mathrm{~nm} \geq 0.150$

\footnotetext{
Target condition and reference standard(s)

Target condition: $H$ pylori infection

Reference standard: endoscopic biopsy with H \& E stain or Giemsa stain Further details:
} 
Lottspeich 2007 (Continued)

Technical specifications: not stated

Performed by: endoscopist and pathologist

Criteria for positive diagnosis: presence of $H$ pylori in biopsy

Flow and timing

Number of indeterminates for whom the results of reference standard was available: not stated

Number of patients who were excluded from the analysis: $44(44 \%)$ for urea

breath test; 0 (0\%) for stool antigen test

\section{Comparative}

Notes

\section{Methodological quality}

\begin{tabular}{llll}
\hline Item Authors' judgement & Risk of bias
\end{tabular}

\section{DOMAIN 1: Patient Selection}

Was a consecutive or random sample of patients No enrolled?

\begin{tabular}{llll}
\hline Was a case-control design avoided? & Yes & \\
\hline Did the study avoid inappropriate exclusions? & Unclear & High & Unclear
\end{tabular}

\section{DOMAIN 2: Index Test Urea breath test- ${ }^{13} \mathrm{C}$}

Were the index test results interpreted without Unclear knowledge of the results of the reference standard?

If a threshold was used, was it pre-specified? Unclear

\section{DOMAIN 2: Index Test Stool Antigen Test}

\section{Were the index test results interpreted without Unclear} knowledge of the results of the reference standard?

If a threshold was used, was it pre-specified?

Yes

Unclear Low

\section{DOMAIN 3: Reference Standard}

Is the reference standards likely to correctly No classify the target condition?

Were the reference standard results interprettests? 
Lottspeich 2007 (Continued)

High

Low

\section{DOMAIN 4: Flow and Timing}

Was there an appropriate interval between index Yes test and reference standard?

Did all patients receive the same reference stan- Yes dard?

Were all patients included in the analysis? Unclear

\section{Unclear}

\section{Luthra 1998}

\section{Study characteristics}

Patient sampling

Type of study: unclear whether prospective or retrospective study

Consecutive or random sample: unclear sampling process

\section{Patient characteristics and setting}

\section{Sample size: 240 \\ Female: not stated \\ Age: not stated}

Presentation:

1. Patients undergoing upper gastrointestinal endoscopy

Excluded:

1. People with upper GI bleeding

2. People with coagulation abnormalities

Setting: not stated

$\begin{array}{ll}\text { Index tests } & \text { Index test: serology } \\ & \text { Further details: } \\ & \text { Technical specifications: Pyloristat (BioWhittaker) } \\ & \text { Performed by: not stated } \\ \text { Criteria for positive diagnosis: not stated }\end{array}$

Target condition and reference standard(s)

Target condition: $H$ pylori infection

Reference standard: endoscopic biopsy with $\mathrm{H}$ \& E stain, immunostain, or

Giemsa stain

Further details:

Technical specifications: not stated

Performed by: endoscopist and pathologist

Criteria for positive diagnosis: presence of $H$ pylori in biopsy

Flow and timing

Number of indeterminates for whom the results of reference standard was available: not stated

Number of patients who were excluded from the analysis: not stated

Comparative

\section{Notes}

\section{Methodological quality}


Luthra 1998 (Continued)

Item

Authors' judgement

Risk of bias

Applicability con-

cerns

DOMAIN 1: Patient Selection

Was a consecutive or random sample of patients en- Unclear rolled?

\begin{tabular}{llll}
\hline Was a case-control design avoided? & Yes & \\
\hline Did the study avoid inappropriate exclusions? & Unclear & Unclear & Unclear \\
\hline DOMAIN 2: Index Test Serology & & \\
\hline
\end{tabular}

Were the index test results interpreted without Unclear
knowledge of the results of the reference standard?

knowledge of the results of the reference standard?

If a threshold was used, was it pre-specified? Unclear

\begin{tabular}{lll}
\hline Unclear & High \\
\hline
\end{tabular}

\section{DOMAIN 3: Reference Standard}

Is the reference standards likely to correctly classify No the target condition?

Were the reference standard results interpreted Unclear

without knowledge of the results of the index tests?

High Low

\section{DOMAIN 4: Flow and Timing}

Was there an appropriate interval between index Unclear test and reference standard?

Did all patients receive the same reference stan- $\quad$ Yes dard?

Were all patients included in the analysis? Unclear

\section{Unclear}

\section{Mana 2001a}

\section{Study characteristics}

Patient sampling Type of study: unclear whether prospective or retrospective study

Consecutive or random sample: consecutive patients

Patient characteristics and setting

Sample size: 182

Female: not stated

Age: not stated 
Mana 2001a (Continued)

Presentation:

1. Patients undergoing upper gastrointestinal endoscopy

2. People not taking $H$ pylori medication

Setting: secondary care, Belgium

Index tests

Index test 1: urea breath test-13C

Further details:

Technical specifications: not stated

Performed by: not stated

Multiple criteria for positive diagnosis:

- Delta over baseline $>3.0 \%$ (10 minutes)

- Delta over baseline $>3.0 \%$ (20 minutes)

- Delta over baseline $>3.0 \%$ (30 minutes)

- Delta over baseline $>3.5 \%$ (10 minutes)

- Delta over baseline $>3.5 \%$ (20 minutes)

- Delta over baseline $>3.5 \%$ (30 minutes)

- Delta over baseline $>4.0 \%$ (10 minutes)

- Delta over baseline $>4.0 \%$ (20 minutes)

- Delta over baseline $>4.0 \%$ (30 minutes)

- Delta over baseline $>4.5 \%$ (10 minutes)

- Delta over baseline $>4.5 \%$ (20 minutes)

- Delta over baseline $>4.5 \%$ (30 minutes)

- Delta over baseline $>5.0 \%$ (10 minutes)

- Delta over baseline $>5.0 \%$ (20 minutes)

- Delta over baseline $>5.0 \%$ (30 minutes)

Target condition and reference standard(s)
Target condition: $H$ pylori infection

Reference standard: endoscopic biopsy with immunohistochemistry and Giemsa stain Further details:

Technical specifications: not stated

Performed by: endoscopist and pathologist

Criteria for positive diagnosis: presence of $H$ pylori in biopsy

Number of indeterminates for whom the results of reference standard was available: not stated

Number of patients who were excluded from the analysis: $0(0 \%)$

\section{Comparative}

Notes

\section{Methodological quality}

\begin{tabular}{llll}
\hline Item & Authors' judgement & Risk of bias & Applicability concerns
\end{tabular}

\section{DOMAIN 1: Patient Selection}

Was a consecutive or random sample of Yes patients enrolled?

\begin{tabular}{ll}
\hline Was a case-control design avoided? & Yes \\
\hline $\begin{array}{l}\text { Did the study avoid inappropriate exclu- } \\
\text { sions? }\end{array}$ & Yes \\
\hline
\end{tabular}


Mana 2001a (Continued)

\section{DOMAIN 2: Index Test Urea breath test-13C}

Were the index test results interpreted Unclear without knowledge of the results of the reference standard?

If a threshold was used, was it pre-speci- No fied?

High

Low

\section{DOMAIN 3: Reference Standard}

Is the reference standards likely to cor- Yes rectly classify the target condition?

Were the reference standard results inter- Unclear preted without knowledge of the results of the index tests?

Unclear

Low

\section{DOMAIN 4: Flow and Timing}

Was there an appropriate interval beUnclear tween index test and reference standard?

Did all patients receive the same refer- Yes ence standard?

Were all patients included in the analysis? Yes

\section{Unclear}

\section{Mansour-Ghanaei 2011}

\section{Study characteristics}

\begin{tabular}{ll} 
Patient sampling & $\begin{array}{l}\text { Type of study: unclear whether prospective or retrospective study } \\
\text { Consecutive or random sample: consecutive patients }\end{array}$ \\
\hline Patient characteristics and setting & Sample size: 125 \\
& Female: $65(52 \%)$ \\
Age: 36 years & Presentation: \\
1. Patients with dyspepsia & Exclusion: \\
1. Recent or past $H$ pylori eradication & 2. Pregnancy \\
3. Severe cardiopulmonary disorders or other life-threatening illnesses & Setting: secondary care, Iran
\end{tabular}


Mansour-Ghanaei 2011 (Continued)

Further details:

Technical specifications: Heliprobe BreathCard

Performed by: not stated

Criteria for positive diagnosis: Counts per minute $>50$ (15 minutes)

Index test 2: serology

Further details:

Technical specifications: not stated

Performed by: not stated

Criteria for positive diagnosis: > $11 \mathrm{IU}$

Target condition and reference standard(s)

Flow and timing

Comparative

Notes
Target condition: $H$ pylori infection

Reference standard: endoscopic biopsy with H \& E stain and Giemsa stain

Further details:

Technical specifications: not stated

Performed by: endoscopist and pathologist

Criteria for positive diagnosis: presence of $H$ pylori in biopsy

Number of indeterminates for whom the results of reference standard was available: not stated

Number of patients who were excluded from the analysis: 0 (0\%)

\section{Methodological quality}

\begin{tabular}{llll}
\hline Item & Authors' judgement & Risk of bias & \multicolumn{1}{c}{$\begin{array}{l}\text { Applicability con- } \\
\text { cerns }\end{array}$} \\
\hline
\end{tabular}

\section{DOMAIN 1: Patient Selection}

Was a consecutive or random sample of patients en- Yes rolled?

\begin{tabular}{llll}
\hline Was a case-control design avoided? & Yes & Low & Les \\
\hline Did the study avoid inappropriate exclusions? & & Unclear & \\
\hline DOMAIN 2: Index Test Urea breath test-14C & & No & High \\
\hline $\begin{array}{l}\text { Were the index test results interpreted without } \\
\text { knowledge of the results of the reference standard? }\end{array}$ & & Low \\
\hline If a threshold was used, was it pre-specified? & & \\
\hline
\end{tabular}

\section{DOMAIN 2: Index Test Serology}

Were the index test results interpreted without Unclear

knowledge of the results of the reference standard?

If a threshold was used, was it pre-specified? Unclear 


\begin{tabular}{ll} 
Unclear & Un \\
\hline DOMAIN 3: Reference Standard &
\end{tabular}

Is the reference standards likely to correctly classify No

the target condition?

Were the reference standard results interpreted Unclear

without knowledge of the results of the index tests?

\begin{tabular}{lll}
\hline High & Low L \\
\hline
\end{tabular}

DOMAIN 4: Flow and Timing

Was there an appropriate interval between index Yes
test and reference standard?

Did all patients receive the same reference stan- Yes

dard?

Were all patients included in the analysis? Yes

Low

Mion 1994

\section{Study characteristics}

\section{Patient sampling}

Patient characteristics and setting
Type of study: retrospective study

Consecutive or random sample: unclear sampling process

\section{Sample size: 95}

Female: not stated

Age: not stated

Presentation:

1. Patients with upper abdominal symptoms

Exclusion:

1. Patients with previous gastric surgery

Setting: secondary care, France
Index test: urea breath test- $13 \mathrm{C}$

Further details:

Technical specifications: not stated

Performed by: not stated

Criteria for positive diagnosis: > + 3 delta 0/00 (30 minutes)
Target condition and reference standard(s)
Target condition: $H$ pylori infection

Reference standard: endoscopic biopsy with Warthin-Starry stain

Further details:

Technical specifications: not stated

Performed by: endoscopist and pathologist

Criteria for positive diagnosis: presence of $H$ pylori in biopsy

\footnotetext{
Flow and timing
}

Number of indeterminates for whom the results of reference standard was available: not stated 
Mion 1994 (Continued)

Number of patients who were excluded from the analysis: not stated

Comparative

Notes

\section{Methodological quality}

\begin{tabular}{llll}
\hline Item Authors' judgement & Risk of bias & $\begin{array}{l}\text { Applicability con- } \\
\text { cerns }\end{array}$
\end{tabular}

\section{DOMAIN 1: Patient Selection}

Was a consecutive or random sample of patients en- Unclear rolled?

\begin{tabular}{lll}
\hline Was a case-control design avoided? & Yes & \\
\hline Did the study avoid inappropriate exclusions? & Unclear & Unclear \\
\hline
\end{tabular}

\section{DOMAIN 2: Index Test Urea breath test-13C}

Were the index test results interpreted without knowl- Unclear edge of the results of the reference standard?

If a threshold was used, was it pre-specified? No

\begin{tabular}{lll}
\hline & High & Low \\
\hline DOMAIN 3: Reference Standard & &
\end{tabular}

Is the reference standards likely to correctly classify Yes the target condition?

Were the reference standard results interpreted with- Unclear out knowledge of the results of the index tests?

\begin{tabular}{llll}
\hline & Unclear & Low \\
\hline DOMAIN 4: Flow and Timing & \\
\hline $\begin{array}{l}\text { Was there an appropriate interval between index test } \\
\text { and reference standard? }\end{array}$ & Yes \\
\hline Did all patients receive the same reference standard? & Yes \\
\hline Were all patients included in the analysis? & Unclear \\
\hline
\end{tabular}

\section{Unclear}

Misawa 1998

\section{Study characteristics}

Non-invasive diagnostic tests for Helicobacter pylori infection (Review) 


\section{Misawa 1998 (Continued)}

Patient sampling

Type of study: unclear whether prospective or retrospective study

Consecutive or random sample: unclear sampling process

\section{Sample size: 114}

Female: 46 (40.4\%)

Age: not stated

Presentation:

1. Patients with gastritis, gastric, or duodenal ulcers

Setting: secondary care, Japan

$\begin{array}{ll}\text { Index tests } & \text { Index test 1a: serology (IgA) } \\ & \text { Further details: } \\ & \text { Technical specifications: GAP-IgA (BioMerica) } \\ & \text { Performed by: not stated } \\ & \text { Criteria for positive diagnosis: not stated } \\ & \\ & \text { Index test 1b: serology (IgG) } \\ & \text { Further details: } \\ & \text { Technical specifications: GAP-IgG (BioMerica) } \\ & \text { Performed by: not stated } \\ & \text { Criteria for positive diagnosis: not stated }\end{array}$

Target condition and reference standard(s)

Target condition: $H$ pylori infection

Reference standard: endoscopic biopsy with immunostaining (Carnoy's solution)

Further details:

Technical specifications: not stated

Performed by: endoscopist and pathologist

Criteria for positive diagnosis: presence of $H$ pylori in biopsy

Flow and timing

Number of indeterminates for whom the results of reference standard was available: not stated

Number of patients who were excluded from the analysis: not stated

Comparative

Notes

\title{
Methodological quality
}

\begin{tabular}{llll}
\hline Item & Authors' judgement & Risk of bias & Applicability concerns \\
\hline
\end{tabular}

DOMAIN 1: Patient Selection

\begin{abstract}
Was a consecutive or random sample of patients Unclear
\end{abstract} enrolled?

\begin{tabular}{llll}
\hline Was a case-control design avoided? & Yes & \\
\hline Did the study avoid inappropriate exclusions? & Unclear & Unclear & Unclear \\
\hline
\end{tabular}

DOMAIN 2: Index Test Serology

Were the index test results interpreted without knowledge of the results of the reference stan-

Unclear dard? 
Misawa 1998 (Continued)

If a threshold was used, was it pre-specified? Unclear

Unclear

High

\section{DOMAIN 3: Reference Standard}

Is the reference standards likely to correctly Yes

classify the target condition?

Were the reference standard results interpret-

Unclear

ed without knowledge of the results of the index

tests?

\begin{tabular}{lll}
\hline Unclear & Low \\
\hline
\end{tabular}

\section{DOMAIN 4: Flow and Timing}

Was there an appropriate interval between index Unclear test and reference standard?

Did all patients receive the same reference stan- Yes

dard?

Were all patients included in the analysis? Unclear

Unclear

Mohammadian 2007

Study characteristics

\begin{tabular}{ll}
\hline Patient sampling & $\begin{array}{l}\text { Type of study: unclear whether prospective or retrospective study } \\
\text { Consecutive or random sample: unclear sampling process }\end{array}$ \\
\hline Patient characteristics and setting & Sample size: 179 \\
& Female: $108(60.3 \%)$ \\
& Age: 54 years \\
& Presentation: \\
& 1. Patients undergoing endoscopy for gastrointestinal problems \\
& Setting: secondary care, Iran \\
\hline Index tests & Index test: serology \\
& Further details: \\
& Technical specifications: not stated \\
& Performed by: not stated \\
Criteria for positive diagnosis: not stated & \\
\hline \multirow{2}{*}{ Target condition and reference standard(s) } & Target condition: $H$ pylori infection \\
& Reference standard: endoscopic biopsy with Giemsa stain \\
& Further details: \\
& Technical specifications: not stated \\
& Performed by: endoscopist and pathologist \\
Criteria for positive diagnosis: presence of $H$ pylori in biopsy & Number of indeterminates for whom the results of reference standard \\
\hline Flow and timing & was available: not stated \\
\hline
\end{tabular}

Non-invasive diagnostic tests for Helicobacter pylori infection (Review) 
Mohammadian 2007 (Continued)

Comparative

Notes

\section{Methodological quality}

\begin{tabular}{llll}
\hline Item Authors' judgement & Risk of bias & $\begin{array}{l}\text { Applicability con- } \\
\text { cerns }\end{array}$
\end{tabular}

\section{DOMAIN 1: Patient Selection}

Was a consecutive or random sample of patients en- Unclear rolled?

\begin{tabular}{lll}
\hline Was a case-control design avoided? & Yes & \\
\hline Did the study avoid inappropriate exclusions? & Unclear & Unclear \\
\hline
\end{tabular}

\section{DOMAIN 2: Index Test Serology}

Were the index test results interpreted without knowl- Unclear edge of the results of the reference standard?

If a threshold was used, was it pre-specified? Unclear

\begin{tabular}{lll}
\hline & Unclear & High \\
\hline DOMAIN 3: Reference Standard &
\end{tabular}

\section{DOMAIN 3: Reference Standard}

Is the reference standards likely to correctly classify the Yes target condition?

Were the reference standard results interpreted without Unclear knowledge of the results of the index tests?

\section{DOMAIN 4: Flow and Timing}

Was there an appropriate interval between index test Unclear and reference standard?

Did all patients receive the same reference standard? Yes

Were all patients included in the analysis? Unclear

Unclear

\section{Study characteristics}




\section{Monteiro 2001a (Continued)}

Patient sampling

Type of study: unclear whether prospective or retrospective study Consecutive or random sample: consecutive patients

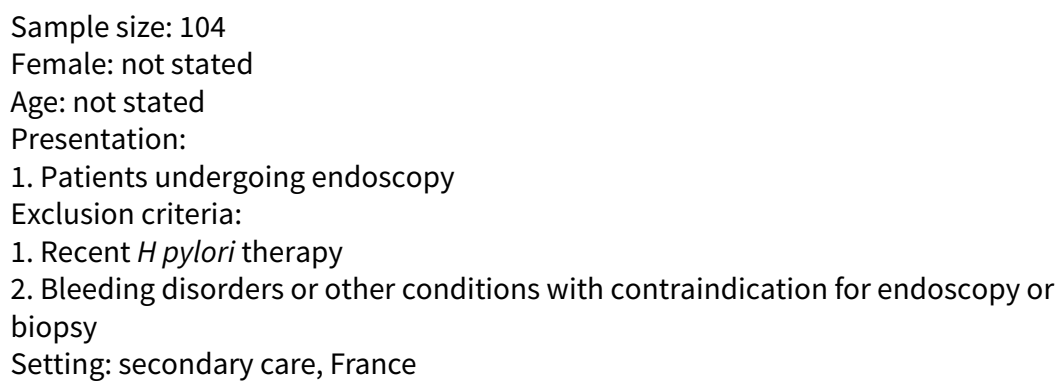

Index tests
Index test 1: urea breath test-13C

Further details:

Technical specifications: ABCA, Europa Scientific

Performed by: not stated

Criteria for positive diagnosis: not stated

Index test 2a: serology

Further details:

Technical specifications: Pyloriset EIA Kit (Orion Diagnostica)

Performed by: not stated

Criteria for positive diagnosis: $>=300$

Index test $2 \mathrm{~b}$ : serology

Further details:

Technical specifications: Helicoblot Immunoblot kit

Performed by: not stated

Criteria for positive diagnosis: not stated

Index test 3: stool antigen test

Further details:

Technical specifications: Premier Platinum HpSA, Meridian

Performed by: not stated

Criteria for positive diagnosis: Absorbance (wavelength not reported) $>=0.160$

Target condition: $H$ pylori infection

Reference standard: endoscopic biopsy with $\mathrm{H}$ \& E stain and Giemsa stain

Further details:

Technical specifications: not stated

Performed by: endoscopist and pathologist

Criteria for positive diagnosis: presence of $H$ pylori in biopsy

Flow and timing

Number of indeterminates for whom the results of reference standard was available: not stated

Number of patients who were excluded from the analysis: $0(0 \%)$

Comparative

Notes

Methodological quality

\begin{tabular}{llll}
\hline Item & Authors' judgement & Risk of bias & Applicability concerns \\
\hline
\end{tabular}

DOMAIN 1: Patient Selection 
Monteiro 2001a (Continued)

Was a consecutive or random sample of patients Yes enrolled?

\begin{tabular}{ll}
\hline Was a case-control design avoided? & Yes \\
\hline Did the study avoid inappropriate exclusions? & Yes \\
\hline
\end{tabular}

\begin{tabular}{llc}
\hline & Low & Low \\
\hline DOMAIN 2: Index Test Urea breath test-13C & & \\
\hline $\begin{array}{l}\text { Were the index test results interpreted without } \\
\text { knowledge of the results of the reference stan- } \\
\text { dard? }\end{array}$ & & Unclear \\
\hline $\begin{array}{l}\text { If a threshold was used, was it pre-specified? } \\
\text { High }\end{array}$
\end{tabular}

\section{DOMAIN 2: Index Test Stool Antigen Test}

Were the index test results interpreted without

Unclear knowledge of the results of the reference standard?

\begin{tabular}{llll}
\hline If a threshold was used, was it pre-specified? & Unclear & Unclear & Low \\
\hline DOMAIN 2: Index Test Serology & & \\
\hline
\end{tabular}

\section{Were the index test results interpreted without Unclear knowledge of the results of the reference stan-} dard?

If a threshold was used, was it pre-specified? Yes

\begin{tabular}{lll}
\hline & Unclear & Low \\
\hline DOMAIN 3: Reference Standard &
\end{tabular}

\section{DOMAIN 3: Reference Standard}

Is the reference standards likely to correctly No classify the target condition?

\section{Were the reference standard results interpret-} tests?

\begin{tabular}{ll}
\hline DOMAIN 4: Flow and Timing & High \\
\hline $\begin{array}{l}\text { Was there an appropriate interval between index } \text { Unclear } \\
\text { test and reference standard? }\end{array}$ \\
\hline $\begin{array}{l}\text { Did all patients receive the same reference stan- } \quad \text { Yes } \\
\text { dard? }\end{array}$ \\
\hline \hline
\end{tabular}


Monteiro 2001a (Continued)

Were all patients included in the analysis? Unclear

Unclear

\title{
Morales 1995
}

\section{Study characteristics}

$\begin{array}{ll}\text { Patient sampling } & \begin{array}{l}\text { Type of study: unclear whether prospective or retrospective study } \\ \text { Consecutive or random sample: unclear sampling process }\end{array}\end{array}$

\begin{tabular}{ll}
\hline Patient characteristics and setting & Sample size: 104 \\
& Female: $52(50 \%)$ \\
Age: 50 years & Presentation: \\
1. Patients with upper abdominal symptoms & Setting: Outpatients, Mexico
\end{tabular}

Index tests Index test 1: urea breath test- ${ }^{14} \mathrm{C}$

Further details:

Technical specifications: not stated

Performed by: not stated

Multiple criteria for positive diagnosis:

First criterion: $\geq 1.6 \%$ excretion (time not stated)

Second criterion: not stated

$\begin{array}{ll}\text { Target condition and reference standard(s) } & \text { Target condition: } H \text { pylori infection } \\ & \text { Reference standard: endoscopic biopsy with Warthin-Starry stain } \\ & \text { Further details: } \\ & \text { Technical specifications: not stated } \\ & \text { Performed by: endoscopist and pathologist } \\ & \text { Criteria for positive diagnosis: presence of } H \text { pylori in biopsy }\end{array}$

Flow and timing

Number of indeterminates for whom the results of reference standard was available: not stated

Number of patients who were excluded from the analysis: not stated

\section{Comparative}

\section{Notes}

\section{Methodological quality}

\begin{tabular}{llll}
\hline Item Authors' judgement & Risk of bias & $\begin{array}{l}\text { Applicability con- } \\
\text { cerns }\end{array}$ \\
\hline
\end{tabular}

\section{DOMAIN 1: Patient Selection}

\begin{abstract}
Was a consecutive or random sample of patients en- Unclear rolled?
\end{abstract}

\begin{tabular}{ll}
\hline Was a case-control design avoided? & Yes \\
\hline Did the study avoid inappropriate exclusions? & Unclear \\
\hline \hline
\end{tabular}


Morales 1995 (Continued)

Unclear

Unclear

\section{DOMAIN 2: Index Test Urea breath test-14C}

Were the index test results interpreted without

Unclear

knowledge of the results of the reference standard?

If a threshold was used, was it pre-specified? No

\begin{tabular}{lll}
\hline & High & Low \\
\hline DOMAIN 3: Reference Standard & &
\end{tabular}

Is the reference standards likely to correctly classify Yes

the target condition?

Were the reference standard results interpreted Unclear

without knowledge of the results of the index tests?

\begin{tabular}{lll}
\hline & Unclear & Low \\
\hline DOMAIN 4: Flow and Timing & &
\end{tabular}

\begin{tabular}{ll}
\hline $\begin{array}{l}\text { Was there an appropriate interval between index } \\
\text { test and reference standard? }\end{array}$ & Unclear \\
\hline $\begin{array}{l}\text { Did all patients receive the same reference stan- } \\
\text { dard? }\end{array}$ & Yes \\
\hline Were all patients included in the analysis? & Unclear \\
\hline
\end{tabular}

\section{Unclear}

\section{Noguera 1998}

\section{Study characteristics}

Patient sampling

Type of study: unclear whether prospective or retrospective study

Consecutive or random sample: unclear

Patient characteristics and setting

Sample size: 38

Female: not stated

Age: not stated

Presentation:

1. Patients undergoing urea breath tests and endoscopic biopsy

Setting: secondary care, Argentina

Index tests

Index test 1: urea breath test-13C

Further details:

Technical specifications: not stated

Performed by: not stated

Multiple criteria for positive diagnosis:

- $>1 \%$ excretion (10 minutes)

- $>1 \%$ excretion (20 minutes) 
Noguera 1998 (Continued)

- $>1 \%$ excretion (30 minutes)
Target condition: $H$ pylori infection

Reference standard: endoscopic biopsy with H \& E stain

Further details:

Technical specifications: not stated

Performed by: endoscopist and pathologist

Criteria for positive diagnosis: presence of $H$ pylori in biopsy
Number of indeterminates for whom the results of reference standard was available: not stated

Number of patients who were excluded from the analysis: 87 (69.6\%)

\section{Comparative}

\section{Notes}

\section{Methodological quality}

\begin{tabular}{llll}
\hline Item & Authors' judgement & Risk of bias & $\begin{array}{l}\text { Applicability con- } \\
\text { cerns }\end{array}$ \\
\hline
\end{tabular}

\section{DOMAIN 1: Patient Selection}

\section{Was a consecutive or random sample of patients en- Unclear} rolled?

\begin{tabular}{llll}
\hline Was a case-control design avoided? & Yes & \\
\hline Did the study avoid inappropriate exclusions? & Unclear & Unclear \\
\hline
\end{tabular}

\section{DOMAIN 2: Index Test Urea breath test-14C}

Were the index test results interpreted without Unclear

\begin{tabular}{llll}
\hline DOMAIN 3: Reference Standard & Unclear & Low \\
\hline $\begin{array}{l}\text { Is the reference standards likely to correctly classify } \\
\text { the target condition? }\end{array}$ & No & \\
\hline $\begin{array}{l}\text { Were the reference standard results interpreted } \\
\text { without knowledge of the results of the index tests? }\end{array}$ & Unclear & High \\
\hline
\end{tabular}

\section{DOMAIN 4: Flow and Timing}

\section{Was there an appropriate interval between index Unclear} test and reference standard? 
Noguera 1998 (Continued)

Did all patients receive the same reference stan- $\quad$ Yes dard?

Were all patients included in the analysis?

No

High

\title{
Novis 1991
}

\section{Study characteristics}

$\begin{array}{ll}\text { Patient sampling } & \begin{array}{l}\text { Type of study: unclear whether prospective or retrospective study } \\ \text { Consecutive or random sample: unclear sampling process }\end{array}\end{array}$

Patient characteristics and setting

\author{
Sample size: 76 \\ Female: not stated \\ Age: not stated
}

Presentation:

1. Patients undergoing endoscopy for gastrointestinal symptoms

Setting: secondary care, Israel

\begin{tabular}{|c|c|}
\hline Index tests & $\begin{array}{l}\text { Index test } 1 \text { : urea breath test- } 14 \mathrm{C} \\
\text { Further details: } \\
\text { Technical specifications: not state } \\
\text { Performed by: not stated } \\
\text { Multiple criteria for positive diagn } \\
\text { - }>4.7 \% \text { excretion ( } 5 \text { minutes) } \\
\text { - }>4.7 \% \text { excretion ( } 10 \text { minutes) } \\
\text { - }>4.7 \% \text { excretion ( } 15 \text { minutes) } \\
\text { - }>4.7 \% \text { excretion ( } 20 \text { minutes) } \\
\text { - }>4.7 \% \text { excretion ( } 25 \text { minutes) }\end{array}$ \\
\hline
\end{tabular}

Target condition and reference standard(s)

Target condition: $H$ pylori infection

Reference standard: endoscopic biopsy with Giemsa stain

Further details:

Technical specifications: not stated

Performed by: endoscopist and pathologist

Criteria for positive diagnosis: presence of $H$ pylori in biopsy

Flow and timing

Number of indeterminates for whom the results of reference standard was available: not stated

Number of patients who were excluded from the analysis: not stated

\section{Comparative}

\section{Notes}

\section{Methodological quality}

\begin{tabular}{llll}
\hline Item Authors' judgement & Risk of bias & $\begin{array}{l}\text { Applicability con- } \\
\text { cerns }\end{array}$
\end{tabular}

DOMAIN 1: Patient Selection 
Novis 1991 (Continued)

Was a consecutive or random sample of patients Unclear enrolled?

\begin{tabular}{ll}
\hline Was a case-control design avoided? & Yes \\
\hline Did the study avoid inappropriate exclusions? & Unclear \\
\hline
\end{tabular}

\begin{tabular}{lll}
\hline Unclear & Unclear \\
\hline
\end{tabular}

\title{
DOMAIN 2: Index Test Urea breath test-14C
}

Were the index test results interpreted without Unclear
knowledge of the results of the reference standard?

knowledge of the results of the reference standard?

If a threshold was used, was it pre-specified? No

\begin{tabular}{lll}
\hline Ligh & Low \\
\hline
\end{tabular}

\section{DOMAIN 3: Reference Standard}

Is the reference standards likely to correctly classi- Yes

fy the target condition?

Were the reference standard results interpreted Unclear
without knowledge of the results of the index tests?

\begin{tabular}{llll}
\hline DOMAIN 4: Flow and Timing & Unclear & Low \\
\hline $\begin{array}{l}\text { Was there an appropriate interval between index } \\
\text { test and reference standard? }\end{array}$ & Yes & \\
\hline $\begin{array}{l}\text { Did all patients receive the same reference stan- } \\
\text { dard? }\end{array}$ & Yes & Unclear \\
\hline Were all patients included in the analysis? & & Unclear \\
\hline
\end{tabular}

\section{Ogata 2001}

\section{Study characteristics}

Patient sampling

Type of study: prospective study

Consecutive or random sample: unclear sampling process

Patient characteristics and setting

\author{
Sample size: 47 \\ Female: 27 (57.4\%) \\ Age: 12 years \\ Presentation: \\ 1. Children with dyspepsia undergoing endoscopy \\ Exclusion: \\ 1. Recent $H$ pylori treatment \\ 2. Immunosuppressive treatment or chemotherapy
}


Ogata 2001 (Continued)

\begin{tabular}{|c|c|}
\hline & $\begin{array}{l}\text { 3. Extradigestive disease } \\
\text { Setting: secondary care, Brazil }\end{array}$ \\
\hline Index tests & $\begin{array}{l}\text { Index test } 1 \text { : urea breath test- } 13 \mathrm{C} \\
\text { Further details: } \\
\text { Technical specifications: Isomed } \\
\text { Performed by: not stated } \\
\text { Criteria for positive diagnosis: > } 3 \% \text { excretion (time not stated) } \\
\text { Index test 2: serology } \\
\text { Further details: } \\
\text { Technical specifications: Cobas Core II (Roche) } \\
\text { Performed by: not stated } \\
\text { Criteria for positive diagnosis: }>7 \mathrm{U} / \mathrm{ml}\end{array}$ \\
\hline Target condition and reference standard(s) & $\begin{array}{l}\text { Target condition: } H \text { pylori infection } \\
\text { Reference standard: endoscopic biopsy with H \& E stain and Giemsa stain } \\
\text { Further details: } \\
\text { Technical specifications: not stated } \\
\text { Performed by: endoscopist and pathologist } \\
\text { Criteria for positive diagnosis: presence of } H \text { pylori in biopsy }\end{array}$ \\
\hline Flow and timing & $\begin{array}{l}\text { Number of indeterminates for whom the results of reference standard was } \\
\text { available: not stated } \\
\text { Number of patients who were excluded from the analysis: not stated }\end{array}$ \\
\hline \multicolumn{2}{|l|}{ Comparative } \\
\hline \multicolumn{2}{|l|}{ Notes } \\
\hline \multicolumn{2}{|l|}{ Methodological quality } \\
\hline Item & $\begin{array}{l}\text { Applicability con- } \\
\text { cerns }\end{array}$ \\
\hline
\end{tabular}

DOMAIN 1: Patient Selection

Was a consecutive or random sample of patients en- Unclear rolled?

\begin{tabular}{llll}
\hline Was a case-control design avoided? & Yes & Unclear & Ungh \\
\hline Did the study avoid inappropriate exclusions? & Unclear & \\
\hline DOMAIN 2: Index Test Urea breath test-13C & Unclear & \\
\hline $\begin{array}{l}\text { Were the index test results interpreted without } \\
\text { knowledge of the results of the reference standard? }\end{array}$ & Unclear & Unclear \\
\hline If a threshold was used, was it pre-specified? & & Low \\
\hline
\end{tabular}

DOMAIN 2: Index Test Serology 
Ogata 2001 (Continued) Were the index test results interpreted without Unclear
knowledge of the results of the reference standard?

\begin{tabular}{llll}
\hline If a threshold was used, was it pre-specified? & Yes & Lnclear & Low \\
\hline
\end{tabular}

\section{DOMAIN 3: Reference Standard}

Is the reference standards likely to correctly classify No the target condition?

Were the reference standard results interpreted

Unclear

without knowledge of the results of the index tests?

\begin{tabular}{lll}
\hline & High & Low \\
\hline DOMAIN 4: Flow and Timing & &
\end{tabular}

Was there an appropriate interval between index Unclear
test and reference standard?

Did all patients receive the same reference stan-
dard?

dard?

Were all patients included in the analysis?

Unclear

\section{Unclear}

\section{Ozturk 2003}

\section{Study characteristics}

\begin{tabular}{|c|c|}
\hline Patient sampling & $\begin{array}{l}\text { Type of study: unclear whether prospective or retrospective study } \\
\text { Consecutive or random sample: unclear sampling process }\end{array}$ \\
\hline Patient characteristics and setting & $\begin{array}{l}\text { Sample size: } 73 \\
\text { Female: } 56(74.6 \%) \\
\text { Age: } 41 \text { years } \\
\text { Presentation: } \\
\text { 1. Patients with dyspepsia } \\
\text { Setting: secondary care, Turkey }\end{array}$ \\
\hline Index tests & $\begin{array}{l}\text { Index test 1a: urea breath test- }{ }^{14} \mathrm{C} \\
\text { Further details: } \\
\text { Technical specifications: Heliprobe BreathCard } \\
\text { Performed by: not stated } \\
\text { Criteria for positive diagnosis: Counts per minute > } 50 \text { (10 minutes) } \\
\text { Index test } 1 \mathrm{~b} \text { : urea breath test- }{ }^{14} \mathrm{C} \\
\text { Further details: } \\
\text { Technical specifications: not stated } \\
\text { Performed by: not stated } \\
\text { Criteria for positive diagnosis: disintegrations per minute > } 100 \text { (10 minutes) }\end{array}$ \\
\hline Target condition and reference standard(s) & Target condition: H pylori infection \\
\hline
\end{tabular}


Ozturk 2003 (Continued)

Reference standard: endoscopic biopsy with Giemsa stain

Further details:

Technical specifications: not stated

Performed by: endoscopist and pathologist

Criteria for positive diagnosis: presence of $H$ pylori in biopsy

Flow and timing

Number of indeterminates for whom the results of reference standard was available: not stated

Number of patients who were excluded from the analysis: not stated

Comparative

Notes

Methodological quality

\begin{tabular}{llll}
\hline Item Authors' judgement & Risk of bias & Applicability concerns
\end{tabular}

DOMAIN 1: Patient Selection Was a consecutive or random sample of patients Unclear
enrolled?

\begin{tabular}{llll}
\hline Was a case-control design avoided? & Yes & \\
\hline Did the study avoid inappropriate exclusions? & Unclear & Unclear & Unclear \\
\hline
\end{tabular}

\section{DOMAIN 2: Index Test Urea breath test-14C}

Were the index test results interpreted without Unclear
knowledge of the results of the reference standard?

If a threshold was used, was it pre-specified? Unclear

\begin{tabular}{lll}
\hline & Unclear & Low \\
\hline DOMAIN 3: Reference Standard &
\end{tabular}

Is the reference standards likely to correctly Yes
classify the target condition?

classify the target condition?

Were the reference standard results interpret- Unclear ed without knowledge of the results of the index tests?

\begin{tabular}{|c|c|c|}
\hline & Unclear & Low \\
\hline \multicolumn{3}{|l|}{ DOMAIN 4: Flow and Timing } \\
\hline $\begin{array}{l}\text { Was there an appropriate interval between index } \\
\text { test and reference standard? }\end{array}$ & Yes & \\
\hline $\begin{array}{l}\text { Did all patients receive the same reference stan- } \\
\text { dard? }\end{array}$ & Yes & \\
\hline
\end{tabular}


Ozturk 2003 (Continued)

Were all patients included in the analysis? Unclear

\section{Unclear}

\section{Peitz 2001}

\section{Study characteristics}

$\begin{array}{ll}\text { Patient sampling } & \begin{array}{l}\text { Type of study: unclear whether prospective or retrospective study } \\ \text { Consecutive or random sample: consecutive patients }\end{array}\end{array}$

\begin{tabular}{ll}
\hline Patient characteristics and setting & Sample size: 145 \\
& Female: $87(60 \%)$ \\
& Age: 59 years \\
Presentation: \\
1. Patients with dyspepsia \\
Exclusion criteria: \\
1. Recent $H$ pylori treatment \\
2. Recent NSAID treatment \\
3. Previous gastric surgery \\
4. Clotting disorders \\
Setting: secondary care, Germany
\end{tabular}

Index tests Index test: serology

Further details:

Technical specifications: Helisa Rapid Whole Blood Test (Cortecs Diagnostics Ltd)

Performed by: not stated

Criteria for positive diagnosis: not stated

\section{Target condition and reference standard(s)}

Target condition: $H$ pylori infection

Reference standard: endoscopic biopsy with H \& E stain and Giemsa stain

Further details:

Technical specifications: not stated

Performed by: endoscopist and pathologist

Criteria for positive diagnosis: presence of $H$ pylori in biopsy

Flow and timing

Number of indeterminates for whom the results of reference standard was available: not stated

Number of patients who were excluded from the analysis: 0 (0\%)

\section{Comparative}

\section{Notes}

\section{Methodological quality}

\begin{tabular}{llll}
\hline Item Authors' judgement & Risk of bias & $\begin{array}{l}\text { Applicability con- } \\
\text { cerns }\end{array}$ \\
\hline
\end{tabular}

\section{DOMAIN 1: Patient Selection}

Was a consecutive or random sample of patients en- Yes

rolled? 
Peitz 2001 (Continued)

Was a case-control design avoided? Yes

Did the study avoid inappropriate exclusions? Yes

\begin{tabular}{llll}
\hline DOMAIN 2: Index Test Serology & Low & Low \\
\hline $\begin{array}{l}\text { Were the index test results interpreted without } \\
\text { knowledge of the results of the reference standard? }\end{array}$ & Unclear & \\
\hline If a threshold was used, was it pre-specified? & Yes & Unclear & High
\end{tabular}

\section{DOMAIN 3: Reference Standard}

Is the reference standards likely to correctly classify No

the target condition?

Were the reference standard results interpreted without knowledge of the results of the index tests?

Unclear

\begin{tabular}{lll}
\hline DOMAIN 4: Flow and Timing & High & Low \\
\hline $\begin{array}{l}\text { Was there an appropriate interval between index } \\
\text { test and reference standard? }\end{array}$ & Unclear \\
\hline $\begin{array}{l}\text { Did all patients receive the same reference stan- } \\
\text { dard? }\end{array}$ & Yes \\
\hline Were all patients included in the analysis? & Yes \\
\hline
\end{tabular}

\section{Unclear}

\section{Peura 1996}

\section{Study characteristics}

$\begin{array}{ll}\text { Patient sampling } & \begin{array}{l}\text { Type of study: unclear whether prospective or retrospective study } \\ \text { Consecutive or random sample: unclear sampling process }\end{array}\end{array}$

\begin{tabular}{ll}
\hline Patient characteristics and setting & Sample size: 200 \\
& Female: $118(59 \%)$ \\
Age: not stated & Presentation: \\
1. Patients undergoing endoscopy \\
Exclusion criteria: \\
1. Recent $H$ pylori treatment \\
2. Gastric surgery \\
Setting: secondary care, USA
\end{tabular}


Peura 1996 (Continued)

Further details:

Technical specifications: not stated

Performed by: not stated

Criteria for positive diagnosis: disintegrations per minute $>200$ (10 minutes)

Target condition and reference standard(s)

Target condition: H pylori infection

Reference standard: endoscopic biopsy with Giemsa stain

Further details:

Technical specifications: not stated

Performed by: endoscopist and pathologist

Criteria for positive diagnosis: presence of $H$ pylori in biopsy

Flow and timing

Number of indeterminates for whom the results of reference standard was available: not stated

Number of patients who were excluded from the analysis: not stated

\section{Comparative}

\section{Notes}

\section{Methodological quality}

\begin{tabular}{llcl}
\hline Item & Authors' judgement & Risk of bias & $\begin{array}{l}\text { Applicability con- } \\
\text { cerns }\end{array}$ \\
\hline
\end{tabular}

\section{DOMAIN 1: Patient Selection}

Was a consecutive or random sample of patients en- Unclear rolled?

\begin{tabular}{llll}
\hline Was a case-control design avoided? & Yes & \\
\hline Did the study avoid inappropriate exclusions? & Unclear & Unclear & Unclear \\
\hline
\end{tabular}

\section{DOMAIN 2: Index Test Urea breath test-14C}

Were the index test results interpreted without Unclear

knowledge of the results of the reference standard?

\begin{tabular}{llll}
\hline If a threshold was used, was it pre-specified? & Unclear & & Low \\
\hline & Unclear & \\
\hline
\end{tabular}

\section{DOMAIN 3: Reference Standard}

Is the reference standards likely to correctly classify Yes

the target condition?

Were the reference standard results interpreted Unclear

without knowledge of the results of the index tests?

\begin{tabular}{lll}
\hline Unclear & Low \\
\hline
\end{tabular}

\section{DOMAIN 4: Flow and Timing}


Peura 1996 (Continued)

Was there an appropriate interval between index Yes test and reference standard?

Did all patients receive the same reference stan- $\quad$ Yes dard?

\section{Study characteristics}

Patient sampling

Patient characteristics and setting
Type of study: unclear whether prospective or retrospective study

Consecutive or random sample: consecutive patients

Sample size: 72

Female: 42 (58.3\%)

Age: 55 years

Presentation:

1. Patients undergoing endoscopy

Exclusion criteria:

1. Recent $H$ pylori treatment

Setting: secondary care, Austria
Index test: stool antigen test

Further details:

Technical specifications: Premier Platinum HpSA (Meridian Diagnostics)

Performed by: not stated

Criteria for positive diagnosis: Absorbance 450/620 nm $\geq 0.100$

\section{Target condition and reference standard(s)}

\section{Target condition: H pylori infection}

Reference standard: endoscopic biopsy (staining not reported, probably $\mathrm{H}$ \& E)

Further details:

Technical specifications: not stated

Performed by: endoscopist and pathologist

Criteria for positive diagnosis: presence of $H$ pylori in biopsy
Number of indeterminates for whom the results of reference standard was available: not stated

Number of patients who were excluded from the analysis: 0 (0\%)

\section{Comparative}

Notes

\section{Methodological quality}

$\begin{array}{llll}\text { Item Authors' judgement } & \text { Risk of bias } & \begin{array}{l}\text { Applicability con- } \\ \text { cerns }\end{array}\end{array}$

DOMAIN 1: Patient Selection 
Puspok 1999 (Continued)

Was a consecutive or random sample of patients en- Yes rolled?

\begin{tabular}{llll}
\hline Was a case-control design avoided? & Yes & Low & Low \\
\hline Did the study avoid inappropriate exclusions? & & & \\
\hline DOMAIN 2: Index Test Stool Antigen Test & Unclear & \\
\hline $\begin{array}{l}\text { Were the index test results interpreted without } \\
\text { knowledge of the results of the reference standard? }\end{array}$ & Unclear & Unclear \\
\hline If a threshold was used, was it pre-specified? & & Low \\
\hline
\end{tabular}

\title{
DOMAIN 3: Reference Standard
}

Is the reference standards likely to correctly classify No the target condition?

Were the reference standard results interpreted Unclear without knowledge of the results of the index tests?

\begin{tabular}{lll}
\hline Ligh & Low \\
\hline
\end{tabular}

\section{DOMAIN 4: Flow and Timing}

Was there an appropriate interval between index Unclear test and reference standard?

Did all patients receive the same reference stan- $\quad$ Yes dard?

Were all patients included in the analysis?

Yes

\section{Unclear}

Qadeer 2009

\section{Study characteristics}

Patient sampling

Type of study: prospective study

Consecutive or random sample: unclear sampling process

Patient characteristics and setting

\author{
Sample size: 100 \\ Female: 50 (50\%) \\ Age: 39 years \\ Presentation: \\ 1. Patients with dyspepsia \\ Exlusion criteria: \\ 1. Recent $H$ pylori therapy \\ 2. Not on anti-coagulant therapy
}


Qadeer 2009 (Continued)

3. Oral anticoagulants or NSAID treatment

Setting: secondary care, Pakistan

\begin{tabular}{ll}
\hline Index tests & $\begin{array}{l}\text { Index test: stool antigen test } \\
\text { Further details: }\end{array}$ \\
& $\begin{array}{l}\text { Technical specifications: not stated } \\
\text { Performed by: not stated } \\
\text { Criteria for positive diagnosis: pink-red band }\end{array}$ \\
\hline Target condition and reference standard(s) & $\begin{array}{l}\text { Target condition: } H \text { pylori infection } \\
\text { Reference standard: endoscopic biopsy with Giemsa stain } \\
\text { Further details: }\end{array}$ \\
& $\begin{array}{l}\text { Technical specifications: not stated } \\
\text { Performed by: endoscopist and pathologist } \\
\text { Criteria for positive diagnosis: presence of } H \text { pylori in biopsy }\end{array}$ \\
\hline Flow and timing & $\begin{array}{l}\text { Number of indeterminates for whom the results of reference standard was } \\
\text { available: not stated } \\
\text { Number of patients who were excluded from the analysis: not stated }\end{array}$ \\
\hline
\end{tabular}

Comparative

Notes

Methodological quality

\begin{tabular}{llll}
\hline Item Authors' judgement & Risk of bias & $\begin{array}{l}\text { Applicability con- } \\
\text { cerns }\end{array}$ \\
\hline
\end{tabular}

\section{DOMAIN 1: Patient Selection}

Was a consecutive or random sample of patients en- Unclear rolled?

\begin{tabular}{llll}
\hline Was a case-control design avoided? & Yes & Unclear & Unclear \\
\hline Did the study avoid inappropriate exclusions? & Unclear & \\
\hline DOMAIN 2: Index Test Stool Antigen Test & Unclear & \\
\hline $\begin{array}{l}\text { Were the index test results interpreted without } \\
\text { knowledge of the results of the reference standard? }\end{array}$ & Unclear & Unclear \\
\hline If a threshold was used, was it pre-specified? & & Low \\
\hline
\end{tabular}

\section{DOMAIN 3: Reference Standard}

Is the reference standards likely to correctly classify Yes the target condition?

Were the reference standard results interpreted without knowledge of the results of the index tests?

Unclear

\begin{tabular}{llc}
\hline Unclear & Low \\
\hline \hline
\end{tabular}


Qadeer 2009 (Continued)

DOMAIN 4: Flow and Timing

Was there an appropriate interval between index Unclear
test and reference standard?

Did all patients receive the same reference stan- $\quad$ Yes dard?
Were all patients included in the analysis?
Unclear

\section{Unclear}

\section{Rafeey 2007}

\section{Study characteristics}

$\begin{array}{ll}\text { Patient sampling } & \begin{array}{l}\text { Type of study: unclear whether prospective or retrospective study } \\ \text { Consecutive or random sample: unclear sampling process }\end{array}\end{array}$

\section{Patient characteristics and setting}

Sample size: 96

Female: 31 (32.3\%)

Age: 8 years

Presentation:

1. Children with dyspepsia or abdominal pain

Exclusion criteria:

1. Recent $H$ pylori treatment

2. Diarrhoea

Setting: secondary care, Iran

\section{Index tests}

Index test: stool antigen test

Further details:

Technical specifications: Equipar HPSA test

Performed by: not stated

Criteria for positive diagnosis: not stated

\section{Target condition and reference standard(s)}

\section{Target condition: $H$ pylori infection}

Reference standard: endoscopic biopsy with H \& E stain and Giemsa stain

Further details:

Technical specifications: not stated

Performed by: endoscopist and pathologist

Criteria for positive diagnosis: presence of $\mathrm{H}$ pylori in biopsy

Flow and timing

Number of indeterminates for whom the results of reference standard was available: not stated

Number of patients who were excluded from the analysis: not stated

Comparative

\section{Notes}

\section{Methodological quality}

\begin{tabular}{llll}
\hline Item Authors' judgement & Risk of bias & $\begin{array}{l}\text { Applicability con- } \\
\text { cerns }\end{array}$ \\
\hline
\end{tabular}


Rafeey 2007 (Continued)

\section{DOMAIN 1: Patient Selection}

Was a consecutive or random sample of patients en- Unclear rolled?

\begin{tabular}{ll}
\hline Was a case-control design avoided? & Yes \\
\hline Did the study avoid inappropriate exclusions? & Unclear \\
\hline
\end{tabular}

\section{DOMAIN 2: Index Test Stool Antigen Test}

\section{Were the index test results interpreted without Unclear}

knowledge of the results of the reference standard?

If a threshold was used, was it pre-specified? Unclear

Unclear

High

\section{DOMAIN 3: Reference Standard}

Is the reference standards likely to correctly classify No the target condition?

Were the reference standard results interpreted Unclear

without knowledge of the results of the index tests?

High Low

\section{DOMAIN 4: Flow and Timing}

Was there an appropriate interval between index Unclear
test and reference standard?

Did all patients receive the same reference stan- Yes dard?

Were all patients included in the analysis? Unclear

Unclear

Rasool 2007

\section{Study characteristics}

\section{Patient sampling}

Patient characteristics and setting

Type of study: unclear whether prospective or retrospective study Consecutive or random sample: consecutive patients

Sample size: 94

Female: $34(36.2 \%)$

Age: 41 years

Presentation:

1. Patients with dyspepsia

Exclusion criteria: 
Rasool 2007 (Continued)

1. Recent $H$ pylori treatment

2. Pregnancy

3. Gastric surgery

Setting: secondary care, Pakistan

Index tests

Index test: urea breath test

Further details:

Technical specifications: Heliprobe BreathCard

Performed by: not stated

Criteria for positive diagnosis: Counts per minute $>50$ (10 minutes)

\section{Target condition and reference standard(s)}

\section{Target condition: H pylori infection}

Reference standard: endoscopic biopsy with H \& E stain and Giemsa stain

Further details:

Technical specifications: not stated

Performed by: endoscopist and pathologist

Criteria for positive diagnosis: presence of $H$ pylori in biopsy

\section{Flow and timing}

Number of indeterminates for whom the results of reference standard was available: not stated

Number of patients who were excluded from the analysis: 0 (0\%)

\section{Comparative}

\section{Notes}

\section{Methodological quality}

\begin{tabular}{llll}
\hline Item Authors' judgement & Risk of bias & $\begin{array}{l}\text { Applicability con- } \\
\text { cerns }\end{array}$
\end{tabular}

\section{DOMAIN 1: Patient Selection}

Was a consecutive or random sample of patients en- Yes rolled?

\begin{tabular}{llll}
\hline Was a case-control design avoided? & Yes & \\
\hline Did the study avoid inappropriate exclusions? & Yes & Low \\
\hline
\end{tabular}

\section{DOMAIN 2: Index Test Urea breath test-14C}

\section{Were the index test results interpreted without Unclear}

knowledge of the results of the reference standard?

If a threshold was used, was it pre-specified? Unclear

\begin{tabular}{llll}
\hline Unclear & Low \\
\hline
\end{tabular}

\section{DOMAIN 3: Reference Standard}

Is the reference standards likely to correctly classify No the target condition? Were the reference standard results interpreted Unclear
without knowledge of the results of the index tests? 
Rasool 2007 (Continued)

High

Low

\title{
DOMAIN 4: Flow and Timing
}

Was there an appropriate interval between index Yes

test and reference standard?

Did all patients receive the same reference stan- $\quad$ Yes

dard?

Were all patients included in the analysis?

Unclear

Unclear

Rathbone 1986

\section{Study characteristics}

Patient sampling

Type of study: unclear whether prospective or retrospective study

Consecutive or random sample: unclear sampling process

Patient characteristics and setting

\author{
Sample size: 73 \\ Female: not stated \\ Age: not stated \\ Presentation: \\ 1. Patients with dyspepsia \\ Setting: secondary care, UK
}

$\begin{array}{ll}\text { Index tests } & \text { Index test: serology } \\ & \text { Further details: } \\ & \text { Technical specifications: not stated } \\ & \text { Performed by: not stated } \\ & \text { Criteria for positive diagnosis: }>\text { Mean + } 2 \text { standard deviations above nor- } \\ & \text { mal level }\end{array}$

Target condition and reference standard(s)

Target condition: $H$ pylori infection

Reference standard: endoscopic biopsy with H \& E stain and Giemsa

stain

Further details:

Technical specifications: not stated

Performed by: endoscopist and pathologist

Criteria for positive diagnosis: presence of $H$ pylori in biopsy

Flow and timing

Number of indeterminates for whom the results of reference standard was available: not stated

Number of patients who were excluded from the analysis: not stated

Comparative

Notes

\section{Methodological quality}

\begin{tabular}{llll}
\hline Item Authors' judgement & Risk of bias & $\begin{array}{l}\text { Applicability con- } \\
\text { cerns }\end{array}$
\end{tabular}


Rathbone 1986 (Continued)

\section{DOMAIN 1: Patient Selection}

Was a consecutive or random sample of patients en- Unclear
rolled?
rolled?

\begin{tabular}{lll}
\hline Was a case-control design avoided? & Yes \\
\hline Did the study avoid inappropriate exclusions? & Unclear & Unclear \\
\hline
\end{tabular}

\section{DOMAIN 2: Index Test Serology}

\section{Were the index test results interpreted without knowl- Unclear} edge of the results of the reference standard?

If a threshold was used, was it pre-specified? No

High Low

\section{DOMAIN 3: Reference Standard} Is the reference standards likely to correctly classify the No
target condition?

Were the reference standard results interpreted without Unclear knowledge of the results of the index tests?

High Low

\section{DOMAIN 4: Flow and Timing}

Was there an appropriate interval between index test Unclear
and reference standard?

Did all patients receive the same reference standard? Yes

Were all patients included in the analysis? Unclear

Unclear

\section{Safe 1993}

\section{Study characteristics}

$\begin{array}{ll}\text { Patient sampling } & \begin{array}{l}\text { Type of study: unclear whether prospective or retrospective study } \\ \text { Consecutive or random sample: unclear sampling process }\end{array}\end{array}$

$\begin{array}{ll}\text { Patient characteristics and setting } & \text { Sample size: } 100 \\ & \text { Female: } 59(59 \%) \\ & \text { Age: } 72 \text { years } \\ & \text { Presentation: } \\ \text { 1. Elderly dyspeptic patients } & \text { Setting: secondary care, UK }\end{array}$


Safe 1993 (Continued)

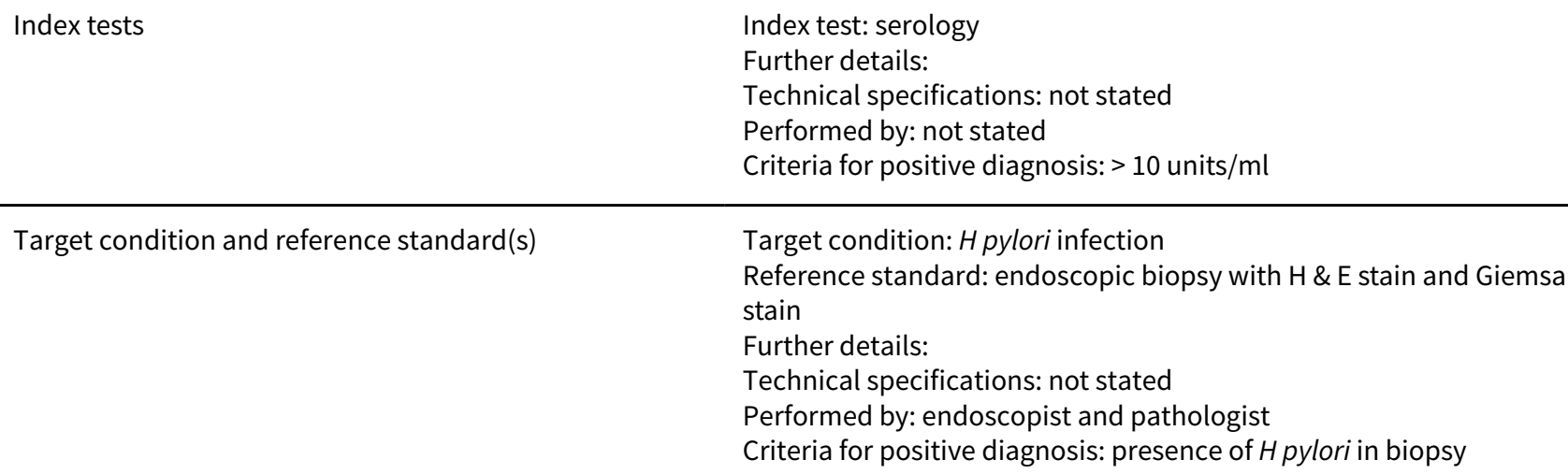

Target condition and reference standard(s)

Flow and timing

Number of indeterminates for whom the results of reference standard was available: not stated

Number of patients who were excluded from the analysis: not stated

\section{Comparative}

\section{Notes}

\section{Methodological quality}

\begin{tabular}{llll}
\hline Item Authors' judgement & Risk of bias & $\begin{array}{l}\text { Applicability con- } \\
\text { cerns }\end{array}$
\end{tabular}

\section{DOMAIN 1: Patient Selection}

\begin{tabular}{lll}
\hline $\begin{array}{l}\text { Was a consecutive or random sample of patients en- } \\
\text { rolled? }\end{array}$ & Unclear \\
\hline Was a case-control design avoided? & Yes & Unclear \\
\hline Did the study avoid inappropriate exclusions? & & Unclear \\
\hline
\end{tabular}

\section{DOMAIN 2: Index Test Serology}

\section{Were the index test results interpreted without knowl- Unclear} edge of the results of the reference standard?

If a threshold was used, was it pre-specified? Yes

\begin{tabular}{llll} 
& Unclear & Low \\
\hline DOMAIN 3: Reference Standard & & Un
\end{tabular}

\section{DOMAIN 3: Reference Standard}

Is the reference standards likely to correctly classify the No target condition?

Were the reference standard results interpreted without Unclear knowledge of the results of the index tests? 
Safe 1993 (Continued)

\section{DOMAIN 4: Flow and Timing}

Was there an appropriate interval between index test Yes and reference standard?

Did all patients receive the same reference standard? Yes

Were all patients included in the analysis? Unclear

Unclear

Salles-Montaudon 2002

\section{Study characteristics}

$\begin{array}{ll}\text { Patient sampling } & \text { Type of study: unclear whether prospective or retrospective study } \\ & \text { Consecutive or random sample: unclear sampling process }\end{array}$

Patient characteristics and setting

Sample size: 107

Female: $71(66.4 \%)$

Age: 85 years

Presentation:

1. Adults $>75$ years

Exclusion criteria:

1. Contraindication to biopsy

Setting: secondary care, Switzerland

Index tests

Index test 1: urea breath test-13C

Further details:

Technical specifications: ABCA, Europa Scientific

Performed by: not stated

Criteria for positive diagnosis: delta over baseline $>3.5 \%$ (30 minutes)

Index test 2: serology

Further details:

Technical specifications: Pyloriset EIA Kit (Orion Diagnostica)

Performed by: not stated

Criteria for positive diagnosis: > 300 Units

Index test 3: stool antigen test

Further details:

Technical specifications: Premier Platinum HpSA, Meridian

Performed by: not stated

Criteria for positive diagnosis: Absorbance (wavelength not reported) $>0.160$

Target condition and reference standard(s)

\section{Target condition: H pylori infection}

Reference standard: endoscopic biopsy with H \& E stain and Giemsa stain

Further details:

Technical specifications: not stated

Performed by: endoscopist and pathologist

Criteria for positive diagnosis: presence of $H$ pylori in biopsy

Flow and timing
Number of indeterminates for whom the results of reference standard was available: not stated

Number of patients who were excluded from the analysis: not stated 
Salles-Montaudon 2002 (Continued)

Comparative

$$
\text { Notes }
$$

\section{Methodological quality}

\begin{tabular}{llll}
\hline Item & Authors' judgement & Risk of bias & $\begin{array}{l}\text { Applicability con- } \\
\text { cerns }\end{array}$ \\
\hline
\end{tabular}

\section{DOMAIN 1: Patient Selection}

Was a consecutive or random sample of patients en- Unclear rolled?

\begin{tabular}{llll}
\hline Was a case-control design avoided? & Yes & \\
\hline Did the study avoid inappropriate exclusions? & Unclear & Unclear
\end{tabular}

\section{DOMAIN 2: Index Test Urea breath test-13C}

Were the index test results interpreted without Unclear
knowledge of the results of the reference standard?

knowledge of the results of the reference standard?

If a threshold was used, was it pre-specified? Unclear

\begin{tabular}{llll}
\hline DOMAIN 2: Index Test Stool Antigen Test & Unclear & Low \\
\hline $\begin{array}{l}\text { Were the index test results interpreted without } \\
\text { knowledge of the results of the reference standard? }\end{array}$ & Unclear & \\
\hline $\begin{array}{l}\text { If a threshold was used, was it pre-specified? } \\
\text { Unclear }\end{array}$ & Unclear & Low \\
\hline
\end{tabular}

\section{DOMAIN 2: Index Test Serology}

Were the index test results interpreted without Unclear

knowledge of the results of the reference standard?

If a threshold was used, was it pre-specified? Yes

\begin{tabular}{llll}
\hline & Unclear & Low \\
\hline DOMAIN 3: Reference Standard & &
\end{tabular}

Is the reference standards likely to correctly classify No the target condition?

Were the reference standard results interpreted Unclear

without knowledge of the results of the index tests?

High Low


Salles-Montaudon 2002 (Continued)

\section{DOMAIN 4: Flow and Timing}

Was there an appropriate interval between index Unclear
test and reference standard?

Did all patients receive the same reference stan- $\quad$ Yes dard?
Were all patients included in the analysis?
Unclear

\section{Unclear}

\section{Schilling 2001}

\section{Study characteristics}

$\begin{array}{ll}\text { Patient sampling } & \begin{array}{l}\text { Type of study: unclear whether prospective or retrospective study } \\ \text { Consecutive or random sample: unclear sampling process }\end{array}\end{array}$

\section{Patient characteristics and setting}

Sample size: 68

Female: 20 (29.4\%)

Age: 62 years

Presentation:

1. Patients with partial gastric resection

Exclusion criteria:

Recent $H$ pylori treatment

Setting: secondary care, Germany

Index tests Index test: urea breath test-13C

Further details:

Technical specifications: not stated

Performed by: not stated

Criteria for positive diagnosis: delta over baseline $>4.0 \%$ (30 minutes)

$\begin{array}{ll}\text { Target condition and reference standard(s) } & \text { Target condition: } H \text { pylori infection } \\ & \text { Reference standard: endoscopic biopsy with Warthin-Starry stain } \\ & \text { Further details: } \\ & \text { Technical specifications: not stated } \\ & \text { Performed by: endoscopist and pathologist } \\ & \text { Criteria for positive diagnosis: presence of } H \text { pylori in biopsy }\end{array}$

Flow and timing

Number of indeterminates for whom the results of reference standard was available: not stated

Number of patients who were excluded from the analysis: not stated

\section{Comparative}

\section{Notes}

\section{Methodological quality}

\begin{tabular}{llll}
\hline Item & Authors' judgement & Risk of bias & $\begin{array}{l}\text { Applicability con- } \\
\text { cerns }\end{array}$
\end{tabular}

DOMAIN 1: Patient Selection 
Schilling 2001 (Continued)

Was a consecutive or random sample of patients en- Unclear rolled?

\begin{tabular}{ll}
\hline Was a case-control design avoided? & Yes \\
\hline Did the study avoid inappropriate exclusions? & Unclear
\end{tabular}

\begin{tabular}{llll}
\hline & Unclear & High \\
\hline DOMAIN 2: Index Test Urea breath test-13C & & \\
\hline $\begin{array}{l}\text { Were the index test results interpreted without } \\
\text { knowledge of the results of the reference standard? }\end{array}$ & & \\
\hline If a threshold was used, was it pre-specified? & Unclear & Unclear & Low \\
\hline
\end{tabular}

\section{DOMAIN 3: Reference Standard}

Is the reference standards likely to correctly classify Yes the target condition?

Were the reference standard results interpreted Unclear without knowledge of the results of the index tests?

\begin{tabular}{lll}
\hline LOMAIN 4: Flow and Timing & Unclear \\
\hline $\begin{array}{l}\text { Was there an appropriate interval between index } \\
\text { test and reference standard? }\end{array}$ & Unclear \\
\hline $\begin{array}{l}\text { Did all patients receive the same reference stan- } \\
\text { dard? }\end{array}$ & Yes & \\
\hline Were all patients included in the analysis? & & Unclear \\
\hline
\end{tabular}

\section{Scuderi 2000}

\section{Study characteristics}

Patient sampling

Patient characteristics and setting
Type of study: unclear whether prospective or retrospective study Consecutive or random sample: unclear sampling process

\author{
Sample size: 250 \\ Female: $127(50.8 \%)$ \\ Age: 58 years \\ Presentation: \\ 1. Patients with dyspeptic symptoms \\ Setting: secondary care, Italy
}

Index tests

Index test: stool antigen test 
Scuderi 2000 (Continued)

Further details:

Technical specifications: Premier Platinum HpSA (Meridian Diagnostics)

Performed by: not stated

Criteria for positive diagnosis: not stated
Target condition: $H$ pylori infection

Reference standard: endoscopic biopsy with Giemsa stain

Further details:

Technical specifications: not stated

Performed by: endoscopist and pathologist

Criteria for positive diagnosis: presence of $H$ pylori in biopsy
Number of indeterminates for whom the results of reference standard was available: not stated

Number of patients who were excluded from the analysis: not stated

\section{Comparative}

\section{Notes}

\section{Methodological quality}

\begin{tabular}{llll}
\hline Item & Authors' judgement & Risk of bias & \multicolumn{1}{c}{$\begin{array}{l}\text { Applicability con- } \\
\text { cerns }\end{array}$} \\
\hline
\end{tabular}

\section{DOMAIN 1: Patient Selection}

Was a consecutive or random sample of patients en- Unclear
rolled?
rolled?

\begin{tabular}{llll}
\hline Was a case-control design avoided? & Yes & \\
\hline Did the study avoid inappropriate exclusions? & Unclear & Unclear & Unclear \\
\hline
\end{tabular}

\section{DOMAIN 2: Index Test Stool Antigen Test}

Were the index test results interpreted without knowl- Unclear
edge of the results of the reference standard?

\begin{tabular}{llll}
\hline If a threshold was used, was it pre-specified? & Unclear & & Unclear \\
\hline & High & Unclear \\
\hline
\end{tabular}

\section{DOMAIN 3: Reference Standard}

Is the reference standards likely to correctly classify the Yes target condition?

Were the reference standard results interpreted without Unclear knowledge of the results of the index tests?

\section{DOMAIN 4: Flow and Timing}




\section{Scuderi 2000 (Continued)}

Was there an appropriate interval between index test Unclear and reference standard?

Did all patients receive the same reference standard?

Yes

Were all patients included in the analysis?

Unclear

Unclear

\section{Segamwenge 2014}

\section{Study characteristics}

\begin{tabular}{ll}
\hline Patient sampling & Type of study: unclear whether prospective or retrospective study \\
& Consecutive or random sample: neither - patients with recent antibiotic treat- \\
ment were excluded
\end{tabular}

Patient characteristics and setting
Sample size: 160
Female: not stated
Age: not stated
Presentation:
1. Patients with dyspepsia
Exclusion criteria
1. Could not tolerate endoscopy
2. Recent $H$ pylori treatment
3. Pain attributable to pancreas or liver
4. NSAID-related dyspepsia
Setting: secondary care, Italy

Index tests

Index test: stool antigen test

Further details:

Technical specifications: Rapid strip HPSA (Meridian Bioscience)

Performed by: not stated

Criteria for positive diagnosis: not stated

Target condition and reference standard(s)

\section{Target condition: H pylori infection}

Reference standard: endoscopic biopsy (staining not reported, probably H \& E)

Further details:

Technical specifications: not stated

Performed by: endoscopist and pathologist

Criteria for positive diagnosis: presence of $H$ pylori in biopsy
Number of indeterminates for whom the results of reference standard was available: not stated

Number of patients who were excluded from the analysis: not stated

\section{Comparative}

Notes

\section{Methodological quality}

\begin{tabular}{llll}
\hline Item & Authors' judgement & Risk of bias & Applicability concerns \\
\hline DOMAIN &
\end{tabular}

DOMAIN 1: Patient Selection 
Segamwenge 2014 (Continued)

Was a consecutive or random sample of patients No enrolled?

\begin{tabular}{llll}
\hline Was a case-control design avoided? & Yes & Unclear \\
\hline Did the study avoid inappropriate exclusions? & Unclear & High \\
\hline DOMAIN 2: Index Test Stool Antigen Test & & Unclear & High \\
\hline $\begin{array}{l}\text { Were the index test results interpreted without } \\
\text { knowledge of the results of the reference stan- }\end{array}$ & & Unclear & Unclear \\
\hline \begin{tabular}{l} 
If a threshold was used, was it pre-specified? \\
\hline
\end{tabular}
\end{tabular}

\section{DOMAIN 3: Reference Standard}

Is the reference standards likely to correctly clas- No sify the target condition?

Were the reference standard results interpret- Unclear ed without knowledge of the results of the index tests?

\begin{tabular}{lll}
\hline Ligh & Low \\
\hline
\end{tabular}

\section{DOMAIN 4: Flow and Timing}

Was there an appropriate interval between index Unclear test and reference standard?

Did all patients receive the same reference stan- Yes dard?

Were all patients included in the analysis? No

High

\section{Selcukcan 2011}

\section{Study characteristics}

Patient sampling

Patient characteristics and setting
Type of study: unclear whether prospective or retrospective study Consecutive or random sample: unclear sampling process 
Selcukcan 2011 (Continued)

1. No recent $\mathrm{H}$ pylori treatment

Setting: secondary care, Turkey

\begin{tabular}{|c|c|}
\hline Index tests & $\begin{array}{l}\text { Index test: urea breath test- }{ }^{14} \mathrm{C} \\
\text { Further details: } \\
\text { Technical specifications: not stated } \\
\text { Performed by: not stated } \\
\text { Criteria for positive diagnosis: not stated }\end{array}$ \\
\hline Target condition and reference standard(s) & $\begin{array}{l}\text { Target condition: } H \text { pylori infection } \\
\text { Reference standard: endoscopic biopsy (staining not reported, probably } H \text { \& } \\
\text { E) } \\
\text { Further details: } \\
\text { Technical specifications: not stated } \\
\text { Performed by: endoscopist and pathologist } \\
\text { Criteria for positive diagnosis: presence of } H \text { pylori in biopsy }\end{array}$ \\
\hline Flow and timing & $\begin{array}{l}\text { Number of indeterminates for whom the results of reference standard was } \\
\text { available: not stated } \\
\text { Number of patients who were excluded from the analysis: not stated }\end{array}$ \\
\hline
\end{tabular}

Comparative

Notes

\section{Methodological quality}

\begin{tabular}{llll}
\hline Item Authors' judgement & Risk of bias & $\begin{array}{l}\text { Applicability con- } \\
\text { cerns }\end{array}$ \\
\hline
\end{tabular}

\section{DOMAIN 1: Patient Selection}

Was a consecutive or random sample of patients en- Unclear rolled?

\begin{tabular}{llll}
\hline Was a case-control design avoided? & Yes & Unclear & Unclear \\
\hline Did the study avoid inappropriate exclusions? & Unclear & & \\
\hline DOMAIN 2: Index Test Urea breath test-14C & Unclear & \\
\hline $\begin{array}{l}\text { Were the index test results interpreted without } \\
\text { knowledge of the results of the reference standard? }\end{array}$ & Unclear & Unclear \\
\hline If a threshold was used, was it pre-specified? & & High \\
\hline
\end{tabular}

\section{DOMAIN 3: Reference Standard}

Is the reference standards likely to correctly classify No the target condition?

Were the reference standard results interpreted without knowledge of the results of the index tests? 
Selcukcan 2011 (Continued)

High

Low

\section{DOMAIN 4: Flow and Timing}

Was there an appropriate interval between index Unclear test and reference standard?

Did all patients receive the same reference stan- $\quad$ Yes dard?

Were all patients included in the analysis?

Unclear

Unclear

\section{Sharbatdaran 2013}

\section{Study characteristics}

Patient sampling

Type of study: unclear whether prospective or retrospective study

Consecutive or random sample: consecutive patients

Patient characteristics and setting

Sample size: 61

Female: 36 (59\%)

Age: 31 years

Presentation:

1. Patients with dyspepsia

Exclusion criteria:

1. Recent $H$ pylori infection

2. Gastric cancer

3. Bleeding during endoscopy

Setting: secondary care, Iran

Index tests

Index test: stool antigen test

Further details:

Technical specifications: GA Generic Assay

Performed by: not stated

Criteria for positive diagnosis: Absorbance $450 \mathrm{~nm}>+0.1$ of negative control

\footnotetext{
Target condition and reference standard(s)
}

Target condition: $H$ pylori infection

Reference standard: endoscopic biopsy with $\mathrm{H}$ \& E stain and Giemsa stain

Further details:

Technical specifications: not stated

Performed by: endoscopist and pathologist

Criteria for positive diagnosis: presence of $H$ pylori in biopsy

Flow and timing

Number of indeterminates for whom the results of reference standard was available: not stated

Number of patients who were excluded from the analysis: 0 (0\%)

\section{Comparative}

Notes

\section{Methodological quality}


Sharbatdaran 2013 (Continued)

Item

Authors' judgement

Risk of bias

Applicability concerns

\section{DOMAIN 1: Patient Selection}

Was a consecutive or random sample of patients en- Yes rolled?

\begin{tabular}{llll}
\hline Was a case-control design avoided? & Yes & \\
\hline Did the study avoid inappropriate exclusions? & Yes & Low & Low \\
\hline
\end{tabular}

\section{DOMAIN 2: Index Test Stool Antigen Test}

Were the index test results interpreted without knowl- Yes edge of the results of the reference standard?

\begin{tabular}{lll}
\hline If a threshold was used, was it pre-specified? & Yes & Low \\
\hline
\end{tabular}

\section{DOMAIN 3: Reference Standard}

Is the reference standards likely to correctly classify No the target condition?

Were the reference standard results interpreted with- Yes out knowledge of the results of the index tests?

High Low

\section{DOMAIN 4: Flow and Timing}

Was there an appropriate interval between index test Unclear and reference standard?

Did all patients receive the same reference standard? Yes

Were all patients included in the analysis? Yes

\section{Unclear}

\section{Sheu 1998a}

\section{Study characteristics}

\begin{tabular}{ll}
\hline Patient sampling & $\begin{array}{l}\text { Type of study: unclear } \\
\text { Consecutive or randor }\end{array}$ \\
\hline Patient characteristics and setting & Sample size: 135 \\
& Female: not stated \\
Age: not stated & Presentation:
\end{tabular}


Sheu 1998a (Continued)

1. Patients with dyspepsia

Setting: secondary care, Mexico

\begin{tabular}{ll}
\hline Index tests & Index test: urea breath test-13C \\
& Further details: \\
& Technical specifications: not stated \\
& Performed by: not stated \\
& Criteria for positive diagnosis: not clearly stated
\end{tabular}

Target condition and reference standard(s)

Target condition: $H$ pylori infection

Reference standard: endoscopic biopsy (staining not reported, probably

$H \& E$ )

Further details:

Technical specifications: not stated

Performed by: endoscopist and pathologist

Criteria for positive diagnosis: presence of $H$ pylori in biopsy

Flow and timing

Number of indeterminates for whom the results of reference standard was available: not stated

Number of patients who were excluded from the analysis: not stated

\section{Comparative}

Notes

\section{Methodological quality}

\begin{tabular}{llll}
\hline Item Authors' judgement & Risk of bias & $\begin{array}{l}\text { Applicability con- } \\
\text { cerns }\end{array}$ \\
\hline
\end{tabular}

\section{DOMAIN 1: Patient Selection}

Was a consecutive or random sample of patients en- Unclear rolled?

\begin{tabular}{lll}
\hline Was a case-control design avoided? & Yes & \\
\hline Did the study avoid inappropriate exclusions? & Unclear & Unclear \\
\hline
\end{tabular}

\section{DOMAIN 2: Index Test Urea breath test-13C}

Were the index test results interpreted without knowl- Unclear edge of the results of the reference standard?

\begin{tabular}{llll}
\hline If a threshold was used, was it pre-specified? & Unclear & \\
\hline & Unclear & High \\
\hline
\end{tabular}

\section{DOMAIN 3: Reference Standard}

Is the reference standards likely to correctly classify the No target condition?

Were the reference standard results interpreted without Unclear knowledge of the results of the index tests? 
Sheu 1998a (Continued)

High

Low

\section{DOMAIN 4: Flow and Timing}

Was there an appropriate interval between index test Unclear and reference standard?

\begin{tabular}{ll}
\hline Did all patients receive the same reference standard? & Yes \\
\hline Were all patients included in the analysis? & Unclear \\
\hline
\end{tabular}

Unclear

\section{Sheu 1998b}

\section{Study characteristics}

\begin{tabular}{|c|c|}
\hline Patient sampling & $\begin{array}{l}\text { Type of study: unclear whether prospective or retrospective study } \\
\text { Consecutive or random sample: unclear sampling process }\end{array}$ \\
\hline Patient characteristics and setting & $\begin{array}{l}\text { Sample size: } 66 \\
\text { Female: not stated } \\
\text { Age: not stated } \\
\text { Presentation: } \\
\text { 1. Patients with gastrectomy } \\
\text { Setting: secondary care, Mexico }\end{array}$ \\
\hline Index tests & $\begin{array}{l}\text { Index test: urea breath test- } 13 \mathrm{C} \\
\text { Further details: } \\
\text { Technical specifications: not stated } \\
\text { Performed by: not stated } \\
\text { Criteria for positive diagnosis: not clearly stated }\end{array}$ \\
\hline Target condition and reference standard(s) & $\begin{array}{l}\text { Target condition: } H \text { pylori infection } \\
\text { Reference standard: endoscopic biopsy (staining not reported, probably } \\
\text { H\&E) } \\
\text { Further details: } \\
\text { Technical specifications: not stated } \\
\text { Performed by: endoscopist and pathologist } \\
\text { Criteria for positive diagnosis: presence of } H \text { pylori in biopsy }\end{array}$ \\
\hline Flow and timing & $\begin{array}{l}\text { Number of indeterminates for whom the results of reference standard } \\
\text { was available: not stated } \\
\text { Number of patients who were excluded from the analysis: not stated }\end{array}$ \\
\hline Comparative & \\
\hline
\end{tabular}

\section{Methodological quality}

\begin{tabular}{llll}
\hline Item Authors' judgement & Risk of bias & \multicolumn{1}{l}{$\begin{array}{l}\text { Applicability con- } \\
\text { cerns }\end{array}$}
\end{tabular}

\section{DOMAIN 1: Patient Selection}


Sheu 1998b (Continued)

Was a consecutive or random sample of patients en- Unclear rolled?

\begin{tabular}{llll}
\hline Was a case-control design avoided? & Yes & \\
\hline Did the study avoid inappropriate exclusions? & Unclear & Unclear & High \\
\hline
\end{tabular}

\section{DOMAIN 2: Index Test Urea breath test-13C}

\section{Were the index test results interpreted without knowl- Unclear} edge of the results of the reference standard?

\begin{tabular}{llll}
\hline If a threshold was used, was it pre-specified? & Unclear & & High \\
\hline DOMAIN 3: Reference Standard & Unclear & \\
\hline
\end{tabular}

Is the reference standards likely to correctly classify the No
target condition?

target condition?

Were the reference standard results interpreted without Unclear

knowledge of the results of the index tests?

\section{No}

knowledge of the results of the index tests?

High

Low

\section{DOMAIN 4: Flow and Timing}

Was there an appropriate interval between index test Unclear
and reference standard?
and reference standard?

\begin{tabular}{ll}
\hline Did all patients receive the same reference standard? & Yes \\
\hline Were all patients included in the analysis? & Unclear \\
\hline
\end{tabular}

\section{Unclear}

\section{Shin 2009}

\section{Study characteristics}

\section{Patient sampling}

Patient characteristics and setting

Type of study: unclear whether prospective or retrospective study Consecutive or random sample: unclear sampling process

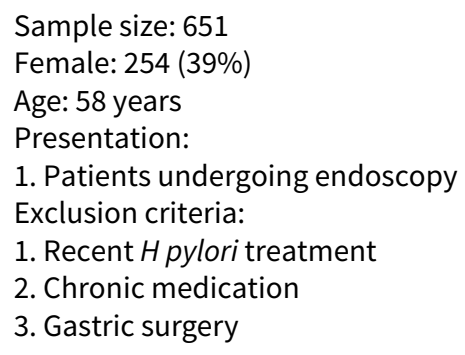

Sample size: 651

Female: 254 (39\%)

Age: 58 years

Presentation:

1. Patients undergoing endoscopy

Exclusion criteria:

1. Recent $H$ pylori treatment

2. Chronic medication

3. Gastric surgery 
Shin 2009 (Continued)

\begin{tabular}{ll} 
& Setting: secondary care, South Korea \\
\hline Index tests & Index test: serology \\
& $\begin{array}{l}\text { Further details: } \\
\text { Technical specifications: Genedia } H \text { pylori } \\
\text { Performed by: not stated } \\
\text { Criteria for positive diagnosis: Absorbance } 450 \mathrm{~nm}>0.406\end{array}$ \\
\hline Target condition and reference standard(s) & Target condition: $H$ pylori infection \\
& $\begin{array}{l}\text { Reference standard: endoscopic biopsy with Giemsa stain } \\
\text { Further details: }\end{array}$ \\
& $\begin{array}{l}\text { Technical specifications: not stated } \\
\text { Performed by: endoscopist and pathologist } \\
\text { Criteria for positive diagnosis: presence of } H \text { pylori in biopsy }\end{array}$ \\
& Number of indeterminates for whom the results of reference standard was \\
Flow and timing & available: not stated \\
Number of patients who were excluded from the analysis: not stated
\end{tabular}

\section{Comparative}

Notes

\section{Methodological quality}

\begin{tabular}{llll}
\hline Item Authors' judgement & Risk of bias & $\begin{array}{l}\text { Applicability con- } \\
\text { cerns }\end{array}$
\end{tabular}

\section{DOMAIN 1: Patient Selection} Was a consecutive or random sample of patients en- Unclear
rolled?

\begin{tabular}{llll}
\hline Was a case-control design avoided? & Yes & \\
\hline Did the study avoid inappropriate exclusions? & Unclear & Unclear \\
\hline
\end{tabular}

\section{DOMAIN 2: Index Test Serology}

Were the index test results interpreted without
knowledge of the results of the reference standard?

knowledge of the results of the reference standard?

If a threshold was used, was it pre-specified? Yes

\begin{tabular}{lll}
\hline & Unclear & Low \\
\hline DOMAIN 3: Reference Standard
\end{tabular}

\section{DOMAIN 3: Reference Standard}

Is the reference standards likely to correctly classify Yes the target condition?

Were the reference standard results interpreted Unclear
without knowledge of the results of the index tests?

\begin{tabular}{l}
\hline Unclear \\
Low
\end{tabular}


Shin 2009 (Continued)

\title{
DOMAIN 4: Flow and Timing
}

Was there an appropriate interval between index Unclear
test and reference standard?

Did all patients receive the same reference stan- Yes dard?
Were all patients included in the analysis?
Unclear

Unclear

\section{Soomro 2012}

\section{Study characteristics}

\section{Patient sampling}

Type of study: unclear whether prospective or retrospective study Consecutive or random sample: unclear sampling process

\section{Patient characteristics and setting}

Sample size: 100

Female: 44 (44\%)

Age: not stated

Presentation:

1. Patients undergoing endoscopic biopsy for dyspepsia or gastritis Setting: secondary care, Pakistan

\section{Index tests}

\author{
Index test: serology \\ Further details: \\ Technical specifications: not stated \\ Performed by: not stated \\ Criteria for positive diagnosis: not stated \\ Index test: stool antigen test \\ Further details: \\ Technical specifications: not stated \\ Performed by: not stated \\ Criteria for positive diagnosis: not stated
}

\begin{tabular}{ll}
\hline Target condition and reference standard(s) & Target condition: $H$ pylori infection \\
& Reference standard: endoscopic biopsy with Giemsa stain \\
& Further details: \\
& Technical specifications: not stated \\
& Performed by: endoscopist and pathologist \\
& Criteria for positive diagnosis: presence of $H$ pylori in biopsy
\end{tabular}

Flow and timing

Number of indeterminates for whom the results of reference standard was available: not stated Number of patients who were excluded from the analysis: not stated

\section{Comparative}

Notes

\section{Methodological quality}


Soomro 2012 (Continued)

Item

Authors' judgement

Risk of bias

Applicability con-

cerns

DOMAIN 1: Patient Selection

Was a consecutive or random sample of patients en- Unclear rolled?

\begin{tabular}{llll}
\hline Was a case-control design avoided? & Yes & \\
\hline Did the study avoid inappropriate exclusions? & Unclear & Unclear & Unclear
\end{tabular}

\section{DOMAIN 2: Index Test Stool Antigen Test}

Were the index test results interpreted without knowl- Unclear edge of the results of the reference standard?

\begin{tabular}{llll}
\hline If a threshold was used, was it pre-specified? & Unclear & & High \\
\hline
\end{tabular}

\section{DOMAIN 2: Index Test Serology}

\section{Were the index test results interpreted without knowl- Unclear}

edge of the results of the reference standard?

\begin{tabular}{llll}
\hline If a threshold was used, was it pre-specified? & Unclear & \\
\hline & Unclear & High \\
\hline
\end{tabular}

\section{DOMAIN 3: Reference Standard}

Is the reference standards likely to correctly classify the Yes target condition?

Were the reference standard results interpreted without Unclear knowledge of the results of the index tests?

Unclear

Low

\section{DOMAIN 4: Flow and Timing}

\section{Was there an appropriate interval between index test Unclear} and reference standard?

\begin{tabular}{ll}
\hline Did all patients receive the same reference standard? & Yes \\
\hline Were all patients included in the analysis? & Unclear \\
\hline
\end{tabular}

\section{Unclear}




\section{Surveyor 1989}

\section{Study characteristics}

$\begin{array}{ll}\text { Patient sampling } & \begin{array}{l}\text { Type of study: unclear whether prospective or retrospective study } \\ \text { Consecutive or random sample: consecutive patients }\end{array}\end{array}$

$\begin{array}{ll}\text { Patient characteristics and setting } & \text { Sample size: } 63 \\ & \text { Female: } 30(47.8 \%) \\ & \text { Age: } 59 \text { years } \\ \text { Presentation: } & \text { 1. Patients with symptoms related to upper gastrointestinal tract undergo- } \\ & \text { ing endoscopy } \\ \text { Setting: secondary care, Australia }\end{array}$

Index tests

Index test: urea breath test- ${ }^{14} \mathrm{C}$

Further details:

Technical specifications: not stated

Performed by: not stated

Criteria for positive diagnosis: not stated

\section{Target condition and reference standard(s)}

Target condition: H pylori infection Reference standard: endoscopic biopsy with H \& E stain, Warthin-Starry stain, and Giemsa stain

Further details:

Technical specifications: not stated

Performed by: endoscopist and pathologist

Criteria for positive diagnosis: presence of $H$ pylori in biopsy

Flow and timing

Number of indeterminates for whom the results of reference standard was available: not stated

Number of patients who were excluded from the analysis: $0(0 \%)$

\section{Comparative}

Notes

\section{Methodological quality}

\begin{tabular}{llll}
\hline Item Authors' judgement & Risk of bias & $\begin{array}{l}\text { Applicability con- } \\
\text { cerns }\end{array}$
\end{tabular}

\section{DOMAIN 1: Patient Selection}

Was a consecutive or random sample of patients en- Yes rolled?

\begin{tabular}{llll}
\hline Was a case-control design avoided? & Yes & \\
\hline Did the study avoid inappropriate exclusions? & Yes & Low & Low \\
\hline
\end{tabular}

\section{DOMAIN 2: Index Test Urea breath test-14C}

Were the index test results interpreted without knowl- Unclear edge of the results of the reference standard? 


\section{DOMAIN 3: Reference Standard}

Is the reference standards likely to correctly classify

the target condition?

Were the reference standard results interpreted with- Unclear

out knowledge of the results of the index tests?

High Low

\section{DOMAIN 4: Flow and Timing}

Was there an appropriate interval between index test Unclear and reference standard?

\begin{tabular}{ll}
\hline Did all patients receive the same reference standard? & Yes \\
\hline Were all patients included in the analysis? & Yes \\
\hline
\end{tabular}

\section{Unclear}

\section{Thobani 1995}

\section{Study characteristics}

\section{Patient sampling}

Patient characteristics and setting
Type of study: unclear whether prospective or retrospective study Consecutive or random sample: unclear sampling process

Sample size: 26

Female: not stated

Age: not stated

Presentation:

1. Patients with upper gastrointestinal symptoms

Setting: secondary care, Pakistan

\author{
Index test: serology \\ Further details: \\ Technical specifications: not stated \\ Performed by: not stated \\ Criteria for positive diagnosis: $>2$
}

\section{Target condition and reference standard(s)}

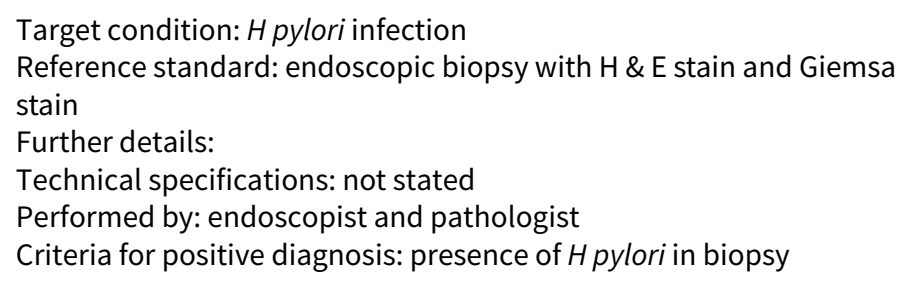

Flow and timing

Number of indeterminates for whom the results of reference standard was available: not stated

Number of patients who were excluded from the analysis: not stated 
Thobani 1995 (Continued)

Comparative

$$
\text { Notes }
$$

\title{
Methodological quality
}

\begin{tabular}{llcl}
\hline Item Authors' judgement & Risk of bias & $\begin{array}{l}\text { Applicability con- } \\
\text { cerns }\end{array}$ \\
\hline
\end{tabular}

\section{DOMAIN 1: Patient Selection}

Was a consecutive or random sample of patients en- Unclear rolled?

\begin{tabular}{lll}
\hline Was a case-control design avoided? & Yes & \\
\hline Did the study avoid inappropriate exclusions? & Unclear & Unclear \\
\hline
\end{tabular}

\section{DOMAIN 2: Index Test Serology}

\begin{abstract}
Were the index test results interpreted without knowl- Unclear
\end{abstract} edge of the results of the reference standard?

\begin{tabular}{llll}
\hline If a threshold was used, was it pre-specified? & Unclear & & Low \\
\hline DOMAIN 3: Reference Standard & Unclear & \\
\hline
\end{tabular}
Is the reference standards likely to correctly classify the No target condition?

Were the reference standard results interpreted without Unclear knowledge of the results of the index tests?

\begin{tabular}{ll}
\hline & High \\
\hline DOMAIN 4: Flow and Timing & \\
\hline $\begin{array}{l}\text { Was there an appropriate interval between index test } \\
\text { and reference standard? }\end{array}$ & Unclear \\
\hline Did all patients receive the same reference standard? & Yes \\
\hline Were all patients included in the analysis? & Unclear \\
\hline
\end{tabular}

\section{Unclear}

\section{Tiwari 2014}

\section{Study characteristics}


Tiwari 2014 (Continued)

Consecutive or random sample: unclear sampling process

$\begin{array}{ll}\text { Patient characteristics and setting } & \text { Sample size: } 30 \\ & \text { Female: } 25(83.3 \%) \\ & \text { Age: not stated } \\ \text { Presentation: } & \text { 1. Patients undergoing endoscopy } \\ \text { Exclusion criteria: } & \text { 1. Recent } H \text { pylori treatment } \\ \text { Setting: secondary care, India }\end{array}$

Index tests Index test: urea breath test- ${ }^{14} \mathrm{C}$

Further details:

Technical specifications: not stated

Performed by: not stated

Criteria for positive diagnosis: disintegrations per minute $>200$ (10 minutes)

$\begin{array}{ll}\text { Target condition and reference standard(s) } & \text { Target condition: } H \text { pylori infection } \\ & \text { Reference standard: endoscopic biopsy (staining not reported, probably H \& } \\ & \text { E) } \\ & \text { Further details: } \\ & \text { Technical specifications: not stated } \\ \text { Performed by: endoscopist and pathologist } \\ \text { Criteria for positive diagnosis: presence of } H \text { pylori in biopsy }\end{array}$

Flow and timing

Number of indeterminates for whom the results of reference standard was available: not stated

Number of patients who were excluded from the analysis: not stated

\section{Comparative}

$$
\text { Notes }
$$

Methodological quality

\begin{tabular}{llll}
\hline Item & Authors' judgement & Risk of bias & $\begin{array}{l}\text { Applicability con- } \\
\text { cerns }\end{array}$ \\
\hline
\end{tabular}

\section{DOMAIN 1: Patient Selection}

Was a consecutive or random sample of patients en- Unclear rolled?

\begin{tabular}{lll}
\hline Was a case-control design avoided? & Yes & Unclear \\
\hline Did the study avoid inappropriate exclusions? & Unclear & Unclear \\
\hline DOMAIN 2: Index Test Urea breath test-14C & & \\
\hline $\begin{array}{l}\text { Were the index test results interpreted without } \\
\text { knowledge of the results of the reference standard? }\end{array}$ & Unclear & Unclear \\
\hline If a threshold was used, was it pre-specified? & Unclear & Low \\
\hline
\end{tabular}


Tiwari 2014 (Continued)

DOMAIN 3: Reference Standard

Is the reference standards likely to correctly classify No the target condition?

Were the reference standard results interpreted Unclear

without knowledge of the results of the index tests?

High Low

\section{DOMAIN 4: Flow and Timing}

Was there an appropriate interval between index Unclear test and reference standard?

Did all patients receive the same reference stan- $\quad$ Yes dard?

Were all patients included in the analysis?

Unclear

Unclear

\section{Trevisani 2005}

\section{Study characteristics}

\begin{tabular}{ll} 
Patient sampling & $\begin{array}{l}\text { Type of study: unclear whether prospective } \\
\text { Consecutive or random sample: unclear sam }\end{array}$ \\
\hline Patient characteristics and setting & Sample size: 105 \\
& Female: $50(47.6 \%)$ \\
& Age: 58 years \\
Presentation: & 1. Patients referred to endoscopy centre \\
& Exclusion criteria: \\
1. Recent $H$ pylori treatment \\
2. Pregnancy or lactation \\
3. Steroids or NSAID treatment \\
4. Prior gastric surgery \\
5. Bleeding peptic ulcer \\
6. Severe concomitant diseases \\
Setting: secondary care, Italy
\end{tabular}

Index tests

Index test 1a: stool antigen test

Further details:

Technical specifications: Amplified IDEA Hp StAR

Performed by: doctor

Criteria for positive diagnosis: Absorbance $450 \mathrm{~nm} \geq 0.190$

Index test $1 \mathrm{~b}$ : stool antigen test

Further details:

Technical specifications: Immunocard Stat

Performed by: doctor

Criteria for positive diagnosis: pink red band ( 5 minutes)

\footnotetext{
Target condition and reference standard(s)

Target condition: $H$ pylori infection
} 
Trevisani 2005 (Continued)

Reference standard: endoscopic biopsy with H \& E stain and Giemsa stain

Further details:

Technical specifications: not stated

Performed by: endoscopist and pathologist

Criteria for positive diagnosis: presence of $H$ pylori in biopsy

Flow and timing

Number of indeterminates for whom the results of reference standard was available:

not stated

Number of patients who were excluded from the analysis: not stated

Comparative

Notes

Methodological quality

\begin{tabular}{llll}
\hline Item & Authors' judgement & Risk of bias & Applicability concerns \\
\hline
\end{tabular}

DOMAIN 1: Patient Selection

Was a consecutive or random sample of pa- Unclear tients enrolled?

\begin{tabular}{ll}
\hline Was a case-control design avoided? & Yes \\
\hline $\begin{array}{l}\text { Did the study avoid inappropriate exclu- } \\
\text { sions? }\end{array}$ & Unclear \\
\hline
\end{tabular}

\begin{tabular}{lll}
\hline & Unclear & Unclear \\
\hline DOMAIN 2: Index Test Stool Antigen Test & & \\
\hline $\begin{array}{l}\text { Were the index test results interpreted with- } \\
\text { out knowledge of the results of the refer- } \\
\text { ence standard? }\end{array}$ & & Unclear \\
\hline If a threshold was used, was it pre-specified? & Unclear & Low \\
\hline
\end{tabular}

DOMAIN 3: Reference Standard

Is the reference standards likely to correctly No classify the target condition?

Were the reference standard results inter- Unclear preted without knowledge of the results of the index tests?

\begin{tabular}{lll}
\hline & High & Low \\
\hline
\end{tabular}

\section{DOMAIN 4: Flow and Timing}

Was there an appropriate interval between Unclear

index test and reference standard? 
Trevisani 2005 (Continued)

Did all patients receive the same reference Yes standard?

Were all patients included in the analysis? Unclear

Unclear

Vandenplas 1992

\section{Study characteristics}

$\begin{array}{ll}\text { Patient sampling } & \begin{array}{l}\text { Type of study: unclear whether prospective or retrospective study } \\ \text { Consecutive or random sample: consecutive patients }\end{array}\end{array}$

\begin{tabular}{ll}
\hline Patient characteristics and setting & Sample size: 95 \\
& Female: $50(52.6 \%)$ \\
& Age: 9 years \\
Presentation: & 1. Children with chronic abdominal pain \\
& Exclusion criteria: \\
& 1. Recent $H$ pylori treatment \\
Setting: secondary care, Belgium
\end{tabular}

Index tests

Index test 1: urea breath test-13C

Further details:

Technical specifications: not stated

Performed by: not stated

Criteria for positive diagnosis: not clearly stated

Index test 2: serology

Further details:

Technical specifications: Malakit Helicobacter pylori (Biolab)

Performed by: not stated

Criteria for positive diagnosis: > Mean +3 standard deviations above normal level

\section{Target condition and reference standard(s)}

\section{Target condition: $H$ pylori infection}

Reference standard: endoscopic biopsy with $\mathrm{H}$ \& E stain and Giemsa stain Further details:

Technical specifications: not stated

Performed by: endoscopist and pathologist

Criteria for positive diagnosis: presence of $H$ pylori in biopsy

Flow and timing

Number of indeterminates for whom the results of reference standard was available: not stated

Number of patients who were excluded from the analysis: 0 (0\%)

\section{Comparative}

\section{Notes}

\section{Methodological quality}

\begin{tabular}{llll}
\hline Item & Authors' judgement & Risk of bias & $\begin{array}{l}\text { Applicability con- } \\
\text { cerns }\end{array}$ \\
\hline
\end{tabular}


Vandenplas 1992 (Continued)

\section{DOMAIN 1: Patient Selection}

Was a consecutive or random sample of patients en- Yes rolled?

\begin{tabular}{ll} 
Was a case-control design avoided? & Yes \\
\hline
\end{tabular}

Did the study avoid inappropriate exclusions?

Yes

Low Low

\section{DOMAIN 2: Index Test Urea breath test-13C}

Were the index test results interpreted without Unclear

knowledge of the results of the reference standard?

If a threshold was used, was it pre-specified? Unclear

\begin{tabular}{lll}
\hline Unclear & High \\
\hline
\end{tabular}

\section{DOMAIN 2: Index Test Serology}

Were the index test results interpreted without Unclear
knowledge of the results of the reference standard?

knowledge of the results of the reference standard?

If a threshold was used, was it pre-specified? Unclear

\begin{tabular}{lll}
\hline & Unclear & Low \\
\hline DOMAIN 3: Reference Standard & &
\end{tabular}

Is the reference standards likely to correctly classify No
the target condition?

Were the reference standard results interpreted Unclear

without knowledge of the results of the index tests?

\begin{tabular}{lll}
\hline DOMAIN 4: Flow and Timing & High & Low \\
\hline $\begin{array}{l}\text { Was there an appropriate interval between index } \\
\text { test and reference standard? }\end{array}$ & Unclear \\
\hline $\begin{array}{l}\text { Did all patients receive the same reference stan- } \\
\text { dard? }\end{array}$ & Yes \\
\hline Were all patients included in the analysis? & Yes
\end{tabular}

Unclear

Villalobos 1992

\section{Study characteristics}


Villalobos 1992 (Continued)

Patient sampling

Type of study: unclear whether prospective or retrospective study

Consecutive or random sample: unclear sampling process

Patient characteristics and setting

\author{
Sample size: 105 \\ Female: $69(65.7 \%)$ \\ Age: not stated \\ Presentation: \\ 1. Patients with dyspepsia \\ Excluded: \\ 1. Recent $H$ pylori treatment \\ 2. Patients taking steroids \\ 3. Patients with coagulopathy \\ 4. Patients allergic to penicillin \\ 5. Pregnancy or lactation \\ Setting: secondary care, Mexico
}

\begin{tabular}{|c|c|}
\hline Index tests & $\begin{array}{l}\text { Index test: urea breath test- } 14 \mathrm{C} \\
\text { Further details: } \\
\text { Technical specifications: not stated } \\
\text { Performed by: not stated } \\
\text { Criteria for positive diagnosis: disintegrations per minute }>1 \text {. }\end{array}$ \\
\hline Target condition and reference standard(s) & $\begin{array}{l}\text { Target condition: } H \text { pylori infection } \\
\text { Reference standard: endoscopic biopsy with Giemsa stain } \\
\text { Further details: } \\
\text { Technical specifications: not stated } \\
\text { Performed by: endoscopist and pathologist } \\
\text { Criteria for positive diagnosis: presence of } H \text { pylori in biopsy }\end{array}$ \\
\hline
\end{tabular}

Flow and timing

Number of indeterminates for whom the results of reference standard was available: not stated

Number of patients who were excluded from the analysis: not stated

Comparative

Notes

\title{
Methodological quality
}

\begin{tabular}{llcl}
\hline Item Authors' judgement & Risk of bias & $\begin{array}{l}\text { Applicability con- } \\
\text { cerns }\end{array}$ \\
\hline
\end{tabular}

DOMAIN 1: Patient Selection

Was a consecutive or random sample of patients Unclear
enrolled?
enrolled?

\begin{tabular}{llll}
\hline Was a case-control design avoided? & Yes & \\
\hline Did the study avoid inappropriate exclusions? & Unclear & Unclear & Unclear \\
\hline
\end{tabular}

DOMAIN 2: Index Test Urea breath test-14C 
Villalobos 1992 (Continued)

Were the index test results interpreted without

Unclear knowledge of the results of the reference standard?

\begin{tabular}{llll}
\hline If a threshold was used, was it pre-specified? & Unclear & Low Unclear & Unclear \\
\hline
\end{tabular}

\section{DOMAIN 3: Reference Standard}

Is the reference standards likely to correctly clas- Yes sify the target condition?

\section{Were the reference standard results interpret- Unclear} ed without knowledge of the results of the index tests?

\begin{tabular}{llll}
\hline DOMAIN 4: Flow and Timing & Unclear & Low \\
\hline $\begin{array}{l}\text { Was there an appropriate interval between index } \\
\text { test and reference standard? }\end{array}$ & Unclear & \\
\hline $\begin{array}{l}\text { Did all patients receive the same reference stan- } \\
\text { dard? }\end{array}$ & Yes & Unclear \\
\hline Were all patients included in the analysis? & & Unclear \\
\hline
\end{tabular}

\section{Wang 2008}

\section{Study characteristics}

\begin{tabular}{ll}
\hline Patient sampling & $\begin{array}{l}\text { Type of study: unclear whether prospective or retrospective study } \\
\text { Consecutive or random sample: neither - patients with recent antibiotic treat- } \\
\text { ment were excluded }\end{array}$ \\
\hline Patient characteristics and setting & Sample size: 123 \\
& Female: $69(56.1 \%)$ \\
& Age: 48 years \\
& Presentation: \\
& 1. Asymptomatic individuals \\
& Exclusion criteria: \\
& 1. Recent $H$ pylori therapy \\
& 2. Gastric surgery \\
& Setting: secondary care, Italy \\
& Index test: serology \\
Further details: & Technical specifications: Assure $H$ pylori Rapid Test (CIM-test, Genelabs Diag- \\
nostics Ltd) & Performed by: not stated \\
Criteria for positive diagnosis: not stated
\end{tabular}




\section{Wang 2008 (Continued)}

Target condition and reference standard(s)
Target condition: $H$ pylori infection

Reference standard: endoscopic biopsy with H \& E stain, Warthin-Starry stain, and Giemsa stain

Further details:

Technical specifications: not stated

Performed by: endoscopist and pathologist

Criteria for positive diagnosis: presence of $H$ pylori in biopsy
Number of indeterminates for whom the results of reference standard was available: not stated

Number of patients who were excluded from the analysis: 214 (63.5\%)

\section{Comparative}

\section{Notes}

\section{Methodological quality}

\begin{tabular}{llll}
\hline Item Authors' judgement & Risk of bias
\end{tabular}

DOMAIN 1: Patient Selection

Was a consecutive or random sample of patients No enrolled?

\begin{tabular}{ll}
\hline Was a case-control design avoided? & Yes \\
\hline Did the study avoid inappropriate exclusions? & Unclea \\
\hline
\end{tabular}

High Unclear

\section{DOMAIN 2: Index Test Serology}

Were the index test results interpreted without Unclear

knowledge of the results of the reference standard?

If a threshold was used, was it pre-specified? Yes

\section{Unclear}

High

\section{DOMAIN 3: Reference Standard}

Is the reference standards likely to correctly classi- No fy the target condition?

Were the reference standard results interpreted Unclear without knowledge of the results of the index tests?

High Low

\section{DOMAIN 4: Flow and Timing}

Was there an appropriate interval between index Unclear
test and reference standard?

Did all patients receive the same reference stan- Yes dard? 
Wang 2008 (Continued)

\section{Wardi 2012}

\section{Study characteristics}

$\begin{array}{ll}\text { Patient sampling } & \begin{array}{l}\text { Type of study: retrospective study } \\ \text { Consecutive or random sample: unclear sampling process }\end{array}\end{array}$

\begin{tabular}{ll}
\hline Patient characteristics and setting & Sample size: 76 \\
& Female: $15(19.7 \%)$ \\
& Age: 70 years \\
& Presentation: \\
& 1. Patients with partial gastrectomy \\
& Setting: secondary care, Israel
\end{tabular}

Index tests Index test: urea breath test - C13

Further details:

Technical specifications: BreathID

Performed by: not stated

Criteria for positive diagnosis: not clearly stated

\section{Target condition and reference standard(s)}

\section{Target condition: $H$ pylori infection}

Reference standard: endoscopic biopsy with H \& E stain and Giemsa

stain

Further details:

Technical specifications: not stated

Performed by: endoscopist and pathologist

Criteria for positive diagnosis: presence of $H$ pylori in biopsy

Flow and timing

Number of indeterminates for whom the results of reference standard was available: not stated

Number of patients who were excluded from the analysis: not stated

\section{Comparative}

\section{Notes}

\section{Methodological quality}

\begin{tabular}{llll}
\hline Item & Authors' judgement & Risk of bias & $\begin{array}{l}\text { Applicability con- } \\
\text { cerns }\end{array}$
\end{tabular}

\section{DOMAIN 1: Patient Selection}

Was a consecutive or random sample of patients en- Unclear rolled?

\begin{tabular}{ll}
\hline Was a case-control design avoided? & Yes \\
\hline Did the study avoid inappropriate exclusions? & Unclear \\
\hline
\end{tabular}

\begin{tabular}{lll}
\hline & Unclear & High \\
\hline
\end{tabular}


Wardi 2012 (Continued)

DOMAIN 2: Index Test Urea breath test-13C

Were the index test results interpreted without knowl- Unclear edge of the results of the reference standard?

\begin{tabular}{llll}
\hline If a threshold was used, was it pre-specified? & No & High & High \\
\hline
\end{tabular}

\section{DOMAIN 3: Reference Standard}

Is the reference standards likely to correctly classify the No target condition?

Were the reference standard results interpreted without Unclear knowledge of the results of the index tests?

High Low

\section{DOMAIN 4: Flow and Timing}

Was there an appropriate interval between index test Unclear
and reference standard?

Did all patients receive the same reference standard? Yes

Were all patients included in the analysis? Unclear

Unclear

\section{Weiss 1994}

\section{Study characteristics}

\begin{tabular}{|c|c|}
\hline Patient sampling & $\begin{array}{l}\text { Type of study: unclear whether prospective or retrospective study } \\
\text { Consecutive or random sample: unclear sampling process }\end{array}$ \\
\hline Patient characteristics and setting & $\begin{array}{l}\text { Sample size: } 95 \\
\text { Female: not stated } \\
\text { Age: not stated } \\
\text { Presentation: } \\
\text { 1. Patients with abdominal pain } \\
\text { Exclusion criteria: } \\
\text { 1. Recent } H \text { pylori treatment } \\
\text { Setting: secondary care, USA }\end{array}$ \\
\hline Index tests & $\begin{array}{l}\text { Index test 1a: serology } \\
\text { Further details: } \\
\text { Technical specifications: not stated } \\
\text { Performed by: not stated } \\
\text { Criteria for positive diagnosis: not stated } \\
\text { Index test } 1 \text { b: serology } \\
\text { Further details: } \\
\text { Technical specifications: Cobas Core anti-H pylori (Roche) } \\
\text { Performed by: not stated }\end{array}$ \\
\hline
\end{tabular}


Weiss 1994 (Continued)

Criteria for positive diagnosis: not stated

Target condition and reference standard(s)

Target condition: $H$ pylori infection

Reference standard: endoscopic biopsy with H \& E stain and Giemsa stain

Further details:

Technical specifications: not stated

Performed by: endoscopist and pathologist

Criteria for positive diagnosis: presence of $H$ pylori in biopsy

Flow and timing

Number of indeterminates for whom the results of reference standard was available: not stated

Number of patients who were excluded from the analysis: not stated

\section{Comparative}

\section{Notes}

\section{Methodological quality}

\begin{tabular}{llll}
\hline Item & Authors' judgement & Risk of bias & Applicability concerns \\
\hline
\end{tabular}

DOMAIN 1: Patient Selection

Was a consecutive or random sample of patients Unclear enrolled?

\begin{tabular}{llll}
\hline Was a case-control design avoided? & Yes & \\
\hline Did the study avoid inappropriate exclusions? & Unclear & Unclear & Unclear \\
\hline
\end{tabular}

\section{DOMAIN 2: Index Test Serology}

Were the index test results interpreted without knowledge of the results of the reference standard?

Unclear

If a threshold was used, was it pre-specified? Unclear

\begin{tabular}{lll}
\hline & Unclear & High \\
\hline DOMAIN 3: Reference Standard &
\end{tabular}

\section{DOMAIN 3: Reference Standard}

Is the reference standards likely to correctly No classify the target condition?

Were the reference standard results interpretUnclear ed without knowledge of the results of the index tests?

High

Low

\section{DOMAIN 4: Flow and Timing}

Was there an appropriate interval between index Unclear test and reference standard? 
Weiss 1994 (Continued)

Did all patients receive the same reference stan- Yes dard?

Were all patients included in the analysis? Unclear

\section{Unclear}

\section{Yan 2003}

\section{Study characteristics}

$\begin{array}{ll}\text { Patient sampling } & \begin{array}{l}\text { Type of study: unclear whether prospective or retrospective study } \\ \text { Consecutive or random sample: neither - patients with recent antibiotic } \\ \text { treatment were excluded }\end{array}\end{array}$

Patient characteristics and setting

Sample size: 31

Female: not stated

Age: not stated

Presentation:

1. Patients undergoing endoscopy

Exclusion criteria:

1. Recent $H$ pylori treatment

Setting: secondary care, China

Index tests

Index test: stool antigen test

Further details:

Technical specifications: not stated

Performed by: not stated

Criteria for positive diagnosis: Absorbance $450 / 630 \mathrm{~nm} \geq 0.120$

$\begin{array}{ll}\text { Target condition and reference standard(s) } & \text { Target condition: } H \text { pylori infection } \\ & \text { Reference standard: endoscopic biopsy with Warthin-Starry stain } \\ & \text { Further details: } \\ & \text { Technical specifications: not stated } \\ & \text { Performed by: endoscopist and pathologist } \\ & \text { Criteria for positive diagnosis: presence of } H \text { pylori in biopsy }\end{array}$

Flow and timing

Number of indeterminates for whom the results of reference standard was available: not stated

Number of patients who were excluded from the analysis: 32 (50.8\%)

\section{Comparative}

\section{Notes}

\section{Methodological quality}

\begin{tabular}{llll}
\hline Item Authors' judgement & Risk of bias & $\begin{array}{l}\text { Applicability con- } \\
\text { cerns }\end{array}$
\end{tabular}

\section{DOMAIN 1: Patient Selection}

Was a consecutive or random sample of patients en- No rolled? 
Yan 2003 (Continued)

Was a case-control design avoided? Yes

\begin{tabular}{llll}
\hline Did the study avoid inappropriate exclusions? & Unclear & High & Unclear \\
\hline DOMAIN 2: Index Test Stool Antigen Test & & \\
\hline $\begin{array}{l}\text { Were the index test results interpreted without } \\
\text { knowledge of the results of the reference standard? }\end{array}$ & Unclear & Unclear & Unclear
\end{tabular}

\section{DOMAIN 3: Reference Standard}

Is the reference standards likely to correctly classify Yes

the target condition?

Were the reference standard results interpreted Unclear

without knowledge of the results of the index tests?

Unclear

Low

\section{DOMAIN 4: Flow and Timing}

Was there an appropriate interval between index Unclear test and reference standard?

Did all patients receive the same reference stan- $\quad$ Yes dard?

Were all patients included in the analysis?

No

High

Yoshimura 2001

\section{Study characteristics}

\begin{tabular}{ll} 
Patient sampling & $\begin{array}{l}\text { Type of study: unclear whether prospective or retrospective study } \\
\text { Consecutive or random sample: unclear sampling process }\end{array}$ \\
\hline Patient characteristics and setting & Sample size: 72 \\
& Female: $34(47.2 \%)$ \\
& Age: 13 years \\
& Presentation: \\
& 1. Children undergoing endoscopy for symptoms such as anaemia and ab- \\
dominal pain & Exclusion criteria: \\
& 1. Recent $H$ pylori treatment \\
Setting: secondary care, Japan
\end{tabular}

Index test 1: urea breath test- $13 \mathrm{C}$ 
Yoshimura 2001 (Continued)

Further details:

Technical specifications: not stated

Performed by: not stated

Criteria for positive diagnosis: delta over baseline $>3.0 \%$ (20 minutes and 30 minutes)

Index test 2: serology

Further details:

Technical specifications: HM-CAP Anti-H pylori-EIA; Kyowa Medics

Performed by: not stated

Criteria for positive diagnosis: $\geq 1.8$

Target condition and reference standard(s)

Target condition: $H$ pylori infection

Reference standard: endoscopic biopsy with $\mathrm{H}$ \& E stain and Giemsa stain

Further details:

Technical specifications: not stated

Performed by: endoscopist and pathologist

Criteria for positive diagnosis: presence of $H$ pylori in biopsy

Flow and timing

Number of indeterminates for whom the results of reference standard was available: not stated

Number of patients who were excluded from the analysis: not stated

\section{Comparative}

\section{Notes}

\section{Methodological quality}

\begin{tabular}{llll}
\hline Item Authors' judgement & Risk of bias & $\begin{array}{l}\text { Applicability con- } \\
\text { cerns }\end{array}$
\end{tabular}

\section{DOMAIN 1: Patient Selection} Was a consecutive or random sample of patients en- Unclear
rolled?

\begin{tabular}{llll}
\hline Was a case-control design avoided? & Yes & \\
\hline Did the study avoid inappropriate exclusions? & Unclear & Unclear \\
\hline
\end{tabular}

\section{DOMAIN 2: Index Test Urea breath test-13C}

Were the index test results interpreted without
knowledge of the results of the reference standard?

\begin{tabular}{llll}
\hline If a threshold was used, was it pre-specified? & Yes & Low \\
\hline
\end{tabular}

\section{DOMAIN 2: Index Test Serology}

\section{Were the index test results interpreted without knowledge of the results of the reference standard?}

Unclear

\author{
Unclear
}


Yoshimura 2001 (Continued)

Unclear

Low

\section{DOMAIN 3: Reference Standard}

Is the reference standards likely to correctly classify No

the target condition?

Were the reference standard results interpreted Unclear

without knowledge of the results of the index tests?

High $\quad$ Low L H

\section{DOMAIN 4: Flow and Timing}

Was there an appropriate interval between index Unclear test and reference standard?

Did all patients receive the same reference stan- Yes
dard?

Were all patients included in the analysis? Unclear

Unclear

Yu 1999

\section{Study characteristics}

\begin{tabular}{|c|c|}
\hline Patient sampling & $\begin{array}{l}\text { Type of study: unclear whether prospective or retrospective study } \\
\text { Consecutive or random sample: neither - patients with recent antibiotic } \\
\text { treatment were excluded }\end{array}$ \\
\hline Patient characteristics and setting & $\begin{array}{l}\text { Sample size: } 88 \\
\text { Female: not stated } \\
\text { Age: not stated } \\
\text { Presentation: } \\
\text { 1. Patients undergoing endoscopy } \\
\text { Exclusion criteria: } \\
\text { 1. Recent } H \text { pylori treatment } \\
\text { Setting: secondary care, Singapore }\end{array}$ \\
\hline Index tests & $\begin{array}{l}\text { Index test: urea breath test- }{ }^{14} \mathrm{C} \\
\text { Further details: } \\
\text { Technical specifications: not stated } \\
\text { Performed by: not stated } \\
\text { Criteria for positive diagnosis: not stated }\end{array}$ \\
\hline Target condition and reference standard(s) & $\begin{array}{l}\text { Target condition: } H \text { pylori infection } \\
\text { Reference standard: endoscopic biopsy with H \& E stain and Warthin-Starry } \\
\text { stain } \\
\text { Further details: } \\
\text { Technical specifications: not stated } \\
\text { Performed by: endoscopist and pathologist } \\
\text { Criteria for positive diagnosis: presence of } H \text { pylori in biopsy }\end{array}$ \\
\hline
\end{tabular}


Yu 1999 (Continued)

Flow and timing
Number of indeterminates for whom the results of reference standard was available: not stated

Number of patients who were excluded from the analysis: 16 (16.5\%)

\section{Comparative}

\section{Notes}

\section{Methodological quality}

\begin{tabular}{llll}
\hline Item Authors' judgement & Risk of bias & $\begin{array}{l}\text { Applicability con- } \\
\text { cerns }\end{array}$
\end{tabular}

\section{DOMAIN 1: Patient Selection}

Was a consecutive or random sample of patients en- No rolled?

\begin{tabular}{ll}
\hline Was a case-control design avoided? & Yes \\
\hline Did the study avoid inappropriate exclusions? & Unclear
\end{tabular}

\begin{tabular}{lll}
\hline High & Unclear \\
\hline
\end{tabular}

\section{DOMAIN 2: Index Test Urea breath test-14C}

Were the index test results interpreted without Unclear
knowledge of the results of the reference standard?

knowledge of the results of the reference standard?

\begin{tabular}{llll}
\hline If a threshold was used, was it pre-specified? & Yes & High \\
\hline
\end{tabular}

\section{DOMAIN 3: Reference Standard}

Is the reference standards likely to correctly classify No the target condition?

Were the reference standard results interpreted Unclear without knowledge of the results of the index tests?

\begin{tabular}{lll}
\hline DOMAIN 4: Flow and Timing & High \\
\hline $\begin{array}{l}\text { Was there an appropriate interval between index } \\
\text { test and reference standard? }\end{array}$ & Unclear \\
\hline $\begin{array}{l}\text { Did all patients receive the same reference stan- } \\
\text { dard? }\end{array}$ & Yes \\
\hline Were all patients included in the analysis? & No
\end{tabular}




\section{Study characteristics}

\begin{tabular}{|c|c|}
\hline Patient sampling & $\begin{array}{l}\text { Type of study: retrospective study } \\
\text { Consecutive or random sample: consecutive patients }\end{array}$ \\
\hline Patient characteristics and setting & $\begin{array}{l}\text { Sample size: } 32 \\
\text { Female: } 14(43.8 \%) \\
\text { Age: } 51 \text { years } \\
\text { Presentation: } \\
\text { 1. Patients undergoing endoscopy } \\
\text { Exclusion criteria: } \\
\text { 1. Recent } H \text { pylori treatment } \\
\text { 2. Gastric surgery } \\
\text { Setting: secondary care, Taiwan, China }\end{array}$ \\
\hline Index tests & $\begin{array}{l}\text { Index test 1: urea breath test-13C } \\
\text { Further details: } \\
\text { Technical specifications: not stated } \\
\text { Performed by: not stated } \\
\text { Criteria for positive diagnosis: delta over baseline > } 2.8 \% \text { (15 minutes) } \\
\text { Index test 2: stool antigen test } \\
\text { Further details: } \\
\text { Technical specifications: Premier Platinum HpSA, Meridian } \\
\text { Performed by: not stated } \\
\text { Multiple criteria for positive diagnosis: } \\
\text { - Absorbance } 450 \mathrm{~nm}>0.140 \\
\text { - Visual assessment by gastroenterologists }\end{array}$ \\
\hline
\end{tabular}

Target condition and reference standard(s)

Target condition: $H$ pylori infection

Reference standard: endoscopic biopsy with $\mathrm{H}$ \& E stain

Further details:

Technical specifications: not stated

Performed by: endoscopist and pathologist

Criteria for positive diagnosis: presence of $H$ pylori in biopsy

Flow and timing

Number of indeterminates for whom the results of reference standard was available: not stated

Number of patients who were excluded from the analysis: $0(0 \%)$

\section{Comparative}

Notes

\section{Methodological quality}

\begin{tabular}{llll}
\hline Item Authors' judgement & Risk of bias & $\begin{array}{l}\text { Applicability con- } \\
\text { cerns }\end{array}$
\end{tabular}

\section{DOMAIN 1: Patient Selection}

Was a consecutive or random sample of patients en- Yes rolled?

Was a case-control design avoided? Yes


Yu 2001 (Continued)

Did the study avoid inappropriate exclusions?

Yes

\begin{tabular}{lcc}
\hline & Low & Low \\
\hline DOMAIN 2: Index Test Urea breath test-13C &
\end{tabular}

DOMAIN 2: Index Test Urea breath test-13C

Were the index test results interpreted without Unclear

knowledge of the results of the reference standard?

If a threshold was used, was it pre-specified? Yes

\begin{tabular}{l}
\hline Unclear \\
Low
\end{tabular}

\section{DOMAIN 2: Index Test Stool Antigen Test}

Were the index test results interpreted without Unclear
knowledge of the results of the reference standard?

knowledge of the results of the reference standard?

\begin{tabular}{lll}
\hline If a threshold was used, was it pre-specified? & Unclear & Low \\
\hline
\end{tabular}

\section{DOMAIN 3: Reference Standard}

Is the reference standards likely to correctly classify No

the target condition?

Were the reference standard results interpreted Unclear
without knowledge of the results of the index tests?

Low

\section{DOMAIN 4: Flow and Timing}

Was there an appropriate interval between index Unclear
test and reference standard?

test and reference standard?

Did all patients receive the same reference stan- $\quad$ Yes
dard?

Were all patients included in the analysis? Yes

\section{Unclear}

$\mathrm{CO} 2$ - carbon dioxide;

$\mathrm{H}$ \& E stain - haematoxylin and eosin stain;

HpSA - H pylori stool antigen;

IgA - immunoglobulin A;

IgG - immunoglobulin G;

NMR - nuclear magnetic resonance;

NSAID - non-steroidal anti-inflammatory

WBC - white blood cell

All other acronyms and abbreviations are the full title of either products or companies producing products included in the study.

Characteristics of studies awaiting classification [ordered by study ID] 
Buhigas-Garcia 2008

\section{Study characteristics}

Patient sampling

Patient characteristics and setting
Index tests
urea breath test- $13 \mathrm{C}$

Target condition and reference standard(s)

Flow and timing

Comparative

Notes

\section{Fazeli 2004}

\section{Study characteristics}

Patient sampling

Patient characteristics and setting

Index tests salivary test, potential index tests of interest

Target condition and reference standard(s)

Flow and timing

Comparative

Notes

Fuke 2009

\section{Study characteristics}

Patient sampling

Patient characteristics and setting

\begin{tabular}{ll}
\hline Index tests & serology
\end{tabular}

Target condition and reference standard(s)

Flow and timing

\section{Comparative}

Notes 
Glupczynski 1991

\section{Study characteristics}

Patient sampling

Patient characteristics and setting
Index tests
urea breath test- $13 \mathrm{C}$

\section{Target condition and reference standard(s)}

Flow and timing

\section{Comparative}

Notes

\section{Karczewska 1997}

\section{Study characteristics}

\section{Patient sampling}

Patient characteristics and setting

\begin{tabular}{ll}
\hline Index tests & serology \\
\hline
\end{tabular}

Target condition and reference standard(s)

\section{Flow and timing}

Comparative

Notes

\section{Kushch 2014}

\section{Study characteristics}

\section{Patient sampling}

Patient characteristics and setting

\begin{tabular}{l}
\hline Index tests \\
\hline Target condition and reference standard(s) \\
\hline Flow and timing \\
\hline Comparative
\end{tabular}


Kushch 2014 (Continued)

Notes

\section{Lappas 1997}

\section{Study characteristics}

Patient sampling

Patient characteristics and setting

Index tests salivary test, potential index tests of interest

Target condition and reference standard(s)

Flow and timing

Comparative

Notes

\section{Lee 1999a}

\section{Study characteristics}

\section{Patient sampling}

Patient characteristics and setting

\begin{tabular}{ll}
\hline Index tests & urea breath test- ${ }^{13} \mathrm{C}$ \\
\hline
\end{tabular}

Target condition and reference standard(s)

\section{Flow and timing}

Comparative

Notes

\section{Martin-de-Argila 1997 \\ Study characteristics}

\section{Patient sampling}

Patient characteristics and setting

Index tests serology

\footnotetext{
Target condition and reference standard(s)
} 
Martin-de-Argila 1997 (Continued)

Flow and timing

Comparative

Notes

Mason 1997

\section{Study characteristics}

Patient sampling

Patient characteristics and setting
Index tests
urea breath test

Target condition and reference standard(s)

Flow and timing

Comparative

Notes

\section{Thong-Ngam 2011}

\section{Study characteristics}

\section{Patient sampling}

Patient characteristics and setting

\begin{tabular}{l}
\hline Index tests \\
\hline Target condition and reference standard(s) \\
\hline Flow and timing \\
\hline Comparative \\
\hline Notes
\end{tabular}

\section{Tokunaga 2005a}

\section{Study characteristics}

\section{Patient sampling}

Patient characteristics and setting 
Tokunaga 2005a (Continued)
Index tests
urea breath test

Target condition and reference standard(s)

Flow and timing

Comparative

Notes

Xu 1995

\section{Study characteristics}

Patient sampling

Patient characteristics and setting

Index tests urea breath test- $13 \mathrm{C}$

Target condition and reference standard(s)

Flow and timing

Comparative

Notes

\section{A T A}

Presented below are all the data for all of the tests entered into the review.

\section{Table Tests. Data tables by test}

\begin{tabular}{lll}
\hline Test & No. of studies & No. of participants \\
\hline 1 Urea breath test-13C & 34 & 3139 \\
\hline 2 Urea breath test-14C & 21 & 1810 \\
\hline 3 Urea breath test - Unknown isotope & 2 & 127 \\
\hline 4 Serology & 34 & 4242 \\
\hline 5 Stool antigen test & 29 & 2988 \\
\hline 6 Urea breath test-13C (delta over baseline $>3 \%(20$ minutes)) & 2 & 254 \\
\hline 7 Urea breath test-13C (delta over baseline $>3 \%(30$ minutes)) & 3 & 333 \\
\hline
\end{tabular}




\begin{tabular}{lll}
\hline Test & No. of studies & No. of participants \\
\hline 8 Urea breath test-13C (delta over baseline $>3.5 \%(30$ minutes)) & 368 \\
\hline 9 Urea breath test-13C (delta over baseline $>4 \%(10$ minutes)) & 236 \\
\hline 10 Urea breath test-13C (delta over baseline $>4 \%(20$ minutes)) & 236 \\
\hline 11 Urea breath test-13C (delta over baseline $>4 \%(30$ minutes)) & 2 & 958 \\
\hline 12 Urea breath test-13C (delta over baseline $>4.5 \%(30$ minutes)) & 10 & 288 \\
\hline 13 Urea breath test-13C (delta over baseline $>5 \%(30$ minutes)) & 3 & 601 \\
\hline 14 Urea breath test-14C (counts per minute $>50)$ & 4 & 471 \\
\hline 15 Urea breath test-14C (disintegrations per minute $>200)$ & 6 & 296 \\
\hline 16 Serology $>7$ units/ml & 2 & 97 \\
\hline 17 Serology $\geq 300$ units & 2 & 234 \\
\hline
\end{tabular}


Test 1. Urea breath test-13C.

Review: Non-invasive diagnostic tests for Helicobacter pylori infection

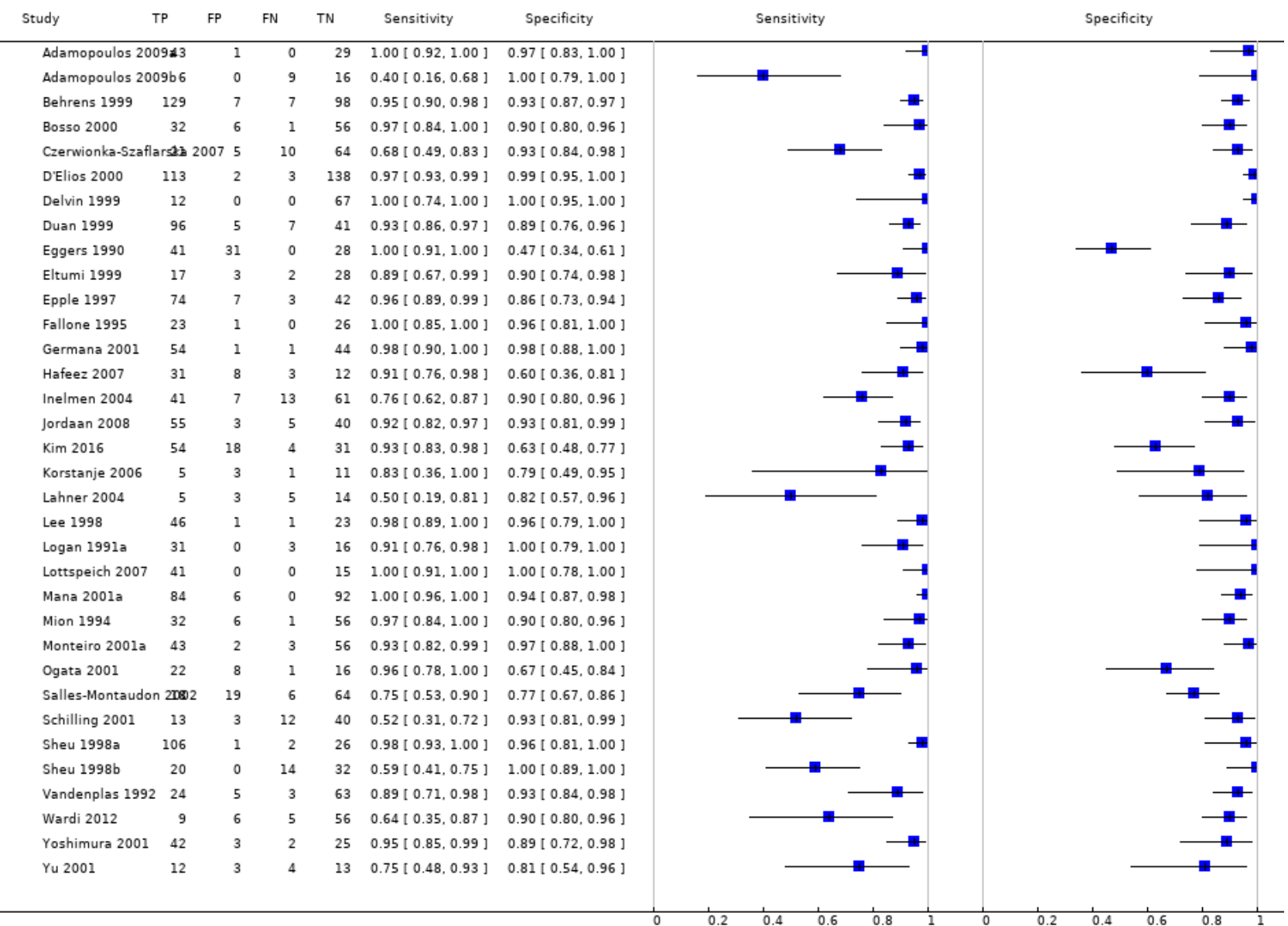


Test 2. Urea breath test-14C.

Review: Non-invasive diagnostic tests for Helicobacter pylori infection
Test: 2 Urea breath test-2+C

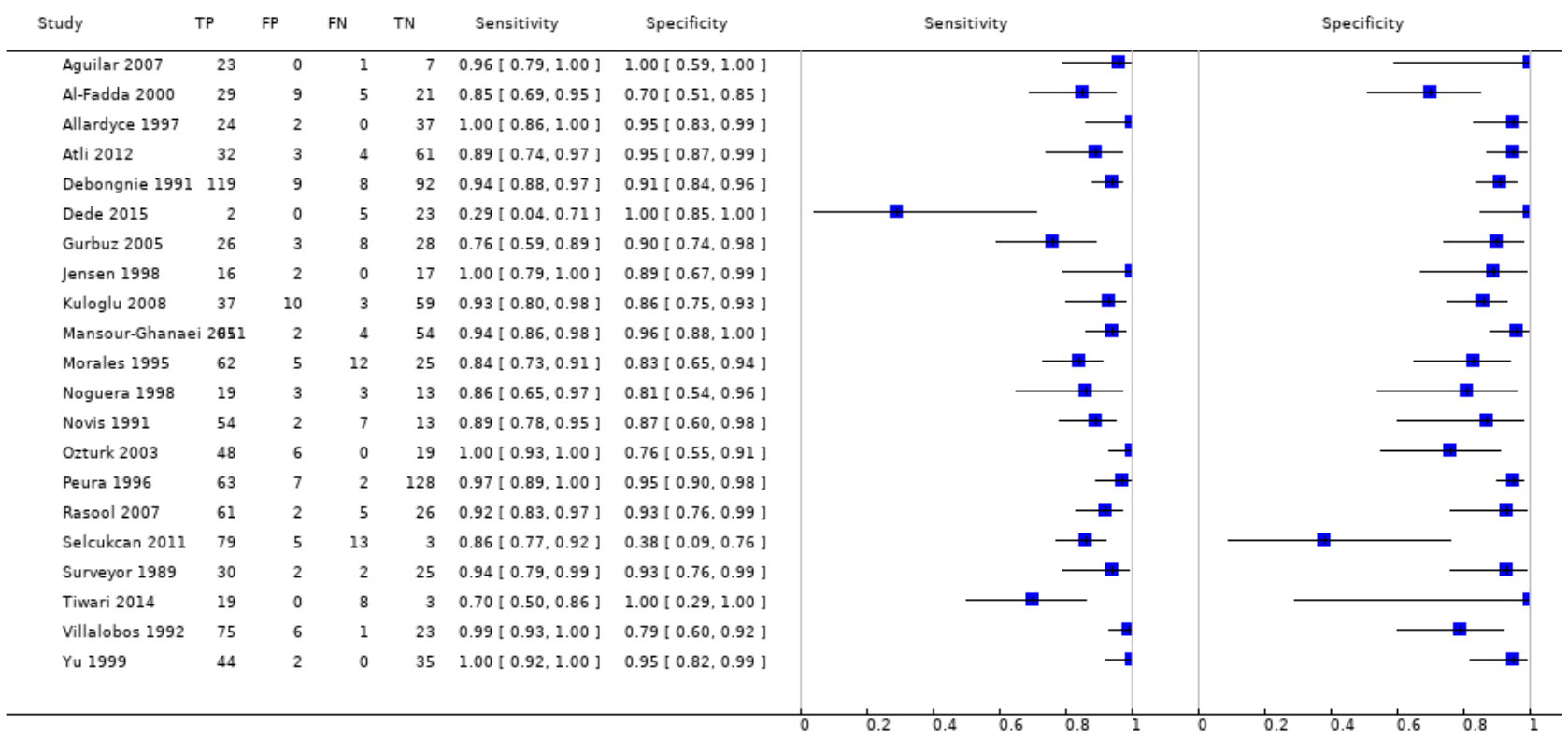

Test 3. Urea breath test - Unknown isotope.

Review: Non-invasive diagnostic tests for Helicobacter pylori infection

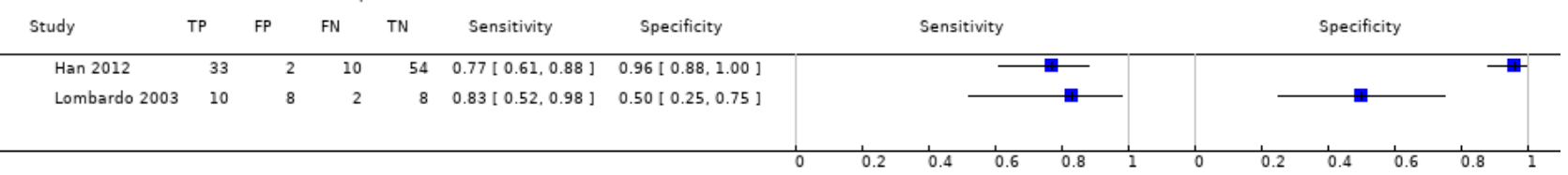


Test 4. Serology. Review: Non-invasive diagnostic tests for Helicobacter pylori infection
Test: 4 Serology

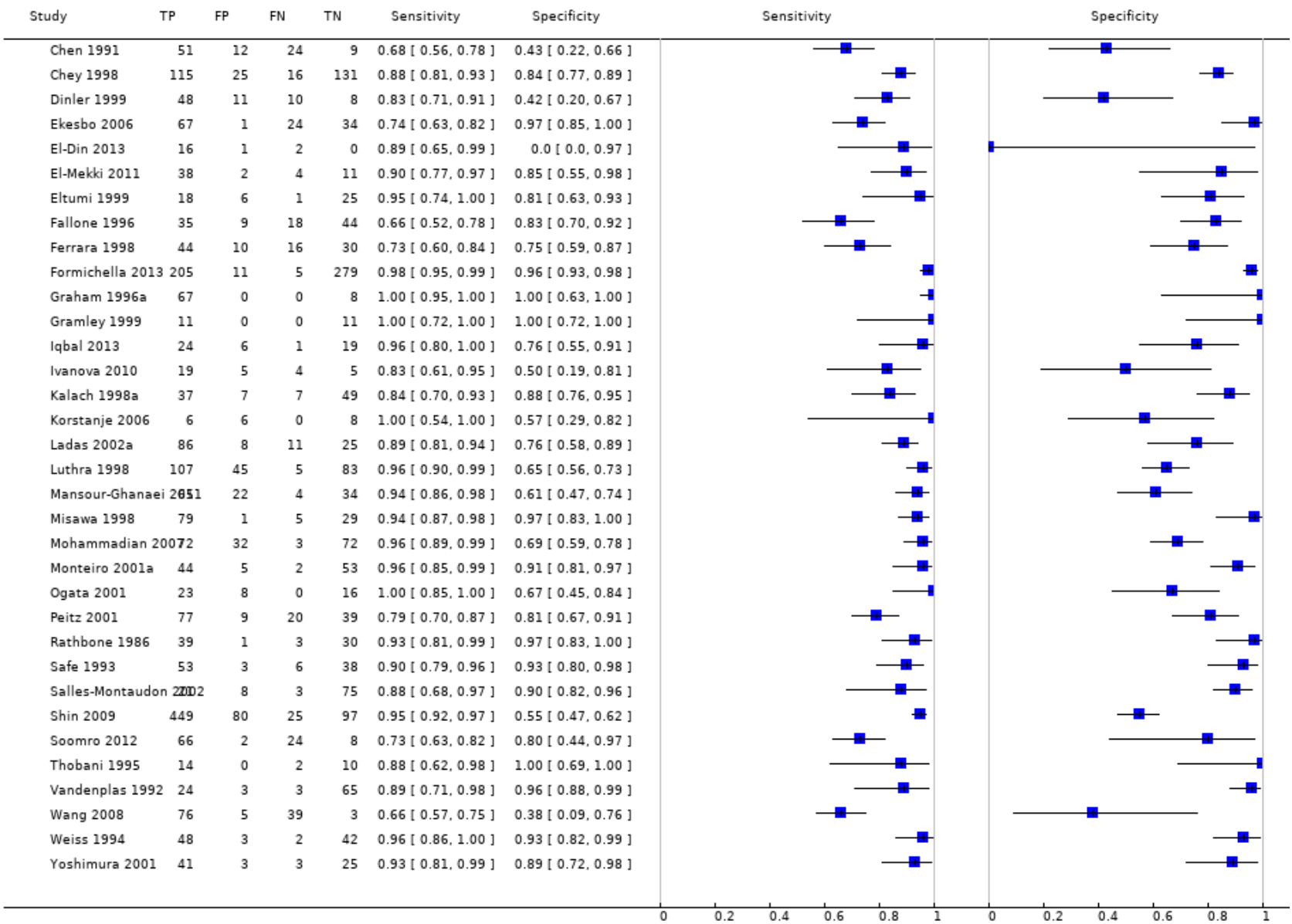


Test 5. Stool antigen test.

Review: Non-invasive diagnostic tests for Helicobacter pylori infection

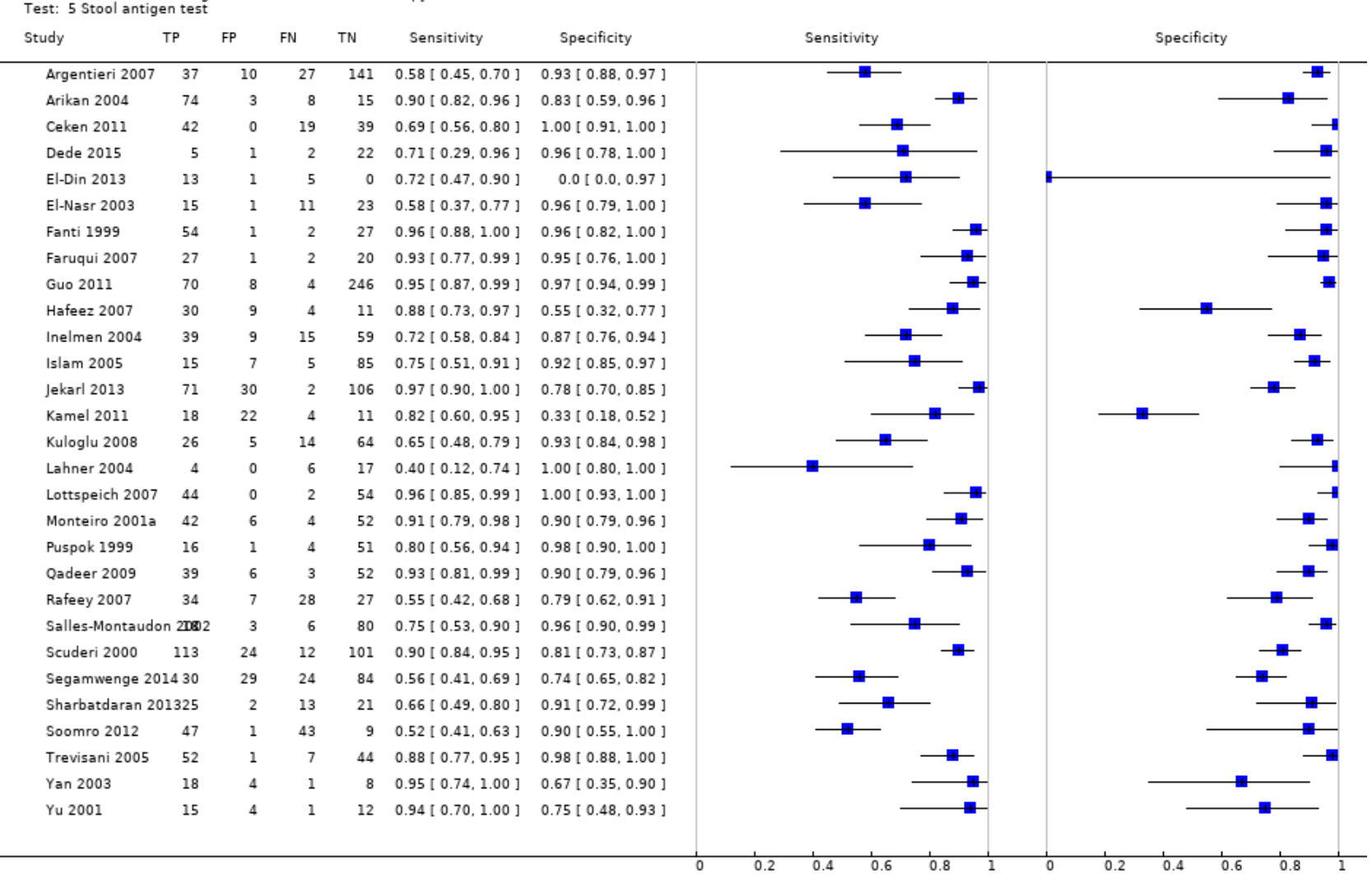

Test 6. Urea breath test-13 C (delta over baseline $>3 \%$ (20 minutes)).

Review: Non-invasive diagnostic tests for Helicobacter pylori infection
Test: 6 Urea breath test-1.t) (delta over baseline $>3 \%$ (20 minutes))

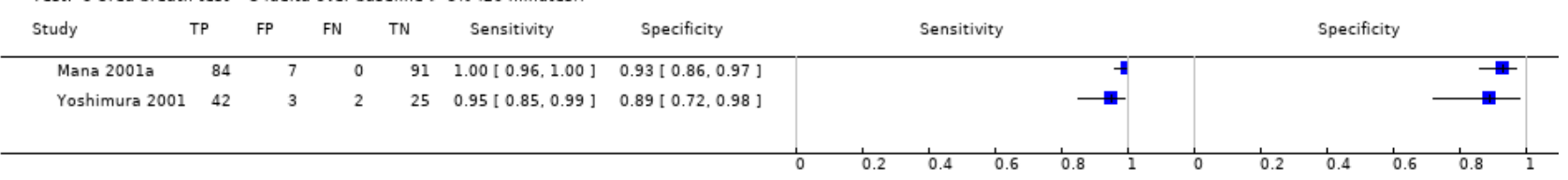

Test 7. Urea breath test-13 C (delta over baseline $>3 \%$ (30 minutes)).

Review: Non-invasive diagnostic tests for Helicobacter pylori infection
Test: 7 Urea breath test ${ }^{-19} \mathrm{C}$ (delta over baseline $>3 \%(30$ minutes))

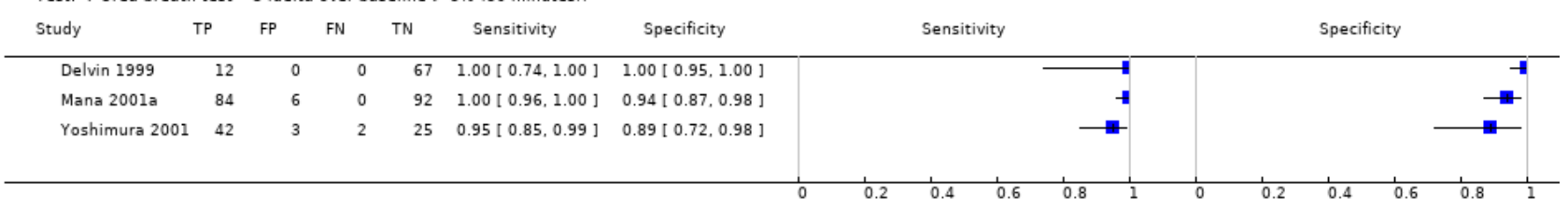


Test 8. Urea breath test-13 $\mathrm{C}$ (delta over baseline $>3.5 \%$ (30 minutes)).

Review: Non-invasive diagnostic tests for Helicobacter pylori infection
Test: 8 Urea breath test $-{ }^{13} \mathrm{C}$ (delta over baseline $>3.5 \%$ ( 30 minutes))

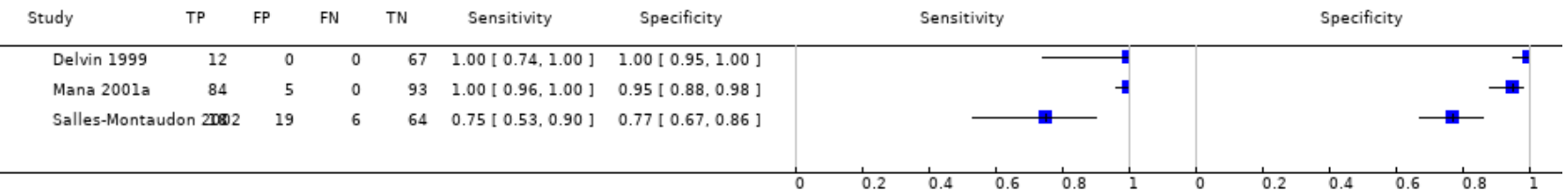

Test 9. Urea breath test-13 C (delta over baseline $>4 \%$ (10 minutes)).

Review: Non-invasive diagnostic tests for Helicobacter pylori infection
Test: 9 Urea breath test-130 (delta over baseline $>4 \%$ (10 minutes))

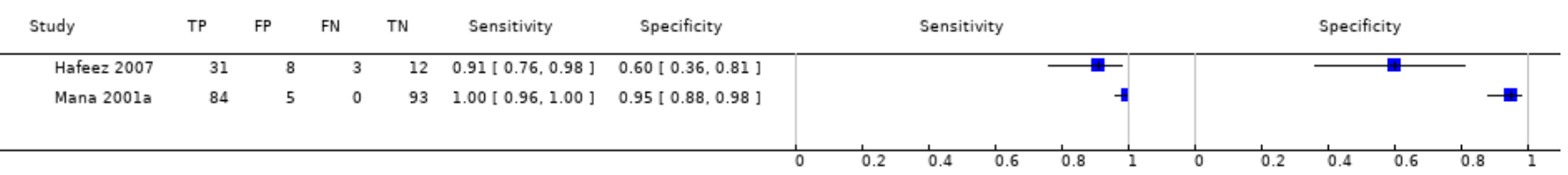

Test 10. Urea breath test- ${ }^{13} \mathrm{C}$ (delta over baseline $>4 \%(20$ minutes)).

Review: Non-invasive diagnostic tests for Helicobacter pylori infection
Test: 10 Urea breath test-12C (delta over baseline $>4 \%(20$ minutes $)$ )

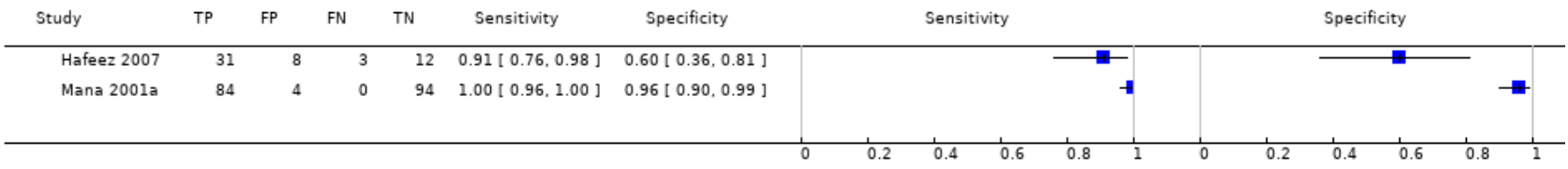

Test 11. Urea breath test-13 $\mathrm{C}$ (delta over baseline $>4 \%$ ( 30 minutes)).

Review: Non-invasive diagnostic tests for Helicobacter pylori infection
Test: 11 Urea breath test.13C (delta over baseline $>4 \%$ ( 30 minutes))

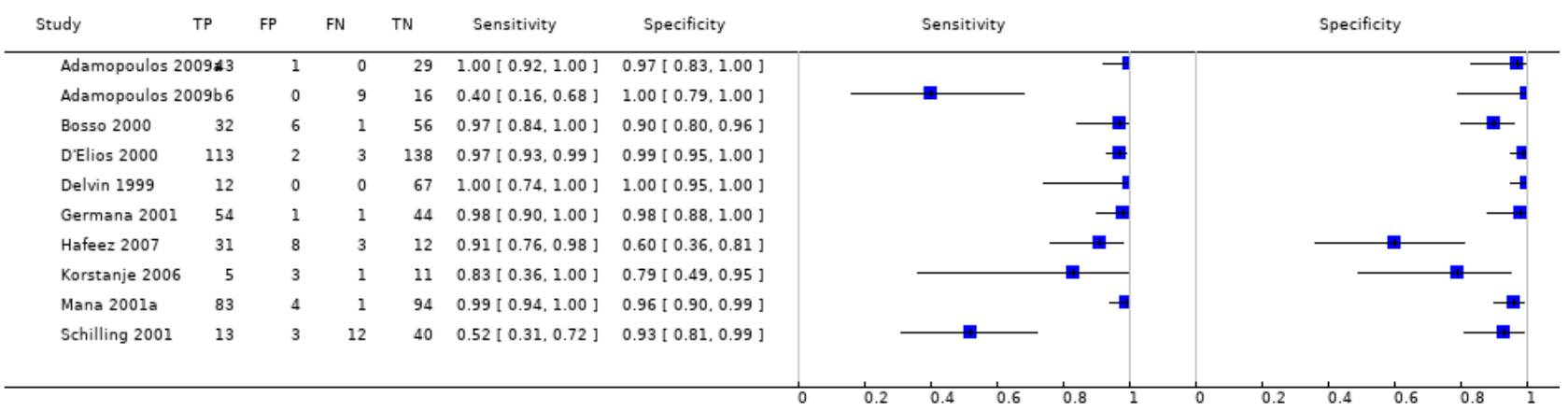


Test 12. Urea breath test- ${ }^{13} \mathrm{C}$ (delta over baseline $>4.5 \%$ (30 minutes)).

Review: Non-invasive diagnostic tests for Helicobacter pylori infection
Test: 12 Urea breath test-13C (delta over baseline $>4.5 \%$ ( 30 minutes)

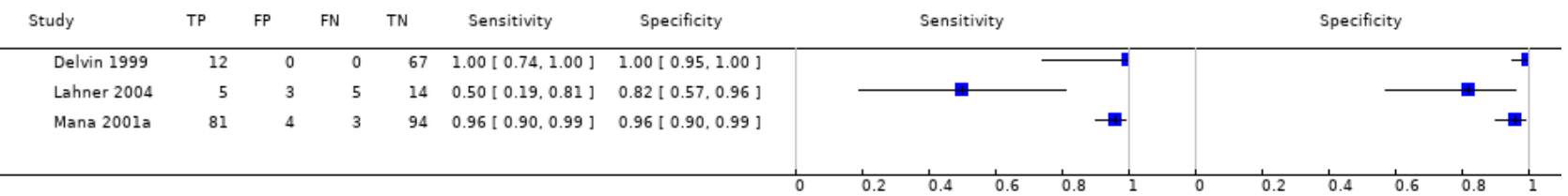

Test 13. Urea breath test-13C (delta over baseline $>5 \%$ ( 30 minutes)).

Review: Non-invasive diagnostic tests for Helicobacter pylori infection
Test: 13 Urea breath test- ${ }^{19} \mathrm{C}$ (delta over baseline $>5 \%(30$ minutes))

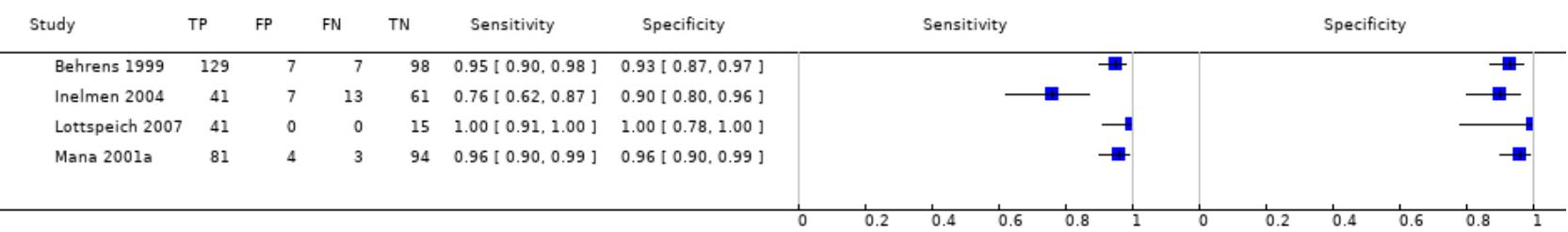

Test 14. Urea breath test-14C (counts per minute $>50$ ).

Review: Non-invasive diagnostic tests for Helicobacter pylori infection

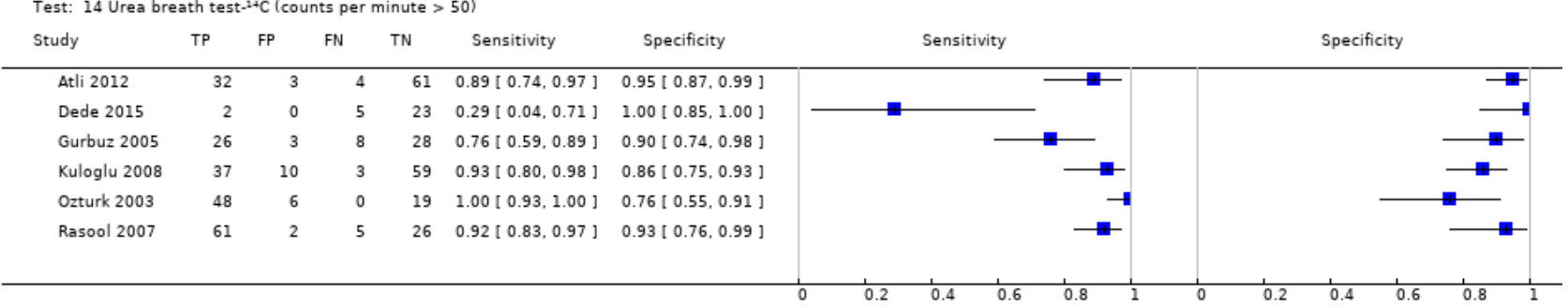

Test 15. Urea breath test-14C (disintegrations per minute $>200$ ).

Review: Non-invasive diagnostic tests for Helicobacter pylori infection

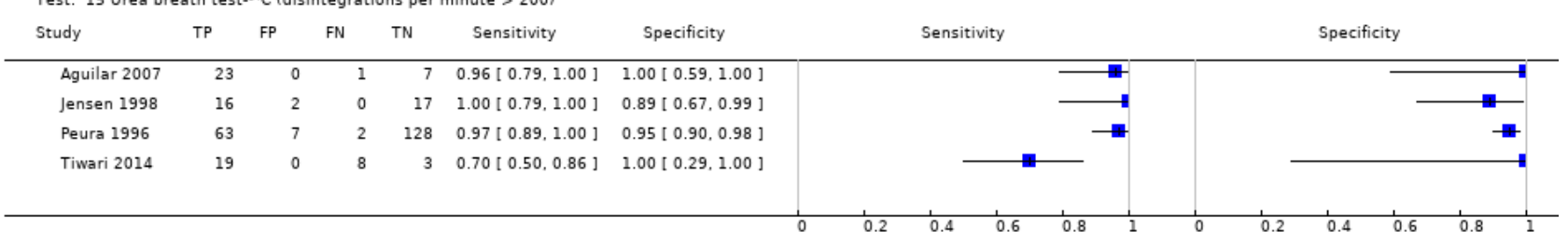


Test 16. Serology $>7$ units $/ \mathrm{ml}$.

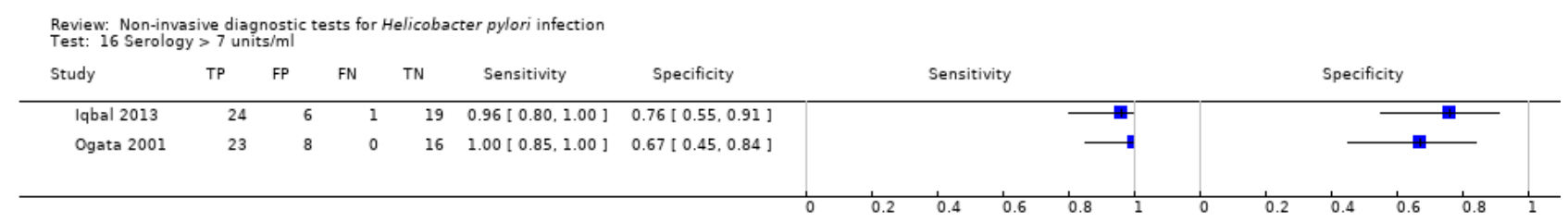

Test 17. Serology $\geq 300$ units.

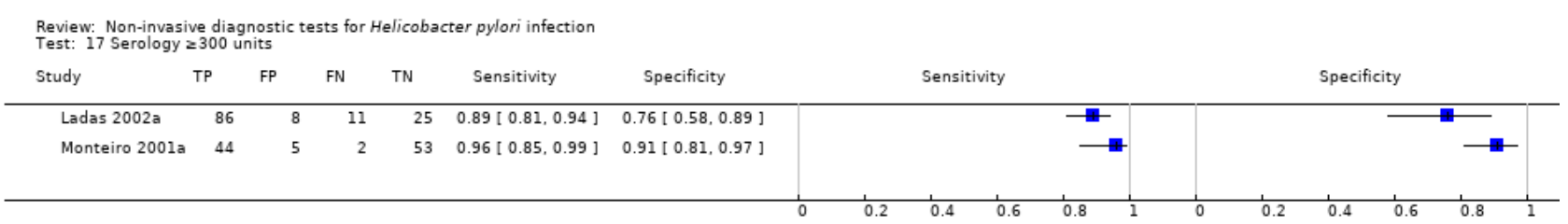

\section{ADDITIONAL TABLES}

Table 1. Summary of results at thresholds commonly reported for urea breath test-13C, urea breath test-14 $C$ and serology

\begin{tabular}{|c|c|c|c|c|}
\hline Threshold & Studies & $\begin{array}{l}\text { Number of par- } \\
\text { ticipants (cases) }\end{array}$ & Sensitivity $(95 \% \mathrm{Cl})$ & Specificity $(95 \% \mathrm{Cl})$ \\
\hline \multicolumn{5}{|l|}{ Urea breath test- ${ }^{13} \mathrm{C}$} \\
\hline Delta over baseline $>3 \%$ ( 20 minutes) & 2 & $254(128)$ & $0.98(0.90$ to 1.00$)$ & 0.92 (0.82 to 0.97$)$ \\
\hline Delta over baseline $>3 \%$ ( 30 minutes) & 3 & $333(140)$ & $0.99(0.92$ to 1.00$)$ & 0.95 (0.90 to 0.98$)$ \\
\hline Delta over baseline $>3.5 \%$ ( 30 minutes) & 3 & $368(120)$ & 0.75 to 1.00 & 0.77 to 1.00 \\
\hline Delta over baseline $>4 \%$ (10 minutes) & 2 & $236(118)$ & 0.91 to 1.00 & 0.60 to 0.95 \\
\hline Delta over baseline $>4 \%$ (20 minutes) & 2 & $236(118)$ & 0.91 to 1.00 & 0.60 to 0.96 \\
\hline Delta over baseline $>4 \%$ (30 minutes) & 10 & $958(423)$ & 0.95 (0.79 to 0.99$)$ & 0.95 (0.87 to 0.98$)$ \\
\hline Delta over baseline $>4.5 \%$ ( 30 minutes) & 3 & $288(106)$ & 0.50 to 0.96 & 0.82 to 0.96 \\
\hline Delta over baseline $>5 \%$ ( 30 minutes) & 4 & $601(315)$ & $0.95(0.49$ to 1.00$)$ & $0.94(0.84$ to 0.98$)$ \\
\hline
\end{tabular}

\section{Urea breath test-14C}

\begin{tabular}{lllll}
\hline Counts per minute $>50(10$ minutes $)$ & 6 & $471(231)$ & 0.89 (0.55 to 0.98) & 0.91 (0.79 to 0.96) \\
\hline $\begin{array}{l}\text { Disintegrations per minute }>200(10 \\
\text { minutes })\end{array}$ & 4 & $296(132)$ & 0.95 (0.33 to 1.00) & 0.95 (0.80 to 0.99) \\
\hline
\end{tabular}

\section{Serology}

\begin{tabular}{lllll}
\hline$>7$ units $/ \mathrm{ml}$ & 2 & $97(48)$ & $0.98(0.74$ to 1.00$)$ & $0.71(0.51$ to 0.86$)$
\end{tabular}


Table 1. Summary of results at thresholds commonly reported for urea breath test-13C, urea breath test-14C and serology (Continued)
$\geq 300$ unit
2
$234(143)$
$0.91(0.82$ to 0.96$)$
$0.86(0.72$ to 0.93$)$

Tests evaluated at the same threshold by more than one study are presented in the table. When there were two or three studies at the same threshold, and little or no heterogeneity was observed in ROC space, estimates of summary sensitivity and summary specificity were obtained by using univariate fixed-effect logistic regression models to pool sensitivities and specificities separately. When there were two or three studies and we observed heterogeneity, we did not perform meta-analysis but report the range of the sensitivities and specificities.

Table 2. Indirect comparison of the accuracy of non-invasive tests for $H$ pylori infection

\begin{tabular}{|c|c|c|c|c|c|}
\hline \multirow[t]{2}{*}{ Index tests } & \multirow{2}{*}{$\begin{array}{l}\text { Studies; } \\
\text { participants (H py- } \\
\text { loripresent) }\end{array}$} & \multirow[t]{2}{*}{$\operatorname{DOR}(95 \% \mathrm{Cl})$} & \multicolumn{3}{|c|}{ Ratio of diagnostic odds ratios $(95 \% \mathrm{Cl}), \mathrm{P}$ value } \\
\hline & & & Urea breath test- ${ }^{13} \mathrm{C}$ & $\begin{array}{l}\text { Urea breath } \\
\text { test-14C }\end{array}$ & Serology \\
\hline $\begin{array}{l}\text { Urea breath } \\
\text { test-13C }\end{array}$ & $34 ; 3139(1526)$ & 153 (73.7 to 316$)$ & - & - & - \\
\hline $\begin{array}{l}\text { Urea breath } \\
\text { test-14C }\end{array}$ & $21 ; 1810(1018)$ & 105 (74.0 to 150$)$ & $\begin{array}{l}1.45 \text { (0.65 to } 3.26) \\
P=0.36\end{array}$ & - & - \\
\hline Serology & $34 ; 4242(2477)$ & $\begin{array}{l}47.4(25.5 \text { to } \\
88.1)\end{array}$ & $\begin{array}{l}3.22(1.24 \text { to } 8.37) \\
P=0.017\end{array}$ & $\begin{array}{l}2.22(1.09 \text { to } 4.51) \\
P=0.028\end{array}$ & - \\
\hline $\begin{array}{l}\text { Stool antigen } \\
\text { test }\end{array}$ & $29 ; 2988(1311)$ & $\begin{array}{l}45.1(24.2 \text { to } \\
84.1)\end{array}$ & $\begin{array}{l}3.39 \text { (1.30 to } 8.83) \\
P=0.013\end{array}$ & $\begin{array}{l}2.33(1.14 \text { to } 4.76) \\
P=0.020\end{array}$ & $\begin{array}{l}1.05 \text { ( } 0.44 \text { to } \\
2.53), \\
\mathrm{P}=0.91\end{array}$ \\
\hline
\end{tabular}

The indirect comparison included all studies that evaluated at least one of the four tests, i.e. all available data. The ratio of diagnostic odds ratios is the diagnostic odds ratio (DOR) of the test in the column divided by the DOR of the test in the row. If the ratio is greater than one, then the test in the column is more accurate than the test in the row; if the ratio is less than one, the test in the row is more accurate than the test in the column.

Table 3. Accuracy of non-invasive tests for $H$ pylori infection at different levels of prevalence

\begin{tabular}{|c|c|c|c|c|c|}
\hline $\begin{array}{l}\text { Prevalence } \\
(\%)\end{array}$ & Specificity & $\begin{array}{l}\text { False posi- } \\
\text { tives } 1\end{array}$ & Test & Sensitivity $(95 \% \mathrm{CI})$ & $\begin{array}{l}\text { Missed cases }(95 \% \\
\mathrm{Cl})\end{array}$ \\
\hline \multirow[t]{4}{*}{42.0} & 0.79 & 122 & Urea breath test- $13 \mathrm{C}$ & 0.98 (0.95 to 0.99$)$ & 10 (5 to 20$)$ \\
\hline & & & Urea breath test- ${ }^{14} \mathrm{C}$ & 0.97 (0.95 to 0.98$)$ & 15 (10 to 20$)$ \\
\hline & & & Serology & 0.93 (0.87 to 0.96$)$ & 31 (17 to 54$)$ \\
\hline & & & Stool antigen test & 0.92 (0.87 to 0.96$)$ & 32 (18 to 57$)$ \\
\hline \multirow[t]{3}{*}{53.7} & 0.79 & 97 & Urea breath test- $13 \mathrm{C}$ & 0.98 (0.95 to 0.99$)$ & 13 (6 to 26$)$ \\
\hline & & & Urea breath test- ${ }^{14} \mathrm{C}$ & 0.97 (0.95 to 0.98$)$ & 19 (13 to 26$)$ \\
\hline & & & Serology & 0.93 (0.87 to 0.96$)$ & 39 (22 to 69$)$ \\
\hline
\end{tabular}


Table 3. Accuracy of non-invasive tests for $\boldsymbol{H}$ pylori infection at different levels of prevalence (Continued)

\begin{tabular}{|c|c|c|c|c|c|}
\hline & & & Stool antigen test & 0.92 (0.87 to 0.96$)$ & 41 (23 to 72 ) \\
\hline \multirow[t]{4}{*}{66.5} & 0.79 & 70 & Urea breath test- $13 \mathrm{C}$ & 0.98 (0.95 to 0.99$)$ & 16 (8 to 32 ) \\
\hline & & & Urea breath test- ${ }^{14} \mathrm{C}$ & 0.97 (0.95 to 0.98$)$ & 23 (16 to 32 ) \\
\hline & & & Serology & 0.93 (0.87 to 0.96$)$ & 49 (27 to 85$)$ \\
\hline & & & Stool antigen test & 0.92 (0.87 to 0.96$)$ & 51 (28 to 89$)$ \\
\hline \multirow[t]{4}{*}{42.0} & 0.90 & 58 & Urea breath test- ${ }^{13} \mathrm{C}$ & 0.94 (0.89 to 0.97$)$ & 23 (12 to 46$)$ \\
\hline & & & Urea breath test- ${ }^{14} \mathrm{C}$ & 0.92 (0.89 to 0.94$)$ & 33 (24 to 46$)$ \\
\hline & & & Serology & 0.84 (0.74 to 0.91$)$ & 67 (39 to 110$)$ \\
\hline & & & Stool antigen test & 0.83 (0.73 to 0.90$)$ & $70(41$ to 114$)$ \\
\hline \multirow[t]{4}{*}{53.7} & 0.90 & 46 & Urea breath test- $13 \mathrm{C}$ & 0.94 (0.89 to 0.97 ) & 30 (15 to 58$)$ \\
\hline & & & Urea breath test- ${ }^{14} \mathrm{C}$ & 0.92 (0.89 to 0.94$)$ & 42 (30 to 58 ) \\
\hline & & & Serology & 0.84 (0.74 to 0.91$)$ & 86 (50 to 140$)$ \\
\hline & & & Stool antigen test & 0.83 (0.73 to 0.90$)$ & 89 (52 to 146$)$ \\
\hline \multirow[t]{4}{*}{66.5} & 0.90 & 34 & Urea breath test- $13 \mathrm{C}$ & 0.94 (0.89 to 0.97$)$ & 37 (18 to 72 ) \\
\hline & & & Urea breath test- ${ }^{14} \mathrm{C}$ & 0.92 (0.89 to 0.94$)$ & 53 (38 to 72 ) \\
\hline & & & Serology & 0.84 (0.74 to 0.91$)$ & $106(62$ to 173$)$ \\
\hline & & & Stool antigen test & 0.83 (0.73 to 0.90$)$ & 111 (64 to 180$)$ \\
\hline \multirow[t]{4}{*}{42.0} & 0.96 & 23 & Urea breath test- $13 \mathrm{C}$ & 0.86 (0.75 to 0.93$)$ & 57 (30 to 103$)$ \\
\hline & & & Urea breath test- ${ }^{14} \mathrm{C}$ & 0.81 (0.76 to 0.86$)$ & 78 (58 to 103 ) \\
\hline & & & Serology & 0.66 (0.52 to 0.79$)$ & 141 (90 to 204) \\
\hline & & & Stool antigen test & 0.65 (0.50 to 0.78$)$ & 146 (93 to 209) \\
\hline \multirow[t]{4}{*}{53.7} & 0.96 & 19 & Urea breath test- $13 \mathrm{C}$ & 0.86 (0.75 to 0.93$)$ & 73 (38 to 132 ) \\
\hline & & & Urea breath test- ${ }^{14} \mathrm{C}$ & 0.81 (0.76 to 0.86$)$ & 100 (74 to 132$)$ \\
\hline & & & Serology & 0.66 (0.52 to 0.79$)$ & 181 (115 to 260$)$ \\
\hline & & & Stool antigen test & 0.65 (0.50 to 0.78$)$ & 187 (119 to 267 ) \\
\hline \multirow[t]{3}{*}{66.5} & 0.96 & 13 & Urea breath test- $13 \mathrm{C}$ & 0.86 (0.75 to 0.93$)$ & 90 (47 to 163 ) \\
\hline & & & Urea breath test- ${ }^{14} \mathrm{C}$ & 0.81 (0.76 to 0.86$)$ & 124 (92 to 163 ) \\
\hline & & & Serology & $0.66(0.52$ to 0.79$)$ & 224 (142 to 322$)$ \\
\hline
\end{tabular}


Table 3. Accuracy of non-invasive tests for $\boldsymbol{H}$ pylori infection at different levels of prevalence (Continued)

${ }_{1}^{1}$ Average number of participants who are diagnosed with $H$ pylori infection but do not have the infection per 1000 tested. The sensitivities were estimated from the SROC curves at fixed values (lower quartile, median and upper quartile) of specificity from the included studies across all tests. Based on these sensitivities and specificities, and quartiles of prevalence from the included studies (across all tests), the numbers of missed $\mathrm{H}$ pylori cases and false positives (i.e. overdiagnosed people) were calculated using a hypothetical cohort of 1000 people suspected of having $H$ pylori infection.

Table 4. Direct comparison of the accuracy of non-invasive tests for $H$ pylori infection

\begin{tabular}{|c|c|c|c|}
\hline Test & Urea breath test-13C & $\begin{array}{l}\text { Urea breath } \\
\text { test-14C }\end{array}$ & Serology \\
\hline $\begin{array}{l}\text { Urea breath } \\
\text { test-13C }\end{array}$ & - & - & - \\
\hline $\begin{array}{l}\text { Urea breath } \\
\text { test-14C }\end{array}$ & $N=0$ & - & - \\
\hline \multirow[t]{4}{*}{ Serology } & $N=7$ & $N=1$ & - \\
\hline & DOR $(95 \% \mathrm{Cl})$ of urea breath test- $13 \mathrm{C}=74.8(95 \% \mathrm{Cl} 17.8$ to 314$)$ & & \\
\hline & DOR $(95 \% \mathrm{Cl})$ of serology $=111(95 \% \mathrm{Cl} 41.2$ to 297$)$ & & \\
\hline & $\begin{array}{l}\text { RDORs }(95 \% \mathrm{Cl}) \text { of urea breath test- } 13 \mathrm{C} \text { versus serology, } \mathrm{P} \text { value } \\
=0.68(95 \% \mathrm{Cl} 0.12 \text { to } 3.70), \mathrm{P}=0.56\end{array}$ & & \\
\hline \multirow[t]{4}{*}{ Stool antigen test } & $N=7$ & $N=2$ & $N=4$ \\
\hline & DOR $(95 \% \mathrm{Cl})$ of urea breath test- $13 \mathrm{C}=46.6(95 \% \mathrm{Cl} 3.30$ to 658$)$ & & \\
\hline & DOR $(95 \% \mathrm{Cl})$ of stool antigen test $=53.0(95 \% \mathrm{Cl} 5.34$ to 527$)$ & & \\
\hline & $\begin{array}{l}\text { RDORs }(95 \% \mathrm{Cl}) \text { of urea breath test- } 13 \mathrm{C} \text { versus stool antigen } \\
\text { test, } \mathrm{P} \text { value }=0.88(95 \% \mathrm{Cl} 0.14 \text { to } 5.56), \mathrm{P}=0.84\end{array}$ & & \\
\hline
\end{tabular}

DOR = diagnostic odds ratio; $\mathrm{N}=$ number of studies; RDORs = ratio of diagnostic odds ratios.

Due to paucity of data and substantial heterogeneity observed in ROC space which precluded the use of simpler meta-analytic models, meta-analyses were not possible for two test comparisons that had more than one study. For the single study of urea breath test-14 $\mathrm{C}$ versus serology (Mansour-Ghanaei 2011), both tests had similar sensitivity, but specificity was higher for urea breath test-14C than for serology. The ratio of diagnostic odds ratios is the DOR of the test in the column divided by the DOR of the test in the row. If the ratio is greater than one, then the test in the column is more accurate than the test in the row; if the ratio is less than one, the test in the row is more accurate than the test in the column.

\section{A P P E N D I C E S}

\section{Appendix 1. Glossary}

Adenomas: a non-cancerous growth arising from the glands and has a structure similar to glands

Anaemia: a condition in which there is a deficiency of red cells or of haemoglobin in the blood, resulting in pallor and weariness

Asymptomatic: without symptoms

Atrophic gastritis: chronic inflammation of the stomach lining, leading to loss of cells lining the stomach usually and their replacement with scar tissue and cell types which line the small bowel 
Dyspepsia: indigestion

Eradication: removal (of)

Flatulence: passing wind excessively

Gastrectomy: partial removal of stomach

Heterogeneity: (in this context) different results in different studies

Heterogeneity: differences in results between studies

Idiopathic thrombocytopaenia purpura: purpura (purplish spots or patches on the skin and inner lining of the mouth) resulting from bleeding due to a reduction in circulating blood platelets caused by antibodies against platelets

Isotopes: atoms of an element with different numbers of neutrons (a part of atom)

Laryngeal: related to voice-box (throat)

Lymphoma: is a form of cancer of the lymphocytes, a type of white blood cells, which normally defend the body against harmful microorganisms such as bacteria, virus, and fungi

Malignancies: cancers

Meta-analysis: combining the results of individual studies to provide a single average result

Pathogenic: causing disease

Quartile: each of four equal groups into which a population can be divided

Serology: blood tests to test the presence of antibodies (substances produced by white cells to defend the body against harmful microorganisms such as bacteria)

Stool antigen test: a laboratory test of stool to diagnose $\mathrm{H}$ plyori infection

Urea breath test: a laboratory test of breath to diagnose $H$ pylori infection

\section{Appendix 2. MEDLINE search strategy}

1. exp Helicobacter pylori/ or Helicobacter/

2. (pylori or pyloridis).mp.

3. Helicobacter.mp.

4. HP.mp.

5. Campylobacter.mp.

6. 1 or 2 or 3 or 4 or 5

7. exp Breath Tests/

8. (breath adj3 test).mp.

9. exp Enzyme-Linked Immunosorbent Assay/

10. (Enzyme-Linked Immunosorbent Assay or ELISA).mp.

11. exp Blotting, Western/

12. (Western adj1 (blot or blotting or immunoblot or immunoblotting)).mp.

13. Latex Fixation Tests/

14. ("latex agglutination test" or "latex fixation test" or LAT).mp.

15. ((stool or "stool antigen" or feces or faeces or fecal or faecal) adj3 test).mp. 
16.7 or 8 or 9 or 10 or 11 or 12 or 13 or 14 or 15

\section{6 and 16}

18. exp animals/ not humans.sh.

\section{17 not 18}

\section{Appendix 3. Embase search strategy}

1. exp Helicobacter pylori/ or Helicobacter/

2. Helicobacter.mp.

3. (pylori or pyloridis or HP).mp.

4. Campylobacter.mp.

5.1 or 2 or 3 or 4

6. urea breath test/

7. (breath adj3 test).mp.

8. enzyme linked immunosorbent assay/

9. (Enzyme-Linked Immunosorbent Assay or ELISA).mp.

10.Western blotting/

11. (Western adj1 (blot or blotting or immunoblot or immunoblotting)).mp.

12. latex agglutination test/

13. ("latex agglutination test" or "latex fixation test" or LAT).mp.

14. exp feces analysis/

15. ((stool or "stool antigen" or feces or faeces or fecal or faecal) adj3 test).mp.

16.6 or 7 or 8 or 9 or 10 or 11 or 12 or 13 or 14 or 15

17.5 and 16

18. exp animal/ not exp human/

19. 17 not 18

\section{Appendix 4. Science Citation Index search strategy}

\#1 TS=(pylori or pyloridis or Helicobacter or HP or Campylobacter)

\#2 TS=("breath test" or Enzyme-Linked Immunosorbent Assay or ELISA or "Western blot" or "Western blotting" or "Western Immunoblot" or "Western Immunoblotting" or ("latex agglutination test" or "latex fixation test" or LAT) or "stool test" or "stool antigen test" or "feces test" or "faeces test" or "fecal test" or "faecal test")

\#3 \#1 AND \#2

\section{Appendix 5. National Institute for Health Research - Health Technology Assessment}

Helicobacter pylori and accuracy

Appendix 6. Criteria for assessment of risk of bias and applicability concerns

\begin{tabular}{|c|c|c|}
\hline $\begin{array}{l}\text { Domain 1: Patient se- } \\
\text { lection }\end{array}$ & Patient sampling & $\begin{array}{l}\text { Symptomatic people and asymptomatic people in whom } H \text { pylori infection sta- } \\
\text { tus is sought so that eradication therapy for } \mathrm{H} \text { pylori can be started }\end{array}$ \\
\hline
\end{tabular}


Was a consecutive or random sample of patients enrolled?
Yes: If a consecutive sample or a random sample of symptomatic people and asymptomatic people in whom $\mathrm{H}$ pylori infection status is sought was included in the study

No: If a consecutive sample or a random sample of symptomatic people and asymptomatic people in whom $\mathrm{H}$ pylori infection status is sought was not included in the study

Unclear: If this information was not available
Was a case-control design avoided?
Yes: If a cohort of symptomatic people and asymptomatic people in whom $H$ pylori infection status was sought were studied

No: If people with $H$ pylori infection were compared with people without $H$ pylori infection (controls). Such studies were excluded

Unclear: As anticipated, we were able to determine whether the design was case-control. So, all studies included in the review to be classified as 'yes' for this item
Did the study avoid inappropriate exclusions?
Yes: If all symptomatic people and asymptomatic people in whom $H$ pylori infection status was sought were included No: If the study excluded patients based on high probability of false negative results (for example, people with bleeding ulcers, gastric atrophy, lymphoma, and recent or current use of proton pump inhibitors or antibiotics) Unclear: If this information was not available
Could the selection of patients have introduced bias?
Low risk of bias: If 'yes' classification for all the above three questions; high risk of bias: if 'no' classification for any of the above three questions; unclear risk of bias: if 'unclear' classification for any of the above three questions, but without a 'no' classification for any of the above three questions
Patient characteristics and setting
Yes: If all symptomatic people and asymptomatic people in whom $H$ pylori infection status was sought were included No: If a proportion of symptomatic people and asymptomatic people in whom $H$ pylori infection status was sought were excluded on the basis of the high probability of false negative results (for example, people with bleeding ulcers, gastric atrophy, lymphoma, and recent or current use of proton pump inhibitors or antibiotics) Unclear: If it was not clear whether the patients have been included on the basis of the probability of $H$ pylori infection
Are there concerns that the included patients and setting do not match the review question?
Low concern: if the patient characteristics and setting were classified as 'yes'; unclear concern: if the patient characteristics and setting were classified as 'unclear'; high concern: if the patient characteristics and setting were classified as 'no'

\section{Domain 2: Index test Index test(s) Urea breath test, serology, and stool antigen test}

Were the index test results interpreted without knowledge of the results of the reference standard?
Yes: If the index test was conducted and interpreted without the knowledge of the results of the reference standard No: If the index test was interpreted with the knowledge of the results of the reference standard

Unclear: If it is not clear whether the index test was interpreted without the knowledge of the results of the reference standard
If a threshold was used, Yes: if a prespecified threshold was used was it prespecified?

Unclear: if it was not clear whether the threshold used was prespecified 
Could the conduct or interpretation of the index test have introduced bias?
Low risk of bias: If 'yes' classification for both questions above; high risk of bias: if 'no' classification for any of the above two questions; unclear risk of bias: if 'unclear' classification for any of the above two questions, but without a 'no' classification for any of the above two questions

\section{Domain 3: Target con- dition and reference standard}

Are there concerns that the index test, its conduct, or interpretation differ from the review question?

\section{Target condition and reference standard(s)}

Is the reference stan-
dard likely to correctly
classify the target con-
dition?

Low concern: If the criteria for a positive index test was clearly stated; high concern: if the criteria for a positive index test was not stated
Target condition: $H$ pylori infection
Reference standard: endoscopic biopsy with histology

Yes: If $H$ pylori infection was confirmed by endoscopic biopsy with special stains or immunohistochemical stains eosin stain in some or all participants
No: If the reference standard was endoscopic biopsy with haemotoxylin and

Unclear: If the reference standard was not described adequately. Such studies were excluded

Were the reference standard results interpreted without knowledge of the results of the index tests?

Yes: If the reference standard was interpreted without the knowledge of the results of the index test

No: If the reference standard was interpreted with the knowledge of the results of the index test

Unclear: It was not clear if the reference standard was interpreted without the knowledge of the results of the index test

Could the reference standard, its conduct, or its interpretation Low risk of bias: If 'yes' classification for both questions above; high risk of bias: if 'no' classification for any of the above two questions; unclear risk of bias: if 'unclear' classification for any of the above two questions, but without have introduced bias? a 'no' classification for any of the above two questions

Are there concerns that the target condition (as defined by the reference standard) does not match the question?

Considering the inclusion criteria for this review, all the included studies were classified as 'low concern' as anticipated

Domain 4: Flow and Flow and timing
timing

People with $H$ pylori infection may have resolution of infection (usually with treatment) and people without $H$ pylori infection may get infected with $H$ pylori if there is a long delay between the index test and reference standard. An arbitrary two weeks were chosen as acceptable delay between the index test and reference standard
Was there an appropriate interval between index test and reference standard?
Yes: If the time interval between index test and reference standard was less than two weeks No: If the time interval between index test and reference standard was more than two weeks, or if any treatment for $\mathrm{H}$ pylori had been performed Unclear: If the time interval between index test and reference standard was unclear or it was not clear if any treatment for $\mathrm{H}$ pylori had been performed

Did all patients receive a reference standard?
Yes: If all patients received a reference standard No: If some of the patients did not receive a reference standard. Such studies were excluded 
Unclear: If it was not clear whether all patients received a reference standard. Such studies were excluded

Therefore, all studies included in the review were classified as 'yes' for this item

\begin{tabular}{ll}
\hline $\begin{array}{l}\text { Did all patients receive } \\
\text { the same reference } \\
\text { standard? }\end{array}$ & $\begin{array}{l}\text { Yes: If all the patients received the same reference standard } \\
\text { No: If different patients received different reference standards }\end{array}$ \\
\hline $\begin{array}{l}\text { Unclear: If this information was not clear } \\
\text { Cluded in the analysis? }\end{array}$ & $\begin{array}{l}\text { Yes: If all the patients were included in the analysis, irrespective of whether the } \\
\text { results were uninterpretable } \\
\text { No: If some patients were excluded from the analysis because of uninter- } \\
\text { pretable results } \\
\text { Unclear: If this information was not clear }\end{array}$ \\
\hline $\begin{array}{l}\text { Could the patient flow } \\
\text { have introduced bias? }\end{array}$ & $\begin{array}{l}\text { Low risk of bias: If 'yes' classification for all the above four questions; high risk } \\
\text { of bias: if 'no' classification for any of the above four questions; unclear risk of } \\
\text { bias: if 'unclear' classification for any of the above four questions, but without } \\
\text { a 'no' classification for any of the above four questions }\end{array}$
\end{tabular}

\section{Appendix 7. Characteristics of excluded studies}

We excluded 1728 references (1727 studies) for the following reasons.

Case-control study (17): Alarcón-Rivera 2011; Benjamin 2012; Cao 2012; De Pascalis 1999; Doweck 1997; Dun 2001; Enroth 2002; Figura 1994; Gao 2015; Gerstenecker 1992; Klein 1996; Marshall 1988c; Mattar 1999; Nishizono 1998; Pantoflickova 2000; Roggero 2002; Veijola $2005 b$

Not a primary research study (147): Abadi 2011; Abut 2006; Adamek 1995; Adamsson 2000; Alpert 1989; Anania 2008; Anonymous 1997; Anonymous 2000; Anonymous 2002a; Anonymous 2002b; Anonymous 2004; Arents 2002; Atherton 1994; Attumi 2011; Barthel 1990; Bateson 1991; Bazzoli 1997b; Bazzoli 1998; Bazzoli 1999; Bellon 2004; Bergmann 1997; Blancas 2004; Blum 1997; Bornschein 2011; Braden 1991; Braden 1992; Braden 2001b; Braden 2007; Braden 2012; Bravos 2000; Breslin 1997; Brown 1993; Calam 1994; Calvet 2015; Canard 2003; Caspary 1995; Chey 2000b; Chiba 1999; Ching 1991b; Ciok 2003; Cirak 2007; Continibali 1991; Corti 2007; Couturier 2014; Cutler 1995b; Cutler 1997; De Argila 2001; De Boer 1995; Dewan 2000; Di Rienzo 2013; Dorta 2005; Drumm 1999; Dyrla 2015; Ebell 1998; Elbast 1999; Elitsur 2005; Falk 1997; Fallone 2000; Farkkila 1996; Ferwana 2015; Fukuda 2002; Fukuda 2003a; Fukuda 2003b; Garcia 1996; Garcia 2006; Gatta 2003a; Gisbert 2000b; Gisbert 2006a; Gisbert 2006b; Gisbert 2006h; Gold 2000; Gold 2014; Gonzalez 2004; Goto 1998; Gottrand 2001; Graham 2000; Graham 2001c; Graham 2010; Guo 2005; Guslandi 2000; Harris 1995; Harris 1998; Hart 1999; Hawtin 1999; Heenan 1989; Hirschl 2005; Ho 2000; Hong 2008; Hoshiya 2001; Hsu 2010; Imperiale 1996; Janssen 2001; Jones 1997b; Kabir 2001; Kalach 1998b; Karakus 2013; Katelaris 1997; Kato 2005b; Kato 2005c; Kato 2010; Laheij 2006; Ling 2013; Malfertheiner 2005; Mana 2000a; Mana 2001b; Megraud 1988; Miftahussurur 2016; Mion 1996; Newell 1989b; Nightingale 1996; Nishikawa 1999; Oderda 1998a; Oderda 2004; Parente 2001; Parente 2002b; Pattison 1996; Payne 2006; Perez 1998; Perri 1995; Perri 2000; Radke 1997; Raedsch 1992; Ratnaraj 2015; Rauws 1987; Rauws 1989b; Satoh 1993; Seo 2004; Seo 2013; Shiba 1998; Snyder 1999; Stirling 1995; Takagi 2002; Tamura 2001; Trevisani 2002; Vaira 1989; Vaira 2000a; Vaira 2000b; Vakil 2000b; Wadstrom 1994; Westblom 1999; Wildgrube 1995; Yakoob 2014; Yamamoto 2008; Zagari 2003; Zhang 2002; Zhelezova 2006; Zhou 2014

Erratum (3): Altindis 2002b; Altindis 2003; Ballam 2000b

\section{Inappropriate population $(79)$}

- In monitoring (33): Al-Assi 1999; Balcilar 2012; Bilardi 2002; Bommelaer 2001; Cutler 1996; Fraser 2003; Gisbert 1999c; Hirschl 1996; Houben 1998; Isomoto 2003; Kato 2000a; Kato 2003b; Kato 2005a; Koizumi 2003; Labenz 1997; Makristathis 2000; Mansour-Ghanaei 2013; Miwa 1998a; Odaka 2002; Oderda 1998b; Osaki 2008; Ploier 1997; Quesada 2006a; Richter 2002; Rollan 1997; Sharma 1999; Shimoyama 2009b; Shimoyama 2011; Sorberg 1997; Thijs 1994; Vaira 1999b; Van't Hoff 2000; Zipser 2000

- Not in humans (1): Foertsch 2010

- Only in H pylori negative people (2): Hahn 2000; Urita 2006

- Only in H pylori positive people (39): Ahmed 2005; Alam 2013; Crabtree 1990; Crabtree 1991a; Crabtree 1991b; Cremonini 2005; Janus 1991; Kopanski 1997; Kryvy 2012; Mirbagheri 2005; Parente 2000a; Parente 2000b; Parente 2002a; Park 2001; Pathak 2012; Perri 1994; Polat 2010; Ren 2010; Savarino 2000b; Shimoyama 1996; Shimoyama 2010; Shirin 2005; Sicinschi 2003a; Slomianski 1994; Slomianski 
1995; Sue 1996; Thongbai 2007; Valle 1997; Van der Est 1990; Van der Wouden 1999; Van Zanten 1998; Van Zanten 1999; Van Zwet 1992; Van Zwet 1994; Veijola 2005a; Weingart 2003; Weingart 2004; Yoo 2007; Zagari 2005

- Only in people with gastrointestinal bleeding (2): Liao 2003; Van Leerdam 2003

- Selection of patients was based on the results of other H pylori tests (1): Falsafi 2014

- Includes people who were being monitored for $\boldsymbol{H}$ pylori status (1): Lin 1992

Inappropriate index test (38): Aguilar-Soto 2004; Alan 2014; Bathe 1996; Boyanova 2003; Busro 2013; Chey 1999b; Chou 1997; Datta 2005; Del Pozo Garcia 2006; Dietz 2001; Elitsur 1999b; El-Zimaity 1998; Garces 2012; Ho 2004; Ismail 2016; Isomoto 2006; Jolley 2007; Kolts 1993; Koumi 2011; Kuo 2002; Li 1996; Loeb 1997; Niv 1998; Notarnicola 1996; Olsson 1993; Rogge 1995; Sayed 2011; Schilling 2003; Shimada 1994; Smith 2010; Smith 2012; Suto 2000a; Tokunaga 1998; Tokunaga 2000; Urita 2000; Urita 2004b; Urita 2007a

Inappropriate target condition (4): Ang 2007b; Lee 2013; Ploier 1996; Witt 1990

Inappropriate reference standards (1182): Abdulqawi 2012; Abu 2015; Abukhadir 1998; Abu-Sbeih 2014; Aceti 1989; Adachi 2002; Adamek 1994; Adiloglu 2007; Agha-Amiri 1999a; Agha-Amiri 1999b; Agha-Amiri 2001; Agudo 2009a; Agudo 2009b; Aguemon 2004; Ahuja 1998; Aje 2010; Aksoy 2003; Aktepe 2011; Alavi 1996b; Albrecht 2012; Alcalde 1994; Alemohammad 1993; Al-Humayed 2008; Ali 1997; Ali 1998; Altindis 2002a; Amendola 2002; Anania 2007; Andersen 1998; Anderson 1993; Andrews 2003; Ang 2007a; Anonymous 1989; Antoine 1995; Antos 2005; Arboleda 2013; Archimandritis 2001; Arents 2001; Arinton 2011; Arita 1982; Arj 2012; Arora 2003; Artiko 2004; Asante 1998; Asfeldt 2004; Ashraf 1999; Atherton 1992; Attallah 2004; Aucher 1998; Auroux 1998; Aziz 2014; Bakka 2002; Ballam 1998; Ballam 2000a; Balon 1997; Baqai 2003; Barbosa 2003; Baryshnikova 2009; Baryshnikova 2012; Baryshnikova 2013; Basso 1999; Bazaz 2005; Bazzoli 1995; Bazzoli 2000; Befrits 1993; Beiki 2005; Bell 1987; Bener 2002; Benito 1999; Bergey 2003; Bermejo 2000a; Bermejo 2000b; Bermejo 2002; Bessede 2011; Best 1992; Best 1994; Bhewa 2007; Bielanski 1996a; Bielanski 1996b; Bielanski 1996c; Bielanski 1997b; Bielanski 1998; Bielanski 1999; Biemond 1997; Billaud 1996; Bjorneklett 1989; Blairon 2009; Blanco 2008; Blanco 2009; Blecker 1993b; Blecker 1993c; Blecker 1993d; Blecker 1993e; Blecker 1993f; Blecker 1994a; Blecker 1994c; Blecker 1994d; Blecker 1995a; Blecker 1995b; Bode 2000; Bode 2001; Bode 2002; Bodger 1999; Bodhidatta 1993; Bolton 1989a; Bolton 1989b; Bonamico 2004; Bongermino 2010; Booka 2005; Borody 2012; Borody 2013; Boudjella 2009; Boukthir 2005; Boyanova 2013; Braden 1993; Braden 1994a; Braden 1994b; Braden 1996; Braden 1999; Braden 2000a; Braden 2000 b; Braden 2000c; Braden 2001a; Bravo 1999; Brennan 2015a; Brennan 2015b; Breslin 1998; Breslin 2000; Bretagne 1998; Briedigkeit 1992; Britto 2002; Brmbolic 1997; Bruce 2005; Bruden 2011; Bruning 2002; Brunner 1989; Buchan 2013; Buhling 2004; Burucoa 2013; Cadranel 1998; Cagdas 2012; Caglar 1999; Calvet 1999; Calvet 2002a; Calvet 2002b; Calvet 2002c; Calvet 2003; Calvet 2005; Calvet 2009; Calvet 2010a; Calvet 2010b; Calvo 2013; Camargos 2003; Camorlinga-Ponce 1998; Campuzano-Maya 2007; Canete 2002; Canete 2003; Cardenas 2006; Cardenas 2008; Cardinali 2003; Carrasco 1998; Caselli 1999; Casswall 1999; Castro 2004; Castro-Fernandez 2004; Cave 1999; Chacon 1995; Chang 1999; Chang 2002; Chattopadhyay 2002; Chattopadhyay 2004; Checchi 2000; Chen 1996; Chen 1997; Chen 2000; Chen 2001a; Chen 2001b; Chen 2002a; Chen 2002b; Chen 2003; Cheng 2004; Cherian 2008; Chey 1997a; Chey 1999a; Chey 2000a; Ching 1991a; Ching 1993; Chisholm 2004; Chmiela 2003; Cho 2000; Cho 2003; Choi 2010; Choi 2011; Christie 1996; Chua 2002; Chung 2001a; Chvalova 1990; Clancy 1994; Cockburn 2001; Coelho 1990; Coelho 1997; Coelho 1999; Coelho 2003; Coelho 2009a; Coelho 2009b; Coelho 2011; Cohen 1999; Colaiocco 1999; Connor 1999; Conti-Nibali 1990; Contreras 2006; Coombs 2001; Corvaglia 1997; Corvaglia 1999; Costa 2001; Crespo 2009; Crispino 2013; Cullen 2002; Cunningham 2010; Cutler 1993; Cutler 1995a; Cutler 1998; Cutler 1999; Da Silva 2010; Dahlberg 1998; Daino 2015; Dan 2013; Danielli 1993; Day 2002; Day 2003; De Angelis 2007; De Bustillo 1998; De Carvalho 2003; De Giacomo 1991; De Laat 2001; De Oliveira 1999; Deankanob 2006; Debongnie 1993; Deguchi 2009; Del Zompo 2014; Delaney 2003; Demiray 2006; Demiray 2012; Demiray-Gurbuz 2012; Demirturk 2003; Desroches 1997; Dhar 1998; Dhesi 2015; Di Fulvio 2003; Di Mario 2009; Di Mario 2010; Di Silvio 1998; Dill 1989; Dill 1990; Ding 1993; Ding 2000; Dolek 2007; Dominguez 2006; Dominguezmunoz 1995; Domínguez-Muñoz 1997; Donati 1997; Dondi 2006; Dore 2004; Douraghi 2013; Drew 1988; Drzymala-Czy 2014; Du 2004; Duan 1994; Duggan 1998; Duggan 1999; Dulbecco 2001; Dulbecco 2003; Dumont 1989; Durdal 2002; DyLimquiaco 2006; Edwards 1997; Elitsur 1997; Elitsur 2004; Elitsur 2009; Ellenrieder 1997; Elnujumi 1991; El-Nujumi 1996; El-Nujumi 1998; ElZaatari 1995; Endtz 2000; Engberg 2003; Engstrand 1992; Enroth 1997a; Enroth 1997b; Erzin 2004; Erzin 2005; Evans 1989; Everts 1996; Faigel 1996a; Faigel 1996b; Faigel 2000; Fakhrjou 2011; Falaknazi 2010; Fallone 1998; Falsafi 2005; Falsafi 2009; Fanti 2001; Fazulzyanova 2012; Fazzio 1995; Feldman 1995; Felz 1997; Ferrante 1999; Festi 1999; Feteih 2009; Feydt-Schmidt 2002; Figura 2005; Figura 2014; Finderle 2013; Fontana 2000; Forne 2000; Fox 1989; Fraser 1996b; Frenck 2006; Fry 2005; Fujisawa 2001; Fukuda 1996; Fukuda 2005; Fukuda 2006; Fusconi 1999; Galleguillos 1998; Gallo 2001; Ganga-Zandzou 2001; Garcia 2000; Garcia-Diaz 2002; Garza-Gonzalez 2003; Gatta 2003b; Gatta 2003c; Gatta 2003d; Gatta 2004a; Gatta 2004b; Gatta 2006; Gatta 2010a; Gatta 2010b; Gatta 2011; Gerards 1999; Ghasemian 2005; Ghoshal 2010; Gilger 2002; Gill 2007; Girdalidze 2013; Gisbert 1999a; Gisbert 1999b; Gisbert 2000a; Gisbert 2000c; Gisbert 2000d; Gisbert 2000e; Gisbert 2000f; Gisbert 2000g; Gisbert 2001; Gisbert 2002a; Gisbert 2002b; Gisbert 2002c; Gisbert 2002d; Gisbert 2003a; Gisbert 2003b; Gisbert 2004a; Gisbert 2006c; Gisbert 2006d; Gisbert 2006e; Gisbert 2006f; Gisbert 2006g; Gisbert 2007; Glassman 1990; Glupczynski 1992; Gobert 1989; Goel 2003; Goh 1995; Gomes 2002; Gomes 2005; Gomez 2000; Gomollon 2003; Gonzalez 2007; Gonzalez 2013; Gonzalez-Cuevas 2001; Good 1991; Goodwin 1987; Gosciniak 1993; Gosciniak 1996; Gosciniak 2000; Gosciniak 2002; Gosciniak 2003; Goto 1995; Graham 1986; Graham 1987; Graham 1996b; Graham 2001a; Graham 2001b; Grino 2001; Grino 2003; Grossi 2000; Guell 2006; Guja 1999; Gulcan 2005; Gupta 2003; Gurbuz 2009; Gutierrez 1999; Gutierrez 2005; Hackelsberger 1998; Haggerty 2005; Hamlet 1995; Hamlet 1999; Han 2006; Hanvivatvong 2004; Hanvivatvong 2006; Harries 1992; Harrison 1998; Hartmann 2003; Hashemi 2008; Hauser 2006; Havlasova 1998; Hawthorne 1999; Hayashi 2003; Heaney 1998; Heanhean 2013; Hegedus 2002; Helvaci 1993; Henze 1988; Henze 1989; Henze 1990; Hidaka 2010; Higazy 2000; Hildebrand 1997; Hino 2004; Hirschl 1991; Hirschl 1993; Ho 1996; Hoang 2006; Hoek 1992; Hollenz 1999; Hooton 2006; Houben 1999; Hu 1995; Hu 2000; Hu 2007; Hu 2011; Huang 1993; Huang 1996; Huang 2000; Huelin 1996; Hung 2002; Hung 2010; Husson 2000; Ibrahim 2012; Ichinose 1998; Ignys 2006; Ilan 1998; Imrie 2001; Iranikhah 2013; Ishihara 2000; Ishizuka 1999; Isomoto 2002; Israeli 2003; Ito 2005; Iwanczak 2005; Jadresin 2000; Jalali 1988; Jensen 1993; Ji 1993; Jiang 2004; Jo 2008; Jo 2014; Johnston 1998; Jonaitis 2007; Jones 1997a; Jones 
2007; Juhasz 2000; Juncal 1998; Kajiwara 1997; Kajiwara 1998; Kakinoki 2001; Kaklikkaya 2006; Kalach 1996; Kalach 2005; Kalach 2009; Kalem 2010; Kang 1999; Kannath 2007; Kao 1993; Kaore 2012; Kaptan 2009; Karsligil 2010; Kasho 1996; Kassa 1996; Katelaris 1998; Kato 1997; Kato 1998; Kato 1999; Kato 2000b; Kato 2000c; Kato 2001a; Kato 2001b; Kato 2001c; Kato 2002a; Kato 2002b; Kato 2002c; Kato 2002d; Kato 2002e; Kato 2003a; Kato 2004a; Kato 2004b; Kato 2004c; Kato 2007; Katsuragi 1998; Kaul 1998; Kawai 2008; Kawakami 2002; Kazemi 2011; Kearney 1999; Kearney 2002; Ken 2013; Kesli 2010; Khafri 2005; Khalifehgholi 2013; Kharchenko 2012; Khorovskaya 2003; Kias 2011; Kikuchi 1999; Kim 1996; Kim 1997; Kim 1999; Kim 2001; Kim 2002; Kim 2009; Kim 2012; Kim 2013; Kim 2014; Kindermann 2000; Kindermann 2001a; Kindermann 2001b; Kishkun 2002; Klyucharova 2013; Kobayashi 2002; Kodama 2004; Kodama 2012; Kokkola 2000; Koletzko 1995; Koletzko 2003; Kolho 2002; Kolho 2006; Kolt 1997; Kondo 2000; Konorev 2013; Konstantopoulos 2001; Konturek 1999; Kopacova 1999; Kopacova 2005; Kopanski 1996; Korkmaz 2013; Korkmaz 2015; Korzonek 1997; Kountouras 1996; Kowalski 1990; Kozaiwa 1997; Kozlov 2006; Krausse 2008; Kroser 1998; Krumbiegel 2000a; Krumbiegel 2000b; Kuang 1998; Kubota 2002; Kubota 2003; Kumbhari 2012; Kumbhari 2013; Kuo 2005; Kushch 2009; Kwon 2004; Kwon 2015; Kyrlagkitsis 2007; Labenz 1996; Ladas 2000; Ladas 2002b; Lahaie 1995; Lai 1997; Laine 1999; Langhorst 2002; Larras 2009; Lee 1999; Lee 2000a; Lee 2000b; Lee 2003; Lee 2014; Lee 2015a; Leja 2009; Lelwala 1990; Leodolter 1997; Leodolter 1998a; Leodolter 1998b; Leodolter 1999a; Leodolter 1999b; Leodolter 2000; Leodolter 2001a; Leodolter 2001b; Leodolter 2001c; Leodolter 2002; Leodolter 2003a; Leodolter 2003b; Leodolter 2004; Lepper 2004; Lerang 1998a; Lerang 1998b; Leszczynska 2009; Leung 1998a; Leung 1998b; Leung 1999; Leung 2001; Leunk 1990; Levine 2004a; Levine 2004b; Lew 1999; Lewin-van 1999; Lewis 1997; Li 1995; Li 2004; Liao 2002; Lie 2012; Lim 2005; Lin 2004a; Lin 2004b; Lin 2004c; Lin 2015; Lindsetmo 2008; Liquornik 1998; Liston 1996; Liu 2002; Lo 2005; Locatelli 2004; Loffeld 1989; Loffeld 1993; Logan 1990; Logan 1991b; Lombardo 1999; Lopez 2001; Lopez 2004; Lopez-Brea 1998; Lotterer 1991; Lotterer 1993a; Lotterer 1993b; Lozniewski 1996; Lu 2005; Lu 2006; Lucio 1999; Luzza 1995; Luzza 1997; Luzza 2000; Ma 2006; Maaroos 2004; Machado 2004; Machado 2006; MacKay 2003; Madico 1995; Mahmood 2010; Maity 2014; Makristathis 1998; Malaty 1996; Malaty 2000; Malaty 2002; Malfertheiner 1988; Malfertheiner 2002; Mana 2000b; Mana 2005; Manes 2000; Manes 2001; Manes 2005; Marchildon 1996; Marchildon 1999; Marchildon 2003; Marshall 1988a; Marshall 1988b; Marshall 1991; Marusic 2006; Masoero 2000; Matougui 2007; Matsuda 2003a; Matsuda 2003b; Matsukura 1995; Matsukura 2004; Matsuo 2000; Mattar 2014; Mauro 2006a; Mauro 2006b; McColl 2003; McNamara 1999; McNulty 1999; Mediero 2007; Megraud 2000; Megraud 2005; Mehrazma 2014; Meijer 1997; Mendall 1992; Menegatti 1997a; Menegatti 1997b; Metz 1998; Metz 2000; Midolo 1995; Minoli 1998; Mion 1997a; Mion 1997b; Mion 2001; Miwa 1997; Miwa 1998b; Miwa 1999; Miwa 2000; Miwa 2001; Mizukami 1994; Moayyedi 1997; Mock 1999; Mohammadi 2008; Moncayo 2006; Monteiro 2001b; Morales 2002; Moshkowitz 1993; Motta 2009; Moulton-Barrett 1993; Mowat 1997; Mowat 1998; Mrevlje 2012; Muhsen 2006; Muñoz 1998; Muñoz 1999; Munster 1993; Murakami 2003; Murakami 2011; Murata 2002; Murphy 2015; Myllyniemi 2007; Myllyniemi 2008; Nagahara 2003; Nair 1995; Nakata 1995; Nakata 2004; Nakayama 2004; Navarro 1992; Negayama 1992; Negrini 1992; Newell 1988; Newell 1991; Ng 2002; Ng 2013; Nguyen 2008a; Nguyen 2008b; Nguyen 2010; Nguyen 2013; Ni 2000; Nijevitch 2001; Nilius 2001; Nishikawa 1996; Nishikawa 2000; Noguchi 2007; Nugalieva 2006; Nurgalieva 2003; Nurgalieva 2008; Nysaeter 1992; Obata 2003; Obradovic 2001; Oderda 1989; Oderda 1999; Oderda 2000; Ogunc 2003; Ohara 1995; Ohara 1996; Ohara 1997; Ohara 1998a; Ohara 1998b; Ohara 2004; Ohkura 1998; Ohkura 2000; Oksanen 1997; Oksanen 1998; Oksanen 2001; Okuda 2002; Okuda 2004; Okuda 2005; Okuda 2010; Okuda 2013; Okuda 2014; Olafsson 2012; Oleastro 2000; Oleastro 2002; Oliaro 2000; Omorogbe 2015; Ong 1993; Opekun 2002; Opekun 2006; Ormand 1990; Ortiz-Olvera 2007; Osman 2014; Osoba 2004; Ou 2013; Ozdemir 2008; Ozturk 2009; Pacheco 2001; Pacheco 2013; Paimela 2006; Palka 2010; Pandya 2014; Pantoflickova 1999; Pantoflickova 2003; Paoluzi 2001; Parejo 1998; Park 2006; Park 2009; Park 2015; Parolova 2012; Patel 1994; Pathak 1992; Pathak 1994; Pathak 2008; Pathak 2011; Pathak 2013; Pathak 2014; Pattison 1997; Pavlitou 1998; Pavlitou 2000; Pawar 2014; Peitz 2000; Peitz 2003; Peitz 2004; Pena 1989; Peng 2000a; Peng 2000b; Peng 2001a; Peng 2001b; Peng 2002; Peng 2003; Peng 2005; Peng 2009; Perets 2014; Perets 2015; Perez 1996; Perezperez 1994; Perna 2002; Perna 2005; Perri 1997a; Perri 1997b; Perri 1998a; Perri 1998b; Perri 1998c; Perri 2002a; Perri 2002c; Perri 2005; Petrovic 2011; Pettersson 2001; Pianko 1999; Pilotto 1999; Pilotto 2000a; Pilotto 2000b; Pilotto 2002; Plebani 1999; Ploier 1995; Pons 2014; Porter 2009a; Porter 2009b; Portorreal 2002; Posteraro 2006; Pourakbari 2011a; Pourakbari 2011b; Pourakbari 2013; Prabakaran 1997; Prell 2009; Prieto 1994; Pronovost 1994; Przyklenk 1990; Pu 2005; Puolakkainen 1997; Puz 2006; Puz 2008; Qibi 2008; Quach 2014; Queiroz 1999; Queiroz 2000; Queiroz 2013; Queralt 2005; Quesada 2006b; Rabbe 1988; Rae 1995; Raguza 2005; Raguza 2010; Rahman 2008; Raju 1994; Ramírez-Lázaro 2011; Ramírez-Lázaro 2015; Rao 2001; Rauws 1989a; Rauws 1989c; Raymond 1999; Raymond 2000; Razaghi 2010; Rechcinski 1997; Redéen 2011; Rehnberg 2001; Reilly 1997; Ren 2005; Reynders 2012; Riaz 2011; Riepl 2000; Ritchie 2009; Rocha 1998; Rocha 2002; Rocha 2004; Roma-Giannikou 2010; Romaozinho 2011; Roth 2001; Rothenbacher 2000a; Rothenbacher 2000b; Rowland 1997a; Rowland 1997b; Sabbi 2005; Sadowski 1998; Saez 2012; Saffari 2003; Salama 1993; Salles-Montaudon 2001; Salomaa-Rasanen 2004; Saltik 2001; Saltik 2003; Sanches 2013; Saneian 2013; Sano 2004; Santogade 1990; Sarker 2003; Sastry 1997; Sato 2012; Savarino 1999; Savarino 2000a; Savarino 2001; Savio 1999; Sawada 2001; Scherbakov 2001; Schmitt 1996; Schuman 1995; Schumann 2006; Schwarzer 2007; Sedlackova 1992; Sen 2005; Sen 2011; Serrano 2008; Sfarti 2009; Shaikh 2005; Sharma 1995; Sharma 1997; She 2009; Sheikhian 2007; Shepherd 2000; Sheu 1997; Sheu 1999a; Sheu 1999b; Sheu 2000a; Sheu 2000b; Sheu 2000c; Sheu 2002; Shimizu 2003a; Shimizu 2003b; Shimoyama 2009a; Shimoyama 2015; Shirin 2001; Shirin 2003; Shukla 2012; Sicinschi 2003b; Siddiqui 2010; Silva 2009; Sito 1994; Slade 1999; Slater 2004; Smith 2006; Sobala 1991; Sokucu 2002; Song 2000; Song 2014; Sonmezoglu 2005; Steen 1995; Stege 2010; Sternberg 1997; Stojkovic 2011; Stone 1997; Storskrubb 2005; Stray-Pedersen 2007; Stuppy 2010; Stuppy 2011; Sudraba 2010; Sudraba 2011; Sugiyama 1991; Sujatha 2013; Sukhanov 2011; Sumona 2009; Sunnerstam 1999; Surveyor 1988; Suto 1997a; Suto 1997b; Suto 1999; Suto 2000b; Suzuki 2010; Syam 2005; Sykora 2002; Sykora 2003; Taha 1992; Taha 1993; Takagi 1993; Takagi 2003; Takahashi 2010; Talebkhan 2009; Talebkhan 2010; Talley 1991; Talley 1992; Talley 1998; Tanahashi 1998; Tanaka 2001; Tanaka 2003; Tanaka 2004; Tanaka 2005; Tanigawa 1996; Taniguchi 1995; Teich 1997; Temelli 2011; Teo 1997; Tepes 2015; Tereshchenko 2014; Tewari 2001; Tham 1993; Tham 1994; Thijs 1995a; Thijs 1995b; Thijs 1996; Thillainayagam 1991; Thomas 1990; Thomas 1999; Tindberg 2001; Tinnert 1998; Tiryaki 2010; Togashi 2006; Tokunaga 2005; Toporowska-Kowalska 2005; Torres 2001; Toyama 1999; Trautmann 1994; Treiber 2000; Trevisani 1998; Trevisani 1999a; Trevisani 1999b; Tseng 2005; Tu 1999; Tucci 1996; Tummala 2007; Uchida 2011; Ueda 2014; Uematsu 2002; Urita 2002; Urita 2004a; Urita 2004c; Us 2002; Uyub 1994; Vafaeimanesh 2014; Vaira 1996; Vaira 1999a; Vaira 1999c; Vaira 2000c; Vaira 2002; Vaira 2009; Vaira 2010a; Vaira 2010b; Vakil 1999; Vakil 2000a; Valdeperez 2003; Valentine 1991; Valle 2013; Van de Wouw 1995; Van de Wouw 1996; Van de Wouw 1997; Van Den 1991; 
Van Der Ende 1999; Van Der Hulst 1999; Van der Hulst 1999; Van der Voort 1998; Van der Voort 1999; Van Doorn 2001; Van Leerdam 2002; Vannella 2009; Vargas 2013; Vaz Coelho 2005; Vecsei 2010; Veenendaal 1995; Veijola 2008; Velayos 2012; Veldhuyzen 1990; Veldhuyzen 1991; Vincent 1999; Vinette 2004; Vivas 1993; Von Wulffen 1988b; Von Wulffen 1993; Vyas 1994; Wallace 2006; Wang 1998; Wang 2000; Wang 2001; Wang 2002; Wang 2003; Wang 2015a; Wang 2015b; Watanabe 2001; Watanabe 2013; Weijnen 2001a; Weijnen 2001b; Westblom 1992; Wilcox 1996; Wildner-Christensen 2002; Wilson 2008; Winiarski 2003b; Winiarski 2003a; Wirtheim 2001; Wisniewska 2002a; Wisniewska 2002b; Wisniewska 2006; Wong 1999; Wong 2000a; Wong 2000b; Wong 2000c; Wong 2001a; Wong 2001b; Wong 2003a; Wong 2003b; Wong 2003c; Wu 1992; Wu 2001a; Wu 2001b; Wu 2003; Wu 2004; Wu 2006a; Wu 2006b; Xia 2000a; Xia 2000b; Xia 2002; Xiao 1991; Yachi 1991; Yakoob 2008; Yamakawa 1993; Yamamoto 1995; Yamamoto 1996; Yamamoto 2000; Yamamoto 2003; Yamamoto 2005; Yamaoka 1998; Yamasaki 2004; Yamashiro 1995; Yan 2010; Yanez 2000; Yang 2005; Yang 2007; Yang 2008a; Yang 2008b; Yang 2015; Yasuda 2009; Ye 2005; Yee 2002; Yilmaz 2006; Yin 2015; Yokota 1990; Yong 2006; Yoshida 1993; Yoshida 2000; Young 1995; Young 1996; Zagari 1998; Zagari 2012; Zalabska 2010; Zambon 2004; Zanetti 2002; Zaremba 1995; Zawadzka-Gralec 2009; Zhang 1990; Zhang 2007; Zheng 2004; Zhou 1996; Zhu 2002a; Zhu 2002b; Zhukhovitskii 2005; Zubillaga 1997; Zubillaga 1999

\section{Lack of data (256)}

- Insufficient diagnostic test accuracy data (25): Allerberger 1996; Baryshnikova 2014; Bilal 2007; Capurso 2006; Casellas 1999; Chehter 2013; Cinar 2004; De Arruda 2001; Faigel 2001; Folwaczny 1999; Formichella 2012; Goettner 2012; Gonzalez 2003; Groves 1997; Herold 2002; Hilker 1994; Hirschl 1990; Konorev 2014; Mendoza 2006; Neri 1999; Neumann 2010; Neumann 2011; Neumann 2012; Reshetnikov 2007; Urita 2007b

- No diagnostic accuracy data (42): Abdullah 1997a; Alem 2002; Bazzoli 1994; Bazzoli 1996; Bojko 1997; Brandi 2006; Brennan 1991; Cacoullis 1991; Cai 2010; Caporali 2003; Cevrioglu 2004; Chang 2000; Chiang 2010; Chong 1995; Cremonini 2000; Czkwianianc 1997; Dowlatshahi 2002; Elitsur 2000; Garza-Gonzalez 2002; Gisbert 1996; Gisbert 2005; Gong 2010; He 1997; Hegedus 2001a; Hegedus 2001b; Herbrink 1988; lijima 1998; Ilga 2008; Inaba 2002; Jabbari 2009; Jung 2002; Matthews 2000; Matthews 2005; Mitchell 1988; Naruki 1996; Nishi 1998; Oak 2011; Rapoport 2014; Rasheed 2014; Rejchrt 2004; Schaefer 1999; Smith 2009

- Not a diagnostic test accuracy study of non-invasive $\boldsymbol{H}$ pylori diagnosis (188): Abdullah 1997b; Adamczyk 2013; Adiloglu 2003; Aguemon 2005; Alavi 1996a; Andersen 1989; Anonymous 1996; Antico 2010; Anwar 2012; Asaka 1988; Asaki 1996; Aulia 2009; Baranskaia 2006; Basinska 2005; Bassler 1992; Bateson 2001; Bauernfeind 1989; Bazzoli 1997a; Bekmen 2008; Bell 1991; Bennedsen 1998; Bennett 2006; Berger 2002; Berker 2003; Berning 2009; Bertschinger 1992; Besherdas 2000; Bielanski 1997a; Bielanski 2000; Bindayna 2006; Birkenfeld 2004; Blashenkov 2013; Bleau 1998; Blecker 1992a; Blecker 1992b; Blecker 1993a; Blecker 1993g; Blecker 1994b; Bode 1998; Bohn 1994; Bolton 1997; Bordin 2013; Braden 1997; Buchvald 1993; Bures 2000; Butler 2000; Buyukbaba-Boral 2005; Buzas 2001; Buzas 2008; Chalkias 2011; Chang 2003; Chang 2012; Chang 2013; Chen 1994; Chen 2009a; Chen 2009b; Chey 1997b; Cho 2008; Chong 1994; Christensen 1992; Chung 2001b; Churchill 1998; Clayton 1992; Collins 1992; Con 2007; Cooreman 1990; Cullen 1992; Czinn 1991; Datta 2003; Dediste 2003; Demir 2001; Devenish 2005; Djurasinovic 2014; Dmitrienko 2009; Dmitrienko 2011; Donati 2000; Dong 2015; Dore 1997; Dore 2003; Dou 2008; Ebara 2000; Elitsur 1999a; Faulde 1991; Fayaz 2014; Fayed 2008; Floch 2012; Fowora 2012; Fradkin 1997; Franceschi 1999; Fraser 1996a; Fraser 1997; Fraser 1998; Fruehauf 2003; Fukuda 2007; Fukuda 2009; Fusconi 1997; Gangaidzo 1995; Geletneky 1996; Gemignani 2013; Gene 2000; Ghosh 2014; Gisbert 1997; Gobert 1988; Goji 2015; Gomez 2011; Gomez-Camarasa 2014; Gong 2014; Gonzalez 2012; Gotoh 1997; Grossi 2012; Grotowski 1998; Groves 2002; Guducuoglu 2010; Gunay 2009; Guven 2011; Harde 2008; Harde 2010; Hartman 1992; Hassan 2013; Huijsdens 2004; Hynes 1998; Hynes 2000; lerardi 2002; lerfone 2003; Ito 2002; Jaff 2011; Jafri 2010; Jaime 2013; Jain 1999; Jane 1999; Janjetic 2010; Janjetic 2011; Janjetic 2015; Janulaityte 1998; Jarbol 2006; Johansen 2004; Jung 2013; Kessenich 2012; Kist 1999; Klein 1999; Koca 2005; Kokkola 1998; Kopanski 1993a; Kopanski 1993b; Kopanski 2002; Kubo 2001; Lamarque 1996; Lassnig 1988; Lemus 2004; Leodolter 2005; Mahony 1988; Marshall 1999; Massarrat 2012; McColl 1997; Meltzer 2013; Miehlke 1996; Murugesan 2011; Nakagawa 1995; Newell 1989a; Nguyen 2012; Niv 2000; Niv 2003; O'Connor 2010; Perez-Perez 1997; Perri 2002b; Perrone 2005; Potashov 1996; Presecki 1997; Salih 2013; Sharma 2015; Shimoyama 2014; Shmuely 2007; Shuber 2002; Smith 2011; Stermer 1997; Taylor 1987; Tormo 2013; Van Bohemen 1988; Van Bohemen 1989; Vesna 2005; Von Wulffen 1988a; Von Wulffen 1989; Vorobjova 1991; Werdmuller 1998; Xie 2008a; Xie 2008b; Zhang 2006; Zhou 2000

- Incorrect data (correct information could not be obtained) (1): Hilker 1996

\section{Appendix 8. Risk of bias and applicability concerns summary for each study included for urea breath test-13C, urea breath test-14C, serology and the stool antigen test}

Figure 12; Figure 13; Figure 14; Figure 15 
Figure 12. Risk of bias and applicability concerns summary: review authors' judgements about each domain for each study included for urea breath test-13C

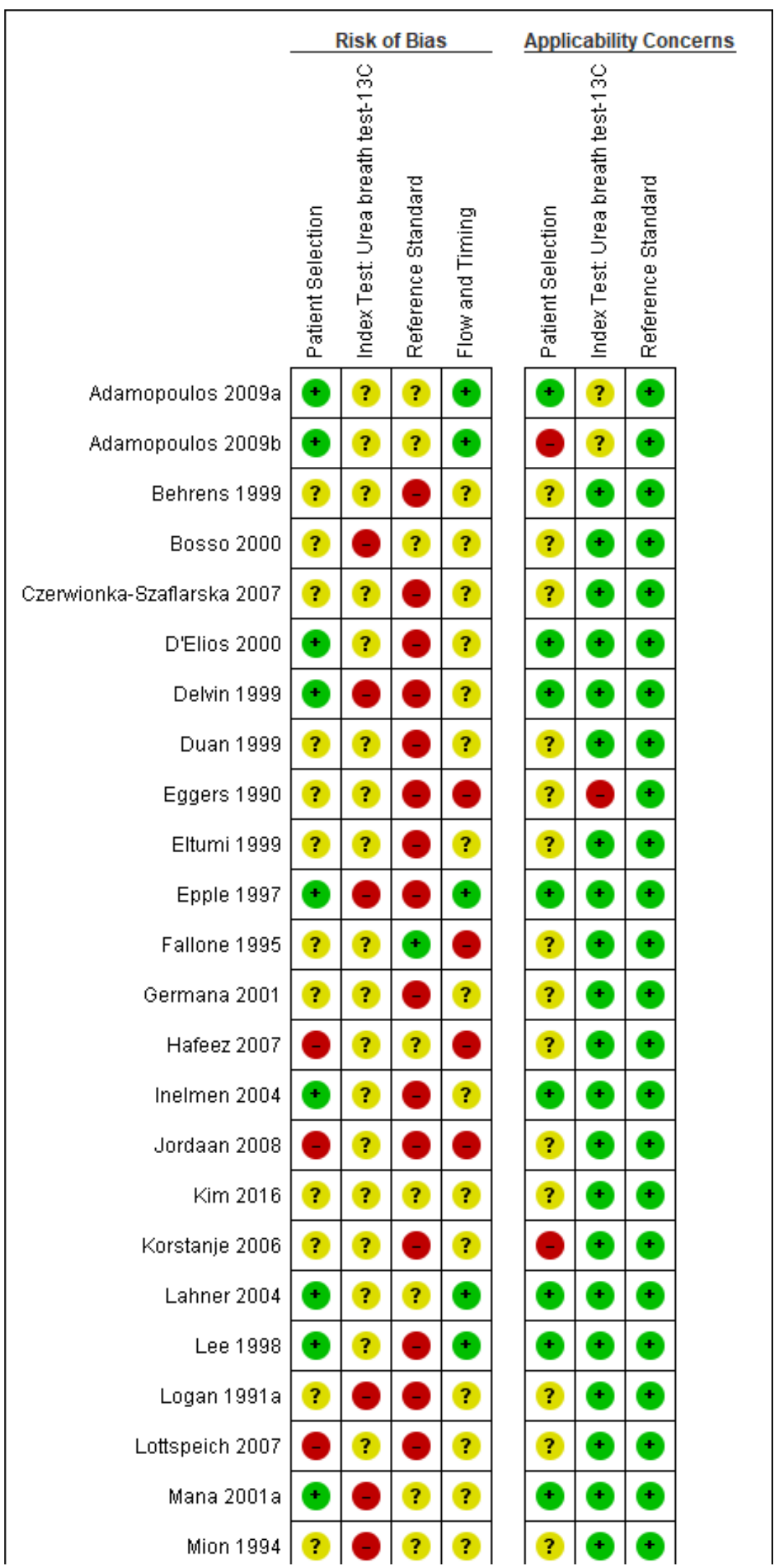


Figure 12. (Continued)

\begin{tabular}{|c|c|c|c|c|c|c|c|}
\hline Mion 1994 & $?$ & $\odot$ & $?$ & $?$ & $?$ & + & + \\
\hline Monteiro 2001a & $\oplus$ & $?$ & - & $?$ & + & $\odot$ & $\oplus$ \\
\hline Ogata 2001 & $?$ & $?$ & - & $?$ & $\odot$ & $\bullet$ & $\odot$ \\
\hline Salles-Montaudon 2002 & $?$ & $?$ & $\odot$ & $?$ & $?$ & + & + \\
\hline Schilling 2001 & $?$ & $?$ & $?$ & $?$ & $\odot$ & + & + \\
\hline Sheu 1998a & $?$ & $?$ & $\odot$ & $?$ & $?$ & $\odot$ & + \\
\hline Sheu 1998b & $?$ & $?$ & $\odot$ & $?$ & $\odot$ & $\odot$ & + \\
\hline Vandenplas 1992 & $\odot$ & $?$ & $\odot$ & $?$ & + & $\odot$ & + \\
\hline Wardi 2012 & $?$ & $\odot$ & $\odot$ & $?$ & $\ominus$ & $\ominus$ & + \\
\hline Yoshimura 2001 & $?$ & $?$ & $\ominus$ & $?$ & $?$ & + & + \\
\hline Yu 2001 & $\odot$ & $?$ & $\odot$ & $?$ & $\odot$ & + & + \\
\hline & Un & & & & Low & & \\
\hline
\end{tabular}


Figure 13. Risk of bias and applicability concerns summary: review authors' judgements about each domain for each study included for urea breath test-14C.

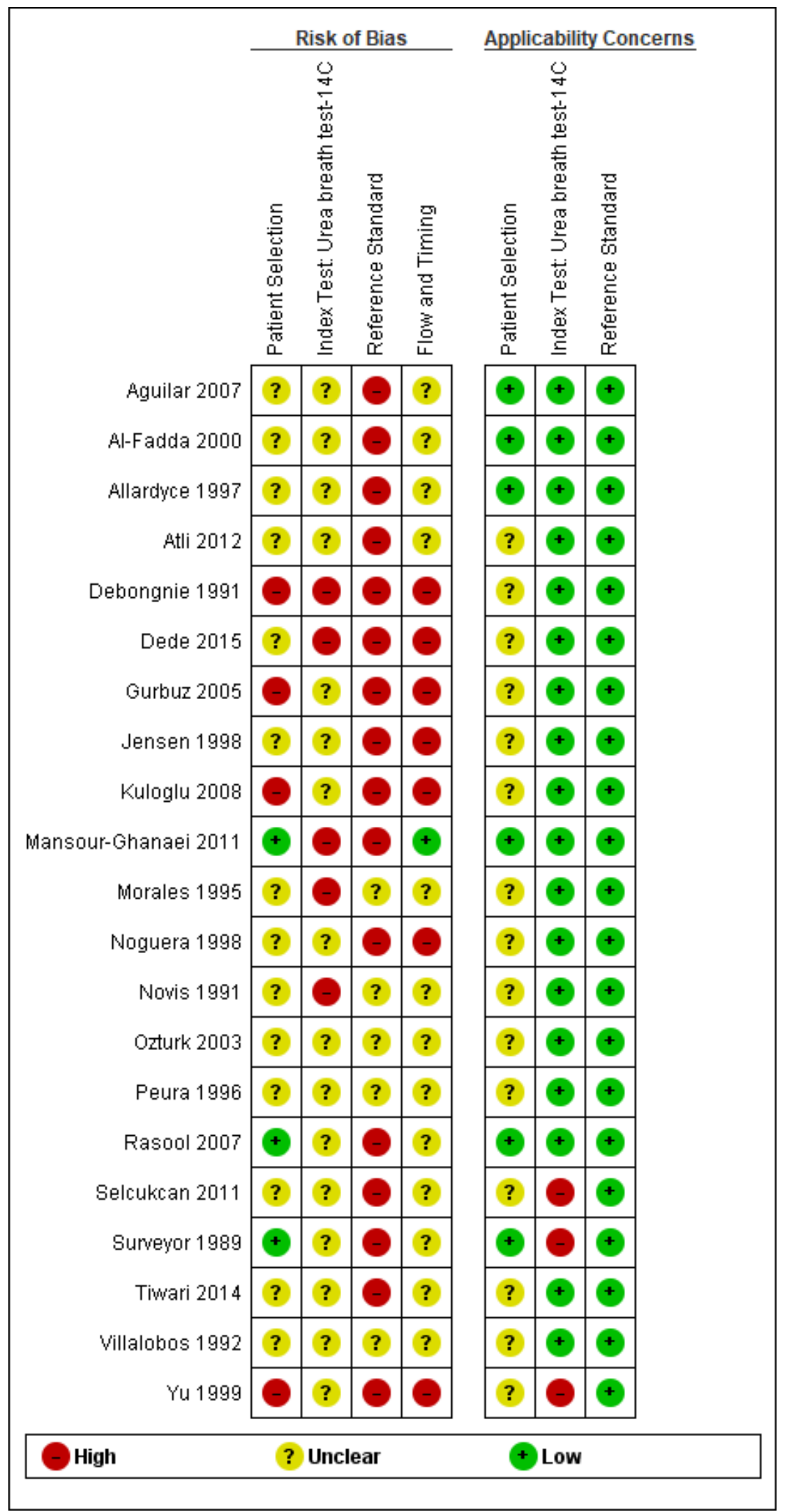


Figure 14. Risk of bias and applicability concerns summary: review authors' judgements about each domain for each study included for serology

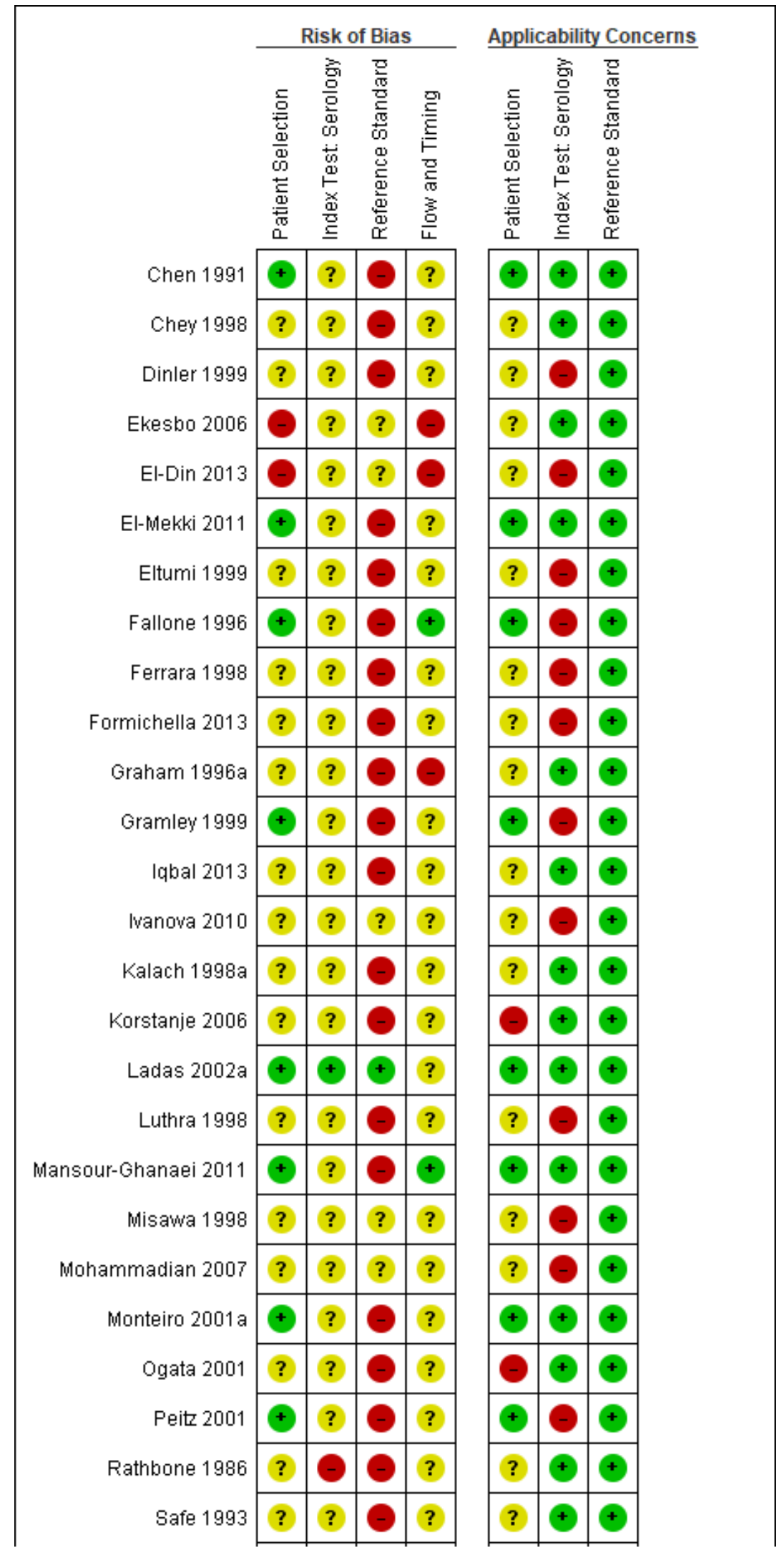

Non-invasive diagnostic tests for Helicobacter pylori infection (Review) 
Figure 14. (Continued)

\begin{tabular}{|c|c|c|c|c|c|c|c|}
\hline Safe 1993 & $?$ & $?$ & $\odot$ & $?$ & $?$ & + & + \\
\hline Salles-Montaudon 2002 & $?$ & $?$ & $\odot$ & $?$ & $?$ & + & + \\
\hline Shin 2009 & $?$ & $?$ & $?$ & $?$ & $?$ & + & + \\
\hline Soomro 2012 & $?$ & $?$ & $?$ & $?$ & $?$ & $\odot$ & + \\
\hline Thobani 1995 & $?$ & $?$ & $\odot$ & $?$ & $?$ & + & + \\
\hline Vandenplas 1992 & $\odot$ & $?$ & $\odot$ & $?$ & $\odot$ & + & + \\
\hline Wang 2008 & $\odot$ & $?$ & $\odot$ & $\odot$ & $?$ & $\odot$ & + \\
\hline Weiss 1994 & $?$ & $?$ & $\odot$ & $?$ & $?$ & $\odot$ & + \\
\hline Yoshimura 2001 & $?$ & $?$ & $\odot$ & $?$ & $?$ & $\odot$ & $\odot$ \\
\hline High & & Uncl & & & & Low & \\
\hline
\end{tabular}


Figure 15. Risk of bias and applicability concerns summary: review authors' judgements about each domain for each study included for the stool antigen test

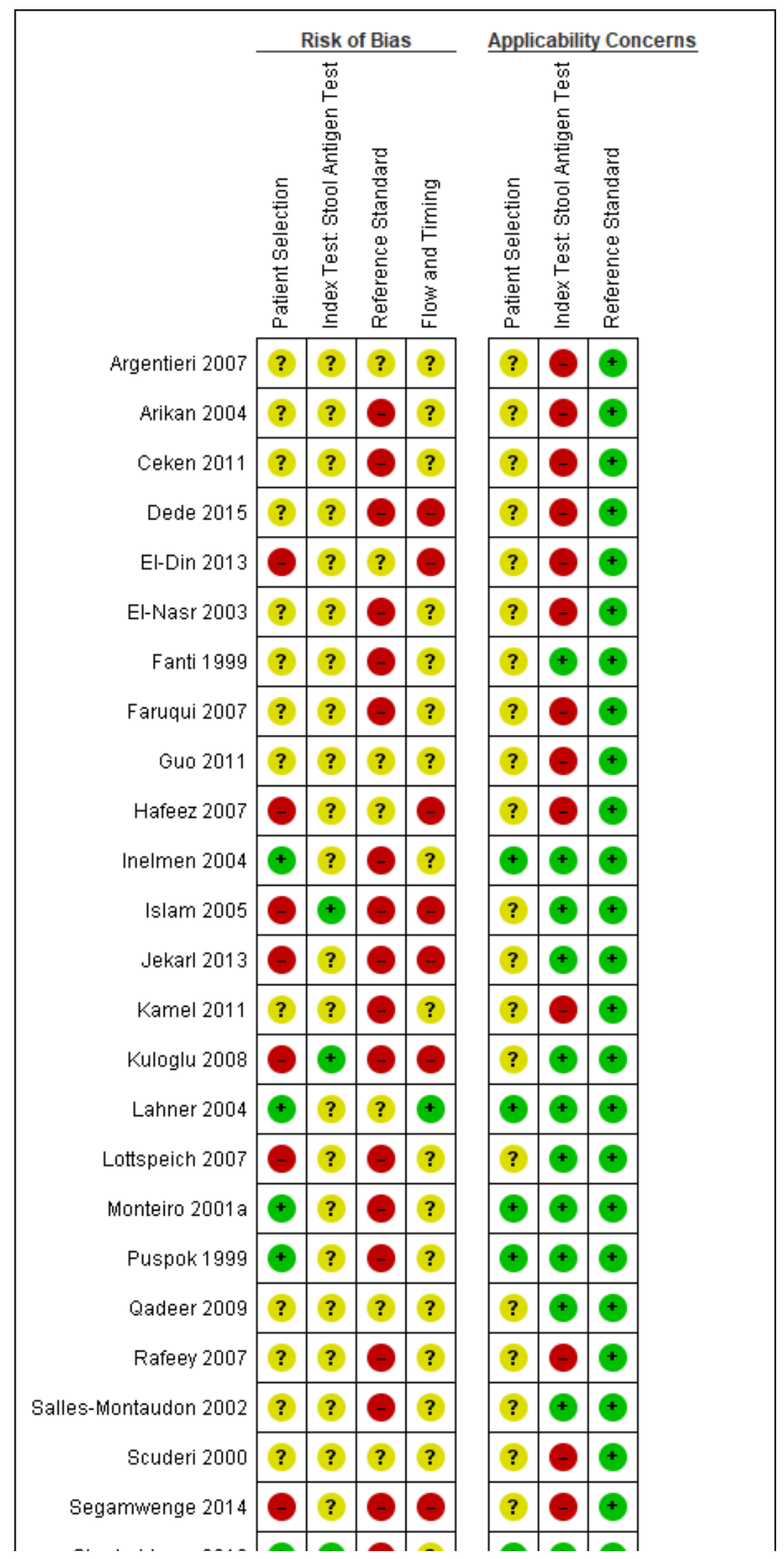


Figure 15. (Continued)

\begin{tabular}{|c|c|c|c|c|c|c|c|}
\hline \multirow{2}{*}{$\begin{array}{l}\text { Segamwenge } 2014 \\
\text { Sharbatdaran } 2013\end{array}$} & $\boldsymbol{\sigma}$ & $?$ & $\boldsymbol{\sigma}$ & $\sigma$ & $?$ & $\boldsymbol{\sigma}$ & + \\
\hline & $\oplus$ & $\odot$ & $\odot$ & $?$ & $\odot$ & + & $\odot$ \\
\hline Soomro 2012 & $?$ & $?$ & $?$ & $?$ & $?$ & $\odot$ & + \\
\hline Trevisani 2005 & $?$ & $?$ & $\odot$ & $?$ & $?$ & $\odot$ & + \\
\hline Yan 2003 & $\odot$ & $?$ & $?$ & $\odot$ & $?$ & $\odot$ & + \\
\hline Yu 2001 & + & $?$ & $\odot$ & $?$ & $\odot$ & + & + \\
\hline & & & & & & Low & \\
\hline
\end{tabular}




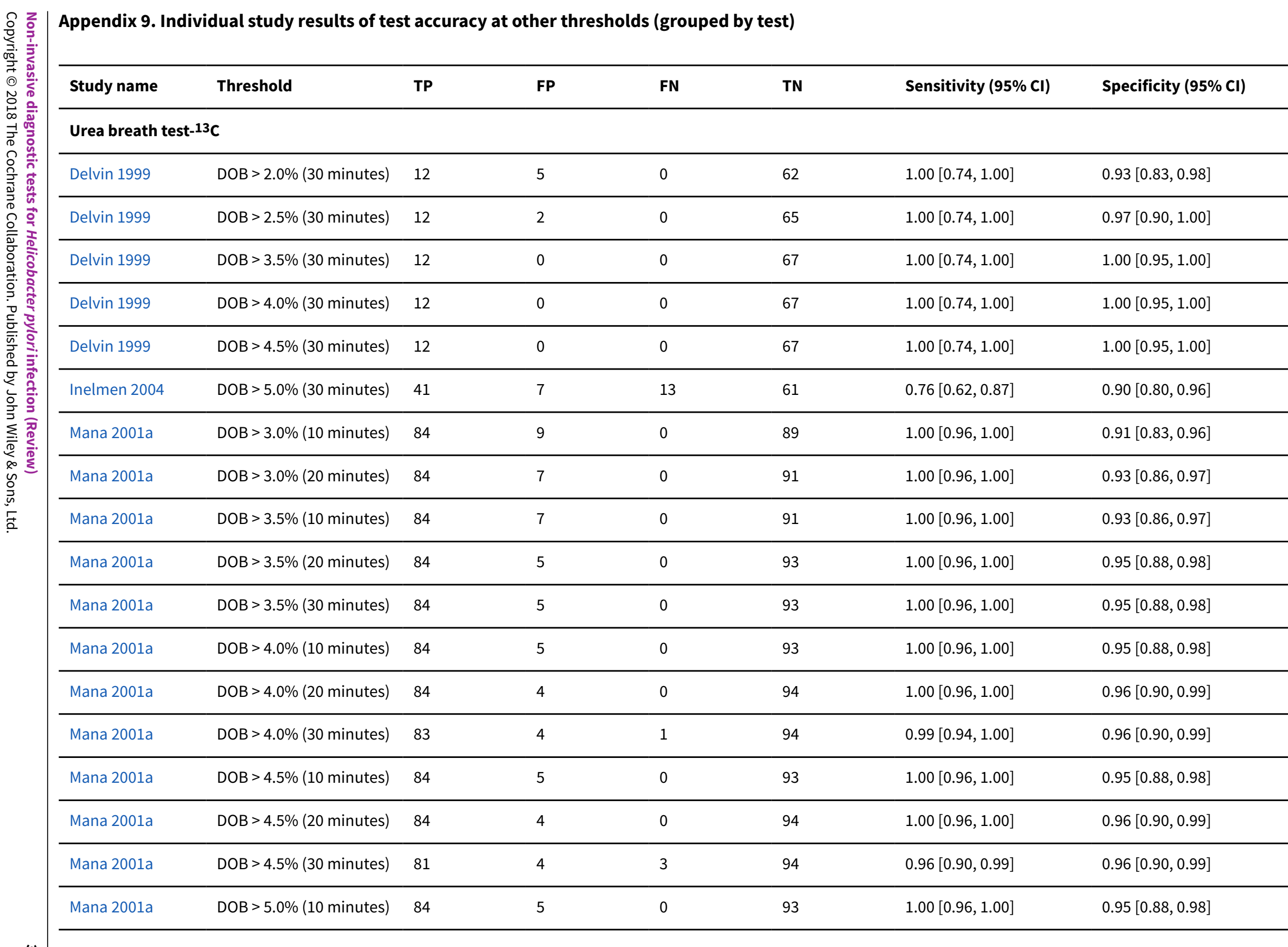


(Continued)

Mana 2001a

DOB $>5.0 \%$ (20 minutes) $\quad 84$

3

95

$1.00[0.96,1.00]$

$0.97[0.91,0.99]$

Mana 2001

$\mathrm{DOB}>5.0 \%$ (30 minutes)

81

4

94

$0.96[0.90,0.99]$

$0.96[0.90,0.99]$

\section{Urea breath test-14C}

\begin{tabular}{|c|c|c|c|c|c|c|c|}
\hline Dede 2015 & CPM > 23 (10 minutes $)$ & 6 & 3 & 1 & 20 & $0.86[0.42,1.00]$ & $0.87[0.66,0.97]$ \\
\hline Dede 2015 & CPM $>29$ (30 minutes $)$ & 5 & 0 & 2 & 23 & $0.71[0.29,0.96]$ & $1.00[0.85,1.00]$ \\
\hline Dede 2015 & CPM $>35$ (20 minutes $)$ & 6 & 0 & 1 & 23 & $0.86[0.42,1.00]$ & $1.00[0.85,1.00]$ \\
\hline Dede 2015 & CPM $>50$ (20 minutes $)$ & 4 & 0 & 3 & 23 & $0.57[0.18,0.90]$ & $1.00[0.85,1.00]$ \\
\hline Dede 2015 & $\mathrm{CPM}>50$ (30 minutes $)$ & 5 & 0 & 2 & 23 & $0.71[0.29,0.96]$ & $1.00[0.85,1.00]$ \\
\hline Morales 1995 & Not stated & 64 & 5 & 10 & 25 & $0.86[0.77,0.93]$ & $0.83[0.65,0.94]$ \\
\hline Noguera 1998 & $\begin{array}{l}>1 \% \text { excretion ( } 20 \text { min- } \\
\text { utes) }\end{array}$ & 19 & 2 & 3 & 14 & $0.86[0.65,0.97]$ & $0.88[0.62,0.98]$ \\
\hline Noguera 1998 & $\begin{array}{l}>1 \% \text { excretion ( } 30 \text { min- } \\
\text { utes) }\end{array}$ & 15 & 1 & 7 & 15 & $0.68[0.45,0.86]$ & $0.94[0.70,1.00]$ \\
\hline Novis 1991 & $\begin{array}{l}>4.7 \% \text { excretion }(10 \\
\text { minutes) }\end{array}$ & 55 & 2 & 6 & 13 & $0.90[0.80,0.96]$ & $0.87[0.60,0.98]$ \\
\hline Novis 1991 & $\begin{array}{l}>4.7 \% \text { excretion }(20 \\
\text { minutes) }\end{array}$ & 50 & 2 & 11 & 13 & $0.82[0.70,0.91]$ & $0.87[0.60,0.98]$ \\
\hline Novis 1991 & $\begin{array}{l}>4.7 \% \text { excretion }(25 \\
\text { minutes) }\end{array}$ & 52 & 2 & 9 & 13 & $0.85[0.74,0.93]$ & $0.87[0.60,0.98]$ \\
\hline Novis 1991 & $\begin{array}{l}>4.7 \% \text { excretion ( } 5 \text { min- } \\
\text { utes) }\end{array}$ & 59 & 3 & 2 & 12 & $0.97[0.89,1.00]$ & $0.80[0.52,0.96]$ \\
\hline Ozturk 2003 & DPM > 100 (10 minutes) & 48 & 5 & 0 & 20 & $1.00[0.93,1.00]$ & $0.80[0.59,0.93]$ \\
\hline
\end{tabular}

Urea breath test - unknown isotope

2

10

$0.77[0.61,0.88]$

$0.96[0.88,1.00]$ 


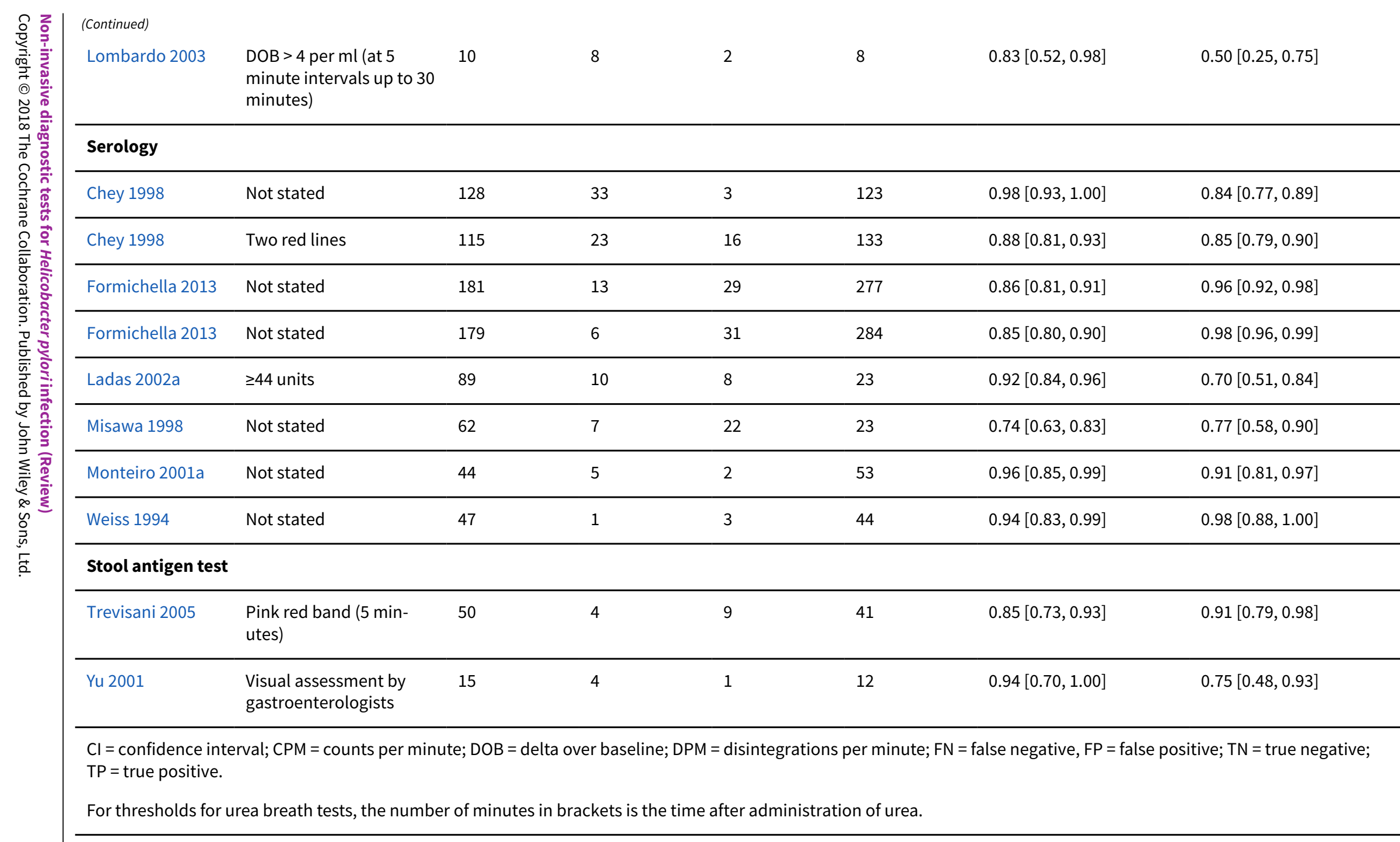


Appendix 10. Availability of data on potential sources of heterogeneity

\begin{tabular}{|c|c|c|c|c|}
\hline \multirow[t]{2}{*}{ Characteristic } & \multicolumn{4}{|l|}{ Test } \\
\hline & $\begin{array}{l}\text { Urea breath test } \\
\mathrm{C}-13\end{array}$ & $\begin{array}{l}\text { Urea breath test } \\
\text { C-14 }\end{array}$ & Serology & $\begin{array}{l}\text { Stool antigen } \\
\text { test }\end{array}$ \\
\hline Number of studies ( $H$ pylori cases/total) & $34(1526 / 3139)$ & $21(1018 / 1810)$ & $34(2477 / 4242)$ & $29(1311 / 2988)$ \\
\hline \multicolumn{5}{|l|}{ Reference standard } \\
\hline Haemotoxylin and eosin stain & 10 & 7 & 8 & 8 \\
\hline Special histological stains & 7 & 5 & 6 & 9 \\
\hline Immunohistochemical stain & 0 & 0 & 2 & 0 \\
\hline Combination & 17 & 9 & 18 & 12 \\
\hline \multicolumn{5}{|l|}{ Participant type } \\
\hline Symptomatic & 19 & 13 & 20 & 17 \\
\hline Asymptomatic & 0 & 0 & 1 & 0 \\
\hline Both & 0 & 1 & 1 & 0 \\
\hline Not stated & 15 & 7 & 12 & 12 \\
\hline \multicolumn{5}{|c|}{ Recent, current proton pump inhibitor or antibiotic use } \\
\hline Yes & 0 & 0 & 0 & 0 \\
\hline No & 18 & 13 & 17 & 19 \\
\hline Both & 2 & 0 & 1 & 2 \\
\hline Not stated & 14 & 8 & 16 & 8 \\
\hline \multicolumn{5}{|l|}{ Recruitment type } \\
\hline Prospective & 6 & 3 & 3 & 4 \\
\hline Retrospective & 4 & 0 & 2 & 0 \\
\hline Not stated & 24 & 18 & 29 & 25 \\
\hline \multicolumn{5}{|l|}{ Publication type } \\
\hline Full text & 32 & 21 & 31 & 29 \\
\hline Abstract & 2 & 0 & 3 & 0 \\
\hline
\end{tabular}

\section{Subtype of tests*}

\section{Serology subtypes}


(Continued)

\begin{tabular}{|c|c|c|c|c|}
\hline ELISA & - & - & 17 & - \\
\hline Latex agglutination test & - & - & 1 & - \\
\hline Western blot & - & - & 3 & - \\
\hline Not stated & - & - & 17 & - \\
\hline \multicolumn{5}{|l|}{ Stool antigen subtypes } \\
\hline Monoclonal antibody & - & - & - & 2 \\
\hline Polyclonal antibody & - & - & - & 3 \\
\hline Not stated & - & - & - & 24 \\
\hline \multicolumn{5}{|l|}{ Risk of bias ${ }^{\dagger}$} \\
\hline Low & 0 & 0 & 0 & 0 \\
\hline High & 32 & 18 & 32 & 27 \\
\hline Unclear & 2 & 3 & 2 & 2 \\
\hline
\end{tabular}

*The same study can feature in more than one category depending upon the number of tests included in the study.

†Studies at low risk of bias in all the QUADAS-2 domains versus those at unclear or high risk of bias.

\section{Appendix 11. Investigation of effect of reference standard on test accuracy}

\begin{tabular}{|c|c|c|c|c|c|}
\hline \multirow[t]{2}{*}{ Test } & \multicolumn{2}{|l|}{ Special stain } & \multicolumn{2}{|c|}{ Haemotoxylin and eosin stain } & \multirow[t]{2}{*}{ P value ${ }^{\star}$} \\
\hline & $\begin{array}{l}\text { Studies; participants } \\
\text { (H pylori cases) }\end{array}$ & DOR $(95 \% \mathrm{CI})$ & $\begin{array}{l}\text { Studies; participants } \\
\text { (cases) }\end{array}$ & DOR $(95 \% \mathrm{CI})$ & \\
\hline $\begin{array}{l}\text { Urea breath } \\
\text { test-13C }\end{array}$ & $7 ; 496(216)$ & $59.5(13.4,265)$ & $10 ; 1154(623)$ & $229(62.3,842)$ & 0.30 \\
\hline $\begin{array}{l}\text { Urea breath } \\
\text { test- }-14 C\end{array}$ & $5 ; 558(324)$ & $123(33.7,446)$ & $7 ; 428(269)$ & $33.1(10.6,103)$ & 0.10 \\
\hline Serology & $6 ; 1112(777)$ & $14.4(2.98,69.6)$ & 8; $813(464)$ & $33.5(7.86,143)$ & 0.22 \\
\hline $\begin{array}{l}\text { Stool antigen } \\
\text { test }\end{array}$ & $9 ; 1124(476)$ & $33.2(9.94,111)$ & $8 ; 626(310)$ & $33.0(9.19,118)$ & 1.0 \\
\hline
\end{tabular}

*P value from likelihood ratio test comparing models with and without the reference standard covariate.

DOR = diagnostic odds ratio. 


\section{CONTRIBUTIONS OF AUTHORS}

LB, SS, AS, AG, BL, and KG identified studies and extracted data for the review. LB entered the characteristics of included and excluded studies. KG and YT analysed the data and wrote the review. MY provided critical comments for the review.

\section{DECLARATIONS OF INTEREST}

This report is independent research funded by the National Institute for Health Research (NIHR Cochrane Programme Grants, 13/89/03 - Evidence-based diagnosis and management of upper digestive, hepato-biliary, and pancreatic disorders). The views expressed in this publication are those of the author(s) and not necessarily those of the NHS, the National Institute for Health Research or the Department of Health.

LB: none known.

SS: none known.

AS: none known.

AG: none known.

BL: none known.

MY: is an Editor with the Cochrane Upper GI and Pancreatic Diseases (UGPD) Review Group. However, other UGPD Editors were responsible for the editorial processing of this review.

KS: none known.

YT: none known.

\section{SOURCES OF SUPPORT}

\section{Internal sources}

- University College London, UK.

\section{External sources}

- National Institute for Health Research, UK.

This project was supported by the National Institute for Health Research, via Cochrane Programme Grant to the CHBG and UGPD groups. The views and opinions expressed therein are those of the authors and do not necessarily reflect those of the Systematic Reviews Programme, NIHR, NHS or the Department of Health.

\section{DIFFERENCES BETWEEN PROTOCOLAND REVIEW}

- We considered urea breath test-14C and urea breath test- ${ }^{13} \mathrm{C}$ as different index tests.

- Because of the paucity of data, we did not stratify the analysis by reference standard; however, we investigated reference standard as a potential source of heterogeneity.

- Because studies reported different thresholds and following recommendation from peer reviewers, we used the HSROC model for the primary analyses. For estimation of summary sensitivities and specificities at specific thresholds, we used univariate fixed-and randomeffects logistic regression models due to paucity of data.

- We performed direct comparisons whenever possible, rather than deciding this on the basis of the number of studies.

\section{INDEX TERMS}

\section{Medical Subject Headings (MeSH)}

*Helicobacter pylori [immunology]; Antigens, Bacterial [analysis]; Biomarkers [analysis]; Breath Tests [*methods]; Feces [ ${ }^{*}$ chemistry]; Helicobacter Infections [blood] [ ${ }^{\star}$ diagnosis] [epidemiology]; Prevalence; Urea [*analysis]

\section{MeSH check words}

Adult; Child; Humans 